DEPARTMENT OF THE INTERIOR

UNITED STATES GEOLOGICAL SURVEY

CHARLES D. WALCOTT, DIREGTOR

\title{
WEIR EXPERIMENTS, COEFFICIENTS, AND FORMULAS
}

BY

ROBERT E. HORTON

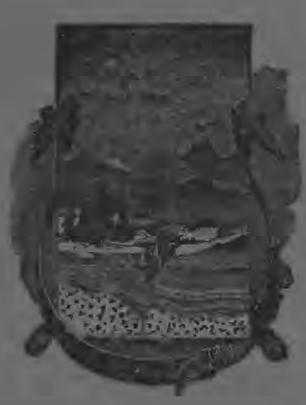

WASHINGTON

GOVERNMENT PRINTING OFEICE

1906 
DEPARTMENT OF THE INTERIOR

UNITED STATES GEOLOGICAL SURVEY

CHARLES D. WALCOTT, DIEECTOR

\section{WEIR EXPERIMENTS, COEFFICIENTS, AND FORMULAS}

BY

ROBERT E. HORTON

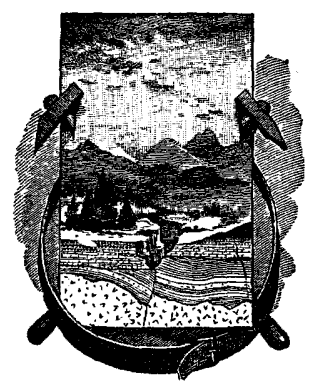

WASHINGTON

GOVERNMENT PRINTING OFFIOE 1906 


\section{CONTENTS AND ILLUSTRATIONS.}

Page.

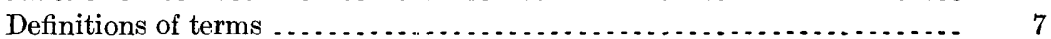

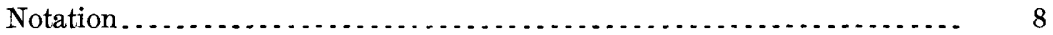

Base formulas.......................................... 9

Equivalent coefficients..................................... 9

Approximate relative discharge over weirs....................... 9

References .............................................. 10

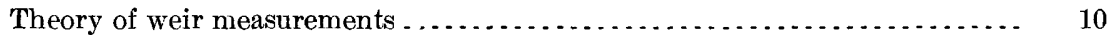

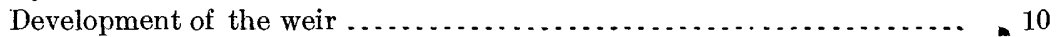

Theorem of Torricelli....................................... 10

Elementary deduction of the weir formula ..................... 11

Application of the parabolic law of velocity to weirs ............. 12

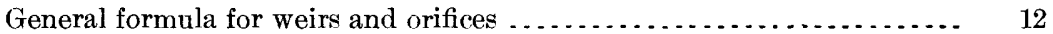

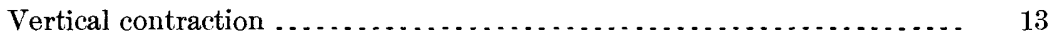

Velocity of approach ......................................... 14

Theoretical formulas....................................... 14

Distribution of velocity in channel of approach................... 16

Distribution of energy in channel of approach ..................... 17

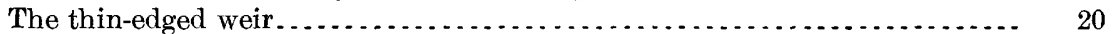

Earlier experiments and formulas ............................. $\quad 20$

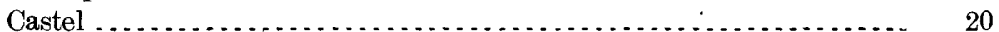

Poncelet and Lesbros.................................... 21

Boileau............................................. 21

East Indian engineers' formula ............................. 22

Experiments and formula of James B. Francis ................... 23

Experiments and formula of Fteley and Stearns................... $\quad 26$

Bazin's experiments....................................... ${ }_{29}$

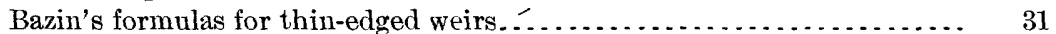

Derived formulas for thin-edged rectangular weirs................. 34

Fteley and Stearns-Francis formula ........................ 34

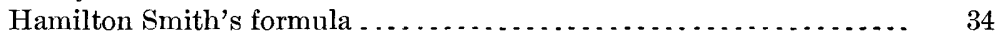

Smith-Francis formula................................... 37

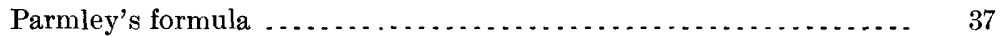

Extension of the weir formulas to higher heads .................... $\quad 39$

Comparison of weir formulas.................................. 40

Comparison of various velocity of approach corrections............ 40

End contractions-incomplete contraction ...................... 44

Compound weir......................................... 46

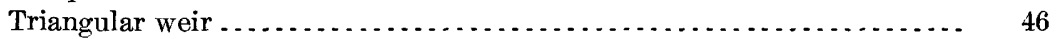

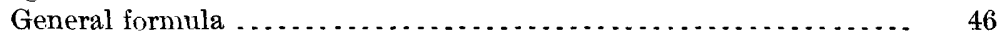

Thomson's experiments .................................. 46 
The thin-edged weir-Continued.

Page.

Trapezoidal weir ......................................... 47

The Cippoletti trapezoidal weir .......................... 47

Cippoletti's formula ...................................... 48

Requirements and accuracy of weir gagings . . . . . . . . . . . . . . . . . . 49

Precautions for standard weir gaging . . . . . . . . . . . . . . . . . . . . .

Plank and beam weirs of sensible crest width ................... 52

Reduction of the mean of several observations of head . . . . . . . . . . . . 52

Effect of error in determining the head on weirs. . . . . . . . . . . . . . . .

Error of the mean where the head varies ...................... 54

Weir not level ............................................. 57

Convexity of water surface in leading channel ..................... 58

Results of experiments on various forms of weir cross sections ............ 59

The use of weirs of irregular section . . . . . . . . .

Modifications of the nappe form ................................. 60

Experimental data for weirs of irregular cross section ............... 61

Base formula for discharge over weirs of irregular cross section . . . . . 62

Bazin's experiments on weirs of irregular cross section............ 63

Bazin's correction for velocity of approach ................. 63

Recomputation of coefficients in Bazin's experiments .......... 66

Cornell University hydraulic laboratory ....................... 85

Experiments of United States Board of Engineers on Deep Waterways. $\quad 86$

Experiments at Cornell University hydraulic laboratory on models of

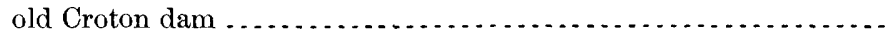

Experiments of United States Geological Survey at Cornell University

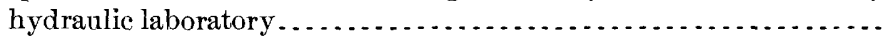

Experiments on model of Merrimac River dam at Lawrence, Mass...

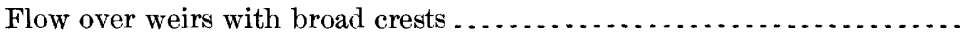

Theoretical formula of Unwin and Frizell ......................

Blackwell's experiments on discharge over broad-crested weirs......

East Indian engineers' formula for broad-crested weirs.............

Fteley and Stearns experiments on broad-crested weirs.............

Bazin's formula and experiments on broad-crested weirs ...........

Experiments of the United States Geological Survey on broad-crested weirs

Table of discharge over broad-crested weirs with stable nappe......

Effect of rounding upstream crest edge. .........................

Experiments on weirs with downstream slope or apron of varying inclination

Triangular weirs with vertical upstream face and sloping aprons .....

Triangular weirs with upstream batter 1:1 and varying slope of apron.

Experiments on weirs of trapezoidal section with upstream slope of

$\frac{1}{2}: 1$, horizontal crest, and varying downstream slopes............

Combination of coefficients for weirs with compound slopes ...........

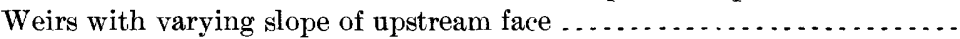

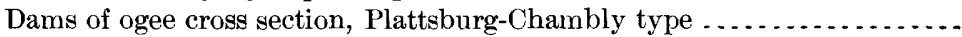

Experiments on discharge over actual dams.......................

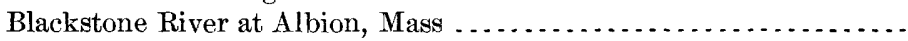

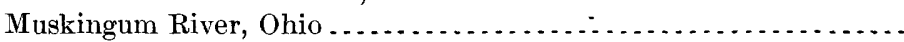

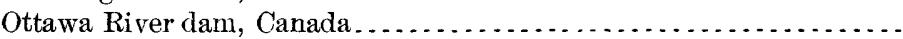

Austin, Tex., dam . . . . . . . . . . . . . . . . . . . . . . . . . . . . .

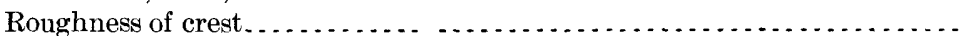

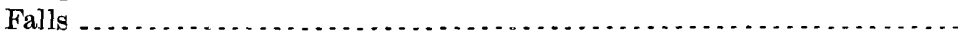

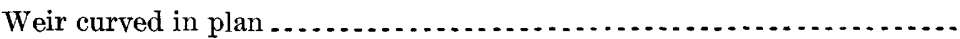


Page.

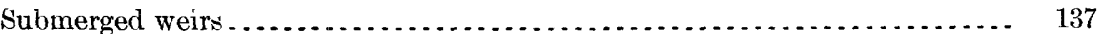

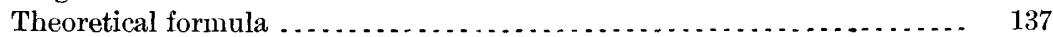

Fteley and Stearns submerged-weir formula $\ldots \ldots \ldots \ldots \ldots \ldots \ldots$

Clemens Herschel's formula ................................... 139

The Chanoine and Mary formula ........................... 140

R. H. Rhind's formula .................................... 141

Bazin's formulas. ......................................... 141

Increase of head by submerged weirs . . . . . . . . . . . . . . . . . . . . . 142

Rankine's formulas. ..................................... 142

Colonel Dyas's formula ................................. 143

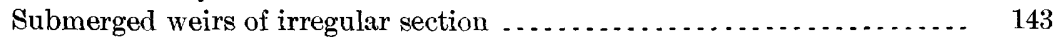

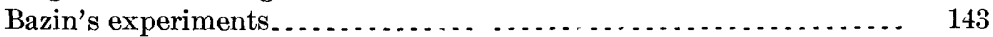

Data concerning East Indian weirs . . . . . . . . . . . . . . . . . . . 144

United States Deep Waterways experiments . . . . . . . . . . . . . . 146

Weir discharge under varying head . . . . . . . . . . . . . . . . . . . . . . . 146

Prismatic reservoir, no inflow ............................... 147

Approximate time of lowering prismatic or nonprismatic reservoir . . . . . 147

Reservoir prismatic, with uniform inflow ..................... 148

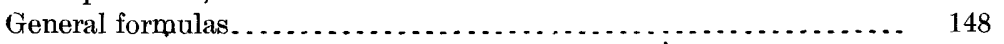

Formulas for time of rise to any head $\mathbf{H}$, prismatic reservoir with uniform inflow.

Table 2. Percentage increase in discharge by. various rates of velocity of approach

Tables 3, 4. Discharge over a thin-edged weir by the Francis formula....

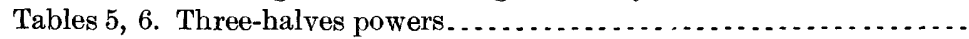

Table 7. Flow over broad-crest weirs with stable nappe $\ldots . . . . . . . . .$.

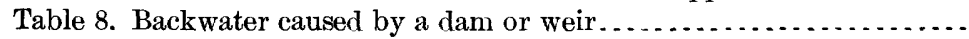
Index

Plate I. Bazin's coefficients .............................. 32

II. Effect of errors in weir experiments ................ 54

III. Modifications of nappe form ....................... 60

IV-XII. Bazin's experiments............................. 66

XIII, XIV. Cornell hydraulic laboratory experiments.............. 86

XV-XVIII. United States Deep Waterways experiments ............. 90

XIX-XXII. Croton dam experiments.......................... 94

XXIII-XXXII. United States Geological Survey experiments .......... 106

XXXIII. Merrimac River dam experiments .................. 108

XXXIV-XXXV. Cross sections of ogee dams ..................... 130

XXXVI. Coefficient diagram for ogee dams ................. 130

XXXVII. Experiments on actual dams.................... 132

XXXVIII. Diagram of variable discharge................... 150

Fig. 1. Torricellian theorem applied to a weir ...................... 11

2. Rectangular orifice ........................................ 12

3. Distribution of velocities ............................... 16

4. Triangular weir ............................................. 46

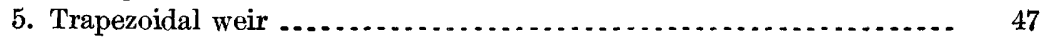




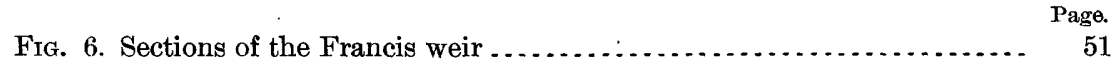

7. Inclined weir ................................................ 57

8. Broad-crested weir ............................................ 110

9. Coefficient curve for triangular weirs. . . . . . . . . . . . . . . . . . 125

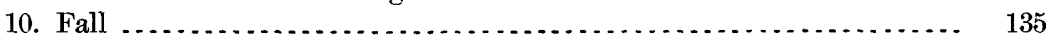

11. Weir curved or angular in plan ............................ 136

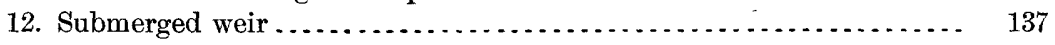

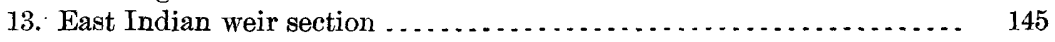

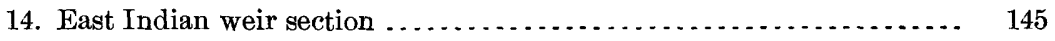

15. Concave backwater surface ............................. 180

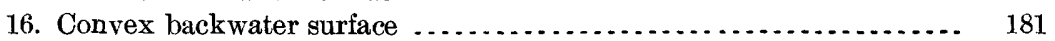




\title{
WEIR EXPERIMENTS, COEFFICIENTS, AND FORMULAS.
}

\author{
By Robert E. Horton.
}

\section{INTRODUCTION.}

\section{DEFINITIONS OF TERMS.}

The word "weir" will be used to describe any structure used to determine the volume of flow of water from measurements of its depth on a crest or sill of known length and form. In this general sense timber and masonry dams having various shapes of section, reservoir overflows, and the like may be weirs. Terms, more or less synonymous, used to describe such weirs are "comb," "wasteway," "spillway," "overwash," "rollway," and "overfall."

The French term "nappe," suggesting the curved surface of a cloth hanging over the edge of a table, has been fittingly used to designate the overfalling sheet of water.

The expression "wetted underneath" has been used to describe the condition of the nappe designated by Bazin as "noyées en dessous," signifying that the water level between the nappe and the toe of the weir is raised by vacuum above the general water level below the weir.

"Thin-edged weir" and "sharp-crested weir" are used to designate a weir in which the nappe, or overfalling sheet, touches only the smooth, sharp upstream corner or edge of the crest, the thickness of which is probably immaterial so long as this condition is fulfilled.

A "suppressed weir" has a channel of approach whose width is the length of the weir crest.

A "contracted weir" has a crest length that is less than the width of the channel of approach.

The term "channel of approach," or "leading channel," defines the body of water immediately upstream from the weir, in which is located the gage by which the depth of overflow is measured.

"Section of approach" may refer to the cross section of the leading channel, if the depth and width of the leading channel are uniform; otherwise it will, in general, apply to the cross section of the channel of approach in which the gage is located. 
"Weir section" refers to the aross section of the overflowing stream in the plane of the weir crest.

"Crest contraction" refers to the diminished cross section of the overflowing stream resulting from the upward curvature of the lower water flaments in passing the crest edge. It does not include the downward curvature of the water surface near the weir crest.

The "vertical contraction of the nappe" includes both the crest contraction and the surface contraction.

"Incomplete contraction" may take place either at the crest or at the ends of a weir, and will occur when the bottom or side walls of the channel of approach are so near the weir as to prevent the complete curvature of the water filaments as they pass the contracting edge.

Dimensions are uniformly expressed in feet and decimals, velocities in feet per second, and quantities of flow in cubic feet per second, unless otherwise stated in the text.

In the preparation of this paper inuch computation has been involved and it is expected that errors will appear, which, if attention is called to them, may be corrected in the future. Information concerning such errors will be guatefully received.

\section{NOTATION.}

The symbols given below are used in the values indicated. The meaning of additional symbols as used and special uses of those that follow are given in the text:

$D=$ Measured or actual depth on the crest of weir, usually determined as the difference of elevation of the weir crest and the water level, taken at a point sufficiently far upstream from the weir to avoid the surface curve.

$H=$ The head corrected for the effect of velocity of approach, or the observed head where there is no velocity of approach. As will be explained, $D$ is applied in formulas like Bazin's, in which the correction for velocity of approach is included in the coefficient. $H$ is applied in formulas where it is eliminated.

$v=$ Mean velocity of approach in the leading channel, usually taken in a cross section opposite which $D$ is determined.

$h=$ Velocity head $=\alpha \frac{v^{2}}{2 g}$.

$g=$ Acceleration by gravity. Value here used 32.16 .

$P=$ Height of weir crest above bottom of channel of approach, where channel is rectangular.

$W=$ Width of channel of approach where $D$ is measured.

$A=$ Area of cross section of channel of approach.

$G=$ Area of channel section where $D$ is measured, per unit length of crest.

$a=$ Area of weir section of discharge $=D L$.

- $L=$ Actual length of weir crest for a suppressed weir, or length corrected for end contractions, if any.

$L^{\prime}=$ Actual length of crest of a weir with end contractions.

$N=$ Number of complete end contractions.

$B=$ Breadth of crest of a broad-crested weir.

$S=$ Batter or slope of erest, feet horizontal to one vertical. 
$d=$ Depth of crest submergence in a drowned or submerged weir.

$Q=$ Volume of discharge per unit of time.

$C, M, m, \mu, \alpha, f$, etc., empirical coefficients.

\section{BASE FORMULAS.}

The following formulas have been adopted by the engineers named:

$$
\begin{array}{rlrl}
Q & =\frac{2}{3} M L H \sqrt{2} g \bar{H} . & & \text { Hamilton Smith (theoretical). } \\
& =\mu L H \sqrt{2 g H .} & & \text { Bazin, with no velocity of approach. } \\
& =m L D \sqrt{2 g D} . & & \text { Bazin, with velocity of approach. } \\
& =C L H^{\frac{3}{2}} . & & \text { Francis }^{a} \text { (used here). } \\
& =C L H^{\frac{3}{2}}+f L . & & \text { Fteley and Stearns. } \\
& \multicolumn{2}{c}{\text { EQUIVALENT COEFFICIENTS. }}
\end{array}
$$

The relations between the several coefficients, so far as they can be given here, are as follows:

$$
\mu=\frac{2}{3} M \text {. }
$$

$M$ is a direct measure of the relation of the actual to the theoretical weir discharge.

$$
\begin{aligned}
& C=\mu \sqrt{2 g}=\frac{2}{3} M \sqrt{2 g}=8.02 \mu=5.35 M . \\
& M=\frac{3}{2} \mu=\frac{3}{2} \frac{C}{\sqrt{2 g}}=0.1870 C . \\
& \mu=\frac{C}{8.02}=0.1247 C .
\end{aligned}
$$

\section{APPROXIMATE RELATIVE DISCHARGE OVER WEIRS.}

For a thin-edged weir, the coefficient $C$ in the Francis formula is $3.33=\frac{10}{3}$. Let $C^{\prime}$ be the coefficient for any other weir, and $x$ the relative discharge as compared with the thin-edged weir, then

$$
\begin{aligned}
& \frac{10}{3}: C^{\prime}:: 1: x \\
& x=\frac{3 C^{\prime}}{10} \quad \text {. . . . . . . . . . . . }
\end{aligned}
$$

or, as a percentage,

$$
x_{1}=100 x=30 C^{\prime} \text {. }
$$

a The coefficient $C$ of Francis includes all the constant or empirical factors appearing in the formula, which is thus thrown into the simplest form for computation. 
This expression will be found convenient in comparing the effect on discharge of various modifications of the weir cross section. For a broad-crested weir with stable nappe, $C_{1}=2.64$, see p. 121 . The discharge over such a weir is thus seen to be 79.2 per cent of that for a thin-edged weir by the Francis formula.

\section{REFERENCES.}

The following authorities are referred to by page wherever cited in the text:

BAziN, H., Recent experiments on flow of water over weirs. Translated by Arthur Marichal and J. C. Trautwine, jr. Proc. Engineers' Club Philadelphia, vol. 7, No. 5, January, 1890, pp. 259-310; vol. 9, No. 3, July, 1892, pp. 231-244; No. 4, October, 1892, pp. 287-319; vol. 10, No. 2, April, 1893, pp. 121-164.

BazıN, H., Expériences nouvelles sur l'écoulement en déversoir, $6^{\text {me }}$ art., Annales des Ponts et Chaussées, Mémoires et Documents, 1898, $2^{\text {me }}$ trimestre, pp. 121-264. This paper gives the results of experiments on weirs of irregular section. Bazin's earlier papers, published in Annales des Ponts et Chaussées, 1888, 1890, 1891,1894 , and 1896, giving results of experiments chiefly relating to thin-edged weirs and velocity of approach, have been translated by Marichal and Trautwine.

Bellasis, E. S., Hydraulics.

Bovey, H. T., Hydraulies.

Francrs, James B., Lowell hydraulic experiments.

Frizell, James P:, Water power.

Fteley, A., and Stearns, F. P., Experiments on the flow of water, etc. Trans. Am.

Soc. Civil Engineers, January, February, March, 1883, vol. 12, pp. 1-118.

Merriman, Mansfield, Hydraulics.

Rafter, George W., On the flow of water over dams. Trans. Am. Soc. Civil Engineers, vol. 44, pp. 220-398, including discussion.

Smith, Hamilton, Hydraulics.

\section{THEORY OF WEIR MEASUREMENTS.}

\section{DEVELOPMENT OF THE WEIR.}

The weir as applied to stream gaging is a special adaptation of mill dam, to which the term weir, meaning a hindrance or obstruction, has been applied from early times. The knowledge of a definite relation between the length and depth of overflow and the quantity also probably antedates considerably the scientific determination of the relation between these elements.

In theory a weir or notch ${ }^{a}$ is closely related to the orifice; in fact, an orifice becomes a notch when the water level falls below its upper boundary.

\section{THEOREM OF TORRICELLI.}

The theorem of Torricelli, enunciated in his De Motu Gravium Naturaliter Accelerato, 1643, states that the velocity of a fluid passing through an orifice in the side of a reservoir is the same as that which would be acquired by a heavy body falling freely through the vertical 
height measured from the surface of the Anid in the reservoir to the center of the orifice.

This theorem forms the basis of hydrokinetics and renders the weir and orifice applicable to stream measurement. The truth of this proposition was confirmed by the experiments of Mariotte, published in 1685. It can also be demonstrated from the laws of dynamies and the principles of energy. ${ }^{a}$

\section{ELEMENTARY DEDUCTION OF THE WEIR FORMULA.}

In deducing a theoretical expression for flow over a weir it is assumed that each filament or horizontal lamina of the nappe is actuated by gravity acting through the head above it as if it were flowing

- through an independent orifice. In fig. 1 the head on the successive orifices being $H_{1}, H_{2}, H_{3}$, etc., and their respective areas $A_{1}, A_{2}, A_{3}$, etc., the total discharge would be

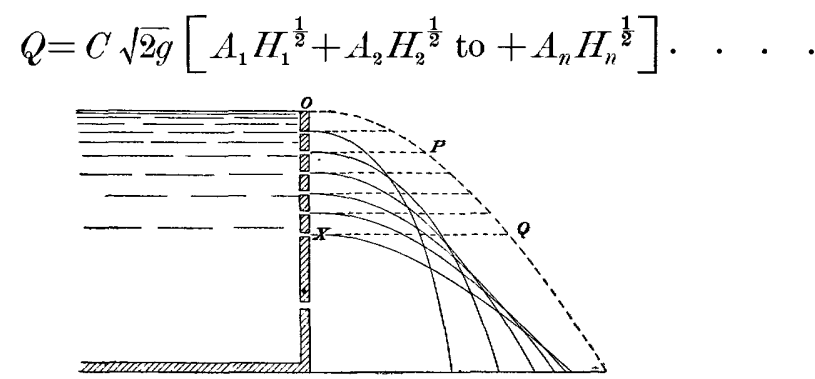

FIG. 1.-Torricellian theorem applied to a weir.

If the small orifices $A$ be considered as successive increments of head $H$, the weir formula may be derived by the summation of the quantities in parentheses. $H$ comprises $n$ elementary strips, the breadth of each is $\frac{H}{n}$. The heads on successive strips are $\frac{H}{n}, \frac{2 H}{n}$, etc., and the total becomes

$$
Q=\frac{L H}{n} \sqrt{2 g}\left(\sqrt{\frac{H}{n}}+\sqrt{\frac{2 H}{n}}+\sqrt{\frac{3 H}{n}}+\right) . . .
$$

where $\frac{L H}{n}=A+A_{1}$, etc., for a rectangular weir. The sum of the series $\sqrt{1}+\sqrt{2}+\sqrt{3}+$ to $\sqrt{n}=\frac{2}{3} n^{\frac{3}{2}}$.

Hence the discharge is

$$
\begin{aligned}
Q & =\frac{L H}{n} \sqrt{2 g} \cdot \sqrt{\frac{H}{n}} \cdot \frac{2}{3} n^{\frac{3}{2}} . \\
& =\frac{2}{3} L H \sqrt{2 g H} .
\end{aligned}
$$

The above summation is more readily accomplished by calculus. 


\section{APPLICATION OF THE PARABOLIC LAW OF VELOCITY TO WEIRS.}

The following elementary demonstration clearly illustrates the character of the weir:

According to Torricelli's theorem (see fig. 1), the velocity $(v)$ of a filament at any depth $(x)$ below surface will be $v=\sqrt{2 g x}$. This is the equation of a parabola having its axis $O X$ vertical and its origin $O$ at water surface. Replacing the series of jets by a weir with crest at $X$, the mean velocity of all the filaments will be the average ordinate of the parabola $O P Q$. The average ordinate is the area divided by the height, but the area of a parabola is two-thirds that of the circumscribed rectangle; hence the mean velocity of flow through the weir is two-thirds the velocity at the crest, $i$. e., two-thirds the velocity due to the total head $H$ on the crest. The discharge for unit length of crest is the head $H$, or area of opening per unit length, multiplied by the mean velocity. This quantity also represents the area of the parabolic velocity curve $O P Q X$. The mean velocity of flow in the nappe occurs, theoretically, at two-thirds the depth on the crest.

The modification of the theoretical discharge by velocity of approach, the surface curve, the vertical contraction at the crest, and the various forms that the nappe may assume under different conditions of aeration, form of weir section, and head control the practical utility of the weir as a device for gaging streams.

\section{GENERAL FORMULA FOR WEIRS AND ORIFICES. $a$}

Consider first a rectangular opening in the side of a retaining vessel. The velocity of flow through an elementary layer whose area is $L d y$ will be from Torricelli's theorem:

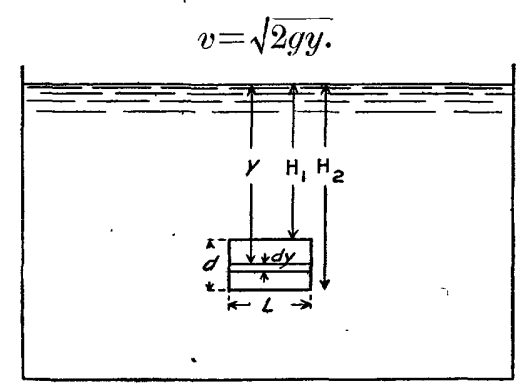

FIG. 2.-Rectangular orifice.

The discharge through the entire opening will be, per unit of time, neglecting contractions,

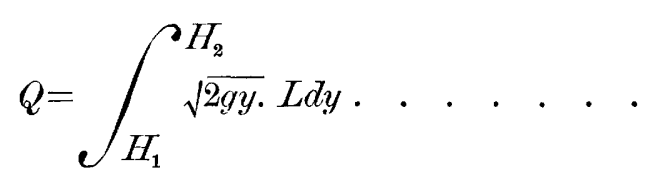

$a$ The correlation of the weir and orifice has been given by Merriman. See Hydraulics, pp. 42-45. 
This is a general equation for the flow through any weir or orifice, rectangular or otherwise, $Q$ being expressed as a function of $y$. In the present instance $L$ is constant. Integrating,

$$
Q=\frac{2}{3} L \sqrt{2 g}\left(H_{2}^{\frac{3}{2}}-H_{1}^{\frac{3}{2}}\right) \cdot . \quad . \quad . \quad .
$$

For a weir or notch, the upper edge will be at surface, $H_{1}=O$, and calling $H_{2}=H$ in equation (5),

$$
\text { · } Q=\frac{2}{3} L \sqrt{2 g} H^{\frac{3}{2}} \text {. . . . . . . . }
$$

In the common formula for orifices, only the head on the center of gravity of the opening is considered.

Expressing $H_{2}$ and $H_{1}$ in terms of the depth $H$ on the center of gravity of the opening and the height of opening $d$, Merriman obtains, after substituting these values in and expanding equation (5) by the binomial theorem, the equivalent formula,

$$
Q=d L \sqrt{2 g h}\left[1-\frac{1}{96} \frac{d^{2}}{H^{2}}-\frac{1}{2048} \frac{d^{4}}{H^{4}}-\frac{1}{21845} \frac{d^{6}}{H^{6}}, \text { etc. }\right] \text {. }
$$

The sum of the infinite series in brackets expresses the error of the ordinary formula for orifices as given by the remainder of the equation. This error varies from 1.1 per cent when $h=d$ to 0.1 per cent when $h=3 d$.

\section{VERTICAL CONTRACTION.}

Practical weir formulas differ from the theoretical formula (6) in that velocity of approach must be considered and the discharge must be modified by a contraction coefficient to allow for diminished section of the nappe as it passes over the crest lip. Velocity of approach is considered on pages 14 to 20. Experiments to determine the weir coefficient occupy most of the remainder of the paper. The nature of the contraction coefficient is here described.

Vertical contraction expresses the relation of the thickness of nappe, $\varepsilon$, in the plane of the weir crest, to the depth on the crest, $H$. If the ratio $s$ were unity, the discharge would conform closely with the expression

$$
Q=2 / 3 L H \sqrt{2 g H} .
$$

The usual coefficient in the weir formula expresses nearly the ratio $s / H$.

The vertical contraction comprises two factors, the surface curve or depression of the surface of the nappe and the contraction of the under surface of the nappe at the crest edge. The latter factor in 
particular will vary with form of the weir cross section, and in general variation in the vertical contraction is the principal source of variation in the discharge coefficient for various forms of weirs.

The usual base weir formula, $Q=2 / 3 L H \sqrt{2 g} \bar{H}$, is elsewhere given for an orifice in which the upper edge is a free surface. If instead the depth on the upper edge of the orifice is $d$, the surface contraction, there results the formula

$$
Q=\frac{2}{3} M L \sqrt{2 g}\left(H^{\frac{3}{2}}-d^{\frac{3}{2}}\right) \cdot \cdot \quad \cdot \quad \cdot \quad \cdot .
$$

This is considered as the true weir formula by Merriman. ${ }^{a}$ In this formula only the crest-lip contraction modifies the discharge, necessitating the introduction of the coefficient. The practical difficulties of measuring $d$ prevent the use of this as a working formula.

Similarly a formula may be derived in which only the effective cross section $s$ is considered, but even this will require some correction of the velocity. Such formulas are complicated by the variation of $s$ and $d$ with velocity of approach. ${ }^{b}$ Hence, practical considerations included, it has commonly been preferred to adopt the convenient base formula for weirs, $Q=\frac{2}{3} M L H \sqrt{2 g H}$, or an equivalent, and throw all the burden of corrections for contraction into the coefficient $M$.

\section{VELOCITY OF APPROACH.}

THEORETICAL FORMULAS.

Before considering the various practical weir formulas in use some general considerations regarding velocity of approach and its effect on the head and discharge may be presented.

In the general formula (4) for the efflux of water when the water approaches the orifice or notch with a velocity $v$, then with free discharge, writing $D+h$ in place of $H$, for a rectangular orifice, we have

$$
Q=\int_{D_{1}+h}^{D_{2}+h} \sqrt{2 g y} \cdot L d y \quad . \quad . \quad . \quad .
$$

$D_{1}$ and $D_{2}$ being the measured depth on upper and lower edges of the orifice, and $h=\frac{v^{2}}{2 g}$, the velocity head.

To assume that $D+h$ equals $H$ is to assume that the water level is

a Hydraulies, p. 123.

$b$ See Trautwine and Marichal's translation of Bazin's Experiments, pp. 231-307, where may also be found other data, including a résumé of M. Boussinesq's elaborate studies of the vertical contraction of the nappe, which appeared in Comptes Rendus de l'Académie des Sciences for October 24, 1887. 
increased by the amount $h$, or, as is often stated, that $H$ is "measured to the surface of still water." This is not strictly correct, however, because of friction and unequal velocities, which tend to make $H-D>h$, as explained below.

For a weir, $\mathrm{D}_{1}$ equals zero; integrating,

$$
Q=\frac{2}{3} L \sqrt{2 \mathscr{g}}\left[(D+h)^{\frac{3}{2}}-h^{\frac{3}{2}}\right]
$$

Since $Q=\frac{2}{3} L \sqrt{2 g} H^{\frac{3}{2}}$, we have

$$
H=\left\{(D+h)^{\frac{3}{2}}-h^{\frac{3}{2}}\right\}^{\frac{2}{3}} \cdot \text {. . . . }
$$

This is the velocity correction formula used by James B. Francis. ${ }^{a}$ Since $h$ appears in both the superior and inferior limits of integration, it is evident that $h$ increases the velocity only, and not the section of discharge. The criticism is sometimes made that Francis's equation has the form of an increase of the height of the section of discharge as well as the velocity.

The second general method of correcting for velocity of approach consists of adding directly to the measured head some function of the velocity head, making

$$
H=D+\alpha h
$$

in the formula

$$
Q=C L H \sqrt{2 g H}
$$

or

$$
Q=C L(D+\alpha h) \sqrt{2 g(D+\alpha h)} . \quad . \quad . \quad \text {. . } 9 b
$$

This is the method employed by Boileau, Fteley and Stearns, and Bazin. No attempt is made to follow theory, but an empirical correction is applied, affecting both the velocity and area of section.

By either method ' $c$ must be determined by successive approximations unless it has been directly measured.

Boileau and Bazin modify ( $9 b)$ so as to include the area of section of channel of approach, and since the velocity of approach equals $Q^{\prime} A$, a separate determination of $v$ is unnecessary. Bazin also combines the factor for velocity of approach with the weir coefficient.

The various modifications of the velocity correction formulas are given in conjunction with the weir formulas of the several experimenters.

$a$ Bovey gives similar proof of this formula for the additional cases of (1) an orifice with free discharge, (2) a submerged orifice, (3) a partially submerged orifice or drowned weir, thus establishing its generality. 


\section{DISTRIBUTION OF VELOCITY IN CHANNEL OF APPROACH.}

The discharge over a weir takes place by virtue of the potential energy of the layer of water lying above the level of the weir crest, which is rendered kinetic by the act of falling over the weir. If the water approaches the weir with an initial velocity, it is evident that some part of the concurrent energy will facilitate the discharge.

The theoretical correction formulas may not truly represent the effect of velocity of approach for various reasons:

1. The fall in the leading channel adjacent to the measuring section is the source of the velocity of approach, and this fall will always be greater than that required to produce the existing velocities, because some fall will be utilized in overcoming friction.

2. The velocity is seldom uniform at all parts of the leading channel and the energy of the water varies accordingly. This effect is discussed later (p. 17).

3. It is not certain just what portion of the energy of the water in the section of the leading channel goes to increase the discharge.

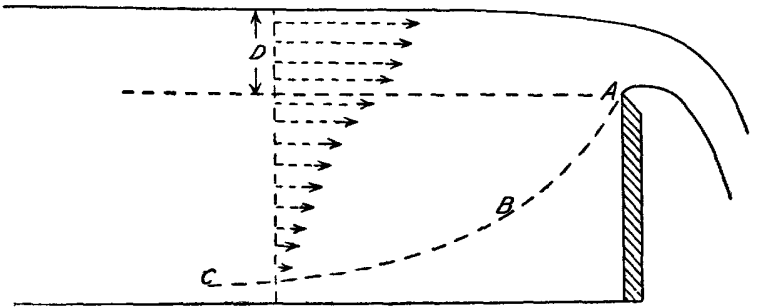

FTa. 3.-Distribution of velocities.

In general the threads of the water in the cross section of the channel of approach to a weir have varying velocities. It follows that, as will be shown, the ratio of the actual energy of the approaching water to the energy due to the mean velocity will be greater than unity, and for this reason the correction for velocity of approach will be greater than if the energy were that due to a fall through a head produced by the mean velpcity $\%$. The more nearly uniform is the velocity of the water in the leading channel the smaller will be the necessary coefficient $\alpha$ in the velocity head formula. The velocity may be rendered very nearly uniform by the use of stilling racks or baffles. Where this was done in the experiments on which a formula was based (that of Francis, for example) a larger velocity of approach correction than that obtained by the author may be necessary in applying the formula to cases where there is wide variation in the velocity in the leading channel. To avoid such a contingency it is desirable, when practicable, to measure head to surface of still water, because more accurate results can be obtained and wash against instruments prevented. 
The vertical and horizontal velocity curves in an open channel usually closely resemble parabolas. A weir interposes an obstruction in the lower part of the channel, checking the bottom velocities. The velocity is not, however, confined to the filaments in line with the section of the discharge opening of the weir. As a result of viscosity of the liquid, the upper rapidly moving layers drag the filaments underneath, and the velocity may extend nearly or quite to the channel bottom. There will usually, however, be a line (A B C, fig. 3), rising as the weir is approached, below which there is no forward velocity.

The line A B C is the envelope of the eurves of vertical velocity in the channel of approach.

There will be a similar area of low velocity at each side of the channel for a contracted weir. The inequality of velocities for such weirs being usually greater than for suppressed weirs, it follows that a larger coefficient in the formula for velocity of approach may be required. This is confirmed by experiment.

Various assumptions have been made as to what portion of the energy of the approaching stream goes to increase the discharge, $(a)$ that resulting from the mean velocity deduced from the discharge divided by the area of the entire section of the channel of approach; (b) that of the mean velocity obtained by using the sectional area of the moving water, above the line A B C, fig. 3 ; $(c)$ that of the filaments lying in line with or nearest to the section of the weir opening, determined approximately by the surface velocity. ${ }^{a}$

\section{DISTRIBUTION OF ENERGY IN CHANNEL OF APPROACH.}

Consider unit width of the channel of approach:

Let $v_{s}=$ Surface velocity .

$v_{m}=$ Mean velocity.

$v_{b}=$ Bottom velocity.

$"=$ Velocity at a height $x$ above bottom.

$X=$ Depth of water in channel of approach.

$w=\mathrm{W}$ eight of unit volume.

The general formula tor kinetic energy is

$$
\text { K. E. }=\frac{W v^{2}}{2 g} \quad \cdot \quad \cdot \quad \cdot \quad \cdot \quad \cdot \quad \cdot
$$

where $W=$ weight of the moving mass.

If the velocity increases uniformly from bottom to surface, the velocity at height $x$ will be

$$
l=v_{b}+\frac{x}{X}\left(v_{s}-v_{b}\right) .
$$


Let $d x$ be the thickness of a lamina one unit wide at height $x$. The total kinetic energy for the depth $X$ will be

$$
\text { K. E. }=\int_{0}^{X}\left(v_{b}+\frac{x}{X}\left(v_{s}-v_{b}\right)\right)^{3} \frac{3^{2}}{2 g} d x \ldots . .
$$

If the velocity is uniform, the total kinetic energy per unit width is found by integration to be

$$
\text { K. E. }=\frac{w X_{m}{ }^{3}}{2 g} \quad \cdot \quad \cdot \quad \cdot \quad \cdot \quad \cdot \quad \cdot
$$

Integrating for the simple case where $n_{b}=0$ and the velocity increases uniformly from the bottom to the surface so that $v_{m}=\frac{v_{s}}{2}$, we have

$$
\text { K. E. }=\frac{u n{ }^{\prime \prime}{ }_{m}{ }^{3}}{g} \cdot \cdot \cdot \cdot \cdot \cdot \cdot \cdot
$$

Comparing this with the expression for kinetic energy of a stream flowing with the uniform velocity $v$ (formula 12), we find the mass energy of the stream with uniformly varying velocity to be twice as great as for the uniform velocity.

By a similar integration the ratio of the total kinetic energy to the kinetic energy corresponding to the mean velocity in the channel of approach can be obtained for any assumption as to the distribution of velocities in the leading channel. The resulting ratio will depend upon the relative areas of section with low and high velocities which go to make up the mean, and in practice it will generally exceed unity.

The lowering of the water surface from the level of a still pond will also be greater in the case of unequal velocities than in the case of a uniform velocity equal to their mean. The theoretical weir formula indicates the same discharge in case of a uniform velocity of approach $v$ as in case of varying velocities whose mean is equal to $v$, although in the former case the actual drawing down of the head if it were measured would be found greater. If $h$ were the velocity head eorresponding to the mean velocity, and if $v_{1}, v_{2}, v_{3}$, etc., $v_{n}$ were the actual velocities in the $n$ unit areas of cross section, the actual velocity head $h^{\prime}$ will be such that

Now;

$$
\frac{Q w}{2 g}\left(v_{1}^{2}+\cdots_{2}^{2}+\text { etc. } v_{n}^{2}\right)=w Q h^{\prime}=\text { Integral K. E. }
$$

$$
\frac{w Q}{2} q v^{2}=w Q h=\mathrm{K} . \text { E. of average velocity. }
$$

As shown above, the integral K. E. is the greater. 
It follows that $h^{\prime}>h$.

If

$$
\boldsymbol{\alpha}=\frac{h^{\prime}}{h}
$$

Then

$$
h^{\prime}=\alpha h \text {. }
$$

Introducing velocity of approach in the discharge formula we substitute $D+h$ for $H$, and integrate between the limits zero and $D$. Hence, for the same discharge, the area of weir section is greater without velocity of approach by nearly the amount $h L$.

For a given measured head $D$, the effect of velocity of approach, whatever it may be, appears as an increase in the mean velocity of discharge in the plane of the weir. The relation of the mean velocity of discharge for a weir with velocity of approach to that for a weir without such velocity is shown by the following expression, the mean head being the same in both cases:

Mean velocity in the plane of the weir $=\frac{Q}{D}$,

then

$$
\frac{Q}{D}: \frac{Q_{1}}{D}:: D^{\frac{3}{2}}:(D+h)^{\frac{3}{2}}-h^{\frac{3}{2}}
$$

It will be seen that the discharge over a weir with velocity of approach is less than that for the same total head and greater than that for the same measured head without velocity of approach, and that with a given measured head the greater the velocity of approach the greater will be the discharge.

In a weir section opening out of still water there is always a considerable surface velocity, the parabolic law (see fig. 3) being modified by fluid friction, which tends to equalize the velocities. Velocity of approach, being usually greater at the surface, furthers this equalization. Some of the kinetic energy of the swifter-moving filaments is transferred to their slower-moving neighbors, the result being that while the kinetic energy of the whole mass $Q$ passing the weir per second remains constant, yet the average velocity is accelerated and the discharge rate is increased as compared with the theoretical quantities. This will be clearer if we consider two contiguous filaments, each having unit section $a$, one with a velocity of 1 , the other of 2 feet per second. The two will discharge $2+1$ units flow per second, having the total kinetic energy indicated below:

$$
\text { K. E. }=\frac{1 \times 1^{a}}{2 g} a w+\frac{2 \times 2^{2}}{2 g} a w=9 \stackrel{a w}{2 g^{\circ}}
$$


If, now, the velocities are equalized, 9 units of kinetic energy will be equally divided between the two filaments, so that, the new velocity being $v$,

$$
\frac{2 a w v \times v^{2}}{2 g}=\frac{9 a w}{2 g}
$$

and

$$
v=\sqrt[3]{\frac{9}{2}}=1.651 \text {. }
$$

The average velocity before equalization was 1.5 .

The discharge from two filaments having equal velocities will be 3.302 units, as compared with 3.00 for two filaments having unequal velocities.

\section{THE THIN-EDGED WEIR.}

\section{EARLIER EXPERIMENTS AND FORMULAS.}

Prior to 1850 the practice of weir measurement was in a somewhat chaotic condition, especially in England, Germany, and the United States. There were many experimental results, but the experiments were made on so small a scale that the various influences affeating the measurements and the lack of proper standards made the results erratic and untrustworthy in detail. Greater advancement had been made in France by such savants as Dubuat, Eytelwein, 'D'Aubuisson, Castel, Poncelet, Lesbros, and Boileau. Some of the work of the early French experimenters has proved, in the light of wider experience, to be of considerable value.

\section{EXPERIMENTS OF CASTEL.}

The first experiments deserving consideration are of those of $\mathbf{M}$. Castel, conducted at the waterworks of Toulouse in 1835 and $1836 .{ }^{a}$ Castel erected his apparatus on a terrace in conjunction with the water tower, which received a continuous supply of 1.32 cubic feet per second, capable of being increased to 1.77 cubic feet per second. The weir consisted of a wooden dam, surmounted by a crest of copper 0.001 foot in thickness, situated in the lower end of a leading channel, 19.5 feet long, 2.428 feet wide, and 1.772 feet deep. Screens were placed across the upper end of the channel to reduce oscillations. The head was measured at a point 1.60 feet upstream from the weir by means of a point gage. The overflow was measured in a zinc-lined tank having a capacity of 113.024 cubic feet. The length of the crest for weirs with suppressed contractions varied from 2.393 to 2.438 feet. Heights of weirs varying from 0.105 to 0.7382 were used, and

a Originally published in Mémoires Acad. Sci. Toulouse, 1837. See D'Aubuisson's Hydraulics, Bennett's translation, pp. 74-77. Data recomputed by Hamilton Smith in his Hydraulies, pp. 80-82 and 138-145. The recomputed coefficients will be found valuable in calculating discharge for very small and very low weirs. 
a similar series of experiments was performed on suppressed weirs $1.184 t$ feet long. The head varied for the longer weirs from aboùt 0.1 to 0.25 foot. Additional experiments were made on contracted weirs having various lengths, from 0.0328 to 1.6483 feet, in a channel 2.428 feet wide, and for lengths from 0.0328 to $0.65+2$ foot in a channel 1.148 feet wide. The experiments on these narrow slit weirs included depths varying from 0.1 or 0.2 foot to a maximum of about 0.8 foot.

D'Aubuisson gives the following formula, derived from the experiments of Castel for a suppressed weir:

$$
Q=3.4872 L D \sqrt{D+0.035 \bar{W}^{2}}
$$

where $W$ is the measured central surface velocity of approach, ordinarily about $1.2 v$.

\section{EXPERIMENTS OF PONCELET AND LESBROS.}

The experiments made by Poncelet and Lesbros, at Metz, in 1827 and 1828, under the auspices of the French Government, were continued by Lesbros in 1836 . The final results were not published, however, until some years later. ${ }^{a}$

The experiments of Poncelet and Lesbros and of Lesbros were performed chiefly on a weir in a fixed copper plate, length 5.562 feet. The head was measured in all cases in a reservoir 11.48 feet upstream, beyond the influence of velocity of approach. The erest depth varied from about 0.05 to 0.60 or 0.80 foot. The experiments of Lesbros are notable from the fact that a large number of forms of channel of approach were employed, including those with contracted and convergent sides, elevated bottoms, ete. The experiments of Lesbros on these special forms of weirs have been carefully recomputed by Hamilton Smith, and may be useful in determining the discharge through weirs having similar modifications. ${ }^{b}$

\section{EXPERIMENTS OF BOILEAU.}

The experiments of Boileau ${ }^{c}$ at Metz, in 1846, included 3 suppressed weirs, having lengths and heights as follows:

(1) Length 5.30 feet, height 1.54 feet.

(2) Length 2.94 feet, height 1.12 feet.

(3) Length 2.94 feet, height 1.60 feet.

The depth of overflow varied from 0.19 to 0.72 foot. Boileau obtained the following formula for a suppressed weir:

$$
Q=3.3455 \frac{P+D}{\sqrt{(P+D)^{2}-D^{2}}} L D^{\frac{3}{2}} \quad . \quad . \quad . \quad .
$$


This formula includes the correction for velocity of approach. The coefficient $C$, it will be noticed, is given as a constant. Boileau afterwards gave a table of corrections varying with the depth, indicating a discharge from 96 to 107 per cent of that obtained with the constant coefficient. Additional experiments by Boileau on suppressed weirs having a crest length of about 0.95 foot have been recomputed by Hamilton Smith. ${ }^{a}$ The heights of weirs were, respectively, 2.028, $2.690,2.018$, and 2.638 feet. In these experiments the discharge was deternined by measurement through orifices.

\section{EAST INDIAN ENGINEERS' FORMULA. ${ }^{b}$}

The East Indian engineers' formula for thin-edged weirs is

where

$$
Q=\frac{2}{3} M L \sqrt{2 g H^{3}}=C L H^{\frac{3}{2}}
$$

Reducing,

$$
\left.\begin{array}{l}
C=\frac{2}{3} \sqrt{2 g} M=5.35 M \\
M=1-\left(\frac{0.04[34.6+H]}{4}\right) .
\end{array}\right\} \quad . \quad . \quad . \quad .
$$

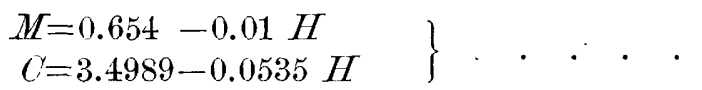

This formula applies to a suppressed weir. Method of correction for velocity of approach is not stated. Coefficient $M I$ has a maximum value 0.654 , and decreases slowly as the head increases. Limits of applicability of formula are not stated. Values of $C$ are given below:

Coefficient Cfor thin-edged weirs, East Indian engineers' formula.c

\begin{tabular}{|c|c|c|c|c|c|c|c|c|c|c|}
\hline $\begin{array}{c}H \text { in } \\
\text { feet. }\end{array}$ & 0.0 & 0.1 & 0.2 & 0.3 & 0.4 & 0.5 & 0.6 & 0.7 & 0.8 & 0.9 \\
\hline 0 & 3.499 & .3 .494 & 3.488 & 3.483 & 3.478 & 3.472 & 3.467 & 3.462 & 3.456 & 3.451 \\
1 & 3.445 & 3.440 & 3.435 & 3.429 & 3.424 & 3.419 & 3.413 & 3.408 & 3.403 & 3.397 \\
2 & 3.392 & 3.386 & 3.381 & 3.376 & 3.370 & 3.365 & 3.360 & 3.354 & 3.349 & 3.344 \\
3 & 3.338 & 3.333 & 3.328 & 3.322 & 3.317 & 3.312 & 3.306 & 3.301 & 3.296 & 3.290 \\
4 & 3.285 & 3.280 & 3.274 & 3.269 & 3.264 & 3.258 & 3.253 & 3.248 & 3.242 & 3.237 \\
5 & 3.221 & 3.226 & 3.221 & 3.215 & 3.210 & 3.205 & 3.199 & 3.194 & 3.189 & 3.183 \\
6 & 3.178 & 3.172 & 3.167 & 3.162 & 3.156 & 3.151 & 3.146 & 3.140 & 3.135 & 3.130 \\
7 & 3.124 & 3.119 & 3.114 & 3.105 & 3.103 & 3.098 & 3.092 & 3.087 & 3.082 & 3.076 \\
8 & 3.071 & 3.066 & 3.060 & 3.055 & 3.050 & 3.044 & 3.039 & 3.034 & 3.028 & 3.023 \\
9 & 3.017 & 3.012 & 3.007 & 3.001 & 2.996 & 2.991 & 2.985 & 2.980 & 2.975 & 2.969 \\
\hline
\end{tabular}

$a$ Hydraulies, pp. 133-135.

$b$ Given in J. Mullins's Irrigation Manual, introduced in United States by G. W. Rafter and used in region of upper Hudson River. Not given in Bellasis's recent East Indian work on hydraulies.

c For East Indian engineers' broad-crested weir formula, using coefficients derived from the above, see p. 114 . 


\section{EXPERIMENTS AND FORMULA OF JAMES B. FRANCIS.}

The experiments on discharge over thin-edged weirs, ${ }^{a}$ upon which the Francis formula is based, were made in October and November, 1852, at the lower locks of the Pawtucket canal, leading from Concord River past the Lowell dam to slack water of Merrimac River. Additional experiments were made by Francis in $1848^{b}$ at the center vent water wheel at the Boott Cotton Mills in Lowell, with gates blocked open and with constant head. A uniform but unknown volume of water was thus passed through the turbine and over a weir having various numbers of end contractions, the effect of which was thus determined. Similar experiments were made in 1851 at the Tremont turbine, ${ }^{c}$ where a constant volume of water was passed over weirs of lengths ranging from 3.5 to 16.98 feet and with from two to eight end contractions. These experiments were made to determine the exponent $n$ in the weir formula

$$
Q=C L H^{n} \text {. }
$$

Francis here found $n=1.47$, but adopted the value $n=1.5=3 / 2$, in the experiments of 1852 .

The Pawtucket canal lock was not in use at the time of the Lowell experiments in 1852 and the miter gates at the upper lock chamber were removed and the weir was erected in the lower hollow quoin of the gate chamber. The middle gates at the foot of the upper chamber were replaced by a bulkhead having a sluice for drawing off the water. A timber flume in the lower chamber of the lock was used as a measuring basin to determine the flow over the weir. Its length was 102 feet and its width about 11.6 feet. A swinging apron gate was so arranged over the crest of the weir that, when opened, the water flowed freely into the measuring basin below, and when closed, with its upper edge against the weir, the overflow passed into a wooden diverting channel, placed across the top of the lock chamber, and flowed into Concord River. An electric sounder was attached to the gate framework, by which a signal was given when the edge of the swinging gate was at the center of the nappe, when either opening or closing. By this means the time of starting and stopping of each experimental period was observed on a marine chronometer. The depth on the weir was observed by hook gages. The readings were taken in wooden stilling boxes, 11 by 18 inches square, open at the top, and having a 1-inch round hole through the bottom, which was about $t$ inches below the weir crest. The weir was in the lower quoin of the gate recess, and the hook gage boxes were in the upper quoin, projecting slightly beyond the main lock walls. In weirs with end 
contractions the full width of the channel was used. For suppressed weirs, a leading channel having a width equal to the length of the weir crest was formed by constructing vertical timber walls within the main canal, extending 20 feet upstream from the weir and having their upper ends flaring about 1 foot toward the canal walls. Water was freely admitted on both sides of these timber walls. The hook gage boxes were outside of this channel. The holes in the bottom were plugged, and flush piezometer pipes were used to connect the hook-gage boxes with the imner face of the side walls of the channel of approach. Observations of the head by hook gage were taken at intervals of about 15 seconds. Each experimental period covered from 190 to 900 seconds. The hook-gage readings were reduced to weir crest level as a datum and arranged in groups of two or three, which agreed closely. The mean head was determined by the correction formula (48). In one period, 18 observations of heads ranged from 0.6310 to 0.6605 foot; their arithmetical mean was 0.6428 ; the computed correction was minus 0.0008 .

The measured head was corrected for velocity of approach by using the theoretical formula given below. The range and character of the experiments, logether with the general results, are shown in the following table:

Thin-edged weir experiments of J. B. Francis at the lower locks, Lowell, Mass., 1852.

\begin{tabular}{|c|c|c|c|c|c|c|c|c|c|c|c|c|c|c|}
\hline \multicolumn{2}{|c|}{$\begin{array}{l}\text { Serial } \\
\text { num- } \\
\text { bers of } \\
\text { experi- } \\
\text { ments. }\end{array}$} & \multirow{2}{*}{ 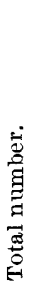 } & \multirow{2}{*}{ 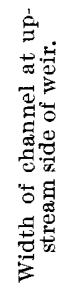 } & \multirow{2}{*}{ 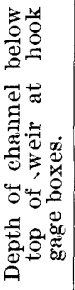 } & \multicolumn{2}{|c|}{$\begin{array}{l}\text { Range of ob- } \\
\text { served head, } \\
\text { in feet. }\end{array}$} & \multicolumn{2}{|c|}{$\begin{array}{l}\text { Range of ve- } \\
\text { locity of } \\
\text { approach, in } \\
\text { feet per } \\
\text { second. }\end{array}$} & \multirow{2}{*}{ 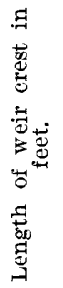 } & \multirow{2}{*}{ 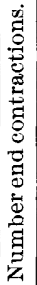 } & \multirow{2}{*}{ 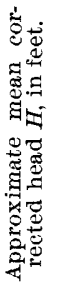 } & \multicolumn{3}{|c|}{$\begin{array}{c}\text { Discharge coefficient } \\
C .\end{array}$} \\
\hline 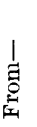 & $\stackrel{1}{d}$ & & & & $\underset{\substack{\mid \\
\text { 点 }}}{\mid}$ & $\stackrel{1}{0}$ & 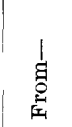 & $\stackrel{1}{\substack{1 \\
\leftrightarrow}}$ & & & & 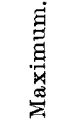 & 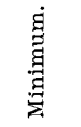 & 冚 \\
\hline 1 & 4 & 4 & 13.96 & 5.048 & 1. 52430 & 1. 56910 & 0.7682 & 0.7889 & 9.997 & 2 & 1.56 & 3. 3318 & 3.3002 & 3.3181 \\
\hline 5 & 10 & 6 & 13.96 & 5. 048 & 1. 23690 & 1. 25490 & .5904 & .6000 & 9.997 & 2 & $1 .: 5$ & 3.3412 & 3.3159 & 3. 3338 \\
\hline 11 & 33 & 23 & 13.96 & 5. 048 & .91570 & 1.06920 & .3951 & .4863 & 9.997 & 2 & 1.00 & 3. 3333 & 3.3110 & 3. 3223 \\
\hline 34 & 35 & 2 & 13.96 & 5.048 & 1.01025 & 1.02625 & .3527 & .3596 & 7.997 & + & 1.02 & 3.3617 & 3. 3586 & 3. 3601 \\
\hline 36 & 43 & 8 & 13.96 & 2.014 & 1. 02805 & 1. 07945 & .9496 & 1. 0049 & 9.997 & 2 & 1.06 & 3.3567 & 3.3498 & 3. 3527 \\
\hline 44 & 50 & 7 & 9.992 & 5.048 & .97450 & .98675 & .6376 & .5455 & 9.995 & 0 & 0.98 & 3.3437 & 3. 3366 & 3.3409 \\
\hline 51 & 55 & $\tilde{y}$ & 9.992 & 5.048 & .99240 & 1.00600 & .5477 & .5589 & 9.995 & 0 & 1.00 & 3.3349 & 3.3243 & 3. 3270 \\
\hline 56 & 61 & 6 & 13.96 & 5.048 & .77690 & .81860 & .3170 & .3405 & 9.997 & 2 & 0.80 & 3. 3287 & 3.3188 & 3.3246 \\
\hline 62 & 66 & 5 & 13.96 & 2.014 & .77115 & .88865 & .6694 & .7963 & 9.997 & 2 & 0.83 & 3.3435 & 3.3376 & 3.3403 \\
\hline 67 & 71 & 5 & 9.992 & 5.048 & .7362 & .81495 & .3659 & .4213 & 9.995 & 0 & 0.80 & 3.3424 & 3.3341 & 3. 3393 \\
\hline 72 & 78 & 7 & 13.96 & 5. 048 & .59190 & .65525 & .2182 & .2509 & 9.997 & 2 & 0.62 & 3.3306 & 3.3237 & 3.3275 \\
\hline 79 & 84 & 6 & 13.96 & 2.014 & .63135 & . (5355 & .5193 & .5496 & 9.997 & 2 & 0.65 & 3.3278 & 3.3244 & 3. 3262 \\
\hline 85 & 88 & 4 & 13.96 & 2.014 & .66940 & .68815 & .4382 & .4526 & 7.997 & 4 & 0.68 & 3.33s2 & 3. 3333 & 3.3368 \\
\hline
\end{tabular}


From a discussion of these experiments Francis presents the final formula-

$$
Q=3.33 L H^{\frac{3}{2}}
$$

If there are end contractions,

$$
L=L^{\prime}-0.1 \mathrm{NH} \text {. }
$$

If there is velocity of approach,

$$
I^{\frac{3}{2}}=\left[(D+h)^{\frac{3}{2}}-h^{\frac{3}{2}}\right] \text {. }
$$

The mean velocity $v$ was determined by successive approximations; $h$ was determined by the usual formula-

$$
h=\frac{v^{2}}{2 g}
$$

The Francis formula for velocity of approach correction is cumbersome, and several substitutes have been devised, some of which are described in the following paragraphs.

(1) Determine the approximate velocity of approach $v_{1}$ by a single trial computation of $Q$, using $D=H$.

Then use

$$
H=D+\frac{v_{1}}{2 g}=D+h
$$

to determine the final value of $Q$. For a given value of $v$ this gives too large a value of $H$, but the approximate value of $v_{1}$ is somewhat too small, partially counterbalancing the error and usually giving a final value of $Q$ sufficiently precise.

(2) By developing into series and omitting the powers $h / D$ above the first, $h$ being always relatively small, the following closely approximate equivalent of the Francis correction formula, given by Emerson, ${ }^{a}$ is obtained:

$$
H=D+h-\frac{2}{3} \sqrt{\frac{h^{3}}{D}} \cdot \cdots \cdot \cdot \cdot \cdot \cdot
$$

(3) Hunking and $\mathrm{Hart}^{b}$ derive from the Francis correction formula the following equivalent expression:

$$
\begin{gathered}
K D^{\frac{3}{2}}=H^{\frac{3}{2}}=(D+h)^{\frac{3}{2}}-h^{\frac{3}{2}} \text {. . . . . . } \\
K=\left[1+\frac{C^{r 2}}{2 g}\left(\frac{D}{G}\right)^{2} K^{2}\right]^{\frac{3}{2}}-\left[\frac{C^{2}}{2 g}\left(\frac{D}{G}\right)^{2} K^{2}\right]^{\frac{3}{2}} .
\end{gathered}
$$

where $G$ is the area of channel section in which $D$ is measured, per unit length of crest. 
For a suppressed weir,

For a contracted weir,

$$
\left.\begin{array}{l}
G=P+D . \\
G=\frac{A}{L^{\prime}-0.1 V D .}
\end{array}\right\} \cdot . \cdot \cdot . \cdot
$$

Hunking and Hart have computed values of $K$ by the solution of the above formula for each 0.005 increment in $D G$ to 0.36 . The results extended by formula (23) are given below.

Velocity of approach correction, factor $K$, Hunking and Hart formula, $H^{\frac{3}{2}}=K D^{\frac{3}{2}}$.

\begin{tabular}{|c|c|c|c|c|c|c|c|}
\hline$D / G$ & 0.0 & 0.1 & 0.2 & 0.3 & 0.4 & 0.5 & 0.6 \\
\hline .000 & 1. 00000 & 1. 002528 & 1.009980 & 1. 022359 & 1. 039840 & 1.062250 & 1.08964 \\
\hline .005 & 1.000006 & 1. 002785 & 1. 010480 & 1. 023110 & 1. 040836 & 1. 063495 & 1. 091134 \\
\hline .010 & 1.000026 & 1. 003053 & 1.010994 & 1.023875 & 1. 041832 & 1. 064740 & 1.092628 \\
\hline .015 & 1.000058 & 1. 003335 & 1. 011519 & 1.024653 & 1.042828 & 1.065985 & 1.094122 \\
\hline .020 & 1. 000103 & 1.003628 & 1. 012057 & 1.025444 & 1.043824 & 1.067230 & 1.095616 \\
\hline .025 & 1. 000161 & 1.003983 & 1. 012607 & . 1.026248 & 1. 045069 & 1.068724 & 1. 097359 \\
\hline .030 & 1.000231 & 1.004251 & 1. 013169 & 1. 027065 & 1. 046065 & 1. 069969 & 1.098853 \\
\hline .035 & 1.000314 & 1.004581 & 1. 013744 & 1. 027895 & 1. 047061 & 1. 071214 & 1. 100347 \\
\hline .040 & 1. 000409 & 1. 004923 & 1. 014331 & 1. 028739 & 1. 048306 & 1.072708 & 1.102090 \\
\hline .045 & 1.000518 & 1. 005278 & 1.014931 & 1. 029596 & 1. 049302 & 1.073953 & 1. 103584 \\
\hline .050 & 1.000638 & 1. 005644 & 1. 015543 & 1.030467 & 1. 050298 & 1. 075198 & 1.105078 \\
\hline .055 & 1.000772 & 1. 006023 & 1.016167 & 1.031350 & 1. 051543 & 1.076692 & 1. 106821 \\
\hline .060 & 1. 000917 & 1. 006414 & 1. 016805 & 1. 032248 & 1. 052788 & 1.078186 & 1.108564 \\
\hline .065 & 1.001075 & 1. 006817 & 1.017455 & 1.033117 & 1. 053784 & 1.079431 & 1. 110058 \\
\hline .070 & 1.001246 & 1. 007232 & 1.018107 & 1. 034113 & 1.055029 & 1.080925 & 1.111801 \\
\hline .075 & 1. 001429 & 1.007659 & 1. 018792 & 1. 035109 & 1. 056274 & 1.082419 & 1.113544 \\
\hline .080 & 1.001624 & 1. 008099 & 1.019480 & 1.035856 & 1. 057270 & 1. 083664 & 1.115038 \\
\hline .085 & 1. 001832 & 1. 008551 & 1.020180 & 1. 036852 & 1.058515 & 1.085158 & 1.116781 \\
\hline .090 & 1. 002051 & 1.009015 & 1. 020893 & 1.037848 & 1. 059760 & 1.086652 & 1.118524 \\
\hline .095 & 1. 002284 & 1. 009491 & 1.021620 & 1. 038844 & 1. 061005 & 1. 088146 & 1. 120267 \\
\hline
\end{tabular}

The general formula for $K$ is too complex for common use. The expressions

and

$$
K=1+0.2489\left(\frac{D}{G}\right)^{2} \quad \cdot \quad \cdot \quad . \quad . \quad .
$$

$$
K=1+\left(\frac{D}{2 G}\right)^{2} \cdot \cdot \quad \cdot \quad . \quad \cdot \quad \cdot \quad . \quad .
$$

are stated to give results correct within one-hundredth and one-fiftieth of 1 per cent, respectively, for values of $h$ less than 0.36 .

\section{EXPERIMENTS AND FORMULAS OF FTELEY AND STEARNS.}

The first series of experiments by Fteley and Stearns on thin-edged weir discharge $^{a}$ were made in March and April, 1877, on a suppressed weir, with crest 5 feet in length, erected in Sudbury conduit below Farm Pond, Metropolitan waterworks of Boston.

Water from Farm Pond was let into the leading channel through

a Fteley, A., and Stearns, F. F., Experiments on the flow of water, etc.: Trans. Am. Soc. C. E., vol. 12, Jan., Feb., Mar., 1883, pp. 1-118. 
head-gates until the desired level for the experiment, as found by previous trial, was reached. A swinging gate was then raised from the crest of the weir and the water was allowed to flow over. The maintenance of a uniform regimen was facilitated by the large area and the consequent small variation of level in Farm Pond, so that the outflow from the gates was sensibly proportional to the height they were raised. The water flowed from the weir into the conduit channel below, and was measured volumetrically. For the smaller heads the length of the measuring basin was 22 feet, and for the larger heads 367 feet.

The crest depth was observed by hook gage in a pail below the weir, connected to the channel of approach by a rubber tube entering the top of the side wall, 6 feet upstream from the weir crest. Hook-gage readings of head were taken every half minute until uniform regimen was established, and every minute thereafter. The depths in the measuring basin were also taken by hook gage. The bottom of the conduit was concave, and was graded to a slope of 1 foot per mile. It was covered with water prerious to each experiment, leaving a nearly rectangular section.

The experiments in 1877 included 31 depths on a suppressed weir of 5 feet crest length, 3.17 feet high. The observed heads varied from 0.0735 to 0.8198 foot.

In 1879 a suppressed weir, with a crest length of 19 feet, was erected in Farm Pond Gate House. Head-gates and screens were close to weir; otherwise the apparatus for measuring head and starting and stopping flow was similar to that used in previous experiments. The crest of the weir was an iron har $3 \frac{1}{2}$ inches wide and one-fourth inch thick, planed and filed and attached to the upper weir timber with screws. No variation in level of the weir crest occurred. $A s$ in the preceding experiments, no by-pass was provided, and the entire overflow entered Sudbury conduit below the weir. The conduit was partly filled with water at the start, leaving a nearly rectangular section, 11,300 feet in length and about 9 feet wide. A difference of 3 feet in water level was utilized in measuring discharge, the total capacity being 300,272 cubic feet. Semipartitions were provided to reduce oscillation of the water. Many observations, covering a considerable period of time, were required to determine the true water level. This series of experiments included 10 depths on a suppressed weir 19 feet long and 6.55 feet high, with measured heads varying from 0.4685 to 1.6038 feet and velocities of approach ranging from 0.151 to 0.840 foot per second.

From measurements on weirs 5 and 19 feet in length, respectively, and from a recalculation of the experiments of James B. Francis, Fteley and Stearns obtained the final formula

$$
Q=3.31 L H^{\frac{3}{2}}+0.007 L \quad . \quad . \quad . \quad . \quad .
$$


In the above, if there is velocity of approach,

$H=D+\alpha h$.

$\alpha=1.5$ for suppressed weirs.

$\alpha=2.05$ for weirs with end contractions.

The value of the velocity head coefficient $\alpha$ was determined from 94 additional experiments on the 5-foot weir in 1878 . These involved measured heads ranging from 0.1884 to 0.9443 foot, heights of weir ranging from 0.50 to 3.47 feet, and velocities of approach reaching a maximum of 2.35 feet per second. Also 17 experiments were made on weirs 3,3.3, and 4 feet long respectively; the first with two and the last two with one end contraction. These experiments included measured heads varying from 0.5574 to 0.8702 foot, and velocities of approach from 0.23 to 1.239 feet per second.

. In all experiments on velocity of approach, the head was measured 6 feet upstream from erest. The width of channel was 5 feet. ${ }^{a}$

Fteley and Stearns found the following values of $\alpha$ for suppressed weirs:

Fteley and Stearns's value of $\alpha$ for suppressed weirs.

\begin{tabular}{|c|c|c|c|c|}
\hline \multirow{2}{*}{$\begin{array}{l}\text { Measured } \\
\text { depth on } \\
\text { weir, } \\
\text { in feet. }\end{array}$} & \multicolumn{4}{|c|}{$\begin{array}{l}\text { Depth of channel of approach below weir } \\
\text { erest, in feet. }\end{array}$} \\
\hline & 0.50 & 1.00 & 1.70 & $2.60 \mathrm{~b}$ \\
\hline 0.2 & 1.70 & 1.87 & 1.66 & 1.51 \\
\hline .3 & 1.53 & 1.83 & 1.65 & 1.50 \\
\hline .4 & 1.53 & 1.79 & 1.63 & 1.49 \\
\hline .5 & 1.53 & 1.75 & 1. 62 & 1.48 \\
\hline .6 & 1.52 & 1.71 & 1.60 & 1.47 \\
\hline .7 & 1.51 & 1.68 & 1.59 & 1.46 \\
\hline .8 & c 1.50 & ce 1.65 & 1.57 & 1.45 \\
\hline .9 & 1. 49 & 1.63 & 1.56 & $c 1.44$ \\
\hline 1.0 & 1.48 & 1.61 & 1.54 & 1.43 \\
\hline 1.1 & & 1.59 & 1. 53 & 1. 42 \\
\hline 1.2 & & 1.57 & 1.51 & 1.41 \\
\hline 1.3 & & 1.55 & 1. 49 & 1.40 \\
\hline 1. 4 & & 1. 54 & 1.48 & 1.39 \\
\hline 1.5 & & 1.52 & 1.46 & 1.38 \\
\hline 1.6 & & 1.51 & 1. 44 & 1.37 \\
\hline 1.7 & & 1. 49 & 1.43 & 1. 36 \\
\hline 1.8 & & & 1.41 & 1.35 \\
\hline 1.9 & & & 1. 40 & 1. 34 \\
\hline 2.0 & & & 1.38 & 1. 33 \\
\hline
\end{tabular}

$a$ Fteley and Stearns, idem, pp. 5-23.

$b$ Applicable to greater heights of weir.

c Limit of experiments. 
Current-meter measurements showed a nearly uniform distribution of velocities in the channel of approach above the 19-foot weir, a fact to be taken account of when the formulas are applied to cases where the velocity of approach varies in different portions of the leading channel.

If there are end contractions, the net length of weir should be determined by the Francis formula,

$$
L=L^{\prime}-0.1 N H \text {. }
$$

The head should be measured at the surface of the channel of approach, 6 feet upstream from the weir crest.

\section{BAZIN'S EXPERIMENTS.}

Bazin's experiments on thin-edged weirs were performed in the side channel of the Canal de Bourgogne, near Dijon, France, and were begun in 1886. Their results were published in Annales des Ponts et Chaussées and have been translated by Marichal and Trautwine. ${ }^{a}$

The standard weir consisted of horizontal timbers 4 inches square, with an iron erest plate 0.276 inch in thickness. Air chambers were placed at the ends of the weir on the downstream side, to insure full aeration of the nappe. End contractions-were suppressed. The height of the first weir was 3.27 feet above channel bottom, and the head was measured in "Bazin pits," one at each side of the channel 16.40 feet upstream from the weir crest. The pit consisted of a lateral chamber in the cement masonry forming the walls of the canal. The chamber was square, 1.64 feet on each side, and communicated with the channel of approach by a circular opening 4 inches in diameter, placed at the bottom of the side wall and having its mouth exactly flush with the face of the wall. The oscillations of the water surface in the lateral chamber were thus rendered much less prominent than in the channel of approach. The water level in the Bazin pit was observed by dial indicators attached to floats, the index magnifying the variations in water level four times, the datum for the indicators having been previously determined by means of hook gages placed above the crest of the weir and by needle-pointed slide gages in the leading channel.

A drop gate was constructed on the crest of the weir to shut off the discharge at will. In each experiment the head-gates through which the water entered the leading channel were first raised and the water was allowed to assume the desired level. The weir gate was then raised, and the head-gates were manipulated to maintain a nearly con-

a Bazin, H., Recent experiments on flow of water over weirs, translated from the French by Marichal and Trautwine: Proc. Engineers' Club Phila., vol. 7, Jan., 1890, pp. 259-310; vol. 9, pp. 231-244, 287-319; vol. 10, pp. 121-164. 
stant inflow. The arithmetical mean of the observations during each period of uniform regimen was used as the measured head for that experiment.

The overflow passed into a measuring channel, 656.17 feet in length, whose walls were made of smooth Portland cement concrete. The channel was 6.56 feet wide, its side walls were 3.937 feet high, and its lower end was closed by water-tight masonry. Its bottom was graded to a slope of about 1:1,000. The volume of inflow was determined by first covering the channel bottom with water, then noting the change of level during each experimental period, the capacity of the channel at various heights having previously been carefully determined. A slight filtration occurred, necessitating a correction of about one-eighth of 1 per cent of the total volume. The observations for each regimen were continued through a period of 12 to 30 minutes.

Sixty-seven experiments were made on a weir 3.72 feet high, includ ing heads from the least up to 1.017 feet. Above this point the volumetric measuring channel filled so quickly as to require the use of a shorter weir. Thirty-eight experiments were made with a standard weir, 3.28 feet long and 3.72 feet high, with heads varying from the least up to 1.34 feet. For heads exceeding 1.34 feet it was necessary to reduce the height of the weir in order that the depth above the weir should not exceed that of the channel of approach. Forty-eight experiments were made on a weir 1.64 feet long and 3.297 feet high, with heads ranging from the least up to 1.780 feet. These experiments sufficed to calibrate the standard weir with a degree of accuracy stated by Bazin as less than 1 per cent of error.

In order, to determine the effect of varying velocities of approach the following additional series of experiments were made on suppressed weirs 2 meters ( 6.56 feet) in length.

Experiments on suppressed weirs 2 meters in length.

\begin{tabular}{|r|c|c|c|}
\hline $\begin{array}{r}\text { Number } \\
\text { of experi- } \\
\text { ments. }\end{array}$ & \multicolumn{2}{|c|}{ Range of head in feet. } & $\begin{array}{c}\text { Height of } \\
\text { experimen- } \\
\text { tal weir, in } \\
\text { feet. }\end{array}$ \\
\cline { 2 - 3 } & From- & To- & rom \\
\hline $28+30$ & 0.489 & 1.443 & 2.46 \\
$29+29$ & .314 & 1.407 & 1.64 \\
$27+41$ & .298 & 1.338 & 1.15 \\
44 & .296 & 1.338 & 0.79 \\
\hline
\end{tabular}

The standard weir was 3.72 feet high, and the experimental weirs were placed 46 to 199 meters downstream. The discharge was not measured volumetrically. A uniform regimen of flow was established and the depths on the two weirs were simultaneously observed during each period of flow. 
These experiments afforded data for the determination of the relative effect of different velocities of approach, corresponding to the different depths of the leading channel.

From these experiments Bazin deduces coefficients for a thin-edged weir 3.72 feet high, for heads up to 1.97 feet, stated to give the true discharge within 1 per cent. ${ }^{a}$

\section{BAZIN'S FORMULAS FOR THIN-EDGED WEIRS.}

Starting with the theoretical formula for a weir without velocity of approach, in the form

and substituting

$$
Q=\mu L H \sqrt{2 g H}
$$

$$
D+\alpha \frac{v^{2}}{2 q}
$$

for $H$, in the case of a weir having velocity of approach, there results,

$$
Q=\mu L\left(D+\alpha \frac{v^{2}}{2 g}\right) \sqrt{2 g\left(D+\alpha \frac{v^{2}}{2 g}\right)} .
$$

Bazin obtained, by mathematical transformation, the equivalent ${ }^{b}$

or

$$
Q=\mu L D \sqrt{2 g D}\left(1+\alpha-\frac{v^{2}}{2 g D}\right)^{\frac{3}{2}}
$$

Bazin writes

$$
Q=\mu\left(1+\alpha \frac{v^{2}}{2 g D}\right)^{\frac{3}{2}} L D \sqrt{2 g D} \text {. }
$$

$$
m=\mu\left(1+\alpha \frac{v^{2}}{2 g D}\right)^{\frac{3}{2}} \text {. . . . . . . . }
$$

for which equation he obtains, by mathematical transformation, the approximate equivalent ${ }^{c}$

$$
m=\mu\left(1+\frac{3}{2} \alpha \frac{v^{2}}{2 g D}\right) \cdot \cdot \cdot \cdot \cdot \cdot \cdot \cdot \cdot
$$

The calculation of the factor " appearing in this formula requires the discharge $Q$ to be known.

Assuming that the channel of approach has a constant depth $P$ below the crest of the weir, and that its width is equa'. to the length of the

a Bazin, H., Expériences nouvelles sur l'écoulement en déversoir: Ann. Ponts et Chaussées, Mém. et Doc., 1898, $2^{\text {me }}$ trimestre. See translation by Marichal and Trautwine in Proc. Eng. Club Phila., vol.7, pp. 259-310; vol. 9, pp. 231-244.

$b$ The steps in the derivation of this formula are given by Trautwine and Marichal in their translation of Bazin's report of his experiments, in Proc. Eng. Club Phila., vol. 7, p. 280.

$c$ The steps in detail are given by Trautwine and Marichal in their translation of Bazin, in Proc. Eng. Club Phila., vol. 7, No. 5, p. 281. 
weir, $v$ may be expressed in terms of these factors, and of the discharge $(Q=m L D \sqrt{2 g D})$.

$$
v=\frac{Q}{L(P+D)}
$$

Using this value of $v$, Bazin obtains the expression

$$
m=\mu\left[1+\omega\left(\frac{D}{D+P}\right)^{2}\right] . \cdot . \cdot . \quad .
$$

where $\omega_{0}=\frac{3}{2} \alpha m^{2} . \quad \omega$ is a nearly constant factor, varying only with $m^{2}$. The value of $\omega$ as well as that of $\alpha$ can be determined by comparative experiments on thin-edged weirs of different heights. ${ }^{a}$

From a discussion of his own experiments and those of Fteley and Stearns, Bazin finally obtained the formulas

$$
\begin{aligned}
& \left.\begin{array}{l}
Q=\mu L H \sqrt{2 g H}, \text { no velocity of approach; } \\
Q=m L D \sqrt{2 g D}, \text { with velocity of approach. }
\end{array}\right\} \text {. } \\
& \mu=0.405+\frac{0.003 \times 3.281}{D}=0.405+\frac{0.00984^{b}}{D} . \quad \text {. }
\end{aligned}
$$

For a weir with velocity of approach $\alpha=\frac{5}{3}$ and $\omega=0.55$. Substituting in equations (27) and (28),

$$
\begin{aligned}
& m=\mu\left(1+\frac{3}{2} \cdot \frac{5}{3} \cdot \frac{v^{2}}{2 g D}\right)=\mu\left(1+2.5 \frac{v^{2}}{2 g D}\right) . . . \\
& m=\mu\left[1+0.55\left(\frac{D}{P+D}\right)^{2}\right] . \text {. . . . . . . }
\end{aligned}
$$

These formulas give values of $m$ agreeing with the results of the experiments within 1 per cent for weirs exceeding about 1 foot in height within the experimental range of head.

Approximately, for heads from 4 inches to 1 foot,

$$
m=0.425+0.21\left(\frac{D}{P+D}\right)^{2} \cdot . \quad . \quad . \quad .
$$

correct within 2 to 3 per cent.

The following table gives Bazin's experimental coefficients, the head and height of weir (originally meters) having been reduced to feet:

\footnotetext{
$a$ For detailed analysis see Trautwine and Marichal, Proc. Eng. Club Phila., vol. 7, pp. 282-283.

$b$ Experimental tabular values of $\mu$ differing very slightly from the formula within the range of Bazin's experiments are also given.
} 
Values of the Bazin coefficient $C$ in the formula $Q=C L H^{\frac{3}{3}}$ for a thin-edged weir, without end contraction.

\begin{tabular}{|c|c|c|c|c|c|c|c|c|c|c|c|}
\hline \multirow{2}{*}{$\begin{array}{c}\text { Measured } \\
\text { head } D .\end{array}$} & \multicolumn{10}{|c|}{ Height of crest of weir above bed of channel of approach, in feet. } & \multirow{2}{*}{$\begin{array}{c}\text { Measured } \\
\text { head } D .\end{array}$} \\
\hline & 0.66 & 0.98 & 1.31 & 1.64 & 1.97 & 2.62 & 3.28 & 4.92 & 6.56 & $\infty$ & \\
\hline Feet. & $C$ & $C$ & $C^{\prime}$ & $C$ & $C$ & C & $C$ & $C$ & $C$ & $C$ & Meters. \\
\hline 0.164 & 3.673 & 3.683 & 3.617 & 3.609 & 3.601 & 3.601 & 3.601 & 3.593 & 3.593 & 3.594 & 0.05 \\
\hline .197 & 3.657 & 3.609 & 3.585 & 3.569 & 3.569 & 3.561 & 3.553 & 3.553 & 3.553 & 3.550 & .06 \\
\hline .230 & 3. 649 & 3. 593 & 3.569 & 3.553 & 3.545 & 3.537 & 3.529 & 3.529 & 3.521 & 3.522 & .07 \\
\hline .262 & 3.657 & 3.585 & 3.553 & 3.537 & 3. 529 & 3.513 & 3.513 & 3.505 & 3.505 & 3. 499 & .08 \\
\hline .295 & 3.665 & 3.585 & 3.545 & 3.529 & 3.513 & 3.497 & 3.497 & 3.489 & 3.481 & 3.481 & .09 \\
\hline .328 & 3.681 & 3.585 & 3.545 & 3.521 & 3. 505 & 3.489 & 3. 481 & 3.473 & 3.473 & 3.466 & .10 \\
\hline .394 & 3.705 & 3.593 & 3.545 & .3 .513 & 3.497 & 3.473 & 3. 465 & 3.449 & 3.449 & 3.441 & .12 \\
\hline .459 & 3.737 & 3. 609 & 3.553 & 3.513 & 3.489 & 3.465 & 3.449 & 3.432 & 3.432 & 3.422 & .14 \\
\hline .525 & 3.777 & 3.633 & 3.561 & 3.513 & 3.489 & 3.457 & 3.440 & 3.424 & 3.416 & 3.405 & .16 \\
\hline .591 & 3.810 & 3. 657 & 3. 569 & 3.521 & 3.489 & 3.457 & 3.432 & 3.416 & 3.408 & 3.392 & .18 \\
\hline .656 & 3.850 & 3. 681 & 3.585 & 3. 529 & 3.497 & 3,457 & 3. 432 & 3.408 & 3.392 & 3.380 & .20 \\
\hline .722 & 3.882 & 3.705 & 3. 601 & 3.545 & 3.505 & 3.457 & 3.432 & 3.400 & 3.392 & 3.371 & .22 \\
\hline .787 & 3.914 & 3.729 & 3. 625 & 3.561 & 3.513 & 3.465 & 3.432 & 3.400 & 3.384 & 3.364 & .24 \\
\hline .853 & 3.946 & 3.753 & 3. 649 & 3.577 & 3. 529 & 3.465 & 3.140 & 3.400 & 3.384 & 3.358 & .26 \\
\hline .919 & 3.978 & 3. 785 & 3.665 & 3. 593 & 3.537 & 3.473 & 3. 440 & 3.400 & 3. 384 & 3. 353 & .28 \\
\hline .984 & 4.010 & 3.810 & 3. 689 & 3. 609 & 3.553 & 3.481 & 3. 449 & 3.400 & 3.376 & 3.348 & .30 \\
\hline 1.050 & & 3.834 & 3.705 & 3.625 & 3.561 & 3.497 & 3.449 & 3.400 & 3.376 & 3.343 & .32 \\
\hline 1.116 & & 3.858 & 3.721 & 3. 641 & 3.577 & 3.505 & 3.457 & 3.400 & 3.376 & 3.338 & .34 \\
\hline 1.181 & & 3.874 & 3.745 & 3.657 & 3.593 & 3.513 & 3.465 & 3.400 & 3.376 & 3.333 & .36 \\
\hline 1. 247 & & 3.898 & 3.761 & 3.673 & 3.601 & 3.521 & 3.465 & 3.400 & 3.376 & 3.328 & .38 \\
\hline 1.312 & & 3.922 & 3.785 & 3.681 & 3.617 & 3.529 & 3.473 & 3.400 & 3.376 & 3.323 & .40 \\
\hline 1.. 378 & ${ }^{-}$ & 8.938 & 3.801 . & 3. 697 & 3.625 & 3.537 & 3.481 . & 3.408 & 3.376 & 3.319 & .42 \\
\hline 1.444 & & 3.962 & 3.818 & 3.713 & 3.641 & 3.545 & 3.489 & 3.408 & 3.376 & 3.316 & .44 \\
\hline 1.509 & & 3.978 & 3.834 & 3.729 & 3.657 & 3.553 & 3.489 & 3. 408 & 3.376 & 3. 311 & .46 \\
\hline 1.575 & & & 3.850 & 3.745 & 3.665 & 3.561. & 3.497 & 3.408 & 3.376 & 3. 306 & .48 \\
\hline 1.640 & & & 3.866 & 3.753 & 3. 681 & 3.569 & 3.505 & 3.416 & 3.376 & 3.303 & .50 \\
\hline 1. 706 & & & 3.874 & 3.769 & 3.689 & 3.577 & 3.513 & 3.416 & 3. 376 & 3.298 & .52 \\
\hline 1.772 & & & 3.890 & 3.785 & 3.697 & 3.585 & 3.513 & 3.416 & 3.376 & 3. 294 & .54 \\
\hline 1.837 & & & 3.906 & 3.793 & 3.713 & 3.593 & 3.521 & 3.424 & 3. 376 & 3. 289 & .56 \\
\hline 1.903 & & & 3.922 & 3.810 & 3.721 & 3.601 & 3.529 & 3.424 & 3.376 & 3.285 & .58 \\
\hline 1.969 & & & 3.930 & 3.818 & 3.737 & 3. 617 & 3.537 & 3.424 & 3.376 & 3. 282 & .60 \\
\hline Meters. & 0.20 & 0.30 & 0.40 & 0.50 & 0.60 & 0.80 & 1.00 & 1.50 & 2.00 & $\infty$ & \\
\hline
\end{tabular}

This table, unfortunately, is inconvenient for interpolation in English units. The values also differ slightly from those computed from the formulas. The table illustrates the difficulty of practical application of a weir formula in which the coefficient varies rapidly both with head and height of weir. 
A table has been added giving values of $\mu$ computed by formula (30) for a thin-edged weir without velocity of approach.

Talues of $\mu$ in the Bazin formula for weirs of infinite height, with no velocity of approach.

\begin{tabular}{|c|c|c|c|c|c|c|c|c|c|c|c|}
\hline $\begin{array}{c}H . \\
\text { Feet. }\end{array}$ & 0. & 0.01 , & 0.02 . & 0.08 & 0.04 & 0.05 & 0.06 . & 0.07 & 0.08 & 0.09 . & 0.1 . \\
\hline 0.0 & & 1. 389 & 0.8970 & 0.7331 & 0. 6510 & 0.6018 & 0.5693 & 0.5457 & 0.5280 & 0.5142 & 0.5034 \\
\hline .1 & 0.5034 & .4944 & .4870 & .4807 & .4753 & .4706 & .4665 & .4628 & .4596 & .4568 & .4542 \\
\hline .2 & .4542 & .4518 & .4497 & .4478 & .4460 & .4444 & .4429 & .4414 & .4401 & .4389 & .4378 \\
\hline .3 & .4378 & .4367 & .4357 & .4348 & .4339 & 4331 & .4324 & .4316 & .4309 & .4302 & .4296 \\
\hline .4 & .4296 & .4290 & .4284 & .4278 & .4273 & .4268 & .4264 & .4260 & .4255 & .4251 & .4247 \\
\hline .5 & .4247 & .4243 & .4239 & .4236 & .4232 & .4229 & .4225 & .4222 & .4219 & .4216 & .4214 \\
\hline .6 & .4214 & .4211 & .4208 & .4206 & .4204 & .4202 & .4200 & .4197 & .1195 & .4193 & .4191 \\
\hline .7 & .4191 & .4189 & .4187 & .4185 & .4183 & .4181 & .4180 & .4178 & .4176 & .4174 & .4173 \\
\hline .8 & .4173 & .4171 & .4170 & .4168 & .4167 & .4166 & .4164 & .4163 & .4162 & .4160 & .4159 \\
\hline .9 & .4159 & .4158 & .4157 & .4156 & .4154 & .4153 & .4152 & .4151 & .4150 & .4149 & .4148 \\
\hline 1.0 & .4148 & .4147 & .4146 & .4146 & .4145 & .4144 & .4143 & .4142 & .4141 & .4140 & .4139 \\
\hline 1.1 & .4139 & .4139 & .4138 & .4137 & .4136 & .4136 & .4135 & .4134 & .4133 & .4133 & .4132 \\
\hline 1.2 & .4132 & .4131 & .4131 & .4130 & .4129 & .4129 & .4128 & .4127 & .4127 & .4126 & .4126 \\
\hline 1.3 & .4126 & .4125 & .4124 & .4124 & .4123 & .4123 & .4122 & .4122 & .4121 & .4121 & .4120 \\
\hline 1.4 & .4120 & .4120 & .4119 & .4119 & .4118 & .4118 & .4117 & .4117 & .4116 & .4116 & .4116 \\
\hline 1.5 & .4116 & . 4115 & .4115 & .4114 & .4114 & .4113 &.+113 & .4113 & .4112 & .4112 & .4112 \\
\hline 1.6 & .4112 & .4111 & .4111 & .4110 & .4110 & .4110 & .4109 & .4109 & .4108 & .4108 & .4108 \\
\hline 1.7 & .4108 & .4108 & .4107 & .4107 & .4107 & .4106 & .4106 & .4106 & .4105 & .4105 & .4105 \\
\hline 1.8 & .4105 & .4104 & .4104 & .4104 & .4103 & .4103 & .4103 & .4103 & .4102 & .4102 & .4102 \\
\hline 1.9 & .4102 & .4102 & .4101 & .4101 & .4101 & .4100 & .4100 & .4100 & .4100 & .4099 & .4099 \\
\hline 2.0 & .4099 & & & & & & & & & & 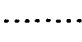 \\
\hline
\end{tabular}

DERIVED FORMULAS FOR THIN-EDGED RECTANGULAR WEIRS.

A number of weir formulas have been derived from subsequent analysis or recomputation of the experiments of Francis, Fteley and Stearns, and Bazin, differing more or less from those given by the experimenters.

FTELEY AND STEARNS-FRANCIS HORMULA. ${ }^{a}$

$$
Q=3.33 L H^{\frac{3}{2}}+0.007 L
$$

Correction for end contractions is to be made by the Francis formula; velocity of approach correction by the Fteley and Stearns formulas

$$
\begin{aligned}
& H=D+1.5 h, \quad \text { for suppressed weir. } \\
& H=D+2.05 h, \quad \text { for contracted weir. }
\end{aligned}
$$

\section{HAMILTON SMITH'S FORMULA. ${ }^{b}$}

The base formula adopted is

$$
Q=\frac{2}{3} M L H \sqrt{2 g H} \cdot \text {. . . . . . }
$$

a Fteley and Stearns, Experiments on the flow of water, etc.: Trans. Am. Soc. C. E., vol. 12, p. 82. $b$ Smith, Hamilton, Hydraulics, pp. 123-132. 
The velocity of approach correction is made by the use of the formulas

$$
\begin{array}{ll}
H=D+1.4 h, & \text { for contracted weirs. }{ }^{a} \\
H=D+1 \frac{1}{3} h, & \text { for suppressed weirs. }
\end{array}
$$

A diagram and tables of values of the coefficient $M$ are given by the author. The correction for partial or complete contraction is included in the coefficient, separate values of $M$ being given for suppressed and contracted weirs.

Making $C=\frac{2}{3} M I \sqrt{2 q}$, the Smith formula (35) may be written

$$
Q=C L H^{\frac{3}{2}}
$$

which is directly comparable with the Francis formula.

Smith's coefficients in the above form are given in the following tables.

\begin{tabular}{|c|c|c|c|c|c|c|c|c|c|}
\hline \multirow{2}{*}{$\begin{array}{c}H= \\
\text { Head, } \\
\text { in feet. }\end{array}$} & \multicolumn{9}{|c|}{$L^{\prime}=$ length of weir, in feet. } \\
\hline & 19 & 15 & 10 & 7 & 5 & 4 & $3 a$ & $2 \alpha$ & $0.66 b$ \\
\hline 0.1 & 3,515 & 3.515 & 3.520 & 3.520 & 3.526 & & & & 3.611 \\
\hline .15 & 3.440 & 3.445 & 3. 445 & 3.451 & 3.451 & 3.461 & 3.472 & 3.488 & 3.542 \\
\hline .2 & 3.397 & 3.408 & 3.408 & 3. 408 & 3.413 & 3.429 & 3.435 & 3.450 & 3.610 \\
\hline .25 & 3.371 & 3.376 & 3. 381 & 3. 386 & 3.392 & 3.403 & 3.413 & 3.429 & 3.494 \\
\hline .3 & 3.349 & 3.354 & 3.360 & 3.365 & 3.376 & $3.3 \$ 6$ & 3.403 & 3.418 & 3.483 \\
\hline .4 & 3. 322 & 3.328 & 3.333 & 3. 314 & 3.360 & 3.371 & 3. 386 & 3.403 & 3.478 \\
\hline .5 & 3.312 & 3.317 & 3.322 & 3. 338 & 3.354 & 3.371 & 3. 386 & 3.408 & 3.478 \\
\hline .6 & 3.306 & 3.312 & 3.317 & 3.333 & 3.354 & 3.371 & 3.392 & 3.413 & 3.483 \\
\hline .7 & 3.306 & 3.312 & 3.317 & 3.338 & 3.360 & 3.376 & 3.397 & 3.424 & 3.494 \\
\hline .8 & 3.306 & 3.317 & 3.322 & 3.344 & 3.365 & 3. 386 & 3. 408 & 3.441 & 3.510 \\
\hline .9 & 3.312 & 3.317 & 3.328 & 3.354 & 3. 375 & 3.397 & 3.418 & 3.451 & \\
\hline 1.0 & 3.312 & 3.322 & 3.338 & 3.360 & 3.386 & 3.408 & 3.429 & 3.467 & \\
\hline 1.1 & 3.317 & 3.328 & 3.344 & 3. 371 & 3.397 & 3.419 & 3.445 & & \\
\hline 1.2 & 3.317 & 3. 333 & 3.349 & 3. 381 & 3.403 & 3.429 & 3.456 & & \\
\hline 1.3 & 3.322 & 3.338 & 3.360 & 3.386 & 3.413 & 3.440 & 3.467 & & \\
\hline 1.4 & 3,328 & 3. 344 & 3.365 & 3. 392 & 3.424 & 3.445 & & & \\
\hline 1.5 & 3. 328 & 3.344 & 3.371 & 3.403 & 3,429 & 3.456 & & & \\
\hline 1.6 & 3.333 & 3.349 & 3.376 & 3. 408 & 3.435 & 3.461 & & & \\
\hline 1.7 & 3. 383 & 3.349 & 3. 381 & 3.413 & . & & & & \\
\hline 2.0 & 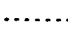 & $\ldots \ldots$ & ....... & ....... & & & & & \\
\hline
\end{tabular}

Hamilton Smith's coefficients for weirs with contraction suppressed at both ends, for use in the formula $Q=C L H H^{3}$.

a The use of the head corresponding to central surface velocity without correction, to determine $D$, is also recommended.

b Approximate. 
Hamilton Smith's coefficients for weirs with two complete end contractions, for use in the formula $Q=C L H^{\frac{3}{2}}$.

\begin{tabular}{|c|c|c|c|c|c|c|c|c|c|c|c|}
\hline \multirow{2}{*}{$\begin{array}{c}H= \\
\text { Head. }\end{array}$} & \multicolumn{11}{|c|}{$L^{\prime}=$ length of weir, in feet. } \\
\hline & 0.66 & $1 a$ & 2 & 2.6 & 3 & 4 & 5 & 7 & 10 & 15 & 19. \\
\hline 0.1 & 3.381 & 3.419 & 3.456 & 3.478 & 3.488 & 3.494 & 3.494 & 3.499 & 3.504 & 3.504 & 3.510 \\
\hline .15 & 3.312 & 3.344 & 3.392 & 3.408 & 3. 413 & 3.419 & 3.424 & 3.424 & 3. 429 & 3.435 & 3.435 \\
\hline .2 & 3.269 & 3.306 & 3.349 & 3.365 & 3.371 & 3.376 & 3.376 & 3. 381 & 3.386 & 3.392 & 3.392 \\
\hline .25 & 3.237 & 3.274 & 3.322 & 3.333 & 3. 338 & 3.344 & 3.349 & 3. 354 & 3.360 & 3.360 & 3.36 .5 \\
\hline .3 & 3.215 & 3.253 & 3. 296 & 3.306 & 3.312 & 3.322 & 3.322 & 3.333 & 3.338 & 3.338 & 3.344 \\
\hline .4 & 3.183 & 3.215 & 3.258 & 3.274 & 3.280 & 3.285 & 3. 290 & 3.301 & 3.306 & 3.312 & 3.317 \\
\hline .5 & 3.156 & 3.189 & 3. 237 & 3. 247 & 3.253 & 3. 264 & 3.269 & 3.280 & 3. 290 & 3.295 & 3.301 \\
\hline .6 & 3. 140 & 3.172 & 3.215 & 3.231 & 3.237 & 3.247 & 3. 253 & 3.269 & 3.280 & 3.285 & 3.290 \\
\hline .7 & 3.130 & 3.156 & 3.199 & 3.210 & 3.226 & 3.231 & 3.242 & 3.258 & 3. 274 & 3.280 & 3.285 \\
\hline .8 & & & 3. 183 & 3. 199 & 3.215 & 3. 221 & 3.231 & 3. 247 & 3.269 & 3.274 & 3. 280 \\
\hline .9 & & & 3.167 & 3. 189 & 3.199 & 3.210 & 3. 226 & 3.242 & 3. 258 & 3.269 & 3. 274 \\
\hline 1.0 & & & 3,156 & 3.172 & 3.183 & 3.199 & 3.215 & 3.281 & 3. 253 & 3.264 & 3. 269 \\
\hline 1.1 & & & 3.140 & 3.162 & 3.172 & 3.189 & 3.205 & 3.226 & 3.242 & 3. 258 & 3.264 \\
\hline 1.2 & & & 3. 130 & 3.151 & 3.162 & 3. 178 & 3. 194 & 3.215 & 3. 237 & 3. 253 & 3.264 \\
\hline 1.3 & & & 3.114 & 3.135 & 3.151 & 3.167 & 3. 199 & 3.205 & 3.231 & 3. 247 & 3.258 \\
\hline 1.4 & & & 3.103 & 3.124 & 3.140 & 3.156 & 3.178 & 3. 199 & 3.221 & 3. 242 & 3.258 \\
\hline 1.5 & & & & 3.114 & 3.130 & 3. 151 & 3.167 & 3.189 & 3.215 & 3. 237 & 3. 253 \\
\hline 1.6 & & & & 3.103 & 3.114 & 3.140 & 3.162 & 3. 183 & 3.210 & 3. 231 & 3.247 \\
\hline 1.7 & & & & & & & & 3.178 & 3.205 & 3.226 & 3.247 \\
\hline 2.0 & & & & & & & & & & $\ldots .$. & $\cdots$ \\
\hline
\end{tabular}

a Approximate.

Hamilton Smith's coefficient C for long weirs.

\begin{tabular}{|c|c|c|c|c|c|c|c|}
\hline$H$ & 0.1 & 0.2 & 0.3 & 0.4 & 0.5 & 0.6 & 0.7 \\
\hline .0 .00 & 3.5096 & 3.3972 & 3.3438 & 3.3170 & 3.3010 & 3.2956 & 3.2849 \\
.01 & 3.4957 & 3.3908 & 3.3411 & 3.3154 & 3.3005 & 3.2945 & 3.2838 \\
.02 & 3.4818 & 3.3844 & 3.3384 & 3.3138 & 3.2999 & 3.2935 & 3.2828 \\
.03 & 3.4678 & 3.3780 & 3.3358 & 3.3122 & 3.2994 & 3.2924 & 3.2817 \\
.04 & 3.4539 & 3.3716. & 3.3331 & 3.3106 & 3.2988 & 3.2913 & 3.2806 \\
.05 & 3.4400 & 3.3652 & 3.3304 & 3.3090 & 3.2983 & 3.2902 & 3.2796 \\
.06 & 3.4314 & 3.3537 & 3.3277 & 3.3074 & 3.2978 & 3.2892 & 3.2785 \\
.07 & 3.4229 & 3.3512 & 3.3250 & 3.3058 & 3.2972 & 3.2881 & 3.2773 \\
.08 & 3.4143 & 3.3488 & 3.3224 & 3.3042 & 3.2967 & 3.2870 & 3.2762 \\
.09 & 3.4058 & 3.3463 & 3.3197 & 3.3026 & 3.2961 & 3.2860 & 3.2752 \\
\hline
\end{tabular}

Hamilton Smith's formula is based on a critical discussion of the experiments of Lesbros, Poncelet and Lesbros, James B. Francis, Fteley and Stearns, and Hamilton Smith; including series with and .without contractions and having crest lengths from 0.66 to 19 feet. 
SMITH-FRANCIS FORMULA.

The Smith-Francis formula, ${ }^{a}$ based on Francis's experiments, reduced to the basis of correction for contractions and velocity of approach used with Hamilton Smith's formula, is,

for a suppressed weir,

$$
Q=3.29\left(L+\frac{H}{7}\right) H^{\frac{3}{2}} \cdot \cdot \cdot \cdot \cdot .
$$

for weir of great length or with one contraction,

$$
Q=3.29 L H^{\frac{3}{2}} \text {. . . . . . . . }
$$

for weir with full contraction,

$$
Q=3.29\left(L-\frac{H}{10}\right) H^{\frac{3}{2}} \text {. . . . . . }
$$

If there is velocity of approach,

$$
\begin{aligned}
H & =D+1.4 h, \quad \text { for a contracted weir. } \\
H & =D+1 \frac{1}{3} h, \quad \text { for a suppressed weir. }
\end{aligned}
$$

PARMLEY'S FORMULA. ${ }^{b}$

Parmley's formula is

$$
Q=C K L D^{\frac{3}{2}} \text {. } \quad . \quad \cdot \quad \cdot \quad . \quad \cdot
$$

If there are end contractions, the correction is to be made by the Francis formula,

$$
L=L^{\prime}-0.1 N H
$$

The factor $K$ represents the correction for velocity of approach.

The factor has been derived by comparing the velocity correction factor in the Bazin formula (formula 32), written in the form

$$
K=\left[1+0.55\left(\frac{a}{A}\right)^{2}\right]
$$

with the approximate Francis correction as deduced by Hunking and Hart (formula 23), written in the form

$$
K=\left[1+0.2489\left(\frac{a}{A}\right)^{2}\right]
$$

where $a$ is the area of the section of discharge, for either a suppressed or contracted weir, and $A$ is the section of the leading channel. It is observed that there is an approximately constant relation between the two corrections, that of Bazin being 2.2 times that of Francis.

$b$ Rafter, G. W., On the flow of water over dams: Trans. Am. Soc. C. E., vol. 44, pp. 350-359, discussion by Walter C. Parmley. 
Parmley adopts the Bazin correction and gives the following table, which may also conveniently be applied in computing discharge by Bazin's formula.

The discharge coefficient $C$ used by Parmley is that for a weir with no velocity of approach, as in the Francis formula. It is not, however, constant. Its values have been deduced from a mean curve representing the experiments of Francis, Fteley and Stearns, and Bazin.

Velocity of approach correction, $K$, Parmley and Bazin formulas.

\begin{tabular}{|r|c|c|c|c|c|c|}
\hline \multicolumn{1}{|c|}{$\frac{1}{A}$} & 0 & 0.1 & 0.2 & 0.3 & 0.4 & 0.5 \\
\hline 0.00 & $\ldots \ldots \ldots .$. & 1.0055 & 1.0220 & 1.0495 & 1.0880 & 1.1375 \\
.01 & 1.0001 & 1.0066 & 1.0243 & 1.0529 & 1.0925 & 1.1431 \\
.02 & 1.0002 & 1.0079 & 1.0266 & 1.0563 & 1.0970 & 1.1487 \\
.03 & 1.0005 & 1.0093 & 1.0291 & 1.0599 & 1.1017 & 1.1545 \\
.04 & 1.0009 & 1.0108 & 1.0317 & 1.0636 & 1.1065 & 1.1604 \\
.05 & 1.0014 & 1.0124 & 1.0344 & 1.0674 & 1.1114 & 1.1664 \\
.06 & 1.0020 & 1.0141 & 1.0372 & 1.0713 & 1.1164 & 1.1725 \\
.07 & 1.0027 & 1.0159 & 1.0401 & 1.0753 & 1.1215 & 1.1787 \\
.08 & 1.0035 & 1.0178 & 1.0431 & 1.0794 & 1.1267 & 1.1850 \\
.09 & 1.0044 & 1.0198 & 1.0463 & 1.0837 & 1.1321 & 1.1915 \\
\hline
\end{tabular}

Parmley's weir formula, coefficient $C$.

\begin{tabular}{|c|c|c|c|c|c|c|c|c|c|c|}
\hline$\underset{\text { feet. }}{D,}$ & 0.00 & 0.01 & 0.02 & 0.03 & 0.04 & 0.05 & 0.06 & 0.07 & 0.08 & 0.09 \\
\hline \multicolumn{11}{|l|}{0.0} \\
\hline .1 & 3. 580 & 3.568 & 3.556 & 3.544 & 3.532 & 3.520 & 3.512 & 3.503 & 3.495 & 3.486 \\
\hline .2 & 3.478 & 3.471 & 3.464 & 3.458 & 3.451 & 3.444 & 3.439 & 3.434 & 3.430 & 3. 425 \\
\hline .3 & 3.420 & 3.416 & 3.412 & 3.408 & 3.404 & 3.400 & 3.397 & 3.394 & 3. 391 & 3.388 \\
\hline .4 & $3.38 \overline{0}$ & 3. 383 & 3. 381 & 3. 380 & 3.378 & 3.376 & 3.374 & 3.373 & 3.371 & 3.370 \\
\hline .5 & 3.368 & 3. 367 & 3. 366 & 3.364 & 3.363 & 3. 362 & 3. 361 & 3.360 & 3.360 & 3.359 \\
\hline .6 & 3. 358 & 3.357 & 3. 356 & 3. 356 & 3.355 & 3. 354 & 3.353 & 3. 353 & 3.352 & 3. 352 \\
\hline .7 & 3. 351 & 3. 351 & 3.350 & 3.350 & 3. 349 & 3. 349 & 3. 348 & 3.348 & 3.347 & 3. 347 \\
\hline .8 & 3. 346 & 3.345 & 3. 345 & 3.344 & 3.344 & 3. 343 & 3.342 & 3.342 & 3. 341 & 3.341 \\
\hline .9 & 3.340 & 3.339 & 3. 339 & 3. 338 & 3. 338 & 3.337 & 3. 336 & 3. 336 & 3.335 & 3. 335 \\
\hline 1.0 & 3.334 & 3. 334 & 3. 333 & 3. 332 & 3.332 & 3. 332 & 3. 331 & 3. 330 & 3. 330 & 3. 329 \\
\hline 1.1 & 3. 329 & 3.328 & $3,32 x$ & 3.328 & 3.327 & 3.326 & 3. 326 & 3.326 & 3.325 & 3.324 \\
\hline 1.2 & 3.324 & 3.324 & 3.323 & 3.322 & 3.322 & 3.322 & 3. 321 & 3. 320 & 3.320 & 3.320 \\
\hline 1.3 & 3.319 & 3.318 & 3.318 & 3.317 & 3.317 & 3.316 & 3.315 & 3.315 & 3.314 & 3. 314 \\
\hline 1.4 & 3.313 & 3.312 & 3. 312 & 3.311 & 3. 311 & 3.310 & 3. 309 & 3. 309 & 3.308 & 3.308 \\
\hline 1.5 & 3.307 & 3.306 & 3.306 & 3. 305 & 3.305 & 3.304 & 3.303 & 3.303 & 3.302 & 3.302 \\
\hline 1.6 & 3. 301 & 3.301 & 3.300 & 3.300 & 3. 299 & 3.298 & 3. 298 & 3298 & 3. 297 & 3.296 \\
\hline 1.7 & 3.296 & 3.295 & 3.295 & 3.294 & 3. 294 & 3.293 & 3. 292 & 3. 292 & 3. 291 & 3. 291 \\
\hline 1.8 & 3.290 & 3. 290 & 3. 289 & 3.288 & 3. 288 & 3.288 & 3. 287 & 3.286 & 3. 286 & 3.285 \\
\hline 1.9 & 3. 285 & 3.285 & 3. 284 & $3.2 \times 4$ & 3.283 & 3.282 & 3.282 & 3.282 & 3. 281 & 3.280 \\
\hline 2.0 & 3.280 & & & & & & & & & 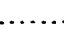 \\
\hline
\end{tabular}




\section{EXTENSION OF THE WEIR FORMULA TO HIGHER HEADS.}

It will be noticed that all the accepted formulas for discharge over thin-edged rectangular weirs are based on experiments in which the head did not exceed 2 feet above crest. It is often desirable to utilize. the weir for stream gagings where the head is greater, especially for the determination of maximum discharge of streams, the head frequently being as large as 6,8 , or even 10 or 12 feet.

In the experiments at Cornell University on weirs of irregular section it was often necessary to utilize depths on the standard weir exceeding the known limit of the formula. A series of experiments was accordingly carried out in which a depth on a standard thin-edged weir (16 feet long) not exceeding the limit of the formula was utilized to determine the discharge over a similar but shorter standard thinedged weir (6.56 feet long) for depth $\leftrightarrow$ up to approximately 5 feet." The results of these experiments, as recomputed, eliminating slight errors in the original, are given below.

It will he noted that the weir was short and the velocity of approach relatively large, yet, according to the results when corrected by the Francis method, the average value of ( ${ }^{\prime}$ for heads from 0.75 to 4.85 feet is 3.296, or 98.98 per cent of the Francis coefficient for a thinedged weir. The average value of $C$ for heads from $0.7 \pm 6$ foot to 2 feet is 3.266 , and for heads from 2 to 4.85 feet, 3.278 .

United States Deep Watermays experiments at Comell hydraulic laboratory for extension of thin-edged weir formula.

\begin{tabular}{|c|c|c|c|c|c|c|c|c|}
\hline \multicolumn{2}{|c|}{$\begin{array}{l}\text { Standard weir, } 16 \\
\text { feet long, } 13.13 \\
\text { feet high. }\end{array}$} & \multicolumn{5}{|c|}{ Lower thin-edged weir: $P=5.2, I=6.56$. } & \multirow{2}{*}{$\begin{array}{l}Q, \text { cubic } \\
\text { feet per } \\
\text { second, } \\
\text { per foot } \\
\text { (cor- } \\
\text { rected). }\end{array}$} & \multirow[b]{2}{*}{$r^{\prime}=\frac{Q}{H^{\frac{3}{2}}}$} \\
\hline $\begin{array}{c}\text { Cor. } D \text {, } \\
\text { longi- } \\
\text { tudinal, } \\
\text { piezome- } \\
\text { ter, cent- } \\
\text { meters. }\end{array}$ & $\begin{array}{l}\text { Q, Bazin } \\
\text { formula, } \\
\text { in cubic } \\
\text { feet per } \\
\text { second. }\end{array}$ & $\begin{array}{l}\text { Observed } \\
P \text {, flush, } \\
\text { piezome- } \\
\text { ter, centi- } \\
\text { meters. }\end{array}$ & $\begin{array}{c}D, \\
\text { in feet. }\end{array}$ & $\frac{D}{P+I I}$ & $\begin{array}{c}K \\
\text { Hunking } \\
\text { and } \\
\text { Hart. }\end{array}$ & $H^{\frac{3}{2}}$ & & \\
\hline $\mathbf{1}$ & 2 & $\mathbf{3}$ & 4 & ; & 6 & $i$ & 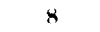 & 9 \\
\hline 12.28 & 14.12 & 22.744 & 0.7462 & 0.1255 & 1.0041 & 0.6469 & $2.106 t$ & 3.256 \\
\hline i5. 30 & 19.42 & 27.855 & .9139 & .1495 & 1.0056 & $.87 \times 7$ & 2.9143 & 3.317 \\
\hline 18.39 & 25.35 & 33.175 & 1.0885 & .1731 & 1.0075 & 1. 1434 & 3.8183 & 3.331 \\
\hline 21.65 & 32.24 & 39.419 & 1. 2933 & .1992 & 1.0099 & 1. 4819 & $4.86 \times 5$ & 3.279 \\
\hline 24.16 & 37.86 & 44.000 & 1. 4436 & .2173 & 1.0122 & 1. 7564 & 5.7252 & 3.260 \\
\hline 27.21 & 45.13 & 49. 699 & 1. 6306 & .2387 & 1.0141 & 2.1116 & 6. 8333 & 2. 236 \\
\hline 30.16 & 52.62 & 55.213 & 1.8115 & .2583 & 1.0166 & 2. 4787 & 7.9750 & 3.218 \\
\hline 30.22 & 52.77 & 55. 128 & 1.8088 & .2581 & 1.0166 & $\because 4730$ & 7. 9977 & 3. 234 \\
\hline 37.90 & 73.46 & 68.238 & 2. 2389 & .3010 & 1.0225 & 3. 4254 & 11. 1516 & 3.226 \\
\hline 44.22 & 92.79 & 80.566 & 2. 6434 & .3370 & 1.0283 & t. 4193 & 14.0960 & 3. 190 \\
\hline 59.00 & 143.90 & 105.639 & 3.4660 & .4000 & 1.0398 & 6. 6095 & 21.8902 & 3.812 \\
\hline 74.22 & 202.37 & 130.286 & 4. 27.47 & .4512 & 1.0504 & 9. 2867 & 30.8008 & 3.317 \\
\hline 81.69 & 233.81 & 142.557 & 4. 6773 & .4735 & 1.0557 & $10.67 \times 9$ & 35.5933 & 3.333 \\
\hline
\end{tabular}

$a$ Rafter, G. W., On the flow of water over dams: Trans. Am. Soc. C. E., vol. 44, p. 397. 
If it is borne in mind that the influences which go to make up variation in the weir coefficient are more potent for low than for larger heads, it may be confidently asserted that the Francis formula is applicable within 2 per cent for heads as great as 5 feet, and by inference it is probably applicable for much greater heads as well.

\section{COMPARISON OF WEIR FORMULAS.}

The later weir formulas all give results agreeing, for the range of heads covered, within the limit of accuracy of ordinary stream measurements. Which of the several formulas to use will be determined by convenience and by the conditions attending the measurements.

The Francis formula is applicable for weirs with perfect bottom contraction and for any head above 0.50 foot.

The Hamilton Smith, Fteley and Stearns, and Bazin formulas are more accurate for very slight heads, or where bottom contraction is imperfect, this element, which tends to increase discharge, being included in the larger velocity of approach correction. These formulas are, however, based on experiments none of which exceeded 2 feet head, and they have not been extended.

For suppressed weirs in rectangular channels having conditions closely duplicating Bazin's experiments, his formula is probably most applicable. The head should preferably be measured in a Bazin pit, opening at the bottom of the channel, 16.4 feet upstream from the weir. In a suppressed weir, if the nappe is allowed to expand laterally after leaving the weir, the computed discharge by any of the formulas should be increased from one-fourth to one-half of 1 per cent.

Comparative discharge by various formulas over weirs of great height and length; no end. contractions nor velocity of approach. $a$

\begin{tabular}{|c|c|c|c|c|c|c|c|c|}
\hline \multirow[t]{2}{*}{ Formula. } & \multicolumn{4}{|c|}{$\begin{array}{c}\text { Coefficient } c \text {, for heads ranging from } \\
0.20 \text { to } 4 \text { feet. }\end{array}$} & \multicolumn{4}{|c|}{$\begin{array}{l}\text { Per cent of discharge by Francis } \\
\text { formula for heads ranging from } \\
0.20 \text { to } 4 \text { feet. }\end{array}$} \\
\hline & 0.20 & 0.50 & 1.00 & 4.00 & 0.20 & 0.50 & 1.00 & 4.00 \\
\hline Castel ..... & 3.4872 & 3.4872 & 3.4872 & 3.4872 & 104.616 & 104.616 & 104.616 & 104.616 \\
\hline Boileau .... & 3.3455 & 3.3455 & 3.3455 & 3.3455 & 100.365 & 100.365 & 100.365 & 100.365 \\
\hline Weisbach ...... & 3.4025 & & 3. 3136 & ….... & 102.075 & & 99.408 & (n........ \\
\hline Francis ........ & 3.33 & 3.33 & 3.33 & 3.33 & 100.00 & 100.0 & 100.0 & 100.0 \\
\hline Fteley and Stearns. . & 3.5004 & 3.3269 & 3.317 & 3.3109 & 105.012 & 99.807 & 99.51 & 99.327 \\
\hline Bazin $\ldots \ldots \ldots \ldots \ldots$ & 3.642684 & 3. 406094 & 3.326696 & 3.26783 & 109.281 & 102.183 & 99.801 & 98.035 \\
\hline Fteley-Stearns-Francis... & 3.3800 & 3.3300 & 3.319 & 3.31375 & 101.400 & 99.90 & 99.570 . & 99.412 \\
\hline Hamilton Smith ........ & 3.3972 & 3.3010 & 3.284 & 3.284 & 101.916 & 99.030 & 98.520 & ..... \\
\hline Smith-Franeis ..... & 3.29 & 3.29 & 3.29 & 3.29 & 98.70 & 98.70 & 98.70 & ......... \\
\hline Parmley ............... & 3.478 & 3.368 & 3.334 & ....... & 104.340 & 101.040 & 100.020 & ......... \\
\hline East Indian engineers .... & 3.488 & 3.472 & 3.445 & 3.285 & 104.640 & 104.16 & 103.35 & 98.550 \\
\hline
\end{tabular}

$a$ Computed by H. R. Beebe, c. E. 
Table showing comparative discharge per foot of crest for suppressed weirs of various lengths, heads, and velocities of approach.a

\begin{tabular}{|c|c|c|c|c|c|}
\hline Length $(L) \ldots .$. & 2 & 2 & 10 & 10 & \\
\hline Height $(P) \ldots \ldots \ldots \ldots \ldots \ldots \ldots \ldots \ldots \ldots \ldots \ldots$ & 1 & 2 & 2 & 4 & 4 \\
\hline 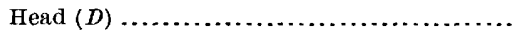 & 1.0 & 1.0 & 1.0 & 1.0 & 4 \\
\hline Approximate velocity of approach $(v)$.. & 1.90 & 1.18 & 1.16 & .68 & 2.15 \\
\hline Castel ...... & 3. 7822 & 3.6127 & 3.6217 & 3.5308 & 30.3037 \\
\hline Boileau ........ & 3.8630 & 3.5484 & 3.5484 & 3. 4144 & 30.9046 \\
\hline Francis . & 3.5373 & 3.4218 & 3.4218 & 3. 3632 & 28.2983 \\
\hline Fteley and Stearns.. & 3. 7268 & 3. 4729 & 3.4730 & 3.3669 & 29.7470 \\
\hline Bazin . . . . . . . . . . . . & 3.7845 & 3.3766 & 3.3766 & 3,4002 & 29.7555 \\
\hline Fteley-Stearns-Francis & 3.7297 & 3.4752 & 3.4752 & 3.3690 & 29.7000 \\
\hline Hamilton Smith . .. & 3.9220 & 3. 6392 & 3.4872 & 3.3878 & ......... \\
\hline Smith-Francis . . & 4.0581 & 3.7109 & 3.4847 & 3. 3876 & 31.573 \\
\hline Parmley & 3. 7924 & 3.5337 & 3.5337 & 3. 3347 & ........ \\
\hline Average. & 3.800 & 3.532 & 3.490 & 3.395 & 30.040 \\
\hline
\end{tabular}

$a$ Computed by H. R. Beebe, C. E.

\section{COMPARISON OF VARIOUS VELOCITY OF APPROACH CORRECTIONS.}

The various modes of correction for velocity of approach used by different investigators can be rendered nearly identical in form, varying, however, in the value of the coefficient $\alpha$ adopted.

Comparative coefficients of correction for velocity of approach for thin-edged weirs with end contractions suppressed.

\begin{tabular}{|c|c|c|}
\hline Experimenter. & $\begin{array}{l}\text { Value of } a \text { in the for- } \\
\text { mula } H=D+a \frac{v^{2}}{2 g}\end{array}$ & $\begin{array}{c}\text { Values of } \omega \text { in } \\
\text { the formula } \\
K=1+\omega\left(\frac{a}{A}\right)^{2}\end{array}$ \\
\hline Boileau $\ldots \ldots \ldots \ldots \ldots$ & $\alpha=1.8$ & \\
\hline Lesbros $\ldots \ldots \ldots$ & $\alpha=1.56$ & \\
\hline Fteley and Stearns $\ldots \ldots \ldots \ldots \ldots \ldots$ & $\alpha=1.5$ & \\
\hline Francis $\ldots \ldots \ldots \ldots \ldots, \ldots, \ldots$ & $a_{\alpha=1}-\frac{2}{3} \sqrt{\frac{h}{D}}$ & $b_{\omega} \omega=0.2489$ \\
\hline Bazin . . . . . . . . & $\alpha=1.69$ or $\frac{5}{3}$ & $\omega=0.55$ \\
\hline
\end{tabular}

a Emerson.

$b$ Hunking and Hart.

The above values were all derived from experiments on thin-edged weirs. Bazin's experiments covered the larger range of velocities and were most elaborate. It may be noted that the correction applied by Bazin is two and two-tenths times that of Francis for a given velocity 
of approach. Bazin's correction is, in effect, an increase in the measured head of 1.69 times the velocity head, while Francis increases the measured head by an amount $\frac{2}{3} \sqrt{\frac{h}{D}}$ less than the velocity head according to Emerson's formula.

Ratio of the vurious corrections for velocitiy of approach for suppressed weirs.

\begin{tabular}{|c|c|c|c|c|}
\hline & Bazin. & $\begin{array}{l}\text { Fteley and } \\
\text { Stearns. }\end{array}$ & $\begin{array}{l}\text { Hamilton } \\
\text { Smith. }\end{array}$ & Francis. \\
\hline Bazin,$\ldots \ldots \ldots \ldots$ & 1.000 & 1. 127 & 1. 271 & 2.2 \\
\hline Fteley and Stearns ..... & .887 & 1. 000 & 1. 128 & 1. 957 \\
\hline Hamilton Smith $\ldots \ldots \ldots \ldots \ldots \ldots \ldots$ & .789 & .887 & 1.000 & 1. 736 \\
\hline Francis . . . . . . . . . & .454 & .511 & .576 & 1.000 \\
\hline
\end{tabular}

The factors in the above table are not strictly accurate, for the reason that the expressions used to deduce the equivalents from the different formulas are in some cases approximations. They serve to illustrate the relative magnitude of the different corrections for thinedged weirs without end contractions. For thin-edged weirs with end contraction, Hamilton Smith uses the coefficient $\alpha=1.4$ and Fteley and Stearns give the coefficient $\alpha=2.05$.

There are no experiments available relative to the value of the velocity correction for other than thin-edged weirs. It is necessary, therefore, to utilize the values above given for weirs of irregular section. It will be seen that it matters little in what manner the correction for velocity of approach is applied, either by directly increasing the observed bead, as in the formulas of Hamilton Smith and Fteley and Stearns, or by including the correction in the weir coefficient, as is done by Bazin, or by utilizing a special formula to derive the corrected head, after the manner of James B. Francis. The three methods can be rendered equivalent in their effect.

The important point is that the corrected result must be the same as that given by the author of the formula which is used to calculate the discharge. As to the relative value of the different modes of applying the correction, it may be said of that of Francis, that in its original form it is cumbersome, but it renders the correction independent of dimensions of the leading channel, as do also the formulas for correction used by Hamilton Smith, and Fteley and Stearns. Inasmuch as the velocity head is a function of the discharge, successive approximations are necessary to obtain the final corrected head by any one of these three formulas.

By using the Hunking and Hart formula the correction for the Francis weir formula becomes fairly simple, as it does not require the determination of the mean velocity of approach by successive approxi- 
mations, but to apply this formula it is necessary to know the dimensions of the leading channel and of the weir section. The approximation given by Emerson is also much simpler than the original Francis formula.

Bazin's method of including the velocity correction in the coefficient makes the weir coefficients obtained by the experiments comparable one with another only when both the head and velocity of approach are the same in both cases. ${ }^{a}$ His correction also involves the dimen* sions of the leading channel as factors. Obviously, in the ease of many broad-crested weirs utilized for measuring flow, the dimensions of the leading channel can not be ascertained accurately and there is great variation of velocity in different portions of the section of approach. It becomes necessary that the correction should be in such a form that it is a function of the velocity and not of the channel dimensions.

It is to be noticed that where an attempt has been made in the weir experiments to eliminate velocity of approach effect from the coefficient the velocity has been nearly equalized by screens and has been determined by successive approximations. It is suggested that where the velocities vary widely they be determined by current meter in several subdivisions of the section, the approximate integral kinetic energy estimated, and a value of $\alpha$ selected depending on the ratio of $\frac{h^{\prime}}{h}$ so obtained, where $h$ is the velocity head corresponding to the mean velocity and $h^{\prime}$ is the velocity head which would result if the actual velocities were equalized. Inasmuch as the surface velocity usually exceeds the mean velocity in the channel of approach in about the same ratio that $h^{\prime}$ exceeds $h$, the suggestion is made by Hamilton $\mathrm{Smith}^{b}$ that where the velocity of approach is unavoidably variable, or the boundaries of the current are uncertain, the surface velocity $v_{\mathrm{s}}$ be measured by floats and applied directly in the determination of the quantity $h$.

The variations in discharge over a thin-edged weir, by the different formulas, are often less than the difference in the correction for velocity of approach would indicate. In the formula of Fteley and Stearns, as compared with Francis, for example, the larger velocity correction is in part compensated by a smaller weir coefficient, and the same is true of the formulas of Hamilton Smith and Bazin for cases where the head is large. 


\section{END CONTRACTIONS-INCOMPLETE CONTRACTION.}

The formula for end contractions deduced by James B. Francis is very generally used. The correction is made to the length of weir, the result obtained being the length of a suppressed weir that will give the same discharge.

$$
L=L^{\prime}-b \mathrm{NH} \text {. }
$$

$b=\mathrm{A}$ coefficient, the value of which, deduced by Francis, is $b=0.1$.

$L^{\prime}=$ Actual length of weir crest.

$L=$ Length of equivalent suppressed weir crest.

$N=$ Number of end contractions.

$H=$ Effective head, feet.

The experiments of Fteley and Stearns, ${ }^{a}$ while somewhat discordant, indicate an average value of $b$ for heads from 0.3 to 1 foot, of about 0.1 . The value of $b$ apparently decreases as the head increases. It also decreases if the end contraction piece is so near the side of the channel as to render the contraction incomplete.

Hamilton Smith shows that side contractions and bottom or crest 'contraction are mutually related, and that the side width of the channel of approach should be fully three times the least dimension of the weir. Usually $L$ is much greater than $H$, and the side width may be made at least as great as $3 H$. The specification of Francis is, side width $>H$.

Smith's rule indicates that to provide complete contraction the area of leading section $A$. must bear a relation to the area of weir section $a$ depending upon the relative head and length of crest.

For three weirs of equal section $a$, the following values of $A$, the necessary channel-section area, are given:

$$
\begin{array}{llll}
L^{\prime}=12 & H=1 & a=12 & A=72=6 a \\
L^{\prime}=4 & H=3 & a=12 & A=264=2.2 a \\
L^{\prime}=1 & H=12 & a=12 & A=105=8.7 a
\end{array}
$$

Hamilton Smith prefers to use separate coefficients for suppressed weirs from those for contracted weirs, the relation between the coefficients being expressed by the formula

$$
C_{p}=C_{c}\left(1+z \frac{S}{R}\right) \cdot . \cdot . \cdot . \quad .
$$

$C_{p}=$ Coefficient for partially suppressed weir, as with complete suppression on sides and full contraction at bottom.

$a$ Fteley and Stearns, Experiments on the flow of water, etc.: Trans. Am. Soc. C. E., vol. 12, pp. 108-113. 
$C_{c}=$ Coefficient for completely contracted weir.

$X=$ Least dimension of weir, whether $L$ or $H$.

$R=$ Wetted perimeter of weir $=L+2 H$.

$Y=$ Distance from any side of weir to the respective side of channel, where there is partial suppression.

$S=$ Length of sides on which there is partial suppression.

Smith's values of contraction coefficient $\approx$ in formula 31 are

$\begin{array}{cc}Y / X & z \\ 3 & 0.000 \\ 2 & .005 \\ 1 & .025 \\ \frac{1}{2} & .06 \\ 0 & .16\end{array}$

The ratio $Y\left(X\right.$ approximately measures the amount of contraction. ${ }^{a}$

Bazin does not give a formula for weirs with end contractions. The Bazin formula may be applied to weirs in which the height of weir is so small that the bottom contraction is partially suppressed. The Bazin coefficient then includes:

1. Effect of contraction from surface curve.

2. Effect of crest contraction and its modification by both velocity of approach and by partial suppression, if any.

3. Effect of velocity of approach proper.

4. Effect of distribution of velocities in channel of approach.

5. Loss of head from friction and eddies.

As the Bazin weirs were very low, and these factors go to increase the correction necessary, it will be seen that the relatively large velocity of approach correction required by Bazin's formula may be readily accounted for.

The experiments of Flinn and Dyer on the Cippoletti weir (see p. 48) indicate that the effect of end contraction may be somewhat greater than that indicated by the Francis formula. Any experiments in which similar volumes of water have been successively passed over weirs with and without end contractions may be utilized to determine the effect of such contractions.

It may be added that a more elaborate study of end contractions is desirable. It is to be borne in mind, however, that to secure greater accuracy in this regard a more complicated or variable correction than that of Francis must probably be used, and the result will be to greatly increase the labor of weir computations in the interest of what is usually a comparatively small matter, the better remedy being probably the use of weirs with end contractions suppressed, wherever practicable.

$a$ Smith, Hamilton, Hydraulics, pp. 118-123. Smith's critical discussion of this subject will be found of value in calculating discharge for weirs with partially suppressed contraction either at sides or bottom. 
COMPOUND WEIR.

A weir with a low-water notch depressed below the general crest level may sometimes be used to advantage in gaging small, variable streams. The discharge over such a weir, constructed with end contractions on both sections, can be calculated as for two separate weirs, the lower short section having end contractions for all heads. The flow over the two upper sections is computed as for a suppressed weir.

Such a weir has been used for the determination of the low-water flow of very small streams, for which purpose it is well adapted, the entire stream when at low stages flowing in the central notch, in a stream relatively deep and narrow.

The measurement of very thin sheets of water on a broad weir is subject to peculiar difficulties, including uncertainty of coefficient, adhesion of nappe to weir face, dispersion by winds, and a large percentage error in the results if there is a small error in measuring the head.

TRIANGULAR WEIR.

GENERAL FORMULA.

Referring to fig. 4, we may write

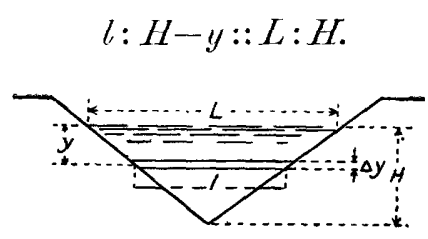

FIG. 4.-Triangular weir.

Substituting, in equation (4),

$$
\begin{aligned}
Q & =\int_{0}^{H} \sqrt{2 g y} \frac{L(H-y)}{H} d y \\
& =\frac{4}{15} L \sqrt{2 g} H^{\frac{3}{2}} \text {. . . . . . . . }
\end{aligned}
$$

\section{THOMSON'S EXPERIMENTS.}

The mean coefficient of contraction for a thin-edged triangular weir deduced experimentally by Prof. James Thomson, of Belfast, is $M=$ $0.617,{ }^{,}$the formula being

$$
Q=\frac{4}{15} M L \sqrt{2 g} H^{\frac{3}{2}}=1.32 L H^{\frac{3}{2}} . . . .
$$

a British Association Report, 1858 (original not consulted). Merriman gives the mean value of $M$ for heads between 0.2 and 0.8 foot as 0.592 . 
For a right-angled notch,

$$
L=2 H \text { and } Q=2.64 H^{\frac{5}{2}} \text {. . . . . }
$$

The length of the contracting edges in a triangular notch being proportional to the depth, it is believed that the coefficient of discharge is somewhat more constant than for a rectangular weir. ${ }^{a}$

\section{TRAPEZOIDAL WEIR.}

The discharge in this case may be determined directly from the integral formula (4) as for a triangular weir, by integrating between the limits $\mathrm{AD}$ and $\mathrm{CE}$, fig. 5. It may also be derived as follows:

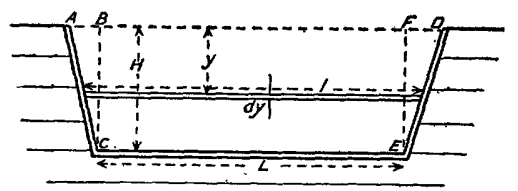

FIG. 5.-Trapezoidal weir.

$z=$ slope of one side to the vertical.

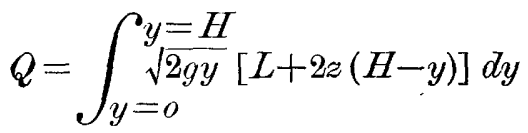

By integration,

$$
Q=\frac{2}{3} \sqrt{2 g} L H^{\frac{3}{2}}+\frac{8}{15} z \sqrt{2 g} H^{\frac{5}{2}} \text {. . . . . . }
$$

in which coefficients of contraction for the horizontal crest and for: the end slopes must be introduced.

THE CIPPOLETTI TRAPEZOIDAL WEIR.

The discharge over a trapezoidal without contraction "would be the sum of that for a rectangular weir added to that for two triangular weirs forming the ends. From the experiments of James B. Francis ${ }^{b}$ it appears that each end contraction reduces the effective length of the weir $0.1 H$. The contraction decreases the discharge by the amount

$$
Q=\frac{2}{3} M \times 0.1 H \sqrt{2 g} H^{\frac{3}{2}}=\frac{2}{3} \frac{M}{10} \sqrt{2 g} H^{\frac{5}{2}}
$$

If the ends of the weir, instead of being vertical, are inclined outward in such manner that the discharge through the added area counterbalances the decrease from the end contraction, then the effective

a The coefficient 2.64 is the same as that deduced for broad crest weirs with stable nappe. A table of values of $2.64 H^{\frac{3}{2}}$ is given on page 177 , which may be applied in calculating flow over triangular weirs.

$b$ Lowell Hydraulic Experiments.

IRR $150-06-4$ 
length of the weir will remain constant as the head increases, the same as in a suppressed weir. The discharge through the end triangle ABC will be, from equation (42),

$$
Q=\frac{4}{15} M z \sqrt{2 g} H^{\frac{3}{2}}
$$

Where $z$ is the width or base of the end triangle. Equating the two expressions for $Q$, and solving for $z$, we find, assuming $M$ to have the same value in both cases,

$$
z=\frac{1}{4} H \text {. . . . . . . . . . . }
$$

This condition defines the (Mippoletti weir. ${ }^{a}$

\section{CIPPOLETTI'S FORMULA.}

Cippoletti derived his formula from a discussion of the experiments of James B. Francis, selecting a coefficient 1 per cent greater, making

$$
Q=\frac{2}{3} \times 0.629 L H \sqrt{2 g} H=3.367 L H^{\frac{3}{2}} \text {. . . . }
$$

$L$ is the length of the crest or base of the trapezoid.

Flinn and Dyer ${ }^{b}$ experimented at the testing flume of the Holyoke Water Power Company by passing the same volume of water successively over a trapezoidal experimental weir and over the gaging weir of the turbine testing flume 19.7 feet downstream. The latter, it is stated, complied in form with Francis's specifications.

The depths were observed by hook gage; eleven readings, as a rule, being taken and their arithmetical mean used for the determination of a head. The thirty-two series of valid experiments range from 0.3 foot depth on a weir with sill length of 3 feet to a head of 1.25 feet on a sill 9 feet long.

The discharge over the standard weir was calculated by the formulas of J. B. Francis and of Hamilton Smith. The correction for velocity of approach at the experimental weir was made by the formula of Hamilton Smith, for use with contracted rectangular weirs,

$$
H=D+1.4 h \text {. }
$$

Flinn and Dyer's coefficients are as follows:

$\begin{array}{ll}\text { Mean of } 32 \text { experiments, } & C=3.283 \\ \text { Mean after rejecting } 5 \text { diminished weights, } C=3.301\end{array}$

In general, the coefficient diminished as the head increased, suggesting that the end inclination should slightly exceed $\frac{1}{4} H$ in the Cippoletti weir, to provide complete compensation, and that the end contraction

$a$ First deseribed by Cesare Cippoletti in Canal Villoresi, Modulo per la Dispensa delle Acque, 1887. $b$ Flinn, A. D., and Dyer, C. W. D., The Cippoletti trapezoidal weir; Trans, Am, Soc. C. E., vol. 32, 1894, pp. 9-33. 
coefficient in the trapezcidal weir may be greater than $0.1 H$, as used by Francis.

The question is complicated by velocity of approach. For example, had the Francis velocity-correction formula been used by Flinn and Dyer, their values of $C$ would have been larger. As a tentative conclusion it is probable that the application of either the Francis formula with his velocity-head correction or the Flinn and Dyer coefficient with the Smith velocity correction will, when applied to a Cippoletti weir, give results as accurate as the precision of the coefficients will justify.

\section{REQUIREMENTS AND ACCURACY OF WEIR GAGINGS.}

\section{PRECAUTIONS FOR STANDARD WEIR GAGING.}

Certain specifications were laid down by James B. Francis as guides in cases where the utmost precision is desired in weir measurements. ${ }^{a}$ The limits of appiicability of the weir have been greatly extended since 1852 , and some of the uncertainties as to the effect of various modifications of weir construction have been removed.

In general, for standard thin-edged weirs-

1. The upstrean crest edge should be sharp and smooth.

2. The overflowing sheet should touch only the upstream crest corner.

3. The nappe should be perfectly aerated.

4. The upstream face of the weir should be vertical.

5. The crest should be level from end to end.

6. The measurements of head should show the true actual elevation of water surface above the level of the weir crest.

7. The depth of leading channel should be sufficient to provide complete crest contractions, and, if they are not suppressed, the width of channel should be sufficient to provide complete end contractions.

8. A weir discharging from a quiet pond is to be preferred. If this is not available, the velocity of approach in the leading channel should be rendered as uniform as possible and correction made therefor by the method employed by the experimenter in deriving the formula.

In order to fulfill these requirements, certain secondary conditions are necessary. The depth on the weir should be measured at a point far enough upstream from the crest to be unaffected by the surface curvature, caused by the discharge. 
The distance upstream to the point of measuring the head has been as follows:

Distance upstream from weir to gage used by wrious experimenters.

\begin{tabular}{|c|c|c|}
\hline Experimenter. & Date. & $\begin{array}{l}\text { Distance } \\
\text { upstream, in } \\
\text { feet. }\end{array}$ \\
\hline Poncelet and Lesbros... & 1828 & 11.48 \\
\hline Lesbros .............. & 1834 & 11. 48 \\
\hline 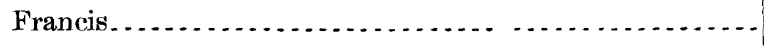 & 1852 & 6.00 \\
\hline Hamilton Smith, jr......... & $1874-1876$ & 7.60 \\
\hline Fteley and Stearns . . . . . . . . . . . . . . . . . . & 1878 & 6. 00 \\
\hline Bazin ................. & 1886 & 16. 40 \\
\hline
\end{tabular}

Six feet upstream from crest is a distance frequently used, but this may be insufficient for suppressed weirs, and also for those having irregular cross sections or upstream slopes. Boileau considered the origin of the surface curvature to be at a distance from the weir equal to about 2.5 times the height of crest above the bottom of the channel of approach, indicating that for a suppressed weir the head should be measured at least this distance from the erest. ${ }^{a}$ For a weir discharging from a still pond the head ean be measured at any considerable distance from the weir. Hamilton Smith ${ }^{b}$ states that, for weirs with full contraction, $H$ can be measured at any convenient point from 4 feet to 10 feet from the crest.

The head may be measured directly by a graduated scale or hook gage, or by means of a piezometer tube having its orifice flush with the side wall of the leading channel, and at right angles to the direction of flow of the water.

The depth of the leading channel in Francis's experiments was 4.6 feet below erest, and Francis lays down the rule that the depth of the leading canal should be at least three times the head on the weir. Hamilton Smith fixes the minimum depth of the leading channel below the crest at $2 H$.

Fteley and Stearns ${ }^{c}$ state that the depth of the leading channel below weir erest should be at least 0.5 foot, in order that correction for velocity of approach may be reliably made for depths occurring in their measurements, and that a greater depth of leading channel is to be preferred.

To provide complete end contractions, Francis states that the distance from the side of the channel of approach to the end of the weir overflow should be at least equal to the depth on the weir. Hamilton

$a$ Fteley and Stearns, Experiments on the flow of water, etc.: Trans. Am. Soc. C. E., vol. 12, p. 47.

$b$ Smith, Hamilton, Hydraulies, pp. 129-131.

c Ibid., pp 112-114. 
Smith considers that the distance from the end of the weir to the side of the channel should be at least $2 \mathrm{H}$, and that the depth of channel below crest, also the side distance, should in no case be less than 1 foot. Francis further specifies that the length of weir crest should be at least three times the depth of overflow. The nappe should not be allowed to expand laterally immediately below a suppressed weir.

In order that the nappe may be perfectly aerated, Francis considers that the fall below crest level on the downstream side should be not less than $\frac{1}{2} H$, increasing for very long weirs or in cases where the downstream channel is shallow. He found, however, no perceptible difference in the discharge for a head of 0.85 foot, whether the water on the downstream side was 1.05 feet or 0.0255 foot below crest level. Fteley and Stearns and Hamilton Smith agree that, if the water is
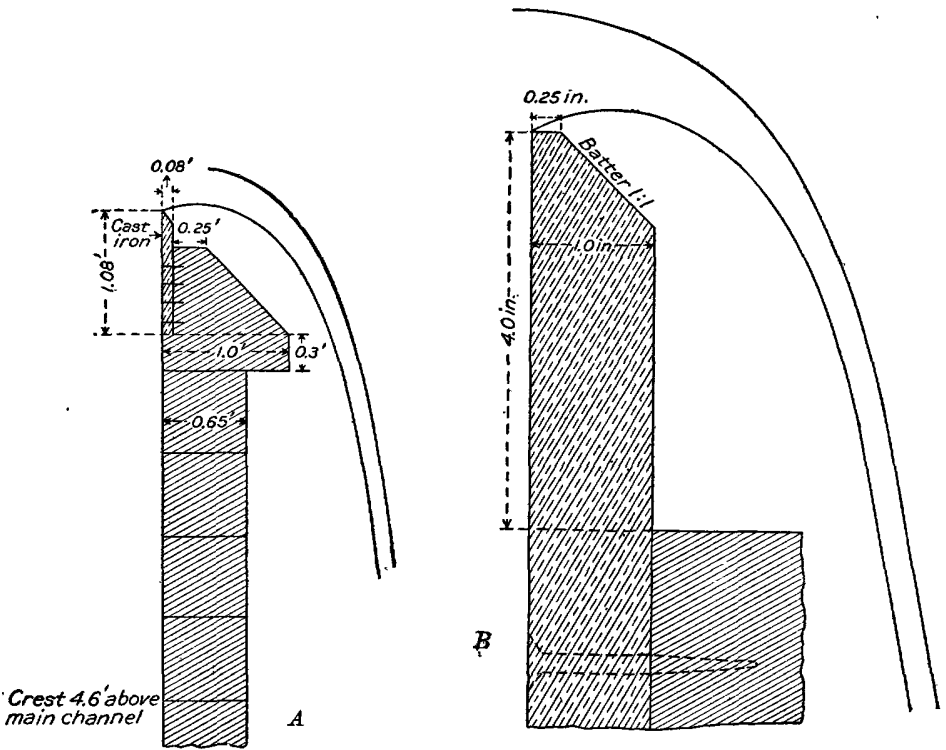

Fig. 6.-Sections of the Francis weir. $A$, General section of weir; $B$, detail of crest.

deep below, it may rise to crest level on downstream side of weir without sensible error, and Fteley and Stearns add that a weir may be submerged to a depth of 15 per cent of the head without an error exceeding 1 per cent.

The thickness of crest lip is immaterial so long as the edge is sharp and square and the nappe cuts free and is freely aerated. The latter conditions require, however, that the crest shall be thin, especially where the head is slight.

Fig. 6 shows cross sections of the crest of the weir used by James B. Francis at the Lower Merrimac locks at Lowell, in 1852, in deriving his formula. The crest consisted of a cast-iron plate 13 inches wide and 1 inch thick, planed true and smooth on all surfaces. Its upper 
edge was chamfered on the downstream side at an angle of $45^{\circ}$ to a thickness of 0.25 inch at the edge. As shown, the nappe cut clear from the top of the crest in an unbroken sheet. The lowest head used by Francis was over 0.5 foot. For very low heads the crest lip should be thinner. A wooden crest tends, by capillary attraction, to cause the nappe to adhere to the flat top surface under low heads. A wooden crest is cheap, easily adjusted, and convenient for temporary use, but it will, in time, tend to become somewhat rounded, reducing the vertical contraction of the nappe.

A cast-iron crest will usually have to be made to order. A large steel angle bar may often be obtained from stock sizes of the rolling mills more cheaply. Such a bar, with legs, say 3 and 6 inches, respectively, with the 6 -inch flat face planed and its edge trued, will form a rigid and permanent crest. The 3-inch leg may be bolted to the top of the timbers forming the body of the weir.

It may be added that approximate corrections for rounding of upstream corner of the crest, inclination of the weir upstream or downstream, or incomplete contractions can be made from data now available. In constructing gaging weirs preference, however, should be given to those forms which render the determination of the discharge the most simple, and the extent to which the preceding specifications may be departed from judiciously will depend upon the exigencies of the case and the purposes for which the results are desired.

\section{PLANK AND BEAM WEIRS OF SENSIBLE CREST WIDTH.}

Experiments on weirs with crest boards 1,2, or 4 inches in thickness were made by Blackwell, Fteley and Stearns, and Bazin. The results show that for depths exceeding 1.5 to 2 times the crest width the nappe will break free, and if properly aerated the coefficient will then be identical with that for a thin-edged weir.

When the nappe adheres to the crest the coefficients are very uncertain for such weirs, adhesion of nappe to downstream face of crest and modified aeration entering to give divergent values.

The precise stage at which the change from an adhering to a free nappe or the reverse occurs is not constant, but variey with velocity of approach and with rate of change of the head as the changing point is approached, being different for a sudden and for a gradual change, and also when the point of change is approached by an increasing as compared with a decreasing head.

\section{REDUCTION OF THE MEAN OF SEVERAL OBSERVATIONS OF HEAD.}

In measuring a constant volume of water, several observations of the head on the weir are desirable, the accuracy of the result, according to the theory of least squares, being proportional to the square root of the number of observations. 
In weir experiments it is often impossible to maintain a perfectly uniform head or regimen. If the variations are minute the arithmetical mean may be used directly. If the variations are of wider range, or if the utmost precision is required, the following correction formula of Francis may be applied: ${ }^{a}$

Let $D_{1}, D_{2}, D_{3}$, etc., $D_{n}$ represent the several successive observed heads.

Let $t_{1}, t_{2}, t_{3}$, etc., $t_{n}$ represent the corresponding intervals of time between the several observations.

Let $T$ represent their sum, or the total time interval.

$Q=$ the total volume of water flowing over the weir in the time $T$.

$D=$ the mean depth on the weir that would discharge the quantity $Q$ in the time $T$.

$L=$ the length of weir crest.

$C=$ the weir coefficient.

We have, very nearly,

Also,

$$
Q=\frac{t_{1}}{2} C L D_{1}^{\frac{3}{2}}+\frac{t_{1}+t_{2}}{2} C L D_{2}^{\frac{3}{2}}+\frac{t_{2}+t_{3}}{2} C L D_{3}^{\frac{3}{2}}+\text { etc. }+\frac{t_{n}}{2} C L D_{n}^{\frac{3}{2}}
$$

$$
Q=T C L D^{\frac{3}{2}}
$$
have

Equating, eliminating the common factor $C L$, and solving for $D$, we

$$
D=\left\{\frac{1}{T}\left(\frac{t_{1}}{2} D_{1}^{\frac{3}{2}}+\frac{t_{1}+t_{2}}{2} D_{2}^{\frac{3}{2}}+\frac{t_{n}+t_{3}}{2} D_{3}^{\frac{3}{2}}+\text { etc. }+\frac{t_{n}}{2} D_{n}^{\frac{3}{2}}\right)\right\}^{\frac{2}{3}}
$$

\section{EFFECT OF ERROR IN DETERMINING THE HEAD ON WEIRS. $b$}

Consider the formula

$$
Q=C L H^{\frac{3}{2}}
$$

Differentiating, we have

$$
d Q=\frac{3}{2} C L \sqrt{H} d H
$$

The error of any gaging when $H+d H$ is taken as the head instead of the true head $H$ being used will be $d Q$, and the ratio of this quantity to the true discharge $Q$ will be

$$
\frac{d Q}{Q}=\frac{3 C L \sqrt{H}}{2 C L H^{\frac{3}{2}}} d H=\frac{3}{2} \frac{d H}{H} \quad . \quad . \quad . \quad . \quad .
$$

This formula will give nearly the correct value of the error if the increment. $d H$ approaches an infinitesimal.

$a$ Francis, J. B., Lowell Hydraulic Experiments, p. 113.

$b$ Rafter, G. W., On the flow of water over dams: Trans. Am. Soc. C. E., vol. 44, p. 686; data here given based on discussion by Walter C. Parmley. 
In the following table is shown the effect of errors of one thousandth, five thousandths, one hundredth, and five hundredths foot, respectively, for various heads. This clearly illustrates both the necessity of proper care and the folly of ultra precision in measuring the relatively large values of $H$ with which we are mainly coneerned. The curves of error on PI. II are equilateral hyperbolas, which have been reduced to straight lines by plotting on logarithmic scales.

Percentage error in discharge resulting from various errors in the measured head on weirs.

\begin{tabular}{|r|c|c|c|c|}
\hline $\begin{array}{c}\text { Head, in } \\
\text { feet. }\end{array}$ & \multicolumn{3}{|c|}{ Error in measured head, in feet. } \\
\cline { 2 - 5 } & 0.001 & 0.005 & 0.01 & 0.05 \\
\hline & Per cent. & Per cent. & Per cent. & Per cent. \\
0.1 & 1.5 & 7.5 & 15 & $\ldots \ldots \ldots .$. \\
.5 & .3 & 1.5 & 3 & 15 \\
1.0 & .15 & .75 & 1.5 & 7.5 \\
5.0 & .03 & .15 & .3 & 1.5 \\
10.0 & .015 & .075 & .15 & .75 \\
\hline
\end{tabular}

An error of a half-tenth foot under 5 feet head causes the same error in the result as an error of one-half hundredth foot with a head of one-half foot.

In weir experiments it is important to know the effect of an error in head $H$ on the resultant coefficient of discharge $C$. The error in $C$ is evidently equivalent to the error in $Q$ found above, where $H$ is constant.

\section{ERROR OF THE MEAN WHERE THE HEAD VARIES.}

In determining the volume of flow over dams where gaging records are kept, the method usually pursued has been to have readings taken twice daily, as at morning and evening, showing the depth flowing over the crest of the dam. The average of the two readings for each day has been found and the volume of flow corresponding to this average head has been taken as the mean rate of flow over the dam for the day.

It is evident, however, that as the discharge varies more rapidly than the head (usually considered to be proportional to the three-halves power of the head), the volume of discharge obtained as above described will be somewhat less than the amount which actually passes over the dam. The following analysis has been made to show the magnitude of the error introduced by using the above method.

Assuming that the initial depth on the crest of the dam is zero, but increases at a uniform rate to $H_{1}$ at the end of a time interval $T$, the 


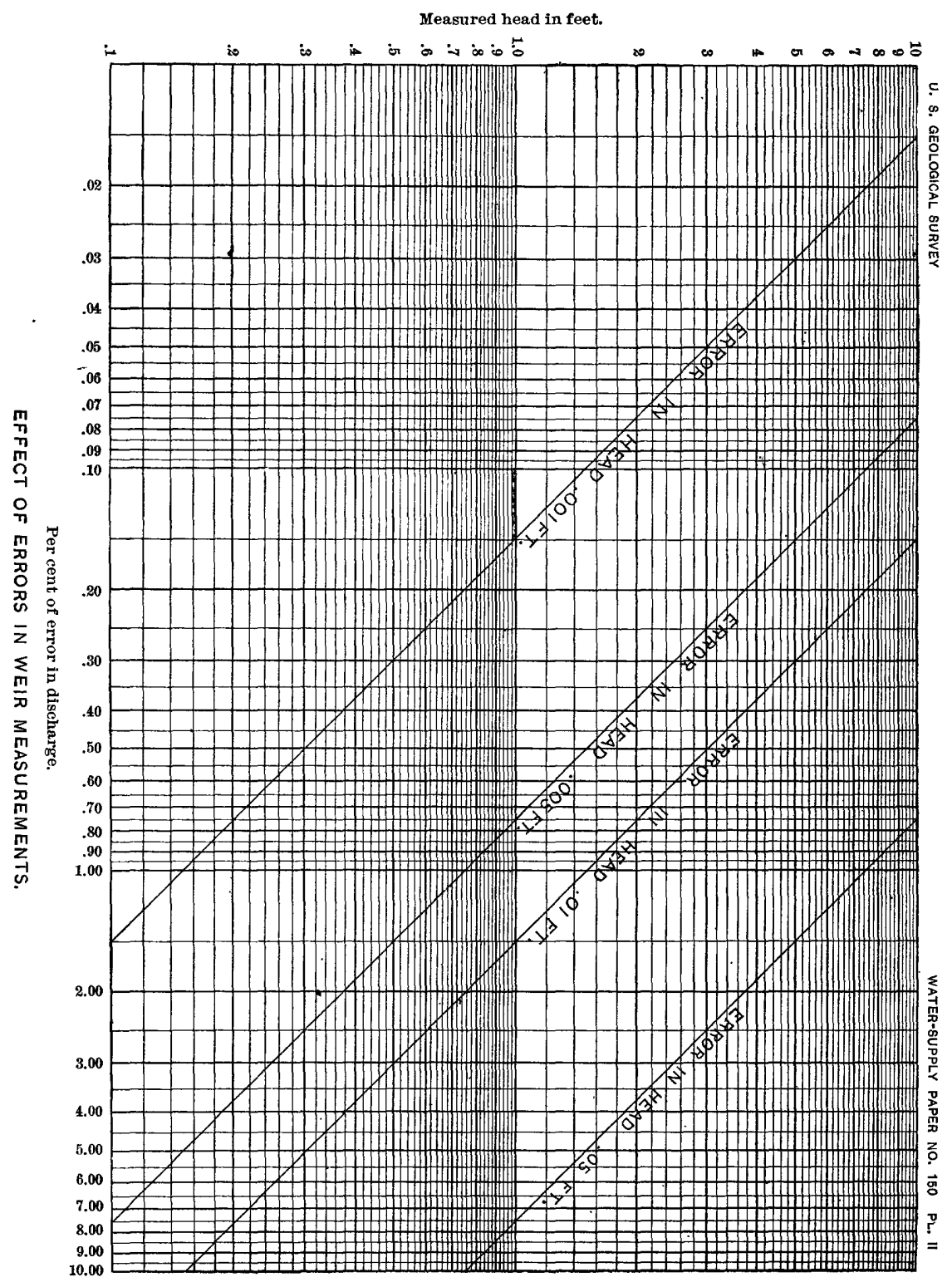


mean head deduced from observations at the beginning and end of the period would be $\frac{1}{2} H_{1}$, the head at any time $t$ would be

$$
H=f t
$$

where $f$ is a constant.

We may write the usual formula for weir discharge $Q=C L H^{\frac{3}{2}}$; then, if the head varies from zero to $H_{1}$, the total volume of flow in the time $T$ will be

$$
Q_{\mathrm{t}}=\int_{0}^{T} Q d t=C L f^{\frac{3}{2}} \int_{0}^{T} t^{\frac{3}{2}} d t=\frac{2}{5} C L f^{\frac{3}{2}} T^{\frac{5}{2}} \ldots
$$

The total discharge corresponding to the average head $\frac{1}{2} H_{1}$ is

$$
Q_{\mathrm{av}}=C L\left(\frac{B_{1}}{2}\right)^{\frac{3}{2}} T=C L\left(\frac{f}{2}\right)^{\frac{3}{2}} T^{\frac{5}{2}} . . .
$$

The ratio of the discharge is

$$
\frac{\text { Volume by average head }}{\text { Actual volume }}=\frac{Q_{\mathrm{av}}}{Q_{\mathrm{t}}}=\frac{\left(\frac{1}{2}\right)^{\frac{3}{2}}}{\frac{2}{5}}=0.8840 \ldots
$$

It appears that where the initial or terminal head is zero the volume of flow determined by using the average head will be 11.6 per cent too small. This percentage of error is the same whatever may be the maximum head $H$, and whether the stream is rising or falling. It is also independent of the rate of change in the head.

Conditions like those above discussed occur at milldams during the season of low water, when the pond is allowed to fill up at night and the water is drawn down to crest level or below during the day when mills are running.

The following example will illustrate. Suppose a sharp-crested weir without end contractions, with erest 1 foot long, on which the water rises to a depth of 1 foot in a period of 10 seconds-

Mean depth on a weir with rarying head.

\begin{tabular}{l|l|l|l|l|l|l|l|l|l|l}
\hline Time, in seconds..................... & 1 & 2 & 3 & 4 & 5 & 6 & 7 & 8 & 9 & 10 \\
Head, in feet, at end of each second... & .1 & .2 & .3 & .4 & .5 & .6 & .7 & .8 & .9 & 1.0 \\
Average head for period............... & .05 & .1 & .15 & .2 & .25 & .3 & .35 & .4 & .45 & .5 \\
Average head, second to second ........ & .05 & .15 & .25 & .35 & .45 & .55 & .65 & .75 & .85 & .95 \\
\hline
\end{tabular}


Using the average head during each second the volume of flow may be approximately integrated by finite differences, as follows, the discharge being taken from Francis's tables:

Discharge orer a weir with varying head.

\begin{tabular}{|c|c|c|}
\hline Time, in seconds. & $\begin{array}{l}\text { Average head, } \\
\text { in feet. }\end{array}$ & $\begin{array}{l}\text { Discharge, in } \\
\text { second-feet. }\end{array}$ \\
\hline 0 to 1 & 0.05 & 0.037 \\
\hline 1 to 2 & .15 & .194 \\
\hline 2 to 3 & .25 & .416 \\
\hline 3 to 4 & .35 & .690 \\
\hline 4 to 5 & .45 & 1.005 \\
\hline 5 to 6 & .55 & 1.358 \\
\hline 6 to 7 & .65 & 1. 745 \\
\hline 7 to 8 & .75 & 2.163 \\
\hline 8 to 9 & .85 & 2. 609 \\
\hline 9 to 10 & .95 & 3. 083 \\
\hline Total .... & $\ldots \ldots \ldots$ & 13.30 \\
\hline
\end{tabular}

The average head for the entire period, 0.5 foot, gives a discharge for 10 seconds of 11.773 second-feet, or 88.5 per cent of that given above, the numerical result agreeing closely with that obtained by analysis. The volume of flow from average head equals seven-eighths of the true integral volume of flow, approximately.

If there is an initial head $H_{o}$, then when the head varies uniformly,

$$
\begin{aligned}
& H=H_{o}+f t \\
& Q=C L H^{\frac{3}{2}}=C L\left(H_{o}+f t\right)^{\frac{3}{2}} .
\end{aligned}
$$

The total volume of flow in time $T$ will be

$$
Q_{\mathrm{t}}=\int_{0}^{T} Q d t=C L \int_{0}^{T}\left(H_{o}+f t\right)^{\frac{3}{2}} d t=\frac{2}{5 f} C L\left(H_{0}+f T\right)^{\frac{5}{2}}-\frac{2}{5 f} C L H_{o}^{\frac{5}{2}}
$$

The average head during time $T$ is

$$
H_{\mathrm{av}}=H_{o}+\frac{1}{2} f T
$$

The total volume of flow corresponding to this head is

$$
Q_{\mathrm{av}}=C L\left(H_{o}+\frac{1}{2} f T\right)^{\frac{3}{2}} T
$$


The ratio of the actual or integral discharge to the discharge by the average head is

$$
\frac{\text { Volume by average head }}{\text { Integral volume }}=\frac{5}{2} f \frac{\left(H_{o}+\frac{1}{2} f T\right)^{\frac{3}{2}} T}{\left[\left(H_{0}+f T\right)^{\frac{5}{2}}-H_{o}^{\frac{5}{2}}\right]} .
$$

The value of this ratio is independent of the coefficient or length of weir, but varies with the rate of change of head.

WEIR NOT LEVEL.

If the crest of a gaging weir is not truly horizontal, but is a little inclined, the discharge may be closely approximated by the use of the average crest depth $H$ in the ordinary formula, or more precisely by the formula below, applicable also to weirs of any inclination.

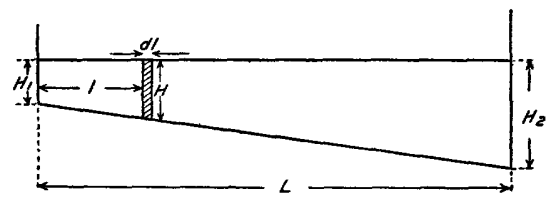

FIG. 7.--Inclined weir

The flow through the elementary width $d l$ is

$$
\begin{aligned}
& d Q=C H^{\frac{3}{2}} d l \\
& H=H_{1}+\frac{H_{2}-H_{1}}{L} l
\end{aligned}
$$

Total discharge $=Q=\int_{0}^{L} C H^{\frac{3}{2}} d l=C^{r} \int_{0}^{L}\left(H_{1}+\frac{H_{2}-H_{1}}{L} l\right)^{\frac{3}{2}} d l$ Integrating,

$$
Q=\frac{2 C L}{5\left(H_{2}-H_{1}\right)}\left(H_{2}^{\frac{5}{2}}-H_{1}^{\frac{5}{2}}\right) \cdot \cdot \cdot \cdot \cdot
$$

In this formula either the mean coefficient deduced by Thomson (see p. 46) for a triangular weir, in which $\frac{2}{5} C=1.32$, or that of Francis, in which $\frac{2}{5} C=1.332$, may be used. If there are end contractions, the net length,

should be used.

$$
L=L^{\prime}-0.2\left(\frac{H_{2}+H_{1}}{2}\right)
$$


The discharge using the average head,

is

$$
H_{a}=\frac{H_{2}+H_{1}}{2}
$$

$$
Q=C L\left(\frac{H_{2}+H_{1}}{2}\right)^{\frac{0}{2}} \cdot \text {. . . . . }
$$

The extent of variation from the true discharge resulting from the use of formula (55) in place of the integral formula (54) is illustrated by the following:

$$
\text { Let } L=10 \text { feet, } H_{a}=1.0 \text { foot, } \frac{2}{5} C=1.332 \text {. }
$$

Discharge by $(55)$ for average head $=33.30$ cubic feet per second. If $H_{2}-H_{1}=0.01$ foot - true discharge, $Q=33.30$ cubic feet per second. If $H_{2}-H_{1}=0.10$ foot - true discharge, $Q=33.30$ cubic feet per second. If $H_{3}-H_{1}=0.50$ foot - true discharge, $Q=33.54$ cubic feet per second.

In general, since the discharge varies more rapidly than the head, the effect of calculating the discharge from the average head will be to give too small discharge, the error increasing with the variation in crest level.

Hence the discharge obtained by using the average crest level for a weir having an inclined or uneven crest will be somewhat deficient. The magnitude of the variations in height of the crest will determine whether the average profile can be used or whether the crest should be subdivided into sections, each comprising portions having very nearly the same elevation (whether adjacent or not), and the discharge over each section computed as for a separate weir.

In general it may be stated that the error in the value of $Q_{1}$ increases directly in proportion as the ratio of the difference in the limiting heads to the average head is increased.

\section{CONVEXITY OF WATER SURFACE IN LEADING CHANNEL.}

If there are wide variations in velocity in the measuring section, the level of the water surface may be affected, since water in motion exerts less pressure than when at rest.

Conditions of equilibrium cause the swift-moving current to rise above the level of the slower-moving portions. If the head is measured near still water at the shore, the result may be slightly too small.

The difference in height ${ }^{a}$ may be expressed in the form,

$$
D_{2}-D_{1}=r_{2} \frac{v_{2}^{2}-v_{1}^{2}}{2 y} \text {. . . . . . . }
$$

The coefficient $r$ is often assumed equal to unity, but evidently varies with the distribution of velocities whose resultant effect it measures. 


\section{RESULTS OF EXPERIMENTS ON VARIOUS FORMS OF WEIR CROSS SECTIONS.}

\section{THE USE OF WEIRS OF IRREGULAR SECTION.}

Many cases arise where it is desired to estimate, approximately, at least, the flow over dams of peculiar cross section.

The construction of so-called standard or thin-edged weirs that shall be permanently useful to measure the flow of large and variable streams is so difficult and expensive as to be frequently impracticable. Existing milldams often afford a convenient substitute. In the following pages are presented the results of the leading experiments to determine proper coefficients for "irregular" weirs, followed by a grouping of experiments on similar models, whether all by one experimenter or not. The data are not always as complete or consistent as could be desired, but the need for fair working coefficients is very great, and, in the line of making use of all the available information, the several diagrams of comparison and the conclusions therefrom are presented, with the understanding that these are not final, although it is quite certain that the laws of coefficient variation are correctly outlined by the data at present available, and they form, therefore, a safe working hypothesis.

Weir models of irregular section are calibrated in order that existing dams of similar cross section may be used for stream gaging. It becomes necessary to calibrate the experimental models for a wider range of heads than has conmonly been employed in experiments on standard thin-edged weirs, in order that the range of rise and fall of the stream from low water to high may be included.

While the recent experimental data include heads as great as from 4 to 6 feet, yet it is often necessary to determine the discharge for still greater heads, and experiments on certain forms with heads up to 10 or 12 feet are needed.

In this connection the greater relative facility of securing accurate results with weirs for high than for low heads may be noted.

The proportional error resulting from variations in crest level, as well as uncertainties as to the nappe form and consequent value of the coefficient, largely disappear as the head increases. The effect of form of crest and friction is also relatively diminished. It is probably true that the coefficients for many ordinary forms of weir section would tend toward a common constant value if the head were indefinitely increased. The above facts render milldams especially useful for the determination of the maximum discharge of streams. Dams can be used for this purpose when the presence of logs and drift carried down by the flood preclude the use of current meters or other gaging instruments. 


\section{MODIFICATIONS OF THE NAPPE FORM.}

The elaborate investigations of Bazin relative to the physics of weir discharge set forth clearly the importance of taking into consideration the particular form assumed by the nappe. This is especially true in weirs of irregular section in which there is usually more opportunity for change of form than for a thin-edged weir. In general the nappe may-

1. Discharge freely, touching only the upstream crest edge.

2. Adhere to top of crest.

3. Adhere to downstream face of crest.

4. Adhere to both top and downstream face.

5. Remain detached, but become wetted underneath.

6. Adhere to top, but remain detached from face and become wetted underneath.

7. In any of the cases where the nappe is "wetted underneath" this condition may be replaced by a depressed nappe, having air imprisoned underneath at less than atmospheric pressure.

The nappe may undergo several of these modifications in succession as the head is varied. The successive forms that appear with an increasing stage may differ from those pertaining to similar stages with a decreasing head. The head at which the changes of nappe form occur vary with the rate of change of head, whether increasing or decreasing, and with other conditions.

The law of coefficients may be greatly modified or even reversed when a change of form takes place in the nappe.

The effect of modifications of nappe form on various irregular weir sections is shown in PI. III. The coefficients are those of Bazin and include velocity of approach. The coefficient curve for any form of weir having a stable nappe is a continuous, smooth line. When the nappe becomes depressed, detached, or wetted underneath during the progress of an experiment, the resulting coefficient curve may consist of a series of discontinuous or even disconnected ares terminating abruptly in "points d'arrêt," where the form of nappe changes. The modifications of nappe form are usually confined to comparatively low heads, the nappe sometimes undergoing several successive changes as the head increases from zero until a stable condition is reached beyond which further increase of head produces no change. The condition of the nappe when depressed or wetted underneath can usually be restored to that of free discharge by providing adequate aeration.

The weir sections shown in PI. III are unusually susceptible of changes of nappe form. Among weirs of irregular section there is a large class for which, from the nature of their section, the nappe can assume only one form unless drowned. Such weirs, it is suggested, may, if properly calibrated, equal or exceed the usefulness of the thin-edged 
Observed depth on weir (feet).

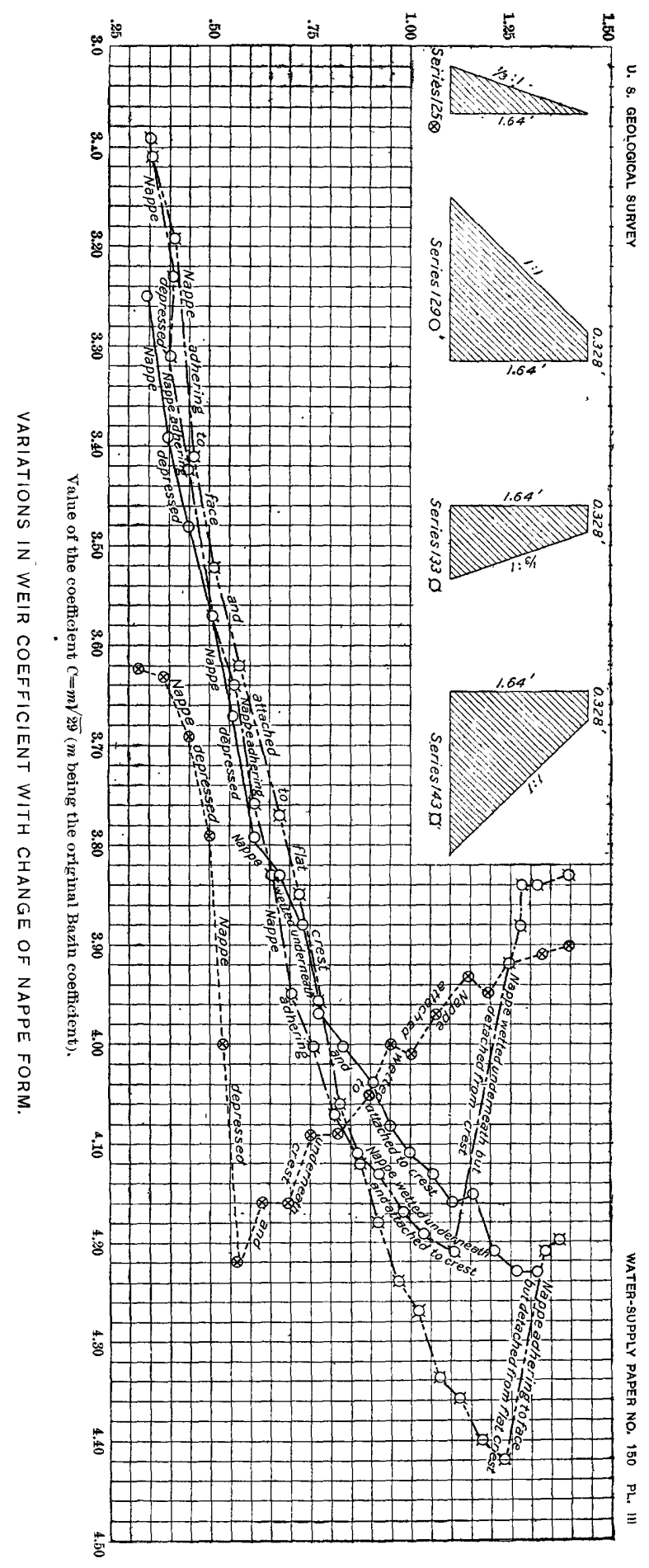

IRR $150-06-5$ 
weir for purposes of stream gaging, because of their greater stability of section and because the thin-edged weir is not free from modification of nappe form for low heads.

As an example, Bazin gives the following coefficients applying to a thin-edged weir 2.46 feet high, with a head of 0.656 foot, under various conditions:

\begin{tabular}{|c|c|c|c|}
\hline Condition of nappe. & $\begin{array}{l}\text { Bazin coeffi- } \\
\text { cient } m \text {. }\end{array}$ & $C=m \sqrt{2 g}$ & $\begin{array}{l}\text { Per cent of } \\
\text { the Francis } \\
\text { coefficient. }\end{array}$ \\
\hline Free discharge, full aeration $\ldots . . . \ldots \ldots \ldots \ldots . . . . . .$. & 0.433 & 3.47 & 104.1 \\
\hline Nappe depressed, partial vacuum underneath ..... & .460 & 3.69 & 110.7 \\
\hline $\begin{array}{l}\text { Nappe wetted underneath, dowr stream water } \\
\text { level, } 0.42 \text { foot below crest....................... }\end{array}$ & .497 & 3.99 & 119.7 \\
\hline $\begin{array}{l}\text { Nappe adhering to downstream face of weir, res- } \\
\text { sault at a distance } . . . . . . . . . . . . . . . . . . . . .\end{array}$ & .554 & 4.45 & 133.5 \\
\hline
\end{tabular}

These coefficients include velocity of approach effect, which tends to magnify their differences somewhat. There is, however, a range of 25 per cent variation in discharge between the extremes. ${ }^{a}$

The departure in the weir coefficient from that applying to a thinedged weir, for most forms of weirs of irregular section, results from some permanent modification of the nappe form. Weirs with sloping upstream faces reduce the crest contraction, broad-crested weirs cause adherence of the nappe to the crest, aprons cause permanent adherence of the nappe to the downstream face.

\section{EXPERIMENTAL DATA FOR WEIRS OF IRREGULAR CROSS SECTION.}

The only experiments on irregular or broad-crested weirs in which the discharge has been determined volumetrically are those of Blackwell on weirs 3 feet broad, of Francis on the Merrimac dam, and of the United States Geological Survey for lower heads, on various forms of section. So far as the writer is aware, all other such experiments have been made by comparison with standard weirs.

In the following pages are included the results of the experiments of Bazin on 29 forms of cross section; also those of the United States Deep Waterways Board under the direction of George W. Rafter, and those of John R. Freeman at Cornell University hydraulic laboratory. The results of 20 series of experiments, chiefly on weirs with broad and ogee crest sections, made under the writer's direction at Cornell University hydraulic laboratory, are here for the first time published.

$a$ Bazin's general discussion of the above and other modifications of the coeffieient has been translated by the writer, and may be found in Rafter's paper, On the flow of water over dams: Trans. Am. Soc. C. E., vol. 44, pp. 254-261. 
As it has been necessary to reduce the experimental data to a uniform basis for purposes of comparison the original data, together with the results obtained by recalculation, have been included for the Bazin, United States Deep Waterways, and Freeman experiments.

BASE FORMULA FOR DISCHARGE OVER WEIRS OF IRREGULAR CROSS SECTION.

Precedent to the opening of the hydraulic laboratory of Cornell University the most elaborate experiments on weirs of irregular cross section were those of Bazin. His experiments were all reduced in such manner as to include the velocity of approach correction in the discharge coefficient.

In America the formula most commonly used is that adopted by James B. Francis, in which velocity of approach is eliminated from the coefficient by correcting the head, thus reducing the conditions as nearly as possible to the basis of no velocity of approach before applying the formula.

In order to render Bazin's results comparable with the later experiments, it has been necessary to adopt a standard or base formula to which all the experiments should be reduced. The considerations leading to the adoption of the formula of Francis here used are given below.

In the process of gaging streams at dams the head is usually measured in comparatively still water in an open pond. This condition could not be duplicated in the Cornell experiments. As the formula of James B. Francis is most simple in form for the case of a weir with no velocity of approach, and as it is often convenient to compare the discharge over a dam with that for a thin-edged weir of standard form, a weir formula of the base form used by Francis has been adopted in reducing the experiments. In this formula,

$Q=C L H^{\frac{3}{2}}$.

$L=$ Length of crest corrected for end contractions, if any.

$H=$ Head on weir crest corrected for velocity of approach by the Francis correction formula or an equivalent method. $C=$ A coefficient determined from experiments on a model dam.

In this connection it may be remarked that the formula of Bazin includes the correction for velocity of approach in the weir coefficient; hence the coefficient for a given weir is comparable only with that for another weir under the same head when the velocity of approach is the same in both cases. Bazin's formula also expresses the velocity of approach implicitly by means of the depth and breadth of the leading channel. In actual gagings the leading channel is often of irregular form, hence it becomes necessary to eliminate the depth and breadth of the channel from the formula. 
There is considerable variation in the magnitude of the correction for velocity of approach used by different experimenters. As a rule, the velocity of approach is negligible at gaging stations at dams. It became necessary, therefore, in reducing these experiments to determine from the measured discharge and observed head what the head would have been had the same discharge taken place over a weir in a still pond. To accomplish this the formula for correction for velocity of approach adopted by James B. Francis has been used. This being the case, it is to be noted that in applying the coefficients, which, as given, have been reduced as nearly as possible to the basis of no velocity of approach, the same method of velocity correction must be used, and if it is used no error will result where the actual velocity of approach is nearly the same as that which occurred in the experiments.

\section{BAZIN'S EXPERIMENTS ON WEIRS OF IRREGUIAR CROSS SECTION.}

These include a wide variety of forms, many of which will seldom be found in America, and the use of which for purposes of gaging would be ill advised.

The small size of the models used, high velocity of approach, and narrow range of heads covered, limit the application of these results. No effort has been made to present all the results in this paper. ${ }^{a}$ Certain series, useful for comparison, have been recomputed as described below, and by grouping similar sections we may determine the general effect of various slope and crest modifications.

BAZIN'S CORRECTION FOR VELOCITY OF APPROACH.

The base formula for weir discharge adopted by Bazin and the method of taking into account the velocity of approach are described in connection with his experiments on thin-edged weirs (p. 31).

The following discussion shows the complex character of the Bazin coefficients, and the fact that they do not express directly the relative discharging capacity of weirs of irregular section.

The effect of velocity of approach is to increase the discharge at a given observed head, $D$, over what it would be if the same head were measured in still water, as in a deep, broad pond.

Bazin's coefficients in the form published are not readily applicable in practice to weirs of other heights, or to weirs in ponds, or otherwise to any but weirs in restricted channels of the depth and width of the weir.

a For complete original data, see Bazin, as translated by Marichal and Trautwine in Proc. Engineers Club Phila., vol. 7, pp. 259-310; vol. 9, pp. 231-244, 287-319: vol. 10, pp. 121-164; also numerous experiments reduced to English units by Rafter and others, Trans. Am. Soc. C. E., vol. 44, pp. 220-398. 
The Bazin coefficients as published may be considered as comprising two principal factors. $M$ being the Bazin coefficient, we may write

$M=F C$.

$F=$ velocity of approach effect.

$C=$ contraction effect.

Bazin uses a correction formula for velocity of approach, derived from the expression

$$
H=D+1.69 \frac{v^{2}}{2 g} \text { or } D+\alpha h .
$$

Consider a standard weir and experimental weir both of the same height, but of different form, the measured depth being the same, and the Bazin coefficients being $M$ and $m$, the velocity of approach and discharge $V$ and $v$ and $Q$ and $q$, respectively, and $C$ and $C_{1}$ the coefficients in a formula in which the velocity of approach correction is eliminated from the coefficient and applied to the head; then the discharge for the standard weir would be,

using the Bazin coefficients,

$$
Q=M L D \sqrt{2 g I}=M^{\prime} D^{\frac{3}{2}}
$$

where $M^{\prime}=M \sqrt{2 g}$ and $L=1.0$;

using the coefficient $C^{\prime}$,

$$
Q=C H^{\frac{3}{2}}=C(D+\alpha h)^{\frac{3}{2}},
$$

taking roots

$$
\left(\frac{C^{\prime}}{M^{\prime}}\right)^{\frac{2}{3}}=\frac{D}{D+\alpha h}
$$

Bazin does not give the quantities of flow in the tables of results of his experiments, hence to determine $l$ it is necessary to calculate $Q$. $v$, and $h$ from the known values $M$ and $D$ and from $P$, the height of weir.

$D$ being the same for both the standard and the experimental weirs, we have for the experimental weir

$$
\left(\frac{C_{1}}{m}\right)^{\frac{2}{3}}=\frac{D}{D+\alpha h_{1}}
$$

$C_{1}$ being the coefficient for the experimental weir, and $h_{1}$ the velocity head. 
Hence, by multiplication,

$$
\left(\frac{m}{\bar{M}}\right)^{\frac{2}{3}}\left(\frac{C}{C_{1}}\right)^{\frac{2}{3}}=\frac{D}{D+\alpha h_{1}} \times \frac{D+\alpha h_{1}}{D}
$$

and

$$
\left(\frac{m}{M}\right)^{\frac{2}{3}}=\left(\frac{C_{1}}{C^{\prime}}\right)^{\frac{2}{3}} \times \frac{D+\alpha l_{i_{1}}}{I I+\alpha l_{i}}
$$

or

$$
\frac{m}{M}=\frac{C_{1}}{C} \times\left(\frac{D+\alpha h_{1}}{D+\alpha h}\right)^{\frac{3}{2}}
$$

The velocity of approach for a given depth on a weir is proportional to $C$, hence, since $h$ is proportional to $v^{2}$, we have

Hence,

$$
\frac{h_{1}}{h}=\left(\frac{C_{1}}{C}\right)^{2}
$$

$$
\bar{M}=\frac{C_{1}}{C^{\prime}}\left(\frac{D+\left(\frac{C_{1}}{C}\right)^{2} \alpha h}{D+\alpha h}\right)^{\frac{3}{2}} \cdot . \quad . \quad \cdot \quad . \quad
$$

The ratio $\frac{m}{M}$ used by Bazin is not, therefore, precisely a measure of the relative discharging capacities of the two weirs under similar conditions of head and velocity of approach, for the reason that the velocity of approach will not be the same for both weirs if the Bazin coefficients are different. The ratio $m / M$ is made up of two factors, one of which, $C_{1} / C$, expresses the absolute relative discharging capacities of the two weirs under similar conditions of head and relocity of approach, and the other expresses the effect of the change in discharging capacity on the velocity of approach for a given depth on a weir of given beight.

Thus the coefficient $M$ for any weir has, by Bazin's method of reduction, different values. for every depth and for every height of weir that may occur.

For reasons elsewhere stated it is preferred to express by $\frac{C}{C_{1}}$ only the relative discharging capacities of the weirs where the velocity of approach is the same in both. It is then practically a measure of the vertical contraction of the nappe, and is constant for a given head for any height of weir, and may be sensibly constant for various depths on the weir. 
RECOMPUTATION OF COEFFICIENTS IN BAZIN'S EXPERIMENTS.

In reporting the results of his experiments on weirs of irregular section, Bazin gives the observed heads on the standard weir of comparison, the absolute coefficient $m$ applying for each depth on the experimental weir and the ratio $m / M$ of the experimental and standard weir coefficients.

The results give coefficients which strictly apply only to weirs having both the same form of section and the same heights as those of Bazin. Although weirs of sectional form geometrically similar to Bazin's are common, yet few actual weirs have the same height as his. There appear to be two elements which may render inaccurate the application of Bazin's absolute coefficients to weirs of varying height: (1) The difference in velocity of approach; (2) the difference in contraction of the nappe for a higher or lower weir.

In order to render the results of Bazin's experiments comparable one with another and with later experiments, a number of series have been recomputed, the velocity of approach being treated in the same manner as in the computation of experiments at Cornell hydraulic laboratory.

The method is outlined below, the references being to the tables of Bazin's experiments given on pages 68 to 81 .

Column 2 gives the observed head reduced to feet for the experimental weir.

Column 4 the absolute coefficient $C_{1}=m \sqrt{\mathscr{Q} g}$.

(These have been reduced from Bazin's original tables.)

Column 5 gives the discharge per foot of crest over the experimental weir calculated by the formula

$$
Q=m L D \sqrt{2} \overline{g D}=C_{1} L D^{\frac{3}{2}},
$$

quantities in column 3 being taken directly from a table of three-halves powers.

In column 6 the actual velocity of approach, $v=\frac{Q}{P+D}$, is given, and in column 7 the velocity head, $h=\frac{v^{2}}{2}$.

The discharga over the standard weir was calculated by Bazin by using his own formula and velocity of approach correction. He does not give the discharge, however, and we have been obliged to work back and obtain it from the data given for the experimental weir.

Having determined the actual discharge and the observed head, we are now at liberty to assume such a law of velocity of approach correction in deducing our new coefficients as we choose. We will therefore deduce the coefficients in such form that when applied to a weir 
U. S. GEOLOGICAL SURVEY .

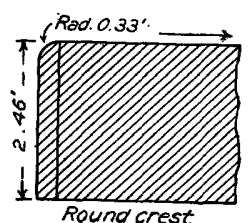

Round crest

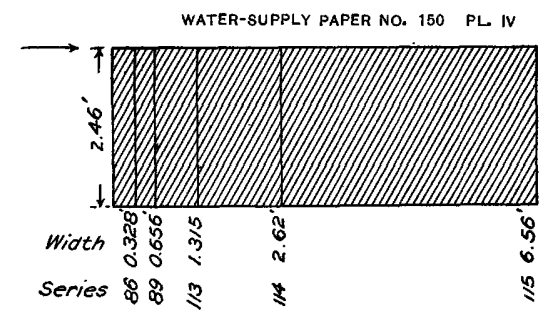

Coeff-

cient

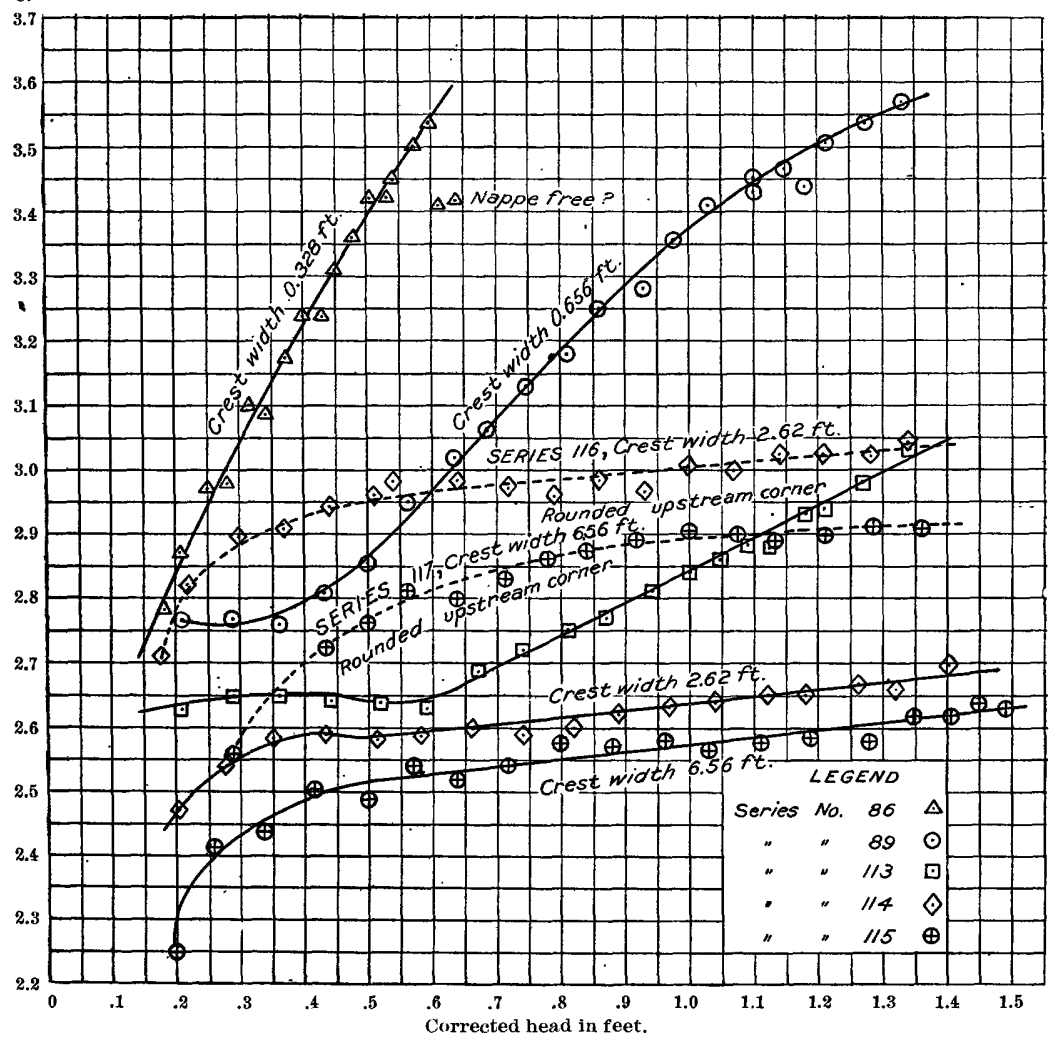

EXPERIMENTS OF BAZIN ON BROAD-CRESTED WEIRS.

Velocity-of-approach correction by the Francis method. 


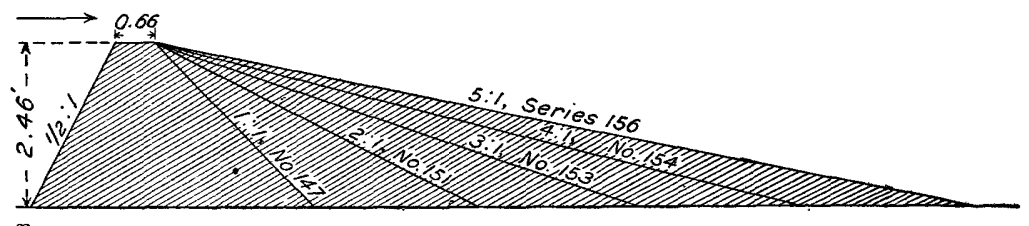

Coeff-
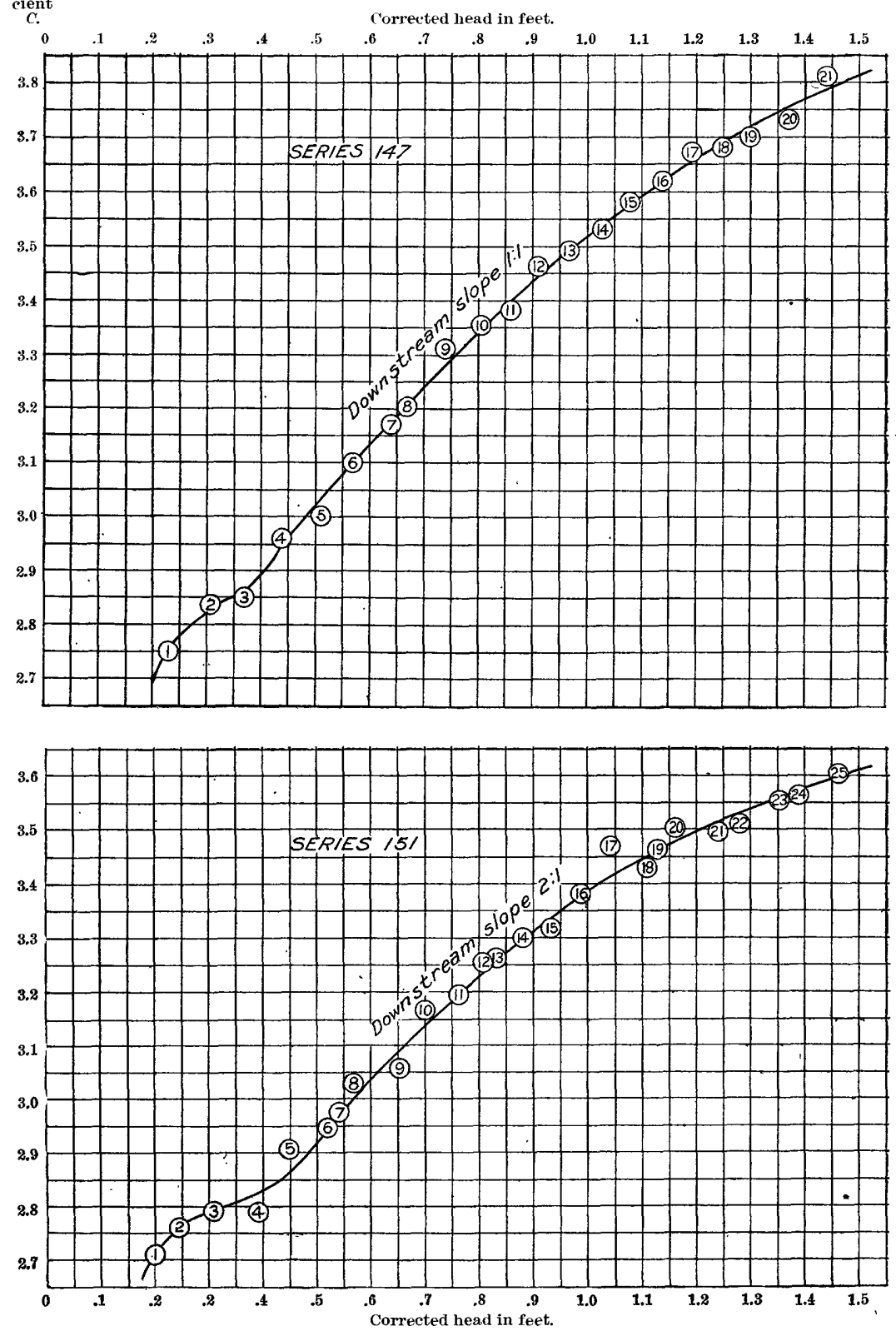

EXPERIMENTS OF BAZIN ON WEIRS OF TRAPEZOIDAL SECTION WITH VARYING DOWNSTREAM SLOPE.

Velocity-of-approach correction by the Francis method. (See also PI. VII.) 
Coeffi-
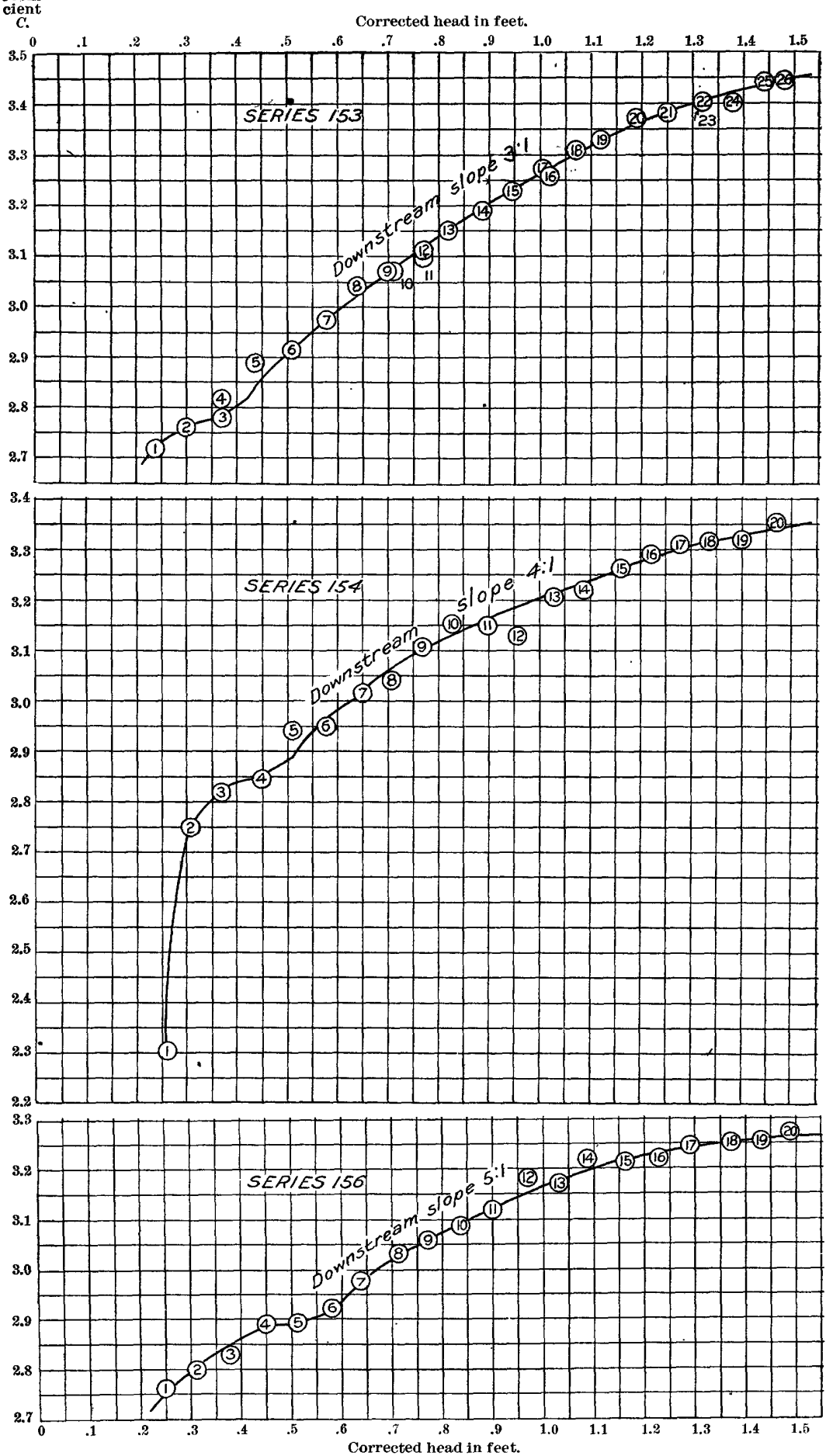

EXPERIMENTS OF BAZIN ON WEIRS OF TRAPEZOIDAL SECTION WITH VARYING DOWNSTREAM SLOPE.

Velocity-of-approach correction by the Francis method. (For cross section see PI. VI.) 


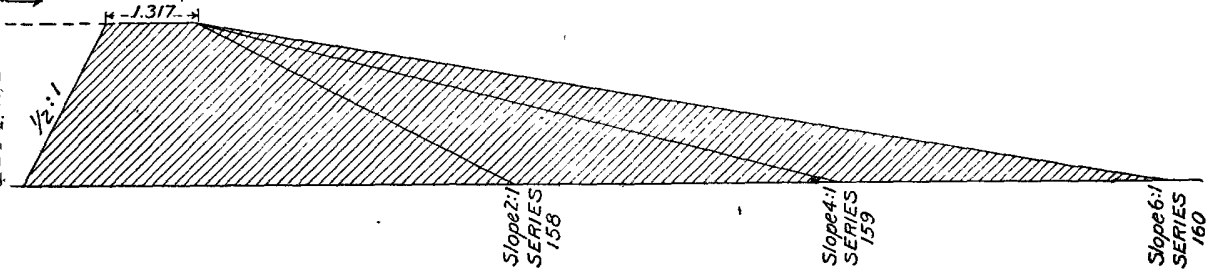

Coeffi-
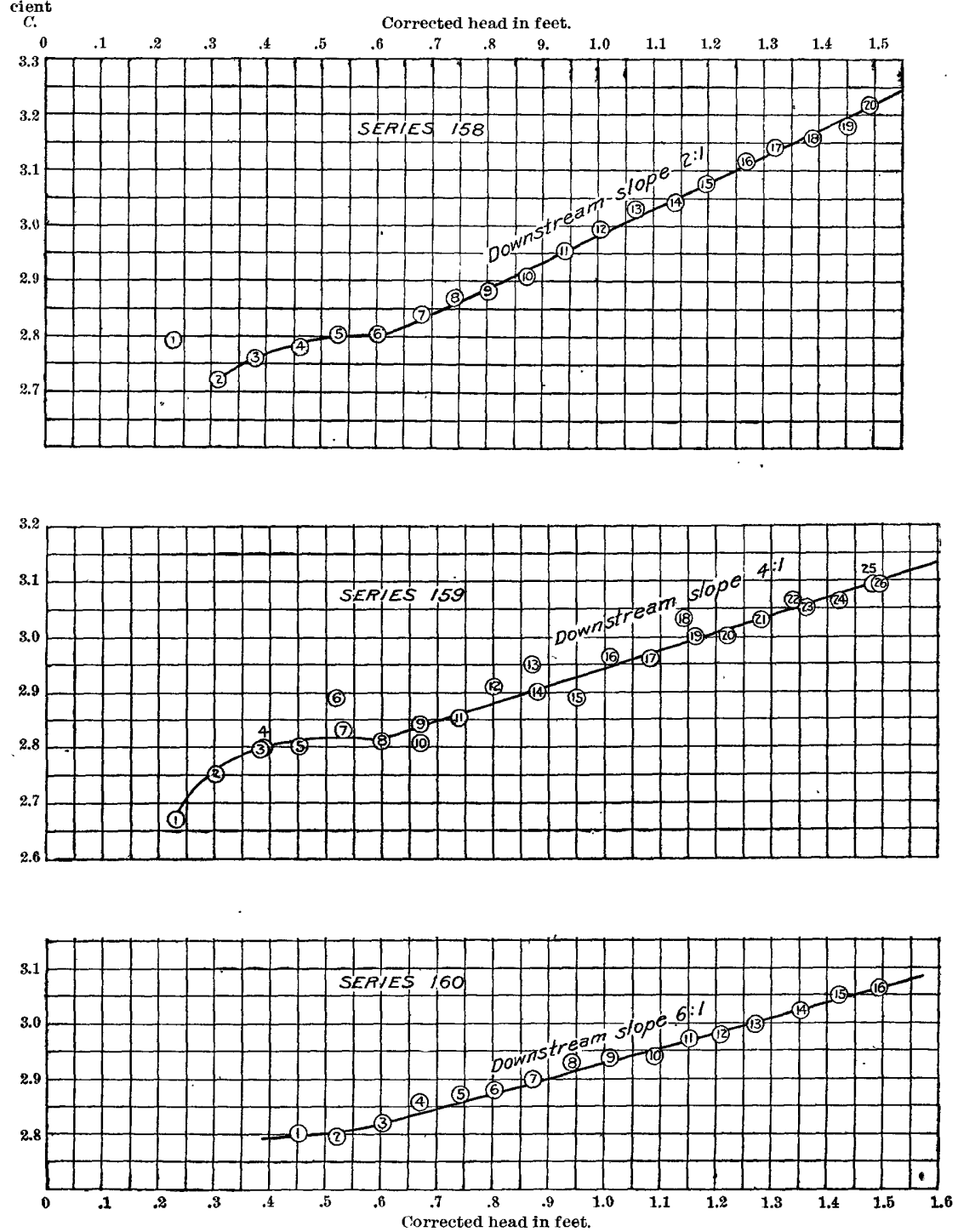

EXPERIMENTS OF BAZIN ON WEIRS OF TRAPEZOIDAL SECTION WITH VARYING DOWNSTREAM SLOPE. 

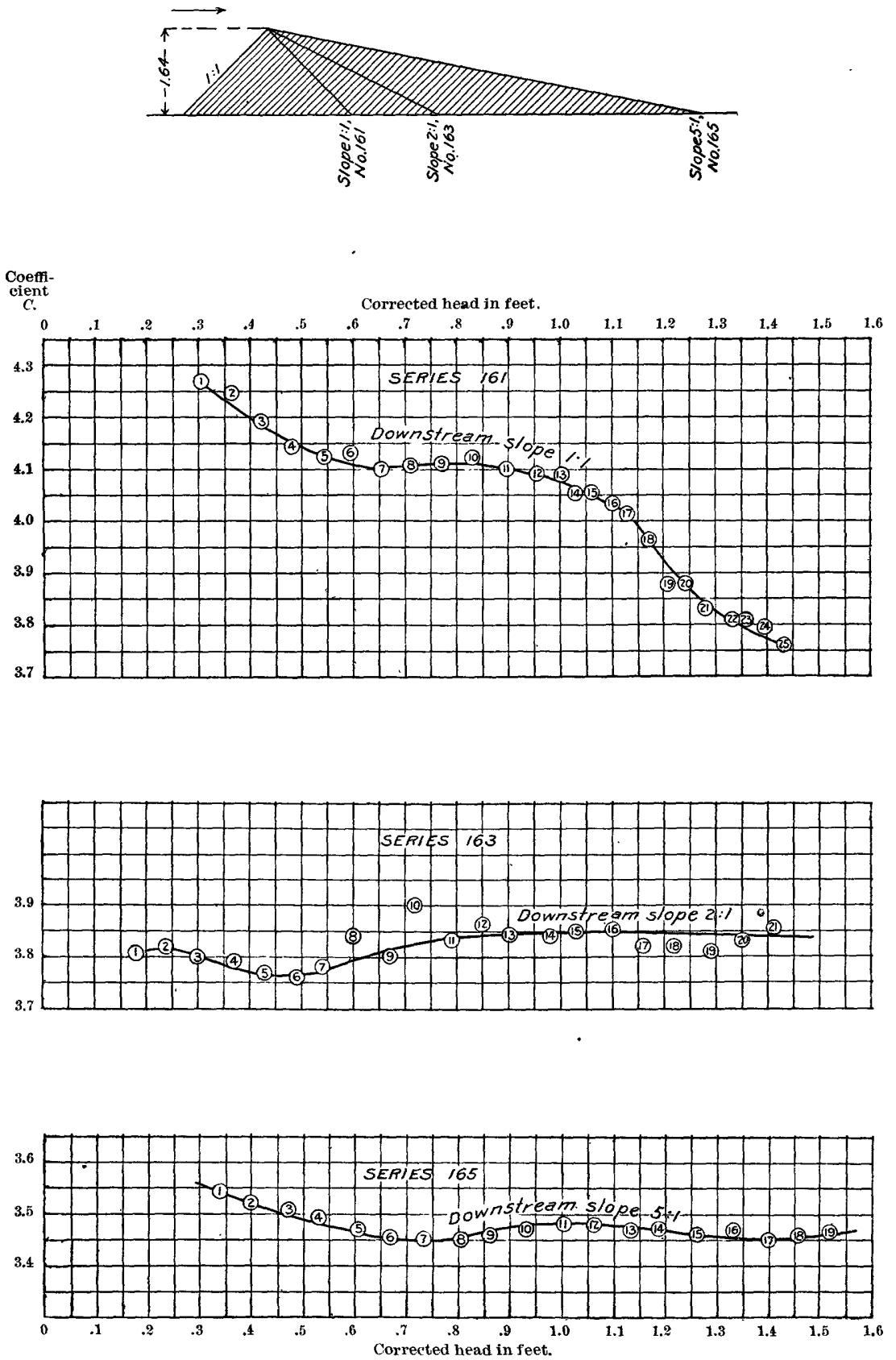

EXPERIMENTS OF BAZIN ON WEIRS OF TRIANGULAR SECTION WITH VARYING DOWNSTREAM SLOPE. 


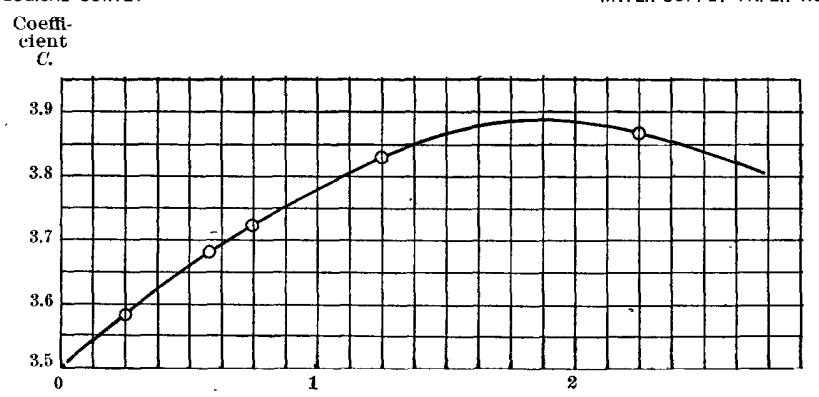

Slope of upstream face. Run for unit rise.

MEAN CONSTANT COEFFICIENTS FOR VARYING SLOPE OF UPSTREAM FACE.

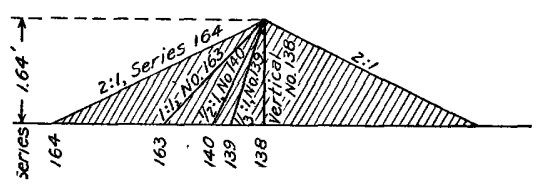

Coeffi-

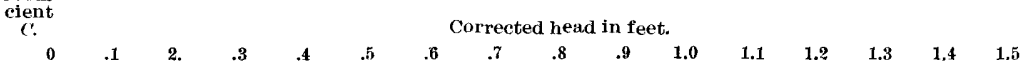

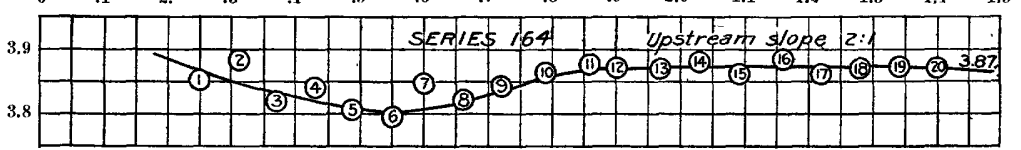
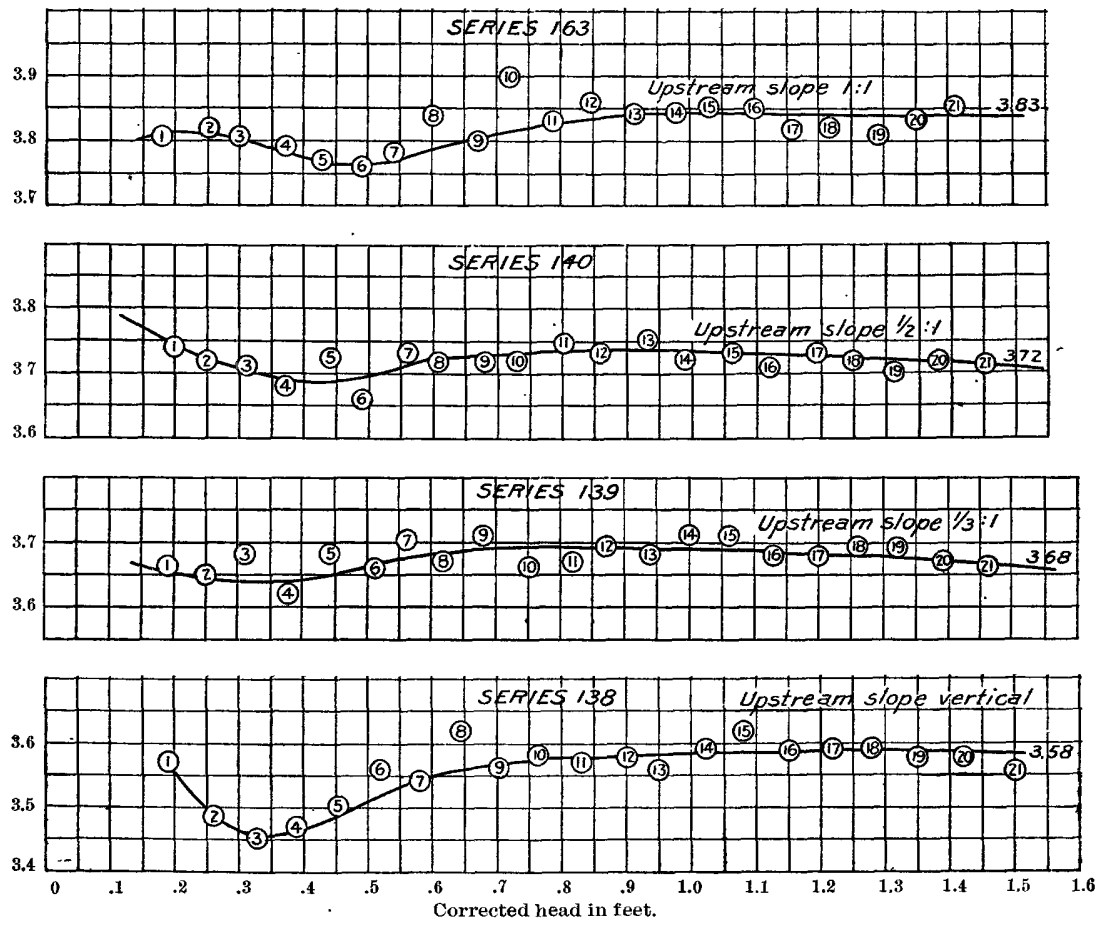

EXPERIMENTS OF BAZIN ON WEIRS OF TRIANGULAR SECTION WITH VARYING UPSTREAM SLOPE. 
Coeffi-
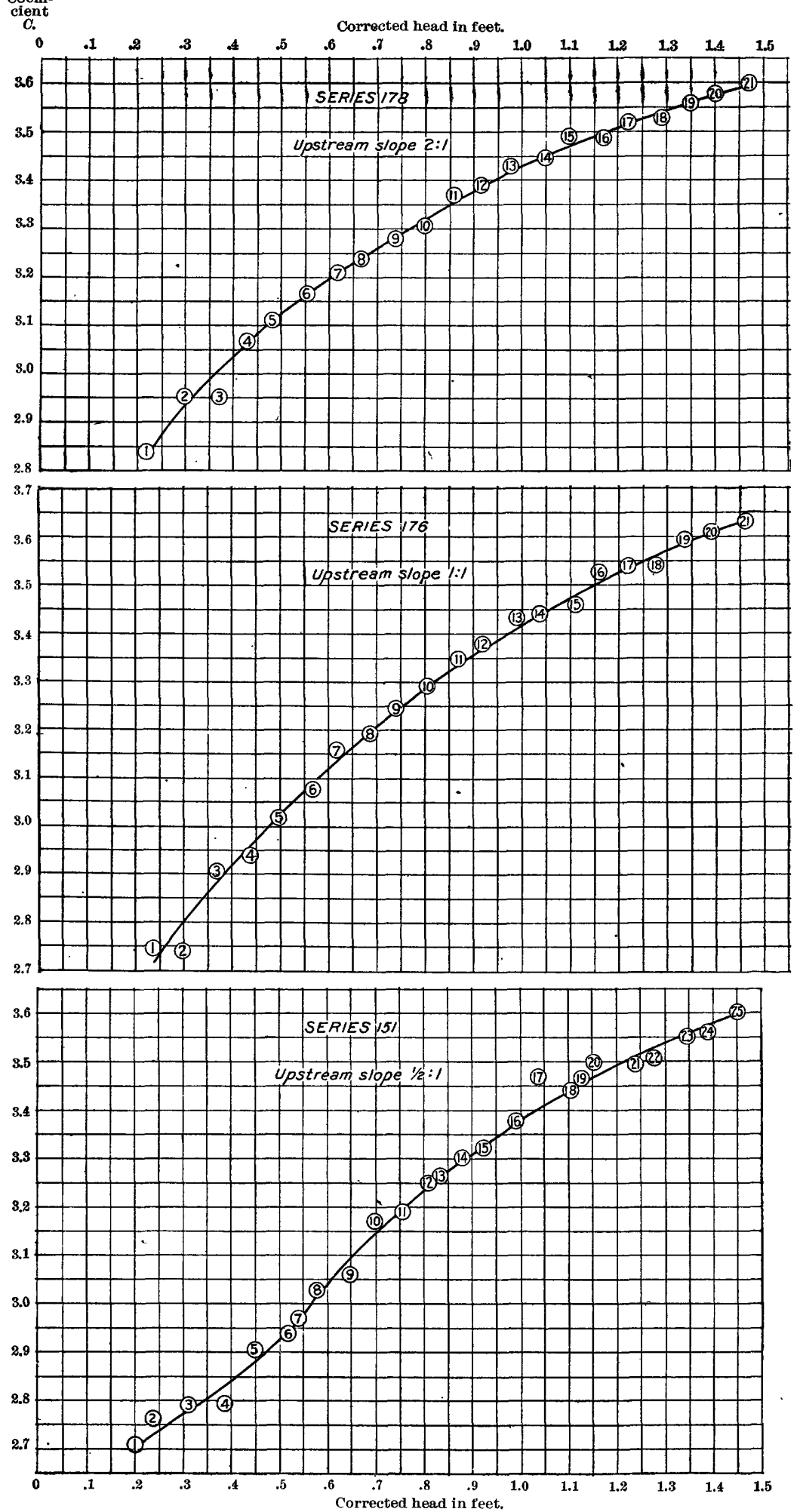

EXPERIMENTS OF BAZIN ON WEIRS OF TRAPEZOIDAL SECTION WITH VARYING UPSTREAM SLOPE.

Velocity-of-approach correction by the Francis method. (For cross section see PI. XII.) 
Coeffi-

cient

C. Corrected head in feet.

$\begin{array}{llllllllllllllll}0 & .1 & .2 & .3 & .4 & .5 & .6 & .7 & .8 & .9 & 1.0 & 1.1 & 1.2 & 1.3 & 1.4 & 1.5\end{array}$
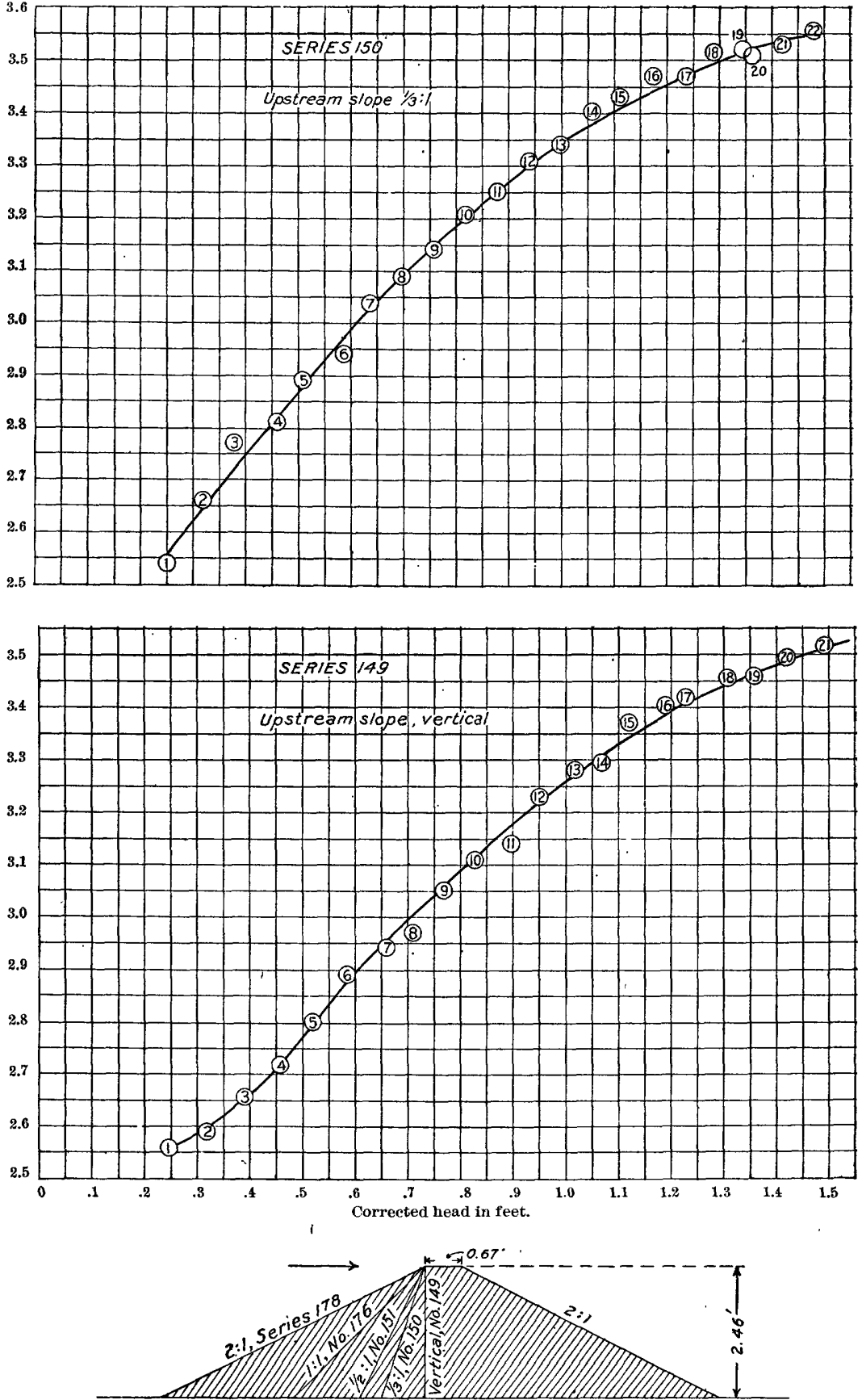

EXPERIMENTS OF BAZIN ON WEIRS OF TRAPEZOIDAL SECTION WITH VARYING UPSTREAM SLOPE.

Velocity-of-approach correction by the Francis method. (See also PI. XI.) 
in which there is velocity of approach we may apply the correction formula of Francis,

$$
H=\left[(D+h)^{\frac{3}{2}}-h^{\frac{3}{2}}\right]^{\frac{2}{3}} .
$$

A sufficient approximation to this formula for our present purposes may be obtained if we simply make

$$
H=D+\frac{v^{2}}{2 g},
$$

where $v$ is the velocity of approach corresponding to the trial dissharge for the head $D$, no successive approximations being made, as rould be necessary to determine the true head $H$ by the Francis cor"ection formula.

For example, in an extreme case, using a thin-edged weir

$$
D=1.0, \quad P=1.0, \quad v \text { (approx. }) \frac{Q}{P+D}=\frac{3.33}{2}=1.665
$$

$$
h=\frac{v^{2}}{2 g}=0.0431 \quad \text { whence } \quad H=D+\frac{v^{2}}{2 g}=1.0431 \text {, }
$$

and $Q=3.547$.

By the Francis correction formula we find, using three successive pproximations,

$$
\begin{aligned}
& Q_{1}=3.5183 \text { giving } v=1.7591 \\
& Q_{2}=3.5387 \text { giving } v=1.7694 \\
& Q_{3}=3.541 \text { as the final discharge, }
\end{aligned}
$$

that the difference is 0.11 of 1 per cent. We are therefore justified in using this method to determine values of $C$ to two places decimals, or to within one-fourth to one-half per cent.

We have also used $\sqrt{2 g}=8.02$, as in the reduction of the Cornell cxperiments.

Column 8 gives the corrected head,

$$
H=D+h .
$$

Column 10 gives the final coefficient $C$ deduced by the formula

$$
C=\frac{Q}{H^{\frac{3}{2}}} \text {. }
$$

Pls. IV to XII show the resulting discharge coefficients. 
Bazin's experiments on weirs of irregular section.

Bazin's Series, No. 86.

Crest length, 6.55 feet.

Crest height, 2.46 feet.

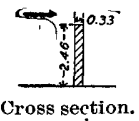

\begin{tabular}{|c|c|c|c|c|c|c|c|c|c|}
\hline Period. & $\begin{array}{c}\text { Observed } \\
\text { head. } \\
\text { experi- } \\
\text { mental } \\
\text { weir } I, \\
\text { in feet. }\end{array}$ & $D^{\frac{3}{2}}$ & $C_{1}$ & $\begin{array}{c}Q, \text { flow } \\
\text { per foot, } \\
\text { experi- } \\
\text { mental } \\
\text { weir, in } \\
\text { cubic feet } \\
\text { per } \\
\text { second. }\end{array}$ & p & $\begin{array}{c}\frac{v^{2}}{2 g} \\
.\end{array}$ & $H$ & $H^{\frac{3}{2}}$ & $C$ \\
\hline 1 & 2 & 3 & 4 & 5 & 6 & 7 & 8 & 9 & 10 \\
\hline 1 & 0.1820 & 0.0777 & 2. 7829 & 0.2160 & 0.082 & & 0.1820 & 0.0777 & 2.78 \\
\hline 2 & .2119 & .0976 & 2.8712 & .2801 & .105 & & .2119 & .0976 & 2.87 \\
\hline 3 & .2509 & .1257 & 2. 9674 & .3733 & .138 & & .2509 & .1257 & 2.97 \\
\hline 4 & .2781 & .1466 & 2.9754 & .4369 & .159 & & .2781 & .1466 & 2.98 \\
\hline 5 & .3067 & .1701 & 3.0957 & .5273 & .190 & 0.0006 & .3073 & .1701 & 3.10 \\
\hline 6 & .3392 & .1974 & 3.0957 & .6119 & .218 & .0008 & .3400 & .1983 & 3.09 \\
\hline 7 & .3678 & .2232 & 3.1839 & .7098 & .251 & .0010 & .3688 & .2241 & 3.17 \\
\hline 8 & .4016 & .2549 & 3.2321 & .8233 & .288 & .0013 & .4029 & .2539 & 3. 24 \\
\hline 9 & .4251 & .2771 & 3.2641 & .9033 & .303 & .0014 & .4265 & .2786 & 3.24 \\
\hline 10 & .4527 & .3049 & 3. 3283 & 1.0153 & .350 & .0019 & .4546 & .3069 & 3.31 \\
\hline 11 & .4770 & .3294 & 3. 3844 & 1.1137 & .379 & .0022 & .4792 & .3315 & 3. 36 \\
\hline 12 & .5075 & .3616 & 3. 4406 & 1.2449 & .420 & .0027 & .5102 & .3642 & 3.42 \\
\hline 13 & .5360 & .3924 & 3. 4807 & 1. 3656 & .455 & .0033 & .5393 & .3957 & 3.45 \\
\hline 14 & .5639 & .4235 & 3. 5368 & 1. 4992 & $.4 \subseteq 6$ & .0039 & .5678 & .4280 & 3.50 \\
\hline 15 & .5973 & .4613 & 3. 5930 & 1.6561 & .542 & .0045 & .6018 & .4671 & 3.54 \\
\hline 16 & a. 5304 & .3858 & 3.4566 & 1. 3349 & .446 & .0031 & .5335 & .3897 & 3.42 \\
\hline 17 & $\alpha, 6082$ & .4683 & 3. 4486 & 1.6156 & .528 & .0044 & .6076 & .4740 & 3.41 \\
\hline 18 & a. 6347 & .5060 & 3.4646 & 1. 7508 & .566 & .0051 & .6398 & .5120 & 3.42 \\
\hline
\end{tabular}

Bazin's Series, No. 89.

Crest length, 6.55 feet.

Crest height, 2.46 feet.

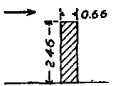

Cross section.

\begin{tabular}{|r|r|r|r|r|r|r|r|r|r|}
\hline 1 & 0.2079 & 0.0948 & 2.7669 & 0.2626 & 0.098 & $\ldots \ldots \ldots$ & 0.2079 & 0.0948 & 2.77 \\
2 & .2873 & .1538 & 2.7669 & .4260 & .155 & $\ldots \ldots .$. & .2873 & .1538 & 2.77 \\
3 & .3641 & .2196 & 2.7669 & .6083 & .216 & 0.0008 & .3649 & .2205 & 2.76 \\
4 & .4337 & .2859 & 2.8230 & .8062 & .279 & .0012 & .4349 & .2869 & 2.81 \\
5 & .4963 & .3494 & 2.8792 & 1.0063 & .340 & .0018 & .4981 & .3515 & 2.86 \\
6 & .5619 & .4213 & 2.9674 & 1.2513 & .414 & .0026 & .5635 & .4235 & 2.95 \\
7 & .6331 & .5036 & 3.0476 & 1.5360 & .498 & .0039 & .6370 & .5084 & 3.02 \\
8 & .6890 & .57195 & 3.0877 & 1.7673 & .560 & .0049 & .6939 & .5782 & 3.06 \\
9 & .7490 & .6482 & 3.1679 & 2.0548 & .640 & .0064 & .7554 & .6561 & 3.13 \\
10 & .7985 & .7135 & 3.2160 & 2.2975 & .705 & .0078 & .8063 & .7236 & 3.18 \\
11 & .8546 & .7906 & 3.2962 & 2.6090 & .785 & .0097 & .8643 & .8031 & 3.25 \\
12 & .9228 & .8867 & 3.3524 & 2.9704 & .879 & .0120 & .9348 & .9041 & 3.28 \\
13 & .9648 & .9479 & 3.4326 & 3.2513 & .949 & .0140 & .9788 & .9687 & 3.36 \\
14 & 1.0236 & 1.0362 & 3.4887 & 3.6163 & 1.038 & .0168 & 1.0404 & 1.0606 & 3.41 \\
15 & 1.0784 & 1.1193 & 3.5288 & 3.9511 & 1.118 & .0195 & 1.0979 & 1.1505 & 3.43 \\
16 & 1.1312 & 1.2028 & 3.5849 & 4.3060 & 1.201 & .0224 & 1.1536 & 1.2396 & 3.47 \\
17 & 1.1866 & 1.2932 & 3.6331 & 4.6943 & 1.292 & .0259 & 1.2125 & 1.3359 & 3.51 \\
18 & 1.2375 & 1.3767 & 3.6732 & 5.0525 & 1.364 & .0288 & 1.2663 & 1.4245 & 3.54 \\
19 & 1.2959 & 1.4754 & 3.7052 & 5.4737 & 1.456 & .0331 & 1.3290 & 1.5321 & 3.57 \\
20 & $a 1.0807$ & 1.1239 & 3.5368 & 3.9786 & 1.122 & .0195 & 1.1002 & 1.1537 & 3.45 \\
21 & $a 1.1587$ & 1.2477 & 3.5448 & 4.4169 & 1.219 & .0231 & 1.1818 & 1.2850 & 3.44 \\
\hline
\end{tabular}

$a$ Nappe free from the erest. 
Bazin's experiments on weirs of irregular section-Continued.

Bazin's Series, No. 113. Crest height, 2.463 feet.

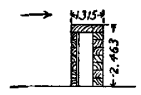

Cross section.

\begin{tabular}{|c|c|c|c|c|c|c|c|c|c|}
\hline Period. & $\begin{array}{l}\text { Observed } \\
\text { head, } \\
\text { experi- } \\
\text { mental } \\
\text { weir } D, \\
\text { in feet. }\end{array}$ & $D^{\frac{3}{2}}$ & $C_{1}$ & $\begin{array}{c}Q, \text { flow } \\
\text { per foot, } \\
\text { experi- } \\
\text { mental } \\
\text { weir, in } \\
\text { cubic feet } \\
\text { per } \\
\text { second. }\end{array}$ & $r$ & $\frac{v^{2}}{2 g}$ & $H$ & $H^{\frac{3}{2}}$ & $C$ \\
\hline 1 & $\mathbf{2}$ & 3 & 4 & 5 & 6 & 7 & 8 & 9 & 10 \\
\hline 1 & 0.208 & 0.0948 & 2.64 & 0.2503 & $\cdots$ & & 0.208 & 0.09484 & 2.63 \\
\hline 2 & .289 & .1554 & 2.66 & .4134 & $\cdots$ & ........ & .289 & .1562 & 2.65 \\
\hline 3 & .363 & .2187 & 2.66 & .5817 & 0.206 & 0.0007 & .3637 & .2196 & 2.65 \\
\hline 4 & .443 & .2949 & 2.65 & .7815 & .269 & .0011 & .4441 & $.296^{\circ}$ & 2. 64 \\
\hline 5 & .518 & .3728 & 2.66 & .9916 & .332 & .0017 & .5197 & .375 & 2.64 \\
\hline 6 & .592 & .4555 & 2.64 & 1. 2025 & .392 & .0024 & .5944 & .4578 & 2.63 \\
\hline 7 & .667 & .5447 & 2.71 & 1. 4761 & .472 & .0034 & .6704 & .549 & 2.69 \\
\hline 8 & .736 & .6314 & 2.75 & 1. 7364 & .542 & .0045 & .7405 & .6377 & 2.72 \\
\hline 9 & .805 & .7223 & 2.78 & 2.0080 & .612 & .0058 & .8108 & .7303 & 2. 75 \\
\hline 10 & .863 & .8017 & 2.80 & 2. 2441 & .672 & .0070 & .8700 & .8115 & 2.77 \\
\hline 11 & .936 & .9056 & 2.85 & 2.5810 & .758 & .0090 & .9450 & .91865 & 2.81 \\
\hline 12 & .989 & .9835 & 2.88 & 2.8325 & .821 & .0105 & .9995 & .9925 & 2.84 \\
\hline 13 & 1.055 & 1.0530 & 2.91 & 3.0641 & .872 & .0118 & 1. 0468 & 1. 068 & 2.86 \\
\hline 14 & 1.076 & 1.1162 & 2.94 & 3.2816 & .925 & .0132 & 1. 0892 & 1. 1364 & 2.88 \\
\hline 15 & 1.114 & 1. 1758 & 2.95 & 3.4686 & .968 & .0143 & 1. 1283 & 1. 1980 & 2. 88 \\
\hline 16 & 1. 159 & 1. 2478 & 3.00 & 3. 7434 & 1.032 & .0165 & 1.1755 & 1.274 & 2.93 \\
\hline 17 & 1. 197 & 1. 3096 & 3.01 & 3. 9419 & 1.075 & .0179 & 1.2149 & 1.339 & 2.94 \\
\hline 18 & 1. 252 & 1. 4009 & 3.06 & 4. 2868 & 1.154 & .0206 & 1. 2726 & 1.436 & 2.98 \\
\hline 19 & 1.320 & 1.5166 & 3.11 & 4. 7166 & 1.246 & .0243 & 1. 3443 & 1.558 & 3. 03 \\
\hline
\end{tabular}

Bazin's Series, No. 114. Crest height, 2.46 feet.

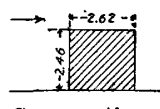

Cross section.

\begin{tabular}{|r|r|r|r|r|r|r|r|r|r|r|}
\hline 1 & 0.204 & 0.0921 & 2.47 & 0.2275 & 0.056 & $\ldots \ldots \ldots$ & 0.204 & 0.0921 & 2.47 \\
2 & .280 & .1482 & 2.54 & .3764 & .137 & $\ldots \ldots \ldots$. & .280 & .1482 & 2.54 \\
3 & .352 & .2089 & 2.59 & .5411 & .193 & 0.0006 & .3526 & .2097 & 2.58 \\
4 & .433 & .28497 & 2.60 & .7409 & .256 & .0011 & .4341 & .2860 & 2.59 \\
5 & .504 & .3578 & 2.59 & .9267 & .313 & .0015 & .5055 & .3594 & 2.58 \\
6 & .578 & .4394 & 2.60 & 1.1424 & .376 & .0022 & .5802 & .4417 & 2.59 \\
7 & .657 & .5325 & 2.62 & 1.3952 & .446 & .0031 & .6601 & .5362 & 2.60 \\
8 & .735 & .6302 & 2.63 & 1.6511 & .517 & .0042 & .7392 & .6353 & 2.59 \\
9 & .810 & .7290 & 2.63 & 1.9173 & .587 & .0054 & .8154 & .7358 & 2.60 \\
10 & .882 & .8283 & 2.65 & 2.1950 & .655 & .0068 & .8888 & .8381 & 2.62 \\
11 & .958 & .9377 & 2.66 & 2.4943 & .728 & .0083 & .9663 & .9494 & 2.63 \\
12 & 1.034 & 1.0514 & 2.68 & 2.8178 & .806 & .0102 & 1.0442 & 1.0667 & 2.64 \\
13 & 1.112 & 1.1727 & 2.69 & 3.1546 & .883 & .0120 & 1.1240 & 1.1917 & 2.65 \\
14 & 1.171 & 1.2672 & 2.70 & 3.4214 & .941 & .0137 & 1.1847 & 1.2899 & 2.65 \\
15 & 1.243 & 1.3858 & 2.73 & 3.7832 & 1.021 & .0161 & 1.2591 & 1.4127 & 2.67 \\
16 & 1.301 & 1.4839 & 2.73 & 4.0510 & 1.078 & .0181 & 1.3191 & 1.5149 & 2.66 \\
17 & 1.384 & 1.6282 & 2.76 & 4.4938 & 1.168 & .0213 & 1.4053 & 1.6654 & 2.70 \\
\hline
\end{tabular}


Bazin's.exporiments on weirs of irregular section-Continued.

Bazin's Series, No. 115 .

Crest height, 2.46 feet.

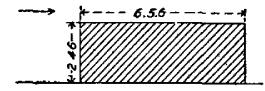

Cross section.

\begin{tabular}{|c|c|c|c|c|c|c|c|c|c|}
\hline Period. & $\begin{array}{l}\text { Observed } \\
\text { head, } \\
\text { experi- } \\
\text { mental } \\
\text { weir } D \text {, } \\
\text { in feet. }\end{array}$ & $D^{\frac{3}{2}}$ & $C_{1}$ & $\begin{array}{c}Q, \text { flow } \\
\text { per foot, } \\
\text { experi- } \\
\text { mental } \\
\text { weir, in } \\
\text { cubic feet } \\
\text { per } \\
\text { second. }\end{array}$ & $v$ & $\frac{v^{2}}{2 g}$ & $I I$ & $H^{\frac{3}{2}}$ & $C$ \\
\hline 1 & 2 & 3 & 4 & 5 & 6 & 7 & 8 & 9 & 10 \\
\hline 1 & 0,196 & 0,0868 & 2.25 & 0.1953 & 0.073 & & 0.196 & 0.0868 & 2.25 \\
\hline 2 & .264 & .1357 & 2.41 & .3270 & .120 & 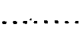 & .264 & .1357 & 2. 41 \\
\hline 3 & .342 & .2001 & 2. 45 & .4902 & .175 & 0.0005 & .3425 & .2005 & 2.44 \\
\hline 4 & .475 & .2674 & 2.51 & .6712 & .233 & .0008 & .4158 & .2683 & 2.50 \\
\hline 5 & .495 & .3483 & 2.50 & .8708 & .290 & .0013 & .4963 & .3494 & 2. 49 \\
\hline 6 & .566 & .4258 & 2.55 & 1.0858 & .358 & .0020 & .5680 & $.42 \varepsilon 1$ & 2. 54 \\
\hline 7 & .638 & .5096 & 2.54 & 1.2944 & .418 & .0027 & .6407 & .5132 & 2. 52 \\
\hline 8 & .716 & .6059 & 2.56 & 1.5511 & .487 & .0037 & .7197 & .6109 & 2.54 \\
\hline 9 & .792 & .7049 & 2.60 & 1.8327 & .563 & .0049 & .7969 & .7115 & 2.58 \\
\hline 10 & .871 & .8129 & 2.60 & 2.1135 & .634 & .0062 & .8782 & .8227 & 2.57 \\
\hline 11 & .948 & .9230 & 2.60 & 2.4098 & .706 & .0078 & .9558 & .9347 & 2.58 \\
\hline 12 & 1.023 & 1. 0347 & 2.61 & 2. 7006 & .775 & .0095 & 1.0325 & 1.0491 & 2.57 \\
\hline 13 & 1.097 & 1.1490 & 2.63 & 3.0219 & .849 & .0112 & 1.1089 & 1.1679 & 2.58 \\
\hline 14 & 1.178 & 1. 2786 & 2.64 & 3.3755 & .928 & .0134 & 1.1914 & 1.2997 & 2.59 \\
\hline 15 & 1.260 & 1.4144 & 2. 65 & 3. 7482 & 1.009 & .0158 & 1. 276 & 1.4414 & 2.58 \\
\hline 16 & 1.330 & 1.5338 & 2. 68 & 4.1106 & 1.085 & .0181 & 1.348 & 1. 5651 & 2.62 \\
\hline 17 & 1.388 & 1. 6353 & 2. 69 & 4. 3990 & 1.144 & .0202 & 1. 408 & 1. 6707 & 2.62 \\
\hline 18 & 1. 424 & 1. 6993 & 2. 70 & 4. 5881 & 1.18 & .0216 & 1.446 & 1.7388 & 2.64 \\
\hline 19 & 1,467 & 1.7768 & 2. 70 & 4. 797 & 1.26 & .0247 & 1.492 & 1.8225 & 2.63 \\
\hline
\end{tabular}

Bazin's Series, No. 116.

Crest height, 2.46 feet.

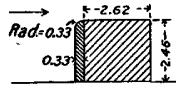

Cross section.

\begin{tabular}{|r|r|l|r|r|r|r|r|r|r|}
\hline 1 & 0.177 & 0.0745 & 2.71 & 0.2019 & 0.076 & $\ldots \ldots \ldots$ & 0.177 & 0.0745 & 2.71 \\
2 & .225 & .1068 & 2.83 & .3022 & .112 & $\ldots \ldots \ldots$ & .225 & .1068 & 2.83 \\
3 & .296 & .1611 & 2.90 & .4672 & .169 & $\ldots \ldots \ldots$ & .296 & .1611 & 2.90 \\
4 & .367 & .2224 & 2.92 & .6494 & .229 & 0.0008 & .3678 & .2232 & 2.91 \\
5 & .435 & .2870 & 2.95 & .8467 & .292 & .0013 & .4363 & .2879 & 2.94 \\
6 & .504 & .3578 & 2.98 & 1.0662 & .360 & .0020 & .5060 & .3599 & 2.96 \\
7 & .537 & .3935 & 2.99 & 1.1776 & .392 & .0024 & .5394 & .3957 & 2.98 \\
8 & .639 & .5108 & 3.01 & 1.5375 & .497 & .0039 & .6429 & .5156 & 2.98 \\
9 & .713 & .6021 & 3.00 & 1.8063 & .569 & .0051 & .7181 & .6084 & 2.97 \\
10 & .781 & .6902 & 3.00 & 2.0706 & .640 & .0064 & .7874 & .6982 & 2.96 \\
11 & .849 & .7823 & 3.02 & 2.3625 & .713 & .0078 & .8568 & .7933 & 2.98 \\
12 & .917 & .8781 & 3.02 & 2.6519 & .793 & .0097 & .9267 & .8925 & 2.97 \\
13 & .986 & .9791 & 3.05 & 2.9863 & .864 & .0115 & .9975 & .9963 & 3.00 \\
14 & 1.053 & 1.0805 & 3.06 & 3.3063 & .942 & .0137 & 1.0667 & 1.1021 & 3.00 \\
15 & 1.120 & 1.1853 & 3.08 & 3.6507 & 1.019 & .0162 & 1.1362 & 1.2108 & 3.02 \\
16 & 1.185 & 1.28995 & 3.09 & 3.9859 & 1.092 & .0185 & 1.2035 & 1.3203 & 3.02 \\
17 & 1.251 & 1.3992 & 3.10 & 4.3375 & 1.169 & .0213 & 1.2723 & 1.4346 & 3.02 \\
18 & 1.317 & 1.5114 & 3.12 & 4.7156 & 1.250 & .0243 & 1.3413 & 1.5529 & 3.04 \\
\hline
\end{tabular}


Bazin's experiments on weirs of irregular section-Continued.

Bazin's Series, No. 117.

Crest height, 2.46 feet.

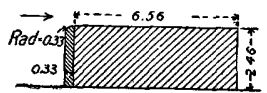

Cross section.

\begin{tabular}{|c|c|c|c|c|c|c|c|c|c|}
\hline Period. & $\begin{array}{l}\text { Observed } \\
\text { head, } \\
\text { experi- } \\
\text { mental } \\
\text { weir } D \text {, } \\
\text { in feet. }\end{array}$ & $D^{\frac{3}{2}}$ & $C_{1}$ & $\begin{array}{l}Q \text {, flow } \\
\text { per foot, } \\
\text { experi- } \\
\text { mental } \\
\text { weir, in } \\
\text { cubic feet } \\
\text { per } \\
\text { second. }\end{array}$ & $v$ & $\frac{v^{2}}{2 g}$ & $H$ & $H^{\frac{3}{2}}$ & $C$ \\
\hline 1 & 2 & 3 & 4 & 5 & 6 & 7 & 8 & 9 & 10 \\
\hline 1 & 0.158 & 0.06282 & 2. 19 & 0.1376 & 0.043 & & 0.158 & 0.0628 & 2. 19 \\
\hline 2 & .204 & .09212 & 2.64 & .2432 & .091 & & .204 & .0921 & 2.64 \\
\hline 3 & .289 & .1554 & 2.57 & .3994 & .145 & . . . . . . & .289 & .1554 & 2.56 \\
\hline 4 & .361 & .21691 & 2.65 & .5126 & .182 & 0.0005 & .3615 & .2178 & 2.35 \\
\hline 5 & .426 & .27808 & 2.73 & .7592 & .263 & .0011 & .4271 & .2791 & 2. 72 \\
\hline 6 & .494 & .34724 & 2.77 & .9619 & .321 & .0016 & .4956 & .3493 & 2. 76 \\
\hline 7 & .562 & .42134 & 2.83 & 1.1924 & .395 & .0025 & .5645 & .4247 & 2. 81 \\
\hline 8 & .635 & .5060 & 2.82 & 1.4267 & .461 & .0033 & .6383 & .5096 & 2.80 \\
\hline 9 & .708 & .59578 & $2.86^{\circ}$ & 1.7049 & .539 & .0045 & .7125 & .6020 & 2.83 \\
\hline 10 & .771 & .67702 & 2.89 & 1.9566 & .606 & .0058 & .7768 & .6849 & $2.86^{\circ}$ \\
\hline 11 & .834 & .76168 & 2.91 & 2. 2155 & .674 & .0070 & .8410 & .7713 & 2.87 \\
\hline 12 & .912 & .87096 & 2.93 & 2.5519 & .758 & .0090 & .9210 & .8839 & 2.89 \\
\hline 13 & .989 & .98352 & 2.95 & 2.9014 & .841 & .0110 & 1.0000 & 1.0000 & 2.90 \\
\hline 14 & 1.064 & 1.0975 & 2.95 & 3.2376 & .919 & .0132 & 1.0772 & 1.1177 & 2.90 \\
\hline 15 & 1.129 & 1.1996 & 2.95 & 3.5388 & .987 & .0152 & 1.1442 & 1.2236 & 2.89 \\
\hline 16 & 1. 197 & 1.3096 & 2.97 & 3.8895 & 1. 062 & .0175 & 1. 2145 & 1.3392 & 2.90 \\
\hline 17 & 1. 267 & 1. 4262 & 2. 98 & 4. 2501 & 1. 139 & .0202 & 1. 2872 & 1.4601 & 2.91 \\
\hline 18 & 1. 336 & 1.5442 & '2. 99 & 4.6172 & 1. 214 & .0228 & 1.3588 & 1.5842 & 2. 91 \\
\hline
\end{tabular}

Bazin's Series, No. 136.

Crest length, 6.519 feet.

Crest height, 2.46 feet.

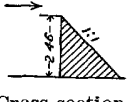

Cross section.

\begin{tabular}{|r|r|r|r|r|r|r|r|r|r|}
\hline 1 & 0.183 & 0.0783 & 3.90 & 0.305 & 0.12 & 0.0002 & 0.1832 & 0.0783 & 3.90 \\
2 & .244 & .1206 & 3.86 & .467 & .17 & .0004 & .2444 & .1206 & 3.87 \\
3 & .304 & .1676 & 3.85 & .647 & .23 & .0008 & .3048 & .1684 & 3.84 \\
4 & .364 & .2196 & 3.86 & .849 & .30 & .0014 & .3654 & .2206 & 3.85 \\
5 & .424 & .2761 & 3.88 & 1.071 & .37 & .0021 & .4261 & .2781 & 3.85 \\
6 & .484 & .3367 & 3.87 & 1.304 & .44 & .0030 & .4870 & .3399 & 3.84 \\
7 & .542 & .3990 & 3.88 & 1.548 & .52 & .0042 & .5462 & .4035 & 3.84 \\
8 & .597 & .4618 & 3.89 & 1.793 & .59 & .0054 & .6024 & .4671 & 3.84 \\
9 & .658 & .5338 & 3.91 & 2.088 & .67 & .0070 & .6650 & .5423 & 3.85 \\
10 & .713 & .6021 & 3.92 & 2.360 & .74 & .0085 & .7215 & .6135 & 3.85 \\
11 & .776 & .6836 & 3.93 & 2.684 & .83 & .0107 & .7867 & .6982 & 3.84 \\
12 & .830 & .7562 & 3.97 & 3.001 & .91 & .0129 & .8427 & .7740 & 3.88 \\
13 & .887 & .8354 & 3.96 & 3.300 & .99 & .0152 & .9022 & .8567 & 3.85 \\
14 & .953 & .9303 & 3.98 & 3.701 & 1.08 & .0181 & .9711 & .9568 & 3.87 \\
15 & 1.010 & 1.0150 & 3.97 & 4.029 & 1.16 & .0209 & 1.0309 & 1.0468 & 3.85 \\
16 & 1.068 & 1.1037 & 4.00 & 4.417 & 1.25 & .0243 & 1.0923 & 1.1411 & 3.87 \\
17 & 1.122 & 1.1885 & 3.99 & 4.748 & 1.33 & .0275 & 1.1495 & 1.2316 & 3.86 \\
18 & 1.179 & 1.2802 & 4.01 & 5.133 & 1.41 & .0309 & 1.2099 & 1.3310 & 3.86 \\
19 & 1.244 & 1.3875 & 4.01 & 5.564 & 1.50 & .0350 & 1.2790 & 1.4446 & 3.85 \\
20 & 1.299 & 1.4805 & 4.01 & 5.935 & 1.58 & .0388 & 1.3378 & 1.5477 & 3.84 \\
21 & 1.361 & 1.5878 & 4.03 & 6.408 & 1.68 & .0439 & 1.4049 & 1.6654 & 3.85 \\
\hline
\end{tabular}


Bazin's experiments on weirs of irregular section-Continued.

Bazin's Series, No. 137.

Crest length, 6.523 feet.

Crest height, 2.46 feet.

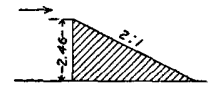

Cross section.

\begin{tabular}{|c|c|c|c|c|c|c|c|c|c|}
\hline Period. & $\begin{array}{l}\text { Observed } \\
\text { head, } \\
\text { experi- } \\
\text { mental } \\
\text { weir } D \text {, } \\
\text { in feet. }\end{array}$ & $D^{\frac{3}{2}}$ & $C_{1}$ & $\begin{array}{c}Q, \text { flow } \\
\text { per foot, } \\
\text { experi- } \\
\text { mental } \\
\text { weir, in } \\
\text { cubic feet } \\
\text { per } \\
\text { second. }\end{array}$ & $v$ & $\frac{v^{2}}{2 g}$ & $H$ & $H^{\frac{3}{2}}$ & $C$ \\
\hline 1 & 2 & 3 & t & 5 & 6 & 7 & 8 & 9 & 1) \\
\hline 1 & 0.268 & 0.1388 & 3.47 & 0.482 & 0.18 & 0.0006 & 0.2686 & 0.1395 & 3.46 \\
\hline 2 & .332 & .1974 & 3.45 & .680 & .24 & .0009 & .3329 & .1922 & 3.54 \\
\hline 3 & .391 & .2445 & 3.50 & .856 & .30 & .0014 & .3924 & .2454 & 3. 49 \\
\hline 4 & .451 & .3029 & 3.47 & 1.051 & .36 & .0020 & .4530 & .3049 & 3.45 \\
\hline 5 & .513 & .3674 & 3. 53 & 1. 295 & .44 & .0030 & .5160 & .3707 & 3.49 \\
\hline 6 & .578 & .4394 & 3.51 & 1. 540 & .51 & .0040 & .5820 & .4440 & 3.47 \\
\hline 7 & .637 & .5084 & 8. 51 & 1. 783 & .57 & .0051 & .6421 & .5144 & 3.47 \\
\hline 8 & .700 & .5857 & 3.55 & 2.080 & .66 & .0068 & .7068 & .5945 & 3.50 \\
\hline 9 & .765 & .6692 & 3.56 & 2. 382 & .74 & .0085 & .7735 & .6797 & 3. 50 \\
\hline 10 & .822 & .7452 & 3.56 & 2. 652 & .81 & .0102 & .8322 & .7589 & 3. 49 \\
\hline 11 & .887 & .8854 & 3.56 & 2.973 & .89 & .0123 & .8993 & .8524 & 3.49 \\
\hline 12 & .946 & .9201 & 3.62 & 3. 334 & .98 & .0149 & .9609 & .9420 & 3.54 \\
\hline 13 & 1.012 & 1.0180 & 3. 59 & 3. 662 & 1.05 & .0171 & 1.0291 & 1.0438 & 3. 51 \\
\hline 14 & 1.078 & 1.1193 & 3.61 & 4.043 & 1.14 & .0202 & 1.0982 & 1.1506 & 3.51 \\
\hline 15 & 1.142 & 1. 2204 & 3.60 & 4. 392 & 1. 22 & .0231 & 1.1651 & 1.2575 & 3. 49 \\
\hline 16 & 1.201 & 1.3162 & 3.62 & 4.778 & 1. 30 & .0263 & 1. 2273 & 1. 3591 & 3.52 \\
\hline 17 & 1.262 & 1. 4178 & 3.62 & 5.140 & 1. 38 & .0296 & 1.2916 & 1. 4686 & 3.50 \\
\hline 18 & 1. 322 & 1.5200 & 3.64 & 5.533 & 1.46 & .0331 & 1. 3551 & 1.5773 & 3.51 \\
\hline
\end{tabular}

Bazin's Series, No. 138.

Crest length, 6.532 feet.

Crest height, 1.64 feet.

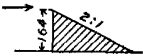

Cross section.

\begin{tabular}{|r|r|r|r|r|r|r|r|r|r|}
\hline 1 & 0.194 & 0.0854 & 3.57 & 0.305 & 0.17 & 0.0004 & 0.1944 & 0.0854 & 3.57 \\
2 & .263 & .1349 & 3.50 & .473 & .25 & .0010 & .2640 & .1357 & 3.48 \\
3 & .327 & .1870 & 3.48 & .651 & .33 & .0017 & .3287 & .1887 & 3.45 \\
4 & .391 & .2445 & 3.50 & .858 & .42 & .0027 & .3937 & .2473 & 3.47 \\
5 & .447 & .2989 & 3.56 & 1.064 & .50 & .0039 & .4519 & .3039 & 3.50 \\
6 & .510 & .3642 & 3.63 & 1.321 & .61 & .0058 & .5158 & .3706 & 3.56 \\
7 & .571 & .4314 & 3.62 & 1.560 & .70 & .0076 & .5786 & .4405 & 3.54 \\
8 & .626 & .4953 & 3.71 & 1.838 & .81 & .0102 & .6362 & .5072 & 3.62 \\
9 & .685 & .5670 & 3.66 & 2.075 & .89 & .0123 & .6973 & .5820 & 3.56 \\
10 & .745 & .6431 & 3.69 & 2.373 & .99 & .0152 & .7602 & .6626 & 3.58 \\
11 & .807 & .7250 & 3.70 & 2.683 & 1.09 & .0185 & .8255 & .7507 & 3.57 \\
12 & .873 & .8157 & 3.72 & 3.036 & 1.21 & .0228 & .8958 & .8481 & 3.58 \\
13 & .927 & .8926 & 3.72 & 3.318 & 1.29 & .0259 & .9529 & .9303 & 3.56 \\
14 & .992 & .9880 & 3.76 & 3.715 & 1.41 & .0309 & 1.0229 & 1.0347 & 3.59 \\
15 & 1.045 & 1.0683 & 3.80 & 4.060 & 1.51 & .0354 & 1.0804 & 1.1224 & 3.62 \\
16 & 1.110 & 1.1695 & 3.78 & 4.422 & 1.61 & .0403 & 1.1503 & 1.2332 & 3.58 \\
17 & 1.176 & 1.2753 & 3.79 & 4.851 & 1.72 & .0460 & 1.2220 & 1.3508 & 3.59 \\
18 & 1.233 & 1.3691 & 3.81 & 5.220 & 1.82 & .0515 & 1.2845 & 1.4550 & 3.59 \\
19 & 1.289 & 1.4645 & 3.82 & 5.577 & 1.90 & .0561 & 1.3451 & 1.5599 & 3.58 \\
20 & 1.355 & 1.5773 & 3.82 & 6.036 & 2.01 & .0628 & 1.4178 & 1.6885 & 3.57 \\
21 & 1.429 & 1.7082 & 3.83 & 6.542 & 2.13 & .0705 & 1.4995 & 1.8362 & 3.56 \\
\hline
\end{tabular}


Bazin's experiments on weirs of irregular section-Continued.

Bazin's Series, No. 145.

Crest length, 6.541 feet.

Crest height, 1.64 feet.

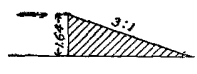

Cross section.

\begin{tabular}{|c|c|c|c|c|c|c|c|c|c|}
\hline Period. & $\begin{array}{l}\text { Observed } \\
\text { head, } \\
\text { experi- } \\
\text { mental } \\
\text { weir } D \text {, } \\
\text { in feet. }\end{array}$ & $D^{\frac{3}{2}}$ & $C_{1}^{\prime}$ & $\begin{array}{c}Q, \text { flow } \\
\text { per foot, } \\
\text { experi- } \\
\text { mental } \\
\text { weir, in } \\
\text { cubic feet } \\
\text { per } \\
\text { seeond. }\end{array}$ & $v^{\prime}$ & $\frac{v^{2}}{2 g}$ & $I I$ & $H^{3}$ & $C^{\prime}$ \\
\hline 1 & 2 & 3 & 4 & 5 & 6 & 7 & 8 & 9 & 10 \\
\hline 1 & 0.359 & 0.2151 & 3.02 & 0.649 & 0.32 & 0.0016 & 0.3606 & 0.2169 & 2.99 \\
\hline 2 & .424 & .2761 & 3.10 & .856 & .42 & .0027 & .4267 & .2790 & 3.07 \\
\hline 3 & .479 & .3315 & 3.18 & 1.053 & .50 & .0039 & .4869 & .3335 & 3.16 \\
\hline 4 & .547 & .4046 & 3. 25 & 1.316 & .60 & .0056 & .5526 & .4112 & 3. 20 \\
\hline $\bar{\jmath}$ & .592 & .4636 & 3.35 & 1.553 & .69 & .0074 & .5994 & .4636 & 3. 33 \\
\hline 6 & .658 & .5838 & 3. 38 & 1.805 & .78 & $\cdot 0095$ & .6675 & .5447 & 3.31 \\
\hline 7 & .720 & .6109 & 3.42 & 2.090 & .89 & .0123 & .7323 & .6263 & 3. 34 \\
\hline 8 & .781 & .6902 & 3,47 & 2.394 & .99 & .0152 & .7962 & .7102 & 3. 37 \\
\hline 9 & .835 & .7631 & 3.49 & 2.663 & 1.07 & .0178 & .8528 & .7878 & 3.38 \\
\hline 10 & .902 & .8567 & 3.53 & 3.025 & 1.19 & .0220 & .9240 & .8882 & 3.41 \\
\hline 11 & .962 & .9435 & 3.53 & 3.332 । & 1.28 & .0255 & .9875 & .9806 & 3.40 \\
\hline 12 & 1.032 & 1.0484 & 3. 53 & 3. 707 , & 1.39 & .0300 & 1.0620 & 1. 0944 & 3. 39 \\
\hline 13 & 1.087 & 1.1333 & 3.58 & 4.045 & 1.48 & .0341 & 1.1211 & 1.1869 & 3.41 \\
\hline 14 & 1.152 & 1.2364 & 3. 58 & 4.403 & 1.58 & .0388 & 1,1908 & 1. 2997 & 3.39 \\
\hline 16 & 1. 210 & 1.3310 & 3.61 & 4.801 & 1.68 & .0439 & 1. 2539 & 1,4042 & 3.42 \\
\hline 16 & 1.274 & 1,4380 & 3.61 & 5.198 & 1.78 & .0493 & 1,3233 & 1.5214 & 3.42 \\
\hline 17 & 1. 334 & 1. 5408 & 3.62 & 5.575 & 1.88 & .0549 & 1. 3889 & 1.6370 & 3.40 \\
\hline 18 & 1.396 & 1. 6494 & 3.64 & 6.006 & 1.98 & .0609 & 1.4569 & 1. 7586 & 3.42 \\
\hline 19 & 1.467 & 1. 7768 & 3.64 & 6.479 & 2.09 & .0679 & 1.5349 & 1.9016 & 3.41 \\
\hline
\end{tabular}

Bazin's Series, No. 141.

Crest length, 6.520 feet.

Crest height, 2.46 feet.

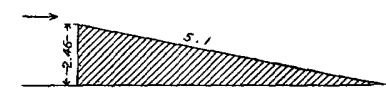

Cross section.

\begin{tabular}{|r|r|r|r|r|r|r|r|r|r|}
\hline 1 & 0.215 & 0.0997 & 3.02 & 0.301 & 0.11 & 0.0002 & 0.2152 & 0.0997 & 3.02 \\
2 & .281 & .1490 & 3.09 & .460 & .17 & .0004 & .2814 & .1490 & 3.09 \\
3 & .355 & .2116 & 3.07 & .650 & .24 & .0009 & .3559 & .2124 & 3.06 \\
4 & .425 & .2771 & 3.04 & .842 & .29 & .0013 & .4263 & .2781 & 3.02 \\
5 & .489 & .3420 & 3.08 & 1.053 & .37 & .0021 & .4911 & .3441 & 3.06 \\
6 & .561 & .4202 & 3.08 & 1.294 & .43 & .0029 & .5639 & .4235 & 3.06 \\
7 & .624 & .4929 & 3.17 & 1.562 &. .1 & .0040 & .6280 & .4976 & 3.14 \\
8 & .692 & .5757 & 3.11 & 1.791 & .57 & .0051 & .6971 & .5820 & 3.08 \\
9 & .758 & .6600 & 3.12 & 2.059 & .64 & .0064 & .7644 & .6678 & 3.08 \\
10 & .822 & .7452 & 3.15 & 2.347 & .72 & .0081 & .8301 & .7562 & 3.10 \\
11 & .888 & .8368 & 3.17 & 2.653 & .79 & .0097 & .8977 & .8509 & 3.12 \\
12 & .956 & .9347 & 3.19 & 2.983 & .87 & .0118 & .9678 & .9523 & 3.13 \\
13 & 1.029 & 1.0438 & 3.17 & 3.309 & .95 & .0140 & 1.0430 & 1.0652 & 3.12 \\
14 & 1.113 & 1.1742 & 3.20 & 3.757 & 1.04 & .0168 & 1.1298 & 1.2012 & 3.13 \\
15 & 1.165 & 1.2575 & 3.21 & 4.045 & 1.12 & .0195 & 1.1845 & 1.2884 & 3.14 \\
16 & 1.237 & 1.3758 & 3.20 & 4.416 & 1.19 & .0220 & 1.2590 & 1.4127 & 3.13 \\
17 & 1.298 & 1.4788 & 3.22 & 1.766 & 1.27 & .0251 & 1.3231 & 1.5218 & 3.13 \\
18 & 1.369 & 1.6018 & 3.22 & 5.152 & 1.34 & .0279 & 1.3969 & 1.6511 & 3.12 \\
19 & 1.431 & 1.7118 & 3.24 & 5.540 & 1.42 & .0313 & 1.4623 & 1.7677 & 3.13 \\
20 & 1.463 & 1.7696 & 3.25 & 5.752 & 1.47 & .0336 & 1.4966 & 1.8307 & 3.14 \\
\hline
\end{tabular}

IRR $150-06-7$ 
Bazin's experiments on weirs of irregular section-Continued.

Bazin's Series, No. 142.

Crest length, 6.523 feet.

Crest height, 2.46 feet.

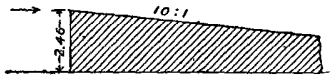

Cross section.

\begin{tabular}{|c|c|c|c|c|c|c|c|c|c|}
\hline Period. & $\begin{array}{c}\text { Observed } \\
\text { head, } \\
\text { experi- } \\
\text { mental } \\
\text { weir } D \text {, } \\
\text { in feet. }\end{array}$ & $D^{\frac{3}{2}}$ & $C_{1}$ & $\left|\begin{array}{c}Q, \text { flow } \\
\text { per foot, } \\
\text { experi- } \\
\text { mental } \\
\text { weir, in } \\
\text { cubic feet } \\
\text { per } \\
\text { second. }\end{array}\right|$ & $v$ & $\frac{v^{2}}{2 g}$ & $H$ & $H^{\frac{3}{2}}$ & $C$ \\
\hline 1 & 2 & 3 & 4 & 5 & 6 & 7 & 8 & 9 & 10 \\
\hline 1 & 0.300 & 0.1643 & 2.83 & 0.464 & 0.17 & 0.0004 & 0.3004 & 0.1643 & 2.82 \\
\hline 2 & .369 & .2242 & 2.87 & .643 & .23 & .0008 & .3698 & .2251 & 2.86 \\
\hline 3 & .447 & .2989 & 2.87 & .851 & .29 & .0013 & .4483 & .2999 & 2.84 \\
\hline 4 & .509 & .3631 & 2.86 & 1.038 & .35 & .0019 & .5109 & .3652 & 2.84 \\
\hline 5 & .591 & .4544 & 2.88 & 1. 308 & .43 & .0029 & .5939 & . 45078 & 2.86 \\
\hline 6 & .656 & .5435 & 2.86 & 1.554 & .50 & .0039 & .6699 & .5484 & 2.83 \\
\hline 7 & .727 & .6199 & 2. 92 & 1.810 & .57 & .0051 & .7327 & .6263 & 2.89 \\
\hline 8 & .795 & .7089 & 2.94 & 2.084 & .64 & .0064 & .8014 & .7155 & 2.91 \\
\hline 9 & .861 & .7989 & 2.94 & 2.349 & .71 & .0078 & .8688 & .8101 & 2. 90 \\
\hline 10 & .934 & .9027 & 2.95 & 2.664 & .78 & .0095 & .9435 & .9158 & 2.91 \\
\hline 11 & 1.007 & 1.0105 & 2.95 & 2.980 & .86 & .0115 & 1.0185 & 1.0286 & 2.89 \\
\hline 12 & 1.079 & 1. 1208 & 2.98 & 3.338 & .94 & .0137 & 1.0927 & 1. 1427 & 2.92 \\
\hline 13 & 1.149 & 1.2316 & 2.98 & 3.665 & 1.01 & .0159 & 1. 1649 & 1. 2575 & 2.92 \\
\hline 14 & 1. 222 & 1.3508 & 2.99 & 4.087 & 1.10 & .0188 & 1. 2408 & 1.3824 & 2.92 \\
\hline 15 & 1.285 & 1.4567 & 3.00 & 4.370 & 1.17 & .0213 & 1. 3063 & 1. 4925 & 2.93 \\
\hline 16 & 1.362 & 1.5895 & 3.00 & 4.770 & 1.25 & .0243 & 1. 3863 & 1.6317 & 2.92 \\
\hline 17 & 1.430 & 1. 7100 & 3.01 & 5.147 & 1.30 & .0263 & 1. 4563 & 1. 7569 & 2.93 \\
\hline
\end{tabular}

Bazin's Series, No. 139.

Crest length, 6.532 feet.

Crest height, 1.64 feet.

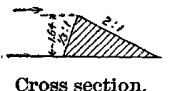

\begin{tabular}{|r|r|r|r|r|r|r|r|r|r|}
\hline 1 & 0.190 & 0.0828 & 3.66 & 0.303 & 0.17 & 0.0004 & 0.1904 & 0.0828 & 3.66 \\
2 & .253 & .1273 & 3.68 & .467 & .25 & .0010 & .2540 & .1280 & 3.65 \\
3 & .312 & .1743 & 3.72 & .647 & .33 & .0017 & .3137 & .1759 & 3.68 \\
4 & .375 & .2297 & 3.66 & .841 & .42 & .0027 & .3777 & .2323 & 3.62 \\
5 & .434 & .2860 & 3.73 & 1.067 & .52 & .0042 & .4382 & .2899 & 3.68 \\
6 & .500 & .3536 & 3.72 & 1.317 & .62 & .0060 & .5060 & .3600 & 3.66 \\
7 & .552 & .4101 & 3.78 & 1.550 & .71 & .0078 & .5598 & .4191 & 3.70 \\
8 & .615 & .4823 & 3.76 & 1.812 & .80 & .0099 & .6249 & .4941 & 3.67 \\
9 & .667 & .5447 & 3.82 & 2.081 & .90 & .0126 & .6796 & .5607 & 3.71 \\
10 & .733 & .6276 & 3.79 & 2.380 & 1.00 & .0155 & .7485 & .6482 & 3.67 \\
11 & .798 & .7128 & 3.80 & 2.709 & 1.11 & .0192 & .8172 & .7385 & 3.67 \\
12 & .852 & .7865 & 3.84 & 3.022 & 1.21 & .0228 & .8748 & .8185 & 3.69 \\
13 & .915 & .8753 & 3.86 & 3.378 & 1.32 & .0271 & .9421 & .9143 & 3.68 \\
14 & .969 & .9538 & 3.87 & 3.692 & 1.41 & .0309 & .9961 & .9940 & 3.71 \\
15 & 1.023 & 1.0347 & 3.92 & 4.038 & 1.52 & .0359 & 1.0589 & 1.0897 & 3.71 \\
16 & 1.092 & 1.1411 & 3.90 & 4.446 & 1.63 & .0413 & 1.1333 & 1.2060 & 3.68 \\
17 & 1.151 & 1.2348 & 3.90 & 4.816 & 1.72 & .0460 & 1.1970 & 1.3096 & 3.68 \\
18 & 1.210 & 1.3310 & 3.94 & 5.240 & 1.84 & .0526 & 1.2626 & 1.4194 & 3.69 \\
19 & 1.258 & 1.4110 & 3.95 & 5.570 & 1.92 & .0573 & 1.3153 & 1.5080 & 3.69 \\
20 & 1.326 & 1.5269 & 3.93 & 6.013 & 2.03 & .0641 & 1.3901 & 1.6388 & 3.67 \\
21 & 1.394 & 1.6459 & 3.93 & 6.484 & 2.13 & .0705 & 1.4645 & 1.7714 & 3.66 \\
\hline & & & & & & & & & \\
\hline
\end{tabular}


Bazin's experiments on weirs of irregular section-Continued.

Bazin's Series, No. 140.

Crest length, 6.532 feet.

Crest height, 1.64 feet.

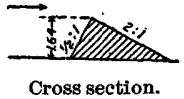

\begin{tabular}{|c|c|c|c|c|c|c|c|c|c|}
\hline Period. & $\begin{array}{c}\text { Observed } \\
\text { head, } \\
\text { experi- } \\
\text { mental } \\
\text { weir } D, \\
\text { in feet. }\end{array}$ & $D^{\frac{3}{2}}$ & $C_{1}$ & $\mid \begin{array}{c}Q, \text { flow } \\
\text { per foot, } \\
\text { experi- } \\
\text { mental } \\
\text { weir, in } \\
\text { cubic feet } \\
\text { per } \\
\text { second. }\end{array}$ & $v$ & $\frac{v^{2}}{2 g}$ & $H$ & $H^{\frac{3}{2}}$ & $C$ \\
\hline 1 & 2 & $\mathbf{3}$ & 4 & 5 & 6 & 7 & 8 & 9 & 10 \\
\hline 1 & 0.192 & 0.0835 & 3.77 & 0.315 & 0.17 & 0.0004 & 0.1924 & 0.0841 & 3.74 \\
\hline 2 & .252 & .1265 & 3.74 & .473 & .25 & .0010 & .2530 & .1273 & 3. 72 \\
\hline 3 & .308 & .1709 & 3.75 & .641 & .33 & .0017 & .3097 & .1726 & 3.71 \\
\hline 4 & .371 & .2260 & 3. 71 & .838 & .42 & .0027 & .3727 & .2278 & 3. 68 \\
\hline 5 & .436 & .2879 & 3. 77 & 1.086 & .52 & .0042 & .4102 & .2919 & 3. 72 \\
\hline 6 & .488 & .3399 & 3. 74 & 1. 276 & .60 & .0056 & .4936 & .3472 & 3. 66 \\
\hline 7 & .549 & .4068 & 3.81 & 1.551 & .71 & .0078 & .5568 & .4157 & 3.73 \\
\hline 8 & .604 & .4694 & 3.82 & 1. 792 & .80 & .0099 & .6139 & .4811 & 3. 72 \\
\hline 9 & .664 & .5411 & 3.83 & 2. 072 & .90 & .0126 & .6766 & .5570 & 3. 72 \\
\hline 10 & .719 & .6096 & 3.84 & 2.342 & .99 & .0152 & .7342 & .6289 & 3. 72 \\
\hline 11 & .785 & .6956 & 3.88 & 2.700 & 1.11 & .0192 & .8042 & .7209 & 3.74 \\
\hline 12 & .837 & .7658 & 3.88 & 2. 968 & 1.20 & .0224 & .8594 & .7961 & 3. 73 \\
\hline 13 & .905 & .8610 & 3.92 & 3.375 & 1.32 & .0271 & .9321 & .8998 & 3. 75 \\
\hline 14 & .961 & .9421 & 3. 90 & 3.674 & 1.41 & .0309 & .9919 & .9880 & 3. 72 \\
\hline 15 & 1.023 & 1.0347 & 3.95 & 4.069 & 1.53 & .0864 & 1. 0594 & 1.0898 & 3. 73 \\
\hline 16 & 1.080 & 1. 1224 & 3.93 & 4.402 & 1.62 & .0408 & 1.1208 & 1.1869 & 3. 71 \\
\hline 17 & 1.143 & 1. 2220 & 3.97 & 4. 843 & 1. 74 & .0471 & 1. 1901 & 1. 2981 & 3.73 \\
\hline 18 & I. 195 & 1.3063 & 3.96 & 5.187 & 1.83 & .0521 & 1. 2471 & 1. 3925 & 3. 72 \\
\hline 19 & 1.254 & 1. 4043 & 3.97 & 5. 558 & 1.92 & .0573 & 1.3113 & 1. 5011 & 3.70 \\
\hline 20 & 1.316 & 1. 5097 & 3.99 & 6.024 & 2.03 & .0641 & 1.3801 & 1. 6211 & 3. 72 \\
\hline 21 & 1.375 & 1. 6123 & 4.01 & 6.456 & 2.14 & .0712 & 1.4462 & 1. 7388 & 3.71 \\
\hline
\end{tabular}

Bazin's Series, No. 147.

Crest length, 6.536 feet.

Crest height, 2.46 feet.

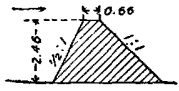

Cross section.

\begin{tabular}{|r|r|r|r|r|r|r|r|r|r|}
\hline 1 & 0.231 & 0.1110 & 2.75 & 0.305 & 0.11 & 0.0002 & 0.2312 & 0.1110 & 2.75 \\
2 & .308 & .1709 & 2.85 & .485 & .18 & .0005 & .3085 & .1709 & 2.84 \\
3 & .373 & .2278 & 2.86 & .652 & .23 & .0008 & .3738 & .2287 & 2.85 \\
4 & .438 & .2899 & 2.97 & .861 & .30 & .0014 & .4394 & .2909 & 2.96 \\
5 & .503 & .3568 & 3.02 & 1.078 & .37 & .0021 & .5051 & .3589 & 3.00 \\
6 & .569 & .4292 & 3.13 & 1.343 & .44 & .0030 & .5720 & .4326 & 3.10 \\
7 & .637 & .5084 & 3.20 & 1.626 & .54 & .0045 & .6415 & .5132 & 3.17 \\
8 & .681 & .5620 & 3.24 & 1.821 & .58 & .0052 & .6862 & .5682 & 3.20 \\
9 & .734 & .6289 & 3.34 & 2.109 & .66 & .0068 & .7408 & .6378 & 3.31 \\
10 & .797 & .7115 & 3.40 & 2.417 & .74 & .0083 & .8053 & .7223 & 3.35 \\
11 & .845 & .7768 & 3.44 & 2.673 & .81 & .0102 & .8552 & .7906 & 3.38 \\
12 & .898 & .8510 & 3.53 & 3.004 & .89 & .0123 & .9103 & .8681 & 3.46 \\
13 & .953 & .9303 & 3.57 & 3.320 & .97 & .0146 & .9676 & .9523 & 3.49 \\
14 & 1.015 & 1.0226 & 3.63 & 3.703 & 1.06 & .0175 & 1.0325 & 1.0484 & 3.53 \\
15 & 1.063 & 1.0960 & 3.67 & 4.037 & 1.15 & .0206 & 1.0836 & 1.1286 & 3.58 \\
16 & 1.115 & 1.1774 & 3.73 & 4.401 & 1.22 & .0231 & 1.1381 & 1.2140 & 3.62 \\
17 & 1.165 & 1.2575 & 3.79 & 4.775 & 1.31 & .0267 & 1.1917 & 1.3013 & 3.67 \\
18 & 1.217 & 1.3426 & 3.83 & 5.132 & 1.40 & .0305 & 1.2475 & 1.3925 & 3.68 \\
19 & 1.265 & 1.4228 & 3.85 & 5.467 & 1.47 & .0336 & 1.2986 & 1.4805 & 3.70 \\
20 & 1.332 & 1.5373 & 3.89 & 5.991 & 1.58 & .0388 & 1.3708 & 1.6053 & 3.73 \\
21 & 1.394 & 1.6459 & 3.98 & 6.567 & 1.68 & .0439 & 1.4379 & 1.7244 & 3.81 \\
\hline
\end{tabular}


Bazin's experiments on weirs of irregular section-Continued.

Bazin's Series, No. 149.

Crest length, 6.518 feet.

Crest height, 2.46 feet.

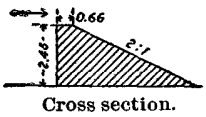

\begin{tabular}{|c|c|c|c|c|c|c|c|c|c|}
\hline Period. & $\begin{array}{c}\text { Observed } \\
\text { head, } \\
\text { experi- } \\
\text { mental } \\
\text { weir } v \text {, } \\
\text { in feet. }\end{array}$ & $D^{\frac{3}{2}}$ & $C_{1}$ & $\left|\begin{array}{c}Q, \text { flow } \\
\text { per foot, } \\
\text { experi- } \\
\text { mental } \\
\text { weir, in } \\
\text { cubic feet } \\
\text { per } \\
\text { second. }\end{array}\right|$ & $v$ & $\frac{v^{2}}{2 g}$ & $H$ & $H^{\frac{3}{2}}$ & $C$ \\
\hline 1 & $? 2$ & 3 & 4 & 5 & 6 & 7 & 8 & 9 & 10 \\
\hline 1 & 0.248 & 0.1235 & 2.55 & 0.316 & 0.12 & 0.0002 & 0.2482 & 0.1235 & 2.56 \\
\hline 2 & .317 & .1785 & 2.58 & .462 & .17 & .0004 & .3174 & .1785 & 2.59 \\
\hline 3 & .390 & .2436 & 2.67 & .651 & .23 & .0008 & .3908 & .2445 & 2.66 \\
\hline 4 & .455 & .3070 & 2. 73 & .838 & .29 & .0013 & .4563 & .3080 & 2. 72 \\
\hline 5 & .521 & .3761 & 2.82 & 1.060 & .36 & .0020 & .5230 & .3782 & 2.80 \\
\hline 6 & .585 & .4475 & 2.89 & 1.295 & .43 & .0030 & .5850 & .4475 & 2.89 \\
\hline 7 & .653 & .5277 & 2.97 & 1.568 & .51 & .0040 & .6570 & .5325 & 2.94 \\
\hline 8 & .705 & .5920 & 3.00 & 1.776 & .56 & .0049 & .7099 & .5983 & 2.97 \\
\hline 9 & .766 & .6705 & 3.08 & 2.067 & .64 & .0064 & .7724 & .6783 & 3.05 \\
\hline 10 & .818 & .7398 & 3.16 & 2.338 & .71 & .0078 & .8258 & .7507 & 3.11 \\
\hline 11 & .882 & .8283 & 3.23 & 2.674 & .80 & .0099 & .8979 & .8509 & 3.14 \\
\hline 12 & .942 & .9143 & 3.30 & 3.016 & .89 & .0123 & .9543 & .9318 & 3.23 \\
\hline 13 & .999 & .9985 & 3.36 & 3.356 & .97 & .0146 & 1.0156 & 1.0241 & 3.28 \\
\hline 14 & 1.051 & 1.0774 & 3. 39 & 3.627 & 1.03 & .0165 & 1.0665 & 1.1006 & 3. 30 \\
\hline 15 & 1.103 & 1.1584 & 3.45 & 4.002 & 1.12 & .0195 & 1.1225 & 1.1885 & 3.37 \\
\hline 16 & 1.165 & 1.2575 & 3.49 & 4. 397 & 1. 20 & .0224 & 1. 1874 & 1. 2932 & 3.40 \\
\hline 17 & 1.209 & 1. 3294 & 3.52 & 4. 682 & 1.27 & .0251 & 1. 2341 & 1. 3708 & 3. 42 \\
\hline 18 & 1. 281 & 1.4499 & 3.57 & 5.177 & 1.38 & .0296 & 1.3106 & 1.5011 & 3.45 \\
\hline 19 & 1.330 & 1.5338 & 3.60 & 5.508 & 1.45 & .0327 & 1. 3627 & 1. 5912 & 3. 46 \\
\hline 20 & 1.385 & 1.6300 & 3.63 & 5.917 & 1.54 & .0369 & 1.4219 & 1.6956 & 3.49 \\
\hline 21 & 1. 446 & 1.7388 & 3.67 & 6.386 & 1.64 & .0418 & 1.4878 & 1.8151 & 3.52 \\
\hline
\end{tabular}

Bazin's Series, No. 150.

Crest length, 6.518 feet.

Crest height, 2.46 feet.

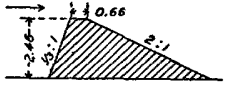

Cross section.

\begin{tabular}{|r|r|r|r|r|r|r|r|r|r|}
\hline 1 & 0.248 & 0.1235 & 2.53 & 0.314 & 0.12 & 0.0002 & 0.2482 & 0.1235 & 2.54 \\
2 & .323 & .1836 & 2.65 & .488 & .16 & .0004 & .3234 & .1836 & 2.66 \\
3 & .379 & .2333 & 2.78 & .648 & .23 & .0008 & .3798 & .2342 & 2.77 \\
1 & .459 & .3110 & 2.82 & .877 & .30 & .0014 & .4604 & .3120 & 2.81 \\
5 & .512 & .3664 & 2.91 & 1.065 & .36 & .0020 & .5140 & .3685 & 2.89 \\
6 & .586 & .4486 & 2.96 & 1.329 & .43 & .0029 & .5889 & .4521 & 2.94 \\
7 & .637 & .5084 & 3.07 & 1.560 & .50 & .0039 & .6409 & .5132 & 3.04 \\
8 & .698 & .5832 & 3.12 & 1.819 & .57 & .0051 & .7031 & .5895 & 3.09 \\
9 & .751 & .6508 & 3.18 & 2.070 & .64 & .0064 & .7574 & .6587 & 3.14 \\
10 & .814 & .7344 & 3.26 & 2.393 & .73 & .0083 & .8223 & .7452 & 3.21 \\
11 & .869 & .8101 & 3.31 & 2.681 & .80 & .0099 & .8789 & .8241 & 3.25 \\
12 & .928 & .8940 & 3.37 & 3.013 & .89 & .0123 & .9403 & .9114 & 3.31 \\
13 & .982 & .9732 & 3.42 & 3.328 & .97 & .0146 & .9966 & .9955 & 3.34 \\
14 & 1.043 & 1.0652 & 3.47 & 3.713 & 1.06 & .0175 & 1.0605 & 1.0913 & 3.40 \\
15 & 1.095 & 1.1459 & 3.51 & 4.037 & 1.13 & .0199 & 1.1149 & 1.1774 & 3.43 \\
16 & 1.152 & 1.2364 & 3.56 & 4.414 & 1.22 & .0231 & 1.1751 & 1.2737 & 3.46 \\
17 & 1.215 & 1.3393 & 3.58 & 4.797 & 1.30 & .0263 & 1.2413 & 1.3825 & 3.47 \\
18 & 1.259 & 1.4127 & 3.63 & 5.118 & 1.38 & .0296 & 1.2856 & 1.4584 & 3.51 \\
19 & 1.315 & 1.5080 & 3.65 & 5.512 & 1.46 & .0331 & 1.3481 & 1.5651 & 3.52 \\
20 & 1.323 & 1.5218 & 3.65 & 5.548 & 1.47 & .0336 & 1.3566 & 1.5807 & 3.51 \\
21 & 1.380 & 1.6211 & 3.68 & 5.962 & 1.55 & .0374 & 1.4174 & 1.6868 & 3.54 \\
22 & 1.439 & 1.7262 & 3.73 & 6.416 & 1.64 & .0418 & 1.480 & 1.8023 & 3.56 \\
\hline
\end{tabular}


Bazin's experiments on weirs of irregular section-Continued.

Bazin's Series, No. 151.

Crest length, 6.550 feet.

Crest height, 2.46 feet.

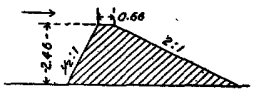

Cross section.

\begin{tabular}{|c|c|c|c|c|c|c|c|c|c|}
\hline Period. & $\begin{array}{c}\text { Observed } \\
\text { head, } \\
\text { experi- } \\
\text { mental } \\
\text { weir } D \text {, } \\
\text { in feet. }\end{array}$ & $D^{\frac{3}{2}}$ & $a_{1}$ & $\begin{array}{c}Q, \text { flow } \\
\text { per foot, } \\
\text { experi- } \\
\text { mental } \\
\text { weir, in } \\
\text { cubic feet } \\
\text { per } \\
\text { second. }\end{array}$ & $v$ & $\frac{\imath^{2}}{2 g}$ & $H$ & $H^{\frac{3}{2}}$ & $C$ \\
\hline 1 & 2 & 3 & 4 & 5 & 6 & 7 & 8 & 9 & 10 \\
\hline 1 & 0.201 & 0. 0901 & 2.71 & 0.244 & 0.09 & 0.0001 & 0.2011 & 0.0901 & 2. 71 \\
\hline 2 & .240 & .1176 & 2.81 & .329 & .12 & .0002 & .2422 & .1191 & 2. 76 \\
\hline 3 & .307 & .1701 & 2.79 & .474 & .17 & .0004 & .3074 & . 1701 & 2.79 \\
\hline 4 & .391 & .2445 & 2.79 & .684 & .24 & .0009 & . 3919 & .2454 & 2.79 \\
\hline 5 & .445 & .2969 & 2.92 & .867 & .30 & .0014 & .4464 & .2979 & 2.91 \\
\hline 6 & .514 & .3685 & 2.95 & 1.089 & .37 & .0021 & .5161 & .3707 & 2.94 \\
\hline 7 & .637 & .3935 & 2.98 & 1.174 & .39 & .0024 & .5394 & .3957 & 2.97 \\
\hline 8 & .573 & .4337 & 3.05 & 1. 324 & .43 & .0030 & .5760 & .4371 & 3.03 \\
\hline 9 & .643 & .5156 & 3.09 & 1. 594 & .51 & .0040 & .6470 & .5204 & 3.06 \\
\hline 10 & .695 & .5795 & 3.20 & 1. 856 & .59 & .0054 & .7004 & .5857 & 3.17 \\
\hline 11 & .756 & .6574 & 3.24 & 2.129 & .66 & .0068 & .7628 & .6665 & 3. 19 \\
\hline 12 & .800 & .7155 & 3.30 & 2. 362 & .72 & .0081 & .8081 & .7263 & 3.25 \\
\hline 13 & .826 & .7507 & 3.31 & 2.486 & .76 & .0090 & .8350 & .7631 & 3.26 \\
\hline 14 & .867 & .8073 & 3. 36 & 2. 712 & .81 & .0102 & .8772 & .8213 & 3. 30 \\
\hline 15 & .921 & .8839 & 3.39 & 2.997 & .89 & .0123 & .9333 & . 9013 & 3.32 \\
\hline 16 & .975 & .9628 & 3.46 & 3. 332 & .97 & .0146 & .9896 & .9850 & 3. 38 \\
\hline 17 & 1.027 & 1.0408 & 3.51 & 3. 653 & 1.04 & .0168 & 1.0438 & 1.0667 & 3.47 \\
\hline 18 & 1.090 & 1.1380 & 3.52 & 4. 013 & 1.13 & .0199 & 1.1099 & 1.1695 & 3.43 \\
\hline 19 & 1.112 & 1.1727 & 3.57 & 4.177 & 1.17 & .0213 & 1.1333 & 1. 2060 & 3.46 \\
\hline 20 & 1.140 & 1. 2172 & 3.60 & 4. 382 & 1.22 & .0231 & 1.1631 & 1. 2543 & 3.50 \\
\hline 21 & 1.209 & 1.3294 & 3.61 & 4.801 & 1.31 & .0267 & 1. 2357 & 1. 3741 & 3.49 \\
\hline 22 & 1. 248 & 1. 3942 & 3. 64 & 5.060 & 1.36 & .0288 & 1. 2768 & 1.4431 & 3.51 \\
\hline 23 & 1.314 & 1.5063 & 3. 68 & 5.557 & 1.47 & .0336 & 1.3476 & 1. 5651 & 3.55 \\
\hline 24 & 1.352 & 1.5721 & 3.71 & 6.825 & 1.52 & 0359 & 1.3879 & 1. 6352 & 3.56 \\
\hline 25 & 1.416 & 1.6850 & 3.75 & 6.337 & 1.64 & .0418 & 1.4578 & 1. 7604 & 3.60 \\
\hline
\end{tabular}


Bazin's experiments on weirs of irregular section-Continued.

Bazin's Series, No. 153.

Crest length, 6.515 feet.

Crest height, 2.46 feet.

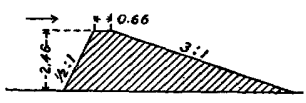

Cross section.

\begin{tabular}{|c|c|c|c|c|c|c|c|c|c|}
\hline Period. & $\begin{array}{l}\text { Observed } \\
\text { head, } \\
\text { experi- } \\
\text { mental } \\
\text { weir } D \text {, } \\
\text { in feet. }\end{array}$ & $D^{\frac{3}{2}}$ & $C_{1}$ & $\begin{array}{c}Q, \text { flow } \\
\text { per foot, } \\
\text { experi- } \\
\text { mental } \\
\text { weir, in } \\
\text { cubic feet } \\
\text { per } \\
\text { second. }\end{array}$ & $v$ & $\frac{v^{2}}{2 g}$ & $H$ & $H^{\frac{3}{2}}$ & $C$ \\
\hline 1 & 2 & $\mathbf{3}$ & 4 & 5 & 6 & 7 & 8 & 9 & 10 \\
\hline 1 & 0.237 & 0.1154 & 2.73 & 0.314 & 0.12 & 0.0002 & 0.2372 & 0.1154 & 2.72 \\
\hline 2 & .301 & .1651 & 2.77 & .457 & .16 & .0004 & .3014 & .1651 & 2.77 \\
\hline 3 & .372 & .2269 & 2.79 & .633 & .22 & .0008 & .3728 & .2278 & 2.78 \\
\hline 4 & .373 & .2278 & 2.83 & .645 & .23 & .0008 & .3738 & .2287 & 2.82 \\
\hline 5 & .440 & .2919 & 2.90 & .847 & .29 & .0013 & .4413 & .2929 & 2.89 \\
\hline 6 & .505 & .3589 & 2.93 & 1.052 & .35 & .0019 & .5069 & .3610 & 2.91 \\
\hline 7 & .576 & .4371 & 3.00 & 1.311 & .43 & .0030 & .5790 & .4406 & 2.98 \\
\hline 8 & .637 & .5084 & 3.07 & 1.560 & .50 & .0039 & .6409 & .5132 & 3.04 \\
\hline 9 & .696 & .5807 & 3.10 & 1.801 & .67 & .0051 & .7011 & .5870 & 3.07 \\
\hline 10 & .701 & .5870 & 3.10 & 1. 820 & .58 & .0052 & .7062 & .5933 & 3.07 \\
\hline 11 & .760 & .6626 & 3.15 & 2.085 & .65 & .0066 & .7666 & .6717 & 3.10 \\
\hline 12 & .762 & .6652 & 3.16 & 2.101 & .65 & .0066 & .7686 & .6743 & 3. 12 \\
\hline 13 & .814 & .7344 & 3.20 & 2.349 & .72 & .0081 & $: 8221$ & .7452 & 3.15 \\
\hline 14 & .879 & .8241 & 3.25 & 2.678 & .80 & .0099 & .8889 & .8381 & 3.20 \\
\hline 15 & .937 & .9071 & 3.29 & 2.984 & .88 & .0120 & .9490 & .9245 & 3. 23 \\
\hline 16 & .993 & .9895 & 3.34 & 3.307 & .96 & .0143 & 1.0073 & 1.0105 & 3.27 \\
\hline 17 & 1.001 & 1.0015 & 3.33 & 3.330 & .96 & .0143 & 1.0153 & 1.0226 & 3. 26 \\
\hline 18 & 1.055 & 1.0836 & 3.40 & 3.672 & 1.05 & .0171 & 1. 0721 & 1.1099 & 3.31 \\
\hline 19 & 1. 102 & 1.1569 & 3. 41 & 3. 956 & 1.11 & .0192 & 1.1212 & 1. 1869 & 3. 33 \\
\hline 20 & 1.170 & 1. 2656 & 3. 46 & 4.394 & 1.21 & .0228 & 1.1928 & 1.3030 & 3.37 \\
\hline 21 & 1. 226 & 1. 3575 & 3.48 & 4. 733 & 1.28 & .0255 & 1.2515 & 1.3992 & 3.38 \\
\hline 22 & 1.290 & 1.4652 & 3.51 & 5.159 & 1. 38 & .0296 & 1.3196 & 1.5166 & 3.40 \\
\hline 23 & 1. 289 & 1.4635 & 3.52 & 5.139 & 1.37 & .0292 & 1.3182 & 1.5132 & 3.40 \\
\hline 24 & 1.347 & 1. 5634 & 3. 53 & 5.507 & 1.45 & .0327 & 1. 3791 & 1.6193 & 3.40 \\
\hline 25 & 1.404 & 1. 6636 & 3.58 & 5.943 & 1.54 & .0369 & 1.4409 & 1.7298 & 3.44 \\
\hline 26 & 1.436 & 1.7208 & 3.58 & 6.158 & 1.58 & .0388 & 1. 4748 & 1. 7914 & 3.44 \\
\hline
\end{tabular}


Bazin's experiments on weirs of irregular section-Continued.

Bazin's Series, No. 154 .

Crest length, 6.516 feet.

Crest height, 2.46 feet.

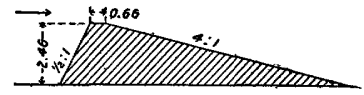

Cross section.

\begin{tabular}{|c|c|c|c|c|c|c|c|c|c|}
\hline Period. & $\begin{array}{l}\text { observed } \\
\text { head, } \\
\text { experi- } \\
\text { mental } \\
\text { weir } D \text {, } \\
\text { in feet. }\end{array}$ & $D^{\frac{3}{2}}$ & $C_{1}^{\prime}$ & $\begin{array}{c}Q, \text { flow } \\
\text { per foot, } \\
\text { experi- } \\
\text { mental } \\
\text { weir, in } \\
\text { cubic feet } \\
\text { per } \\
\text { second. }\end{array}$ & $v$ & $\frac{v^{2}}{2 g}$ & $H$ & $H^{\frac{3}{2}}$ & $C$ \\
\hline 1 & 2 & 3 & 4 & 5 & 6 & 7 & 8 & $\mathbf{9}$ & 10 \\
\hline 1 & 0.236 & 0.1147 & 2. 70 & 0.311 & 0.12 & 0.0002 & 0.2632 & 0.1349 & 2.30 \\
\hline 2 & .308 & .1709 & 2. 74 & .469 & .17 & .0004 & .3084 & .1709 & 2.74 \\
\hline 3 & .373 & .2278 & 2.83 & .645 & .23 & .0008 & .3738 & .2287 & 2. 82 \\
\hline 4 & .447 & .2989 & 2.85 & .852 & .29 & .0013 & .4483 & 2999 & 2.84 \\
\hline 5 & .508 & .3621 & 2.95 & 1.068 & .36 & .0020 & .5100 & .3642 & 2.94 \\
\hline 6 & .577 & .4382 & 2.97 & 1.301 & .37 & .0021 & .5791 & .4406 & 2.95 \\
\hline 7 & .643 & .5156 & 3.04 & 1. 569 & .51 & .0040 & .6470 & .5204 & 3.02 \\
\hline 8 & .706 & .5983 & 3.07 & 1.821 & .57 & .0051 & .7111 & .5996 & 3.04 \\
\hline 9 & .760 & .6626 & 3.17 & 2.102 & .65 & .0066 & .7666 & .6717 & 3.11 \\
\hline 10 & .823 & .7466 & 3.20 & 2.389 & .73 & .0083 & .8313 & .7576 & 3.16 \\
\hline 11 & .888 & .8368 & 3.20 & 2.678 & .80 & .0099 & .8979 & .8509 & 3.15 \\
\hline 12 & .946 & .9201 & 3.24 & 2. 981 & .87 & .0118 & .9578 & .9376 & 3.18 \\
\hline 13 & 1.011 & 1.0165 & 3.28 & 3. 334 & .96 & .0143 & 1,0253 & 1.0377 & 3.21 \\
\hline 14 & 1.075 & 1. 1146 & 3.31 & 3.674 & 1.03 & .0165 & 1. 0915 & 1.1396 & 3.22 \\
\hline 15 & 1. 138 & 1. 2140 & 3. 36 & 4.066 & 1.13 & .0199 & 1.1579 & 1. 2461 & 3.26 \\
\hline 16 & 1.195 & 1. 3063 & 3.37 & 4. 415 & 1.20 & .0224 & 1. 2174 & 1.3426 & 3.29 \\
\hline 17 & 1. 250 & 1. 3975 & 3.40 & 4. 760 & 1.28 & .0255 & 1. 2755 & 1.4397 & 3.31 \\
\hline 18 & 1.310 & 1. 4994 & 3.43 & 5.145 & 1.36 & .0288 & 1. 3388 & 1.5494 & 3.32 \\
\hline 19 & 1.370 & 1. 6035 & 3.45 & 5.520 & 1.44 & .0322 & 1. 4022 & 1.6601 & 3.32 \\
\hline 20 & 1.430 & 1. 7100 & 3.48 & 5.951 & 1. 53 & .0364 & 1. 4664 & 1.7750 & 3.35 \\
\hline
\end{tabular}


Bazin's experiments on weirs of irregular section-Continued.

Bazin's Series, No. 156.

Crest height, 2.46 feet.

Crest width, 0.66 foot.

Upstream slope, $\frac{1}{2}$ to 1 .

Downstream slope, 5 to 1 .

\begin{tabular}{|c|c|c|c|c|c|c|c|c|c|}
\hline Period. & $\begin{array}{l}\text { Observed } \\
\text { head, } \\
\text { experi- } \\
\text { mental } \\
\text { weir } D \text {, } \\
\text { in feet. }\end{array}$ & $I^{\frac{3}{3}}$ & $C_{1}$ & $\begin{array}{c}Q, \text { flow } \\
\text { per foot, } \\
\text { experi- } \\
\text { mental } \\
\text { weir, in } \\
\text { cubic feet } \\
\text { per } \\
\text { second. }\end{array}$ & $r$ & $\begin{array}{l}\vartheta^{2} \\
2 \dot{g}\end{array}$ & $H$ & $H^{\frac{3}{2}}$ & $C$ \\
\hline 1 & $\mathbf{2}$ & 3 & 4 & 5 & 6 & 7 & 8 & 9 & 10 \\
\hline 1 & 0.246 & 0.1220 & 2.76 & 0.337 & 0.12 & 0.0002 & 0.2462 & 0.1220 & 2.76 \\
\hline 2 & .311 & .1734 & 2.80 & .486 & .17 & .0004 & .3114 & .1734 & 2.80 \\
\hline 3 & .382 & .2361 & 2.84 & .671 & .24 & .0009 & .3829 & .2370 & 2.83 \\
\hline 4 & .446 & .2979 & 2.90 & .864 & .30 & .0014 & .4474 & .2989 & 2.89 \\
\hline 5 & .508 & .3621 & 2. 91 & 1. 054 & .36 & .0020 & .5100 & .3642 & 2.89 \\
\hline 6 & .576 & .4371 & 2.95 & 1. 289 & .42 & .0027 & .5787 & .4406 & 2.92 \\
\hline 7 & .638 & .5096 & 3. 01 & 1. 534 & .49 & .0037 & .6417 & .5144 & 2.98 \\
\hline 8 & .703 & .5895 & 3. 06 & 1.804 & .57 & .0051 & .7081 & .5958 & 3.03 \\
\hline 9 & .764 & .6678 & 3.10 & 2.070 & .64 & .0064 & .7704 & .6757 & 3.06 \\
\hline 10 & .834 & .7617 & 3.13 & 2.384 & .72 & .0081 & .8421 & .7727 & 3.08 \\
\hline 11 & .888 & .8368 & 3.17 & 2.653 & .79 & .0097 & .8977 & .8510 & 3.12 \\
\hline 12 & .956 & .9347 & 3.24 & 3.028 & .88 & .0120 & .9680 & .9524 & 3.18 \\
\hline 13 & 1.018 & 1.0272 & 3. 22 & 3. 309 & .95 & .0140 & 1.0320 & 1. 0484 & 3. 16 \\
\hline 14 & 1.074 & 1.1130 & 3.30 & 3.673 & 1.04 & .0168 & 1.0908 & 1.1396 & 3.22 \\
\hline 15 & 1. 139 & 1. 2156 & 3.29 & 3.999 & 1. 11 & .0192 & 1.1582 & 1.2462 & 3. 21 \\
\hline 16 & 1.203 & 1. 3194 & 3. 31 & 4. 367 & 1. 19 & .0220 & 1.2250 & 1. 3558 & 3.22 \\
\hline 17 & 1.267 & 1.4262 & 3. 34 & 4.764 & 1.26 & .0247 & 1.2917 & 1. 4686 & 3.24 \\
\hline J8 & $1.3+1$ & 1.5529 & 3. 36 & 5.218 & 1.37 & .0292 & 1.3702 & 1. 6035 & 3.25 \\
\hline 19 & 1. 394 & 1. 6459 & 3.36 & 5.530 & 1.43 & .0318 & 1.4258 & 1. 7028 & 3.25 \\
\hline 20 & 1.457 & 1. 7587 & 3. 39 & 5.962 & 1.52 & .0359 & 1. 4929 & 1. 8241 & 3.27 . \\
\hline
\end{tabular}

Bazin's Series, No. 158 . Crest length, 6.520 feet. Crest height, 2.46 feet.

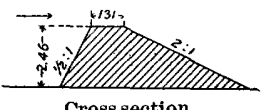

Cross section.

\begin{tabular}{|r|r|r|r|r|r|r|r|r|r|}
\hline 1 & 0.234 & 0.1132 & 2.79 & 0.316 & 0.12 & 0.0002 & 0.2342 & 0.1132 & 2.79 \\
2 & .312 & .1743 & 2.72 & .474 & .17 & .0004 & .3124 & .1743 & 2.72 \\
3 & .383 & .2370 & 2.77 & .656 & .23 & .0008 & .3838 & .2379 & 2.76 \\
4 & .457 & .3090 & 2.79 & .862 & .29 & .0013 & .4583 & .3100 & 2.78 \\
5 & .530 & .3858 & 2.81 & 1.085 & .36 & .0020 & .5320 & .3880 & 2.80 \\
6 & .600 & .4648 & 2.82 & 1.311 & .43 & .0030 & .6030 & .4683 & 2.80 \\
7 & .672 & .5509 & 2.86 & 1.576 & .50 & .0039 & .6759 & .5557 & 2.84 \\
8 & .733 & .6276 & 2.90 & 1.821 & .57 & .0051 & .7381 & .6340 & 2.87 \\
9 & .799 & .7142 & 2.91 & 2.078 & .64 & .0064 & .8054 & .7223 & 2.88 \\
10 & .860 & .7975 & 2.95 & 2.354 & .71 & .0078 & .8678 & .8087 & 2.91 \\
11 & .930 & .8969 & 3.00 & 2.691 & .79 & .0097 & .9397 & .9114 & 2.95 \\
12 & .984 & .9761 & 3.04 & 2.967 & .86 & .0115 & .9955 & .9925 & 2.99 \\
13 & 1.055 & 1.0836 & 3.10 & 3.348 & .95 & .0140 & 1.0690 & 1.1053 & 3.03 \\
14 & 1.125 & 1.1933 & 3.12 & 3.713 & 1.04 & .0168 & 1.1418 & 1.2204 & 3.04 \\
15 & 1.177 & 1.2769 & 3.15 & 4.022 & 1.10 & .0188 & 1.1958 & 1.3029 & 3.08 \\
16 & 1.243 & 1.3858 & 3.19 & 4.434 & 1.20 & .0224 & 1.2654 & 1.4228 & 3.12 \\
17 & 1.297 & 1.4771 & 3.22 & 4.766 & 1.27 & .0251 & 1.3221 & 1.5200 & 3.14 \\
18 & 1.361 & 1.5878 & 3.25 & 5.168 & 1.35 & .0283 & 1.3893 & 1.6370 & 3.16 \\
19 & 1.412 & 1.6779 & 3.30 & 5.544 & 1.43 & .0348 & 1.4468 & 1.7406 & 3.18 \\
20 & 1.457 & 1.7587 & 3.32 & 5.839 & 1.49 & .0345 & 1.4915 & 1.8215 & 3.22 \\
\hline
\end{tabular}


Bazin's experiments on weirs of irregular section-Continued.

Bazin's Series, No. 159.

Crest length, 6.511 feet.

Crest height, 2.46 feet.

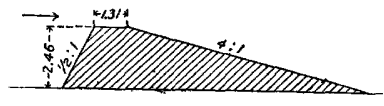

Cross section.

\begin{tabular}{|c|c|c|c|c|c|c|c|c|c|}
\hline Period. & $\begin{array}{c}\text { Observed } \\
\text { head, } \\
\text { experi- } \\
\text { mental } \\
\text { weir } D \text {, } \\
\text { in feet. }\end{array}$ & $I^{\frac{3}{2}}$ & $C_{1}^{\prime}$ & $\begin{array}{c}Q, \text { flow } \\
\text { per foot, } \\
\text { experi- } \\
\text { mental } \\
\text { weir, in } \\
\text { cubic feet } \\
\text { per } \\
\text { second. }\end{array}$ & $v$ & $\frac{v^{2}}{2 g}$ & $H$ & $H^{\frac{3}{2}}$ & $C^{\prime}$ \\
\hline I & 2 & 3 & 4 & 5 & 6 & 7 & 8 & 9 & 10 \\
\hline 1 & 0.234 & 0.1132 & 2,68 & 0.303 & 0.11 & 0.0002 & 0.2342 & 0.1132 & 2.68 \\
\hline 2 & .304 & .1676 & 2.75 & .462 & .17 & .0004 & .3044 & .1676 & 2.74 \\
\hline 3 & .379 & .2333 & 2.82 & .657 & .23 & .0008 & 3798 & .2342 & 2.80 \\
\hline 4 & .387 & .2408 & 2.82 & .680 & .24 & .0009 & .3879 & .2417 & 2.81 \\
\hline 5 & .457 & .3090 & 2.81 & .868 & .30 & .0014 & .4584 & .3100 & 2.80 \\
\hline 6 & .516 & .3707 & 2.91 & 1.079 & .36 & .0020 & .5180 & .3728 & 2.89 \\
\hline 7 & .526 & .3815 & 2.84 & 1.085 & .36 & .0020 & .5280 & .3836 & 2.83 \\
\hline 8 & .599 & .4636 & 2.82 & 1.308 & .43 & .0030 & .6020 & .4671 & 2.81 \\
\hline 9 & .664 & .5411 & 2.87 & 1. 553 & .50 & .0039 & .6679 & .5460 & 2.84 \\
\hline 10 & .670 & .5484 & 2.83 & 1. 552 & .49 & .0037 & .6737 & .5533 & 2.80 \\
\hline 11 & .735 & .6302 & 2.88 & 1.813 & .56 & .0049 & .7399 & .6366 & 2.85 \\
\hline 12 & .797 & .7115 & 2.94 & 2.092 & .64 & .0064 & .8034 & .7196 & 2.91 \\
\hline 13 & .861 & .7989 & 2.99 & 2.389 & .72 & .0081 & .8693 & .8101 & 2.95 \\
\hline 14 & .876 & .8199 & 2.94 & 2.411 & .72 & .0081 & .8843 & .8311 & 2.90 \\
\hline 15 & .935 & .9042 & 2.93 & 2.649 & .78 & .0095 & .9445 & .9172 & 2.89 \\
\hline 16 & .994 & .9910 & 3.01 & 2.983 & .86 & .0115 & 1.0055 & 1.009 & 2.96 \\
\hline 17 & 1.068 & 1.1037 & 3.03 & 3. 333 & .94 & .0137 & 1.0817 & 1.1255 & 2.96 \\
\hline 18 & 1.126 & 1. 1948 & 3.10 & 3. 704 & 1.03 & .0165 & I. 1425 & 1.2204 & 3.04 \\
\hline 19 & 1.145 & 1. 2252 & 3.05 & 3.751 & 1.04 & .0168 & 1.1618 & 1. 2526 & 3.00 \\
\hline 20 & 1.198 & 1. 3112 & 3.08 & 4. 035 & 1.10 & .0188 & 1.2168 & 1. 3425 & 3.00 \\
\hline 21 & 1.261 & 1.4161 & 3. 11 & 4. 416 & 1.19 & .0220 & 1. 2830 & 1. 4583 & 3.03 \\
\hline 22 & 1. 320 & 1.5166 & 3.15 & $4.777^{\circ}$ & 1.27 & .0251 & 13451 & 1.5599 & 3.06 \\
\hline 23 & 1. 332 & 1. 5373 & 3.13 & 4.820 & 1. 27 & .0251 & 1.3571 & 1.5808 & 3.05 \\
\hline 24 & 1. 389 & 1. 6370 & 3.14 & 5. 150 & 1.33 & .0275 & 1. 4165 & 1.6850 & 3.06 \\
\hline 25 & 1.445 & 1.7370 & 3.19 & 5.551 & 1. 42 & .0313 & 1.4763 & 1. 7932 & 3.09 \\
\hline 26 & 1. 456 & 1. 7569 & 3.19 & 5.614 & 1. 43 & .0348 & 1. 4908 & 1.8188 & 3.09 \\
\hline
\end{tabular}


Bazin's experiments on weirs of irregular section-Continued.

Bazin's Series, No. 160.

Crest height, 2.46 feet.

Crest width, 1.31 feet.

Upstream slope, $\frac{1}{2}$ to 1 .

Downstream slope, 6 to 1 .

\begin{tabular}{|c|c|c|c|c|c|c|c|c|c|}
\hline Period. & $\begin{array}{c}\text { Observed } \\
\text { head. } \\
\text { experi- } \\
\text { mental } \\
\text { weir } D, \\
\text { in feet. }\end{array}$ & $D^{\frac{3}{2}}$ & $C_{1}$ & $\begin{array}{c}Q, \text { flow } \\
\text { per foot, } \\
\text { experi- } \\
\text { mental } \\
\text { weir, in } \\
\text { cubic feet } \\
\text { per } \\
\text { second. }\end{array}$ & $v$ & $\frac{v^{2}}{2 g}$ & $H$ & $H^{\frac{3}{2}}$ & $C$ \\
\hline 1 & $\mathbf{2}$ & 3 & 4 & $\tilde{5}$ & 6 & 7 & 8 & 9 & 10 \\
\hline 1 & 0.451 & 0.3029 & 2.81 & 0.8540 & 0.29 & 0.0013 & 0.4523 & 0.3039 & 2.80 \\
\hline 2 & .522 & .3772 & 2. 82 & 1. 0637 & .36 & .0020 & .5240 & .3793 & 2.80 \\
\hline 3 & .593 & .4567 & 2.84 & 1.2970 & .42 & .0027 & .5957 & .4601 & 2.82 \\
\hline 4 & .663 & .5399 & 2.88 & 1.5549 & .50 & .0039 & .6669 & .5447 & 2.86 \\
\hline 5 & .735 & .6302 & 2.89 & 1.8213 & .57 & .0051 & .7401 & .6366 & 2. 86 \\
\hline 6 & .798 & .7128 & 2. 91 & 2.0742 & .64 & .0064 & .8044 & .7209 & 2.88 \\
\hline 7 & .863 & .8017 & 2. 92 & 2. $3 \$ 10$ & .70 & .0076 & .8706 & .8129 & 2.88 \\
\hline 8 & .930 & .8969 & 2.97 & 2.6638 & .78 & .0095 & .9395 & . 9100 & 2.93 \\
\hline 9 & .998 & .9970 & 2.99 & 2.9810 & .86 & .0115 & 1.0095 & 1.0135 & 2. 94 \\
\hline 10 & 1.074 & 1.1130 & 3.02 & 3.3361 & .95 & .0140 & 1.0880 & 1.1349 & 2.94 \\
\hline 11 & 1. 129 & 1. 1996 & 3.03 & 3.6348 & 1.01 & .0159 & 1.1449 & 1. 2252 & 2.97 \\
\hline 12 & 1.193 & 1.3030 & 3.06 & 3. 9872 & 1.09 & .0185 & 1. 2115 & 1.3334 & 2.98 \\
\hline 13 & 1.254 & 1. 4043 & 3.08 & 4. 3252 & 1.16 & .0209 & 1. 2749 & 1. 4397 & 3.00 \\
\hline 14 & 1. 326 & 1. 5269 & 3.10 & 4. 7334 & 1.25 & .0243 & 1. 3503 & 1. 5686 & 3.02 \\
\hline 15 & 1. 389 & 1. 6370 & 3.14 & 5.1402 & 1.34 & .0279 & 1.4169 & 1. 6867 & 3.05 \\
\hline 16 & 1.457 & 1. 7587 & 3.16 & 5.5575 & 1. 42 & .0313 & 1.4883 & 1.8151 & 3.06 \\
\hline
\end{tabular}

Bazin's Series, No. 161.

Crest length, 6.543 feet.

Crest height, 1.64 feet.

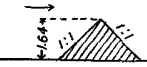

Cross section.

\begin{tabular}{|r|r|r|r|r|r|r|r|r|r|}
\hline 1 & 0.298 & 0.1627 & 4.31 & 0.701 & 0.36 & 0.0020 & 0.3000 & 0.1643 & 4.27 \\
2 & .354 & .2107 & 4.30 & .906 & .45 & .0031 & .3571 & .2133 & 4.25 \\
3 & .413 & .2654 & 4.26 & 1.131 & .56 & .0049 & .4179 & .2702 & 4.19 \\
4 & .472 & .3243 & 4.23 & 1.371 & .65 & .0066 & .4786 & .3314 & 4.14 \\
5 & .529 & .3847 & 4.22 & 1.625 & .75 & .0087 & .5377 & .3946 & 4.12 \\
6 & .581 & .4429 & 4.25 & 1.883 & .85 & .0112 & .5922 & .4555 & 4.13 \\
7 & .639 & .5108 & 4.24 & 2.167 & .95 & .0140 & .6530 & .5277 & 4.11 \\
8 & .693 & .5770 & 4.26 & 2.458 & 1.05 & .0171 & .7101 & .5983 & 4.11 \\
9 & .750 & .6495 & 4.28 & 2.782 & 1.16 & .0209 & .7709 & .6770 & 4.11 \\
10 & .804 & .7209 & 4.31 & 3.107 & 1.27 & .0251 & .8291 & .7548 & 4.12 \\
11 & .864 & .8031 & 4.31 & 3.461 & 1.38 & .0296 & .8936 & .8452 & 4.10 \\
12 & .919 & .8810 & 4.32 & 3.806 & 1.49 & .0345 & .9535 & .9303 & 4.09 \\
13 & .960 & .9406 & 4.33 & 4.073 & 1.57 & .0383 & .9983 & .9970 & 4.08 \\
14 & .992 & .9880 & 4.30 & 4.248 & 1.61 & .0403 & 1.0323 & 1.0484 & 4.05 \\
15 & 1.019 & 1.0287 & 4.31 & 4.434 & 1.67 & .0434 & 1.0624 & 1.0944 & 4.05 \\
16 & 1.056 & 1.0851 & 4.28 & 4.665 & 1.72 & .0460 & 1.1020 & 1.1569 & 4.03 \\
17 & 1.083 & 1.1271 & 4.27 & 4.825 & 1.78 & .0493 & 1.1323 & 1.2044 & 4.01 \\
18 & 1.118 & 1.1821 & 4.24 & 5.003 & 1.81 & .0509 & 1.1689 & 1.2640 & 3.96 \\
19 & 1.157 & 1.2445 & 4.17 & 5.171 & 1.84 & .0526 & 1.2096 & 1.3310 & 3.88 \\
20 & 1.187 & 1.2932 & 4.16 & 5.380 & 1.90 & .0561 & 1.2431 & 1.3858 & 3.88 \\
21 & 1.225 & 1.3558 & 4.12 & 5.378 & 1.95 & .0591 & 1.2841 & 1.4550 & 3.83 \\
22 & 1.263 & 1.4194 & 4.09 & 5.808 & 2.00 & .0622 & 1.3252 & 1.5252 & 3.81 \\
23 & 1.289 & 1.4635 & 4.11 & 6.001 & 2.05 & .0653 & 1.3543 & 1.5756 & 3.81 \\
24 & 1.326 & 1.5269 & 4.08 & 6.242 & 2.10 & .0686 & 1.3946 & 1.6476 & 3.79 \\
25 & 1.359 & 1.5843 & 4.08 & 6.446 & 2.15 & .0719 & 1.4309 & 1.7118 & 3.76 \\
\hline & & & & & & & & & \\
\hline
\end{tabular}


Bazin's experiments on weirs of irregular section-Continued.

Bazin's Series, No. 163.

Crest length, 6.535 feet.

Crest height, 1.64 feet.

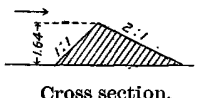

\begin{tabular}{|c|c|c|c|c|c|c|c|c|c|}
\hline Period. & $\begin{array}{l}\text { Observed } \\
\text { head, } \\
\text { experi- } \\
\text { mental } \\
\text { weir } D \text {, } \\
\text { in feet. }\end{array}$ & $D^{\frac{3}{2}}$ & $G_{1}$ & $\mid \begin{array}{c}Q, \text { flow } \\
\text { per foot, } \\
\text { experi- } \\
\text { mental } \\
\text { weir, in } \\
\text { cubic feet } \\
\text { per } \\
\text { second. }\end{array}$ & $v$ & $\frac{v^{2}}{2 g}$ & $H$ & $H^{\frac{3}{2}}$ & $C$ \\
\hline 1 & 2 & 3 & 4 & 5 & 6 & 7 & 8 & 9 & 10 \\
\hline 1 & 0.184 & 0.0790 & 3.81 & 0.301 & 0.17 & 0.0004 & 0.1844 & 0.0790 & 3.81 \\
\hline 2 & .244 & .1206 & 3.83 & .4633 & .25 & .0009 & .2449 & .1213 & 3.82 \\
\hline 3 & .303 & .1668 & 3.84 & .641 & .33 & $.00 \%$ & .3047 & .1684 & 3. 81 \\
\hline 4 & .366 & .2215 & 3.83 & .850 & .42 & .0027 & .3687 & .2241 & 3. 79 \\
\hline 5 & .423 & .2751 & 3.83 & 1. 053 & .51 & .0040 & .4270 & .2791 & 3.77 \\
\hline 6 & .486 & .3388 & 3.82 & 1.295 & .61 & .0058 & .4915 & .3441 & 3.76 \\
\hline 7 & .536 & .3924 & 3.86 & 1.513 & .69 & .0074 & .5434 & .4001 & 3.78 \\
\hline 8 & .593 & .4567 & 3.94 & 1.799 & .81 & .0102 & .6032 & .4683 & 3.84 \\
\hline 9 & .653 & .5277 & 3.91 & 2.063 & .90 & .0126 & .6656 & .5435 & 3. 80 \\
\hline 10 & .702 & .5882 & 4.04 & 2.376 & 1.01 & .0159 & .7179 & .6084 & 3.90 \\
\hline 11 & .769 & .6744 & 3.98 & 2.683 & 1.11 & .0188 & .7878 & .6945 & 3. 84 \\
\hline 12 & .827 & .7521 & 4.02 & 3.023 & 1. 22 & .0231 & .8501 & .7837 & 3.86 \\
\hline 13 & .882 & .8283 & 4.02 & 3. 329 & 1. 32 & .0271 & .9091 & .8667 & 3.84 \\
\hline 14 & .949 & .9245 & 4.04 & 3. 735 & 1.44 & .0322 & .9812 & .9717 & 3.84 \\
\hline 15 & .998 & .9970 & 4.06 & 4. 048 & 1.53 & .0364 & 1.0344 & 1.0514 & 3.85 \\
\hline 16 & 1.056 & 1. 0851 & 4.06 & 4. 425 & 1. 64 & .0418 & 1.0978 & 1.1505 & 3.85 \\
\hline 17 & 1.114 & 1.1758 & 4. 05 & 4.779 & 1.74 & .0471 & 1.1611 & 1.2510 & 3.82 \\
\hline 18 & 1. 171 & 1. 2672 & 4.07 & 5.169 & 1. 84 & .0526 & 1.2236 & 1. 3541 & 3.82 \\
\hline 19 & 1. 231 & 1.3658 & 4.07 & 5.576 & 1.94 & .0585 & 1. 2895 & 1.4635 & 3. 81 \\
\hline 20 & 1. 285 & 1.4567 & 4.12 & 6.014 & 2.06 & .0660 & 1.3510 & 1.5703 & 3.83 \\
\hline 21 & 1. 339 & 1.5495 & 4.17 & 6.464 & 2.17 & .0732 & 1.4122 & 1. 6779 & 3.85 \\
\hline
\end{tabular}

Bazin's Series, No. 164.

Crest length, 6.534 feet.

Crest height, 1.64 feet.

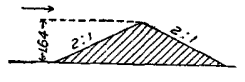

Cross section.

\begin{tabular}{|r|r|r|r|r|r|r|r|r|r|}
\hline 1 & 0.244 & $0.120 t$ & 3.86 & 0.467 & 0.25 & 0.0009 & 0.2449 & 0.1213 & 3.85 \\
2 & .305 & .1685 & 3.91 & .659 & .34 & .0018 & .3068 & .1701 & 3.88 \\
3 & .367 & .2224 & 3.87 & .359 & .43 & .0030 & .3700 & .2251 & 3.82 \\
4 & .425 & .2771 & 3.90 & 1.080 & .52 & .0042 & .4292 & .2810 & 3.84 \\
5 & .482 & .3346 & 3.87 & 1.296 & .61 & .0058 & .4878 & .3409 & 3.80 \\
6 & .540 & .3968 & 3.87 & 1.536 & .70 & .0076 & .5476 & .4057 & 3.79 \\
7 & .592 & .4555 & 3.94 & 1.797 & .81 & .0102 & .6022 & .4671 & 3.85 \\
8 & .651 & .5252 & 3.94 & 2.069 & .90 & .0126 & .6636 & .5410 & 3.82 \\
9 & .702 & .5882 & 3.97 & 2.334 & .99 & .0152 & .7172 & .6071 & 3.84 \\
10 & .766 & .6705 & 4.00 & 2.684 & 1.11 & .0188 & .7848 & .6955 & 3.86 \\
11 & .817 & .7385 & 4.03 & 2.978 & 1.21 & .0228 & .8398 & .7699 & 3.87 \\
12 & .877 & .8213 & 4.05 & 3.325 & 1.32 & .0271 & .9041 & .8595 & 3.87 \\
13 & .939 & .9100 & 4.07 & 3.704 & 1.44 & .0322 & .9722 & .9583 & 3.86 \\
14 & .993 & .9895 & 4.10 & 4.055 & 1.54 & .0369 & 1.0299 & 1.0453 & 3.88 \\
15 & 1.052 & 1.0790 & 4.09 & 4.417 & 1.64 & .0418 & 1.0938 & 1.1442 & 3.86 \\
16 & 1.115 & 1.1774 & 4.12 & 4.862 & 1.76 & .0482 & 1.1632 & 1.2543 & 3.88 \\
17 & 1.162 & 1.2526 & 4.13 & 5.163 & 1.84 & .0526 & 1.2146 & 1.3392 & 3.86 \\
18 & 1.219 & 1.3459 & 4.15 & 5.602 & 1.96 & .0597 & 1.2787 & 1.4465 & 3.87 \\
19 & 1.277 & 1.4431 & 4.18 & 6.019 & 2.06 & .0660 & 1.3430 & 1.5564 & 3.87 \\
20 & 1.330 & 1.5338 & 4.19 & 6.411 & 2.16 & .0725 & 1.4025 & 1.6601 & 3.86 \\
\hline
\end{tabular}


Bazin's experiments on weirs of irregular section-Continued.

Bazin's Series, No. 165.

Crest length, 6.544 feet.

Crest height, 1.64 feet.

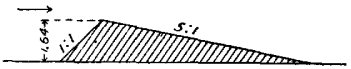

Cross section.

\begin{tabular}{|c|c|c|c|c|c|c|c|c|c|}
\hline Period. & $\begin{array}{c}\text { Observed } \\
\text { head, } \\
\text { experi- } \\
\text { mental } \\
\text { weir } D \text {, } \\
\text { in feet. }\end{array}$ & $D^{\frac{3}{2}}$ & $C_{1}$ & $\begin{array}{c}Q, \text { flow } \\
\text { per foot, } \\
\text { experi- } \\
\text { mental } \\
\text { weir, in } \\
\text { cubic feet } \\
\text { per } \\
\text { second. }\end{array}$ & $v$ & $\frac{v^{2}}{2 g}$ & $I I$ & $H^{\frac{3}{9}}$ & $C$ \\
\hline 1 & 2 & 3 & 4 & 5 & 6 & 7 & 8 & 9 & 10 \\
\hline 1 & 0.337 & 0.1957 & 3.56 & 0.698 & 0.35 & 0.0019 & 0.3389 & 0.1974 & 3.54 \\
\hline 2 & .401 & .2540 & 3.56 & .904 & .44 & .0030 & .4040 & .2568 & 3.52 \\
\hline 3 & .464 & .3161 & 3.56 & 1.125 & .54 & .0045 & .4685 & .3202 & 3.51 \\
\hline 4 &.$\dot{28}$ & .3836 & 3.55 & 1.363 & .63 & .0062 & .5342 & .3902 & 3. 49 \\
\hline 5 & .593 & .4567 & 3.54 & 1. 618 & .73 & .0083 & .6013 & .4660 & 3.47 \\
\hline 6 & .656 & .5313 & 3.54 & 1. 880 & .82 & .0105 & .6665 & .5435 & 3.46 \\
\hline 7 & .720 & .6109 & 3.54 & 2.162 & .92 & .0132 & .7332 & .6276 & 3.44 \\
\hline 8 & .783 & .6929 & 3.55 & 2.461 & 1.02 & .0162 & .7992 & .7142 & 3.45 \\
\hline 9 & .843 & .7740 & 3.58 & 2.771 & 1.11 & .0192 & .8622 & .8003 & 3. 46 \\
\hline 10 & .904 & .8595 & 3.61 & 3.103 & 1.22 & .0231 & .9271 & .8926 & 3.47 \\
\hline 11 & .969 & .9538 & 3. 63 & 3. 462 & 1. 33 & .0275 & .9965 & .9910 & 3. 48 \\
\hline 12 & 1.029 & 1.0438 & 3.63 & 3. 789 & 1.42 & .0313 & 1.0603 & 1.0913 & 3. 47 \\
\hline 13 & 1.090 & 1.1380 & 3.64 & 4.150 & 1.52 & .0359 & 1.1259 & 1.1948 & 3.47 \\
\hline 14 & 1.153 & 1. 2381 & 3.65 & 4.526 & 1.62 & .0408 & 1. 1938 & 1. 3046 & 3.47 \\
\hline 15 & 1.217 & 1.3426 & 3.66 & 4. 904 & 1. 71 & .0455 & 1. 2625 & 1.4178 & 3.46 \\
\hline 16 & 1.279 & 1.4465 & 3.68 & 5. 336 & 1.83 & .0521 & 1. 3311 & 1. 5355 & 3.48 \\
\hline 17 & 1. 341 & 1.5529 & 3.68 & 5. 704 & 1.92 & .0573 & 1. 3983 & 1.6530 & 3. 45 \\
\hline 18 & 1.401 & 1. 6583 & 3.69 & 6.125 & 2.02 & .0634 & 1. 4644 & 1.7714 & 3.46 \\
\hline 19 & 1.448 & 1.7424 . & 3. 73 & 6.490 & 2.10 & .0686 & 1.5166 & 1.8680 & 3.47 \\
\hline
\end{tabular}

Bazin's Series, No. 176.

Crest length, 6.519 feet.

Crest height, 2.46 feet.

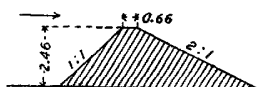

Cross section.

\begin{tabular}{|r|r|r|r|r|r|r|r|r|r|}
\hline 1 & 0.237 & 0.1154 & 2.7 & 0.317 & 0.12 & 0.0002 & 0.2372 & 0.1154 & 2.75 \\
2 & .296 & .1611 & 2.74 & .441 & .16 & .0004 & .2964 & .1611 & 2.74 \\
3 & .365 & .2206 & 2.92 & .645 & .23 & .0008 & .3658 & .2214 & 2.91 \\
4 & .439 & .2909 & 2.95 & .858 & .30 & .0014 & .4404 & .2919 & 2.94 \\
5 & .494 & .3472 & .34 & 1.055 & .36 & .0020 & .4960 & .3494 & 3.02 \\
6 & .565 & .4247 & 3.10 & 1.318 & .43 & .0030 & .5680 & .4281 & 3.08 \\
7 & .618 & .4858 & 3.19 & 1.550 & .50 & .0039 & .6219 & .4905 & 3.16 \\
8 & .682 & .5632 & 3.22 & 1.813 & .58 & .0052 & .6872 & .5695 & 3.18 \\
9 & .733 & .6276 & 3.29 & 2.066 & .65 & .0066 & .7396 & .6366 & 3.24 \\
10 & .797 & .7115 & 3.35 & 2.385 & .73 & .0083 & .8073 & .7250 & 3.29 \\
11 & .861 & .7989 & 3.41 & 2.724 & .82 & .0105 & .8715 & .8129 & 3.35 \\
12 & .910 & .8681 & 3.45 & 2.995 & .89 & .0123 & .9223 & .8853 & 3.38 \\
13 & .974 & .9613 & 3.51 & 3.373 & .98 & .0149 & .9889 & .9835 & 3.43 \\
14 & 1.027 & 1.0408 & 3.53 & 3.671 & 1.05 & .0171 & 1.0441 & 1.0667 & 3.44 \\
15 & 1.088 & 1.1349 & 3.57 & 4.034 & 1.14 & .0202 & 1.1082 & 1.1663 & 3.46 \\
16 & 1.139 & 1.2156 & 3.62 & 4.416 & 1.23 & .0235 & 1.1625 & 1.2526 & 3.52 \\
17 & 1.196 & 1.3079 & 3.65 & 4.782 & 1.30 & .0263 & 1.223 & 1.3508 & 3.54 \\
18 & 1.248 & 1.3942 & 3.68 & 5.115 & 1.38 & .0296 & 1.2776 & 1.4448 & 3.54 \\
19 & 1.303 & 1.4874 & 3.73 & 5.558 & 1.47 & .0336 & 1.3366 & 1.5460 & 3.60 \\
20 & 1.355 & 1.5773 & 3.75 & 5.925 & 1.55 & .0374 & 1.3924 & 1.6423 & 3.61 \\
21 & 1.420 & 1.6921 & 3.80 & 6.422 & 1.66 & .0428 & 1.4628 & 1.7695 & 3.63 \\
\hline
\end{tabular}


Bazin's experiments on weirs of irregular section-Continued.

Bazin's Series, No. 178.

Crest length, 6.518 feet.

Crest height, 2.46 feet.

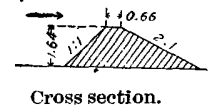

\begin{tabular}{|c|c|c|c|c|c|c|c|c|c|}
\hline Period. & $\begin{array}{c}\text { Observed } \\
\text { head } \\
\text { experi- } \\
\text { mental } \\
\text { weir } D \text {, } \\
\text { in feet. }\end{array}$ & $D^{\frac{3}{2}}$ & $C_{1}$ & $\begin{array}{c}Q, \text { flow } \\
\text { per foot, } \\
\text { experi- } \\
\text { mental } \\
\text { weir, in } \\
\text { eubie feet } \\
\text { per } \\
\text { second. }\end{array}$ & $v$ & $\frac{v^{2}}{2 g}$ & $H$ & $H^{\frac{3}{2}}$ & $C$ \\
\hline 1 & 2 & 3 & 4 & 5 & 6 & 7 & 8 & 9 & 10 \\
\hline 1 & 0.222 & 0.1046 & 2.83 & 0.297 & 0.11 & 0.0002 & 0.2222 & 0.1046 & 2.84 \\
\hline 2 & .299 & .1635 & 2.95 & .482 & .17 & .0004 & .2994 & . 1635 & 2.95 \\
\hline 3 & .367 & .2224 & 2.96 & .658 & .23 & .0008 & .3678 & .2233 & 2. 95 \\
\hline 4 & .431 & .2830 & 3.08 & .872 & .30 & .0014 & .4324 & .2840 & 3.07 \\
\hline 5 & .491 & .3441 & 3.13 & 1.077 & .37 & .0021 & . 4931 & . 3462 & 3.11 \\
\hline 6 & .556 & .4146 & 3.19 & 1. 323 & .47 & .0034 & . 5594 & .4180 & 3.16 \\
\hline 7 & .614 & .4811 & 3.24 & 1. 558 & .51 & .0040 & .6180 & .4858 & 3.21 \\
\hline 8 & .669 & .5472 & 3.28 & 1.794 & .57 & .0051 & . 6741 & .5533 & 3.24 \\
\hline 9 & .732 & .6263 & 3.33 & 2. 085 & .65 & .0066 & . 7386 & .6353 & 3.28 \\
\hline 10 & .789 & .7009 & 3.36 & 2.355 & .73 & .0083 & .7973 & .7115 & 3.31 \\
\hline 11 & .847 & .7796 & 3.43 & 2. 675 & .81 & .0102 & .8572 & .7934 & 3.37 \\
\hline 12 & .906 & .8624 & 3.46 & 2.983 & .89 & .0123 & .9183 & .8795 & 3.39 \\
\hline 13 & .966 & .9494 & 3.51 & 3. 331 & .97 & .0146 & .9806 & .9716 & 3. 43 \\
\hline 14 & 1.028 & 1.0423 & 3.53 & 3.671 & 1.05 & .0171 & 1.0451 & 1.0683 & 3.44 \\
\hline 15 & 1. 083 & 1. 1271 & 3. 58 & 4.045 & 1. 14 & .0202 & 1.1032 & 1. 1584 & 3. 49 \\
\hline 16 & 1.142 & 1.2204 & 3.60 & 4.392 & 1.22 & .0231 & 1.1651 & 1. 2575 & 3.49 \\
\hline 17 & 1.195 & 1. 3063 & 3. 64 & 4. 755 & 1.30 & .0263 & 1. 2213 & 1. 3492 & 3.52 \\
\hline 18 & 1. 259 & 1.4127 & 3.66 & 5.170 & 1.39 & .0300 & 1.2890 & 1.4635 & 3.53 \\
\hline 19 & 1. 314 & 1.5063 & 3. 69 & 5. 572 & 1.48 & .0341 & 1. 3481 & 1. 5651 & 3.56 \\
\hline 20 & 1.366 & 1. 5965 & 3.72 & 5.952 & 1.55 & .0374 & 1.4034 & 1.6618 & 3.58 \\
\hline 21 & 1.424 & 1. 6992 & 3.75 & 6. 375 & 1.65 & .0423 & 1.4663 & 1.7750 & 3. 59 \\
\hline
\end{tabular}

CORNELL UNIVERSITY HYDRAULIC LABORATORY. ${ }^{a}$

This laboratory, erected in 1898, includes a reservoir formed by a masonry dam on Fall Creek, at Itbaca, N. Y. An experimental channel is supplied with water from the pond and has, as its general dimensions, length, 400 feet; breadth, 16 feet; depth, 10 feet; bottom grade, 1:500. Fall Creek drains an area of 117 square miles, and affords a minimum water supply estimated at 12 second-feet. The hydraulic laboratory is located at Triphammer Falls, where a descent of 189 feet occurs. The weirs used in the experiments here described were erected in the concrete-lined experimental channel. The water supply was regulated by wooden head-gates, operated by lever, rack, and pinion, the outflow from the canal passing over the declivity below.

$a$ In reducing the experiments at Cornell hydraulie laboratory the value of $g$ for Ithaca, latitude $42^{\circ} 27^{\prime}$, altitude 500 feet, has been taken as 32.16 , making $\sqrt{2 g}=8.02, \frac{1}{2 g}=0.015547, \frac{2}{3} V \overline{2 g}=5.35$. 
EXPERIMENTS OF UNITED STATES BOARD OF ENGINEERS ON DEEP W ATERW AYS.

These experiments were performed at Cornell University hydraulic laboratory in May and June, 1899, for the United States Board of Engineers on Deep Waterways, under the immediate direction of George W. Rafter, engineer for water supply, in conjunction with Prof. Gardner S. Williams. The results of the original computations were published in Trans. Am. Soc. C. E., vol. 44, together with an extended discussion. In the experiments a closely regulated volume of water was passed over a standard thin-edged weir which was placed near the upper end of the experimental canal and had a height of 13.13 feet and a crest length of 16 feet, end contractions suppressed. The nappe was aerated, but was not allowed to expand on downstream side. The water flowed down the experimental canal past a series of screens and baffles and over the experimental weir placed at the lower end of the channel.

The experimental weirs were about 4.5 feet high and 6.56 feet crest length. A leading channel of planed boards, 6.56 feet wide and 48 feet in length, extended upstream from the experimental weir, having at its upper end flaring sides extending 8.3 feet upstream and meeting the sides of the main channel.

The head on both weirs was read by means of open manometers connected to galvanized-iron piezometer pipes, placed horizontally across the bottom of the narrow leading channel, 37 feet upstream from the weir. At the standard weir two piezometers were used, one termed the middle piezometer, placed across the leading chanuel, 8 inches above the bottom and 10 feet upstrean from the standard weir. A second or upstream piezometer was placed 25 feet upstream from the standard weir. Readings of both piezometers were taken. It was decided, however, to use the middle piezometer as the basis of calculation of discharge over the standard weir. Near the close of the experiments it was found that this did not give results agreeing with those which would have been obtained from a piezometer placed flush with the bottom of the channel, as is shown to be necessary from the experiments of H. F. Mills ${ }^{a}$ and others. A correction curve was accordingly deduced from comparative experiments between the middle piezometer and the flush piezometer, and the readings of the middle piezometer thus corrected were applied in the Bazin formula to calculate the discharge over the standard weir for heads not exceeding the limit of Bazin's experiments. For depths on the standard weir greater than 2 feet the discharge was computed by using coefficients deduced for higher heads on a shorter experimental weir, on the basis of the Francis formula. Owing to the uncertainty as to the piezometers and

a Mills, H. F., Experiments upon piezometers used in hydraulic investigations, Boston, 1878. 


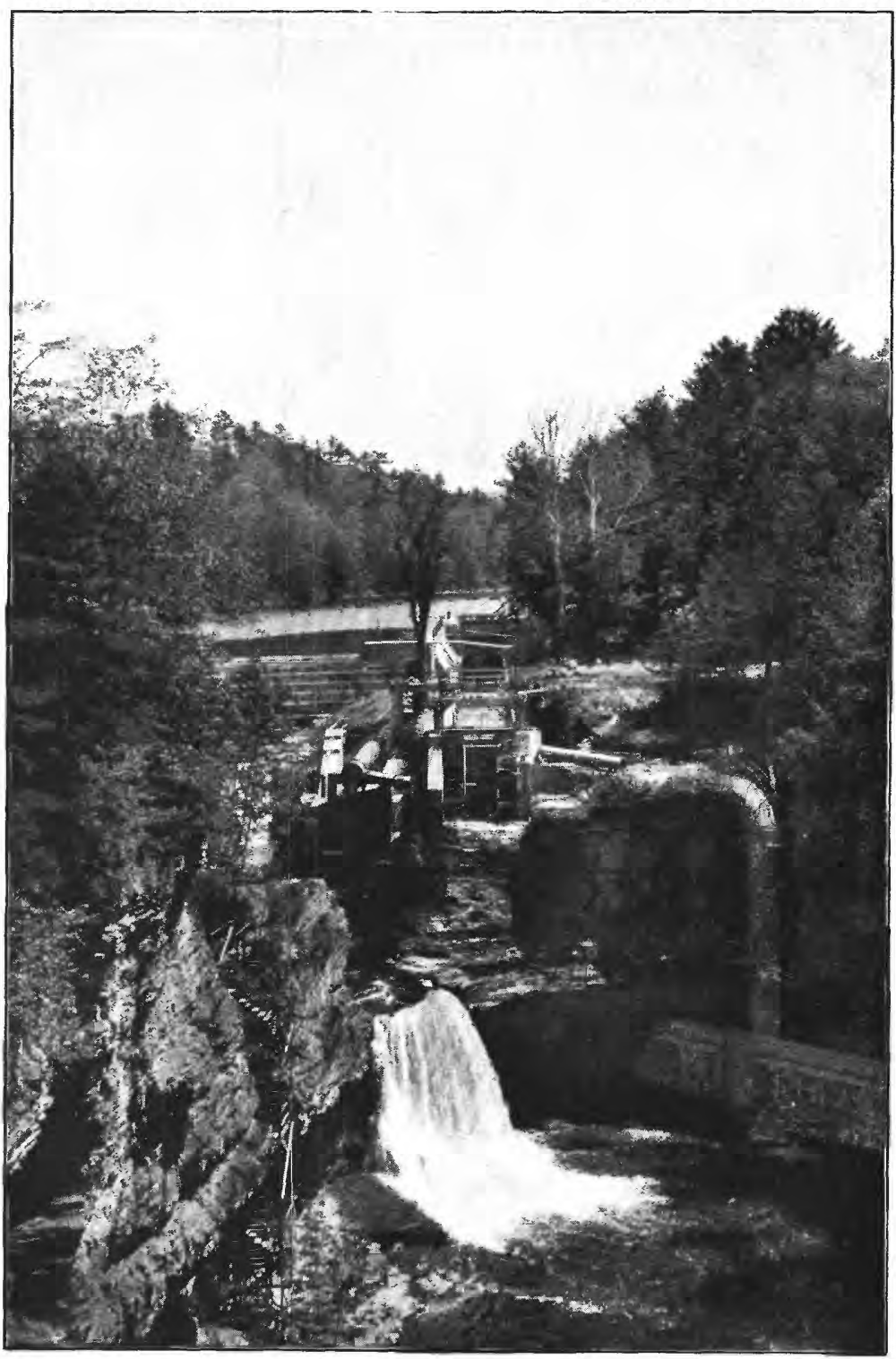

CORNELL HYDRAULIC LABORATORY, ARRANGED FOR WEIR EXPERIMENTS. 
other conditions, the original results of the experiments were credited with a possible error of 5 or 6 per cent.

In connection with the experiments on models of the Croton dam, a very thorough comparison of the so-called upstream piezometer with other methods of obtaining the head on a standard weir was made by Professor Williams. It was found that the upstream piezometer gave the actual head on the standard weir correctly. These results were communicated to the writer, and a recomputation of the Deep Waterways experiments has been made, using readings of the upstream piezometer to calculate the standard weir discharge by Bazin's formula. This method of calculation eliminates the necessity for correcting the piezometer readings at the standard weir, as was necessary in the previous reductions. The discharge over the experimental weir has been calculated from readings of a piezometer placed 38 feet upstream from the weir and 8 inches above channel bottom, corrected to the basis of a flush piezometer.

The United States Deep Waterways experiments included, for each experimental model, a smaller number of heads or periods than either the Croton or United States Geological Survey experiments. They were also the first experiments of the kind conducted at the Cornell laboratory, and the experience gained has probably contributed to the securing of somewhat greater accuracy in the later experiments. It is believed, however, that, as recomputed, the United States Deep Waterways experiments do not differ much in accuracy from those made on models of the Croton dam, which are stated by John R. Freeman to be reliable within about 2 per cent. The coefficients obtained by recomputation, when compared with the original United States Deep Waterways coefficient, show few differences exceeding 2 per cent. The variations are plus and minus in about equal numbers, and it is believed that these experiments are entitled to grèater weight than they have hitherto received.

In the accompanying tables a summary of the recomputation is given.

IRR $150-06-8$ 
Recomputation of Inited States Ileep Waterways Board experiments on flow of water over model dams, Cornell Lnicersity hydraulic laboratory, 1899.

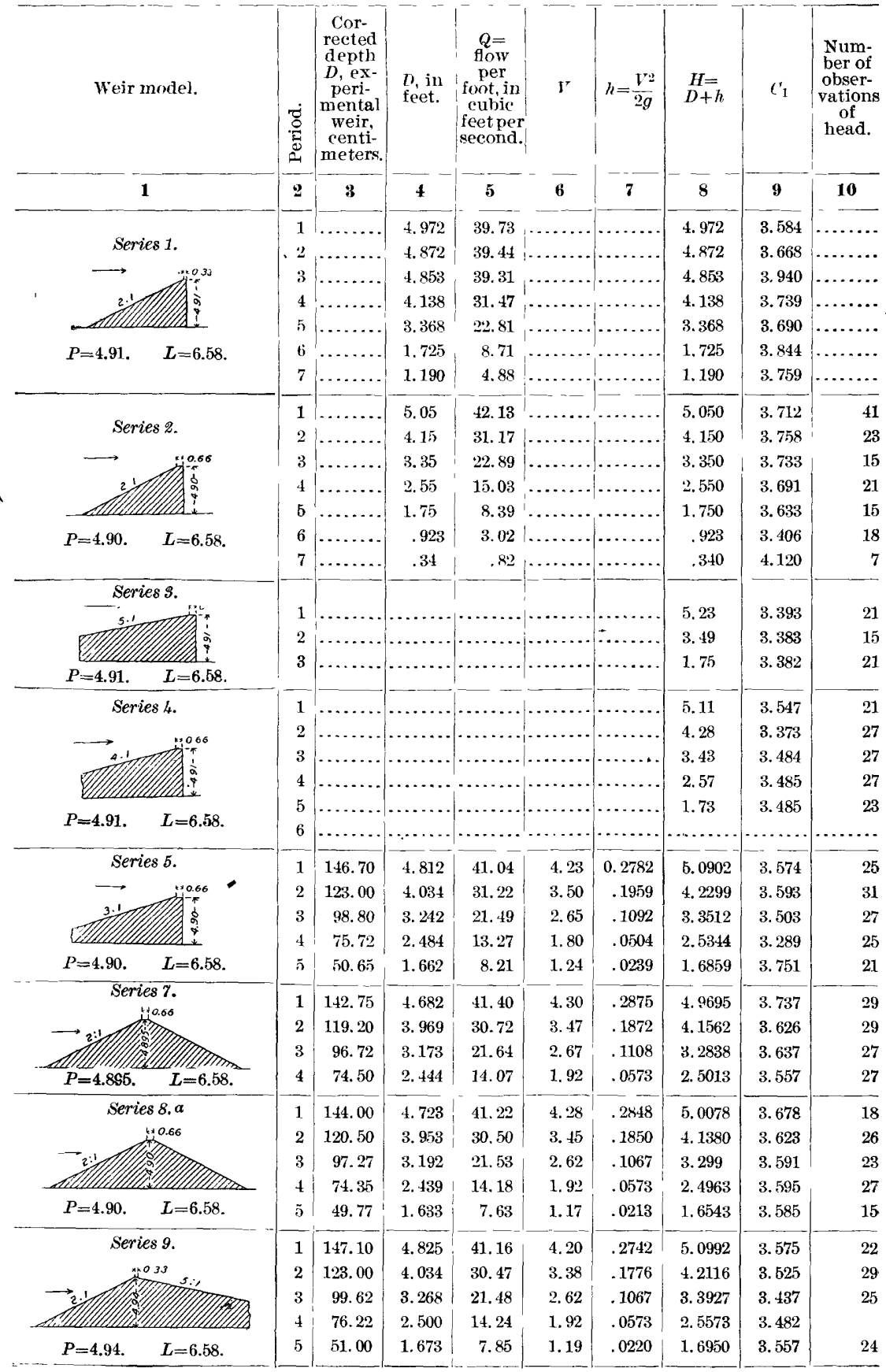

a same as series 7, but upstream face covered with $\frac{1}{4}$-inch mesh galvanized wire netting. 
Recomputation of United States Deep Waterways Board experiments on flow of water over model dams, Cornell University hydraulic laboratory, 1899-Continued.

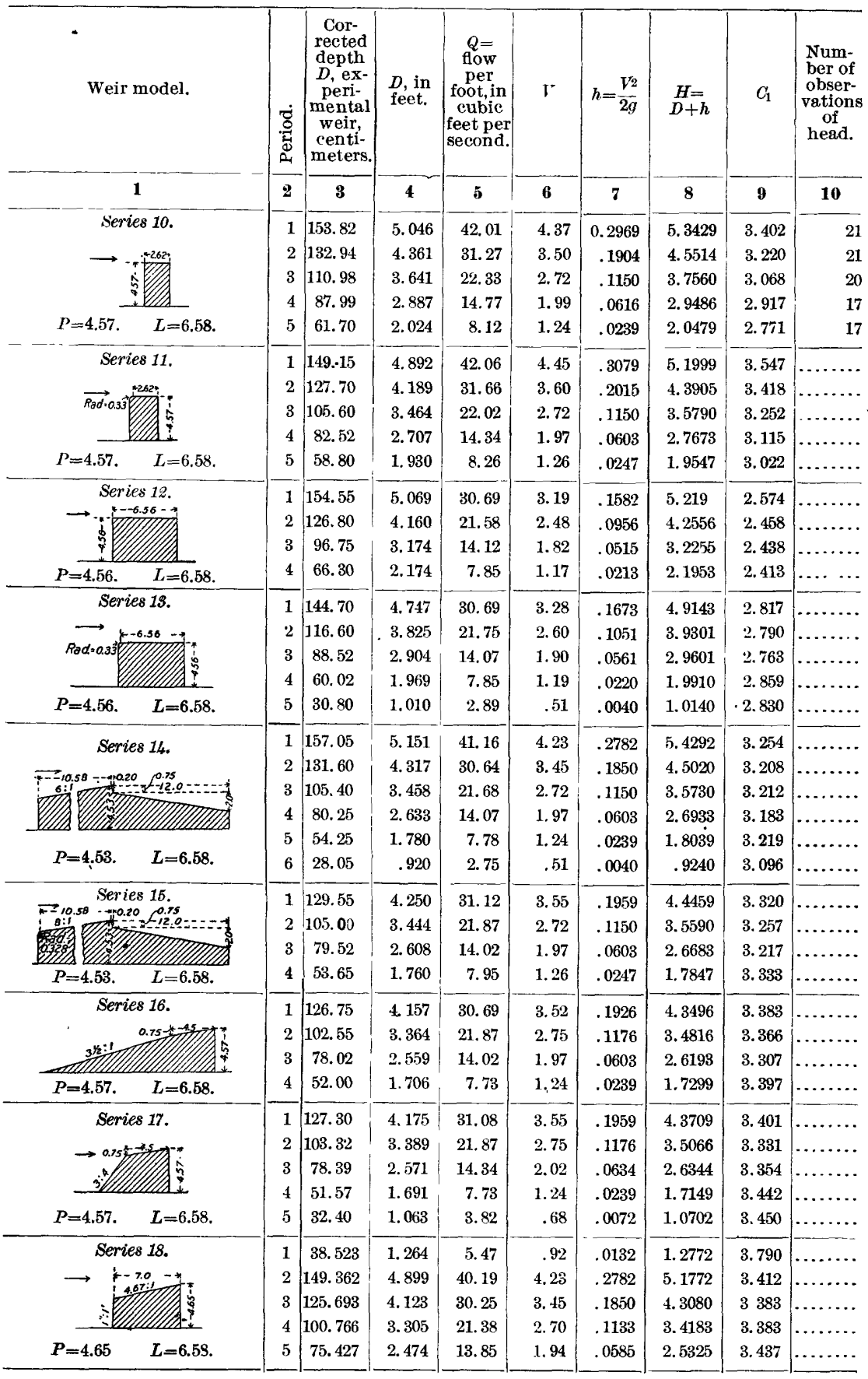


Recomputation of Inited States Deep Waterways Board experiments on flow of water over model dams, Cornell University hydraulic laboratory, 1899-Continued.

\begin{tabular}{|c|c|c|c|c|c|c|c|c|c|}
\hline Weir model. & 总 & $\begin{array}{c}\text { Cor- } \\
\text { rected } \\
\text { depth } \\
D \text {, ex- } \\
\text { peri- } \\
\text { mental } \\
\text { weir, } \\
\text { centi- } \\
\text { meters. }\end{array}$ & $\begin{array}{l}D \text {, in } \\
\text { feet. }\end{array}$ & $\begin{array}{c}Q= \\
\text { flow } \\
\text { per } \\
\text { foot, in } \\
\text { cubic } \\
\text { feet per } \\
\text { second. }\end{array}$ & $V$ & $h=\frac{V^{2}}{2 g}$ & $\begin{array}{l}H= \\
D+h\end{array}$ & $C_{1}$ & $\begin{array}{l}\text { Num- } \\
\text { ber of } \\
\text { obser- } \\
\text { vations } \\
\text { of } \\
\text { head. }\end{array}$ \\
\hline 1 & $\mathbf{2}$ & 3 & 4 & 5 & 6 & 7 & 8 & 9 & 10 \\
\hline & 1 & 27.04 & 0.8869 & 2. 75 & 0.44 & 0.0030 & 0.8899 & 3.276 & \\
\hline Series 19. & 2 & 51.36 & 1.685 & 7. 46 & 1. 07 & .0178 & 1. 7028 & 3.357 & \\
\hline $\overrightarrow{x-\frac{1}{1.0}}--10 p x^{1.04}$ & 3 & 142.128 & 4.662 & 40.04 & 4.20 & .2742 & 4.9362 & 3.651 & $\ldots \ldots$ \\
\hline $30^{\circ}$ & 4 & 119.442 & 3.918 & 29.62 & 3. 23 & .1622 & 4.0802 & 3.594 & $\cdots$ \\
\hline & 5 & 97.858 & 3.210 & 20.78 & 2.45 & .0933 & 3. 3033 & 3.461 & $\cdots$ \\
\hline \multirow{2}{*}{$P=5.28 . \quad L=6.58}$. & 6 & 77.246 & 2.534 & 14.17 & 1.82 & .0515 & 2.5855 & 3.401 & .......... \\
\hline & 7 & 53.42 & 1. 752 & 7.68 & 1.09 & .0185 & 1.7705 & 3. 260 & $\cdots$ \\
\hline
\end{tabular}

Column 5 shows the discharge over the experimental weir per foot of crest, deduced from the readings of the upstream piezometer at the standard weir, by Bazin's formula, and corrected for slight leakage.

Column 3 shows the head on the experimental weir, in centimeters, taken by a piezometer 38 feet upstream and 8 inches above channel bottom, corrected to reduce it to the equivalent reading of the flush piezometer.

Column 4 shows the equivalent head in feet.

Column 6 shows the absolute velocity of approach.

Column 7 shows the velocity head.

Column 8 shows the head corrected for velocity of approach; the correction being made by the simple addition of the velocity head to the measured head, which is assumed to be a sufficiently precise equivalent to the Francis correction formula for this purpose.

Column 9 gives the coefficient $C_{1}$, deduced from the foregoing.

The resulting coefficient diagrams are shown on Pls. XV to XVIII, inclusive.

EXPERIMENTS AT CORNELL UNIVERSITY HYDRAULIC LABORATORY ON MODELS OF OLD CROTON DAM. ${ }^{a}$

These experiments were made in November and December, 1899, by Prof. Gardner S. Williams, under the direction of John R. Freeman. The standard weir used was located near the head of the experimental canal, water being admitted and regulated by head-gates in the usual manner. The standard weir was 11.25 feet high and 16 feet long on the crest. The experimental weir was placed 232.5 feet farther downstream, and also occupied the full width of the experimental canal. The models of the Croton dam were constructed of framed timber and were 6 to 9 feet high. 
Coeffi-

cient
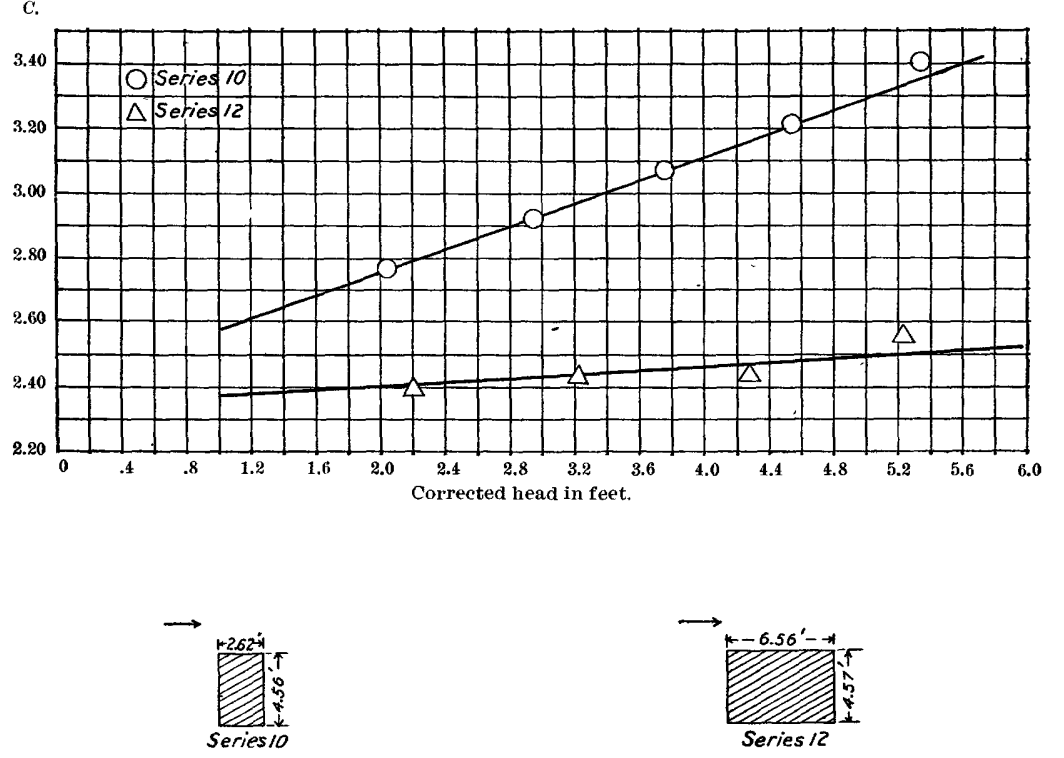

Coeff-
cient
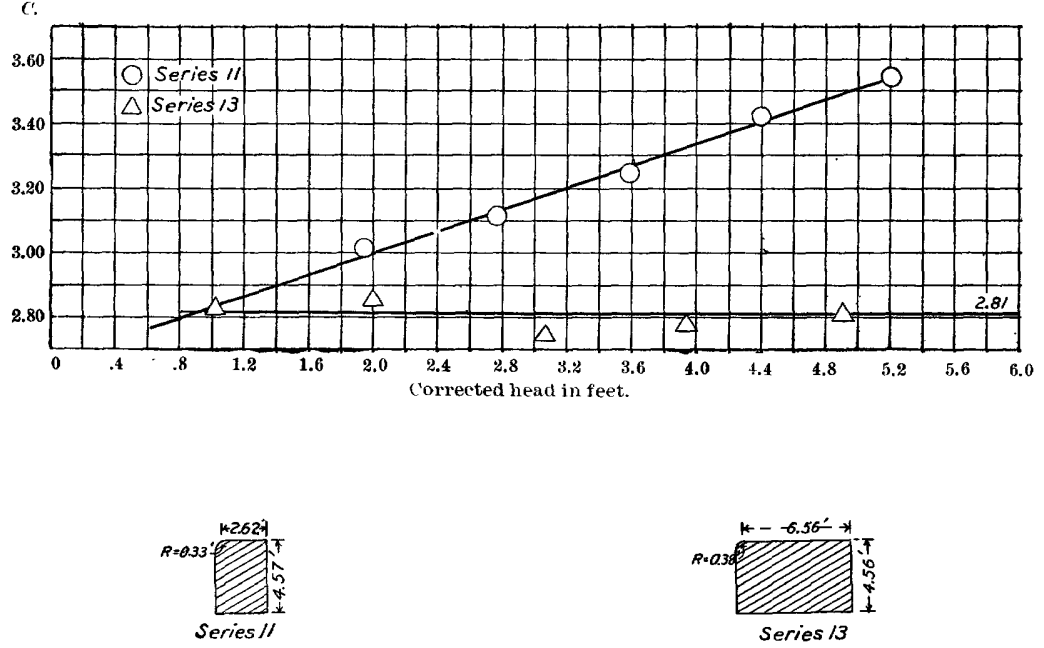

EXPERIMENTS OF UNITED STATES DEEP WATERWAYS BOARD AT CORNELL UNIVERSITY, 1899. 


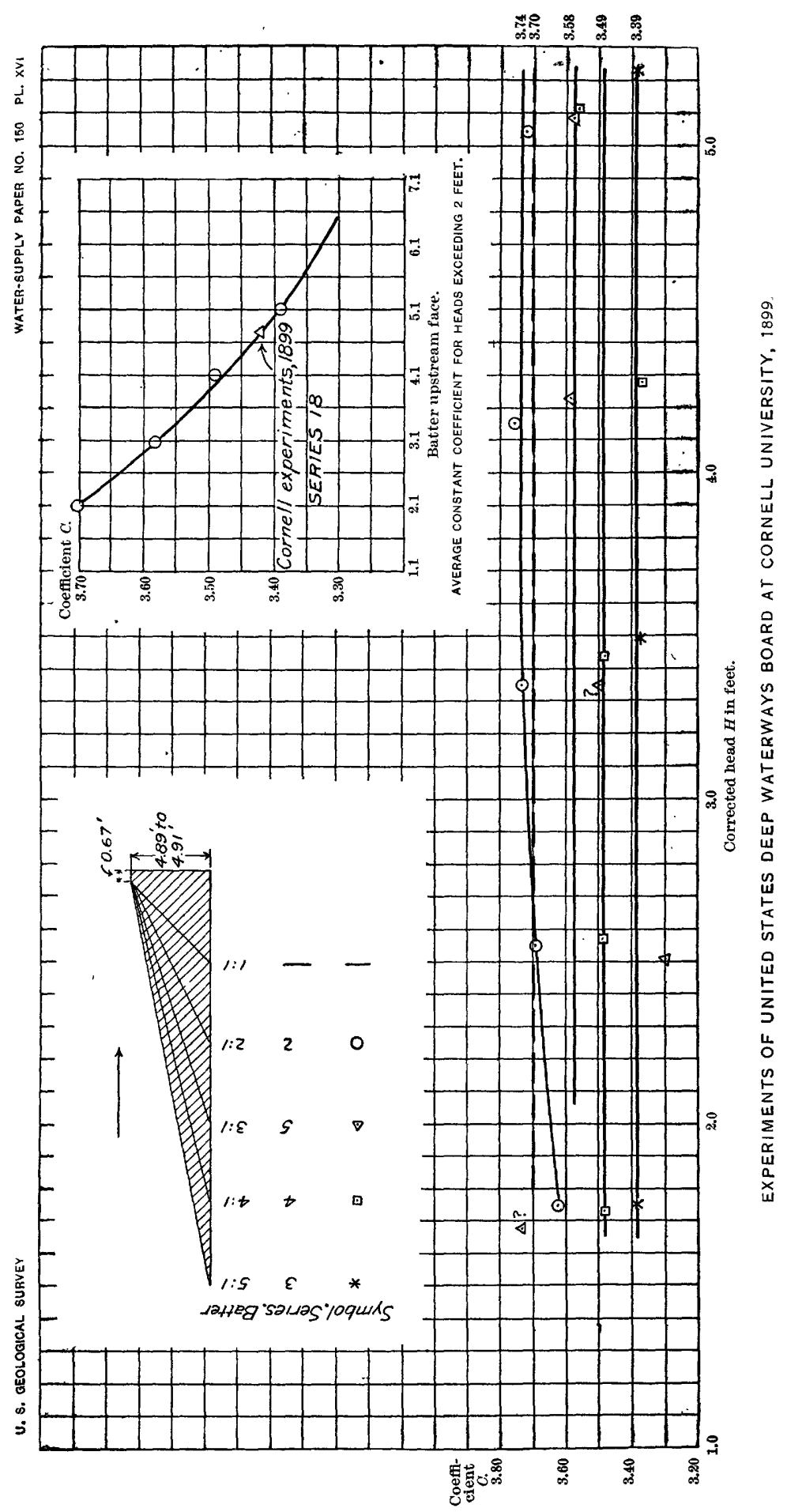



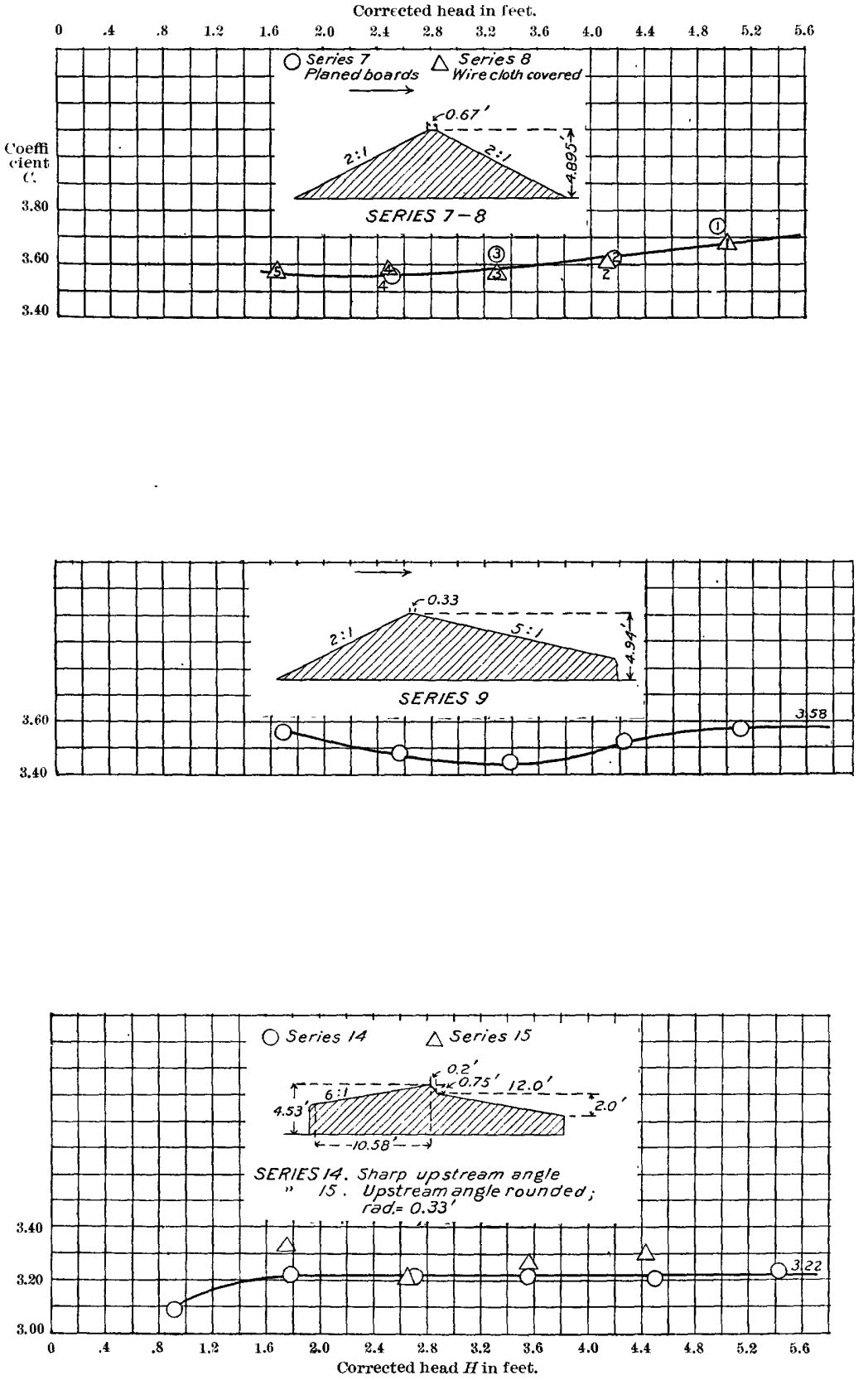

EXPERIMENTS OF UNITED STATES DEEP WATERWAYS BOARD AT CORNELL UNIVERSITY, 1899. 


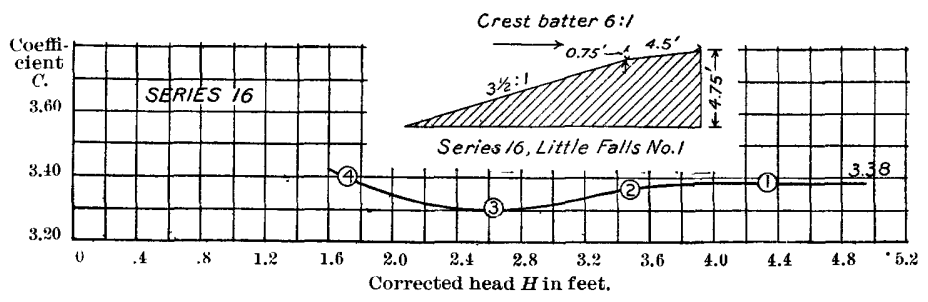

\section{Crest batter 6:l}
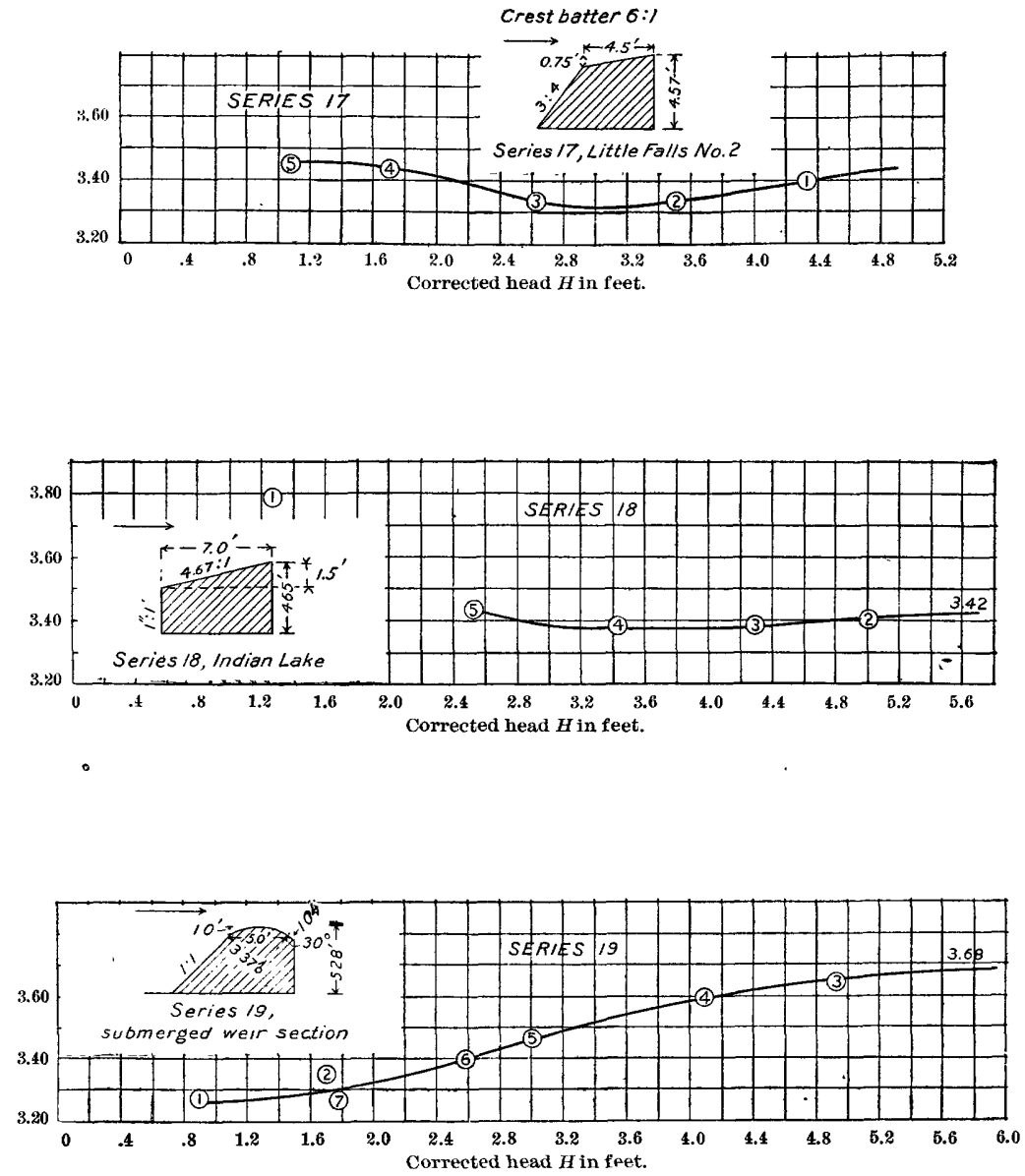

EXPERIMENTS OF UNITED STATES DEEP WATERWAYS BOARD AT CORNELL UNIVERSITY, 1899. 
The head on the weirs was measured by means of open glass manometers connected to piezometer tubes in the channel above each weir. The piezometer tubes were made of 1-inch galvanized-iron pipe with small holes drilled along the sides, the ends being plugged. At the standard weir three piezometers were used, placed parallel to the current, at about mid-depth of the channel, one being near each side and one at mid-width of the channel, the mid-length of the pipes being 26.5 feet upstream from the standard weir. A hook gage in the same section was used to check the observed head.

Experiments on volume of flow over models of old Croton dam, Cornell University hydraulic laboratory, 1899.

\begin{tabular}{|c|c|c|c|c|c|c|c|}
\hline & $\begin{array}{c}\text { Period } \\
\text { No. }\end{array}$ & $\begin{array}{l}\text { Ob. } \\
\text { served } \\
\text { depth } \\
\text { on } \\
\text { model } \\
\text { dam, } \\
\text { in feet. }\end{array}$ & $\begin{array}{c}\text { Mean } \\
\text { veloc- } \\
\text { ity of } \\
\text { ap- } \\
\text { proach, } \\
\text { in feet } \\
\text { per } \\
\text { pecond. }\end{array}$ & $\begin{array}{l}\text { Correc- } \\
\text { tion } \\
\text { for } \\
\text { veloc- } \\
\text { ity of } \\
\text { ap- } \\
\text { proach, } \\
\text { in feet. }\end{array}$ & $\begin{array}{l}\text { Cor- } \\
\text { rected } \\
\text { head } \\
\text { on } \\
\text { model } \\
\text { dam, } \\
\text { in feet. }\end{array}$ & $\begin{array}{c}\text { Dis- } \\
\text { charge } \\
\text { over } \\
\text { model } \\
\text { dam } \\
\text { per } \\
\text { foot of } \\
\text { length, } \\
\text { in cu- } \\
\text { bic feet } \\
\text { per sec- } \\
\text { ond. }\end{array}$ & $C_{1}$ \\
\hline 1 & 2 & 3 & $t$ & 5 & 6 & 7 & 8 \\
\hline \multirow{6}{*}{$\begin{array}{l}\text { Round crest, old Croton dam, smooth pine, } \\
\text { crest and slope } 16 \text { feet long. Nov. } 28-29 \text {, } \\
1899 .\end{array}$} & 1 & 2. 7229 & 1.685 & 0.0439 & 2. 7668 & 14. 762 & 3. 208 \\
\hline & 2 & 2.1857 & 1. 283 & .0259 & 2. 2116 & 10. 562 & 3. 211 \\
\hline & 3 & 1. 4388 & .749 & .0087 & 1. 4475 & 5.604 & 3.218 \\
\hline & 4 & .9830 & .449 & .0031 & .9861 & 3. 154 & 3.222 \\
\hline & 5 & .5907 & .219 & .0008 & .5915 & 1. 451 & 3.190 \\
\hline & 6 & .1230 & .024 & .0000 & .1230 & .147 & 3. 408 \\
\hline \multirow{7}{*}{$\begin{array}{l}\text { Series 1a-Model A. } \\
\text { ound crest, old Croton dam, unplaned } \\
\text { plank, crest } 16 \text { feet long, smooth slope. } \\
\text { Nov. 6, 1899. }\end{array}$} & 1 & 2.0897 & .978 & .0149 & 2.1046 & 9.578 & 3.137 \\
\hline & 2 & 1.8293 & .810 & .0102 & 1.8395 & 7.883 & 3.160 \\
\hline & 3 & 1.5878 & .661 & .0068 & 1.5946 & 6.284 & 3.121 \\
\hline & 4 & 1. 2562 & .467 & .0034 & 1. 2596 & 4. 287 & 3. 032 \\
\hline & 5 & .9929 & .338 & .0018 & .9947 & 3.006 & 3.030 \\
\hline & 6 & .6301 & .175 & .0004 & .6305 & 1.494 & 2.988 \\
\hline & 7 & .4871 & .111 & .0002 & .4873 & .991 & 2.913 \\
\hline \multirow{9}{*}{$\begin{array}{l}\text { Round erest, old Croton dam, } 16 \text {-foot smooth } \\
\text { crest, rough slope formed of cleats and } \\
\text { stone to simulate concrete and riprap. Dec. } \\
\text { 4, } 1899 \text {. }\end{array}$} & 1 & 2.9227 & 1. 839 & .0526 & 2.9753 & 16. 175 & 3. 240 \\
\hline & 2 & 2.8591 & 1.794 & .0500 & 2.9091 & 15.969 & 3. 218 \\
\hline & 3 & 2.4948 & 1.516 & .0357 & 2.5305 & 12.933 & 3. 213 \\
\hline & 4 & 2.1420 & 1.248 & .0241 & 2.1661 & 10.211 & 3. 203 \\
\hline & 5 & 1. 6238 & .880 & .0120 & 1. 6358 & 6.740 & 3.222 \\
\hline & 6 & 1.2597 & .623 & .0060 & 1. 2657 & 4. 548 & 3. 194 \\
\hline & 7 & 1.1419 & .545 & .0046 & 1.1465 & 3.913 & 3. 188 \\
\hline & 8 & .7196 & .288 & .0013 & .7209 & 1.945 & 3.178 \\
\hline & 9 & .4873 & .166 & .0004 & .4877 & 1. 087 & 3. 192 \\
\hline \multirow{5}{*}{$\begin{array}{l}\text { Round crest, old Croton dam, } 16 \text {-foot crest, } \\
\text { covered with wire cloth of No. } 18 \text { wire, } \\
\frac{1}{4} \text {-inch mesh, a rough slope, as in series } 2 . \\
\text { Nov. } 28,1899 .\end{array}$} & 1 & 2.0030 & 1.124 & .0197 & 2.0187 & 9.037 & 3.148 \\
\hline & 2 & 1. 4091 & .712 & . .0078 & 1. 4129 & 5. 308 & 3.161 \\
\hline & 3 & .8675 & .366 & .0021 & .8656 & 2.527 & 3. $13 \mathrm{~s}$ \\
\hline & 4 & .4288 & .133 & .0003 & .4251 & .861 & 3. 099 \\
\hline & 5 & .1184 & .020 & .0000 & .1144 & .124 & 3.205 \\
\hline
\end{tabular}

a In experiments with wire cloth over crest, 0.004 foot is deducted from observed depth to compensate for thickness of wire. 
Experiments on volume of flow ocer models of old Croton dam, Cornell University hydraulic taboratory, 1899-Continued.

\begin{tabular}{|c|c|c|c|c|c|c|c|}
\hline . & $\begin{array}{c}\text { Period } \\
\text { No. }\end{array}$ & $\begin{array}{c}\text { Ob- } \\
\text { served } \\
\text { depth } \\
\text { on } \\
\text { model } \\
\text { dam, } \\
\text { in feet. }\end{array}$ & $\begin{array}{l}\text { Mean } \\
\text { veloc- } \\
\text { ity of } \\
\text { ap- } \\
\text { proach, } \\
\text { in feet } \\
\text { per } \\
\text { second. }\end{array}$ & $\begin{array}{l}\text { Correc- } \\
\text { tion } \\
\text { for } \\
\text { veloc- } \\
\text { ity of } \\
\text { ap- } \\
\text { proach, } \\
\text { in feet. }\end{array}$ & $\begin{array}{c}\text { Cor- } \\
\text { rected } \\
\text { head } \\
\text { on } \\
\text { model } \\
\text { dam, } \\
\text { in feet. }\end{array}$ & $\begin{array}{c}\text { Dis- } \\
\text { charge } \\
\text { over } \\
\text { model } \\
\text { dam } \\
\text { per } \\
\text { foot of } \\
\text { length, } \\
\text { in cubic } \\
\text { feet per } \\
\text { second. }\end{array}$ & $c_{1}$ \\
\hline . & 2 & 3 & 4 & 5 & 6 & 7 & 8 \\
\hline $\begin{array}{l}\qquad \text { Series } 1-\text { Hodel } B \text {. } \\
\text { Angular crest, old Croton dam, } 16 \text {-foot crest, } \\
\text { all unplaned plank. Nov. } 15,1899 \text {. }\end{array}$ & $\begin{array}{l}1 \\
2 \\
3 \\
4 \\
5\end{array}$ & $\begin{array}{r}1.8635 \\
.9246 \\
.6419 \\
.3481 \\
.1787\end{array}$ & $\begin{array}{r}0.973 \\
.370 \\
.219 \\
.090 \\
.034\end{array}$ & $\begin{array}{r}0.0147 \\
.0021 \\
.0008 \\
.0001 \\
.0000\end{array}$ & $\begin{array}{r}1.8782 \\
.9267 \\
.6427 \\
.3482 \\
.1787\end{array}$ & $\begin{array}{r}9.506 \\
3.272 \\
1.870 \\
.741 \\
.272\end{array}$ & $\begin{array}{l}3.693 \\
3.668 \\
3.630 \\
3.606 \\
3.601\end{array}$ \\
\hline $\begin{array}{l}\qquad \text { Series } 2-\text { Model B. } \\
\text { Angular crest, old Croton dam, 16-foot 11n- } \\
\text { planed plank, crest slope roughened with } \\
\text { cleats and stone. Nov, } 28,1899 \text {. }\end{array}$ & $\begin{array}{l}1 \\
2 \\
3 \\
4 \\
5 \\
6\end{array}$ & $\begin{array}{r}2.4126 \\
1.5251 \\
.9611 \\
.5157 \\
.3051 \\
.0890\end{array}$ & $\begin{array}{r}1.298 \\
.736 \\
.391 \\
.162 \\
.077 \\
.012\end{array}$ & $\begin{array}{l}.0262 \\
.0084 \\
.0024 \\
.0004 \\
.0001 \\
.0000\end{array}$ & $\begin{array}{r}2.4388 \\
1.5335 \\
.9685 \\
.5161 \\
.3052 \\
.0890\end{array}$ & $\begin{array}{r}13.478 \\
6.945 \\
3.466 \\
1.369 \\
.631 \\
.094\end{array}$ & $\begin{array}{l}3.539 \\
3.667 \\
3.665 \\
3.692 \\
3.742 \\
3.540\end{array}$ \\
\hline $\begin{array}{c}\text { Series } 2 \text {-Continued model } B . \\
\text { Conditions as in preceding. Nov. } 16,1899 .\end{array}$ & $\begin{array}{l}1 \\
2 \\
3 \\
4 \\
5\end{array}$ & $\begin{array}{r}1.8930 \\
.9605 \\
.7028 \\
.3941 \\
.1952\end{array}$ & $\begin{array}{l}.988 \\
.391 \\
.251 \\
.108 \\
.039\end{array}$ & $\begin{array}{l}.0151 \\
.0024 \\
.0010 \\
.0002 \\
.0000\end{array}$ & $\begin{array}{r}1.9081 \\
.9629 \\
.7038 \\
.3943 \\
.1952\end{array}$ & $\begin{array}{r}9.683 \\
3.465 \\
2.165 \\
.900 \\
.314\end{array}$ & $\begin{array}{l}\text { 3. } 674 \\
3.667 \\
\text { 3. } 667 \\
\text { 3. } 635 \\
\text { 3. } 641\end{array}$ \\
\hline $\begin{array}{l}\text { Series } 3-\text { Hodel } B \text {. } \\
\text { Angular erest, old Croton dam, wire eloth on } \\
\text { crest, rough slope. Nov. } 16,1899 .\end{array}$ & $\begin{array}{l}1 \\
2 \\
3 \\
4\end{array}$ & $\begin{array}{r}2.0053 \\
.9787 \\
.7391 \\
.1785\end{array}$ & $\begin{array}{r}1.047 \\
.389 \\
.259 \\
.032\end{array}$ & $\begin{array}{l}.0170 \\
.0024 \\
.0011 \\
.0000\end{array}$ & $\begin{array}{r}a 2.0183 \\
.9771 \\
.7362 \\
.1745\end{array}$ & $\begin{array}{r}10.385 \\
3.463 \\
2.241 \\
.260\end{array}$ & $\begin{array}{l}3.622 \\
3.586 \\
3.548 \\
3.567\end{array}$ \\
\hline $\begin{array}{l}\text { Series } 1-\text { Model } C \text {. } \\
\text { Round erest, old Croton dam, 12-inch timber } \\
\text { on crest, } 16 \text { feet long, rough slope. Dec. } \\
1,1899 .\end{array}$ & $\begin{array}{l}4 \\
5 \\
6 \\
7 \\
8\end{array}$ & $\begin{array}{r}1.9941 \\
1.1817 \\
.8832 \\
.6873 \\
.4986 \\
.2992 \\
.1177 \\
.0846\end{array}$ & $\begin{array}{r}1.097 \\
.512 \\
.328 \\
.222 \\
.141 \\
.071 \\
.019 \\
.009\end{array}$ & $\begin{array}{l}.0187 \\
.0010 \\
.0017 \\
.0008 \\
.0003 \\
.0001 \\
.0000 \\
.0000\end{array}$ & $\begin{array}{r}2.0128 \\
1.1857 \\
.8849 \\
.6881 \\
.4989 \\
.2993 \\
.1177 \\
.0846\end{array}$ & $\begin{array}{r}9.904 \\
4.211 \\
2.594 \\
1.722 \\
1.065 \\
.522 \\
.139 \\
.067\end{array}$ & $\begin{array}{l}3.468 \\
3.262 \\
3.116 \\
3.017 \\
3.022 \\
3.188 \\
3.450 \\
2.723\end{array}$ \\
\hline $\begin{array}{l}\text { Scries } 1-\text { Continued moclel } C: \\
\text { Conditions as in preceding. Dec. } 4,1899 \text {. }\end{array}$ & $\begin{array}{l}1 \\
2 \\
3 \\
4 \\
5\end{array}$ & $\begin{array}{r}2.7146 \\
2.4519 \\
1.5566 \\
1.1046 \\
.1070\end{array}$ & $\begin{array}{r}1.632 \\
1.436 \\
.774 \\
.016 \\
.0165\end{array}$ & $\begin{array}{l}.0414 \\
.0320 \\
.0093 \\
.0000 \\
.0000\end{array}$ & $\begin{array}{r}2.7560 \\
2.4839 \\
1.5659 \\
.1046 \\
.1070\end{array}$ & $\begin{array}{r}15.917 \\
13.629 \\
6.660 \\
.112 \\
.118\end{array}$ & $\begin{array}{l}3.479 \\
3.482 \\
3.399 \\
3.311 \\
3.371\end{array}$ \\
\hline $\begin{array}{l}\text { Series } 1-\text { Model } D \text {. } \\
\text { Angular crest, old Croton dam, 12-inch tim- } \\
\text { ber, on } 16 \text {-foot crest, rough slope. Nov. } 16 \text {, } \\
\text { 1899. }\end{array}$ & $\begin{array}{l}1 \\
2 \\
3\end{array}$ & $\begin{array}{r}1.2390 \\
.7885 \\
.4448\end{array}$ & $\begin{array}{l}.495 \\
.249 \\
.113\end{array}$ & $\begin{array}{l}.0038 \\
.0010 \\
.0002\end{array}$ & $\begin{array}{r}1.2428 \\
.7895 \\
.4450\end{array}$ & $\begin{array}{l}5.026 \\
2.415 \\
1.054\end{array}$ & $\begin{array}{l}3.628 \\
3.443 \\
3.551\end{array}$ \\
\hline
\end{tabular}

$a$ In experiments with wire cloth over crest, 0.004 foot is deducted from observed depth to com. pensate for thickness of wire. 
Experiments on volume of flow over models of old Croton dam, Cornell University hydraulic laboratory, 1899-Continued.

\begin{tabular}{|c|c|c|c|c|c|c|c|}
\hline • & $\begin{array}{l}\text { Period } \\
\text { No. }\end{array}$ & $\begin{array}{l}\text { Ob- } \\
\text { served } \\
\text { depth } \\
\text { on } \\
\text { model } \\
\text { dam, } \\
\text { in feet. }\end{array}$ & $\begin{array}{l}\text { Mean } \\
\text { veloc- } \\
\text { ity of } \\
\text { ap- } \\
\text { proach, } \\
\text { in feet } \\
\text { per } \\
\text { second. }\end{array}$ & $\left\{\begin{array}{c}\text { Correc- } \\
\text { tion } \\
\text { for } \\
\text { veloc- } \\
\text { ity of } \\
\text { ap- } \\
\text { proach, } \\
\text { in feet. }\end{array}\right.$ & $\begin{array}{c}\text { Cor- } \\
\text { rected } \\
\text { head } \\
\text { on } \\
\text { model } \\
\text { dam, } \\
\text { in feet. }\end{array}$ & \begin{tabular}{|c|} 
Dis- \\
charge \\
over \\
model \\
dam \\
per \\
foot of \\
length \\
incubic \\
feet per \\
second.
\end{tabular} & $c_{1}$ \\
\hline 1 & 2 & $\mathbf{3}$ & 4 & 5 & 6 & 7 & 8 \\
\hline \multirow{8}{*}{$\begin{array}{l}\text { 16-foot angular crest, old Croton dam, with- } \\
\text { out timber, but with obstructed channel, } \\
\text { with sharp contraction. Nov. } 18,1899 \text {. }\end{array}$} & 1 & 2.3051 & 1. 154 & 0.0207 & 2.3258 & 11. 778 & 3.321 \\
\hline & 2 & 1.8125 & .845 & .0111 & 1.8236 & 8.214 & 3.336 \\
\hline & 3 & 1. 2278 & .507 & .0040 & 1. 2318 & 4. 632 & 3. 388 \\
\hline & 4 & .8598 & .313 & .0015 & .8613 & 2.744 & 3.433 \\
\hline & $\bar{b}$ & .5745 & .179 & .0005 & .5750 & 1.516 & 3.477 \\
\hline & 6 & .3245 & .078 & .0001 & .3246 & .641 & 3.466 \\
\hline & 7 & .1120 & .017 & .0000 & .1120 & .133 & 3. 548 \\
\hline & 8 & .1102 & .017 & .0000 & .1102 & .140 & 3.827 \\
\hline & 1 & 1. 4569 & .636 & .0063 & 1. 4632 & 5.957 & 3.366 \\
\hline & 2 & .9168 & .338 & .0018 & .9186 & 2.982 & 3. 387 \\
\hline Series 1-Model E, repeated. & 3 & .6866 & .237 & .0009 & .6875 & 2.037 & 3.573 \\
\hline Conditions as in preceding. & 4 & .4820 & .148 & .0003 & .4823 & 1.240 & 3. 702 \\
\hline 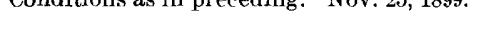 & 5 & .2811 & .071 & .0001 & .2812 & .579 & 3.883 \\
\hline & 6 & .1416 & .028 & .0000 & .1416 & .226 & 4.203 \\
\hline & 1 & 2.2927 & 1. 139 & .0202 & 2.3129 & a11. 613 & 3.302 \\
\hline Series 2-Model $E$. & 2 & 2. 2914 & 1.138 & .0202 & 2.3116 & $b 11.606$ & 3. 302 \\
\hline 1 & 3 & 1.1395 & .473 & .0034 & 1. 1429 & 4.278 & 3. 501 \\
\hline Angular erest, old Croton dam, 16 feet long & 4 & 1. 1403 & .453 & .0031 & 1.1434 & a 4.097 & 3.351 \\
\hline without timber, and with slope instead of & 5 & 1. 1006 & .448 & .0031 & 1. 1037 & b4. 034 & 3.479 \\
\hline sharp edge to upstream end of obstruction. & 6 & 1.1099 & .457 & .0032 & 1.1131 & 4.119 & 3.507 \\
\hline Nov. 27, 1899. & 7 & .4763 & .141 & .0003 & .4766 & 1. 180 & 3.586 \\
\hline & 8 & .0233 & .031 & .0000 & .0233 & .025 & 7.029 \\
\hline
\end{tabular}

a Trap open.

$b_{\text {Trap closed. }}$

At the experimental weir two similar piezometers, each about one third of the width of the channel from the side, were used. Owing to the long back slope of some of the model dams, the head was measured 69.75 feet upstream from, the crest of the experimental weirs. Readings of all the piezometers were taken at half-minute intervals, two and sometimes three observers working at each weir. The mean of ten to twenty observations was used to determine the head for each period in the experiment. Freeman states that he considers the results of these experiments for heads up to 2.5 feet, including all sources of errors, as certainly correct within 2 per cent, and probably much closer. In reducing the experiments, the head on the experimental weir is corrected by a method comparable with that of Francis. Freeman does not give the resulting coefficients for the weir formula, but presents the results in the form of diagrams showing the discharge per foot of crest for the various models. In the accompanying tables the computations have been carried out to 
show the coefficients, some errors in the original data having been omitted.

Column 3 shows the observed head on the experimental dam, in feet.

Column 7 shows the computed discharge over the experimental dam, per foot of crest. This was deternined by calculating the discharge over the standard weir by means of both the Francis and Bazin formulas, the mean of the two having been used. The result corrected for slight leakage, divided by 16 (the length in feet of the experimental weir model), appears in column 7 .

Columns 4 and 5 show the velocity of approach and the corresponding velocity head at the experimental weir. The velocity of approach correction was made by adding directly the velocity head as given to the observed depth on the model dam, this being considered a sufficiently close approximation to the Francis method of correction.

Columns 1 to 7 are taken from the original computations. The coefficient $C_{1}$ has been computed from the data in columns 6 and 7 by the formula

$$
C_{1}=\frac{Q}{H^{\frac{3}{2}}} .
$$

Pls. XIX to XXII show the resulting coefficients applicable in the formula here adopted,

$$
Q=U_{1} L H^{\frac{3}{2}},
$$

correction for velocity of approach being made by the Francis correction formula or an equivalent method.

These experiments were performed for the specific purpose of determining the discharge over the old Croton dam. They include two main groups: (1) Experiments on round-crested portion of the dam; (2) experiments on the angular-crested portion of the dam. Each group includes series of experiments on: $(a)$ Model of smoothplaned pine; $(b)$ model of unplaned plank; $(c)$ model with cleats and fragments of stone on the upstream slope to simulate the natural back filling; $(d)$ model with rough slope and with $\frac{1}{4}$-inch-mesh wire cloth on crest to simulate cut stone; (e) model surmounted by 12-inch-square timber on crest. Experiments were added with a construction to simulate a natural rock ledge lying upstream from the angular portion of the dam.

The experiments were abbreviated owing to lateness of season and trouble from air in the gage pipes.

The value of the results is limited by the narrow range of heads covered. The models were of unusual forms, and show some peculiar differences when an attempt is made to compare the results with those of other weirs of similar slopes. The data are of value as showing the effect of various degrees of roughness on the discharge. 
Coeffi-

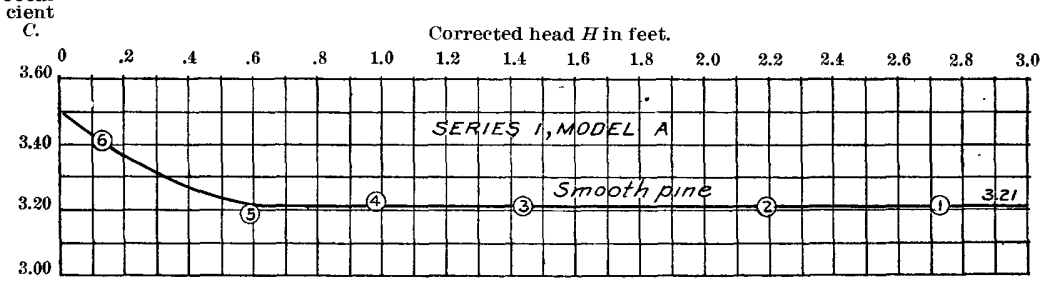
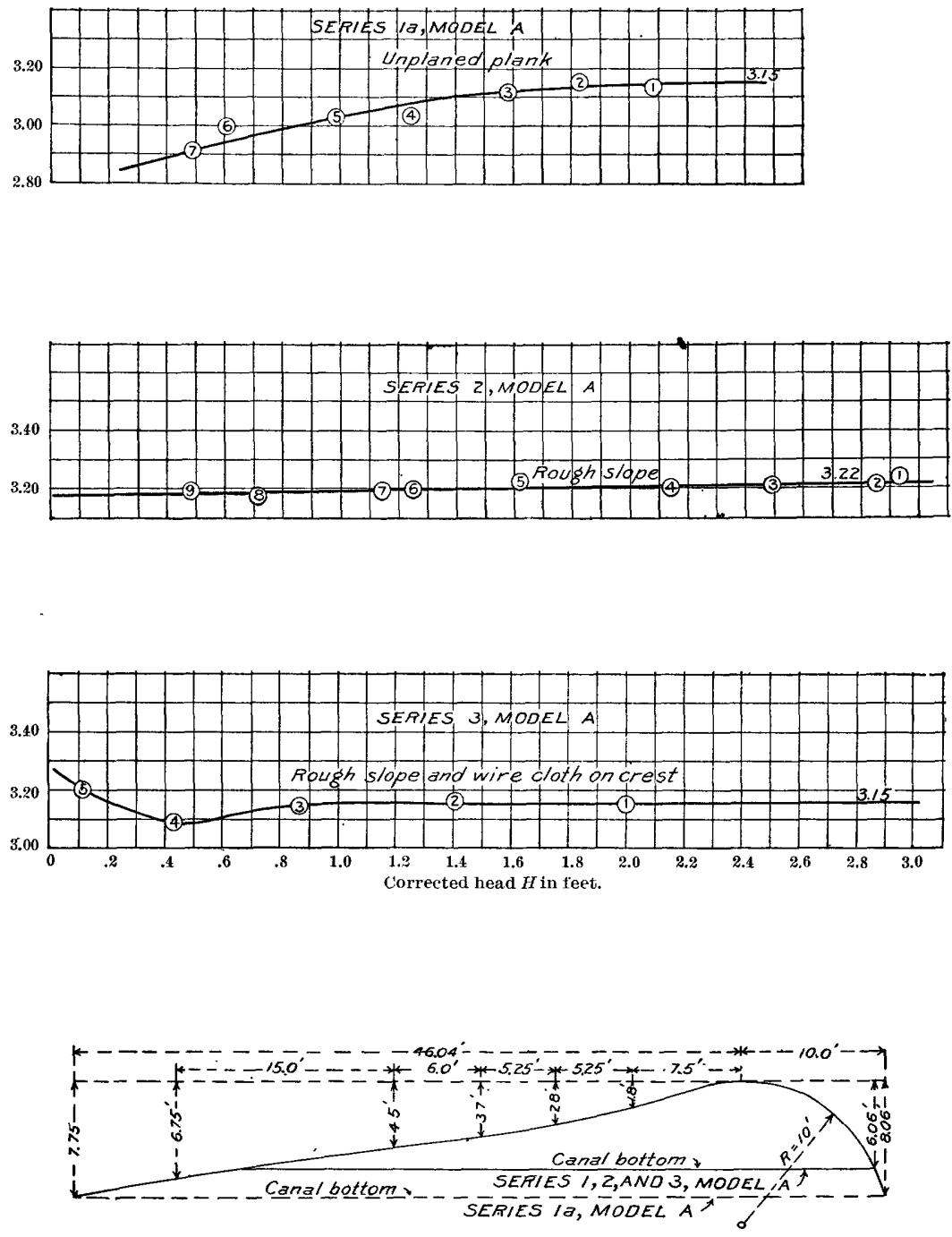

EXPERIMENTS ON ROUND.CRESTED MODELS OF OLD CROTON DAM:

$1 \mathrm{RR} 150-06-9$ 

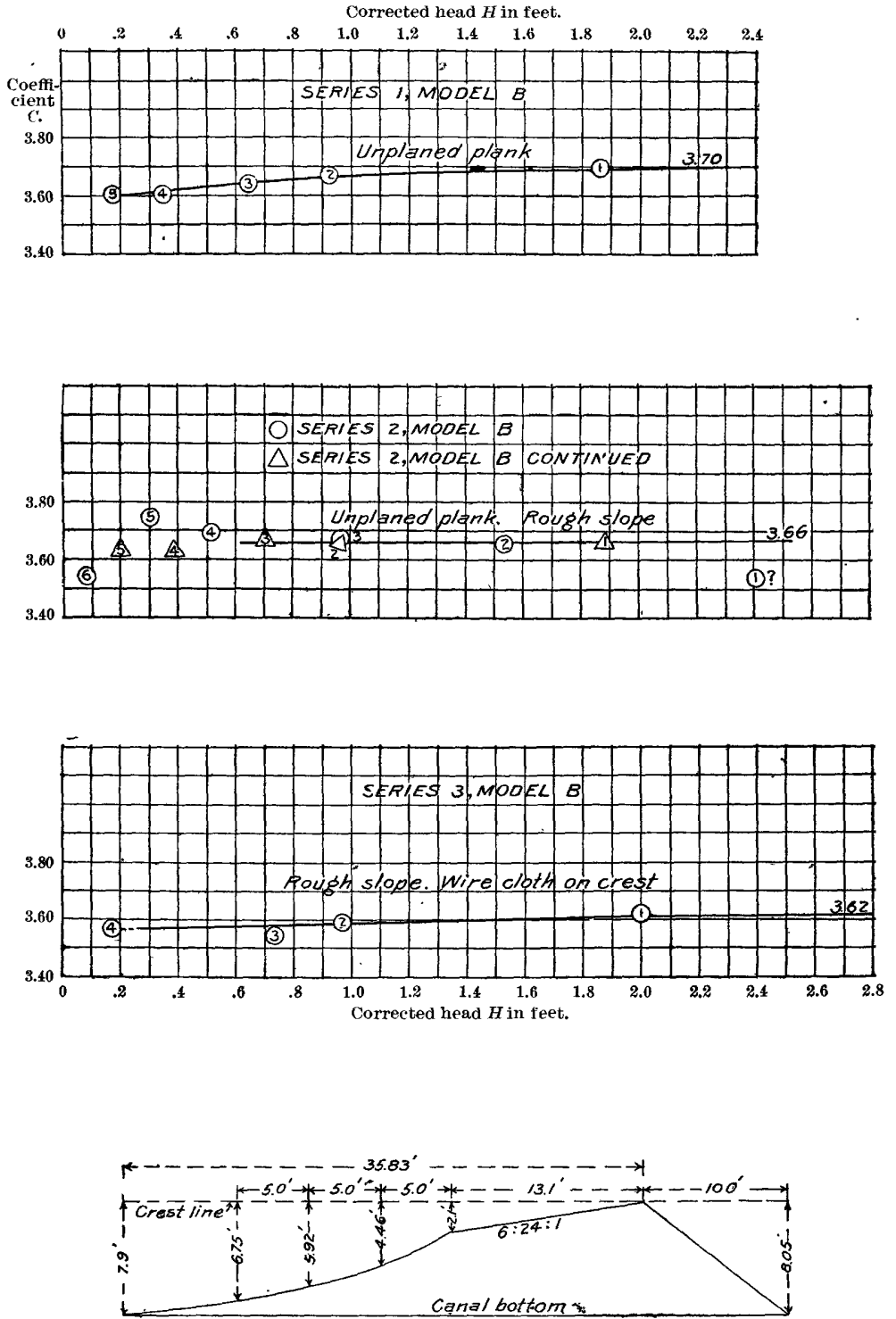

SEARES I ANB Z, MODEL $B$

SERIE'S 3 , MODEL B, ROU'GH SLOPE

EXPERIMENTS ON ANGULAR-CRESTED MODELS OF OLD CROTON DAM. 

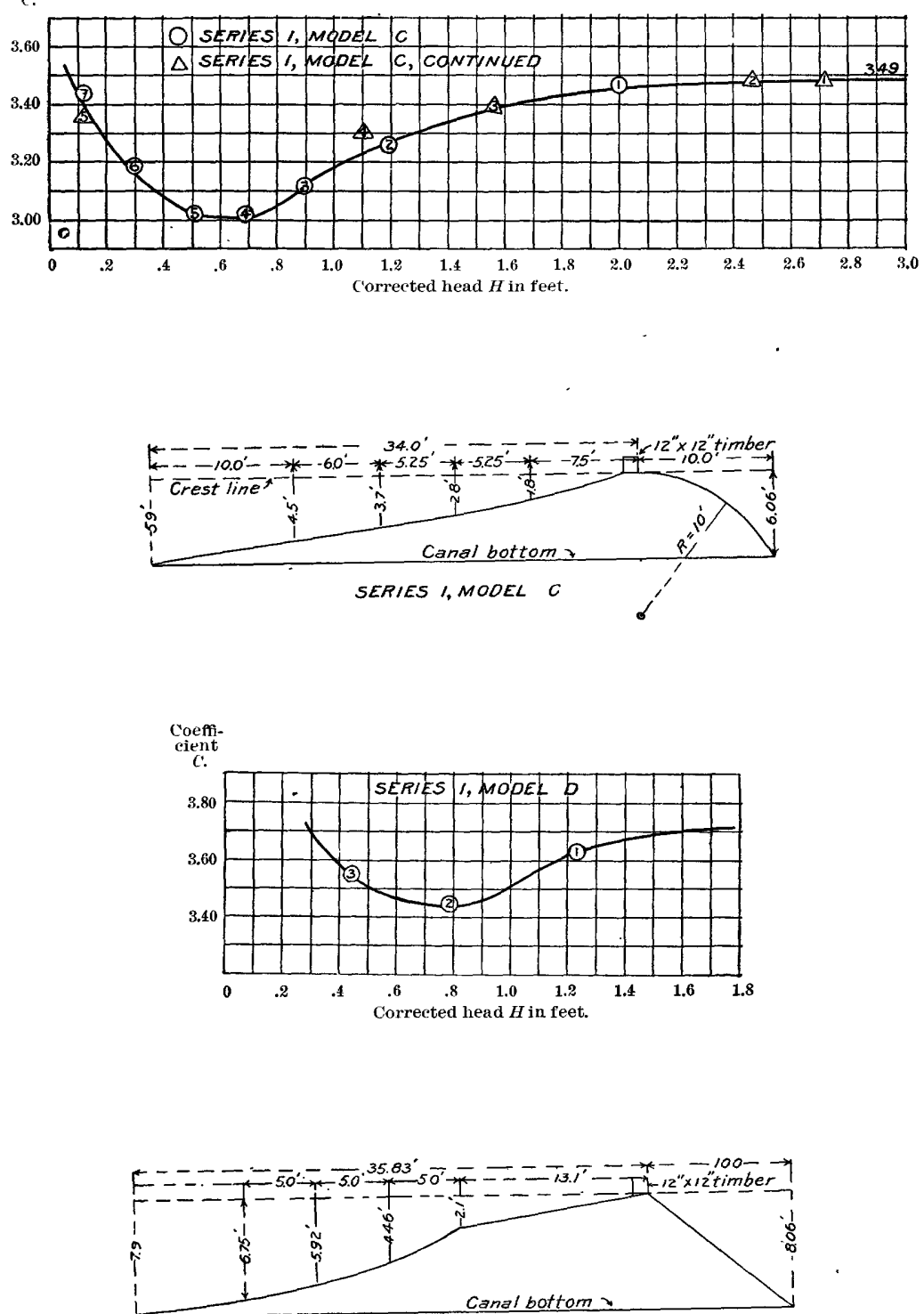

SERIES /, MODEL D

OLD CROTON DAM MODELS WITH CREST TIMBER. 
U. 8. GEOLOGICAL SURVEY

WATER-SUPPLY PAPER NO. $150 \quad$ PL. $X X 11$ Coeffi

cient

c.
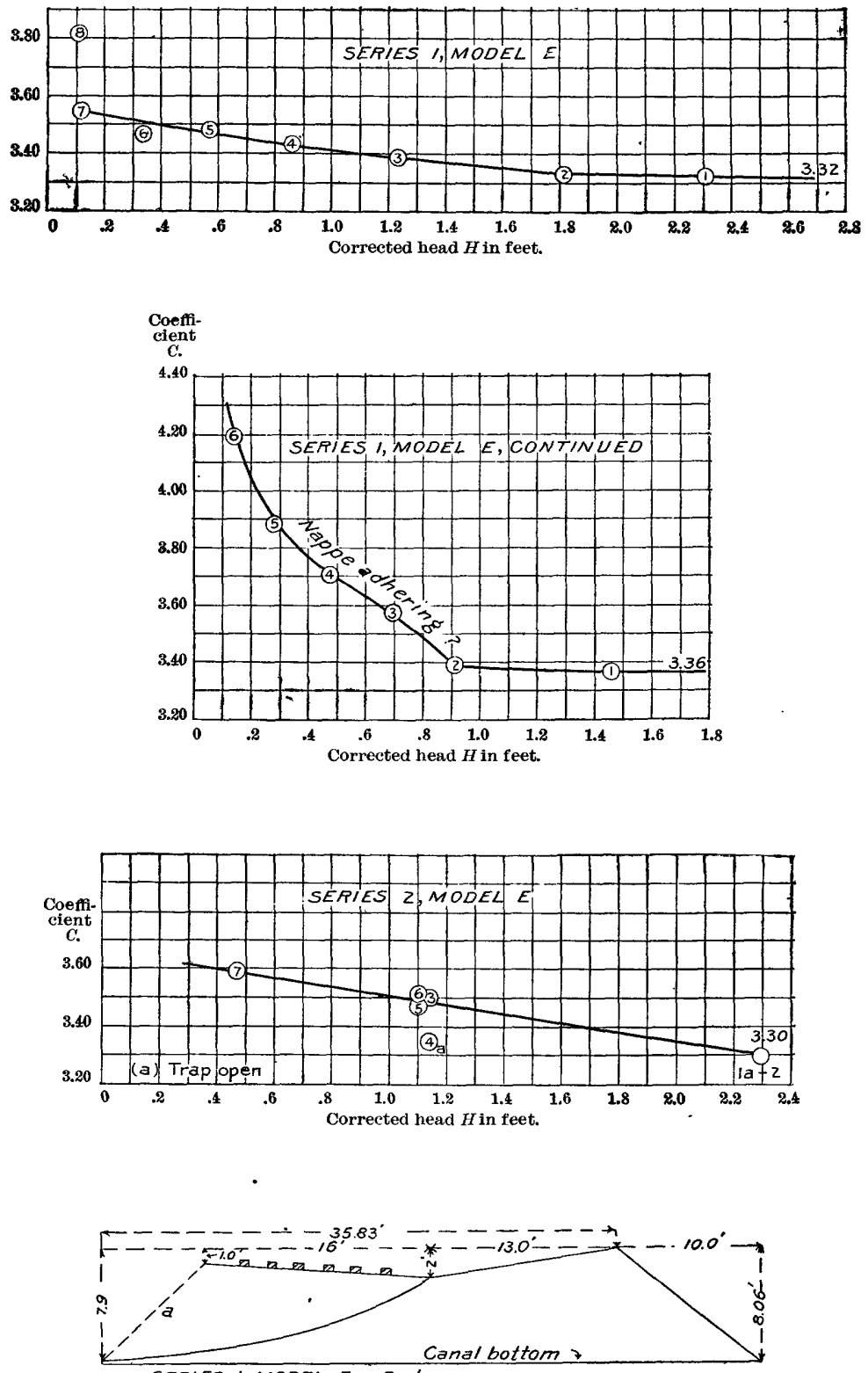

SERIES I, MODEL $E$. End a open

SERIES 2.MODEL $E$ End a with sloping approach

ANGULAR CROTON DAM MODEL, WITH CONSTRUCTION TO SIMULATE ROCK LEDGE. 


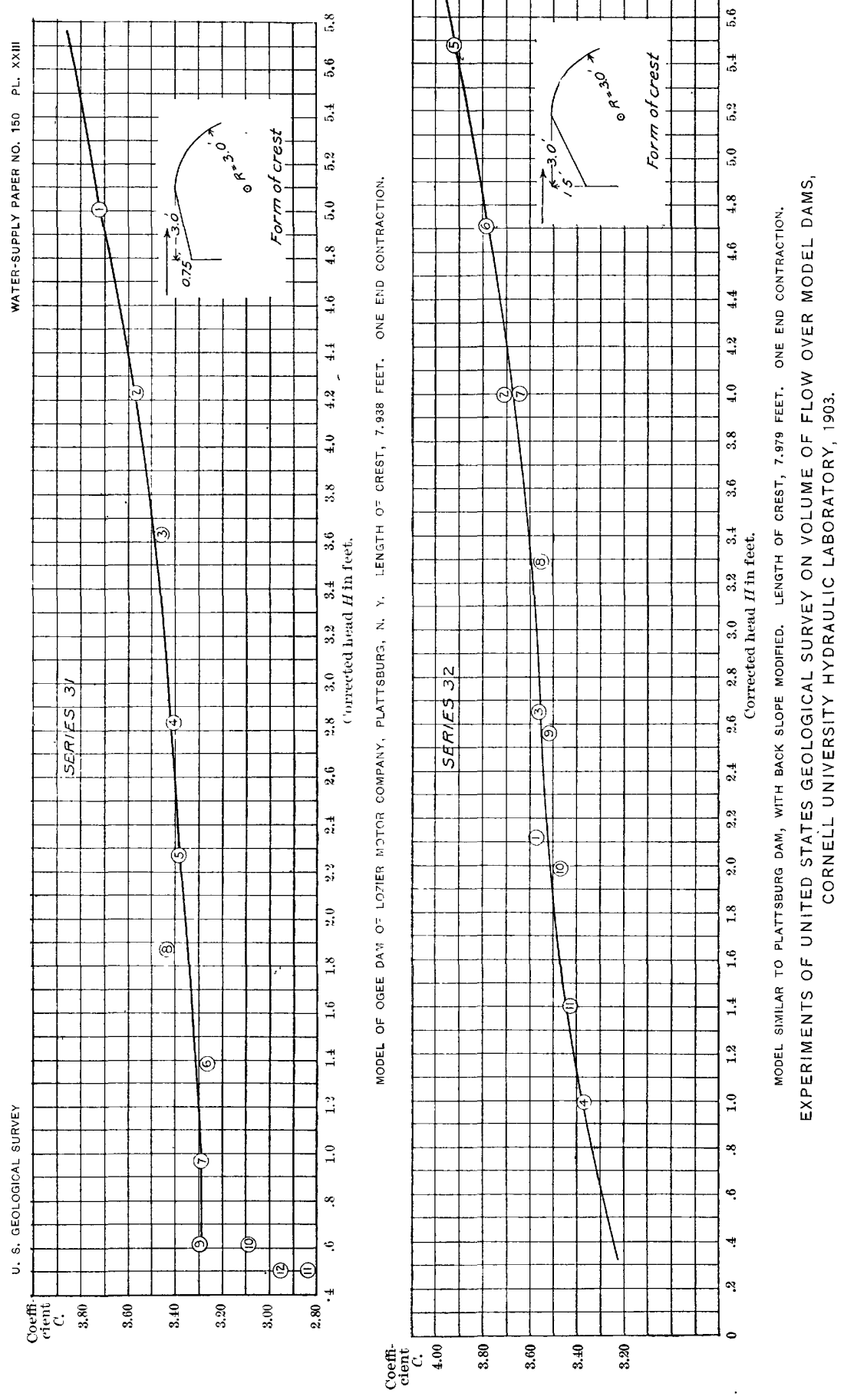




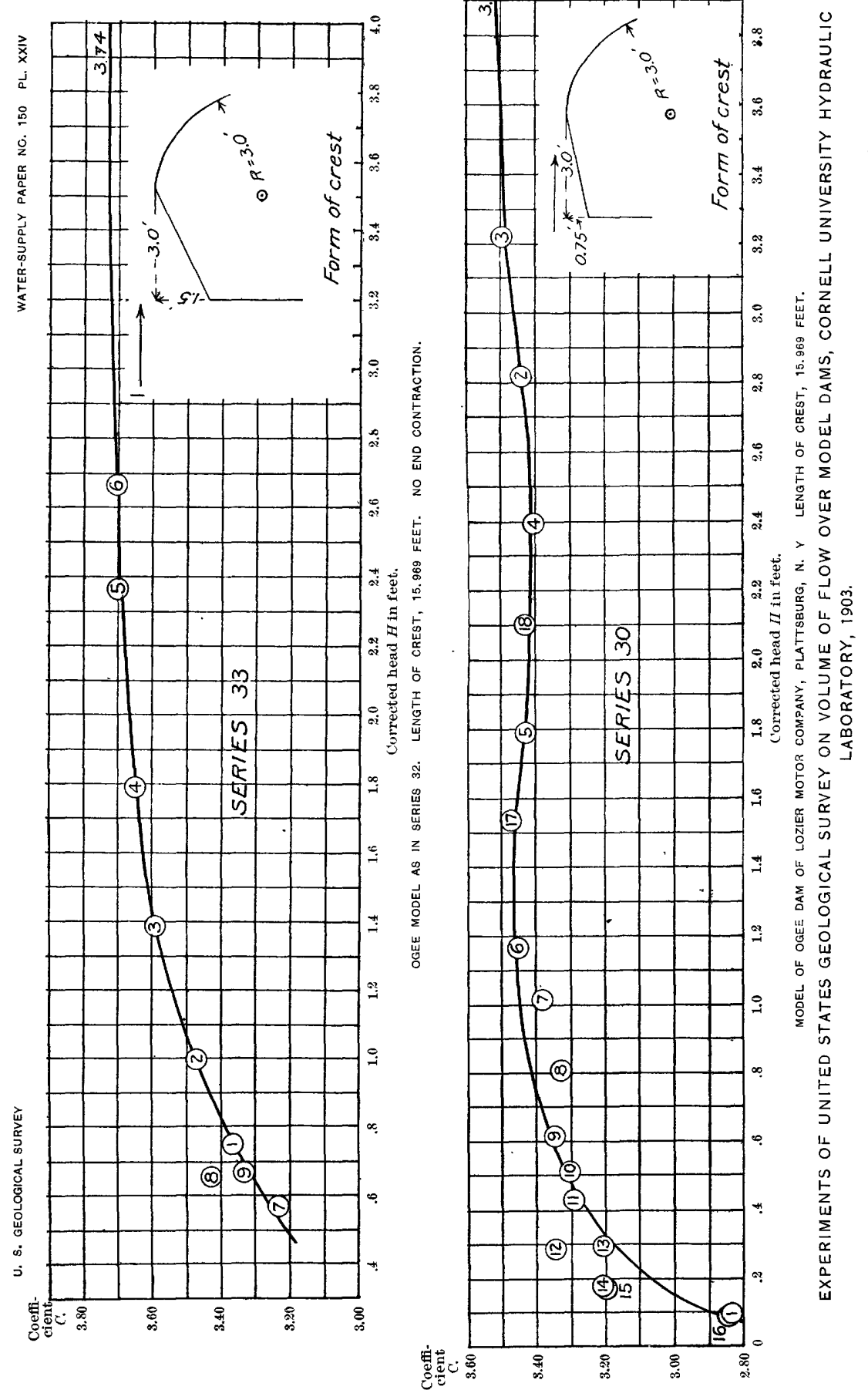


EXPERIMENTS OF UNITED STATES GEOLOGICAL SURVEY AT CORNELL UNIVERSITY HYDRAULIC LABORATORY.

In April, 1903, the writer was instructed to plan and execute a series of experiments on models of dams similar to those in use at gaging stations of the Geological Survey in New York, Michigan, and elsewhere.

The experiments were performed at the hydraulic laboratory of Cornell University, mainly during the months of May and June, 1903, and were conducted, under the supervision of the writer, by Prof. Gardner S. Williams, director of the laboratory.

The various types of dams most commonly occurring were grouped as follows:

1. Weirs with hroad horizontal or slightly inclined crests.

2. Weirs with vertical downstrean faces and inclined upstream slopes.

3. Weirs having compound slopes, including those with inclined upstream faces and with either broad crests or with sloping aprons.

4. Completely or partially curved weir sections, including those of ogee profile.

It was found impossible to include in the experiments all the forms of section desired, and it was accordingly determined to limit the experiments to the thorough study of two classes - weirs with broad crests and weirs with ogee sections-and to extend, if possible, the measurements to inchude dams with vertical downstream faces and sloping upstream approaches. The order of operation used in previous experiments was transposed, the experimental models being built on a bulkhead forming the standard weir hitherto used and located near the head of the experimental canal.

The quantity of water passing over the experimental weir was measured on a standard weir below, 6.65 feet high and having a crest length of 15.93 feet. The head on the standard weir was measured in a Bazin pit, 3 by 4 feet in section, reaching to the depth of the bottom of the canal, and communicating therewith through a pipe $t$ inches in diameter and about 3.5 feet long, opening at the bottom of the channel of approash, 29.88 feet upstream from the weir. The head on the standard weir was observed in the gage pit by means of a hook gage reading to millimeters and estimated to about one-fifth millimeter. The conditions at the standard weir were thus closely comparable to those obtained in Bazin's experiments, and his formula for this height and length of weir was applied to determine the discharge. Observations to determine the leakage between the experimental and standard weirs were made, and corrections were applied for whatever leakage was indicated, the amount being usually less than 0.01 cubic foot per second per foot of crest. The discharge over the standard weir was com- 
puted in cubic meters per second and has been reduced to cubic feet pe: second, the discharge table being as follows:

Discharge over standard weir at different heads.

\begin{tabular}{|r|c|r|r|}
\hline $\begin{array}{c}\text { Head, in } \\
\text { meters. }\end{array}$ & $\begin{array}{c}\text { Q in cubic } \\
\text { meters, per } \\
\text { second. }\end{array}$ & $\begin{array}{c}\text { Head, in } \\
\text { meters. }\end{array}$ & $\begin{array}{c}\text { Q in cubic } \\
\text { meters, per } \\
\text { second. }\end{array}$ \\
\hline 0.05 & 0.111863 & 0.60 & 4.21730 \\
.10. & .296230 & .70 & 5.34459 \\
.15 & .53207 & .80 & 6.57096 \\
.20 & .81166 & .90 & 7.89078 \\
.25 & 1.12871 & 1.00 & 9.30650 \\
.30 & 1.48032 & 1.10 & 10.81066 \\
.40 & 2.27850 & 1.20 & 12.40420 \\
.50 & 3.19350 & & \\
\hline
\end{tabular}

The discharge curve for the standard weir has also been carefully checked by comparing the depth flowing over with that on a similar weir, using the formula and method of determining the head adopted by Fteley and Stearns; it has also been checked by float and current-meter measurements, and for lower heads by meanś of volumetric measurement of the discharge in the gaging channel, so that it is believed that the discharge in these experiments is known within 1 or 2 per cent of error as a maximum.

The work of calibrating the standard weir had been accomplished by Professor Williams and his assistants before the experiments of the United States Geological Survey were taken up, so that somewhat more certainty attaches to the results of these later experiments than to earlier experiments made before the standard-weir discharge had been thoroughly checked.

It was the wish of the Geological Survey that the conditions at the experimental weirs should conform to those actually existing at dams which are utilized as weirs, in connection with the stream-gaging operations. In such cases it is often impracticable to utilize gage pits of the form adopted by Bazin or to use piezometer or hook gages. The usual method is to read the depth directly on a graduated vertical scale or measure the distance to water surface from a suitable bench mark. The method adopted in the weir experiments consisted of reading directly the distance to water surface from bench marks located above the central line of the channel. The readings were taken by means of a needle-pointed plumb boh attached to a steel tape forming a point gage, readings being taken to thousandths of a foot.

Two gages were used, one located 10.3 feet upstream from the crest and another 16.059 feet upstream. In series XXXV and following, for the higher heads, the readings of the upstream tape were used. For heads where no general difference was apparent the average of the readings of the two tapes was taken. In general, the 
surface curve did not perceptibly affect the reading of the gage nearest the weir for depths below 3 feet. The readings of the tapes were checked from time to time by observations with hook gages, thus practically eliminating the effect of temperature on the tapes. Observations of the head were usually taken at intervals of thirty seconds. Great care was used to maintain a uniform regimen of flow during each experimental period, and the variations of head were very slight. The character of the observations is illustrated by the following data taken from the experiments:

Readings of tapes to determine head at experimental weir.

\begin{tabular}{|c|c|c|c|}
\hline \multicolumn{2}{|c|}{$\begin{array}{l}\text { Series } \mathrm{XL} . \\
\text { Period } 10 . \\
\text { Date } 6,22,03 .\end{array}$} & \multicolumn{2}{|c|}{$\begin{array}{l}\text { Series XLI. } \\
\text { Period } 5 . \\
\text { Date } 6,23,03 .\end{array}$} \\
\hline Time. & Readings. & Time. & Readings \\
\hline h. $\quad$ m. $\quad s$. & & $m$ & \\
\hline \multirow{4}{*}{$\begin{array}{lll}12 & 37 & 40\end{array}$} & 42.681 & $\begin{array}{lll}1 & 34 & 30\end{array}$ & 43.633 \\
\hline & .681 & & .632 \\
\hline & .680 & & .633 \\
\hline & .681 & & .630 \\
\hline $\begin{array}{lll}12 & 39 & 00\end{array}$ & .682 & & .630 \\
\hline \multirow[t]{4}{*}{$\begin{array}{lll}12 & 52 & 30\end{array}$} & 42.680 & & .633 \\
\hline & .681 & & .635 \\
\hline & .680 & & .635 \\
\hline & .679 & & .634 \\
\hline $\begin{array}{lll}12 & 54 & 30\end{array}$ & .680 & & .633 \\
\hline Mean & 42.6805 & & $\begin{array}{r}.000 \\
635\end{array}$ \\
\hline \multicolumn{2}{|c|}{$\begin{array}{l}\text { Series XLITI. } \\
\text { Period 3. } \\
\text { Date } 6,26.03 .\end{array}$} & & $\begin{array}{l}.630 \\
.635\end{array}$ \\
\hline Time. & Readings. & & .633 \\
\hline \multirow{9}{*}{$\begin{array}{ccc}h . & m . & 8 . \\
12 & 36 & 20\end{array}$} & & & 630 \\
\hline & 2. 305 & & 630 \\
\hline & .302 & & 630 \\
\hline & .302 & & 630 \\
\hline & .302 & & 634 \\
\hline & .301 & & .630 \\
\hline & .302 & & .628 \\
\hline & .301 & & .630 \\
\hline & $\begin{array}{r}300 \\
300\end{array}$ & & .632 \\
\hline \multirow[t]{2}{*}{ Mean } & 2.3015 & $\begin{array}{lll}1 & 51 & 20\end{array}$ & 631 \\
\hline & & Mean & 43.6317 \\
\hline
\end{tabular}


For the lower heads the discharge over the experimental weir was volumetrically determined by measuring the rise of water in the canal, as follows:

List of experimental periods for which the discharge was volumetrically determined.

\begin{tabular}{|c|l|l|l|r|r|}
\hline Series. & \multicolumn{1}{|c|}{ Periods. } & Series. & Periods. & Series. & Periods. \\
\hline 30 & $1,13,14,16$ & 39 & 1 & & \\
31 & 10,11 & 40 & 1,2 & 44 & $1,2,3$ \\
34 & $1,9,10$ & 41 & 13,14 & 45 & $1,2,3$ \\
37 & $5 a$ & 43 & $1,2,3$ & 46 & $1,2,3$ \\
38 & 5,6 & $43 a$ & $1,2,3,4$ & 47 & $1,2,3$ \\
\hline
\end{tabular}

Enited Stutes Greological Survey experiments at Cornell Eniversity hydranlic laboratory on model of Plattshurg dem.

[Series No. XXx. Height of weir $=P$, 11.2n feet; length of weir crest $=L, 15.969$ feet; width of channel $=b, 15.970$ feet; height of upstream crest corner, 10.50 feet; crest width, 3 feet.]

\begin{tabular}{|c|c|c|c|c|c|c|c|c|c|c|}
\hline \multirow[b]{2}{*}{ No. } & \multicolumn{4}{|c|}{$\begin{array}{l}\text { Measured head on experimen- } \\
\text { tal weir, in feet. }\end{array}$} & \multirow{2}{*}{$\begin{array}{c}A= \\
\text { area of } \\
\text { section } \\
\text { per } \\
\text { foot of } \\
\text { crest. }\end{array}$} & \multirow{2}{*}{$\begin{array}{c}m= \\
\text { mean } \\
\text { veloc- } \\
\text { ity } \\
\text { of ap- } \\
\text { proach, } \\
\text { in feet } \\
\text { per sec- } \\
\text { ond. }\end{array}$} & \multicolumn{2}{|c|}{$\begin{array}{l}\text { Head corrected } \\
\text { for velocity } \\
\text { of approach, } \\
\text { in feet. }\end{array}$} & \multirow{2}{*}{$\begin{array}{c}Q=\text { dis- } \\
\text { charge } \\
\text { per } \\
\text { foot of } \\
\text { crest, } \\
\text { in cu- } \\
\text { bic feet } \\
\text { persec- } \\
\text { ond. }\end{array}$} & \multirow{2}{*}{$\begin{array}{c}\text { Dis- } \\
\text { charge } \\
\text { coeffi- } \\
\text { cient } \\
C_{1} .\end{array}$} \\
\hline & $\begin{array}{l}\text { Num- } \\
\text { ber of } \\
\text { obser- } \\
\text { ra- } \\
\text { tions. }\end{array}$ & $\begin{array}{l}\text { Maxi- } \\
\text { mum. }\end{array}$ & $\begin{array}{l}\text { Mini- } \\
\text { mum. }\end{array}$ & $\begin{array}{l}\text { Mean } \\
=D .\end{array}$ & & & $H^{\frac{3}{2}}$ & $H$ & & \\
\hline 1 & 2 & 3 & 4 & 5 & 6 & 7 & 8 & 9 & 10 & 11 \\
\hline 1 & 92 & 0.0993 & 0.0818 & 0.096 & 11.347 & 0.007 & 0.030 & 0.096 & 0.084 & 2.835 \\
\hline 2 & 31 & .7993 & .7863 & 2. 790 & 14.041 & 1.155 & 4. 710 & 2. 810 & 16.218 & 3. 443 \\
\hline 3 & 19 & 3. 1993 & 3.1473 & 3.187 & 14.438 & 1.396 & 5. 766 & 3.216 & 20.152 & 3.495 \\
\hline 4 & 26 & 2.3993 & 2.3473 & $2.3 \times 1$ & 13.635 & .926 & 3. 710 & $2.396^{\circ}$ & 12.631 & 3.405 \\
\hline 5 & 29 & 1. 7973 & 1. 7853 & 1. 793 & 13.043 & 636 & 2. 412 & 1. 799 & 8.282 & 3.433 \\
\hline 6 & 27 & 1.1808 & 1.1723 & 1.174 & 12.425 & .354 & 1. 274 & 1.176 & 4. 399 & 3.454 \\
\hline 7 & 18 & 1.0133 & 1.0073 & 1.010 & 12. 260 & .280 & 1.016 & 1.011 & 3. $43 \%$ & 3. 381 \\
\hline 8 & 16 & .8043 & .8003 & $.80^{2}$ & 12.053 & .200 & .719 & .803 & ‥ 409 & 3.348 \\
\hline 9 & 34 & .6143 & .6113 & .613 & 11.864 & .136 & . 481 & .614 & 1. 608 & 3.345 \\
\hline 10 & 24 & .5083 & .5073 & .508 & 11.758 & .102 & .362 & .509 & 1. 195 & 3.302 \\
\hline 11 & 15 & $.42 \times 3$ & .4263 & .427 & 11. 678 & .079 & .280 & .428 & .921 & 3.296 \\
\hline 12 & 20 & .2943 & .2903 & .291 & 11.542 & .046 & .157 & .291 & .526 & 3.344 \\
\hline 13 & 32 & .2933 & .2903 & .292 & 11.543 & .044 & .158 & .292 & .506 & 3.209 \\
\hline 14 & 21 & .1783 & .176 .3 & .178 & 11.427 & .021 & .075 & .178 & .240 & 3.202 \\
\hline 15 & 24 & .1793 & .1783 & .179 & 11. 429 & .020 & .076 & .179 & .226 & 2.976 \\
\hline 16 & 40 & .0893 & . 01893 & .089 & 11.840 & .007 & .027 & .089 & .076 & 2,841 \\
\hline 17 & 26 & 1.5373 & 1. 5303 & $1.58 \mathrm{i2}$ & 12.783 & .517 & 1.904 & 1.535 & 6.607 & 3.471 \\
\hline 18 & 25 & 2.1033 & 2.0843 & 2.094 & 13.345 & .793 & 3.051 & 2.104 & 10.576 & 3.466 \\
\hline
\end{tabular}


United States Geological Surrey experiments at Cornell University hydraulic laboratory on model of Plattsourg dam-Continued.

[Series No. XXXI. Height of weir $=P, 11.25$ feet; length of weir crest $=L, 7.938$ feet: width of channel $=b, 15.970$ feet; height of upstream crest corner, 10.50 feet; width of crest, 3 feet.]

\begin{tabular}{|c|c|c|c|c|c|c|c|c|c|c|c|}
\hline \multirow{2}{*}{ No. } & \multicolumn{4}{|c|}{$\begin{array}{l}\text { Measured head on experimen- } \\
\text { tal weir, in feet. }\end{array}$} & \multirow{2}{*}{$\begin{array}{l}A= \\
\text { area of } \\
\text { section } \\
\text { per } \\
\text { foot of } \\
\text { erest. }\end{array}$} & \multirow{2}{*}{$\begin{array}{c}\imath= \\
\text { mean } \\
\text { veloc- } \\
\text { ity } \\
\text { of ap- } \\
\text { proach, } \\
\text { in feet } \\
\text { per } \\
\text { second. }\end{array}$} & \multicolumn{2}{|c|}{$\begin{array}{l}\text { Head corrected } \\
\text { for velocity } \\
\text { of approach, } \\
\text { in feet. }\end{array}$} & \multirow{2}{*}{$\begin{array}{c}Q=\text { dis- } \\
\text { charge } \\
\text { per } \\
\text { foot of } \\
\text { crest. } \\
\text { in cu- } \\
\text { bic feet } \\
\text { per } \\
\text { second. }\end{array}$} & \multirow{2}{*}{$\begin{array}{c}\text { Dis- } \\
\text { charge } \\
\text { coeffi- } \\
\text { cient } C_{1}^{\prime} .\end{array}$} & \multirow{2}{*}{$\begin{array}{l}L=\text { ef- } \\
\text { fective } \\
\text { length } \\
\text { of erest } \\
\text { weir. }\end{array}$} \\
\hline & $\begin{array}{l}\text { Num- } \\
\text { ber of } \\
\text { obser- } \\
\text { va- } \\
\text { tions. }\end{array}$ & $\begin{array}{l}\text { Maxi- } \\
\text { mum. }\end{array}$ & $\begin{array}{l}\text { Mini- } \\
\text { mum. }\end{array}$ & $\begin{array}{l}\text { Mean } \\
=D\end{array}$ & & & $H^{\frac{3}{2}}$ & $H$ & & & \\
\hline 1 & 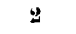 & 3 & 4 & 5 & 6 & 7 & 8 & 9 & 10 & 11 & 12 \\
\hline 1 & 25 & 5. 1003 & 4. 9273 & 5.0014 & 259.535 & 1. 201 & 11.257 & 5.023 & 41.925 & 3.724 & 7. 436 \\
\hline 2 & 15 & 4. 2873 & 4.1693 & 4. 2214 & 247.078 & .945 & 8.714 & 4.235 & 31.086 & 3.567 & 7.514 \\
\hline 3 & 44 & 3,6893 & 3.5253 & 3. 6191 & 507.460 & .356 & 6.890 & 3. 621 & 23.868 & 3. 464 & 7.580 \\
\hline 4 & 21 & 2.8213 & 2. 8003 & 2.8185 & 224.674 & .551 & 4.743 & 2.823 & 16.170 & 3.409 & 7.656 \\
\hline 5 & 39 & 2. 2713 & 2. 2623 & 2.2696 & 215.780 & .412 & 3.425 & 2.273 & 11.545 & 3.377 & 7.711 \\
\hline 6 & 40 & 1. 3903 & 1. 3813 & 1. 3861 & 201.998 & .206 & 1.633 & 1.387 & 5. 338 & 3.269 & 7. 799 \\
\hline 7 & 26 & .9673 & .9653 & .9663 & 195.094 & .125 & .950 & .966 & 3.120 & 3. 284 & 7.811 \\
\hline 8 & 25 & 1.8793 & 1. 8723 & 1.8749 & 209.605 & .326 & 2.570 & 1. 876 & 8.814 & 3.429 & 7.750 \\
\hline 9 & 30 & .6093 & .6083 & .6087 & 189.383 & .065 & .475 & .609 & 1.562 & 3.288 & 7.877 \\
\hline 10 & 18 & .6073 & .6063 & .6063 & 189. 345 & .060 & .472 & .606 & 1. 4.56 & 3.083 & 7.877 \\
\hline 11 & 10 & .3023 & .2993 & .3017 & 184.471 & .020 & .165 & .301 & .469 & 2.838 & 7. 908 \\
\hline 12 & 19 & .3003 & .2993 & .3017 & 184. 481 & .021 & .166 & .302 & .490 & 2.956 & 7.908 \\
\hline
\end{tabular}

[Series No. XXXII. Height of weir $=P$, 11.25 feet; length of weir crest $=L, 7.979$ feet; width of channel $=b, 15.970$ feet; height of upstream crest corner, 9.75 feet; width of erest, 3 feet.]

\begin{tabular}{|r|r|r|r|r|r|r|r|r|r|r|r|}
\hline 1 & 10 & 2.1193 & 2.0943 & 2.1173 & 213.476 & 0.004 & 3.081 & 2.117 & 11.029 & 3.580 & 7.767 \\
2 & 23 & 4.0343 & 3.9883 & 4.0053 & 243.627 & .928 & 8.055 & 4.018 & 29.846 & 3.706 & 7.577 \\
3 & 26 & 2.6693 & 2.6333 & 2.6469 & 221.934 & .535 & 4.317 & 2.651 & 15.398 & 3.567 & 7.714 \\
4 & 34 & .9953 & .9923 & .9942 & 195.540 & .135 & .992 & .994 & 3.342 & 3.370 & 7.880 \\
5 & 32 & 5.5543 & 5.2983 & 5.4712 & 267.038 & 1.404 & 12.855 & 5.487 & 50.440 & 3.924 & 7.430 \\
6 & 27 & 4.7343 & 4.6443 & 4.6947 & 254.637 & 1.141 & 10.235 & 4.714 & 38.704 & 3.782 & 7.508 \\
7 & 27 & 4.0173 & 3.9883 & 4.0007 & 240.808 & .925 & 8.040 & 4.013 & 29.395 & 3.656 & 7.578 \\
8 & 28 & 3.3053 & 3.2673 & 3.2890 & 232.188 & .701 & 5.984 & 3.296 & 21.278 & 3.556 & 7.649 \\
9 & 31 & 2.5863 & 2.5193 & 2.5596 & 220.539 & .506 & 4.104 & 2.564 & 14.460 & 3.524 & 7.723 \\
10 & 28 & 1.9913 & 1.9693 & 1.9801 & 211.285 & .357 & 2.790 & 1.982 & 9.686 & 3.471 & 7.781 \\
11 & 53 & 1.4113 & 1.4023 & 1.4015 & 202.044 & .221 & 1.661 & 1.402 & 5.704 & 3.434 & 7.899 \\
\hline
\end{tabular}

IRR $150-06-10$ 
United States Geological Survey experiments at Cornell Unicersity hydraulic laboratory on. model of Plattsburg dam-Continued.

[Series No. XXXIII. Height of weir $=P$, 11.25 feet; length of weir crest $=L, 15.969$ feet; width of channel $=b, 15.970$ feet; height of upstream crest corner, 9.79 feet; width of crest, 3 feet. ]

\begin{tabular}{|c|c|c|c|c|c|c|c|c|c|c|}
\hline \multirow{2}{*}{ No. } & \multicolumn{4}{|c|}{$\begin{array}{l}\text { Measured head on experimen- } \\
\text { tal weir, in feet. }\end{array}$} & \multirow{2}{*}{$\begin{array}{c}A= \\
\text { area of } \\
\text { section } \\
\text { per } \\
\text { foot of } \\
\text { crest. }\end{array}$} & \multirow{2}{*}{$\begin{array}{c}p= \\
\text { mean } \\
\text { veloc- } \\
\text { ity } \\
\text { of ap- } \\
\text { proach, } \\
\text { in feet } \\
\text { per sec- } \\
\text { ond. }\end{array}$} & \multicolumn{2}{|c|}{$\begin{array}{l}\text { Head corrected } \\
\text { for velocity } \\
\text { of approach, } \\
\text { in feet. }\end{array}$} & \multirow{2}{*}{$\begin{array}{c}Q=\text { dis- } \\
\text { charge } \\
\text { per } \\
\text { foot of } \\
\text { crest } \\
\text { in cubic } \\
\text { feet per } \\
\text { sec- } \\
\text { ond. }\end{array}$} & \multirow{2}{*}{$\begin{array}{l}\text { Dis- } \\
\text { charge } \\
\text { coeffi- } \\
\text { cient } \\
C_{1} .\end{array}$} \\
\hline & $\begin{array}{l}\text { Num- } \\
\text { ber of } \\
\text { obser- } \\
\text { va- } \\
\text { tions. }\end{array}$ & $\begin{array}{l}\text { Maxi- } \\
\text { mum. }\end{array}$ & $\begin{array}{l}\text { Mini- } \\
\text { mum. }\end{array}$ & $\begin{array}{l}\text { Mean } \\
=D\end{array}$ & & & $H^{\frac{3}{2}}$ & $H$ & & \\
\hline 1 & $\mathbf{9}$ & 3 & 4 & 5 & 6 & 7 & 8 & 9 & 10 & 11 \\
\hline 1 & 15 & 0.7563 & 0.7493 & 0.752 & 12.003 & 0.183 & 0.653 & 0.753 & 2.197 & 3.363 \\
\hline 2 & 43 & .9973 & .9873 & .992 & 12.243 & .281 & .990 & .993 & 3.439 & 3.473 \\
\hline 3 & 29 & 1. 3963 & 1. 3903 & 1. 394 & 12.644 & .468 & 1. 651 & 1. 397 & 5.913 & 3.580 \\
\hline 4 & 33 & 1.7893 & 1. 7803 & 1. 781 & 13.034. & .671 & 2.396 & 1. 790 & 8.747 & 3.651 \\
\hline 5 & 23 & 2.3733 & 2. 3363 & 2. 352 & 13. 603 & .990 & 3.641 & 2,367 & 13.464 & 3.698 \\
\hline 6 & 24 & 2. 6683 & 2. 6503 & 2.660 & 13.910 & 1.170 & 4.387 & 2.680 & 16. 272 & 3. 709 \\
\hline 7 & 52 & .5593 & .5493 & .553 & 11. 803 & 1. 183 & .432 & .572 & 1. 397 & 3. 232 \\
\hline 8 & 42 & .6603 & .6493 & .653 & 11.904 & .152 & .528 & .654 & 1. 808 & 3.422 \\
\hline 9 & 12 & .6804 & .6783 & .679 & 11.930 & .156 & .560 & .680 & 1. 966 & 3. 330 \\
\hline
\end{tabular}

[Series No. XXXIV. Height of weir $=P, 11.25$ feet; leugth of weir crest $=L, 15.969$ feet; width of channel $=b, 15.970$ feet; height of upstream crest corner, 8.37 feet; width of crest, 3 feet.]

\begin{tabular}{|r|r|r|r|r|r|r|r|r|r|r|}
\hline 1 & 16 & 0.6453 & 0.6383 & 0.641 & 11.891 & 0.137 & 0.513 & 0.641 & 1.632 & 3.182 \\
2 & 16 & .6423 & .6383 & .640 & 11.891 & .141 & .513 & .640 & 1.680 & 3.276 \\
3 & 21 & 2.0253 & 2.0043 & 2.015 & 13.266 & .816 & 2.882 & 2.025 & 10.826 & 3.756 \\
4 & 19 & 1.6303 & 1.6203 & 1.628 & 12.878 & .592 & 2.086 & 1.633 & 7.627 & 3.656 \\
5 & 19 & 1.2333 & 1.2293 & 1.232 & 12.483 & .391 & 1.371 & 1.235 & 4.877 & 3.555 \\
6 & 14 & .9523 & .9483 & .950 & 12.201 & .261 & .927 & .951 & 3.185 & 3.434 \\
7 & 20 & .4013 & .3983 & .400 & 11.650 & .070 & .253 & .400 & .815 & 3.225 \\
8 & 10 & .6243 & .6243 & .624 & 11.875 & .136 & .493 & .625 & 1.613 & 3.269 \\
9 & 32 & .2243 & .2203 & .222 & 11.473 & .029 & .105 & .222 & .328 & 3.133 \\
10 & 39 & .1103 & .1093 & .110 & 11.360 & .009 & .036 & .110 & .100 & 2.777 \\
11 & 14 & 5.0963 & 5.0793 & 3.089 & 14.340 & 1.509 & 5.515 & 3.122 & 21.636 & 3.923 \\
12 & 25 & 2.7763 & 2.7263 & 2.749 & 14.000 & 1.258 & 4.615 & 2.772 & 17.612 & 3.816 \\
13 & 31 & 2.4383 & 2.3963 & 2.421 & 13.672 & 1.051 & 3.805 & 2.437 & 14.374 & 3.778 \\
14 & 25 & 2.8013 & 2.7963 & .800 & 12.050 & .194 & .716 & .800 & 2.341 & 3.271 \\
\hline
\end{tabular}


United States (reological Survey experiments at Cornell University hydraulic laboratery on model of Chambly dam.

[Series No. XXXV. Height of weir $=P, 11.25$ feet; length of weir crest $=L, 15.969$ feet; width of channel $=b, 15.970$ feet; height of upstream crest corner, 10.25 feet; width of erest 4.5 feet.]

\begin{tabular}{|c|c|c|c|c|c|c|c|c|c|c|}
\hline \multirow[b]{2}{*}{ No. } & \multicolumn{4}{|c|}{$\begin{array}{l}\text { Measured head on experimen- } \\
\text { tal weir, in feet. }\end{array}$} & \multirow{2}{*}{$\begin{array}{c}A= \\
\text { area of } \\
\text { section } \\
\text { per } \\
\text { foot of } \\
\text { crest. }\end{array}$} & \multirow{2}{*}{$\begin{array}{c}v= \\
\text { mean } \\
\text { veloc- } \\
\text { ity } \\
\text { of ap- } \\
\text { proach, } \\
\text { in ieet } \\
\text { per } \\
\text { second. }\end{array}$} & \multicolumn{2}{|c|}{$\begin{array}{l}\text { Head corrected } \\
\text { for velocity } \\
\text { of approach, } \\
\text { in feet. }\end{array}$} & \multirow{2}{*}{$\begin{array}{l}Q=\text { dis- } \\
\text { charge } \\
\text { per } \\
\text { foot of } \\
\text { crest } \\
\text { in cubic } \\
\text { feet per } \\
\text { second. }\end{array}$} & \multirow{2}{*}{$\begin{array}{c}\text { Dis- } \\
\text { charge } \\
\text { coeffi- } \\
\text { cient } \\
C_{1} .\end{array}$} \\
\hline & $\begin{array}{l}\text { Num- } \\
\text { ber of } \\
\text { obser- } \\
\text { va- } \\
\text { tions. }\end{array}$ & $\begin{array}{l}\text { Maxi- } \\
\text { mum. }\end{array}$ & $\begin{array}{l}\text { Mini- } \\
\text { mum. }\end{array}$ & $\begin{array}{l}\text { Mean } \\
=D .\end{array}$ & & & $H^{\frac{3}{2}}$ & $H$ & & \\
\hline 1 & 2 & 3 & 4 & 5 & 6 & 7 & 8 & 9 & 10 & 11 \\
\hline 1 & 64 & 2.5503 & 2. 5463 & 0.549 & 11.799 & 0.110 & $0.40 \bar{\tau}$ & 0.549 & 1. 297 & 3.189 \\
\hline 2 & 55 & 1.0103 & 1.0063 & 1.008 & 12. 259 & .272 & 1.014 & 1. 009 & 3. 331 & 3.285 \\
\hline 3 & 40 & 1. 5643 & 1.5523 & 1. 559 & 12.810 & .511 & 1.954 & 1. 563 & 6. 548 & 3. 352 \\
\hline 4 & 40 & 2.0273 & 2. 0133 & 2.021 & 13. 272 & .744 & 2.890 & 2.029 & 9.874 & 3.416 \\
\hline 5 & 38 & 1. 7513 & 1.7303 & 1. 739 & 12.990 & .602 & 2.304 & 1. 744 & 7.816 & 3.392 \\
\hline 6 & 45 & 1.2673 & 1. 2583 & 1. 262 & 12.513 & .379 & 1. 422 & 1. 265 & 4. 747 & 3. 337 \\
\hline 7 & 41 & .7593 & $.75+3$ & .757 & 12.008 & .176 & .660 & .758 & 2.114 & 3.205 \\
\hline 8 & 43 & .4453 & .4373 & .441 & 11. 692 & .079 & .293 & .411 & .919 & 3.132 \\
\hline 9 & 20 & .3043 & .3003 & .302 & 11.553 & .045 & .166 & .302 & .525 & 3.159 \\
\hline 11 & 18 & 3. 7303 & 3. 7063 & 3. 755 & 15.006 & 1.740 & 7.403 & 3.798 & 26.114 & 3.528 \\
\hline 12 & 17 & 3.2193 & 3. 1813 & 3.195 & 14. 446 & 1.406 & 5. 789 & 3.224 & 20.319 & 3. 510 \\
\hline 13 & 17 & 3.0023 & 2.9873 & 2.987 & 14. 238 & 1. 283 & 5. 224 & 3.011 & 18. 267 & 3.496 \\
\hline 14 & 18 & 2.6743 & 2. 6643 & 2.642 & 13.892 & 1.077 & 4. 334 & 2.658 & 14.963 & 3.452 \\
\hline 15 & 23 & 2. 3533 & 2. 3283 & 2. 317 & 13.569 & .901 & 3. 555 & 2.330 & 12. 221 & 3.438 \\
\hline 16 & 22 & 1.4923 & 1.4873 & 1. 463 & 12. 713 & .478 & 1. 775 & 1. 466 & 6.072 & 3.420 \\
\hline 17 & 37 & .2103 & .2093 & .184 & 11.435 & .023 & .079 & .184 & .258 & 3. 260 \\
\hline 18 & 25 & .3913 & .3903 & .391 & 11. 642 & .065 & .245 & .391 & .758 & 3.096 \\
\hline 19 & 17 & .3313 & .3313 & .331 & 11.582 & .053 & .191 & .331 & .609 & 3.194 \\
\hline 20 & 24 & .2523 & .2523 & .253 & 11.504 & .035 & .127 & .253 & .404 & 3.258 \\
\hline 21 & 21 & .2203 & .2193 & .221 & 11.472 & .028 & .104 & .221 & .325 & 3.120 \\
\hline 22 & 24 & .1843 & .1833 & .183 & 11. 434 & .021 & .078 & .183 & .238 & 3. 039 \\
\hline 23 & 19 & .1323 & .1313 & .132 & 11.383 & .012 & .048 & .132 & .136 & 2. 826 \\
\hline 24 & 20 & .0823 & .0823 & .083 & 11. 384 & .007 & .024 & .083 & .079 & 3.321 \\
\hline
\end{tabular}

[Series No. XXXVI. Height of weir $=P, 11.25$ feet; length of weir erest $=L, 15.969$ feet; width of channel $=b, 15.970$ feet; height of npstream crest corner, 10.50 feet; width of crest, 4.5 feet, with 4 inches radius quarter round.]

\begin{tabular}{|r|r|r|r|r|r|r|r|r|r|r|}
\hline 1 & 18 & 2.7653 & 2.6913 & 2.741 & 13.991 & 1.185 & 4.591 & 2.764 & 16.586 & 3.610 \\
2 & 18 & 2.3513 & 2.2913 & 2.316 & 13.567 & .936 & 3.558 & 2.330 & 12.698 & 3.569 \\
3 & 30 & 2.9373 & 2.8923 & 1.915 & 13.166 & .702 & 2.666 & 1.923 & 9.243 & 3.467 \\
4 & 23 & 1.5173 & 1.4993 & 1.507 & 12.758 & .501 & 1.857 & 1.511 & 6.390 & 3.441 \\
5 & 21 & 1.1143 & 1.1013 & 1.111 & 12.361 & .320 & 1.173 & 1.112 & 3.950 & 3.367 \\
6 & 19 & .7553 & .7493 & .753 & 12.004 & .177 & .654 & .753 & 2.123 & 3.248 \\
7 & 22 & .4943 & .4903 & .492 & 11.743 & .095 & .345 & .492 & 1.113 & 3.221 \\
\hline
\end{tabular}


thited States Feological Survey experiments at Cornell hydraulic laboratory on model of Dolgeville dam with injured rpron.

[Series No. XXXVII. Height of weir $=P, 11.25$ feet: length of weir crest $=L, 15.969$ feet; width of channel $=b, 15.970$ feet; height of upstream crest corner, 10.25 feet; width of crest, 6 feet.]

\begin{tabular}{|c|c|c|c|c|c|c|c|c|c|c|}
\hline \multirow{2}{*}{ No. } & \multicolumn{4}{|c|}{$\begin{array}{l}\text { Measured head on experimen- } \\
\text { tal weir, in feet. }\end{array}$} & \multirow{2}{*}{$\begin{array}{c}A= \\
\text { area of } \\
\text { section } \\
\text { per foot } \\
\text { of } \\
\text { crest. }\end{array}$} & \multirow{2}{*}{$\begin{array}{c}v= \\
\text { mean } \\
\text { veloc- } \\
\text { ity of } \\
\text { ap- } \\
\text { proach, } \\
\text { in feet } \\
\text { per sec- } \\
\text { ond. }\end{array}$} & \multicolumn{2}{|c|}{$\begin{array}{l}\text { Head corrected } \\
\text { for velocity } \\
\text { of approach, } \\
\text { in feet. }\end{array}$} & \multirow{2}{*}{$\begin{array}{c}Q=\text { dis- } \\
\text { charge } \\
\text { per } \\
\text { foot of } \\
\text { crest, } \\
\text { in cul- } \\
\text { bic feet } \\
\text { per sec- } \\
\text { ond. }\end{array}$} & \multirow{2}{*}{$\begin{array}{l}\text { Dis- } \\
\text { charge } \\
\text { coeff- } \\
\text { cient } \\
C_{1} .\end{array}$} \\
\hline & $\begin{array}{l}\text { Nom- } \\
\text { obser- } \\
\text { va- } \\
\text { tions. }\end{array}$ & $\begin{array}{l}\text { Mraxi- } \\
\text { munim. }\end{array}$ & $\begin{array}{l}\text { Mini- } \\
\text { mum. }\end{array}$ & $\underset{D}{\operatorname{Mean}}=$ & & & $H^{\frac{3}{2}}$ & $H$ & & \\
\hline $\mathbf{1}$ & 2 & 3 & 4 & 5 & 6 & 7 & 8 & 9 & 10 & 11 \\
\hline 1 & 30 & 0.9203 & $0_{+} 9113$ & 0.916 & 12.166 & 0.251 & 0.878 & 0.917 & 3.049 & 3. 474 \\
\hline 2 & 35 & 3.5613 & 3.4283 & 3.565 & 14.816 & 1.535 & 6.828 & 3.599 & 22.744 & 3.331 \\
\hline 3 & 28 & 2.9123 & 2.8573 & 2.927 & 14.178 & 1.170 & 5.060 & 2.947 & 16.593 & 3.279 \\
\hline 4 & 52 & 2,3293 & 2.2903 & 2,324 & 13.574 & .906 & 3.570 & 2.336 & 12.297 & 3. 444 \\
\hline 5 & 59 & 1. 6413 & 1. 6213 & 1.635 & 12.885 & .585 & 2.100 & 1.640 & $7.5 \pm 4$ & 3.593 \\
\hline $5 a$ & 41 & 1.3973 & 1. 3923 & .455 & 11.666 & .069 & .267 & .415 & .810 & 3.029 \\
\hline
\end{tabular}

United States Geological Survey experiments at Cornell hydranlic laboratory on model of Dolgerille dam.

[Series No. XXXVII. Height of weir $=P, 11.25$ feet; length of weir erest $=L, 15.969$ feet; width of channel $=7,15.970$ feet; height of upstream crest corner, 10.25 feet; width of crest, 600 feet.]

\begin{tabular}{|c|c|c|c|c|c|c|c|c|c|c|}
\hline \multirow{2}{*}{ No. } & \multicolumn{4}{|c|}{$\begin{array}{l}\text { Measured head on experimen- } \\
\text { tal weir, in feet. }\end{array}$} & \multirow{3}{*}{$\begin{array}{c}A= \\
\text { area of } \\
\text { section } \\
\text { per foo } \\
\text { of } \\
\text { rrest. } \\
\\
-6\end{array}$} & \multirow{2}{*}{$\begin{array}{c}y= \\
\text { mean } \\
\text { veloc- } \\
\text { ity of } \\
\text { ap- } \\
\text { proach, } \\
\text { in feet } \\
\text { per sec- } \\
\text { ond. }\end{array}$} & \multicolumn{2}{|c|}{$\begin{array}{l}\text { Head corrected } \\
\text { for velocity } \\
\text { of approach, } \\
\text { in feet. }\end{array}$} & \multirow{2}{*}{$\begin{array}{c}2=\text { dis- } \\
\text { charge } \\
\text { per } \\
\text { foot of } \\
\text { crest, } \\
\text { in cu- } \\
\text { bic feet } \\
\text { per sec- } \\
\text { ond. }\end{array}$} & \multirow{2}{*}{$\begin{array}{c}\text { Dis- } \\
\text { charge } \\
\text { coeffi- } \\
\text { cient } \\
C_{1} .\end{array}$} \\
\hline & $\begin{array}{l}\text { Dum- } \\
\text { ber of } \\
\text { obser- } \\
\text { va- } \\
\text { tions. }\end{array}$ & $\begin{array}{l}\text { Maxi- } \\
\text { mum. }\end{array}$ & $\begin{array}{l}\text { Mini- } \\
\text { mum. }\end{array}$ & $\begin{array}{c}\text { Mean }= \\
I .\end{array}$ & & & $H^{\frac{3}{2}}$ & $H$ & & \\
\hline 1 & 2 & 3 & 4 & 5 & & 7 & 8 & 9 & 10 & 11 \\
\hline 1 & 32 & 0.3973 & 0.3913 & 0.395 & 11.646 . & 0.068 & 0.249 & 0.396 & 0.790 & 3. 176 \\
\hline 2 & 36 & 1. 6843 & 1. 6713 & 1. 689 & 12.940 & .605 & 2. 206 & 1.695 & 7.826 & 3. 548 \\
\hline 3 & 25 & 1.1143 & 1.1093 & 1.112 & 12.362 & .333 & 1.175 & 1.114 & 4. 113 & 3.501 \\
\hline 4 & 32 & .7513 & .7473 & .749 & 12.000 & .185 & .649 & .750 & 2. 223 & 3. 426 \\
\hline 5 & 34 & .5093 & .5083 & .504 & 11.754 & .101 & .358 & .504 & 1. 186 & 3.310 \\
\hline 6 & 24 & .2173 & .2113 & .209 & 11.460 & .026 & .096 & .209 & .294 & 3. 081 \\
\hline 7 & 27 & 3.4726 & 3. 4586 & 3.470 & 14.721 & 1. 466 & 6.551 & 3.501 & 21.583 & 3.295 \\
\hline 8 & 34 & 3.1176 & 3.0806 & 3.100 & 14.351 & 1.271 & 5.521 & 3.124 & 18.238 & 3. 303 \\
\hline 9 & 29 & $2.6176^{\circ}$ & 2.5926 & 2.605 & 13.856 & 1.019 & 4. 243 & 2.621 & 14. 124 & 3.329 \\
\hline 10 & 30 & 2. 2096 & 2. 1806 & 2.198 & 13.449 & .846 & 3.283 & 2. 209 & 11.381 & 3. 467 \\
\hline 11 & 28 & 1.9306 & 1.8156 & 1.920 & 13.171 & .726 & 2.677 & 1.928 & 9.558 & 3.570 \\
\hline 12 & 28 & 1.5286 & 1.5106 & 1.517 & 12.768 & .514 & 1.872 & 1.519 & 6.557 & 3.503 \\
\hline
\end{tabular}

[Series No. XXXIX. Height of weir $=P, 11.25$ feet; length of weir crest $=L, 15.969$ feet; width of channel $=b, 15.700$ feet; height of upstream crest corner, 10.25 feet; width of crest, 6 feet.]

\begin{tabular}{|c|c|c|c|c|c|c|c|c|c|c|}
\hline 1 & 96 & 0.6883 & $0670 ?$ & 0.683 & 11.934 & 0.170 & 0.565 & 0.684 & 2.027 & 3.586 \\
\hline 2 & 20 & 0.6883 & 0.6793 & .683 & 11.934 & .167 & .565 & .684 & 1.995 & 3.530 \\
\hline 3 & $2 \cdot 3$ & .4183 & . 4153 & . 118 & 11. 668 & .081 & .270 & .418 & .944 & 3. 497 \\
\hline 4 & 33 & 3,9806 & 3.9206 & 3.943 & 15. 194 & 1. 721 & 7.956 & 3.985 & 26.150 & 3.287 \\
\hline 5 & 24 & 3.1506 & 3,1366 & 3.145 & 14. 396 & 1. 280 & 5. 642 & 3.169 & 18. 431 & 3. 266 \\
\hline 6 & 23 & 2. 5066 & 2. 4806 & $.2,488$ & 13.739 & .966 & 3.958 & 2. 502 & 13. 268 & 3.352 \\
\hline 7 & 36 & 1.8986 & 1.8756 & 1. 884 & 13. 135 & .699 & 2. 601 & 1. 891 & 9. 186 & 3.532 \\
\hline 8 & 32 & 1.2716 & 1. 2626 & 1. 268 & 12.518 & .401 & 1. 432 & 1. 270 & 5.025 & 3. 509 \\
\hline 9 & 39 & .8286 & .8206 & .826 & 12.077 & .218 & .752 & .827 & 2.639 & 3.494 \\
\hline 10 & 32 & .5626 & .5606 & .561 & 11.811 & .125 & .420 & .561 & 1.481 & 3.526 \\
\hline
\end{tabular}


United States Geological Survey experiments at Cornell hydraulic laboratory on model of fat-top weirs with vertical faces.

[Series No. XL. Height of weir $=P, 11.25$ feet; length of weir crest $=L, 15.969$ feet; width of channe]= $b, 15.970$ feet; width of broad erest, 0.479 foot; nappe aerated.]

\begin{tabular}{|c|c|c|c|c|c|c|c|c|c|c|}
\hline \multirow[b]{2}{*}{ No. } & \multicolumn{4}{|c|}{$\begin{array}{l}\text { Measured head on experimen- } \\
\text { tal weir, in feet. }\end{array}$} & \multirow{2}{*}{$\begin{array}{c}A= \\
\text { area of } \\
\text { section } \\
\text { per foot } \\
\text { of } \\
\text { crest. }\end{array}$} & \multirow{2}{*}{$\begin{array}{l}y= \\
\text { mean } \\
\text { veloc. } \\
\text { ity of } \\
\text { ap- } \\
\text { proach, } \\
\text { in feet } \\
\text { per sec- } \\
\text { ond. }\end{array}$} & \multicolumn{2}{|c|}{$\begin{array}{l}\text { Head corrected } \\
\text { for velocity } \\
\text { of approach, } \\
\text { in feet. }\end{array}$} & \multirow{2}{*}{$\begin{array}{l}Q=\text { dis- } \\
\text { charge } \\
\text { per } \\
\text { foot of } \\
\text { crest, } \\
\text { in cubic } \\
\text { feet per } \\
\text { second. }\end{array}$} & \multirow{2}{*}{$\begin{array}{c}\text { Dis- } \\
\text { charge } \\
\text { coeffi- } \\
\text { cient } \\
C_{1} .\end{array}$} \\
\hline & $\begin{array}{l}\text { Num- } \\
\text { ber of } \\
\text { obser- } \\
\text { va- } \\
\text { tions. }\end{array}$ & $\begin{array}{l}\text { Maxi- } \\
\text { mum. }\end{array}$ & $\begin{array}{l}\text { Mini- } \\
\text { mum. }\end{array}$ & $\stackrel{\text { Mean }}{D}=$ & & & $H^{\frac{3}{2}}$ & $H$ & & \\
\hline 1 & 2 & 3 & 4 & 5 & 6 & 7 & 8 & 9 & 10 & 11 \\
\hline 1 & 19 & 0.6343 & 0.6293 & 0.631 & $11.88^{\circ}$ & 0.133 & 0.502 & 0.632 & 1.580 & 3. 148 \\
\hline 2 & 17 & .2643 & .2593 & .260 & 11.511 & .030 & .133 & .260 & .343 & 2.584 \\
\hline 3 & 18 & .2613 & .2513 & .264 & 11.515 & .033 & .136 & .264 & .380 & 2. 794 \\
\hline 4 & 30 & .1216 & .1206 & .124 & 11.375 & .011 & .044 & .124 & .129 & 2.943 \\
\hline 5 & 33 & 1.9916 & 1.9816 & 1. 989 & 13. 238 & .710 & 2.821 & 1.996 & 9.401 & 3. 332 \\
\hline 6 & 36 & 1. 6256 & 1. 6106 & 1. 618 & 12.868 & .530 & 2.065 & 1. 622 & 6.819 & 3.301 \\
\hline 7 & 26 & 1.2556 & 1.2496 & 1.256 & 12.507 & .377 & 1.412 & 1. 259 & 4.713 & 3. 338 \\
\hline 8 & 21 & .9756 & .9706 & .977 & 12.228 & .262 & .967 & .978 & 3. 209 & 3.318 \\
\hline 9 & 21 & .8213 & .8163 & .820 & 12.070 & .204 & .743 & .820 & 2.469 & 3.325 \\
\hline 10 & 10 & .6513 & 6493 & .650 & 11. 900 & .139 & .524 & .650 & 1.654 & 3.154 \\
\hline 11 & 10 & .4503 & .4483 & .449 & 11. 700 & .074 & .301 & .449 & .867 & 2.881 \\
\hline
\end{tabular}

[Series No. XLI. Height of weir $=P, 11.25$ feet; length of weir crest $=L, 15.969$ feet; width of channel $=b, 15.970$ feet; width of broad crest, 1.646 feet; nappe partly aerated.]

\begin{tabular}{|r|r|r|r|r|r|r|r|r|r|r|}
\hline 1 & 25 & 3.8606 & 3.8256 & 3.842 & 15.092 & 1.692 & 7.651 & 3.883 & 25.531 & 3.337 \\
2 & 25 & 3.1906 & 3.1666 & 3.177 & 14.428 & 1.317 & 5.730 & 3.202 & 18.995 & 3.315 \\
3 & 26 & 2.6906 & 2.6656 & 2.674 & 13.925 & 1.050 & 4.413 & 2.690 & 14.624 & 3.314 \\
4 & 31 & 2.0306 & 2.0116 & 2.022 & 13.272 & .680 & 2.889 & 2.028 & 9.021 & 3.123 \\
5 & 28 & 1.6043 & 1.5973 & 1.601 & 12.852 & .462 & 2.032 & 1.604 & 5.936 & 2.922 \\
6 & 27 & 1.2373 & 1.2293 & 1.233 & 12.484 & .307 & 1.372 & 1.234 & 3.835 & 2.796 \\
7 & 25 & .9443 & .9393 & .942 & 12.192 & .203 & .915 & .942 & 2.476 & 2.706 \\
8 & 34 & .6733 & .6693 & .671 & 11.922 & .123 & .575 & .692 & 1.472 & 2.560 \\
9 & 30 & .4893 & .4873 & .488 & 11.739 & .078 & .341 & .488 & .910 & 2.669 \\
10 & 18 & .3303 & .3293 & .330 & 11.581 & .045 & .190 & .330 & .520 & 2.742 \\
11 & 34 & .2113 & .2093 & .210 & 11.461 & .024 & .096 & .210 & .272 & 2.827 \\
12 & $\ldots .$. & $\ldots . .$. &...$\ldots$ & .122 & 11.373 & .011 & .043 & .122 & .130 & 3.047 \\
13 & 22 & .1253 & .1213 & .788 & 12.038 & .153 & .699 & .788 & 1.840 & 2.631 \\
14 & 20 & .4206 & .4136 & .417 & 11.668 & .064 & .270 & .417 & .750 & 2.782 \\
15 & 44 & .4206 & .4126 & .417 & 11.668 & .065 & .270 & .417 & .759 & 2.815 \\
\hline
\end{tabular}

[Series No. XLII. Height of weir=P, 11.25 feet; length of weir crest $=L, 15.969$ feet; width of ehannel $=b, 15.970$ feet; width of broad crest, 12.239 feet; nappe partly aerated.]

\begin{tabular}{|r|r|r|r|r|r|r|r|r|r|r|}
\hline 1 & 33 & 0.1706 & 0.1626 & 0.168 & 11.418 & 0.016 & 0.069 & 0.168 & 0.180 & 2.611 \\
2 & 32 & 4.3706 & 4.3416 & 4.353 & 15.604 & 1.584 & 9.196 & 4.389 & 24.716 & 2.688 \\
3 & 26 & 3.8316 & 3.8006 & 3.809 & 15.060 & 1.321 & 7.510 & 3.835 & 19.896 & 2.649 \\
4 & 38 & 3.0446 & 3.0256 & 3.032 & 14.283 & .971 & 5.317 & 3.046 & 13.876 & 2.610 \\
5 & 32 & 3.7356 & 3.7186 & 1.728 & 12.979 & .467 & 2.278 & 1.732 & 6.066 & 2.663 \\
6 & 29 & 3.5856 & 3.5776 & 2.580 & 13.831 & .787 & 4.166 & 2.589 & 10.882 & 2.612 \\
7 & 38 & 3.3966 & 3.3806 & 3.387 & 14.638 & 1.130 & 6.285 & 3.406 & 16.535 & 2.631 \\
8 & 27 & 2.2506 & 2.2406 & 2.243 & 13.494 & .657 & 3.373 & 2.249 & 8.870 & 2.629 \\
9 & 34 & 1.4706 & 1.4526 & 1.449 & 12.700 & .369 & 1.748 & 1.451 & 4.682 & 2.701 \\
10 & 22 & 1.0986 & 1.0906 & 1.096 & 12.347 & .253 & 1.149 & 1.097 & 3.129 & 2.723 \\
11 & 36 & .6406 & .6376 & .639 & 11.890 & .116 & .511 & .639 & 1.375 & 2.689 \\
12 & 28 & .6126 & .6106 & .611 & 11.862 & .109 & .478 & .611 & 1.290 & 2.700 \\
\hline
\end{tabular}


United States Geological Survey experiments at Cornell hydraulic laboratory on model of fat-top weirs with vertical faces-Continued.

[Series No. XLIII. Height of weir $=P, 11.25$ feet; length of weir crest $=L, 15.969$ feet; width of channel= $b, 15.970$ feet; width of broad crest, 16.302 feet; surface somewhat rough; nappe partly aerated.]

\begin{tabular}{|c|c|c|c|c|c|c|c|c|c|c|}
\hline \multirow{2}{*}{ No. } & \multicolumn{4}{|c|}{$\begin{array}{l}\text { Measured head on experimen- } \\
\text { tal weir, in feet. }\end{array}$} & \multirow{2}{*}{$\begin{array}{c}A= \\
\text { area of } \\
\text { section } \\
\text { per foot } \\
\text { of } \\
\text { crest. }\end{array}$} & \multirow{2}{*}{$\begin{array}{c}n= \\
\text { mean } \\
\text { veloc- } \\
\text { ity or } \\
\text { ap- } \\
\text { proach, } \\
\text { in feet } \\
\text { per sec- } \\
\text { ond. }\end{array}$} & \multicolumn{2}{|c|}{$\begin{array}{l}\text { Head corrected } \\
\text { for yelocity } \\
\text { of approach, } \\
\text { in feet. }\end{array}$} & \multirow{2}{*}{$\begin{array}{l}Q=\text { dis } \\
\text { charge } \\
\text { per } \\
\text { foot of } \\
\text { crest. } \\
\text { inl cubic } \\
\text { feet per } \\
\text { second. }\end{array}$} & \multirow{2}{*}{$\begin{array}{l}\text { Dis- } \\
\text { charge } \\
\text { coeff- } \\
\text { cient } \\
C_{1} .\end{array}$} \\
\hline & $\begin{array}{l}\text { ber of } \\
\text { obser- } \\
\text { va- } \\
\text { tions. }\end{array}$ & $\begin{array}{l}\text { Maxi- } \\
\text { mutm. }\end{array}$ & $\begin{array}{l}\text { Mini- } \\
\text { mum. }\end{array}$ & $\begin{array}{c}\text { Mean }= \\
D .\end{array}$ & & & $H^{\frac{3}{2}}$ & $H$ & & \\
\hline 1 & $\mathbf{2}$ & 3 & 4 & $\mathbf{5}$ & 6 & 7 & 8 & 9 & 10 & 11 \\
\hline 1 & 12 & 0.8536 & 0.8506 & 0.851 & 12.102 & 0.168 & 0.786 & 0.852 & 2.027 & 2.579 \\
\hline 2 & 12 & .4496 & .4426 & .447 & 11. 698 & .069 & .299 & .447 & .811 & 2.713 \\
\hline 3 & 10 & .3246 & .3106 & .312 & 11. 563 & .040 & .174 & .312 & .468 & 2.684 \\
\hline 4 & 26 & .6936 & .6856 & .689 & 11. 940 & .129 & .573 & .690 & 1.544 & 2. 696 \\
\hline 5 & 33 & 4.4506 & 4. 4176 & 4.432 & 15.683 & 1. 595 & 9.449 & 4. 469 & 25.011 & 2.647 \\
\hline 6 & 27 & 3.6806 & 3.6306 & 3.661 & 14. 912 & 1. 251 & 7. 076 & 3. 686 & 18.657 & 2.637 \\
\hline 7 & 34 & 2.9426 & 2. 9306 & 2. 935 & 14.186 & .930 & 5.062 & 2.948 & 13.200 & 2.608 \\
\hline 8 & 30 & 2.3626 & 2,3586 & 2.360 & 13.611 & .706 & 3.644 & 2.368 & 9.607 & 2.637 \\
\hline 9 & 23 & 1. 8956 & 1. 8866 & 1.890 & 13.141 & .520 & 2.607 & 1.894 & 6.811 & 2. 624 \\
\hline 10 & 25 & 1. 4826 & 1. $4756^{\circ}$ & 1. 480 & 12.731 & .374 & 1.804 & 1. 482 & 4.767 & 2.531 \\
\hline 11 & 26 & 1. 2086 & 1. $202 b^{\circ}$ & 1. 206 & 12.457 & $.2 \times 2$ & 1.327 & 1.208 & 3.520 & 2.652 \\
\hline
\end{tabular}

[Series No. XlIIIa. Height of weir $=P, 11.25$ feet. length of weir crest $=L, 15.969$ feet; width of channel $=b, 15.970$ feet; width of broad crest, 16.302 feet: smooth planed surface.]

\begin{tabular}{|r|r|r|r|r|r|r|r|r|r|r|}
\hline 1 & 19 & 0.3626 & 0.3596 & 0.361 & 11.612 & 0.050 & 0.217 & 0.361 & 0.576 & 2.653 \\
2 & 20 & .2496 & .2426 & .246 & 11.497 & .026 & .122 & .246 & .305 & 2.494 \\
3 & 44 & .1686 & .1646 & .167 & 11.418 & .013 & .068 & .167 & .153 & 2.240 \\
4 & 16 & .9906 & .9846 & .986 & 12.236 & .214 & .980 & .986 & 2.618 & 2.673 \\
5 & 28 & .9856 & .9776 & .981 & 12.232 & .210 & .973 & .982 & 2.568 & 2.638 \\
6 & 23 & .7886 & .7826 & .786 & 12.036 & .158 & .697 & .786 & 1.847 & 2.651 \\
7 & 31 & .6226 & .6206 & .621 & 11.872 & .110 & .490 & .622 & 1.309 & 2.670 \\
8 & 21 & .4976 & .4946 & .496 & 11.747 & .080 & .350 & .496 & .945 & 2.704 \\
9 & 25 & .3926 & .3906 & .392 & 11.643 & .058 & .246 & .392 & .670 & 2.728 \\
10 & 31 & $.2 \times 06$ & .2786 & .280 & 11.530 & .036 & .148 & .280 & .421 & 2.848 \\
11 & 28 & .1606 & .1606 & .161 & 11.411 & .016 & .064 & .161 & .184 & 2.851 \\
12 & 24 & .0776 & .0756 & .077 & 11.327 & .006 & .021 & .077 & .066 & 3.127 \\
\hline
\end{tabular}

[Series No. XLIV. Height of weir $=P, 11.25$ feet; length of weir crest=L, 15.969 feet; width of ehannel $=b, 15,970$ feet; wid th of broad crest, 8.980 feet.]

\begin{tabular}{|r|r|r|r|r|r|r|r|r|r|r|}
\hline 1 & 27 & 0.3136 & 0.3116 & 0.312 & 11.563 & 0.040 & 0.174 & 0.312 & 0.469 & 2.691 \\
2 & 20 & .1596 & .1576 & .159 & 11.410 & .014 & .064 & .159 & .163 & 2.570 \\
3 & 32 & .4196 & .4176 & .419 & 11.670 & .05 & .271 & .419 & .679 & 2.504 \\
4 & 20 & 3.0666 & 3.0506 & 3.058 & 14.309 & .986 & 5.386 & 3.073 & 14.105 & 2.619 \\
5 & 19 & 2.3306 & 2.3116 & 2.319 & 13.569 & .686 & 3.547 & 2.326 & 9.307 & 2.624 \\
6 & 17 & 2.8656 & 2.8186 & 1.856 & 13.107 & .512 & 2.537 & 1.860 & 6.712 & 2.646 \\
7 & 31 & 1.5166 & 1.5106 & 1.513 & 12.763 & .386 & 1.864 & 1.515 & 4.928 & 2.642 \\
8 & 28 & 1.2556 & 1.2506 & 1.252 & 12.503 & .297 & 1.404 & 1.254 & 3.718 & 2.649 \\
9 & 31 & 1.0396 & 1.0356 & 1.038 & 12.289 & .228 & 1.059 & 1.039 & 2.803 & 2.646 \\
10 & 29 & .8996 & .8916 & .897 & 12.148 & .186 & .850 & .897 & 2.254 & 2.652 \\
11 & 26 & .7326 & .7306 & .732 & 11.983 & .140 & .627 & .732 & 1.676 & 2.676 \\
12 & 32 & .5046 & .5006 & .502 & 11.753 & .083 & .356 & .502 & .971 & 2.727 \\
\hline
\end{tabular}


United States Geological Survey experiments at Cornell hydraulic laboratory on model of flat-top weirs with vertical faces-Continued.

[Series No. XLV. Height of weir $=P, 11.25$ feet; length of weir crest $=L, 15.969$ feet; width of channel $=b, 15.970$ feet; width of broad crest, 5.875 feet; nappe partly aerated.]

\begin{tabular}{|c|c|c|c|c|c|c|c|c|c|c|}
\hline \multirow{2}{*}{ No. } & \multicolumn{4}{|c|}{$\begin{array}{l}\text { Measured head on experimen- } \\
\text { tal weir, in feet. }\end{array}$} & \multirow{2}{*}{$\begin{array}{c}A= \\
\text { area of } \\
\text { section } \\
\text { per foot } \\
\text { of } \\
\text { crest. }\end{array}$} & \multirow{2}{*}{$\begin{array}{c}\ell^{\prime}= \\
\text { mean } \\
\text { veloc- } \\
\text { ity of } \\
\text { ap- } \\
\text { proach, } \\
\text { 1n feet } \\
\text { per } \\
\text { second. }\end{array}$} & \multicolumn{2}{|c|}{$\begin{array}{c}\text { Head corrected } \\
\text { for velocity } \\
\text { of approach, } \\
\text { in feet. }\end{array}$} & \multirow{2}{*}{$\begin{array}{l}Q=\text { dis- } \\
\text { charge } \\
\text { per } \\
\text { foot of } \\
\text { crest, } \\
\text { incubic } \\
\text { feet per } \\
\text { second. }\end{array}$} & \multirow{2}{*}{$\begin{array}{l}\text { Dis- } \\
\text { charge } \\
\text { coeffi- } \\
\text { cient } \\
G_{1} \text {. }\end{array}$} \\
\hline & $\begin{array}{l}\text { ber of } \\
\text { obser- } \\
\text { va- } \\
\text { tions. }\end{array}$ & $\begin{array}{l}\text { Maxi- } \\
\text { mum. }\end{array}$ & $\begin{array}{l}\text { Mini- } \\
\text { mum. }\end{array}$ & $\begin{array}{c}\text { Mean } \\
\quad D\end{array}$ & & & $H^{\frac{3}{2}}$ & $H$ & & \\
\hline 1 & $\mathbf{z}$ & 3 & 4 & $\tilde{\mathbf{s}}$ & 6 & 7 & 8 & 9 & 10 & 11 \\
\hline 1 & 24 & 0.1766 & 0.1726 & 0.174 & 11. 424 & 0.018 & 0.072 & 0.174 & 0.207 & 2.857 \\
\hline 2 & 32 & .2556 & .2526 & .253 & 11.504 & .029 & .127 & .253 & .337 & 2.647 \\
\hline 3 & 38 & .3906 & .3886 & .390 & 11. 640 & .055 & .243 & .390 & .641 & 2.635 \\
\hline 4 & 31 & .9906 & .9786 & .982 & 12. 233 & .209 & .975 & .983 & 2.557 & 2.624 \\
\hline 5 & 31 & 1. 2456 & 1. 2396 & 1. 242 & 12.492 & .293 & 1. 386 & 1. 243 & 3.666 & 2. 645 \\
\hline 6 & 32 & .9126 & .9066 & .908 & 12.159 & .189 & .367 & .909 & 2. 294 & 2.646 \\
\hline 7 & 42 & .7346 & .7306 & .733 & 11. 983 & .139 & .627 & .733 & 1. 670 & 2.663 \\
\hline 8 & 26 & 1. 0006 & .9916 & 1.996 & 13. 247 & .564 & 2.830 & 2.001 & 7. 469 & 2. 639 \\
\hline 9 & 33 & .5906 & .5806 & 1.585 & 12.836 & .410 & 2.000 & 1.587 & 5.264 & 2.632 \\
\hline 10 & 23 & .5916 & .5896 & .590 & 11.841 & .103 & .454 & .590 & 1. 220 & 2.689 \\
\hline 11 & 36 & .5216 & .5116 & .520 & 11.771 & .087 & .376 & .521 & 1.022 & 2.722 \\
\hline
\end{tabular}

[Series No. XLVI. Height of weir $=P, 11.25$ feet; length of weir erest=L, 15.969 feet; width of channel $=b, 15.970$ feet; width of broad crest, 3.174 feet; nappe partly aerated.]

\begin{tabular}{|r|r|r|r|r|r|r|r|r|r|r|}
\hline 1 & 26 & 0.2526 & 0.2446 & 0.250 & 11.501 & 0.029 & 0.125 & 0.250 & 0.333 & 2.665 \\
2 & 41 & .1916 & .1896 & .191 & 11.441 & .019 & .083 & .191 & .221 & 2.660 \\
3 & 34 & .4186 & .4156 & .417 & 11.668 & .066 & .269 & .417 & .766 & 2.845 \\
4 & 23 & 2.9686 & 2.9416 & 2.965 & 14.216 & 1.048 & 5.147 & 2.981 & 14.901 & 2.895 \\
5 & 30 & 2.4956 & 2.4806 & 2.486 & 13.737 & .803 & 3.943 & 2.496 & 11.032 & 2.798 \\
6 & 32 & 2.0376 & 2.0126 & 2.030 & 13.280 & .594 & 2.903 & 2.055 & 7.895 & 2.720 \\
7 & 33 & 1.6006 & 1.5906 & 1.597 & 12.847 & .417 & 2.022 & 1.599 & 5.360 & 2.650 \\
8 & 32 & 1.2326 & 1.2286 & 1.232 & 12.483 & .291 & 1.370 & 1.234 & 3.628 & 2.647 \\
9 & 32 & .9726 & .9706 & .972 & 12.222 & .208 & .959 & .972 & 2.549 & 2.658 \\
10 & 31 & .7866 & .7816 & .784 & 12.035 & .154 & .695 & .785 & 1.856 & 2.670 \\
11 & 38 & .6026 & .6006 & .602 & 11.852 & .106 & .467 & .602 & 1.254 & 2.686 \\
12 & 33 & .5056 & .5026 & .503 & 11.754 & .082 & .357 & .503 & .967 & 2.706 \\
\hline
\end{tabular}

[Series No. XLVII. Height of weir $=P, 11.25$ feet; length of weir crest=L, 15.969 feet; width of channel $=b, 15.970$ feet; width of broad crest, 0.927 foot; nappe partly aerated.]

\begin{tabular}{|r|r|r|r|r|r|r|r|r|r|r|}
\hline 1 & 27 & 0.1666 & 0.1636 & 0.165 & 11.416 & 0.016 & 0.067 & 0.165 & 0.180 & 2.690 \\
2 & 29 & .2816 & .2726 & .278 & 11.529 & .033 & .147 & .278 & .377 & 2.563 \\
3 & 31 & .4156 & .4106 & .412 & 11.663 & .060 & .265 & .412 & .700 & 2.644 \\
4 & 29 & 2.9446 & 2.9206 & 2.933 & 14.184 & 1.187 & 5.076 & 2.954 & 16.840 & 3.318 \\
5 & 29 & 2.5306 & 2.5116 & 2.522 & 13.772 & .970 & 4.037 & 2.535 & 13.360 & 3.314 \\
6 & 26 & 2.0196 & 2.0106 & 2.014 & 13.264 & .722 & 2.874 & 2.021 & 9.572 & 3.331 \\
7 & 29 & 1.5786 & 1.5706 & 1.592 & 12.842 & .512 & 2.015 & 1.596 & 6.582 & 3.266 \\
8 & 30 & 1.2296 & 1.2236 & 1.226 & 12.477 & .345 & 1.361 & 1.228 & 4.308 & 3.166 \\
9 & 27 & 1.0096 & 1.0046 & 1.007 & 12.258 & .248 & 1.012 & 1.008 & 3.046 & 3.008 \\
10 & 34 & .7786 & .7756 & .777 & 12.027 & .163 & .685 & .777 & 1.965 & 2.869 \\
11 & 27 & .6296 & .6276 & .629 & 11.879 & .117 & .499 & .629 & 1.389 & 2.786 \\
12 & 30 & .4616 & .4606 & .461 & 11.712 & .073 & .313 & .461 & .859 & 2.744 \\
\hline
\end{tabular}


Inited States Geological Survey experiments at Cornell hydraulic laborutory on model of Nerrimac River dam, at Lawrence, Mass.

[Height of weir $=P, 6.65$ feet; length of weir crest $=L, 9.999$ feet; width of channel $=b, 15.97$ feet.]

\begin{tabular}{|c|c|c|c|c|c|c|c|c|c|c|}
\hline \multirow{2}{*}{ No. } & \multicolumn{4}{|c|}{$\begin{array}{l}\text { Measured head on experimen- } \\
\text { tal weir, in feet. }\end{array}$} & \multirow{2}{*}{$\begin{array}{c}A= \\
\text { area of } \\
\text { section } \\
\text { per } \\
\text { foot of } \\
\text { crest. }\end{array}$} & \multirow{2}{*}{$\begin{array}{l}n= \\
\text { mean } \\
\text { veloc- } \\
\text { ity } \\
\text { of ap- } \\
\text { proach, } \\
\text { in feet } \\
\text { persec- } \\
\text { ond. }\end{array}$} & \multicolumn{2}{|c|}{$\begin{array}{l}\text { Head eorrected } \\
\text { for velocity } \\
\text { of approach, } \\
\text { in feet. }\end{array}$} & \multirow{2}{*}{$\begin{array}{l}Q=\text { dis- } \\
\text { charge } \\
\text { yer } \\
\text { foot of } \\
\text { crest, } \\
\text { incubic } \\
\text { feet per } \\
\text { second. }\end{array}$} & \multirow{2}{*}{$\begin{array}{l}\text { Dis- } \\
\text { charge } \\
\text { coeff- } \\
\text { cient } \\
C_{1} .\end{array}$} \\
\hline & $\begin{array}{l}\text { Num- } \\
\text { ber of } \\
\text { obser- } \\
\text { va- } \\
\text { tions. }\end{array}$ & $\begin{array}{l}\text { Maxi- } \\
\text { mum. }\end{array}$ & $\begin{array}{l}\text { Mini- } \\
\text { mumı. }\end{array}$ & $\underset{D}{\operatorname{Mean}}=$ & & & $H^{\frac{3}{2}}$ & $H$ & & \\
\hline 1 & 2 & 3 & 4 & 5 & 6 & 7 & 8 & 9 & 10 & 11 \\
\hline $1 a$ & & & & 4.001 & 10.651 & 2. 618 & 8.288 & 4.094 & 27.893 & 3.365 \\
\hline $2 a$ & & & & 3.980 & 10.580 & 2.563 & 8.054 & 4.018 & 27.120 & 3.367 \\
\hline $3 a$ & & & & 3.630 & 10.280 & 2. 309 & 7.029 & 3.670 & 23.740 & 3.377 \\
\hline 21 & & & & 3.630 & 10.280 & 2. 319 & 7.029 & 3.670 & 23. 738 & 3.377 \\
\hline 10 & & & & 3.166 & 9.816 & 1.939 & 5.769 & 3.216 & 19.039 & 3.300 \\
\hline 11 & & & & 2.815 & 9.465 & 1. 654 & 4.837 & 2.860 & 15.660 & 3.237 \\
\hline 22 & & & & 2.510 & 9.160 & 1.424 & 4.067 & 2.548 & 13.049 & 3.208 \\
\hline 23 & & & & 2.223 & 8.873 & 1. 200 & 3.361 & 2.244 & 10.652 & 3.169 \\
\hline 12 & & & & 2.130 & 8.780 & 1.127 & 3.150 & 2.149 & 9.898 & 3.142 \\
\hline 1 & & & & 2.041 & 8.691 & 1.066 & 2.933 & 2.049 & 9.265 & 3.158 \\
\hline 24 & & & & 1.850 & 8.500 & .982 & 2.542 & 1.868 & 7. 929 & 3.113 \\
\hline 2 & & & & 1.746 & 8.396 & .860 & 2.327 & 1.756 & 7. 2227 & 3.105 \\
\hline 3 & & & & 1.64 .5 & 8.290 & .802 & 2. 302 & 1.743 & 6.651 & 2.889 \\
\hline 13 & & & & 1. 496 & 8.146 & . 691 & 1.832 & 1.497 & 5. 631 & 3.074 \\
\hline 4 & & & & 1.322 & 7.972 & .600 & 1.528 & 1. 327 & 4. 791 & 3.135 \\
\hline 25 & & & & 1.268 & 7.918 & .556 & 1. 434 & 1.272 & 4.410 & 3.075 \\
\hline 5 & & & & 1.089 & 7.739 & .462 & 1.141 & 1.092 & 3.581 & 3.138 \\
\hline 6 & & & & .764 & 7.414 & .284 & .669 & .765 & 2. 108 & 3.151 \\
\hline 7 & & & & .584 & 7.234 & .195 & .417 & .585 & 1.412 & 3.158 \\
\hline 9 & $\cdots$ & & & .583 & 7.233 & .192 & .446 & .584 & 1. 389 & 3.114 \\
\hline 19 & ..... & & & .198 & 6.848 & .039 & .088 & .198 & 0.270 & 3.067 \\
\hline
\end{tabular}

In the accompanying tables (pp. 98-106), columns 2, 3, and 4 show, respectively, the number of observations of head and the maximum and minimum readings in each experimental period. In column 5 is given the mean head on the experimental weir deduced from the tape observations above described. Column 6 shows the area of cross section of the channel of approach per foot of crest. For suppressed weirs this quantity equals the sum of the height of weir plus the measured depth on crest. For weirs with one end contraction the quantity $A$ is obtained by dividing the total area of the water section. where $D$ is measured, by the net length of the weir crest corrected for the end contraction. For those series where the depth on the experimental weir was increased by contracting the weir to about onehalf of the channel width and introducing one end contraction, the net length of crest has been determined by the method of Francis, by deducting one tenth the head from the measured length of crest. The discharge per foot of crest of the experimental weir given in column 10 has been deduced from the discharge over the standard weir, 


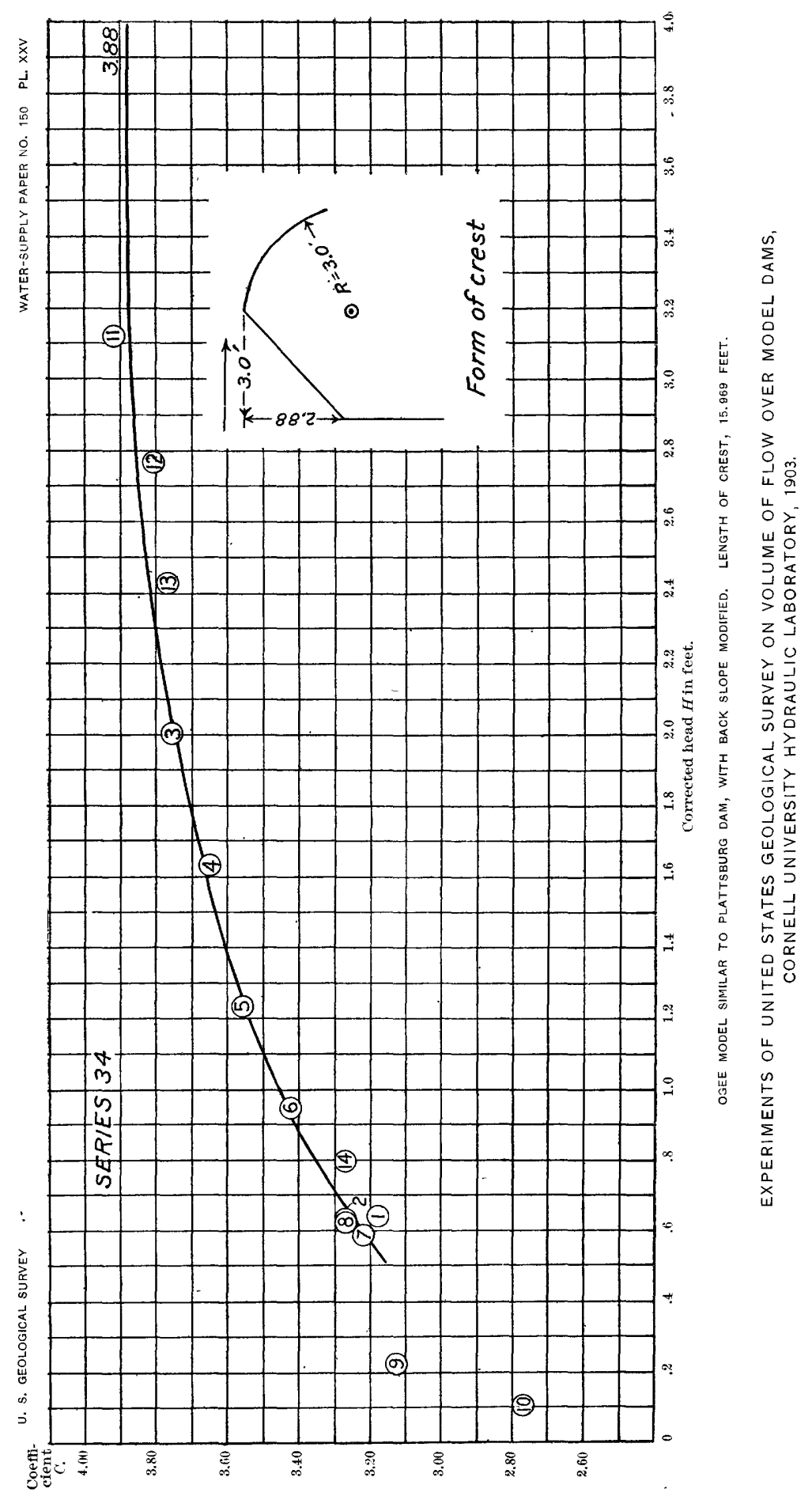


Plates XXIII and XXIV will be found immediately preceding
age 95. 

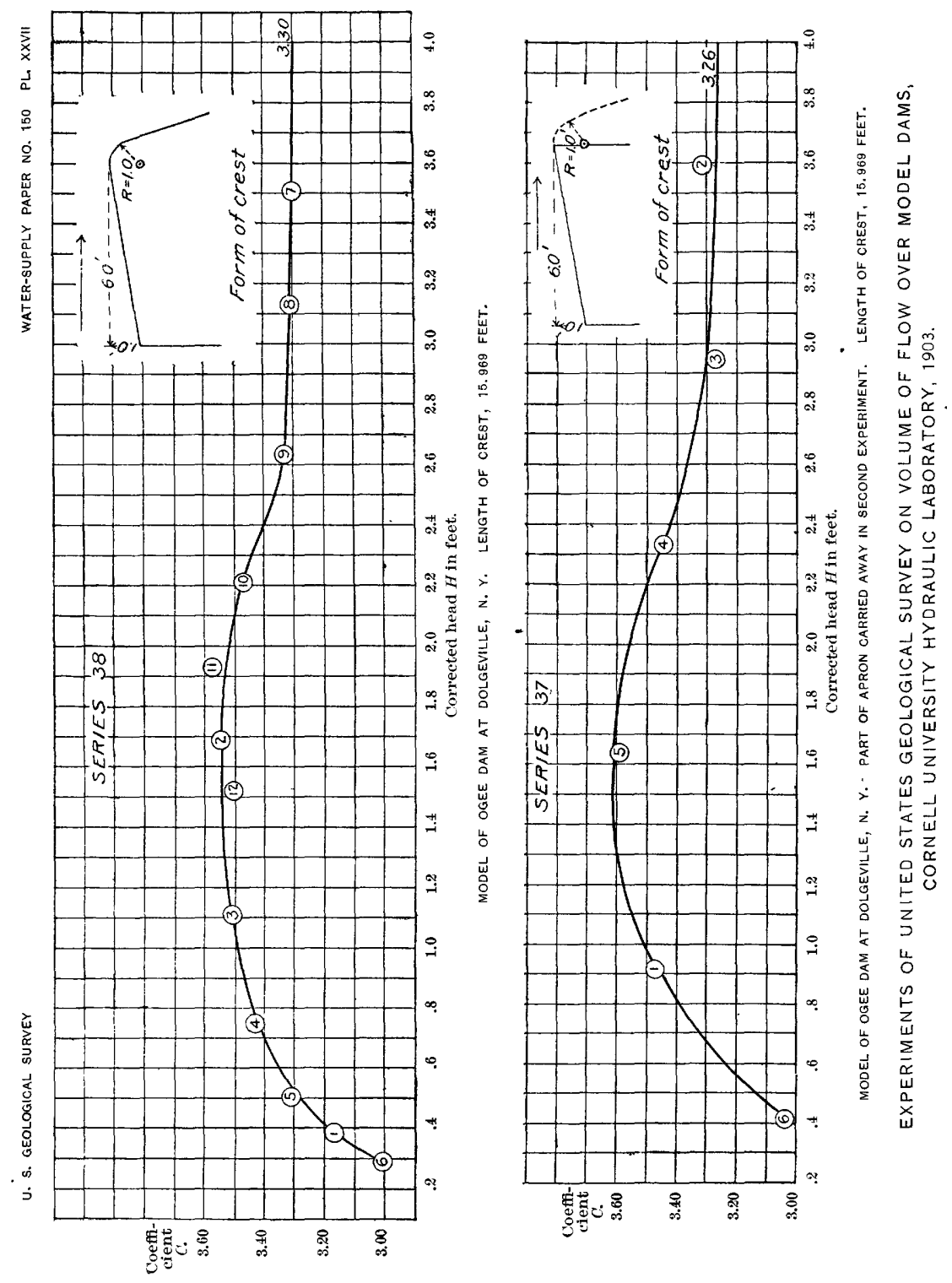


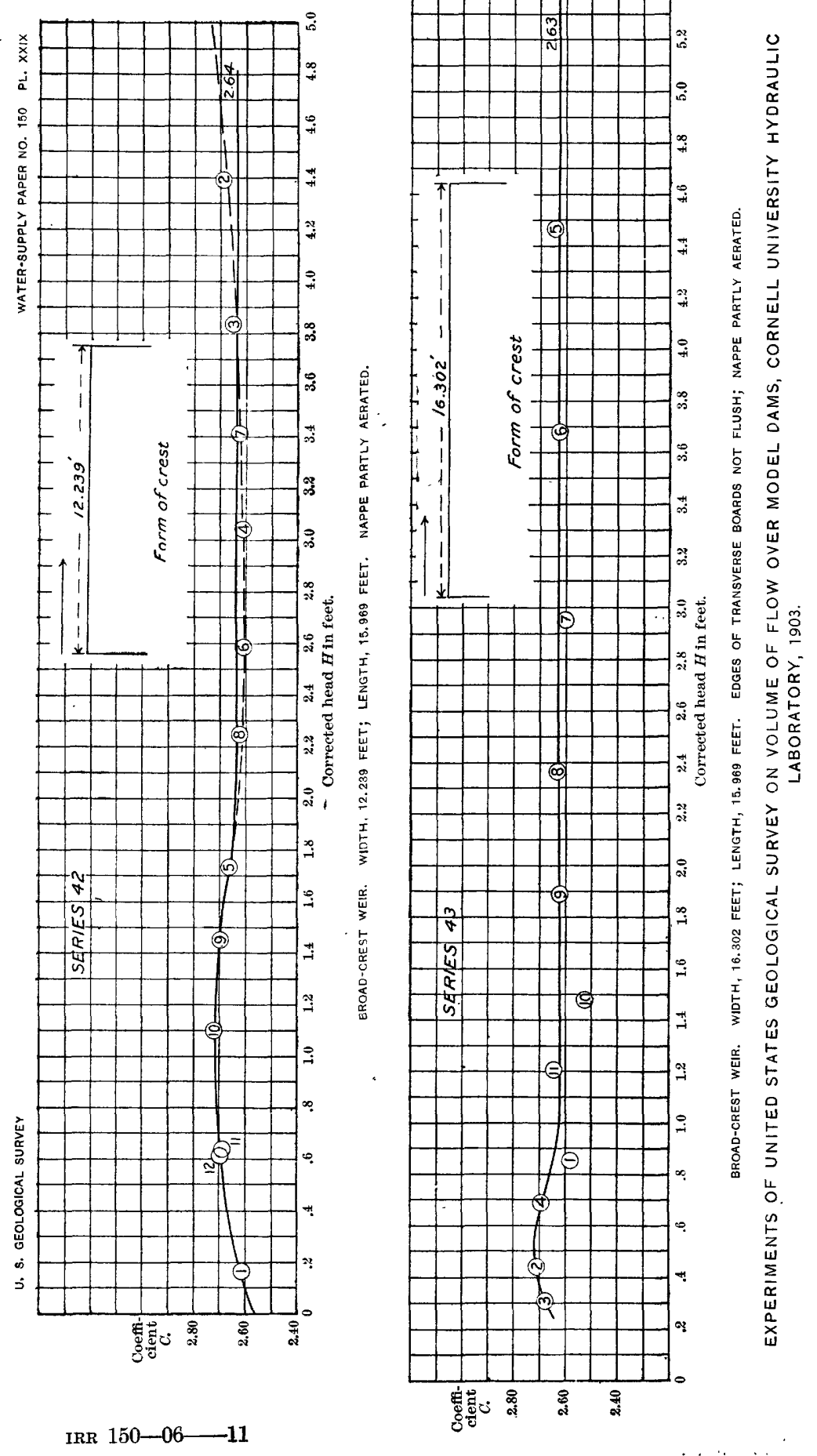




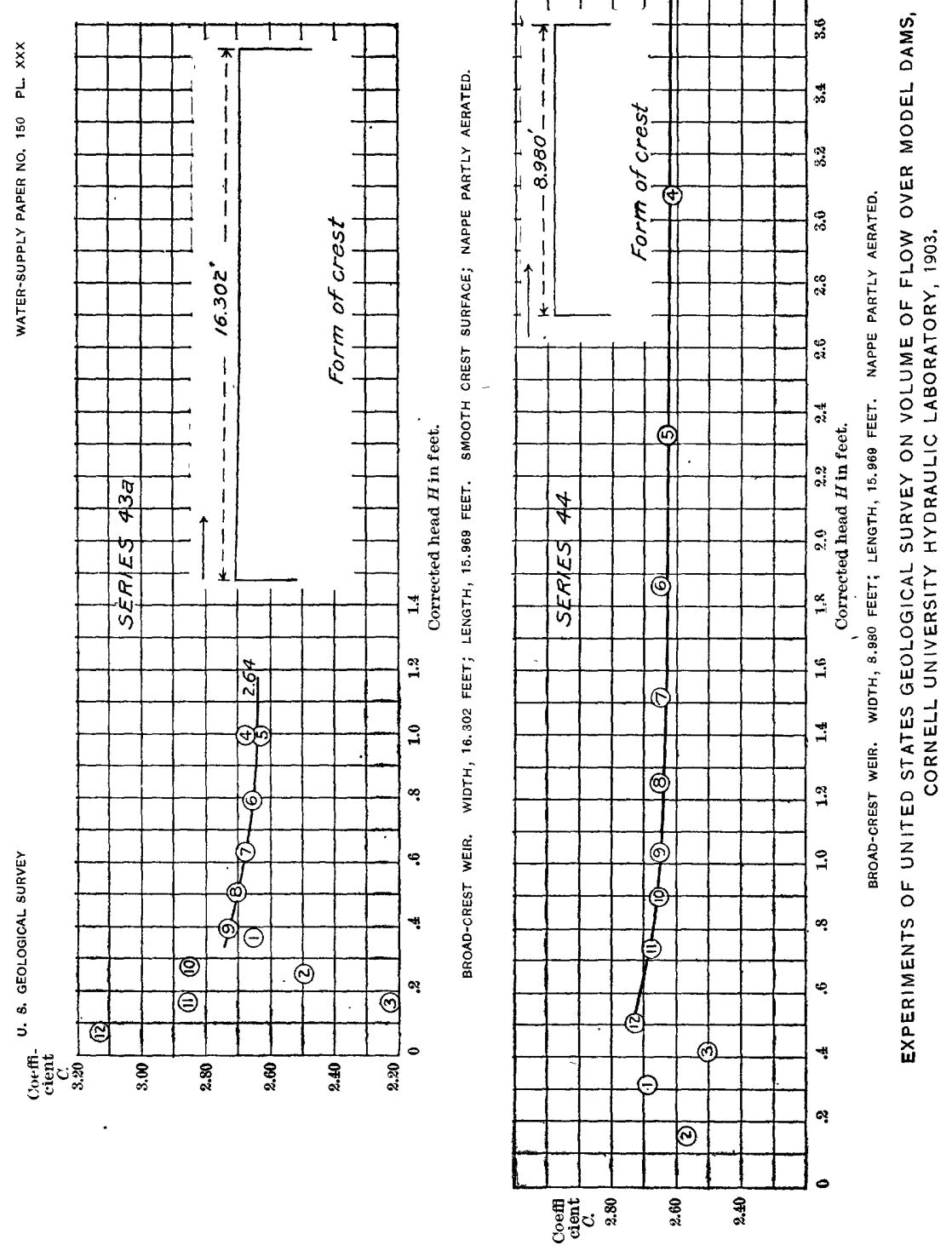




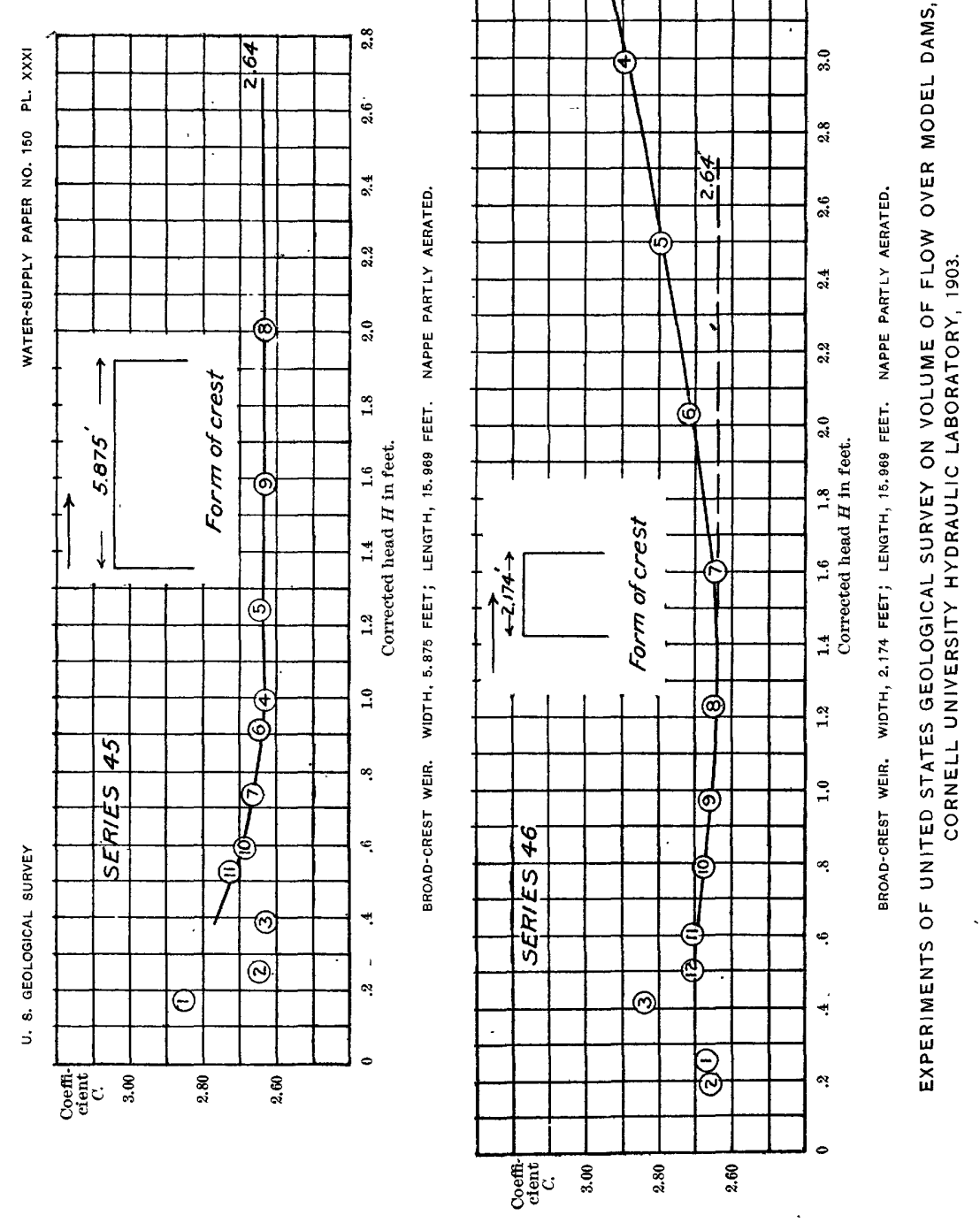




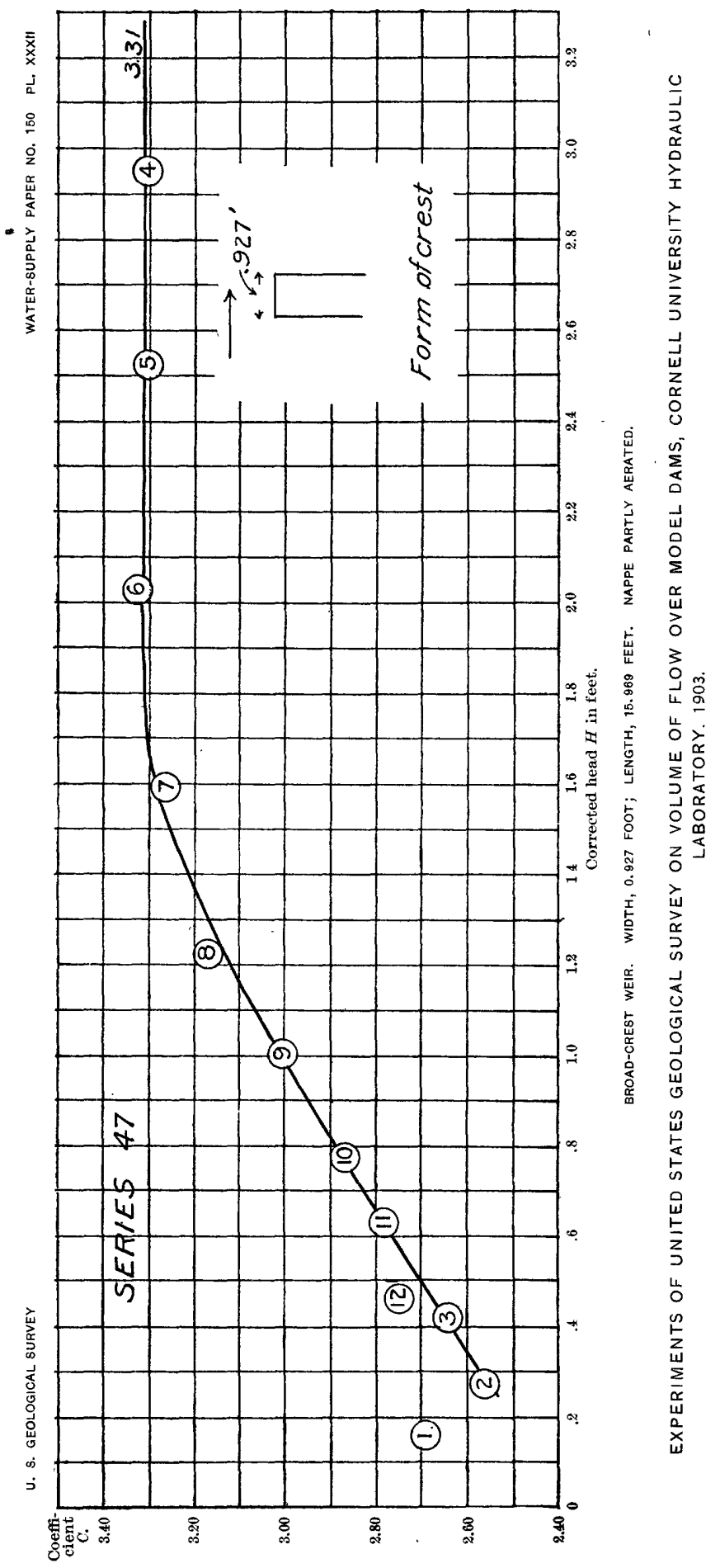


obtained, as described above, by dividing the total discharge by the net length of the experimental weir. The mean velocity of approach $v$, given in column 7 , has been obtained by the formula

$$
v=\frac{Q}{A}
$$

The correction for velocity of approach has heen carefully computed by the Francis formula

$$
H^{\frac{3}{2}}=(D+h)^{\frac{3}{2}}-h^{\frac{3}{2}}
$$

where

$$
h=\frac{v^{2}}{2 g} .
$$

The resulting values of $H^{\frac{3}{2}}$ are giren in column 8 . The corresponding values of $H$, given in column 9, have been obtained by interpolation from a table of three-halves powers. The discharge coefficient $C_{1}$ given in column 11 has been obtained by the formula

$$
C_{1}=\frac{Q}{I I^{3}}
$$

This coefficient represents the discharge per linear foot of crest, if the head is 1 foot, with no velocity of approach, it being the coefficient in a weir formula of the same form as that used by J. B. Francis for a thin-edged weir.

Pls. XXIII to XXXII show the coefficient diagrams deduced from these experiments.

EXPERIMENTS ON MODEL OF DAM OF THE ESSEX COMPANY, MERRIMAC RIVER, AT LAWRENCF, MASS. ${ }^{t}$

A series of experiments covering five different deptbs on crest was made by eJames B. Francis at lower locks, Lowell, Mass., November, 1852. The model had a crest length of 9.999 feet, with end contractions suppressed. Height of water was measured by hook gage in a chamber at one side of the channel, 6 feet upstrean from crest, so arranged as to give substantially the height of the still-water surface above the crest without correction for velocity of approach. The discharge was volumetrically determined as in Francis's thin-edged weir experiments.

The experiments of Francis covered depths on crest ranging from 0.5872 foot to 1.6338 feet. From these experiments he deduced the formula for discharge,

$$
Q=3.01208 L^{1.53} \text {. }
$$


If the discharge were expressed in terms of the usual formula, $Q=C_{1} L H^{\frac{3}{2}}$, with a varying coefficient $C_{1}$, we should have a continuously increasing coefficient.

A series of experiments on a similar model dam, 6.65 feet high, with crest length of 15.932 feet, was made at Cornell University hydraulic laboratory in 1903. The model there used differed from that shown by Francis only in the substitution of a flatter upstream slope near the bottom of the canal, as shown in Pl. XXXIII. The end contractions were suppressed and the depth on crest was measured with steel tape and plumb bob suspended over center of channel at points 14.67 feet and 29.82 feet, respectively, upstream from crest of experimental weir. Discharge was previously measured over the standard weir, calibrated by Bazin's and Fteley and Stearns's formulas, located at head of experimental canal.

The experiments covered a range of heads varying from 0.198 foot to 4.94 feet. In the majority of the experiments the head was observed at both points. The upper point of measuring depth was at the upstream end of the inclined approach. The lower point was over the incline, where the area of the section of approach was smaller and the velocity larger than in the deeper channel above. The experiments have been reduced with reference to the heads measured 29.82 feet upstream from crest. By comparison of the depths simultaneously observed at the two points correction factors have been deduced for the reduction of the remaining experiments, in which the head was observed at the downstream point of observation only.

The observed head has been corrected for velocity of approach by the formula of Francis. The resulting mean coefficient curve, based on 19 valid observations, shows a larger coefficient of discharge in the formula $Q=C_{1} L H^{\frac{3}{2}}$ than does that of Francis.

For a head of 1 foot the formula of Francis for the Merrimac dam gives a discharge of 90.3 per cent of that for a thin-edged weir. The Cornell experiments show 94.5 per cent of the discharge over a thinedged weir under the same head. 


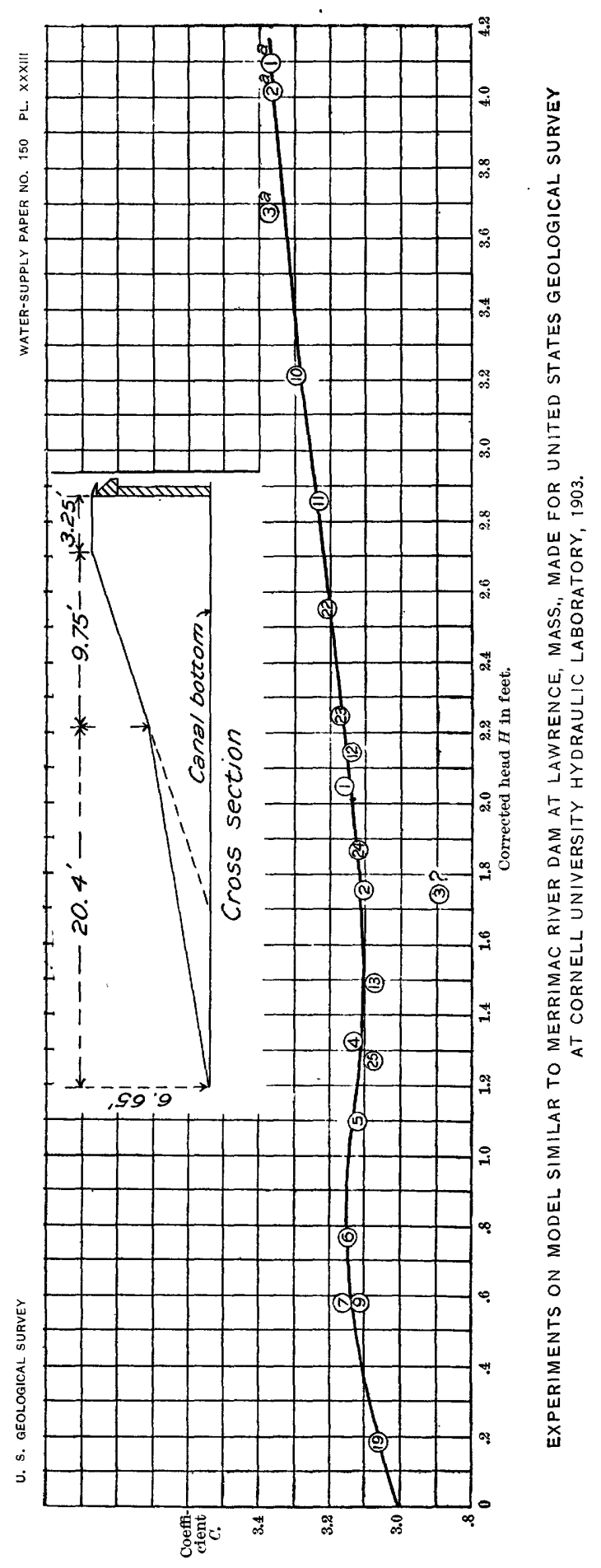


Discharge per foot of crest, Francis formula for Merrimac dam, compared with Cornell experiments on similar cross section.

\begin{tabular}{|c|c|c|c|c|c|c|c|}
\hline \multirow{2}{*}{$\begin{array}{l}\text { Depth on } \\
\text { crest, } H \text {. }\end{array}$} & \multirow{2}{*}{$\begin{array}{l}Q \text { per foot of } \\
\text { crest, in cu- } \\
\text { bic feet per } \\
\text { second, } \\
\text { Francis. }\end{array}$} & \multicolumn{2}{|c|}{$\begin{array}{l}\text { Coefficient } C_{1} \text { in formula } \\
\qquad Q=C_{1} L H^{\frac{3}{2}}\end{array}$} & \multirow{2}{*}{$\begin{array}{l}\text { Denth on } \\
\text { erest, } H .\end{array}$} & \multirow{2}{*}{$\begin{array}{l}Q \text { per foot of } \\
\text { crest, in cu- } \\
\text { bic feet per } \\
\text { second, } \\
\text { Francis. }\end{array}$} & \multicolumn{2}{|c|}{$\begin{array}{c}\text { ('oetficient } C_{1} \text { in formula } \\
\qquad=C_{1} L H^{\frac{3}{2}} \text {. }\end{array}$} \\
\hline & & $\begin{array}{l}\text { Francis's } \\
\text { formula. }\end{array}$ & $\begin{array}{l}\text { Cornell ex- } \\
\text { periments. }\end{array}$ & & & $\begin{array}{l}\text { Francis's } \\
\text { formula. }\end{array}$ & $\begin{array}{l}\text { Cornell ex- } \\
\text { periments. }\end{array}$ \\
\hline 0.15 & 0.1653 & 2. 845 & 3.05 & 0.85 & 2. 3490 & 2. 997 & \\
\hline .20 & .2567 & 2.871 & 3.06 & .90 & 2.5636 & 3.002 & 3.15 \\
\hline .25 & .3611 & 2. 889 & 3.07 & .95 & 2. 7846 & 3.007 & 3.15 \\
\hline .30 & .4774 & 2. 905 & 3. 08 & 1.00 & 3. 0121 & 3.012 & 3.15 \\
\hline .35 & .6043 & 2.913 & 3. 09 & 1. 15 & 3. 7500 & 3. 041 & 3. 13 \\
\hline .40 & .7431 & 2.937 & 3.11 & 1. 25 & 4.2378 & 3.033 & 3. 12 \\
\hline .45 & .8877 & 2.940 & 3.12 & 1. 50 & 5. 6012 & 3. 048 & 3. 10 \\
\hline .50 & 1.0430 & 2.940 & 3.13 & 1.75 & & & 3. 12 \\
\hline .55 & 1. 206 & 2.956 & 3.135 & 2.00 & 8.6975 & 3.075 & 3.14 \\
\hline .60 & 1. 379 & 2. 966 & 3.14 & 2.50 & $\ldots \ldots \ldots$ & 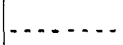 & 3.20 \\
\hline .65 & 1.5581 & 2.973 & 3.14 & 3.00 & 16. 1750 & 3.113 & 3. 26 \\
\hline .70 & 1. 7452 & 2. 980 & 3.14 & 3.50 & …..... & $\ldots . .$. & 3.31 \\
\hline .75 & 1.9395 & 2.986 & 3.14 & 4.00 & 25.1200 & 3.140 & 3.36 \\
\hline .80 & 2. 1408 & 2. 992 & 3.15 & & & & \\
\hline
\end{tabular}

Aside from Blackwell's experiments the Francis formula for the Merrimac dam was until recently the only one available for a large dam of irregular section, and for want of more appropriate data it has been used for the calculation of discharge over many forms of weirs of irregular section, and in spite of Francis's explicit caution, it has been applied where the heads differed widely from those used in the original experiments.

Considering the limited experiments on which it is based, Francis's Merrimac dam formula gives good agreement with the much more - extended experiments on a similar section made at Cornell hydraulic laboratory. 


\section{FLOW OVER WEIRS WITH BROAD CRESTS.}

\section{THEORETICAL FORMULA OF UNWIN AND FRIZELL. ${ }^{a}$}

Consider a weir of such breadth that the nappe becomes of sensibly uniform depth in the portion $B C$, fig. 8 , the upstream corner of the weir being rounded to prevent vertical contraction and the surface slightly inclined downstream so that it becomes parallel with the surface of the nappe $B C$.

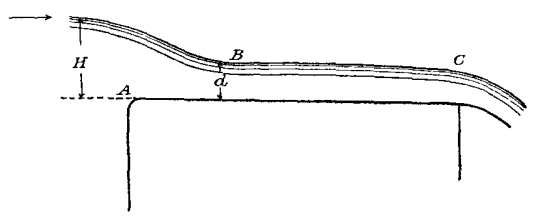

FIG. 8.-Broad-crested weir.

The fall causing the velocity $V$ in the section $B C$ is $H-d$. It follows that if $v$ is the mean velocity in $B C$

$$
v=\sqrt{2 g(\overline{H-d})} \quad Q=L d v=L d \sqrt{2 g(H-d)}
$$

In this equation $Q$ is 0 when $d=0$ or $d=H$. There must, therefore, be an intermediate value of $\bar{d}$. for which $Q$ will be a maximum. Differentiating we find for the condition of a maximum,

$$
\frac{d Q}{d d}=0=L \sqrt{\overline{2 g}}\left[\sqrt{H-\bar{d}}-\frac{1}{2} \frac{d}{\sqrt{H-\bar{d}}}\right]
$$

Giving $H-d=\frac{d}{2}$ and $d=\frac{2}{3} H$, or, for maximum discharge, one-third the head would be expended in producing the velocity of flow. With this value of $d$ the expression for discharge becomes

or if

$$
\left.\begin{array}{rl}
Q & =\frac{2 L H}{3 \sqrt{3}} \sqrt{2 g H}=0.38490 L H \sqrt{2 g H} \\
\sqrt{2 g} & =8.02, \\
Q & =3.087 L H^{\frac{3}{2}}
\end{array}\right\} \cdot \cdot \cdot \cdot
$$

In this formula frictional resistance has been neglected. The discharge given is the maximum for the conditions, and would result only if the stream discharges itself in accordance with the "principle of least energy."

Blackwell's experiments, given elsewhere, show a considerably larger coefficient for weirs 3 feet broad, slightly inclined downward, than for those with horizontal crests.

a Given by W. C. Unwin, in article 1 on Hydrodynamics in Ency. Brit. Independently derived by J. P. Frizell. See his Water Power, pp. 198-200. 
Let $d=K H$, then from the formula first given

$$
\begin{aligned}
& Q=L K H \sqrt{2 g H(1-K}) \\
& =K \sqrt{2 g(1-K) L H^{\frac{3}{2}}} \\
& \qquad C_{1}=8.02 K \sqrt{1-K} \quad \text {. . . . . . . }
\end{aligned}
$$

The theoretical coefficient $C_{1}$ can be computed from this equation if $K$ has been determined experimentally.

From profiles taken in connection with United States Deep Waterways experiments at Cornell University hydraulic laboratory in 1899 the following values of $D$ and $d$ for broad-crested weirs have been scaled and the ratio $d: D$ computed. $D$ was taken 4 feet upstream from the upper face of the weir, and does not include velocity of approach correction; values of $d_{1}$ and $d_{2}$ were taken at the lower-crest lip and center of crest, respectively. The value of $d_{3}$ at center of

\begin{tabular}{|c|c|c|c|c|c|}
\hline & & $D$ & $d_{1}$ & $d_{2}$ & $K=\frac{d_{2}}{D}$ \\
\hline$=$ & 1 & 0.90 & 0.35 & 0.52 & 0.58 \\
\hline & 2 & 1.15 & .45 & .68 & .59 \\
\hline & 3 & 1.80 & .75 & 1. 14 & .63 \\
\hline & 4 & 2.60 & 1.20 & 1.75 & .67 \\
\hline$\infty$ & 5 & 3.55 & 1. 72 & 2.52 & $.7 \mathbf{i}$ \\
\hline Broad-crested weir. & 6 & 5.15 & 2.20 & 3.15 & .61 \\
\hline \multirow{5}{*}{ 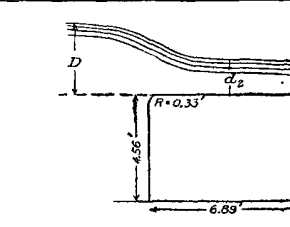 } & 1 & 1.00 & .35 & .50 & .50 \\
\hline & 2 & 1.32 & .53 & .70 & .50 \\
\hline & 3 & 1.98 & .75 & .98 & .50 \\
\hline & 4 & 2.85 & 1.08 & 1. 70 & .60 \\
\hline & 5 & 3.90 & 1.50 & 2.50 & .64 \\
\hline Broad-crested weir. & 6 & 4.65 & 2.10 & 3.10 & .61 \\
\hline
\end{tabular}
crest has been used in the computations.

Values of $D$ and $d$ for broad-crested weirs.

For low heads a sudden drop begins near the upstream crest corner and terminates at a distance 1.5 to $2 D$ below the upstream corner. From this point to within a distance about equal to $D$ from the downstream crest corner the surface is nearly parallel with the crest. If the width of crest is not greater than 2.5 to $3 D$ the nappe passes over the broad crest in a continuous surface curve, becoming more nearly convex as the ratio $D / B$ increases.

For low heads Cornell experiment 13, crest 6.56 feet wide; with rounded upstream corner, complies very well with the theory of dis- 
charge in accordance of the principle of least energy. The coefficient computed as above is

$$
\begin{aligned}
C_{1}^{\prime} & =8.02 \times 0.585 \sqrt{1-0.585} \\
& =8.02 \times 0.585 \times 0.6442 \\
& =3.02
\end{aligned}
$$

The experimental coefficient with head corrected for velocity of approach is 2.82 .

The following additional data may be cited:

Trautwine" quotes data of Elwood Morris, C. E., for Clegg's dam, Cape Fear River, North Carolina. Horizontal crest 8.42 feet wide, vertical faces. $I I=1.25$ feet. $d$ (throughout central portion of crest) $=0.50$ foot. $d \cdot H=0 . \pm 0$.

Thos. T. Johnston ${ }^{b}$ gives data of elaborate profiles of the nappe for Desplaines River dam, Illinois. Horizontal planed stone coping, vertical downstream face; upstream face batter, 12:1. $\quad H=0.587$ foot. $d=0.315$ to 0.307 foot in central, nearly level portion at distances 1.5 to 4 feet from upstream edge of crest. Johnston and Cooley deduce the coefficient $C=1.69$ for this case.

\section{BLACKWELL'S EXPERIMENTS ON DISCHARGE OF WATER OVER BROAD}

CRESTED WEIRS.

Experiments made by Thomas E. Blackwell, ${ }^{c}$ M. Inst. C. E., are of interest as being probably the first recorded for weirs with broad crests. The discharge was volumetrically measured, and the conditions were generally favorable to accuracy. The experiments were made on a side pond of the Kennet and Avon Canal, 106,200 square feet surface area, closed by a lock at each end, the water being admitted from time to time as required, the relation between area of reservoir and volume of discharge being such that there was no sensible variation in water level during an experiment.

The weir was constructed in a dock to which the water had access through an irregularly shaped channel 40 feet in width, cut off from the main pond by a submerged masonry wall 9 feet wide, situated 25 feet upstream from the weir, having its top 18 inches to 20 inches below water surface.

The water level in the pond being constant when outflow took place, the weir, which had a crest adjustable in a vertical plane, was set with its crest level at the depth below water surface desired for an experiment, by means of adjusting screws at the ends of the weir; the water

a Engineers' Pocket Book.

$b$ Johnston, T. T., and Cooley, E. L., New experimental data for flow over a broad-crest dam: Jour. Western Soc. Engrs., vol. 1, Jan., 1896, pp. 30-51.

c Original paper before Institution of Civil Engineers of London, reprinted in the Journal of the Franklin Institute, Philadelphia, March and April, 1852. 
was then allowed to waste through the weir until a uniform regimen of flow was established.

A gaging tank having a floor of brick laid in cement, with plank sides, and 449.39 cubic feet capacity, was erected at the foot of the weir. At a given signal the lid of this tank was raised, the time noted, and the rate of filling of the tank recorded by several observers. Such leakage from the tank as occurred was separately measured and allowed for. There was no correction for velocity of approach or for end contractions.

The wind was so slight as to be negligible, except during one series when there was a brisk wind blowing downstream. The experimenter states that parallel experiments on a quiet day indicated an increase of about 5 per cent in discharge due to this wind.

The crest of the thin-edged weir consisted of an iron plate barely one-sixteenth inch thick. A square-top plank 2 inches thick was attached to the weir, and an apron of deal boards, roughly planed so as to form an uninterrupted continuation downstream, constituted the wide-crested weir used in the experiments.

The coefficient $C_{1}$ from Blackwell's experiments has been worked out and is given in the following table. The measured depths taken in inches have also been reduced to feet.

IRR $150-06-12$ 
Blackwell's experiments on broad-crested weirs, Kennet and Avon Canal, England, 1850.

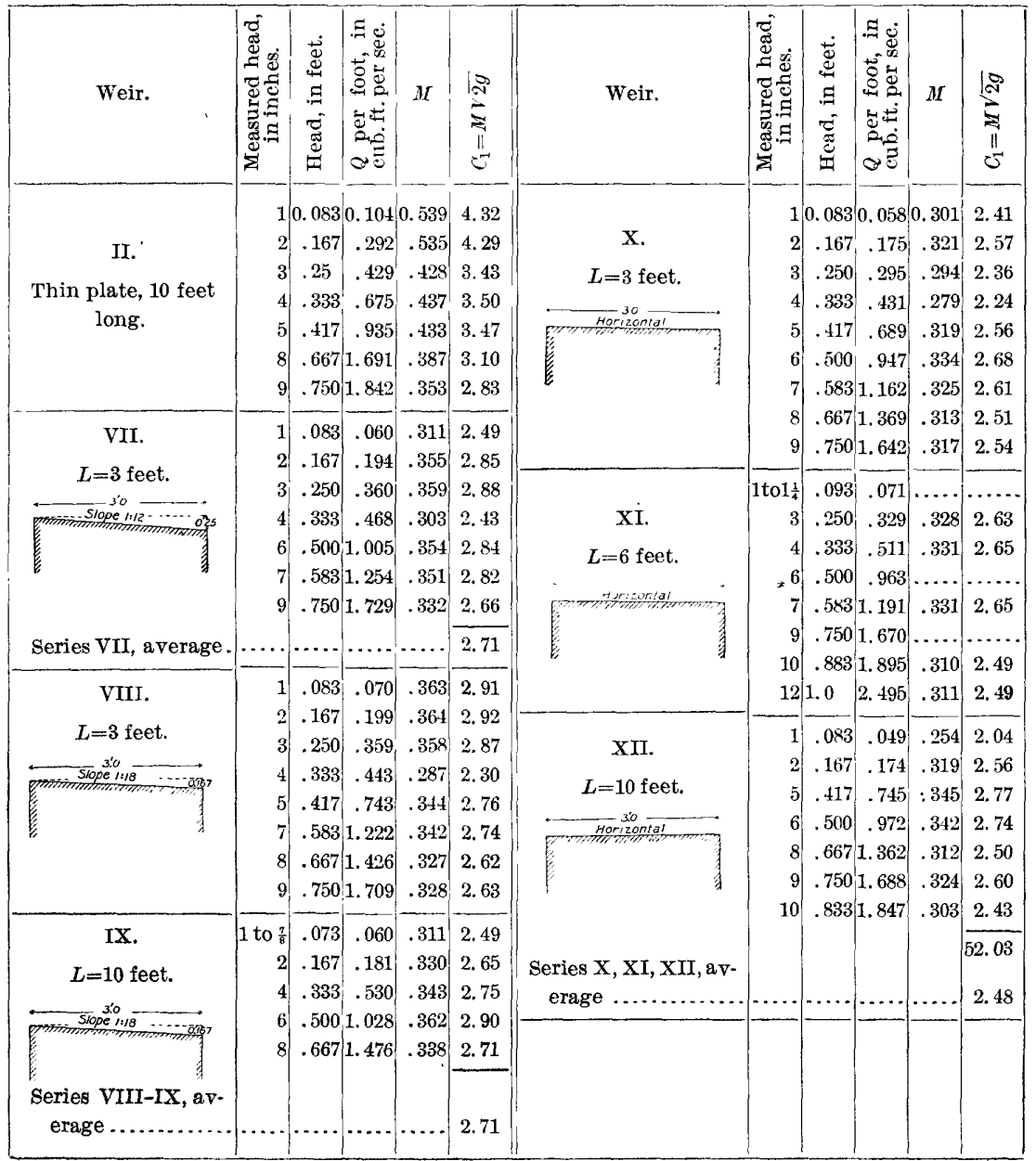

\section{EAST INDIAN ENGINEERS' FORMULA FOR BROAD-CRESTED WEIRS. ${ }^{a}$}

\section{This formula is}

$$
Q=\frac{2}{3} M^{\prime} L H \sqrt{2 g H}, \text { or if } \sqrt{2 g}=8.02, Q=5.35 M^{\prime} L H^{\frac{3}{2}}=C_{1} L H^{\frac{3}{2}}
$$

Where $M^{\prime}=$ coefficient for thin-edged weir ${ }^{b}=0.654-0.01 H$,

$$
M^{\prime}=M-\frac{0.025 M(B+1)}{H+1} \quad \cdot \quad \cdot \quad .
$$

$a$ Mullins, Gen. Joseph, Irrigation Manual, Madras, 1890.

$b$ See table giving values of $M$ and equivalent values of $C$, p. 22 . 
Experimental data not given. This formula gives values of $M^{\prime}$ or $C_{1}$ decreasing as breadth of crest $B$ increases, and for low heads increasing to a maximum for a head of about 1 foot, then slowly decreasing.

The formula reduces to

$$
C_{1}=C\left(\frac{H+1-0.025(B+1)}{H+1}\right)=R C
$$

For $B=0$

$$
C_{1}=C \frac{H+0.975}{H+1}=R C
$$

which differs by the ratio $R$ from the equivalent value of $C$ for a thin-edged weir.

Values of coefficient $C_{1}$ of discharge over " broad-crested weir and of $R$, the ratio of the

\begin{tabular}{|c|c|c|c|c|c|c|c|c|}
\hline$B$ & \multicolumn{2}{|c|}{1 foot. } & \multicolumn{2}{|c|}{2 feet. } & \multicolumn{2}{|c|}{3 feet. } & \multicolumn{2}{|c|}{4 feet. } \\
\hline & $R$ & $C_{1}$ & $R$ & $C_{1}$ & $R$ & $C_{1}^{\prime}$ & $R$ & $\mathrm{C}_{1}$ \\
\hline 1 & 0.975 & 3.359 & 0.962 & 3.316 & 0.95 & 3. 319 & 0. 938 & 3.230 \\
\hline 2 & .983 & 3. 335 & .975 & 3. 307 & .967 & 3.279 & .958 & 3.251 \\
\hline 3 & .988 & 3. 296 & .981 & 3.275 & .975 & 3. 255 & .969 & 3. 234 \\
\hline 4 & .990 & 3. 253 & .985 & 3.237 & $: 98$ & 3.220 & .975 & 3. 204 \\
\hline 5 & .992 & 3. 204 & 988 & 3. 191 & .983 & 3.177 & .979 & 3.164 \\
\hline 6 & .993 & 3.155 & .989 & 3.144 & .986 & 3.132 & .982 & 3.121 \\
\hline 7 & .994 & 3.104 & .991 & 3.095 & .988 & 3.085 & .984 & 3.075 \\
\hline 8 & .994 & 3.054 & .992 & 3. 045 & .989 & 3.037 & .986 & 3.028 \\
\hline 9 & .995 & 3.003 & .992 & 2.995 & .99 & 2.988 & .988 & 3.042 \\
\hline 10 & .995 & 2.950 & .993 & 2.944 & .991 & 2. 937 & .989 & 2.930 \\
\hline & \multicolumn{2}{|c|}{5 feet. } & \multicolumn{2}{|c|}{6 feet. } & \multicolumn{2}{|c|}{7 feet. } & \multicolumn{2}{|c|}{8 feet. } \\
\hline & $R$ & $C_{1}^{\prime}$ & $R$ & $C_{1}$ & $R$ & $C_{1}$ & $R$ & $C_{1}$ \\
\hline 1 & 0.925 & 3.182 & 0.912 & 3.144 & 0.9 & 3. 100 & 0.888 & 3.057 \\
\hline 2 & .95 & 3.22 & .942 & 3. 194 & .933 & 3. 166 & .925 & 3. 138 \\
\hline 3 & .962 & 3. 213 & .956 & 3. 192 & .95 & 3.171 & .944 & 3. 150 \\
\hline 4 & .97 & 3.193 & .965 & 3. 171 & .96 & 3.154 & .955 & 3.138 \\
\hline 5 & .975 & 3. 149 & .971 & 3.137 & .967 & 3.123 & .962 & 3.110 \\
\hline 6 & .978 & 3.11 & .975 & 3.098 & .971 & 3.080 & .968 & 3.076 \\
\hline 7 & .981 & 3.06 & .978 & 3.057 & .975 & 3. 046 & .972 & $3.036^{\circ}$ \\
\hline 8 & .983 & 3,017 & .980 & 3.012 & .977 & 2. 999 & .975 & 2.994 \\
\hline 9 & .985 & 2. 97 & .982 & 2. 966 & .98 & 3.019 & .978 & 2.950 \\
\hline 10 & .986 & 2.92 & .984 & 2.916 & .982 & 2. 910 & .979 & 2. 093 \\
\hline
\end{tabular}
former to $C$ the coefficient of discharge over a thin-edged weir, by Mullins's formula.

The values of $C_{1}$ given in the above table have been deduced from the corresponding values of $C$ for a thin-edged weir by Mullins's formula. The ratio $R$ may, if desired, be applied approximately to correct values of $C$ derived from other standard weir formulas. 


\section{FTELEY AND STEARNS EXPERIMENTS ON BROAD-CRESTED WEIRS. ${ }^{a}$}

The formula of Fteley and Stearns is based on five series of experiments made in the Sudbury River conduit, Boston, 1877, on weirs 2,3, 4,6 , and 10 inches wide, respectively. Suppressed weirs 5 feet long were used, the depths being as follows:

Fteley and Stearns experiments.

\begin{tabular}{|r|r|r|r|}
\hline $\begin{array}{r}\text { Width of } \\
\text { erest, in } \\
\text { inches. }\end{array}$ & $\begin{array}{c}\text { Number } \\
\text { of experi- } \\
\text { ments. }\end{array}$ & \multicolumn{2}{|c|}{$\begin{array}{c}\text { Range of depth observed } \\
\text { on brests, in feet. }\end{array}$} \\
\hline 2 & 7 & 0.1158 & 0.2926 \\
3 & 21 & .1307 & .4619 \\
4 & 25 & .1318 & .6484 \\
6 & 22 & .1320 & .8075 \\
10 & 17 & .1352 & .8941 \\
\hline
\end{tabular}

The results are given by the authors in the form of a table of corrections to be added algebraically to the measured head for the broadcrested weir to obtain the head on a thin-edged weir that would give the same discharge.

Fteley and Stearns's correction $c$ may be found approximately from the formula

$$
\left.c=0.2016 \sqrt{\left[(0.807 B-H)^{2}+0.2146 B^{2}\right.}\right]-0.1876 B \text { B . }
$$

or if $k=0.2016, n=0.1876, n=0.2146, O=0.807$, then

$$
Q=C L\left[H-m B+Z \sqrt{(O B-H)^{2}+n B^{2}}\right]^{\frac{3}{2}} \quad . \quad .
$$

If the head on a broad-crested weir is $H$, the discharge will be

$$
Q=C L(H+c)^{\frac{3}{2}} \quad \text {. . . . . . . }
$$

$C^{r}$ being the coefficient of discharge for thin-edged weirs.

If $C_{1}$ is the coefficient for the broad weir, then we may also write

Hence

$$
Q=C_{1} L H^{\frac{3}{2}}
$$

$$
\frac{C_{1}}{C}=\left(\frac{H+c}{H}\right)^{\frac{3}{2}} \cdot \cdot \cdot \cdot \cdot \cdot \cdot \cdot .
$$

From formula (66) have been calculated Fteley and Stearns's coefficients for weirs with nappe adhering to crest for nse in the formula

$$
Q=C L H^{\frac{3}{2}},
$$

$a$ Fteley and Stearus, Experiments on the flow of water, etc.: Trans. Am. Soc. C. E., vol. 12, pp. 86-96. 
correction for velocity of approach being made by adding $1.5 \frac{v^{2}}{2 g}$ to the measured head to obtain $H^{a}$

Values of the ratio $\frac{C_{1}^{\prime}}{C}$ of the coefficient of discharge for a broad-crested weir, by Fteley and Stearns's experiments, to that for a thin-edged weir.

\begin{tabular}{|c|c|c|c|c|c|c|}
\hline \multirow{2}{*}{$H$} & \multicolumn{6}{|c|}{ Width of erest, in inches. } \\
\hline & 3 & 4 & 6 & 8 & 10 & 12 \\
\hline 0.0 & & & $\cdots .$. & . & . & \\
\hline .1 & 0.7466 & 0. 74798 & 0.7562 & 0.7589 & 0.7576 & 0.7576 \\
\hline .2 & .8234 & .7878 & .7740 & .7679 & .7644 & .7624 \\
\hline .3 & .9172 & .8524 & .8003 & .7809 & .7727 & .7685 \\
\hline .4 & .9963 & .9201 & .8353 & .8003 & .7850 & .7768 \\
\hline .5 & … & .9806 & .8781 & .8255 & .8003 & .7865 \\
\hline .6 & & 1.0030 & .9230 & .8567 & .8199 & .7989 \\
\hline .7 & & & .9391 & .8911 & .8424 & .8150 \\
\hline .8 & & & .9997 & .9245 & .8695 & .8339 \\
\hline .9 & & & 1.0317 & .9553 & .8983 & .8552 \\
\hline 1.0 & & & & .9835 & .9406 & .8824 \\
\hline 1.1 & & & & 1.0090 & .9508 & .9027 \\
\hline 1.2 & & & & 1.0317 & .9732 & .9252 \\
\hline 1.3 & & & & 1. 0499 & .9948 & .9465 \\
\hline 1.4 & * & & & $\cdots \ldots$. & 1.0148 & .9657 \\
\hline 1.5 & & & & & 1.0317 & .9850 \\
\hline
\end{tabular}

BAZIN'S FORMULA AND EXPERIMENTS ON BROAD-CRESTED WEIRS.

These included series of about 20 periods each for depths not exceeding 1.4 feet on weirs of $0.164,0.328,0.656,1.315,2.62$, and 6.56 feet breadth of crest. The coefficient $C_{1}$ in the formula $Q=C_{1} L H^{3}$, deduced from a recomputation of the experiments on weirs 2.46 feet high, using the Francis velocity of approach correction, is given on Pl. IV.

Other experiments were made for the four narrower weirs with heights 1.148 and 1.64 feet, to determine the comparative velocity of approach effect.

Bazin shows that if the nappe is free from the downstream face of the weir it may assume two forms: (1) It may adhere to the horizontal crest surface; (2) it may become detached at the upstream edge in such a manner as to flow over the crest without touching the downstream edge. In the second case the influence of the flat crest evidently disappears and the discharge is like that over a thin-edged weir. The nappe usually assumes this form when the depth I) exceeds twice the breadth of crest $B$, but it may occur whenever the depth exceeds $\frac{3}{2} B$. Between these limits the nappe is in a state of instability; it tends to detach itself from the crest, and may do so under the

a Fteley and Stearns's formula for a thin-edged weir lias been used to calculate $Q$ in deriving these coefficients, the experiments having been made under conditions similar to those under which their formula was derived. 
influence of any external disturbance, as, for example, the entrance of air or the passage of a floating object over the weir.

When the nappe adheres to the crest, the coefficient $C_{1}$ depends chiefly on the ratio $D / B$ and may be represented by the formula

$$
C_{1}=C(0.70+0.185 D / B) \text {. . . . . }
$$

in which $C^{\prime}$ is the coefficient for a thin-edged weir.

When $D / B=1.50$ to $2, C / C=0.98$ to 1.07 if the nappe adheres to crest, or $C_{1}^{\prime} C^{\prime}=1.00$ if nappe is detached, and for $D / B>2, C_{1} / C=1.00$. Between the limits $D=1.5 B$ and $I=2 B$ the value which the coefficient $C_{1}$ will assume in a particular case is uncertain. Bazin considers that his formula gives accurate results for adhering nappes with breadth of crests up to 2 or 3 feet. For a crest 6.56 feet wide and $D=1.476$ feet he finds the result by formula (67) 93.4 per cent of that given directly by the experiment.

T'alues of the ratio $C_{1} / C^{\prime}$, for a broad-crested weir, with adhering nappe, by Bazin's formula. ${ }^{a}$

\begin{tabular}{|c|c|c|c|c|c|c|c|c|c|c|}
\hline \multirow{2}{*}{$D / B$} & \multicolumn{10}{|c|}{$C_{1} / C^{\prime}=0.700+0.185 D / B$} \\
\hline & 0 & 0.01 & 0.02 & 0.03 & 0.04 & 0.05 & 0.06 & 0.07 & 0.08 & 0.09 \\
\hline 0.0 & 0.700 & 0.7018 & 0.7037 & 0.7056 & 0.7074 & 0.7092 & 0.7111 & 0.7130 & 0.7148 & 0.7166 \\
\hline .1 & .7185 & .7204 & .7222 & .7240 & .7259 & .7278 & .7296 & .7314 & .7333 & .7352 \\
\hline .2 & .7370 & .7388 & .7407 & .7426 & .7444 & .7462 & .7481 & .7500 & .7518 & .7536 \\
\hline .3 & .7555 & .7574 & .7592 & .7610 & .7629 & .7648 & .7666 & .7684 & .7703 & .7722 \\
\hline .4 & .7740 & .7758 & .7777 & .7796 & .7814 & .7832 & .7851 & .7870 & .7888 & .7906 \\
\hline .5 & .7925 & .7944 & .7962 & .7980 & .7999 & .8018 & .8036 & .8054 & .8073 & .8092 \\
\hline 6 & .8110 & .8128 & .8147 & .8166 & .8184 & .8202 & .8221 & .8240 & .8258 & .8276 \\
\hline .7 & .8295 & .8314 & .8332 & .8350 & .8369 & .8388 & .8406 & .8424 & .8443 & .8462 \\
\hline .8 & .8480 & .8498 & .8517 & .8536 & .8554 & .8572 & .8591 & .8610 & .8628 & .8646 \\
\hline .9 & .8665 & .8684 & .8702 & .8720 & .8739 & .8758 & .8776 & .8794 & .8813 & .8832 \\
\hline 1.0 & .8850 & .8868 & .8887 & .8906 & .8924 & .8942 & .8961 & .8980 & .8998 & .9016 \\
\hline 1.1 & .9035 & .9054 & .9072 & .9090 & .9109 & .9128 & .9146 & .9164 & .9183 & .9202 \\
\hline 1.2 & .9220 & .9238 & .9257 & .9276 & .9294 & .9312 & .9331 & .9350 & .9368 & .9386 \\
\hline 1.3 & .9405 & .9424 & .9442 & .9460 & .9479 & .9498 & .9516 & .9534 & .9553 & .9572 \\
\hline 1.4 & .9590 & .9608 & .9627 & .9646 & .9664 & .9682 & .9701 & .9719 & .9738 & .9756 \\
\hline 1.5 & .9775 & .9794 & .9812 & .9830 & .9849 & .9868 & .9886 & .9904 & .9923 & .9942 \\
\hline
\end{tabular}

$a$ If there is velocity of approach, the value of $D / B$, not $H / B$, should be used as an argument. The ratio $C_{1} / C$ may be applied in a formula which includes the velocity of approach correction, either in the head $H$ or in the coefficient.

Bazin's formula gives ratios which continually increase as $H$ increases, $B$ remaining constant, and which continually decrease as $B$ increases, $I I$ remaining constant. It gives, however, a constant ratio for all widths or heads where the ratio $I I B$ is unchanged.

Compared with their respective standard weir formulas, Mullins's formula gives for a broad-crested weir a continuously decreasing ratio of discharge as $B$ increases from zero, $H$ remaining constant, and a continuously increasing discharge as $H$ increases from zero, $B$ remaining constant; Fteley and Stearus's experiments give a discharge ratio which is less than unity, but which varies in an irregular manner, depending on the head and breadth of weir. 
On referring to $\mathrm{Pl}$. IV, in which the Bazin coefficients are given in a form comparable with the experiments of the United States Geological Survey, it will be noticed that, except for the lowest heads, the coefficient curves are simple linear functions of the head. The rate of increase of the coefficients as the head increases grows rapidly less as the breadth of the weir increases, indicating that for a very broad weir the coefficient would be sensibly constant throughout the range of stability of the nappe.

For the narrower weirs the coefficients tend to increase rapidly almost from the start toward the value for a thin-edged weir or detached nappe. For the weirs 2.62 and 6.56 feet breadth of crest the total variation in the coefficient for the range of heads covered by the experiments is comparatively small. The average coefficients are as follows:

Average Bazin coefficients, broad-crested weirs.

\begin{tabular}{|c|c|c|c|c|}
\hline \multirow{2}{*}{$\begin{array}{c}\text { Bazin series } \\
\text { No. }\end{array}$} & \multirow{2}{*}{$\begin{array}{l}\text { Crest width, } \\
\text { in feet. }\end{array}$} & \multicolumn{2}{|c|}{ Range of head, in feet. } & \multirow{2}{*}{$\begin{array}{l}\text { Average con- } \\
\text { stant coeffi- } \\
\text { cient, } C_{1} \text {. }\end{array}$} \\
\hline & & From- & To- & \\
\hline 113 & 1. 312 & Lowest. & 0.60 & 2.64 \\
\hline \multirow{2}{*}{114} & \multirow{2}{*}{2.624} & \multirow{2}{*}{0.35} & .85 & 2.59 \\
\hline & & & 1. 32 & 2.62 \\
\hline 115 & 6.56 & .55 & Highest. & $a 2.58$ \\
\hline
\end{tabular}

$\alpha$ Coefficient increases slowly throughout.

The average coefficients show a fair agreement with the constant coefficient for broad-crested weirs with stable nappe deduced from the experiments of the United States Geological Survey (page 120).

EXPERIMENTS OF THE UNITED STATES GEOLOGICAL SURVEY ON BROADCRESTFD WEIRS.

The method of conducting these experiments and the detailed results are given on pages 95-107. The coefficient curves are presented on Pls. XXVIII to XXXII. It may be remarked here that the models were larger and the range of breadth of crest and depth of flow experimented upon was greater than in the earlier experiments described. In general, the laws of behavior of the nappe pointed out by Fteley and Stearns and Bazin were confirmed. 
The following table presents a résumé of the results:

Résumé of United States Geological Survey experiments on broad-crested weirs.

\begin{tabular}{|c|c|c|c|c|c|c|c|c|c|}
\hline \multirow{3}{*}{ Series. } & \multirow{3}{*}{$\begin{array}{l}\text { Breadth } \\
\text { of crest, } \\
\text { in feet. }\end{array}$} & \multirow{3}{*}{$\begin{array}{c}\text { Nappe } \\
\text { un- } \\
\text { stable } \\
\text { for } \\
\text { heads } \\
\text { less } \\
\text { than } \\
\text { values } \\
\text { below, } \\
\text { in feet. }\end{array}$} & \multirow{3}{*}{$\begin{array}{c}\text { Nappe } \\
\text { de- } \\
\text { tached } \\
\text { from } \\
\text { crest } \\
\text { at } \\
\text { head, } \\
\text { in feet. }\end{array}$} & \multicolumn{4}{|c|}{$\begin{array}{c}\text { Coefficient } C_{1} \text { varies between } \\
\text { the limits- }\end{array}$} & \multicolumn{2}{|c|}{$\begin{array}{l}\text { Coefficient } \\
\text { constant. }\end{array}$} \\
\hline & & & & \multicolumn{2}{|c|}{ Head, in feet. } & \multicolumn{2}{|c|}{ Coefficient. } & \multirow{2}{*}{$\begin{array}{l}\text { Above } \\
\text { head, } \\
\text { in feet. }\end{array}$} & \multirow[b]{2}{*}{$C_{1}$} \\
\hline & & & & From- & To- & From- & To- & & \\
\hline 40 & 0.479 & $0.3^{\circ}$ & 0.8 & 0.3 & 0.8 & 2.64 & 3.32 & 0.8 & 3. 32 \\
\hline 47 & .927 & .3 & 1.8 & .3 & 1.8 & 2.57 & 3. 31 & 1.8 & 3.31 \\
\hline 41 & 1.646 & .7 & 2.8 & .7 & 2.8 & 2.56 & 3.32 & 2.8 & 3.32 \\
\hline 46 & 3.174 & .5 & & .5 & 1.3 & 2.70 & 2.64 & 1.3 & Increases \\
\hline 45 & 5.875 & .5 & $\ldots \ldots$ & .5 & .9 & 2. 72 & 2.64 & .9 & 2. 64 \\
\hline 44 & 8. 980 & .5 & ......... & .5 & 2.0 & 2. 73 & 2. 62 & 2.0 & 2.62 \\
\hline 42 & 12.239 & & & .2 & 2.0 & $\begin{array}{l}2.62 \\
2.73\end{array}$ & 2.64 & 2.0 & a 2.64 \\
\hline 43 & 16. 302 & & & .3 & 1.1 & 2.68 & $\begin{array}{l}2.72 \\
2.63\end{array}$ & 1.1 & $b 2.63$ \\
\hline $43 a$ & 16.302 & .4 & & .4 & 1.0 & 2.72 & 2.64 & 1.0 & 2.64 \\
\hline Averag & & & & & & & & & 2.634 \\
\hline
\end{tabular}

a Coefficient shows tendency to increase slowly with head.

$b$ Edges of planed and matched boards not flush. Crest smoothed in series $43 a$.

The deductions that follow have been based on a consideration of earlier experiments as well as those here given for the first time.

1. For depths below 0.3 to 0.5 foot the nappe is very unstable, owing probably to magnified effect of crest friction and to the varying aeration or adhesion of the nappe to the downstream weir face.

2. For heads from 0.5 foot to 1 or 2 feet for very broad weirs, or from 0.5 foot to the point of detachment for narrower weirs, the coefficient is somewhat variable and changes in an uncertain manner. For the broader weirs, the range of variation of $C_{1}$ between the depths indieated is narrow, from 2.73 to 2.62 .

3. When the nappe becomes detached the coefficient remains nearly identical with that for a thin-edged weir. For the narrower weirs the coefficient increases rapidly within the range of tendency to detachment indicated by Bazin, i. e., for heads between $D$ and $2 D$.

4. On the broader weirs for depths exceeding 1 to 2 feet up to the limit of the experiments (about 5 feet), the experiments indicate a sensibly constant coefficient for all depths. Where there is any tendency to variation within the range indicated there is a gradual increase in $C_{1}$.

For weirs of 5 to 16 feet breadth the experiments show no conspicuous tendency for the coefficient $C_{1}$ to change with variation in either $H$ or $B$, the range of value of $C_{1}^{\gamma}$ being from 2.62 to 2.64 .

The line of detachment of the nappe for a weir of 5 feet breadth would be 7.5 to 10 feet head or perhaps more, and a higher head for 
broader crests. If this depth were ever reached it may be surmised that the coefficient $C_{1}$ would increase to about 3.33 at the point of detachment. It would also appear, as is in fact indicated in Bazin's formula, that the coefficient should very slowly increase with $H$ and decrease as $B$ increases, independent of the tendency to detachment of the nappe, and owing to the decreased relative effect of crest friction and contraction.

The United States Geological Survey experiments indicate that this effect is of relatively little significance for large heads and broad weirs, and hence a constant coefficient covering a wide range may be safely adopted.

The average coefficient, 2.64 , which we have tentatively chosen for weirs exceeding 3 feet in breadth under heads exceeding 2 feet, may apparently be applied for considerably lower heads for weirs of 5 feet or more crest breadth with but small error.

TABLE OF DISCHARGE OVER BROAD-CRESTED WEIRS WITH STABLE NAPPE.

A table has been calculated, using $C_{1}=2.6+$ and covering beads varying by 0.1 foot increment from zero to 10 feet (p. 177). It is considered applicable-for weirs of 3 feet or more crest breadth when $H / B$ lies between the general limits 0.25 to 1.5 . The coefficient 2.64 gives a discharge 79.2 per cent of that for a thin-edged weir by the Francis formula. The relative discharge obtained by other formulas and experimenters is shown in the following table:

Comparison of broad-crested weir formulas and experiments gining percentage of discharge over a thin-edged weir."

\begin{tabular}{l|r|r|r|r|r|r|r|r|r|r}
\hline & \multicolumn{2}{|c|}{1 foot width. } \\
\cline { 2 - 7 } \\
Formula or experiments.
\end{tabular}

a No velocity of approach.

$b$ East Indian engineers' formula, given in Mullins's Irrigation Manual, Madras Presidency.

$r$ Weir 2.17 feet broad.

$d$ Weir 5.88 feet broad.

Considering the low heads used, it may be noted that before Bazin's experiments only those of Blackwell included a weir breadth sufficient to eliminate the early tendency to detachment and permit the existence of the stable period for which a constant coefficient applies. 
Blackwell's experiments on weirs 3 feet broad indicate a maximum coefficient $C_{1}$ of 2.65 to 2.77 for a head of about 0.5 foot, decreasing as the head increased.

The experiments of the United States Deep Waterways Board on models with 2.62 and 6.56 foot crest width are shown on Pl. XV. For the narrower weir the coefficient increased uniformly with the head. The nappe did not leave the crest, although the experiments were continued to the limit $H B=2$, at which stage the coefficient exceeded that for a thin-edged weir. For the broader weir the coefficients are much less variable and the curves indicate that the coefficients approach a constant as the breadth of crest is increased.

It will be noted that considerable care must be exercised in determining the condition of the nappe for broad-crested weirs of inconsiderable width, while for those of greater breadth the wind may exert considerable influence on the nappe on the broad crest under lower heads. The constant coefficient 2.64 has been deduced from experiments on weirs with smooth, planed crests and sharp upstream crest angles. The effect of crest roughness on weir discharge is discussed on page 133 .

\section{EFFECT OF ROUNDING UPSTREAM CREST EDGE.}

Experiments by Fteley and Stearns ${ }^{a}$ indicate that the effect of rounding the upstream crest corner is to virtually lower the weir, by allowing the water to pass over with less vertical contraction. To determine the discharge over a thin-edged weir, with upstream crest - corner rounded to a radius $R$, add to the measured head the quantity

$$
K=0.70 R \text {. . . . . . . . . }
$$

The above formula was deduced by Fteley and Stearns from experiments on weirs with crest radii of one-fourth, one-half, and 1 inch. For heads not exceeding $0.17,0.26$, and 0.45 foot, respectively, the nappe adhered to the crest, and the formula does not apply.

The correction formula (68) is equivalent to increasing the discharge coefficient in the ratio

or nearly in the ratio

$$
\left(\frac{H+0.7 R}{H}\right)^{\frac{3}{2}}
$$

$$
\frac{H+R}{\bar{H}}
$$

A second series of experiments was made with rounded upstream edges of similar radii applied to a crest 4 inches wide, giving the correction formula for this case,

$$
K=0.41 R
$$


where $K$ is a correction to be added to the measured head before applying the formula for discharge over the broad-crested weir. This formula is applicable for depths of not less than 0.17 and 0.26 foot, respectively, on weirs with radii of one-fourth and one-half inch. Fteley and Stearns's formulas show the effect to decrease with the breadth of crest. It also decreases, when expressed as a percentage, with the head. These formulas are probably applicable to weirs with smaller, though not to those with greatly larger, radii than those of the experimental weirs.

Bazin experimented upon two weirs, duplicated in the United States Deep Waterways experiments, having crest widths of 2.624 and 6.56 feet, respectively, with an upstream crest radius of 0.328 foot $(\mathrm{Pl}$. IV).

Broad-crested weirs with rounded upstream corner.

\begin{tabular}{|c|c|c|c|c|}
\hline \multirow{3}{*}{$\begin{array}{l}\text { Head, in } \\
\text { feet. }\end{array}$} & \multicolumn{4}{|c|}{ Coefficient $C_{1}$, Bazin's experiments. } \\
\hline & \multicolumn{2}{|c|}{ Crest width, 2.62 feet. } & \multicolumn{2}{|c|}{ Crest width, 6.56 feet. } \\
\hline & $\begin{array}{l}\text { With angle } \\
\text { crest. }\end{array}$ & $\begin{array}{l}\text { With round- } \\
\text { ed crest. }\end{array}$ & $\begin{array}{c}\text { With angle } \\
\text { crest. }\end{array}$ & $\begin{array}{l}\text { With round- } \\
\text { ed crest. }\end{array}$ \\
\hline 0.25 & 2.52 & 2.85 & 2.40 & 2.58 \\
\hline .50 & 2.59 & 2.95 & 2.515 & 2.76 \\
\hline 1.00 & 2.64 & 3.00 & 2.575 & 2.89 \\
\hline \multirow[t]{2}{*}{1.50} & 2.69 & 3.04 & 2.635 & 2.92 \\
\hline & \multicolumn{4}{|c|}{ Coefficient $C_{1}$, United States Deep Waterways experi- } \\
\hline 1.50 & 2.67 & 2.92 & 2.39 & 2.81 \\
\hline 2.00 & 2.75 & 3.00 & 2.41 & 2.81 \\
\hline 3.00 & 2.93 & 3.17 & 2.44 & 2.81 \\
\hline 4.00 & 3.11 & 3.34 & 2.47 & 2.81 \\
\hline 5.00 & 3.30 & 3.51 & 2.50 & 2.81 \\
\hline 6.00 & Nappe free. & 3.00 & 2.53 & 2.81 \\
\hline
\end{tabular}

United States Deep Waterways series 14 and 15, Pl. XV, show the effect of rounding the upstream crest corner, radius 0.33 foot, on a model of the Rexford flats, New York, dam. In this case, with a weir 22 feet broad with 6:1 slope on each face, the effect of rounding becomes comparatively slight, the average increase being about 2 per cent.

United States Geological Survey experiments, series Nos. XXXV and XXXVI, Pl. XXVI, show the effect of the addition of a 4-inch radius ( 0.33 foot), quarter-round extension to the upstream face of the model of an ogee-section dam, having 4.5 feet crest width, $4.5: 1$ slope. 
Effect of rounded upstream crest corner on an ogee dam.

\begin{tabular}{|c|r|r|r|}
\hline $\begin{array}{c}\text { Head, in } \\
\text { feet. }\end{array}$ & $\begin{array}{c}\text { Chambly } \\
\text { model, } \\
\text { series 35. }\end{array}$ & $\begin{array}{c}\text { Same, with } \\
\text { rounded up- } \\
\text { stream crest } \\
\text { corner. }\end{array}$ & $\begin{array}{c}\text { Difference } \\
\text { per cent of } \\
\text { Francis's } \\
\text { coefficient. }\end{array}$ \\
\hline 0.50 & 3.18 & 3.29 & +1.5 \\
1.00 & 3.30 & 3.34 & +1.2 \\
2.00 & 3.42 & 3.51 & +2.7 \\
3.00 & 3.49 & 3.64 & +4.5 \\
\hline
\end{tabular}

\section{EXPERIMENTS ON WEIRS WITH DOWNSTREAM SLOPE, OR APRON, OF VARYING INCLINATION.}

Aside from the experiments of Blackwell on weirs with very slight inclination and a few series by other experimenters on weirs of irregular section involving aprons, the data on this subject are limited to those of Bazin's experiments.

Bazin selected a number of weir types, each having a constant top width, height, and upstream inclination and applied to each a number of different downstream slopes. ${ }^{a}$

TRIANGULAR WEIRS WITH VERTICAL UPSTREAM FACE AND SLOPING APRONS.

Such weirs are occasionally used, as where the apron slopes to the stream bed in log slides. A similar form in which the downstream slope terminates at a greater or less distance from the vertical upstream face is not uncommon, and to this form the Bazin experiments may probably be applied, provided the breadth of the sloping apron is considerable. The experiments are of special interest, however, as showing the effect of attaching a sloping apron to the downstream face of a thin-edged weir, and by inference affording an indication of the effect of a similar apron attached to any form of cross section. The results of Bazin's experiments recomputed on the basis of the Francis formula are shown on Pl. V.

Four series of experiments on weirs 2.46 feet high are included. For all these series the coefficient $C$ tends to remain nearly constant for the range of heads covered, 0.2 foot to 1.5 feet, there being a slight increase in $C$ with the lower heads only.

Two series on weirs 1.64 feet high are also given. In series 145 , slope of apron $3: 1$, there is a general increase in coefficient with head below 0.9 foot. Series 138, for a weir 1.64 feet high, is duplicated on a weir 2.46 feet high, and the latter series is given preference in the general curve. The lower weirs indicate in both cases slightly higher coefficients, possibly owing to the incomplete elimination of the effect of excessive velocity of approach.

a Bazin did not attempit to collate the results extensively. His general résumé has been translated by the writer, and may be found in Rept. U. S. Board of Engineers on Deep Waterways, pt. 2, 1900, pp. 646-658. 
The average constant coefficients for the several series are shown in the following table:

Mean coefficients, triangular weirs with varying apron slope.

\begin{tabular}{|c|c|c|c|c|c|c|c|}
\hline \multirow{2}{*}{ Series. } & Height. & Slope. & \multicolumn{2}{|c|}{ Range of head. } & \multicolumn{2}{|c|}{ Range of c. } & Average $\%$ \\
& & & From- & To- & From- & To- & \\
\hline 136 & 2.46 & $1: 1$ & 0.3 & 1.40 & 3.84 & 3.88 & 3.85 \\
137 & 2.46 & $2: 1$ & .3 & 1.6 & 3.48 & 3.52 & 3.50 \\
138 & 1.64 & $2: 1$ & .7 & 1.5 & 3.56 & 3.58 & 3.57 \\
145 & 1.64 & $3: 1$ & .9 & 1.5 & 3.39 & 3.41 & 3.40 \\
141 & 2.46 & $5: 1$ & .6 & 1.5 & 3.08 & 3.14 & 3.13 \\
142 & 2.46 & $10: 1$ & .75 & 1.5 & 2.90 & 2.93 & 2.91 \\
\hline
\end{tabular}

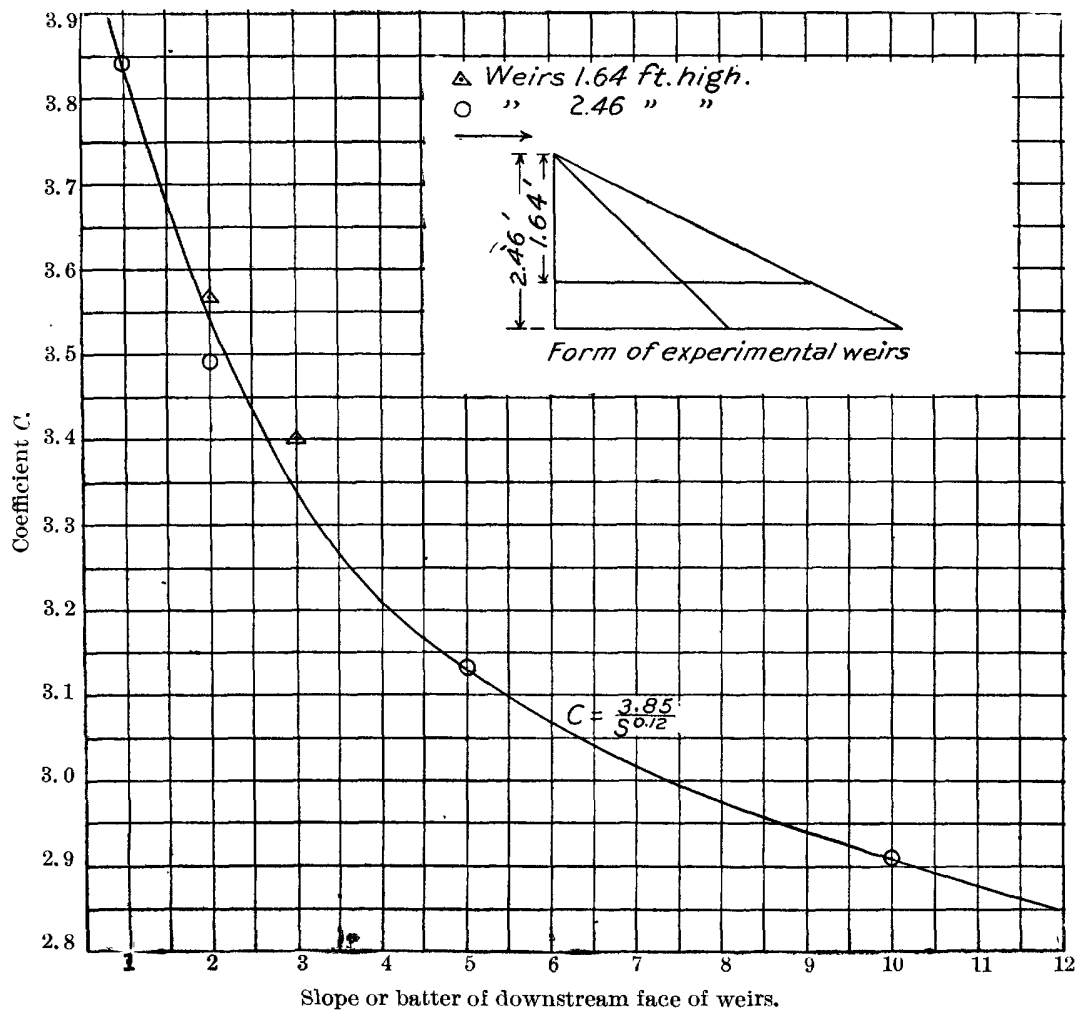

FIG. 9.-Coefficient curve for triangular weirs.

The mean coefficients have also been plotted on fig. 9 and a general curve drawn. This curve becomes approximately a straight line when plotted on logarithmic cross-section paper. Its equation expressed in logarithmic form is

$$
C=\frac{3.85}{S^{0.12}} \quad \cdot \quad \cdot \quad \cdot \quad \cdot \cdot \cdot \cdot .
$$

where $S$ is the batter or slope of apron. 
If $S=6$, then, solving by logarithms,

$$
\begin{aligned}
\log 6 & =0.7781513 \\
\log 6^{0.12} & =0.0933782 \\
\log \frac{1}{6^{0.12}} & =9.9066218 \\
\log 3.85 & =0.5854607 \\
\log C & =0.4920825 \\
C & =3.105
\end{aligned}
$$

Fig. 9 gives $\mathrm{C}=3.07$; the difference is 1 per cent.

The following conclusions deduced from the recomputed data conform in general with those of Bazin:

1. For steep apron slopes where the nappe tends to break free, the apron materially increases the discharge by permitting a partial vacuum to be formed underneath the nappe.

2. For flat apron slopes the conditions approach those for a horizontal crest.

3. For an apron slope of about $3: 1$, the discharge is nearly the same as for a thin-edged weir.

4. For slopes greater than $3: 1$ the apron diminishes the discharge the amount of diminution increasing as the slope becomes flatter.

TRIANGULAR WEIRS WITH UPSTREAM BATTER 1:1 AND VARYING SLOPE OF APRON.

Three series of experiments by Bazin are included (Pl. IX), all made from weirs 1.64 feet high. The results are comparable among themselves, but owing to the high velocity of approach their general applicability is less certain.

Series No. 161, downstream slope 1:1, shows a generally decreasing coefficient with an apparent tendency to become constant through a narrow range of heads, from 0.5 to 0.9 foot, with $C=$ about 4.11 .

Series No. 163 and 165, with apron slopes of $2: 1$ and 5:1, give coefficient lines, which may be fairly represented by the constants 3.82 and 3.47 , respectively. These coefficients compare with those for vertical weirs with the same apron slopes as follows:

Comparative coefficients.

\begin{tabular}{|c|c|c|c|}
\hline $\begin{array}{c}\text { Batter of } \\
\text { apron. }\end{array}$ & $\begin{array}{c}\text { Vertical } \\
\text { face. } \\
C\end{array}$ & $\begin{array}{c}\text { Face in- } \\
\text { clined 1:1. } \\
C\end{array}$ & $\begin{array}{c}\text { Difference, } \\
\text { per cent, } \\
\text { Francis's } \\
\text { coefficient. }\end{array}$ \\
\hline $1: 1$ & 3.85 & 4.11 & +7.8 \\
$2: 1$ & 3.53 & 3.82 & +8.7 \\
$5: 1$ & 3.13 & 3.47 & +10.2 \\
\hline
\end{tabular}


EXPERIMENTS ON WEIRS OF TRAPEZOIDAL SECTION WITH UPSTREAM SLOPE OF $\frac{1}{2}: 1$, HORIZONTAL CREST, AND VARYING DOWNSTREAM SLOPES.

Five series of Bazin's experiments on weirs 2.46 feet high, with crest width of 0.66 foot, are shown on Pls. VI and VII. The curves indicate coefficients increasing with the head, the rate of increase being more rapid for the steeper apron slopes. There is a tendency to depression at about 0.4 foot head, representing, possibly, the point at which the nappe changes from adhering to depressed condition on the downstream face. The curves are all convex, and apparently approach a constant, which was not, however, reached within the limit of experiments, except, perhaps, for the flattest slope of 5:1. The coefficients increase in value as the steepness of the apron slope increases.

Three series of experiments on weirs similar to those above described, but with flat crests 1.317 feet wide, are shown on Pl. VIII. The coefficient curves are of uncertain form for heads below 0.6 foot. For greater heads they may be represented by inclined straight lines. The coefficients increase uniformly with the head, the initial values for 0.6 foot head being nearly the same for the several slopes, the increase being more rapid for the steeper downstream slopes.

It may be seen from the following table that increased width of the flat crest, as compared with that of the preceding weir, causes a decrease in the discharge.

Comparative coefficients at 1-foot head, weirs with fat crests and $\frac{1}{2}: 1$ upstream slope.

\begin{tabular}{|c|c|c|}
\hline \multirow{2}{*}{$\begin{array}{c}\text { Slope of } \\
\text { apron. }\end{array}$} & \multicolumn{2}{|c|}{ Crest width, in feet. } \\
\cline { 2 - 3 } & 0.66 & 1.317 \\
\hline $1: 1$ & 3.52 & $\ldots \ldots \ldots$. \\
$2: 1$ & 3.38 & 2.985 \\
$3: 1$ & 3.265 & $\ldots \ldots \ldots .$. \\
$4: 1$ & 3.205 & 2.94 \\
$5: 1$ & 3.195 & $\ldots \ldots . .$. \\
$6: 1$ & $\ldots \ldots . . .$. & 2.93 \\
\hline
\end{tabular}

\section{COMBINATION OF COEFFICIENTS FOR WEIRS WITH COMPOUND SLOPES.}

Series 163 for an apron slope 2:1 represents a weir form which would be produced by placing, vertical face to vertical face, a weir with back slope 1:1 and a weir with apron slope 2:1. For the former, Bazin's experiments indicate 10 per cent excess discharge over that for a thinedged weir, and for the latter (from Pl. V) $C=3.50$, equivalent to 5 
per cent excess over a thin-edged weir. If the discharge over the 1:1 upstream slope was similarly increased by the addition of an apron, $C$ would be $3.66 \times 1.05=3.84$. Pl. IX indicates $C=3.82$.

The above method of determining the coefficient for weir of irregular cross section by combining the coefficients for two principal elements of which it is composed, as separate weirs, is restricted in its application and may lead to inconsistencies.

\section{WEIRS WITH VARYING SLOPE OF UPSTREAM FACE.}

Experiments were made by Bazin on thin-edged weirs inclined at various angles. Bazin found the ratio of the coefficient of discharge to that for a vertical thin-edged weir to be sensibly constant for all heads within the limits of his experiments, 0.0 to 1.5 feet. Bazin's results were expressed in the form of a modulus by which to multiply the coefficient for a vertical weir to obtain that for an inclined weir. Assuming the Francis coefficient 3.33 to apply to a vertical weir, the coefficients for weirs of various inclinations would be as follows:

Coefficients for inclined weirs, Bazin's experiments.

\begin{tabular}{|c|c|c|c|}
\hline & & $\begin{array}{c}\text { Bazin's } \\
\text { modulus. }\end{array}$ & C \\
\hline & 1 horizontal to 1 vertical... & 0.93 & 3.097 \\
\hline \multirow[t]{2}{*}{ Upstream inclination of the weir.. } & 2 horizontal to 3 vertical... & .94 & 3.130 \\
\hline & 1 horizontal to 3 vertical... & .96 & 3. 197 \\
\hline \multirow[t]{3}{*}{ Vertical weir..... } & (n, & 1.00 & 3.330 \\
\hline & 1 horizontal to 3 vertical... & 1.04 & 3.463 \\
\hline & 2 horizontal to 3 vertical... & 1.07 & 3.563 \\
\hline \multirow[t]{3}{*}{ Downstream inclination of the weir } & $\{1$ horizontal to 1 vertical... & 1.10 & 3. 663 \\
\hline & 2 horizontal to 1 vertical... & 1.12 & 3.996 \\
\hline & 4 horizontal to 1 vertical... & 1.09 & 3.630 \\
\hline
\end{tabular}

On Pl. XVI are shown the results of United States Deep Waterways experiments on weirs 4.9 feet high, having horizontal erests 0.67 foot broad, and with various inclinations of the upstream slope. The experiments cover heads from 1.75 to 5.2 feet, but only 3 or 4 points are given on each coefficient curve. The results indicate in a general way, however, nearly constant coefficients for each inclination of the upstream face. The values of the coefficients are considerably. smaller than those obtained by Bazin, whose experiments were on weirs 2.46 feet high with sharp erests.

Pls. X, XI, and XII show the results of experiments of Bazin on weirs of irregular section, with various upstream slopes. Pl. X includes 5 series of experiments on weirs 1.64 feet high, with sharp 
crest angles, and 2:1 downstream slopes. The coefficient curves show a depression period at from 0.3 to 0.7 foot head, beyond which the coefficients may be fairly represented by constants up to 1.5 foot head (the limit of the experiment). A general curve showing the constant coefficient in terms of a downstream slope or batter has been added. This indicates a maximum coefficient of discharge for an upstream slope of about $2.6: 1$. Bazin found, for thin-edged weirs, with inclined downstream slopes, a maximum coefficient for an inclination of $30^{\circ}$, or $1 \frac{3}{4}: 1$.

Pls. XI and XII show coefficient curves for weirs having the same upstream slopes as in Pl. X, but 2.46 feet high, and with flat crests 0.67 foot wide. The coefficient curves are convex outward, indicating that they may approach constant values at some point beyond the limits of the experiments. The marked difference in character of these coefficient curves, as compared with those in the preceding group, is notable. For weirs with flat crests 0.67 foot wide the coefficients for a given head uniformly increase as the slope becomes flatter up to a batter of about $1 \frac{3}{4}: 1$. They are also greater for all heads within the limit of the experiments than the coefficients for weirs with sharp crest angles. The comparative values are indicated in the following table:

Comparative coefficients, weirs with varying upstream slope.

\begin{tabular}{|c|c|c|c|c|}
\hline \multirow{3}{*}{$\begin{array}{l}\text { Up- } \\
\text { stream } \\
\text { slope. }\end{array}$} & \multirow{3}{*}{$\begin{array}{l}\text { Pl. X, } \\
\text { sharp crest, } \\
2: 1 \text { down- } \\
\text { stream } \\
\text { slope; aver- } \\
\text { age con- } \\
\text { stant coef- } \\
\text { ficient. }\end{array}$} & \multicolumn{3}{|c|}{$\begin{array}{l}\text { Pls. XI and XII, } 0.67 \text { feet } \\
\text { crest width, } 2: 1 \text { down- } \\
\text { stream slope. }\end{array}$} \\
\hline & & \multicolumn{3}{|c|}{ Head, in feet. } \\
\hline & & 0.5 & 1.0 & 1.5 \\
\hline & $C$ & $C$ & $C$ & $C^{\prime}$ \\
\hline Vert. & 3.58 & 2.78 & 3.26 & 3.51 \\
\hline$\frac{1}{3}: 1$ & 3.68 & 2.87 & 3.34 & 3.56 \\
\hline$\frac{1}{2}: 1$ & 3.72 & 2.92 & 3.38 & 3.62 \\
\hline $1: 1$ & 3.83 & 3.03 & 3.42 & 3.65 \\
\hline $2: 1$ & 3.87 & 3.13 & 3.43 & 3.61 \\
\hline
\end{tabular}

It will be seen that the addition of the flat crest has an effect in this case similar to that observed in Pls. VI and VIII, showing the results of experiments by Bazin on weirs with various downstream slopes.

United States Deep Waterways series No. 7, Pl. XVII, may be compared with Bazin's series No. 178, shown on PI. XI. 'The former gives a coefficient of 3.55 for a head of 2 feet on a weir 4.895 feet high, the coefficient slowly increasing with the head. The latter gives a coefficient of 3.6 for a head of 1.5 feet, decreasing rapidly as the head decreases. 
United States Geological Survey series No. XXXIX, Pl. XXVIII, and United States Deep Waterways series No. 18, Pl. XVIII, represent weirs with vertical downstream faces and inclined crests. The upstream slope does not, however, extend back to the bottom of the channel of approach, but is cut off abruptly by a vertical upstream face. The average coefficients deduced from these series have been plotted on a general curve on Pl. XVI, the coefficients agreeing closely with those of the United States Deep Waterways experiments on weirs of similar upstream slope, extending to the channel bottom. United States Geological Survey series No. XXX represents the Dolgeville dam, with rounded crest removed, leaving a trapezoid with crest 6 feet broad and 1 foot lower at upstream than at downstream edge. The coefficient is not constant, but apparently approaches a constant value of about 3.25 for heads exceeding 3 feet. United States Deep Waterways series No. 18 represents a model of the spillway of the Indian Lake dam, having a crest $\tau$ feet wide, 1.5 feet lower at upstream than at downstream edge, which gives an average constant coefficient of 3.42 .

It is suggested that if the upstream slope of an inclined weir is continued back 6 feet or more and terminates in a vertical upstream face, the discharge coefficient will not differ materially from that for an upstream slope extending to the channel bottom.

\section{DAMS OF OGEE CROSS SECTION, PLATTSBURG-CHAMBLY TYPE.}

The United States Geological Survey experiments on dams of this type are shown on Pls. XXIII to XXVII. Cross sections of the various dams, with lines indicating the comparative size of the models used in the United States Geological Survey experiments, are shown on Pl. XXXIV. Cross sections of other ogee dams used as weirs are shown on Pl. XXXV.

This class includes dams with downstream crest radius sufficiently large to retain the nappe always in contact, yet not so large as to simulate a broad flat erest. We thus exclude the Dolgeville section on the one hand, in which the nappe as observed in the existing dam partially or completely breaks free near the crest for other than very low stages, and on the other hand, the Austin dam, with a crest radius of 20 feet, which appears, from the meager data available, to lie outside this class.

We have arranged the available data in order, advancing with decreased breadth and increased inclination of sloping upstream face.

The coefficients for various depths are as follows: 
U. 8. GEOLOGICAL SURVEY

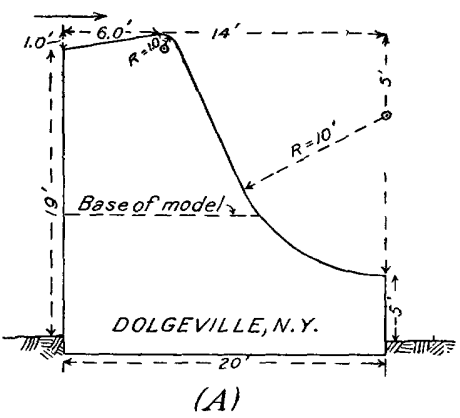

WATER-SUPPLY PAPER NO. 150 PL. XXXIV

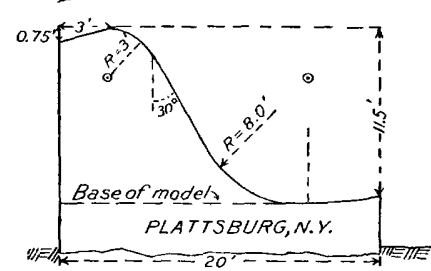

(B)

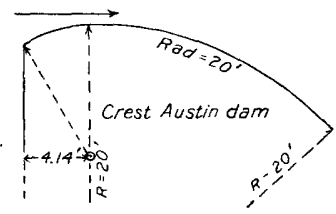

$(E)$
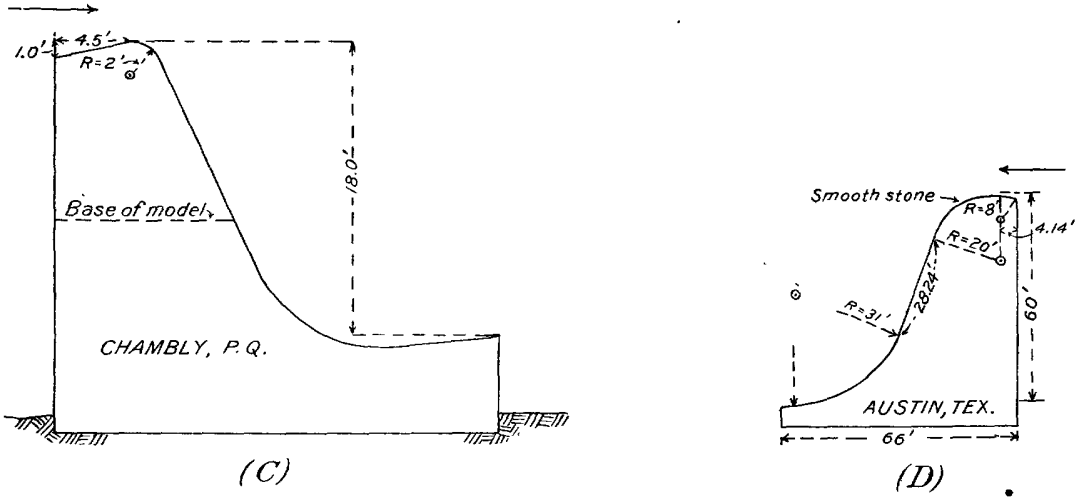

COMPARATIVE SIZE OF MODELS AND SECTIONS OF OGEE DAMS. 
u. 8. GEOLOGICAL SURVEY

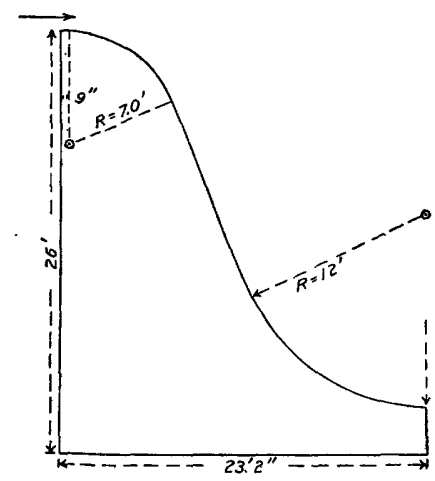

BEAVER RIVER;N.Y.
WATER-SUPPLY PAPER NO. 150 PL. XXXV

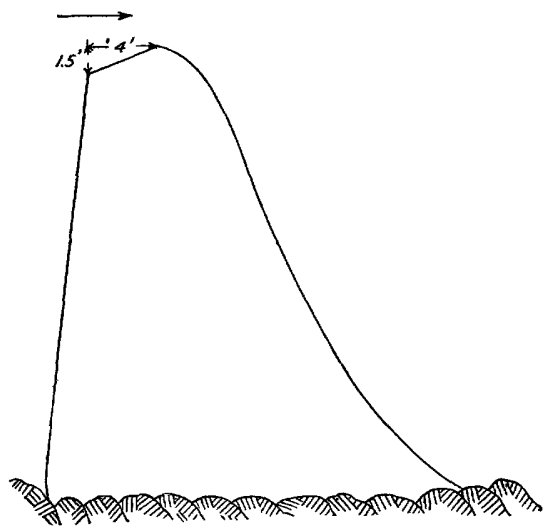

HANNAWA FALLS, N.Y.

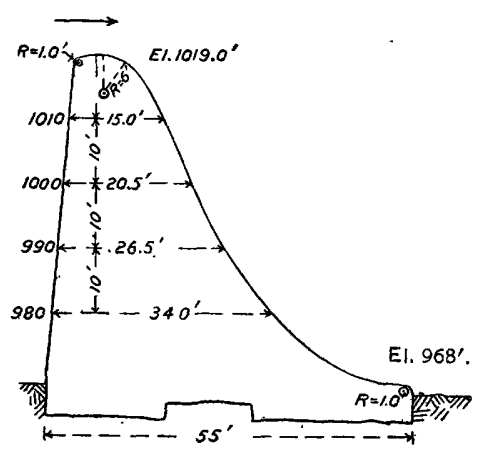

TRENTON FALLS, N. Y:

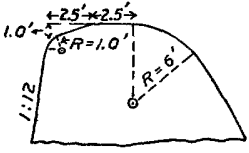

Crest, Trenton Fal/s

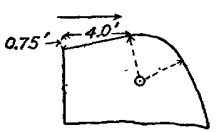

Honk Falls, N.Y. crest section

CROSS SECTIONS OF OGEE DAMS. 


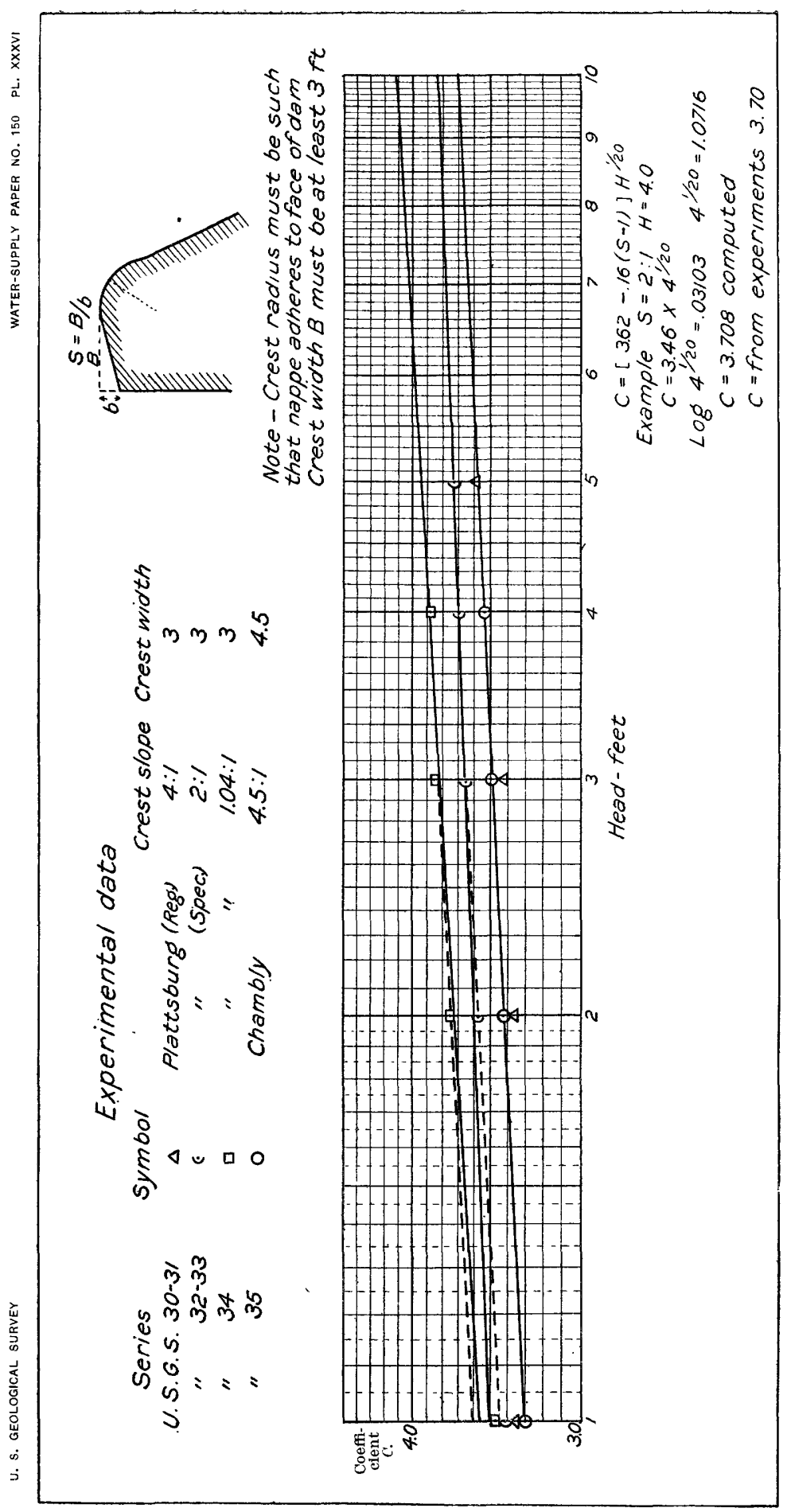

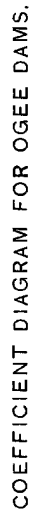


Comparative coefficients, dams of ogee cross section.

\begin{tabular}{|c|c|c|c|c|c|c|c|c|}
\hline \multirow{2}{*}{ 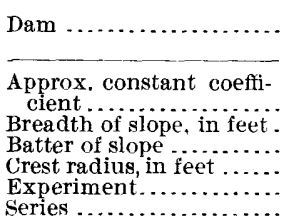 } & \multirow{2}{*}{$\begin{array}{c}\text { Cham- } \\
\text { bly. }\end{array}$} & \multirow{2}{*}{ 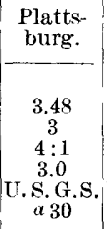 } & \multicolumn{6}{|c|}{ Modified Plattsburg. } \\
\hline & & & \begin{tabular}{|c}
3.48 \\
3 \\
$4: 1$ \\
3.0 \\
3.0 \\
C.S.G.S. \\
b. 31
\end{tabular} & $\begin{array}{c}3.48 \\
3 \\
4: 1 \\
3.0 \\
\text { Mean of } \\
30-31\end{array}$ & \begin{tabular}{|c}
3.70 \\
3 \\
$2: 1$ \\
$2: 1$ \\
3.0 \\
U. G. G.s. \\
$b 32$
\end{tabular} & $\begin{array}{c}3.70 \\
3 \\
2: 1 \\
3.0 \\
\text { U.S.G.S. } \\
\text { a } 33\end{array}$ & $\begin{array}{c}3.70 \\
3 \\
2: 1 \\
3.0 \\
\text { Mean of } \\
32-33\end{array}$ & $\begin{array}{c}\text {. } \\
3 \\
1.04: 1 \\
3.0 \\
\text { U. S. G.s. } \\
34\end{array}$ \\
\hline Hear 0.5 foot . . & ...... & 3.22 & $\ldots \ldots$ & ... & 3.29 & 3.22 & 3.255 & .... \\
\hline 1.0 foot..... & 3.30 & 3.43 & 3.29 & 3.36 & 3.37 & 3.44 & 3.405 & 3.46 \\
\hline 2.0 feet $\ldots$. & 3.42 & 3.42 & 3.35 & 3.385 & 3.51 & 3.67 & 3.59 & 3.75 \\
\hline 3.0 feet $\ldots .$. & 3.49 & 3.47 & 3.43 & 3.45 & 3.57 & 3.72 & 3.645 & 3.87 \\
\hline 4.0 feet....... & 3.53 & 3.52 & 3.54 & 3.53 & 3.67 & $3.7 \pm$ & 3.705 & 3.88 \\
\hline 5.0 feet .. & & & 3.62 & & 3.73 & & & \\
\hline 6.0 feet $\therefore .$. & & & & & & & & \\
\hline
\end{tabular}

It appears that the rounded crest changes the character of the law of coefficient from a value tending toward a constant for each back slope to a slowly increasing function of the head. Compared with the constant coefficients for weirs with similar upstream slopes extending back to canal bottom, and with vertical faces, we find that the constant values deduced for these cases correspond with the values of the varying coefficients for ogee sections at a medium head of 2 to 4 feet.

By plotting the data for weirs of ogee section on logarithmic crosssection paper the following convenient approximate formula has been deduced, applicable for weirs with 2 or 3 feet crest radius and upstream slopes 3 to 4.5 feet broad. $S$ indicates the batter ratio of the slope, $\frac{\text { horizontal run }}{\text { vertical rise }}$.

$$
C=[3.62-0.16(S-1)] H^{\frac{1}{20}}
$$

If $S=2: 1 \quad H= \pm .0 \quad C=3.46 \times 4^{\frac{1}{20}}$

$$
\log 4^{2^{\frac{1}{2}}}=0.030103 \quad C=3.46 \times 1.0716=3.70 .
$$

The experiments give $C=3.74$.

\section{EXPERIMENTS ON DISCHARGE OVER ACTUAL DAMS.}

On Pl. XXXVII are shown the results of a number of experiments made by measuring the discharge over existing dams by means of floats or current meters. Aside from those for the Austin, Tex., dam, the data have been collected by Mr. George T. Nelles. ${ }^{a}$

$a$ Discussion of paper by G. W. Rafter on the fiow of water over dams: Trans. Am. Soc. C. E., vol. 44, pp. $359-362$. 
BLACKSTONE RIVER AT ALBION, MASS.

This is a timber dam 217 feet long, with horizontal crest 1 foot wide, vertical downstream face, and upstream slope covered with riprap. Discharge was measured by current meter 500 feet below dam, and the depth was measured by hook gage 20 feet upstream from crest. Coefficients have not been corrected to elininate velocity of approach. They illustrate the uncertainty of discharge for broad-crested weirs of small width under low heads.

\section{MUSKINGUM RIVER, OHIO.}

Discharge was measured by rod floats in a cross section 500 feet above the dams, which are constructed of timber cribs filled with stone. Data by Maj. W. H. Bixby, U. S. Army.

Disharge data for Muskingum River dams.

\begin{tabular}{|c|c|c|c|c|c|c|c|c|}
\hline $\begin{array}{l}\text { Num- } \\
\text { ber of } \\
\text { dam. }\end{array}$ & $\begin{array}{l}\text { Length } \\
\text { on crest, } \\
\text { in feet. }\end{array}$ & $\begin{array}{l}\text { Mean } \\
\text { height. is } \\
\text { feet. }\end{array}$ & $\begin{array}{l}\text { Area of } \\
\text { discharge } \\
\text { section, in } \\
\text { square } \\
\text { feet. }\end{array}$ & $\begin{array}{l}\text { Dis- } \\
\text { charge, } \\
\text { in cubic } \\
\text { feet per } \\
\text { second. }\end{array}$ & $\begin{array}{c}\text { Meai } \\
\text { velocity, } \\
\text { in feet per } \\
\text { second. }\end{array}$ & $\begin{array}{c}\text { Full over } \\
\text { dam, in } \\
\text { feet. }\end{array}$ & $\begin{array}{l}\text { Observed } \\
\text { depth on } \\
\text { erest, in } \\
\text { feet. }\end{array}$ & $\begin{array}{l}\text { Coeffi- } \\
\text { cient } C\end{array}$ \\
\hline 3 & 848 & 12.6 & 7,765 & 18,118 & 2. 333 & 8.00 & 2. 86 & 4. 419 \\
\hline 4 & 535 & 15.9 & 8,360 & 25,559 & 3.045 & 6.70 & 4.66 & 4. 723 \\
\hline 7 & 472 & 14.2 & 8,230 & 21,015 & 2. 553 & 7.00 & 4. 40 & 4.812 \\
\hline 8 & 515 & 16.0 & 7,330 & 22,310 & 3.044 & 5.16 & 5.90 & 3.015 \\
\hline
\end{tabular}

The depth on crest has not been corrected to eliminate velocity of approach.

OTYAWA RIVER DAM, CANADA.

Data by T. C. Clark, C. E. Dam 30 feet high, with upstream and downstream faces planked and sloping $3: 1$, forming sharp crest angle at junction.

Discharge data for Ottawa River dam.

\begin{tabular}{|r|r|r|r|}
\hline $\begin{array}{c}\text { Length of } \\
\text { dam, in feet. }\end{array}$ & $\begin{array}{c}\text { Depth on } \\
\text { crest, in feet. }\end{array}$ & $\begin{array}{c}\text { Discharge, } \\
\text { in cubic feet } \\
\text { per second. }\end{array}$ & $\begin{array}{c}\text { Discharge } \\
\text { coefficient } \alpha !\end{array}$ \\
\hline 1,600 & 2.5 & 26,000 & 4.106 \\
1,760 & 10.0 & 190,000 & 3.408 \\
\hline
\end{tabular}

These data are notable as giving the only authentic value of discharge over a dam under so great a head as 10 feet. The high coefficient found for a head of 2.5 feet renders the results somewhat doubtful. 


\section{AUSTIN, TEX., DAM. ${ }^{a}$}

A series of current-meter measurements of the discharge over this dam were made in January and March, 1900. Several observations at each depth have been combined. The resulting mean coefficients are given in the following table:

Discharge coefficients for the Austin, Tex., dam.

\begin{tabular}{|c|c|c|c|c|c|c|c|}
\hline \multirow{2}{*}{ Date. } & \multirow{2}{*}{$\begin{array}{l}\text { Num- } \\
\text { ber. }\end{array}$} & \multirow{2}{*}{$H$} & \multirow{2}{*}{$\begin{array}{l}H=\text { depth } \\
\text { at crest } \\
\text { of dam. }\end{array}$} & \multicolumn{2}{|c|}{$\begin{array}{c}\text { Range of vari- } \\
\text { ation of } c\end{array}$} & \multirow{2}{*}{$\begin{array}{l}\text { Number } \\
\text { of de- } \\
\text { termina- } \\
\text { tions. }\end{array}$} & \multirow{2}{*}{$\begin{array}{c}\text { Average } \\
\text { value } \\
\text { of } C .\end{array}$} \\
\hline & & & & From- & To- & & \\
\hline 1900. & & & & & & & \\
\hline Jan. 15 & 1 & 1.09 & 0.838 & 3.09 & 3.14 & $t$ & 3. 132 \\
\hline Jan. 18 & 2 & .72 & .625 & 3.00 & 3.11 & 11 & 3.053 \\
\hline Jan. 26 & 3 & .42 & .33 & 3.06 & 3.13 & 4 & 3.112 \\
\hline Mar. 28 & 4 & 1. 44 & 1.04 & 3.32 & 3.36 & 3 & 3. 333 \\
\hline Mar. 28 & 5 & 1. 32 & .96 & 3.26 & 3.33 & 5 & 3.302 \\
\hline Average & & & & & & & 3. 186 \\
\hline
\end{tabular}

\section{ROUGHNESS OF CREST.}

The models used in weir experiments have usually been constructed of planed and matched timber. In actual dams a wide variety of conditions exist, including, in the order of roughness, sheet-steel crests, boards smoothed by wear and rendered slippery by water soaking and fungus growths, unplaned boards, dressed masonry, formed concrete, rubble and undressed ashlar, with earth, cobble, or broken-stone approaches. For the determination of the extent, if any, to which the coefficient applying for a smooth-crested dam must be modified to apply to any of these conditions, the following data are available.

UNITED STATES DEEP WATERWAYS, SERIES 7 AND 8 (PL. XVII).

Model dams, 4.9 feet high, 2: 1 slope on both faces. The mean coefficients are about 1 per cent greater for crest of planed boards than for crest covered with one-fourth-inch mesh wire cloth. 
CROTON DAM, ROUND-CREST SECTION, MODEL A (PL. XIX).

Crest rounded, radius 10 feet. Upstream slope about 6:1.

Comparative coefficients with narying roughness, Choton round crest.

\begin{tabular}{|c|c|c|c|c|}
\hline Series... & 1 & $1 \mathrm{a}$ & 2 & 3 \\
\hline $\begin{array}{l}\text { Head, in } \\
\text { feet. }\end{array}$ & $\begin{array}{c}\text { Smooth-pine } \\
\text { erest. }\end{array}$ & $\begin{array}{l}\text { Unplaned- } \\
\text { plank crest } \\
\text { and slope.a }\end{array}$ & $\begin{array}{l}\text { Broken- } \\
\text { stone siope, } \\
\text { unplaned } \\
\text { crest. }\end{array}$ & $\begin{array}{l}\text { Broken- } \\
\text { stone slope, } \\
\text { wire cioth } \\
\text { on crest. }\end{array}$ \\
\hline 0.25 & 3.34 & 2.84 & 3.18 & 3. 16 \\
\hline .50 & 3.24 & 2.91 & 3. 18 & 3.09 \\
\hline 1.00 & 3.21 & 3.04 & 3. 19 & 3.15 \\
\hline 1.50 & 3.21 & 3. 12 & 3.20 & 3.15 \\
\hline 2.00 & 3.21 & 3.15 & 3.21 & 3.15 \\
\hline 2.50 & 3.21 & 3.15 & 3.22 & 3.15 \\
\hline 3.00 & 3.21 & $\ldots \ldots$ & 3.22 & 3.15 \\
\hline
\end{tabular}

a'This series appears doubtful.-R. E. H.

CROTON DAM, ANGULAR SECTION, MODEL B (PL. XX).

Apron slope 1.25:1, upstream slope $6.24: 1$ for 13 feet, then rough, and slope about 4:1 to bottom.

Comparative coefficients, varying roughness, Croton angular crest.

\begin{tabular}{|r|r|r|r|}
\hline Series. & $\begin{array}{c}\text { Unplaned } \\
\text { plank. }\end{array}$ & $\begin{array}{c}\text { Unplaned } \\
\text { plank, } \\
\text { rough-stone } \\
\text { approach. }\end{array}$ & $\begin{array}{c}\text { Rough-stone } \\
\text { approach, } \\
\text { wire cloth } \\
\text { on erest. }\end{array}$ \\
\hline 0.25 & 3.61 & $\ldots \ldots \ldots .$. & 3.56 \\
.50 & 3.63 & 3.66 & 3.57 \\
1.00 & 3.67 & 3.66 & 3.58 \\
1.50 & 3.68 & 3.66 & 3.60 \\
2.00 & 3.70 & 3.66 & 3.61 \\
2.50 & 3.70 & 3.66 & 3.62 \\
\hline
\end{tabular}

The data given above are somewhat discordant, but indicate that in general the decrease in discharge resulting from the roughness of the various materials forming the crests and approaches of dams will not exceed from 1 to 2 per cent for low heads, and usually decreases as the depth of overflow increases. 


\section{FALLS.}

Bellasis ${ }^{a}$ presents the following analysis for a fall in which there is neither a raised weir nor a lateral reduction in section. If $x$ is the mean velocity at $C D$, near to $A B$, then $v$ is both the velocity of approach and the velocity in the weir formula

$$
v=\frac{2}{3} c \sqrt{2 q\left(D+\alpha \frac{n^{2}}{2 q}\right)}
$$

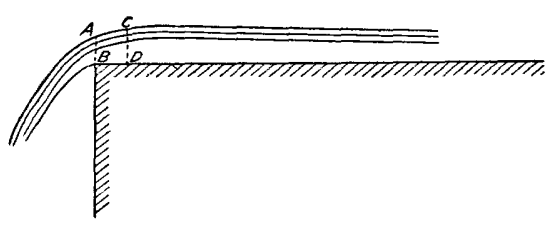

FrG. 10.-Fall.

where $c$ is a coefficient of velocity.

$$
\begin{aligned}
v^{2} & =\frac{4}{9} c^{2} 2 g D+\frac{4}{9} \alpha c^{2} v^{2} \\
\left(1-\frac{4}{9} \alpha c^{2}\right) v^{2} & =\frac{4}{9} c^{2} 2 g D \\
v & =\frac{\frac{2}{3} c \sqrt{2 g D}}{\sqrt{1-\frac{4}{9}} \alpha c^{2}}
\end{aligned}
$$

Making $\alpha=1.00$ and $c=0.79$.

$$
\begin{aligned}
v & =\frac{3.424 \sqrt{D}}{\sqrt{1-0.277}}=4.74 \sqrt{D} \ldots . \quad . \quad . \quad . \\
Q & =v D L=4.74 L D^{\frac{3}{2}}
\end{aligned}
$$

The depth $D$ is to be measured so near $A B$ that the water shall have acquired its velocity of efflux. The depth will, of course, be affected by the surface curve, the upstream extension of which will be longer according as the slope of the leading channel is flatter, being very great for a horizontal channel. The formula needs experimental verification, but affords a convenient basis of approximation of the flow through troughs and sluices and over aprons and falls.

Experimental data for $c$ are needed. 


\section{WEIR CURVED IN PLAN.}

Milldams of both wood and masonry are often constructed to bow upstream, sometimes to secure the added strength of arched form, or to secure additional spillway length, or to follow the crest of a favorable rock ledge, or to throw the ice-bearing current away from intake gates. The dam may follow the are of a circle, or, as is common with timber dams, there may be an abrupt angle in the plan of the dam. Fig. 11 shows a graphical comparison of curved and angle dams with a straight dam across the same channel, the former being each 13.5 per cent longer than the straight crested dam.

If such an arched spillway opens out of a broad, deep pond, the discharge over it would be greater than for a straight overfall very nearly in proportion to the excess in length of the arc as compared with the length of its chord.

When the stream is confined in a restricted channel, the increased velocity of approach above the longer spillway will become a factor. Thus if two dams-one straight, the other arched-were placed in the same straight, uniform channel, and the depth on crest measured at the same distance upstream from each, then, with the same measured head on both, the velocity of approach to the arched dam would be

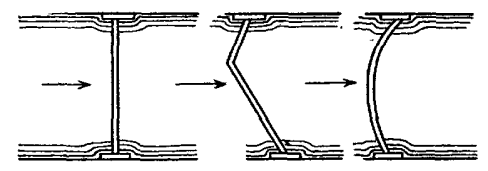

FIG. 11.-Weir curved or angular in plan.

greater nearly in the same proportion that its length of crest and discharge are greater than for the straight crest. Properly corrected for velocity of approach, the arched dam will give a correct measurement of the discharge, the length of the arc being used as the crest length. When the length of the arc greatly exceeds the channel width, the velocity of approach may become excessive, introducing uncertainty as to the proper correction coefficient, difficulty in measuring the head, and an uplifting of the central swifter-flowing portion of the stream surface.

The circular overflow lip of a vertical artesian-well casing is sometimes used to approximate the flow, the measured depth of water above the lip of the pipe, together with its circumference, being used in the weir formula. ${ }^{a}$

\footnotetext{
a Experiments showing the discharge over a circular weir to be proportional to the length of the arc were made by Simpson at Chew Magna, Somersetshire, England, 1850, not recorded in detail.
} 


\section{SUBMERGED WEIRS.}

THEORETICAL FORMULA.

In a "submerged," "drowned," "incomplete," or "partial" weir the water on the downstream side stands above the crest level.

The submerged weir is not extensively used as a device for stream gaging. A knowledge of the relations of head, rise, and discharge of such weirs is, however, of great importance in works of river improvement, canals, etc., and the leading formulas are here presented.

It may be added that for situations where head can not be sacrificed, precluding the use of an ordinary weir, and where the velocity is not a continuous function of the depth, as in race ways, making a channelrating curve inapplicable, the use of submerged weirs to measure or control the discharge merits consideration. Their use for such purposes as the equable division and distribution of water in power canals has hitherto been very restricted, owing to the lack of experimental coefficients.

Let $H=$ Head on upstream side, corrected for velocity of approach. $D=$ Measured head, upstream side of weir.

$d=$ Measured head, downstream side of weir, or the depth of drowning, taken below the ressault.

$Z=$ Difference of elevation, upstream and downstream sides $=H-d$.

$P=$ Height of weir above channel bottom.

$L=$ Length of weir crest, feet.

$v=$ Mean velocity of approach.

$\triangle=$ Head on a thin-edged weir that would give the same discharge.

$M^{\prime}$ and $C^{\prime}$ coefficients of discharge for a submerged weir.

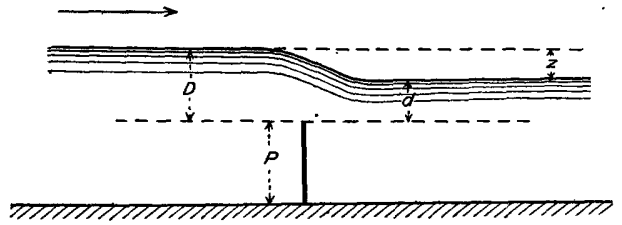

Fra. 12,-Submerged weir.

The theoretical formula of Dubuat for discharge is obtained by regarding the overflow as composed of two portions, one through the upper part $D-d$, treated as free discharge, the other through the lower part $d$, treated as flow through a submerged orifice.

Combining the two discharges,

$$
Q=Q_{1}+Q_{2}=\frac{2}{3} \sqrt{2 g} L(D-d)^{\frac{3}{2}}+L d \sqrt{2 g(D-d)}
$$

IRR $150-06-14$ 
By reducing, including a coefficient, and using the head $H$ corrected for velocity of approach, we have the general formula for a submerged weir.

$$
Q=\frac{2}{3} N I^{\prime} L \sqrt{2 q Z}\left(H+\frac{d}{2}\right)=C^{\prime} L\left(H+\frac{d}{2}\right) \sqrt{Z} .
$$

The head due to the velocity of retreat should in strictness be subtracted from the depth of submergence $d$. This is not commonly done, however, in the experiments, where the usual method of producing the submergence is by damming and retarding the water below. In practice, if the velocity of retreat is large, the correction should be made.

The theory of formula (73) makes $C^{\prime \prime}=1.5$ times the value of the coefficient $\dot{C}^{\dot{\gamma}}$ in the free portion of the discharge. ${ }^{a}$ This value is adopted by Dubuat and Weisbach.

D'Aubuisson gives $C^{\prime}=1.43 C$.

Francis's early experiments make $C^{\prime}=1.38 C^{\text {? }}$.

From gage records of large rock-filled crib dams on Kentucky River, having planked upstream slope 3:1 and vertical steps below crest-height of dams about 20 feet, heads 4 to 7.5 feet, mean 5.3 feet-Nelles found results as follows:

Dam No. 3, water falling slowly 4 days, $\quad C^{\prime}=1.5 C^{y}$.

Dam No. 2, water falling slowly 3 days, $\quad C^{\prime}=1.53 C$.

Dam No. 1 , water rising and falling slowly 5 days, $C^{\prime \prime}=1.46 C$.

\section{FTELEY AND STEARNS SUBMERGED-WEIR FORMULA. $b$}

Fteley and Stearns use the base formula

$$
Q=C L\left(H+\frac{d}{2}\right) \sqrt{Z} \cdot \cdot \cdot \cdot \cdot \cdot
$$

Coefficients for the above formula were derived from experiments on thin-edged weirs, by Fteley and Stearns and by J. B. Francis, and give correct results for weirs for which the free discharge would be correctly ealculated by the Francis formula.

The head on upstream side varied from 0.3251 to 0.9704 foot, and d $\bar{H}$ varied from -0.063 to 0.081 with air under nappe, and from 0.077 to 0.975 with no air under nappe, and in applying the formula the same conditions should be complied with. The authors comment that where sufficient head can not be obtained for a weir of the usual freedischarge type, a submerged weir may be used, provided that the head does not vary greatly.

\footnotetext{
a See valuable discussion of submerged weirs by Geo. T. Nelles in Trans. Am. Soc. C. E., vol. 44, pp. 359-383.

b Fteley and Stearns, Experiments on the flow of water, etc.: Trans. Am. Soc. C. E., vol, 12, pp. 101-108.
} 
From a large-scale curve Fteley and Stearns derive the following table of coefficient $C$, for formula (74):

Fteley and Stearns's coefficients for submerged weirs.

\begin{tabular}{|c|c|c|c|c|c|c|c|c|c|c|}
\hline \multicolumn{1}{l}{} & 0.00 & 0.01 & 0.02 & 0.03 & 0.04 & 0.05 & 0.06 & 0.07 & 0.08 & 0.09 \\
\hline 0.0 & $\ldots . .$. & 3.330 & 3.331 & 3.335 & 3.343 & 3.360 & 3.368 & 3.371 & 3.372 & 3.370 \\
.1 & 3.365 & 3.359 & 3.352 & 3.343 & 3.335 & 3.327 & 3.318 & 3.310 & 3.302 & 3.294 \\
.2 & 3.286 & 3.278 & 3.271 & 3.264 & 3.256 & 3.249 & 3.241 & 3.234 & 3.227 & 3.220 \\
.3 & 3.214 & 3.267 & 3.201 & 3.194 & 3.188 & 3.182 & 3.176 & 3.170 & 3.165 & 3.159 \\
.4 & 3.155 & 3.150 & 3.145 & 3.140 & 3.135 & 3.131 & 3.127 & 3.123 & 3.119 & 3.116 \\
.5 & 3.113 & 3.110 & 3.107 & 3.104 & 3.102 & 3.100 & 3.098 & 3.096 & 3.095 & 3.093 \\
.6 & 3.092 & 3.091 & 3.090 & 3.090 & 3.689 & 3.089 & 3.089 & 3.090 & 3.090 & 3.091 \\
.7 & 3.092 & 3.093 & 3.095 & 3.097 & 3.099 & 3.102 & 3.105 & 3.109 & 3.113 & 3.117 \\
.8 & 3.122 & 3.127 & 3.131 & 3.137 & 3.143 & 3.150 & 3.156 & 3.164 & 3.172 & 3.181 \\
.9 & 3.190 & 3.200 & 3.209 & 3.221 & 3.233 & 3.247 & 3.262 & 3.280 & 3.300 & 3.325 \\
\hline
\end{tabular}

Where $\frac{d}{H}$ is less than $0.15 Q$ is not sensibly affected by submergence. Where $\frac{d}{H}$ is from 0.5 to $0.8 C$ may be taken at 3.10 .

Correction for velocity of approach was made by the formula $H=D+\frac{v^{2}}{2 g}$. No correction was made for velocity of retreat.

The formula is probably applicable to larger dams and greater depths by selecting proper values of $C, \frac{d}{H}$ being a relative quantity.

A number of empirical formulæ for submerged-weir discharge are also used.

\section{CLEMENS HERSCHEL'S FORMULA. a}

Herschel's formula, based on experiments of J. B. Francis, 1848, Fteley and Stearns, 1877, and J. B. Francis, 1883, is

$$
Q=3.33 L(N H)^{\frac{3}{2}}=3.33 L \triangle^{\frac{3}{2}}
$$

In this formula the measured head ${ }^{b}$ is reduced to an equivalent head that would give the same discharge over a free overflow. The value of the coefficient $N=\frac{\triangle}{H}$ depends on the proportional submergence $\frac{d}{H}$.

$\alpha$ Hershel, Clemen, The problem of the submerged weir: Trans. Am. Soc. C. E., vol. 14, May, 1885, pp. 190-196.

$b$ Corrected for velocity of approach by method for Francis's formula before applying in above formula. 
The values of this ratio, together with their probable error, are given below.

Coefficient N, Herschel's submerged-ueir formula. ${ }^{a}$

\begin{tabular}{|c|c|c|c|c|c|c|c|c|c|c|}
\hline$\frac{d}{D}$ & 0.0 & 0.01 & 0.02 & 0.03 & 0.04 & 0.05 & 0.06 & 0.07 & 0.08 & 0.09 \\
\hline 0.0 & 1.000 & 1. 004 & 1.006 & 1.006 & 1.007 & 1.007 & 1.007 & 1.006 & 1. 006 & 1.005 \\
\hline .1 & 1.005 & 1. 003 & 1.002 & 1.000 & .998 & .996 & .994 & .992 & .989 & .987 \\
\hline .2 & .985 & .982 & .980 & .977 & .975 & .972 & .970 & .967 & .964 & .961 \\
\hline .3 & .959 & .956 & .953 & .950 & .947 & .944 & .941 & .938 & .935 & .932 \\
\hline .4 & .929 & .926 & .922 & .919 & .915 & .912 & .908 & .904 & .900 & .896 \\
\hline .5 & .892 & .888 & .884 & .880 & .875 & .871 & .866 & .861 & .856 & .851 \\
\hline .6 & .846 & .841 & .836 & .830 & .824 & .818 & .813 & .806 & .800 & .794 \\
\hline .7 & .787 & .780 & .773 & .766 & .758 & .750 & .742 & .732 & .723 & .714 \\
\hline .8 & .703 & .692 & .681 & .669 & .656 & .644 & .631 & .618 & .604 & .590 \\
\hline .9 & .574 & .557 & .539 & .520 & .498 & .471 & .441 & .402 & .352 & .275 \\
\hline
\end{tabular}

$a$ Values for $\frac{d}{D}$ exceeding 0.80 less accurately determined.

$\frac{d}{\bar{D}}=0.02$ to 0.14 , variation of $N= \pm 0.005$ to 0.007 .

$=0.15$ to 0.22 , variation of $N= \pm 0.008$ to 0.010 .

$=0.24$ to 0,32 , variation of $N= \pm 0.012$ to 0.014 .

$=0.33$ to 0.41 , variation of $N= \pm 0.015$ to 0.017 .

$=0.42$ to 0.59 , variation of $N= \pm 0.018$.

$=0.60$ to 0.65 , variation of $N= \pm 0.017$ to 0.015 .

$=0.66$ to .071 , variation of $N= \pm 0.014$ to 0.012 .

$=0.72$ to .084 , variation of $N= \pm 0.011$ to 0.009 .

This table indicates that for depths of submergence not exceeding 20 per cent, the head will not ordinarily be increased more than 2 per cent.

The discharge over a submerged weir, according to Herschel's formula, bears the ratio $N^{\frac{3}{2}}$ to that over an unsubmerged weir under the same head.

THE CHANOINE AND MARY FORMULA.

$$
Q=M^{\prime} L H \sqrt{2 g Z} \text {. }
$$

This expression has a form similar to that for the ordinary formula for submerged orifices. It is applicable only under conditions identical with those for which $M^{\prime}$ has been determined. ${ }^{a}$ 
R. H. RHIND'S FORMULA. "

$$
Q=M^{\prime} L \sqrt{2 g}\left[d \sqrt{Z+0.01 v^{2}}+\frac{2}{3} Z \sqrt{Z+0.035 v^{2}}\right] .
$$

This may be reduced to the theoretical formula (73) by omitting the correction for velocity of approach.

\section{BAZIN'S FORMULAS. $b$}

By duplicating, with various depths of submergence, his experiments on thin-edged weirs Bazin deduced the foilowing expressions for the coefficients for submerged weirs to be applied in the discharge formula

$$
Q=m^{\prime} L D \sqrt{2 g D} \text {. }
$$

Let $P$ represent, as heretofore, the height of weir crest above channel bottom, the coefficient $m$ being that which would apply to the same weir with free discharge.

(1) Accurate formula with small values of $d$ :

$$
m^{\prime}=m\left[1.06+0.16\left(\frac{d}{P}-0.05\right) \frac{P}{D}\right] . . \quad . \quad . \quad .
$$

(2) Accurate formula with large values of $d$ :

$$
m^{\prime}=m\left[\left(1.08+0.18 \frac{d}{P}\right) \sqrt[3]{\frac{D-d}{D}}\right] \quad \text {. . . . }
$$

(3) Approximate formula for all cases:

$$
m^{\prime}=m\left(1.05+0.21 \frac{D}{P}\right) \sqrt[3]{\frac{D-d}{D}} \quad \text {. . . . . . . }
$$

The above formulas are for weirs without end contractions.

The coefficient $m$ contains the correction for velocity of approach of the free-discharge weir, and $m^{\prime}$ contains the necessary factor (if any) for the resulting modification of the velocity of approach effect, when the weir becomes drowned. They are only strictly accurate, therefore, when $m^{\prime}$ is substituted for $m$ in Bazin's formula.

In Bazin's formulas the height $P$ of the weir enters as a controlling factor in (1), and is present less prominently in (2) and (3).

The modification by drowning is made to depend on $\frac{d}{P}$ in (2), and on this ratio and that of the cube root of $\frac{D-d}{D}$ jointly in formula (3). It is often difficult to determine $P$ or to apply these formulas to a weir fed by a large pond and having end contractions.

\footnotetext{
a Proe. Inst. Civil Engineers, 1886.

b Bazin, H., Expériences nouvelles sur l'écoulement en déversoir, 6̧̣ art., Ann. Ponts et Chaussées, Mémoires et Documents, 1898.
} 
Assume $P=\infty$

Then (2) becomes

$$
m^{\prime}=m \times 1.08 \sqrt[3]{\frac{D-\bar{d}}{I \prime}}=m \times 1.08 \sqrt[3]{\frac{Z}{I I}} \quad . \quad . \quad .
$$

and differs from (3) when similarly reduced only in the substitution of 1.05 for 1.08 as a coefficient.

$$
\text { Ex. } \quad D=4^{\prime} . \quad d=2^{\prime} \quad P=\infty
$$

If

$$
\begin{aligned}
& m=0.425 \\
& m^{\prime}=0.425 \times 1.08 \sqrt[3]{\frac{2}{4}}=0.364,
\end{aligned}
$$

\begin{tabular}{|c|c|c|c|c|c|c|}
\hline$d$, feet........... & .25 & .50 & .75 & .25 & .50 & ז \\
\hline$H$, feet . & 2.0 & 2.0 & 2.0 & 1.0 & 1.0 & 1.0 \\
\hline$d / I \ldots .$. & $\frac{1}{3}$ & $\frac{1}{4}$ & $\frac{3}{9}$ & $\frac{1}{4}$ & $\frac{1}{8}$ & $\frac{3}{4}$ \\
\hline & \multicolumn{6}{|c|}{ Percentage of unsubmerged-weir discharge. } \\
\hline Fteley-Stearns.. & 99.91 & 95.06 & 89.29 & 95.01 & 82.61 & 64.02 \\
\hline Herschel..... & 100.15 & 95.83 & 90.56 & 95.83 & 84.24 & 64.95 \\
\hline Bazin (3)..... & 100.43 & 95,40 & 89.78 & 95.40 & 83.34 & 66.15 \\
\hline
\end{tabular}

the discharge being 89.4 per cent of that over an unsubmerged weir under the same head.

Comparison of submerged-uveir formulas. ${ }^{a}$

$a$ Weir assumed to be very high so that there is no velocity of approach or of retreat. The coeficient of discharge for a thin-edged weir with free discharge has been taken at 3.33 for the FteleyStearns and Herschel formulas.

\section{INCREASE OF HEAD BY SUBMERGED WEIRS.}

Any of the submerged-weir formulas may be transformed into expressions giving the rise in water level caused by the construction of a submerged weir in a channel or canal; in this form they are most useful in the design of slack-water navigation works.

\section{RANKINE'S FORMULAS. ${ }^{a}$}

Weir not drowned, with flat or slightly rounded crest:

$$
H=\Delta=\sqrt[3]{\frac{Q^{2}}{7 L^{2}}}, \text { approximate . . . . . . }
$$

Weir drowned:

First approximation-

$$
H^{\prime}=\Delta+d
$$

Second approximation--

$$
\left.H=H^{\prime}-d\left(1-\frac{5}{4} \frac{d}{H^{\prime}-d}\right)\right\}
$$


COLONEL IMAS'S FORMULA. ${ }^{a}$

This is intended to determine the height of a weir on the crest of a fall in an irrigation or other canal to maintain a desired uniform depth and slope.

$D=$ Depth on weir, feet.

$X=$ Depth of uniform channel, feet.

$P=X-D=$ Height of weir necessary.

$A=$ Area uniform channel section, feet.

$R=$ Hydraulic radius, feet.

$S=$ Slope or fall in feet, per foot.

$L=$ Leng th of weir crest, feet.

$$
D=\left(\frac{900 A^{2} R S}{L^{2}}\right)^{\frac{1}{3}}-125.8122 R S \quad \cdot \quad \cdot \quad \cdot
$$

If $A=1000 \quad X=10^{\prime} \quad R=8.33 \quad S=0.001 \quad L=100$,

$$
\begin{aligned}
I & =\left[\frac{900 \times 1000^{2} \times 8.33 \times 0.001}{10000}\right]^{\frac{1}{3}}-125.81 \times 8.33 \times 0.001 \\
& =9.0856-1.0441=8.04 \\
P & =10-8.04=1.96 \text { feet. }
\end{aligned}
$$

In this case length of weir equals width of channel, and the velocity of approach would be the mean velocity, which by Kutter's formula will vary, say, from 8 to 10 feet per second under the conditions, depending on the value of the coefficient of roughness $n$. This would make the flow in the channel 8,000 to 10,000 cubic feet per second.

As a check on the calculated depth $D$, it will be found that the flow over a weir 100 feet long under a head 8.04 feet (corrected for the large velocity of approach) will also be from, say, 8,000 to 10,000 cubic feet per second, depending upon the coefficient used in the weir formula.

\section{SUBMERGED WEIRS OF IRREGULAR SECTION.}

For certain forms of irregular weirs having rertical downstream faces, the discharge when subject to submergence may probably be approximated by applying the ratio of drowned to free discharge for a thin-edged weir similarly submerged as a correction to the coefficient for free discharge over the weir in question. For broad-crested weirs or weirs with aprons this method probably will not be applicable.

\section{BAZIN'S EXPERIMENTS.}

For many of the model weirs of irregular section for which free. discharge coefficients were obtained by Bazin, duplicate series of coefficients with various degrees of subnergence were also obtained. 
Many of these data have been reduced to English units by Nelles. ${ }^{a}$ Evidently each form of weir section will require a special formula or table of coefficients, and little more can be done than to refer to the original data for each specific case.

By way of general illustration of the character of submergence effect on weirs of irregular section, the writer has deduced the following roughly approximate formulas from Bazin's experiments on triangular weirs with vertical upstream faces and sloping aprons. The weirs were 2.46 feet high and the end contractions were suppressed. Coefficient curves for free discharge are given on $\mathrm{Pl}$. V.

Three series are included:

Series 195 , batter of face $1: 1$.

Series 196 , batter of face $2: 1$.

Series 197, batter of face $5: 1$.

Experiments in which the proportional submergence $\frac{d}{D}$ was nearly the same were grouped, and the average values of $\triangle, D$, and $d$ were determined. From these the mean values of $\frac{\Delta}{D}$ and $\frac{d}{D}$ were computed and platted and a straight-line formula deduced.

$$
\begin{aligned}
\frac{\triangle}{D} & =0.72+b\left(1-\frac{d}{D}\right) \\
b & =0.08+0.17 B .
\end{aligned}
$$

The initial effect occurs when

$$
\frac{d}{D}=\frac{0.17 B-0.20}{17 B+0.08} \text {. . . . . . . . }
$$

In the above formulas $\Delta$ is the measured head on a weir with free overflow, having the same form of cross section, that would give the same discharge. $D$ is the depth on the submerged weir, $d$ is the depth of submergence, and $B$ is the batter or slope of the apron.

\section{DATA CONCERNING EAST INDIAN WEIRS.}

The following data compiled by Nelles ${ }^{b}$ are derived from observations on actual dams under heads unusually great. The calculated coefficients in the ordinary weir formula $(a)$

$$
Q=M^{\prime} L H \sqrt{2 g H}
$$

in the theoretical submerged-weir formula $(b)$

$$
Q=M^{\prime} L \sqrt{2 g Z}\left(d+\frac{2}{3} Z\right),
$$

and in the Rhind formula (77) are given in columns 14, 13, and 12, respectively (p. 145), the observed bead being corrected for velocity of approach. 


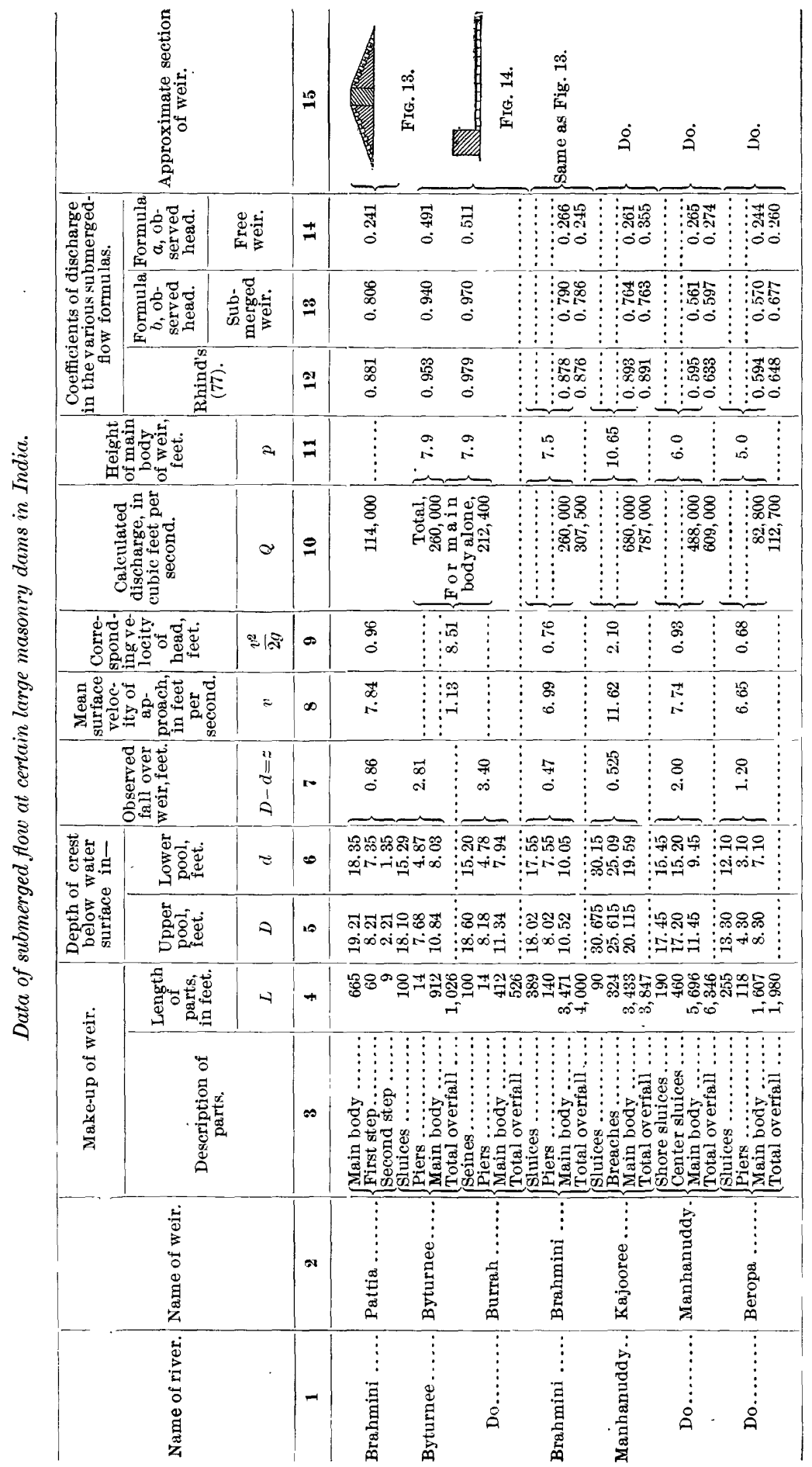




\section{UNITED STATES DEEP WATERWAYS EXPERIMENTS. ${ }^{a}$}

These experiments were made in 1899 at Cornell University hydraulic laboratory on a model having completely rounded profile, being a design for a submerged dam for regulation of Lake Erie.

The coefficient curve for free discharge is given on PI. XVI. The absolute coefficients and the relative discharge with various degrees of submergence are shown below. The Francis formula is used.

$$
Q=C^{\prime} L H^{\frac{3}{2}} \text {. }
$$

Absolute roefficients.

\begin{tabular}{|c|c|c|}
\hline$D$ & $\begin{array}{c}\text { Submer- } \\
\text { gence from } \\
\text { backwater. }\end{array}$ & \multicolumn{1}{|c|}{$\epsilon^{\prime \prime}$} \\
\hline Feet. & Feet: & \\
0.0 & 0.00 & 3.70 \\
.1 & .66 & 3.67 \\
.2 & 1.32 & 3.64 \\
.3 & 1.98 & 3.60 \\
.4 & 2.64 & 3.54 \\
.5 & 3.30 & 3.47 \\
.6 & 3.99 & 3.36 \\
.7 & 4.62 & 3.17 \\
.8 & 5.28 & 2.88 \\
.9 & 5.94 & 2.30 \\
\hline
\end{tabular}

Relative coefficients, Whited States Deep Watervays submerged-ueir model.

\begin{tabular}{|c|c||c|c|}
\hline$\frac{d}{H}$ & \multicolumn{1}{c|}{$\bar{C}^{\prime \prime}$} & \multicolumn{1}{c|}{$\frac{h}{H}$} & \multicolumn{1}{c|}{$\frac{C^{\prime}}{U}$} \\
\hline 0.0 & 1.000 & 0.5 & 0.937 \\
.1 & .991 & .6 & .907 \\
.2 & .983 & .7 & .856 \\
.3 & .972 & .8 & .778 \\
.4 & .956 & .9 & .621 \\
& & 1.0 & \\
\hline
\end{tabular}

$C$ is the coefficient for free discharge over a similar weir under the same head.

\section{WEIR DISCHARGE UNDER VARYING HEAD.}

Problems of weir discharge under varying head occur in the design of storage reservoirs for river regulation, and in determining the maximum discharge of streams. 
An effort has been made in the present chapter to record the various working formulas resulting from the solution of this mathematically difficult portion of the theory of the weir, and to give numerical data to facilitate calculations.

It is assumed that there is no velocity of approach, or, if any, that the head has been corrected therefor. The weir coefficient is also assumed to continue constant through the range of variation of the head.

Notation:

$T=$ Time in seconds required for the head to change between two assigned values.

$H_{o}=$ Initial depth on weir, feet.

$H_{t}=$ Depth on weir at the time $t$.

$S=$ Reservoir surface area, square feet.

$L=$ Length of overflow weir, feet.

$I=$ Rate of inflow to reservoir, cubic feet per second.

$Q=$ Rate of outflow at time $t$.

PRISMATIC RESERVOIR, NO INFLOW, TIME REQUIRED TO LOWER WATER SURFACE FROM $H_{0}$ TO $H_{i}$ a

Where

$$
\begin{aligned}
& d Q=C L H^{\frac{3}{2}} d t=-S d H \\
& d t=-\frac{S}{C L H^{\frac{3}{2}}} d H
\end{aligned}
$$

$$
\begin{aligned}
\int_{0}^{T} d t & =-\frac{S}{C L} \int_{C ! I_{0}}^{P H_{t}} I^{-\frac{3}{2}} d I I \\
T & =\frac{2 S}{C L}\left(\frac{1}{\sqrt{H_{t}}}-\frac{1}{\sqrt{H_{o}}}\right) . \quad . \quad . \quad . \quad .
\end{aligned}
$$

$$
C=\frac{2}{3} M \sqrt{2 g}=5.35 M
$$

$$
T=\infty \text {, when } H_{t}=0 .
$$

If $S=1,000,000, \quad H_{0}=4, \quad H_{t}=0.1, \quad C=3.33, \quad$ and $L=100$,

$$
T=\frac{2}{100} \times \frac{3,000,000}{10}\left(\frac{\sqrt{10}}{1}-\frac{1}{2}\right)=15,972 \text { seconds }=4.44 \text { hours. }
$$

To lower the reservoir from $H=4$ to $H=1$ would require 3,000 seconds.

\section{APPROXIMATE TIME OF LOWERING PRISMATIC OR NONPRIS- MATIC RESERVOIR.}

Choosing small successive values of $H_{o}-H_{t}$, we may solve this problem approximately, as shown in the following table:

Time required to lower reservoir from $H_{o}$ to $H_{t}=\frac{\left(H_{o}-H_{t}\right) S}{\operatorname{Mean} Q}$ 
We may take the mean discharge between the narrow limits $H_{o}$ and $H_{t}$,

$$
Q_{\mathrm{m}}=\frac{C L}{2}\left(H_{o}^{\frac{3}{2}}+H_{t}^{\frac{3}{2}}\right) \quad \cdot \quad \cdot \quad \cdot \quad \cdot .
$$

or, using the average head,

$$
Q_{\mathrm{m}}=C L\left(\frac{H_{0}+H_{t}}{2}\right)^{\frac{3}{2}} \cdot \ldots . . .
$$

In the following example we have used the latter value, and have made $H_{0}-I_{t}=0.5$ foot. A similar solution may be made for a nonprismatic reservoir, using successive values of $\frac{S_{1}+S_{2}}{2}$ as the reservoir area, and determining the increments of $T$ by formula (88).

Example of varying discharge.

\begin{tabular}{|r|r|r|r|r|r|r|}
\hline$H_{o}$ & $H_{t}$ & $\begin{array}{c}\text { Average } \\
H\end{array}$ & Q per second. & $\frac{1000}{\bar{Q}}$ & $\begin{array}{c}T \text { for incre- } \\
\text { ment } \\
H_{o}-H_{t}\end{array}$ & $\begin{array}{r}\text { Total } T \text { in } \\
\text { secondis. }\end{array}$ \\
\hline 4.0 & 3.5 & 3.75 & $2,417.0$ & 0.4137 & 207 & 207 \\
3.5 & 3.0 & 3.25 & $1,951.0$ & .5126 & 256 & 463 \\
3.0 & 2.5 & 2.75 & $1,519.0$ & .6580 & 330 & 793 \\
2.5 & 2.0 & 2.25 & $1,124.0$ & .8970 & 448 & 1,241 \\
2.0 & 1.5 & 1.75 & 771.0 & 1.2970 & 650 & 1,891 \\
1.5 & 1.0 & 1.25 & 465.4 & 2.1500 & 1,070 & 2,961 \\
\hline
\end{tabular}

The total time required in seconds is 2,961 , as compared with 3,000 by formula ( 87 ).

The time required, using the average $Q$ instead of the average $H$ in the calculation, that is, using formula (89) instead of (90), is $2,933.5$ seconds.

The time $T$ is directly proportional to the area of storage surface and inversely proportional to the length of spillway. It is also usually proportional to the value of $C^{\gamma}$ in the weir formula.

\section{RESERVOIR PRISMATIC, WITH UNIFORM INFLOW. $a$}

GENERAL FORMULAS.

Starting with reservoir full to crest level, $H_{o}=0$, to find the time required for the depth of overflow to reach a given stage, $H_{i}$. 
When individual values of the increment $H_{2}-H_{1}$ are small, not over 0.5 foot each, if successive values are taken, we have approximately:

$$
\begin{aligned}
& t=\frac{S\left(H_{2}-H_{1}\right)}{I-\frac{Q_{1}+Q_{2}}{2}} \cdot \cdot \cdot \quad \cdot \quad \cdot \quad \cdot \quad . \\
& I=\frac{2\left(H_{2}-H_{1}\right) S+Q_{1}+Q_{2}}{2 t}
\end{aligned}
$$

$t=$ time required to rise through the increment $H_{2}-H_{1}$.

A summation of the successive values of $t$ required for the water to rise each increment will give the total time of rise from $H_{o}$ to $H_{t}$. Formula (92) will give the maximum run-off from a catchment area tributary to a reservoir if two successive values of $H$ and the corresponding value of $t$ are known.

Formula (92) may also be used to determine $T$ for a nonprismatic reservoir with a variable rate of inflow by choosing such increments, $H_{2}-H_{1}$, that the average values of $S, I$, and $Q$ will be nearly correct. Variations in the weir coefficient $C$ may also be considered.

FORMULAS FOR TIME OF RISE TO ANY HEAD H, PRISMATIC RESERVOIR WITH UNIFORM INFLOW.

Several analytical solutions of this problem have been made. Starting at spillway level, let $I I_{a}$ equal the depth of overflow corresponding to the quantity of inflow $I$. The problem is stated by the following differential equation whose primitive is required:

(Rate inflow - rate outflow) $d t=d$ (increase in storage), or

$$
\left(I-C L H^{\frac{3}{2}}\right) d t=S d H \quad \cdot \quad \cdot \quad \cdot \quad . \quad .
$$

In the solution, mathematical substitutions are necessary in order to render the time-outflow equation integrable in known forms. A very clear demonstration for a special value of $C$ has been given by Frizell. ${ }^{a}$ By modifying Frizell's formula to adapt it to the use of any value of $C$ in the weir formula, the following equation is obtained:

$$
\frac{3 C L b}{2 S} T=\text { nat. } \log \sqrt{\frac{H+b \sqrt{H}+b^{2}}{b-\sqrt{H}}}+\sqrt{3} \tan ^{-1} \sqrt{\frac{1}{3}}-\sqrt{3} \tan ^{-1} \frac{2 \sqrt{H}+b}{b \sqrt{3}}
$$

where $b=\sqrt[3]{\frac{I}{C L}}$

When $H=H_{a}$, the second member becomes the sum of an infinite and two finite quantities, $T$ is then infinite, and the outflow can never 
become equal to the inflow, or $I I$ can never equal $H_{a}$, which quantity it approachess as a limit as $T$ increases. Frizell places $H=r H_{a}, r$ having any value less than unity, and, being very nearly unity, $\sqrt{r}$ will be more nearly so, and is taken as equal to unity, without great error, enabling the two inverse trigonometric constants to be evaluated in terms of arc, giving finally:

$$
T=\frac{2 S^{r}}{3\left(C^{2} L^{2} I\right)^{\frac{1}{3}}}\left(\text { nat. } \log \frac{\sqrt{1+\sqrt{r}+r}}{1-\sqrt{r}}-0.88625\right) .
$$

Nat. $\log N=2.302585 \log _{10} N$

E. Ludlow Gould" gives the following formula, identical with the above except in the form of the constant of integration:

$$
\begin{aligned}
& T=\frac{2 S}{3\left(C^{2} L^{2} I\right)^{\frac{1}{3}}}\left[\text { nat. } \log \frac{\sqrt{1+\sqrt{r}+r}}{1-\sqrt{r}}\right. \\
& \quad-\sqrt{3}\left\{\tan ^{-1} \frac{2}{\sqrt{3}}\left(\frac{1}{2}+\sqrt{r}\right)-\frac{\pi}{6} !\right] . . . .
\end{aligned}
$$

$r=\frac{H}{H_{a}}$ as before. Gould does not consider $\sqrt{r}$ constant, but derives the values of the function in brackets for various values of $r$, from which the following table has been derived:

$$
\phi=\left[\text { nat. } \log \frac{\sqrt{1+\sqrt{r}+r}}{1-\sqrt{r}}-\sqrt{3}\left\{\tan ^{-1} \frac{2}{\sqrt{3}}\left(\frac{1}{2}+\sqrt{r}\right)-\frac{\pi}{6}\right\}\right] \text {. }
$$

Values of $\phi$, Gould's formula.

\begin{tabular}{|r|c|c|c|c|c|c|c|c|c|c|}
\hline \multicolumn{1}{r|}{$\vec{H}_{u}$} & 0 & 1 & 2 & 3 & 4 & 5 & 6 & 7 & 8 & 9 \\
\hline 0.0 & 0.0000 & 0.0153 & 0.0306 & 0.0459 & 0.0613 & 0.0766 & 0.0919 & 0.1072 & 0.1226 & 0.13788 \\
.1 & .1532 & .16854 & .1838 & .1992 & .2155 & .2319 & .2483 & .2646 & .2810 & .2973 \\
.2 & .3137 & .3301 & .3464 & .3628 & .3791 & .3955 & .4137 & .4319 & .4501 & .4683 \\
.3 & .4865 & .5047 & .5229 & .5411 & .5593 & .5775 & .5957 & .6139 & .6321 & .6534 \\
.4 & .6747 & .6960 & .7173 & .7386 & .7598 & .7811 & .8024 & .8237 & .8450 & .8663 \\
.5 & .8876 & .9137 & .9399 & .9660 & .9921 & 1.0183 & 1.0444 & 1.0705 & 1.0966 & 1.1128 \\
.6 & 1.1489 & 1.1750 & 1.2012 & 1.2322 & 1.2674 & 1.3027 & 1.3380 & 1.3733 & 1.4086 & 1.4439 \\
.7 & 1.4792 & 1.5145 & 1.5498 & 1.5851 & 1.6203 & 1.6556 & 1.7073 & 1.7590 & 1.8107 & 1.8624 \\
.8 & 1.9141 & 1.9658 & 2.0176 & 2.0715 & 2.1488 & 2.2262 & 2.3035 & 2.3808 & 2.4582 & 2.5355 \\
.9 & 2.6129 & 2.7681 & 2.9233 & 3.0785 & 3.2347 & 3.3889 & 3.5441 & 4.0096 & 4.47504 .9405 \\
\hline
\end{tabular}

$a$ Engineering News, Dec. 5, 1901, pp. 430-431. 


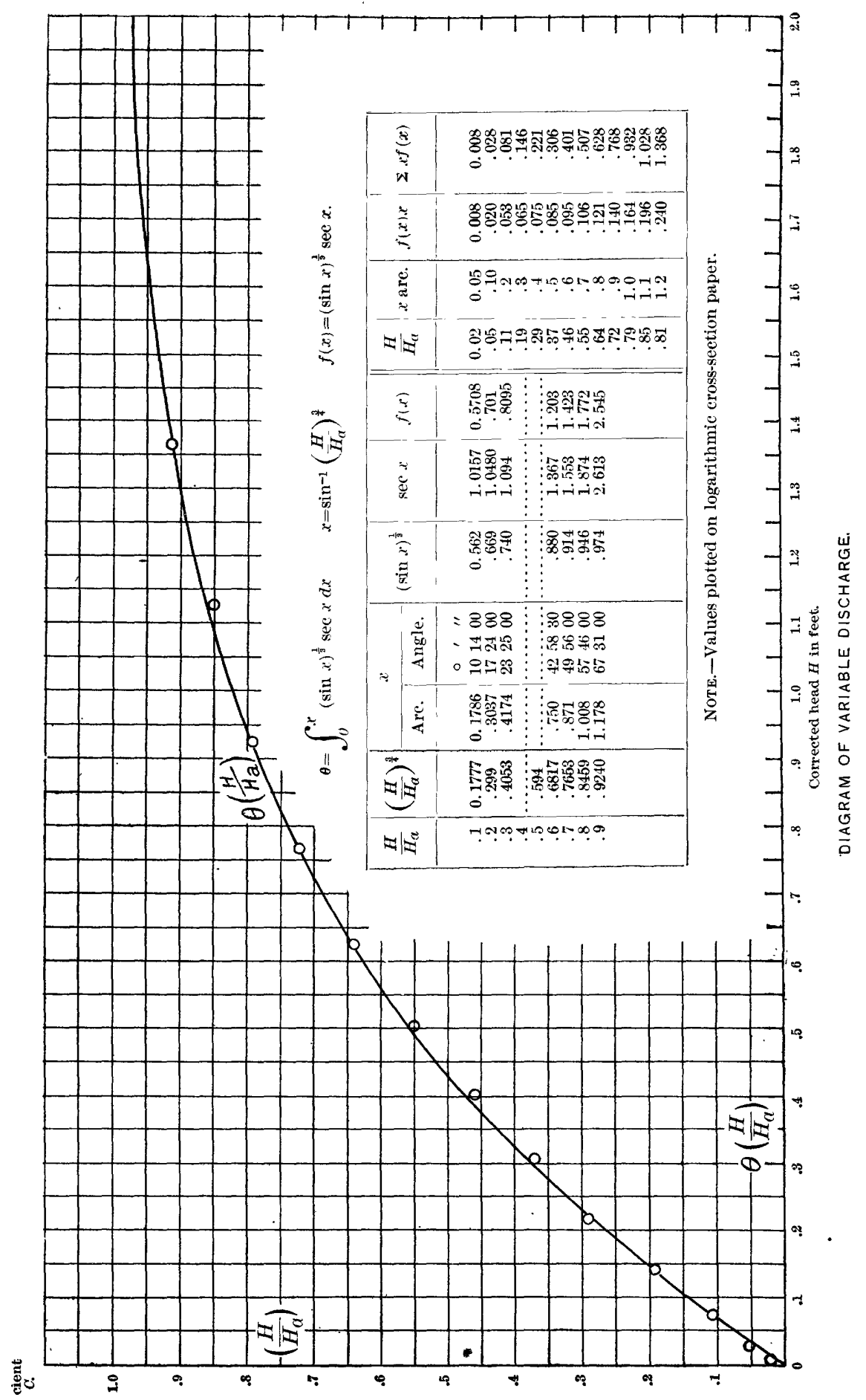


We may write formula (9)

$$
T=\phi\left(\frac{H}{H_{a}}\right) \times \frac{2 S}{3 \sqrt[3]{C^{2} L^{2} I}} \cdot \ldots . \quad . \quad . \quad .
$$

R. S. Woodward suggests the formula ${ }^{a}$

where

$$
\left.\begin{array}{l}
T=\frac{4 S}{3 \sqrt[3]{C^{2} L^{2} I}} \int^{X}(\sin X)^{\frac{1}{3}} \text { sec } X d X \\
X=\sin ^{-1} \sqrt{\frac{C L H^{\frac{3}{2}}}{I}}=\sin ^{-1}\left(\frac{H}{H_{a}}\right)^{\frac{3}{4}}
\end{array}\right\}
$$

This, like the preceding expressions, becomes infinity when the integral is carried over the entire range $X=0$ to $X=\frac{\pi}{2}$, conforming with the physical conditions.

The writer has evaluated this function for finite values of $\frac{H}{H_{a}}$ by mechanical quadrature, as shown in the diagram, Pl. XXXVIII. The diagram illustrates the rapid rise until a head closely approaching $H_{a}$ is attained, occupying a comparatively short time interval, while for further increments of head the time interval is relatively very great.

E. Sherman Gould ${ }^{b}$ gives the same integral developed as an infinite series

$$
T=\frac{2 S H}{I}\left[\frac{1}{2}+\frac{K}{5}+\frac{K^{2}}{8}+\cdots+\frac{K^{n}}{2+3_{n}}\right]
$$

where

$$
\begin{aligned}
K & =\left(\frac{H}{H_{a}}\right)^{\frac{3}{2}} . \\
\text { If } 9\left(\frac{H}{H_{a}}\right) & =\left[\frac{K^{o}}{2}+\frac{K^{1}}{5}+\frac{K^{2}}{8}+\cdots+\frac{K^{n}}{2+3}\right] \\
T & =\frac{2 S H}{I} \times 9\left(\frac{H}{H_{a}}\right)=\frac{2 S}{\sqrt[3]{C^{2} L^{2} I}} 9\left(\frac{H}{H_{a}}\right) .
\end{aligned}
$$


If we write

$$
F=\frac{2 S}{3 \sqrt[3]{C^{2} L^{2} I}}
$$

then Frizell's formula may be written

$$
\left.\begin{array}{l}
T=F \times \rho\left(\frac{H}{H_{a}}\right) \\
T=F \times \phi\left(\frac{H}{H_{a}}\right) \\
T=2 F \psi\left(\frac{H}{H_{a}}\right)
\end{array}\right\} .
$$

E. L. Gould's formula may be written

Woodward's formula may be written

E. Sherman Gould's formula may be written $T=F \times 9\left(\frac{I I}{I_{a}}\right)$

The formulas are therefore identical, the transcendental factors bearing the relation,

$$
\rho\left(\frac{H}{H_{a}}\right)=\phi\left(\frac{H}{H_{a}}\right)=2 \psi\left(\frac{I I}{I I_{a}}\right)=9\left(\frac{H}{H_{a}}\right)
$$

The E. L. Gould, Woodward, and E. S. Gould formulas are applicable for any value of the ratio $\frac{I I}{H_{a}}$. That of Frizell can be strictly applied only when $\frac{H}{H_{a}}$ is nearly unity. In the E. S. Gould formula $\vartheta\left(\frac{H}{H_{a}}\right)$ converges very slowly as the argument approaches unity. For rough calculations E. S. Gould gives the rule

$$
T I-T C L(\mu H)^{\frac{3}{2}}=S H
$$

where $\mu$ is the coefficient in the weir formula for reducing final head to mean head.

$$
T=\frac{S H}{I-\left(Y L(\mu H)^{\frac{3}{2}}\right.} \cdot \cdot \cdot \cdot \cdot \cdot \cdot
$$

The ratio $\mu$ of the constant mean head which would give the total discharge $S H$ in the time $T$ he finds by trial.

E. S. Gould gives the values

$$
\begin{aligned}
\mu & =0.67 \text { for small values of } H \\
\text { to } \mu & =0.75 \text { for large values of } H \text {. }
\end{aligned}
$$

Comparing the formulas,

Let $S=1,000,000$ square feet

$$
\begin{aligned}
& C=3.33=\frac{10}{3} \\
& L=100 \\
& I=10,000 \text { cubic feet per second } \\
& H_{a}=\left(\frac{I}{C L}\right)^{\frac{2}{3}}=30^{\frac{2}{3}}=9.655 \text { feet. }
\end{aligned}
$$


Required the time to rise to a height $H_{a}=0.9 I=8.6895$ feet.

$$
F=\frac{2 S^{\prime}}{3 \sqrt[3]{C^{2} \bar{L}^{2} I}}=643.5
$$

Frizell

E. L. Gould

Woodward
(95) $T=1677.6$ seconds.

(96) $T=1681.5$ seconds.

(99) $T=1660.2$ seconds.

E. S. Gould (approximate) (103) $T=1488.3$ seconds.

The difference in the value of $T$ by the first three formulas represents the difference in the values of the transcendental portions of the equations as evaluated by different methods.

The time required to rise from $H_{a}$ to $H_{b}$ will be the difference of the times $T_{1}$ and $T_{2}$ by the above formulas.

\section{NONPRISMATIC RESERVOIR, UNIFORM INFLOW.}

$$
\text { P. P. L. O'CONNELI. " }
$$

Representing the reservoir by a cone having its apex at distance $A$, below plane of the overflow,

$$
\text { Area at overflow level }=S_{0}=\pi(\alpha A)^{2}
$$

Area at any other level $\left.=S=\pi[\alpha(A+H)]^{2}\right\}$

where $\alpha$ is the slope of the sides, or where there is $\alpha$ foot horizontal run to 1 foot vertical rise. From (104) with $S_{0}$ and $\alpha$ given, $A$ may be determined.

Where the factor

$$
I_{1}=\sqrt[3]{\frac{I}{C L}}
$$

$$
\begin{aligned}
T=\frac{\pi \alpha^{2}}{C L}[ & -4 A \sqrt{H}-\frac{2}{3} H^{\frac{3}{2}}-\frac{2}{3} I_{1}^{3} \text { nat. } \log \frac{I_{1}^{3}-H^{\frac{3}{2}}}{I_{1}{ }^{3}} \\
& -\frac{\left(2 A I_{1}{ }^{2}+A^{2}\right)}{3 I_{1}} \text { nat. } \log \left(\frac{\left[\sqrt{H-I_{1}}\right]^{2}}{I+I_{1} \sqrt{H+I_{1}^{2}}}\right) \\
& \left.+\frac{2 A^{2}-4 A I_{1}^{2}}{3 I_{1}} \sqrt{3} \tan ^{-1}\left(\frac{-\sqrt{3 H}}{2 I_{1}+\sqrt{H}}\right)\right] .
\end{aligned}
$$




\section{E. L. GOULD. ${ }^{a}$}

Calling $i$ the angle of inclination of the banks, $P_{o}$ the perimeter, at spillway level, exclusive of overflow,

$$
\begin{gathered}
S=S_{o}+B H+B_{1} H^{2} \text { where } B=P_{o} \cot i \\
B_{1}=\pi \cot i^{2} \quad r=\frac{H}{H_{1}} \\
r=\frac{2}{3 I^{\frac{1}{3}} C^{2} L^{2}}\left[\left(S_{0}(C L)^{\frac{4}{3}}+B(I C L)^{\frac{2}{3}}\right) \text { nat. } \log \frac{\sqrt{1+\sqrt{r}+r}}{1-\sqrt{r}}\right. \\
-\left(S_{o}(C L)^{\frac{4}{3}}-B(I C L)^{\frac{2}{3}}\right) \sqrt{3}\left\{\tan ^{-1} \frac{1+2 \sqrt{r}}{\sqrt{3}}-\frac{\pi}{6}\right\} \\
-B_{1} 1^{\frac{4}{3}}\left\{\text { nat. } \log \left(1-r^{\frac{3}{2}}\right)+r^{\frac{3}{2}}\right\}-B(I C L)^{\left.\frac{2}{3} \sqrt{r}\right]}
\end{gathered}
$$

For $i=90^{\circ}$ and $B=0$, the above formula reduces to (96), the equation for a prismatic reservoir.

\section{VARIABLE INFLOW, NONPRISMATIC RESERVOIR.}

This problem may be solved by dividing the reservoir into successive levels, and solving by the formulas previously given, as if each layer represented a portion of a reservoir with a constant inflow equal to the average rate, or if the formulas for prismatic reservoir are used, then each layer will be supposed to represent a portion of a prismatic reservoir of area equal to the average area of the layer.

Mullins's formula may often be more conveniently used and a better solution be obtained than by attempting to average the area and inflow, as would be necessary to apply the analytical formulas given.

The general differential equation for rise in time $T$ with a variahle inflow and reservoir area is

$$
(I-Q) d T=S d H \quad \text {. . . . . . }
$$

If we can express $I$ as a function of $T$, and $S$ and $Q$ as functions of $H$, and integrate between the limits $H=0, H=H_{1}$, we may obtain an equation between $H$ and $T$ similar to those given for prismatic reservoirs with constant inflow.

We may write the ordinary weir formula,

$$
Q=C L H^{\frac{3}{2}}
$$


The area $S$ can usually be readily expressed in terms of the area at crest level and slope of the reservoir sides (assumed constant within the narrow limits $0, H$ ); the inflow $I$ often increases nearly as a linear function of $T$ while a stream is rising rapidly; we have, then,

$$
\begin{aligned}
Q_{t} & =C L H^{\frac{3}{2}} \\
S_{t} & =S_{o}+2 \alpha \sqrt{S_{0}} I+\alpha^{2} H^{2} \\
I_{t} & =I_{0}+f T .
\end{aligned}
$$

Substituting in (107)

$$
\left(I_{o}+f T-C L H^{\frac{3}{2}}\right) d T=\left(S_{o}+2 \alpha \sqrt{S_{o}} H+\alpha^{2} H^{2}\right) d H .
$$

The complete primitive of this differential equation can be determined only as an infinite series. ${ }^{a}$

Rivers during flood usually rise rapidly and fall slowly. The timeinflow function can sometimes be approximated by a modified sinusoid.

where $n=$ or $>1$

$$
I=I_{o}+I_{m} \sin (b t)^{\frac{1}{n}} \text {. . . . . . . }
$$

$T=$ Total duration of flood.

$I_{m}=$ Maximum rate of inflow.

$T_{m}=$ Time elapsed from beginning of rise to maximum.

The constants are so chosen that the arc value of the duration of the flood from stage $I_{0}$ through to the same stage is $\pi$, or,

$$
(b t)^{\frac{1}{n}}=\pi \quad b=\frac{\pi^{n}}{T} \quad . \quad . \quad . \quad . \quad . \quad .
$$

For the maximum we will have, differentiating (109),

$$
\begin{gathered}
\cos \left(b T_{m}\right)^{\frac{1}{n}}=0, \quad \text { or }\left(b T_{m}\right)^{\frac{1}{n}}=\frac{\pi}{2} \quad . \quad . \\
\text { or } b=\frac{1}{T_{m}}\left(\frac{\pi}{2}\right)^{n}=\frac{\pi^{n}}{T} \quad \text { or } \quad \frac{T}{T_{m}}=2^{n} \\
n=\log \frac{T}{T_{m}} \times \frac{1}{\log 2}=3.32204 \log \left(\frac{T}{T_{m}}\right) . \quad . \quad .
\end{gathered}
$$

common logarithms being used.

If $T=1000$ and if $T_{m}=200$, then $n=3.322 \log 5=2.322$,

$$
b=\frac{\pi^{2.322}}{1000}=0.0143, \text { and } \frac{1}{n}=0.43066
$$

$a$ Seddon, James A., C. E. (Proc. Am. Soc. C. E., vol. 24, June, 1898, pp. 559-598), has solved equation (108) for the Great Lakes reservoir system, assuming an annual cycle following the law $I=I_{m}+A$ $\sin T, I_{m}$ being the mean inflow and $T$ the time arc on a circle whose circumference represents one year.' He also assumes $Q=Q_{0}+b H$, or a linear function of the height $H$. 
Example of variable flood discharge computed by formula (109).

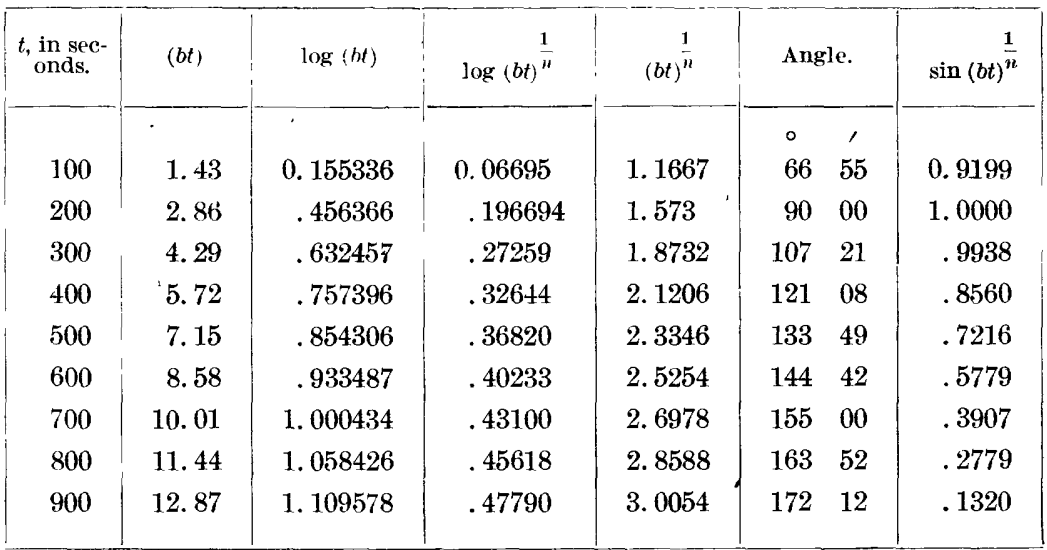

The form of the graph of the flood may be determined by plotting the quantities in the last column of this table in terms of $t$. The resulting curve rises rapidly to a maximum when $t=200$, after which it descends slowly.

\section{TABLES FOR CALCULATIONS OF WEIR DISCHARGE.}

The investigations at Cornell University have greatly extended the limit for which weir coefficients are definitely known. The experiments of Bazin did not reach beyond 1.8 feet head maximum. The tables of Francis for thin-edged weirs extended to a head of 3 feet.

The experiments at Cornell have furnished the coefficients for a variety of weir forms for heads up to 4,5 , and 6 feet. At such heads the nappe form has become stable for nearly all forms of weirs. We may now predict the probable extension of the coefficient curves for higher heads with more confidence than could be done by starting from a lower datum.

Owing to their usefulness in the approximate determination of flood discharges, the weir tables have been carried up to a head of 10 feet.

In the tables here given the head is uniformly expressed in feet. For computing the flow over irrigation modules and other small weirs where the head is measured in inches, weir tables expressed with the inch as the argument of head are convenient. Numerous tables of this character are available. The following may be referred to:

The Emerson weir tables, computed by Charla A. Adams, pages 251-285 of Emerson's Hydrodynamics, published by J. and W. Jolly, Holyoke, Mass. These give discharge in cubic feet per minute for weirs with two end contractions having lengths of $2,3,4,5,6,7,8,10,12,16$, and 20 feet. The discharge is computed by the Francis formula for heads from 0.001 foot to 2 feet, advancing by thousandths of a foot, with auxiliary table of decimal equivalents of fractional parts of inches. 
The Measurement and Division of Water, Bulletin No. 27, Agricultural Experiment Station, Fort Collins, Colo. This publication gives tables of discharge in cubic feet per second, computed by the Francis formula, for a weir 1 foot long, for heads in inches and sixteenths, from $\frac{1}{15}$ inch to 30 inches, with auxiliary table for end contractions, and for velocity of approach correction by the Fteley and Stearns rule $\left(H=D+\frac{3}{2} h\right)$. A similar weir table for a weir 1 inch long is given. Also a table of discharge for Cippoletti weirs $\left(C=3.36 \frac{2}{3}\right)$, for lengths of crest sill of $1,1.5,2,3,4$, 5 , and 10 feet. Head in inches and decimals with feet equivalents.

Special Instructions to Watermasters as to Measurements of Water, State Engineer's Office, Salt Lake City, Utah, 1896. Table of discharge, in cubic feet per second, for 1-foot crest, based on the Francis formula, with auxiliary table for end contractions and velocity of approach. The head is expressed in inches and thirty-seconds (with equivalents in feet) for $\frac{1}{32}$ inch to 36 inches. A similar table for heads in inches and sixteenths, from $\frac{1}{15}$ to 36 inches, gives the discharge in cubic feet per second by the Francis formula for weirs with two end contractions and for the crest lengths of $1,1 \frac{1}{2}$, $2,2 \frac{1}{2}, 3,4,5,6,7,8,9,10,11$, and 12 feet. A table for trapezoidal weirs $(C=3.367)$ of various crest lengths is also given.

California Hydrography, by J. B. Lippincott, Water-Supply Paper No. 81, United States Geological Survey. This publication contains a table of weir discharge in cubic feet per second for heads, advancing by sixteenths, from $\frac{1}{16}$ inch to 10 inches (with equivalent decimals of a foot), for weirs with two end contractions having crest lengths as follows: $4,6,9,12,15$, and 18 inches, $2,2.5,3,3.5,4,4.5,5,6,7,8$, $9,10,12,14,16,18$, and 20 feet. Based on the Francis formula. Also published as a circular.

The tables that follow are all original computations, with exception of the "Francis weir tables," page 162, and the table of head due to various velocities, page 158 .

TABLE I.-HEAD DUE TO VARIOUS VELOCITIES. $a$

This table gives values of the expression

$$
h=\frac{v^{2}}{2 g}
$$

based on the constant of gravity for the latitude and altitude of Lowell, Mass.,

$$
g=32.1618, \frac{1}{2 g}=0.01554639 .
$$


TABLE 1. - Values of $h=\frac{v^{2}}{2 g}$, or heads due to velocities from 0 to 4.99 feet per second.

\begin{tabular}{|c|c|c|c|c|c|c|c|c|c|c|}
\hline$v$ & 0.00 & 0.01 & 0.02 & 0.03 & 0.04 & 0.05 & 0.06 & 0.07 & 0.08 & 0.09 \\
\hline 0.0 & 0.0000 & 0.0000 & 0.0000 & 0.0000 & 0.0000 & 0.0000 & 0.0001 & 0.0001 & 0.0001 & 0.0001 \\
\hline .1 & .0002 & .0002 & .0002 & .0003 & .0003 & .0003 & .0004 & .0004 & $\cdot 0005$ & .0006 \\
\hline .2 & .0006 & .0007 & .0008 & .0008 & .0009 & .0010 & .0011 & .0011 & " 0012 & .0013 \\
\hline .3 & .0014 & .0015 & .0016 & .0017 & .0018 & .0019 & .0020 & .0021 & $\cdot 0022$ & .0024 \\
\hline .4 & .0025 & .0026 & .0027 & .0029 & .0030 & .0031 & .0033 & .0034 & $\cdot 0036$ & .0037 \\
\hline .5 & .0039 & .0040 & .0042 & .0044 & .0045 & .0047 & .0049 & .0051 & $\cdot 0052$ & .0054 \\
\hline .6 & .0056 & .0058 & .0060 & .0062 & .0064 & .0066 & .0068 & .0070 & $\cdot 0072$ & .0074 \\
\hline .7 & .0076 & .0078 & .0081 & .0083 & .0085 & .0087 & .0090 & .0092 & .0095 & .0097 \\
\hline .8 & .0099 & .0102 & .0105 & .0107 & .0110 & .0112 & .0115 & .0118 & .0120 & .0123 \\
\hline .9 & .0126 & .0129 & .0132 & .0134 & .0137 & .0140 & .0143 & .0146 & .0149 & .0152 \\
\hline 1.0 & 0.0155 & 0.0159 & 0.0162 & 0.0165 & 0.0168 & 0.0171 & 0.0175 & 0.0178 & 0.0181 & 0.0185 \\
\hline .1 & .0188 & .0192 & .0195 & .0199 & .0202 & .0206 & .0209 & .0213 & .0216 & .0220 \\
\hline .2 & .0224 & .0228 & .0231 & .0235 & .0239 & .0243 & .0247 & .0251 & .0255 & .0259 \\
\hline .3 & .0263 & .0267 & .0271 & .0275 & .0279 & .0283 & .0288 & .0292 & .0296 & .0300 \\
\hline .4 & .0305 & .0309 & .0313 & .0318 & .0322 & .0327 & .0331 & .0336 & .0341 & .0345 \\
\hline .5 & .0350 & .0354 & .0359 & .0364 & .0369 & .0374 & .0378 & .0383 & .0388 & .0393 \\
\hline .6 & .0398 & .0403 & .0408 & .0413 & .0418 & .0423 & .0428 & .0434 & .0439 & .0444 \\
\hline .7 & .0449 & .0455 & .0460 & .0465 & .0471 & .0476 & .0482 & .0487 & .0493 & .0498 \\
\hline .8 & .0504 & .0509 & .0515 & .0521 & .0526 & .0532 & .0538 & .0544 & .0549 & .0555 \\
\hline .9 & .0561 & .0567 & .0573 & .0579 & .0585 & .0591 & .0597 & .0603 & .0609 & .0616 \\
\hline 2.0 & 0.0622 & 0.0628 & 0.0634 & 0.0641 & 0.0647 & 0.0653 & 0.0660 & 0.0666 & 0.0673 & 0,0679 \\
\hline .1 & .0686 & .0692 & .0699 & .0705 & .0712 & .0719 & .0725 & .0732 & .0739 & .0746 \\
\hline .2 & .0752 & .0759 & .0766 & .0773 & .0780 & .0787 & .0794 & .0801 & .0808 & .0815 \\
\hline .3 & .0822 & .0830 & .0837 & .0844 & .0851 & .0859 & .0866 & .0873 & 0881 & .0888 \\
\hline .4 & .0895 & .0903 & .0910 & .0918 & .0926 & .0933 & .0941 & .0948 & .0956 & .0964 \\
\hline .5 & .0972 & .0979 & .0987 & .0995 & .1003 & .1011 & .1019 & .1027 & .1035 & .1043 \\
\hline .6 & .1051 & .1059 & .1067 & .1075 & .1084 & . 1092 & .1100 & .1108 & .1117 & .1125 \\
\hline .7 & .1133 & .1142 & .1150 & .1159 & .1167 & .1176 & .1184 & . 1193 & .1201 & . 1210 \\
\hline .8 & .1219 & .1228 & .1236 & .1245 & . 1254 & . 1263 & . 1272 & .1281 & . 1289 & .1298 \\
\hline .9 & .1307 & .1316 & .1326 & .1335 & .1344 & . 1353 & .1362 & .1371 & .1381 & . 1390 \\
\hline 3.0 & 0.1399 & 0.1409 & 0.1418 & 0.1427 & 0.1437 & 0.1446 & 0.1456 & 0.1465 & 0.1475 & 0.1484 \\
\hline .1 & .1494 & .1504 & .1513 & .1523 & .1533 & .1543 & .1552 & .1562 & .1572 & .1582 \\
\hline .2 & .1592 & . 1602 & . 1612 & .1622 & . 1632 & .1642 & . 1652 & .1662 & .1673 & . 1683 \\
\hline .3 & .1693 & .1703 & .1714 & .1724 & .1734 & .1745 & .1755 & . 1766 & . 1776 & .1787 \\
\hline $.4^{\circ}$ & .1797 & .1808 & .1818 & .1829 & .1840 & .1850 & .1861 & .1872 & .1883 & . 1894 \\
\hline .5 & .1904 & .1915 & .1926 & . 1937 & .1948 & .1959 & . 1970 & 1981 & 1992 & .2004 \\
\hline .6 & .2015 & .2026 & .2037 & .2049 & . 2060 & .2071 & . 2083 & .2094 & .2105 & .2117 \\
\hline .7 & .2128 & .2140 & .2151 & .2163 & .2175 & .2186 & .2198 & . 2210 & .2221 & . 2233 \\
\hline .8 & .2245 & .2257 & .2269 & .2280 & .2292 & .2304 & .2316 & .2328 & .2340 & .2352 \\
\hline .9 & .2365 & .2377 & .2389 & .2401 & .2413 & .2426 & .2438 & .2450 & .2463 & .2475 \\
\hline 4.0 & 0.2487 & 0.2500 & 0.2512 & 0.2525 & 0.2537 & 0.2550 & 0.2563 & -0.2575 & 0.2588 & 0.2601 \\
\hline .1 & .2613 & .2626 & .2639 & .2652 & .2665 & .2677 & .2690 & .2703 & .2716 & .2729 \\
\hline .2 & .2742 & .2755 & .2769 & .2782 & .2795 & .2808 & .2821 & .2835 & .2848 & . 2861 \\
\hline .3 & .2875 & .2888 & .2901 & .2915 & .2928 & .2942 & .2955 & .2969 & .2982 & .2996 \\
\hline .4 & .3010 & .3023 & .3037 & .3051 & .3065 & .3079 & .3092 & .3106 & .3120 & .3134 \\
\hline .5 & .3148 & .3162 & .3176 & .3190 & .3204 & .3218 & .3233 & .3247 & .3261 & . 3275 \\
\hline .6 & .3290 & .3304 & .3318 & .3333 & . 3347 & .3362 & .3376 & .3390 & .3405 & .3420 \\
\hline .7 & .3434 & .3449 & .3463 & .3478 & .3493 & .3508 & . 3622 & .3537 & . 3552 & .3567 \\
\hline .8 & .3582 & .3597 & .3612 & .3627 & .3642 & .3657 & .3672 & .3687 & .3702 & .3717 \\
\hline .9 & .3733 & .3748 & . 3763 & .3779 & . 3794 & .3809 & 3825 & .3840 & .3856 & .3871 \\
\hline
\end{tabular}


This value will suffice in ordinary corrections for velocity of approach for localities in the United States.

Velocity of approach correction.

Francis, and as used in portions of this paper (approximate) ........ $H=D+h$

Fteley and Stearns, contracted weir ........................... $H=D+1.5 h$

Hamilton Smith, suppressed weir ..............................

Hamilton Smith, contracted weir..............................

TABLE 2.-PERCENTAGE INCREASE IN DISCHARGE BY VARIOUS RATES OF VELOCITY OF APPROACH.

This table has been calculated from the Francis correction formula,

$$
H^{\frac{3}{2}}=(D+h)^{\frac{3}{2}}-h^{\frac{3}{2}} .
$$

The percentage increase in discharge over that at the same measured head with no velocity of approach is

$$
\text { Percentage }=100 \frac{H^{\frac{3}{2}}-D^{\frac{3}{2}}}{D^{\frac{3}{2}}}=K \quad \cdot \quad \cdot
$$




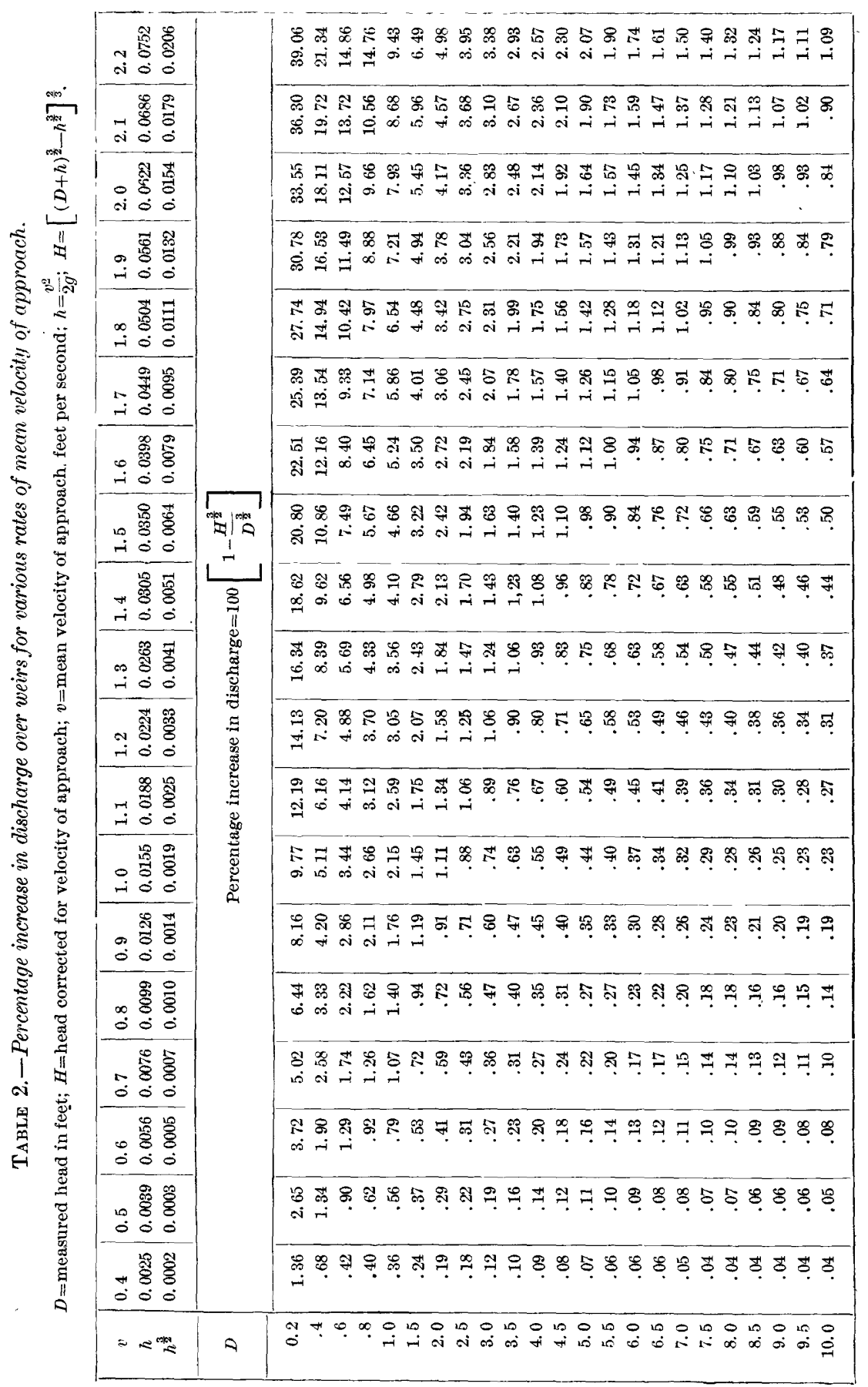




\begin{tabular}{|c|c|c|}
\hline 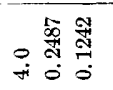 & \multirow{18}{*}{ 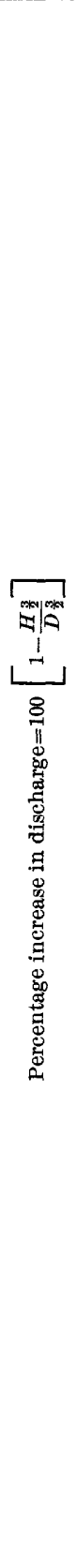 } & 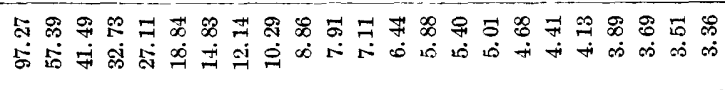 \\
\hline 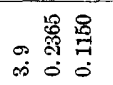 & & 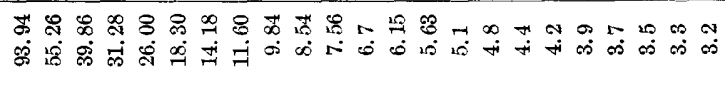 \\
\hline 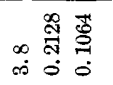 & & 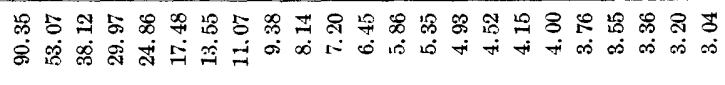 \\
\hline 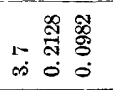 & & 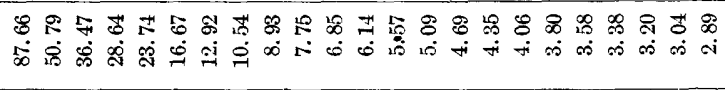 \\
\hline 空㝕 & & 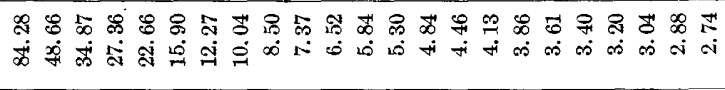 \\
\hline 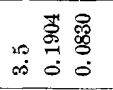 & & 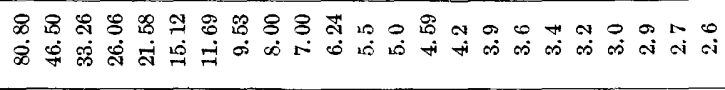 \\
\hline 总点 & & 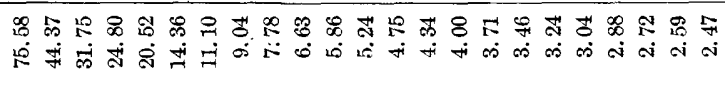 \\
\hline$\infty \begin{array}{l}0.8 \\
\infty\end{array}$ & & 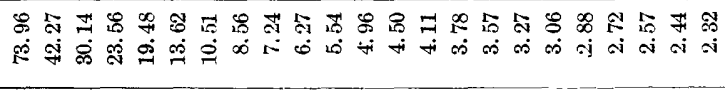 \\
\hline 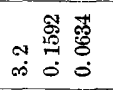 & & 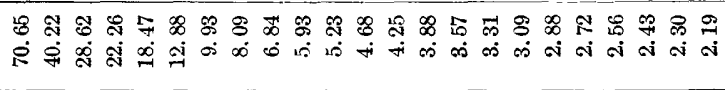 \\
\hline 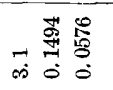 & & 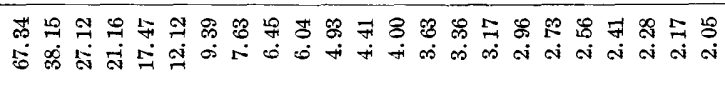 \\
\hline 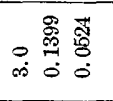 & & 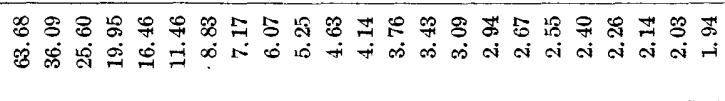 \\
\hline o & & 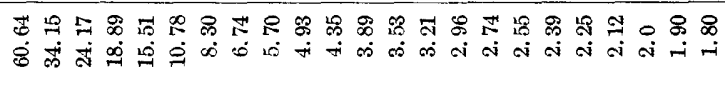 \\
\hline 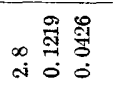 & & 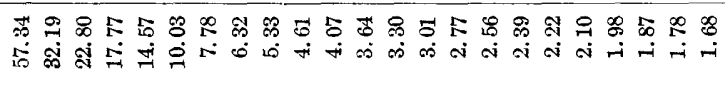 \\
\hline 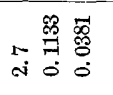 & & 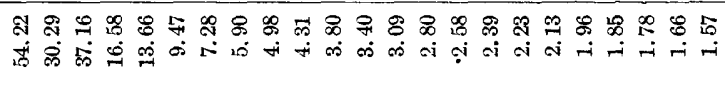 \\
\hline 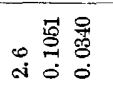 & & 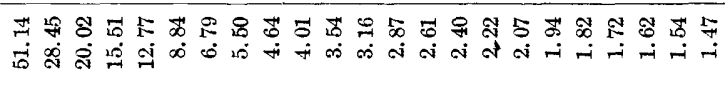 \\
\hline 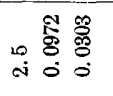 & & 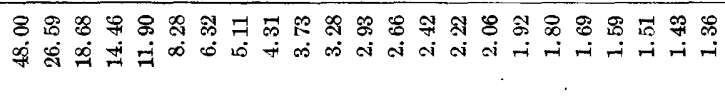 \\
\hline 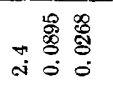 & & 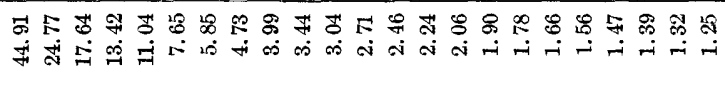 \\
\hline 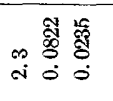 & & 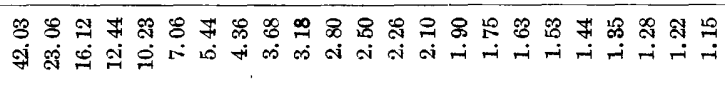 \\
\hline$\approx \approx$ 幽 & $\theta$ & 궁 \\
\hline
\end{tabular}


To use this table the discharge corresponding to the measured head $D$ may be taken directly from Table 3 or 4 and the quantity so obtained increased by the percentage indicated in Table 2. This table is especially useful where the velocity of approach is measured directly. If the velocity of approach is determined from the approximate discharge by the formula $v=\frac{Q}{A}$, successive approximate corrections may be required.

Table 2 shows directly the relative error intrøducea by various velocities of approach. The large error introduced by moderate velocities with low heads and the comparatively small error resulting from higher velocities under great heads are conspicuous.

\section{TABLES 3 AND 4--DISCHARGE OVER A THIN-EDGED WEIR BY THE FRANCIS FORMULA.}

These tables give the discharge in cubic feet per second, for a crest length of 1 foot, without contractions, computed by the formula

$$
Q=3.33 L H^{\frac{3}{2}} \text {. }
$$

TABLE 3.-Discharge over a thin-edged weir per foot of crest.

\begin{tabular}{|c|c|c|c|c|c|c|c|c|c|c|}
\hline Head $H$, feet. & .000 & .001 & .002 & .003 & .004 & .005 & .006 & .007 & .008 & .009 \\
\hline 0.00 & 0.0000 & 0.0001 & 0.0003 & 0.0005 & 0.0008 & 0.0012 & 0.0015 & 0.0020 & 0.0024 & 0.0028 \\
\hline .01 & .0033 & .0038 & .0044 & .0049 & .0055 & .0061 & .0067 & .0074 & .0080 & .0087 \\
\hline .02 & .0094 & .0101 & .0109 & .0116 & .0121 & .0132 & .0140 & .0148 & .0156 & .0164 \\
\hline .03 & .0173 & .0182 & .0191 & .0200 & .0209 & .0218 & $.02: 27$ & .0237 & .0247 & .0256 \\
\hline .04 & .0266 & .0276 & .0287 & .0297 & .0307 & .0318 & .0829 & .0339 & .0350 & .0361 \\
\hline .05 & .0372 & .0384 & .0395 & .0406 & .0418 & .0430 & .0441 & .0453 & .0465 & .0477 \\
\hline .06 & .0489 & .0502 & .0514 & .0527 & .0539 & .0552 & .0565 & .0578 & .0590 & .0604 \\
\hline .07 & .0617 & .0630 & .0643 & .0657 & .0670 & .0684 & .0698 & .0712 & .0725 & .0739 \\
\hline .08 & .0753 & .0768 & .0782 & .0796 & .0811 & .0825 & .0840 & .0855 & .0869 & .0884 \\
\hline .09 & .0899 & .0914 & .0929 & .0944 & .0960 & .0975 & .0990 & .1006 & .1022 & .1037 \\
\hline 0.10 & 0.1053 & 0.1069 & 0.1085 & 0.1101 & 0.1117 & 0.1133 & 0.1149 & 0.1166 & 0.1182 & 0.1198 \\
\hline .11 & .1215 & .1231 & .1248 & .1265 & .1282 & .1299 & .1316 & .1333 & .1350 & .1367 \\
\hline .12 & .1384 & .1402 & .1419 & .1436 & .1454 & .1472 & .1489 & .1507 & .1525 & .1543 \\
\hline .13 & .1561 & .1579 & .1597 & .1615 & .1633 & .1652 & .1670 & .1689 & .1707 & .1726 \\
\hline .14 & .1744 & .1763 & .1782 & .1801 & .1820 & .1839 & .1858 & .1877 & .1896 & .1915 \\
\hline .15 & .1935 & .1954 & .1973 & .1993 & .2012 & .2032 & .2052 & .2072 & .2091 & .2111 \\
\hline .16 & .2131 & .2151 & .2171 & .2191 & .2212 & .2232 & .2252 & .2273 & .2293 & .2314 \\
\hline .17 & .2334 & .2355 & .2375 & .2396 & .2417 & .2438 & .2459 & .2480 & .2501 & .2522 \\
\hline .18 & .2543 & .2564 & .2586 & .2607 & .2628 & .2650 & .2671 & .2693 & .2714 & .2736 \\
\hline .19 & .2758 & .2780 & .2802 & .2823 & .2845 & .2867 & .2890 & .2912 & .2934 & .2956 \\
\hline 0.20 & 0.2978 & 0.3001 & 0.3023 & 0.3046 & 0.3068 & 0.3091 & 0.3113 & 0.3136 & 0.3159 & 0.3182 \\
\hline .21 & .3205 & .3228 & .3250 & .3274 & .3297 & .3320 & .3343 & .3366 & , 3389 & .3413 \\
\hline .22 & .3436 & .3460 & .3483 & .3507 & .3530 & .3554 & .3578 & .3601 & .3625 & .3649 \\
\hline .23 & .3673 & .3697 & .3721 & .3745 & .3769 & .3794 & .3818 & .3842 & .3866 & .3891 \\
\hline .24 & .3915 & .3940 & .3964 & . 3989 & .4014 & .4088 & .4063 & .4088 & .4113 & .4138 \\
\hline .25 & .4162 & .4187 & .4213 & .4238 & .4263 & .4288 & .4313 & .4339 & .4364 & .4389 \\
\hline .26 & .4415 & .4440 & .4466 & .4491 & .4517 & .4543 & .4568 & .4594 & .4620 & .4646 \\
\hline .27 & .4672 & .4698 & .4724 & .4750 & .4776 & .4802 & .4828 & .4855 & .4881 & .4907 \\
\hline .28 & .4934 & .4960 & .4987 & .5013 & .5040 & .5067 & .5093 & .5120 & .5147 & .5174 \\
\hline .29 & .5200 & .5227 & .5254 & .5281 & .5308 & .5336 & .5363 & .5390 & .5417 & .5444 \\
\hline
\end{tabular}


TABLE 3.-Discharge over a thin-edged weir per foot of crest-Continued.

\begin{tabular}{|c|c|c|c|c|c|c|c|c|c|c|}
\hline Head $H$, feet. & .000 & .001 & .002 & .008 & .004 & .005 & .006 & .007 & .008 & .009 \\
\hline 0.30 & 0.5472 & 0.5499 & 0.5527 & 0.5554 & 0.5582 & 0.5609 & 0.5637 & 0.5664 & 0.5692 & 0.5720 \\
\hline .31 & .5748 & .5775 & .5803 & .5831 & .5859 & .5887 & .5915 & .5943 & .5972 & .6000 \\
\hline .32 & .6028 & .6056 & .6085 & .6113 & .6141 & .6170 & .6198 & .6227 & .6255 & .6284 \\
\hline .33 & .6313 & .6341 & .6370 & .6399 & .6428 & .6457 & .6486 & .6515 & .6544 & .6573 \\
\hline .34 & .6602 & .6631 & .6660 & .6689 & .6719 & .6748 & .6777 & .6807 & .6836 & .6866 \\
\hline .35 & .6895 & .6925 & .6954 & .6984 & .7014 & .7043 & .7073 & .7103 & .7133 & .7163 \\
\hline .36 & .7193 & .7223 & .7253 & .7283 & .7313 & .7343 & .7373 & .7404 & .7434 & .7464 \\
\hline .37 & .7495 & .7525 & .7555 & .7586 & .7616 & .7647 & .7678 & .7708 & .7739 & .7770 \\
\hline .38 & .7800 & .7831 & .7862 & .7893 & .7924 & .7955 & .7986 & .8017 & .8048 & .8079 \\
\hline .39 & .8110 & .8142 & .8173 & .8204 & .8235 & .8267 & .8298 & .8330 & .8361 & .8393 \\
\hline 0.40 & 0.8424 & 0.8456 & 0.8488 & 0.8519 & 0.8551 & 0.8583 & 0.8615 & 0.8646 & 0.8678 & 0.8710 \\
\hline .41 & .8742 & .8774 & .8806 & .8838 & .8870 & .8903 & .8935 & .8967 & .8999 & .9032 \\
\hline .42 & .9064 & .9096 & .9129 & .9161 & .9194 & .9226 & .9259 & .9292 & .9324 & .9357 \\
\hline .43 & .9390 & .9422 & .9455 & .9488 & .9521 & .9554 & .9587 & .9620 & .9653 & .9686 \\
\hline .44 & .9719 & .9752 & .9785 & .9819 & .9852 & .9885 & .9919 & .9952 & .9985 & 1.0019 \\
\hline .45 & 1.0052 & 1.0086 & 1.0119 & 1.0153 & 1.0187 & 1.0220 & 1.0254 & 1.0288 & 1.0321 & 1.0355 \\
\hline .46 & 1. 0389 & 1.0423 & 1.0457 & 1. 0491 & 1.0525 & 1.0559 & 1.0593 & 1.0627 & 1.0661 & 1. 0696 \\
\hline .47 & 1.0730 & 1. 0764 & 1. 0798 & 1. 0833 & 1. 0867 & 1.0901 & 1.0936 & 1.0970 & 1.1005 & 1. 1039 \\
\hline .48 & 1.1074 & 1.1109 & 1.1143 & 1.1178 & 1.1213 & 1.1248 & 1. 1282 & 1.1317 & 1.1352 & 1.1387 \\
\hline .49 & 1.1422 & 1.1457 & 1.1492 & 1.1527 & 1. 1562 & 1.1597 & 1.1632 & 1.1668 & 1.1703 & 1.1738 \\
\hline 0.50 & 1. 1773 & 1.1809 & 1. 1844 & 1.1879 & 1.1915 & 1.1950 & 1.1986 & 1.2021 & 1. 2057 & 1.2093 \\
\hline .51 & 1. 2128 & 1. 2164 & 1.2200 & 1. 2235 & 1. 2271 & 1. 2307 & 1. 2343 & 1. 2379 & 1.2415 & 1. 2451 \\
\hline .52 & 1.2487 & 1. 2523 & 1.2559 & 1.2595 & 1. 2631 & 1.2667 & 1. 2703 & 1. 2740 & 1.2776 & 1. 2812 \\
\hline .53 & 1.2849 & 1.2885 & 1. 2921 & 1. 2958 & 1. 2994 & 1. 3031 & 1. 3067 & 1. 3104 & 1. 3141 & 1. 3177 \\
\hline .54 & 1.3214 & 1.3251 & 1.3287 & 1. 3324 & 1. 3361 & 1. 3398 & 1. 3435 & 1. 3472 & 1. 3509 & 1. 3546 \\
\hline .55 & 1. 3583 & 1.3620 & 1.3657 & 1.3694 & 1. 3731 & 1. 3768 & 1. 3806 & 1. 3843 & 1.3880 & 1.3918 \\
\hline .56 & 1.3955 & 1. 3992 & 1.4030 & 1.4067 & 1. 4105 & 1.4142 & 1. 4180 & 1. 4217 & 1.4255 & 1.4293 \\
\hline .57 & 1.4330 & 1. 4368 & 1.4406 & 1. 4444 & 1. 4481 & 1.4519 & 1.4557 & 1.4595 & 1.4633 & 1.4671 \\
\hline .58 & 1. 4709 & 1.4747 & 1. 4785 & 1.4823 & 1. 4862 & 1.4900 & 1. 4938 & 1.4976 & 1.5014 & 1. 5053 \\
\hline .59 & 1. 5091 & 1. 5130 & 1. 5168 & 1.5206 & 1.5245 & 1. 5283 & 1. 5822 & 1. 5361 & 1.5399 & 1.5438 \\
\hline 0.60 & 1.5476 & 1.5515 & 1. 5554 & 1. 5593 & 1.5631 & 1.5670 & 1.5709 & 1.5748 & 1.5787 & 1.5826 \\
\hline .61 & 1. 5865 & 1.5904 & 1. 5943 & 1. 5982 & 1. 6021 & 1. 6060 & 1. 6100 & 1. 6139 & 1. 6178 & 1.6217 \\
\hline .62 & 1. 6257 & 1. 6296 & 1. 6335 & 1. 6375 & 1. 6414 & 1.6454 & 1. 6493 & 1. 6533 & 1. 6572 & 1. 6612 \\
\hline .63 & 1. 6652 & 1. 6691 & 1. 6731 & 1. 6771 & 1.6810 & 1.6850 & 1. 6890 & 1. 6930 & 1.6970 & 1.7010 \\
\hline .64 & 1.7050 & 1.7090 & 1.7130 & 1.7170 & 1. 7210 & 1. 7250 & 1. 7290 & 1.7330 & 1.7370 & 1. 7410 \\
\hline .65 & 1. 7451 & 1. 7491 & 1. 7581 & 1.7572 & 1. 7612 & 1.7652 & 1. 7693 & 1.7733 & 1. 7774 & 1. 7814 \\
\hline .66 & 1.7855 & 1. 7896 & 1. 7986 & 1. 7977 & 1. 8018 & 1.8058 & 1. 8099 & 1. 8140 & 1. 8181 & 1. 8221 \\
\hline .67 & 1. 8262 & 1.8303 & 1.8344 & 1.8385 & 1. 8426 & 1.8467 & 1.8508 & 1.8549 & 1.8590 & 1.8632 \\
\hline .68 & 1.8673 & 1. 8714 & 1.8755 & 1.8796 & 1. 8838 & 1. 8879 & 1.8920 & 1.8962 & 1.9003 & 1.9045 \\
\hline .69 & 1. 9086 & 1.9128 & 1. 9169 & 1. 9211 & 1.9252 & 1.9294 & 1. 9336 & 1.9377 & 1.9419 & 1.9461 \\
\hline 0.70 & 1.9503 & 1.9544 & 1.9586 & 1.9628 & 1.9670 & 1.9712 & 1.9754 & 1.9796 & 1.9838 & 1.9880 \\
\hline .71 & 1.9922 & 1.9964 & 2.0006 & 2.0048 & 2.0091 & 2. 0133 & 2.0175 & 2.0217 & 2. 0260 & 2. 0302 \\
\hline .72 & 2,0344 & 2.0387 & 2. 0429 & 2. 0472 & 2.0514 & 2.0557 & 2. 0599 & 2.0642 & 2. 0684 & 2.0727 \\
\hline .73 & 2.0770 & 2,0812 & 2.0855 & 2. 0898 & 2.0941 & 2. 0983 & 2.1026 & 2.1069 & 2,1112 & 2.1155 \\
\hline .74 & 2.1198 & 2.1241 & 2.1284 & 2. 1327 & 2.1370 & 2.1413 & 2.1456 & 2. 1499 & 2. 1543 & 2.1586 \\
\hline .75 & 2.1629 & 2. 1672 & 2.1716 & 2. 1759 & 2. 1802 & 2. 1846 & 2. 1889 & 2. 1932 & 2.1976 & 2.2019 \\
\hline .76 & 2.2063 & 2.2107 & 2.2150 & 2.2194 & 2.2237 & 2.2281 & 2. 2325 & 2.2369 & 2.2412 & 2.2456 \\
\hline t & 2. 2500 & 2. 2544 & 2.2588 & 2. 2632 & 2.2675 & 2. 2719 & 2. 2763 & 2. 2807 & 2. 2851 & 2. 2896 \\
\hline .78 & 2.2940 & 2.2984 & 2.3028 & 2. 3072 & 2. 3116 & 2. 3161 & 2. 3205 & 2. 3249 & 2. 3293 & 2. 3338 \\
\hline .79 & 2.3382 & 2.3427 & 2.3471 & 2.3515 & 2.3560 & 2. 3604 & 2. 3649 & 2. 3694 & 2. 3738 & 2.3783 \\
\hline
\end{tabular}


TABLE 3.-Discharge over a thin-edged weir per foot of crest-Continued.

\begin{tabular}{|c|c|c|c|c|c|c|c|c|c|c|}
\hline Head $H$, feet. & .000 & .001 & .002 & .003 & .004 & .005 & .006 & .007 & .008 & .009 \\
\hline 0.80 & 2.3828 & 2.3872 & 2. 3917 & 2.3962 & 2.4006 & 2.4051 & 2.4096 & 2. 4141 & 2.4186 & 2.4231 \\
\hline .81 & 2.4276 & 2.4321 & 2.4366 & 2.4411 & 2.4456 & 2.4501 & 2.4546 & 2.4591 & 2.4636 & 2.4681 \\
\hline .82 & 2.4727 & 2. 4772 & 2. 4817 & 2. 4862 & 2.4908 & 2.4953 & 2.4999 & 2.5044 & 2.5089 & 2. 5135 \\
\hline .83 & 2. 5180 & 2.5226 & 2.5271 & 2.5317 & 2. 5363 & 2.5408 & 2.5454 & 2.5500 & 2.5545 & 2. 5591 \\
\hline .84 & 2.5637 & 2.5683 & 2.5728 & 2. 5774 & 2.5820 & 2.5866 & 2.5912 & 2. 5958 & 2.6004 & 2.6050 \\
\hline .85 & 2. 6096 & 2. 6142 & 2. 6188 & 2.6234 & 2.6280 & 2.6327 & 2.6373 & 2.6419 & 2.6465 & 2.6511 \\
\hline .86 & 2.6558 & 2. 6604 & 2.6650 & 2.6697 & 2.6743 & 2. 6790 & 2.6836 & 2.6883 & 2.6929 & 2. 6976 \\
\hline .87 & 2.7022 & 2.7069 & 2.7116 & 2.7162 & 2.7209 & 2.7256 & 2.7302 & 2.7349 & 2.7396 & 2.7443 \\
\hline .88 & 2.7490 & 2.7536 & 2.7583 & 2.7630 & 2.7677 & 2.7724 & 2.7771 & 2.7818 & 2. 7865 & 2. 7912 \\
\hline .89 & 2.7959 & 2.8007 & 2.8054 & 2.8101 & 2.8148 & 2.8195 & 2.8243 & 2.8290 & 2.8337 & 2.8385 \\
\hline 0.90 & 2.8432 & 2.8479 & 2.8527 & 2.8574 & 2.8622 & 2.8669 & 2.8717 & 2.8764 & 2.8812 & 2.8860 \\
\hline .91 & 2.8907 & 2.8955 & 2.9003 & 2.9050 & 2.9098 & 2. 9146 & 2.9194 & 2.9241 & 2. 9289 & 2. 9337 \\
\hline .92 & 2. 9385 & 2.9433 & 2.9481 & 2.9529 & 2.9577 & 2.9625 & 2. 9673 & 2. 9721 & 2.9769 & 2.9817 \\
\hline .93 & 2.9865 & 2. 9914 & 2.9962 & 3.0010 & 3.0058 & 3.0107 & 3. 0155 & 3. 0203 & 3.0252 & 3. 0300 \\
\hline .94 & 3. 0348 & 3.0397 & 3.0445 & 3.0494 & 3. 0542 & 3. 0591 & 3.0639 & 3. 0688 & 3.0737 & 3. 0785 \\
\hline .95 & 3.0834 & 3.0883 & 3.0931 & 3.0980 & 3.1029 & 3.1078 & 3.1127 & 3.1175 & 3.1224 & 3. 1273 \\
\hline .96 & 3. 1322 & 3.1371 & 3.1420 & 3. 1469 & 3.1518 & 3.1567 & 3.1616 & 3.1665 & 3.1714 & 3. 1764 \\
\hline .97 & 3. 1813 & 3.1862 & 3. 1911 & 3. 1960 & 3.2010 & 3. 2059 & 3. 2108 & 3.2158 & 3. 2207 & 3. 2257 \\
\hline .98 & 3. 2306 & 3.2355 & 3.2405 & 3. 2454 & 3.2504 & 3.2554 & 3.2603 & 3. 2653 & 3.2702 & 3. 2752 \\
\hline .99 & 3.2802 & 3. 2851 & 3.2901 & 3. 2951 & 3. 3001 & 3.3051 & 3.3100 & 3. 3150 & 3.3200 & 3.3250 \\
\hline 1.00 & 3.3300 & 3.3350 & 3. 3400 & 3.3450 & 3.3500 & 3.3550 & 3.3600 & 3.3650 & 3.3700 & 3. 3751 \\
\hline .01 & 3.3801 & 3. 3851 & 3. 3901 & 3. 3951 & 3. 4002 & 3.4052 & 3. 4102 & 3.4153 & 3.4203 & 3.4254 \\
\hline .02 & 3. 4304 & 3.4354 & 3,4405 & 3.4455 & 3.4506 & 3. 4557 & 3. 4607 & 3. 4658 & 3.4708 & 3. 4759 \\
\hline .03 & 3.4810 & 3.4860 & 3.4911 & 3.4962 & 3. 5013 & 3.5063 & 3.5114 & 3. 5165 & 3.5216 & 3. 5267 \\
\hline .04 & 3. 5318 & 3. 5369 & 3.5420 & 3.5471 & 3. 5522 & 3. 5573 & 3. 5624 & 3. 5675 & 3.5726 & 3.5777 \\
\hline .05 & 3. 5828 & 3.5880 & 3. 5931 & 3.5982 & 3. 6033 & 3.6085 & 3.6136 & 3.6187 & 3.6239 & 3.6290 \\
\hline .06 & 3. 6342 & 3. 6393 & 3. 6444 & 3. 6496 & 3.6547 & 3. 6599 & 3. 6651 & 3. 6702 & 3. 6754 & 3. 6805 \\
\hline .07 & 3.6857 & 3. 6909 & 3. 6960 & 3. 7012 & 3. 7064 & 3. 7116 & 8.7167 & 3. 7219 & 3. 7271 & 3. 7323 \\
\hline .08 & 3. 7375 & 3.7427 & 3. 7479 & 3. 7531 & 3. 7583 & 3. 7635 & 3. 7687 & 3. 7739 & 3. 7791 & 3. 7843 \\
\hline .09 & 3.7895 & 3.7947 & 3.8000 & 3. 8052 & 3.8104 & 3.8156 & 3.8209 & 3.8261 & 3.8313 & 3.8365 \\
\hline 1.10 & 3.8418 & 3.8470 & 3. 8523 & 3.8575 & 3.8628 & 3.8680 & 3.8733 & 3.8785 & 3. 8838 & 3.8890 \\
\hline .11 & 3. 8943 & 3. 8996 & 3. 9048 & 3. 9101 & 3. 9154 & 3. 9206 & 3. 9259 & 3. 9312 & 3. 9365 & 3.9418 \\
\hline .12 & 3. 9470 & 3. 9523 & 3. 9576 & 3. 9629 & 3.9682 & 3.9735 & 3.9788 & 3. 9841 & 3. 9894 & 3.9947 \\
\hline .13 & 4.0000 & 4.0053 & 4. 0106 & 4.0160 & 4.0213 & 4.0266 & 4.0819 & 4.0372 & 4.0426 & 4.0479 \\
\hline .14 & 4. 0532 & 4.0586 & 4.0639 & 4.0692 & 4.0746 & 4.0799 & 4.0853 & 4. 0906 & 4.0960 & 4. 1013 \\
\hline .15 & 4. 1067 & 4. 1120 & $4.117 t$ & 4. 1228 & 4. 1281 & 4.1335 & 4.1389 & 4.1442 & 4. 1496 & 4.1550 \\
\hline .16 & 4.1604 & 4.1657 & 4.1711 & 4.1765 & 4. 1819 & 4.1873 & 4. 1927 & 4. 1981 & 4.2035 & • 4.2089 \\
\hline .17 & 4.2143 & 4.2197 & 4.2251 & 4. 2305 & 4. 2359 & 4. 2413 & 4. 2467 & 4.2522 & 4.2576 & 4.2630 \\
\hline .18 & 4. 2684 & 4. 2738 & 4.2793 & 4.2847 & 4.2901 & 4.2956 & 4,3010 & 4. 3065 & 4.3119 & 4.3173 \\
\hline .19 & 4. 3228 & 4. 3282 & 4.3337 & 4.3392 & 4.3446 & 4. 3501 & 4. 3555 & 4. 3610 & 4.3665 & 4. 3719 \\
\hline 1.20 & 4. 3774 & 4.3829 & 4. 3883 & 4. 3938 & 4. 3993 & 4.4048 & 4.4103 & 4.4158 & 4.4212 & 4.4267 \\
\hline .21 & 4. 4322 & 4.4377 & 4. 4432 & 4.4487 & 4. 4542 & 4. 4597 & 4.4652 & 4.4707 & 4.4763 & 4.4818 \\
\hline .22 & 4.4873 & 4.4928 & 4. 4983 & 4. 5038 & 4. 5094 & 4. 5149 & 4. 5204 & 4.5260 & 4.5315 & 4. 5370 \\
\hline .23 & 4.5426 & 4. 5481 & 4. 5537 & 4. 5592 & 4.5647 & 4.5703 & 4.5759 & 4. 5814 & 4.5870 & 4. 5925 \\
\hline .24 & 4. 5981 & 4. 6036 & 4. 6092 & 4. 6148 & 4. 6203 & 4. 6259 & 4.6315 & 4. 6371 & 4.6427 & 4. 6482 \\
\hline .25 & 4. 6538 & 4. 6594 & 4. 6650 & 4. 6706 & 4.6762 & 4. 6818 & 4.6874 & 4. 6930 & 4.6986 & 4. 7042 \\
\hline .26 & 4. 7098 & 4. 71.54 & 4. 7210 & 4. 7266 & 4. 7322 & 4. 7378 & 4.7435 & 4. 7491 & 4. 7547 & 4. 7603 \\
\hline .27 & 4.7660 & 4. 7716 & 4. 7772 & 4. 7829 & 4.7885 & 4. 7941 & 4. 7998 & 4. $805 t$ & 4.8111 & 4. 8167 \\
\hline .28 & 4. 8224 & 4. 8280 & 4. 8337 & 4. 8398 & 4.8450 & 4.8506 & 4. 8563 & 4.8620 & 4.8676 & 4.8733 \\
\hline .29 & 4.8790 & 4.8847 & 4.8903 & 4,8960 & 4.9017 & 4. 9074 & 4.9131 & 4.9187 & 4.9244 & 4.9301 \\
\hline
\end{tabular}


TABLE 3.-Discharge over a thin-edged weir per foot of crest-Continued.

\begin{tabular}{|c|c|c|c|c|c|c|c|c|c|c|}
\hline Head $H$, feet. & .000 & .001 & .002 & .003 & .004 & .005 & .006 & .007 & .008 & .009 \\
\hline 1.30 & 4. 9358 & 4.9415 & 4.9472 & 4.9529 & 4.9586 & 4.9643 & 4.9700 & 4.9757 & 4. 9814 & 4.9872 \\
\hline .31 & $4.99 z 9$ & 4.9986 & 5. 0043 & 5.0100 & 5.0158 & 5.0215 & 5.0272 & 5.0330 & 5.0387 & 5.0444 \\
\hline .32 & 5.0502 & 5.0559 & 5.0616 & 5.0674 & 5.0731 & 5.0789 & 5. 0846 & 5.0904 & 5.0961 & 5.1019 \\
\hline .33 & 5.1077 & 5.1134 & 5.1192 & 5.1249 & 5.1307 & 5.1365 & 5.1423 & 5.1480 & 5. 1538 & 5.1596 \\
\hline .34 & 5.1654 & 5.1712 & 5.1769 & 5.1827 & 5. 1885 & 5.1943 & 5. 2001 & 5.0259 & 5.2117 & 5.2175 \\
\hline .35 & 5.2233 & 5. 2291 & 5. 2349 & 5. 2407 & 5. 2465 & 5.2523 & 5. 2582 & 5.2610 & 5. 2698 & 5.2756 \\
\hline .36 & 5.2814 & 5.2873 & 5.2931 & 5. 2989 & 5. 3048 & 5.3106 & 5. 3164 & 5. 3223 & 5. 3281 & 5.3340 \\
\hline .37 & 5.3398 & 5.3456 & 5. 3515 & 5. 3573 & 5. 3632 & 5.3691 & 5.3749 & 5.3808 & 5. 3866 & 5.3925 \\
\hline .38 & 5.3984 & 5.4142 & 5.4101 & 5.4160 & 5. 4219 & 5.4277 & 5.4336 & 5.4395 & 5. 4454 & 5. 4513 \\
\hline .39 & 5.4572 & 5.4630 & 5.4689 & 5.4748 & 5.4807 & 5.4866 & 5.4925 & 5. 4984 & 5.5043 & 5. 5102 \\
\hline $1.40^{\circ}$ & 5.5162 & 5.5221 & 5.5280 & ธ. 5339 & 5. 5398 & 5. 5457 & 5. 5516 & 5.5576 & 5. 5635 & 5. 5694 \\
\hline .41 & 5. 5754 & 5.5813 & 5. 5872 & 5. 5932 & 5. 5991 & 5. 6050 & 5. 6110 & 5. 6169 & 5. 6229 & 5. 6288 \\
\hline .42 & 5. 6348 & 5. 6407 & 5. 6467 & 5. 6526 & 5. 6586 & 5.6646 & 5. 6705 & 5. 6765 & 5. 6825 & 5. 6884 \\
\hline .43 & ร. 6944 & 5. 7004 & 5. 7064 & ร. 7123 & 5. 7183 & 5.7243 & 5.7303 & 5.7363 & 5. 7423 & 5. 7482 \\
\hline .44 & 5.7542 & 5. 7602 & 5. $7662^{\circ}$ & 5. 7722 & $5.778^{2}$ & 5. 7842 & 5. 7902 & 5. 7962 & 5.8023 & 5.8083 \\
\hline .45 & 5.8143 & $5.820 \mathrm{~s}$ & 5.8263 & 5.8323 & 5.8384 & 5.8414 & 5. 8504 & 5. 8564 & 5.8625 & 5.8685 \\
\hline .46 & 5. 8745 & 5. 8806 & 5.8856 & 5. 8926 & 5. 8987 & 5.9047 & 5. 9108 & 5.9168 & 5. 9229 & 5. 9289 \\
\hline .47 & 5.9350 & 5.9410 & 5.9471 & 5.9532 & 5.9592 & 5.9653 & 5.9714 & 5.9774 & 5. 9835 & 5.9896 \\
\hline .48 & 5.9957 & 6.0017 & 6.0078 & 6.0139 & 6.0200 & 6. 0261 & 6.0322 & 6. 0382 & 6.0443 & 6.0504 \\
\hline .49 & 6. 0565 & 6.0626 & 6.0687 & 6.0748 & 6. 0809 & 6.0870 & 6. 0931 & 6.0993 & 6.1054 & 6.1115 \\
\hline 1.50 & 6.1176 & 6.1237 & 6.1298 & 6.1360 & 6.1421 & b. 1482 & 6.1543 & 6. 1605 & 6.1666 & 6.1727 \\
\hline .51 & 6.1789 & 6.1850 & 6.1912 & 6.1973 & 6.2034 & 6. 2096 & 6.2157 & 6. 2219 & 6.2280 & 6.2342 \\
\hline .52 & 6.2404 & 6.2465 & 6.2527 & 6.2588 & 6.2650 & 6.2712 & 6.2773 & 6.2835 & 6.2897 & 6.2959 \\
\hline .53 & 6. 3020 & 6. 3082 & 6. 3144 & 6.3206 & 6. 3268 & 6.3330 & 6.3391 & 6.3453 & 6.3515 & 6.3577 \\
\hline .54 & 6.3639 & 6. 3701 & 6.3763 & 6.3825 & 6.3887 & 6. 3949 & 6.4012 & 6.4074 & 6.4136 & 6.4198 \\
\hline .55 & 6.4260 & 6.4322 & 6.4385 & 6.4447 & 6.4509 & 6.4571 & 6.4634 & 6. 4696 & 6.4758 & 6.4821 \\
\hline .56 & 6. 4883 & 6.4945 & 6.5008 & 6.5070 & 6.5133 & 6.5195 & 6. 5258 & 6.5320 & 6.5383 & 6. 5445 \\
\hline .57 & 6.5508 & 6.5570 & 6. 5633 & 6.5696 & 6. 5758 & 6.5821 & 6.5884 & 6. 5946 & 6. 6009 & 6. 6072 \\
\hline .58 & 6.6135 & 6. 6198 & 6.6260 & 6. 6323 & 6.6386 & 6. 6449 & 6.6512 & 6.6575 & 6.6638 & 6.6701 \\
\hline .59 & 6.6764 & 6.6827 & 6.6890 & 6.6953 & 6.7016 & 6. 7079 & 6. 7142 & 6. 7205 & 6. 7268 & 6. 7331 \\
\hline 1.60 & 6.7394 & 6.7458 & 6.7521 & 6. 7584 & 6.7647 & 6. 7711 & 6. 7774 & 6.7837 & 6. 7901 & 6. 7964 \\
\hline .61 & 6.8027 & 6. 8091 & 6.8154 & 6.8217 & 6. 8281 & 6.8344 & 6.8408 & 6.8471 & 6.8535 & 6.8598 \\
\hline .62 & 6.8662 & 6.8726 & 6.8789 & 6.8853 & 6.8916 & 6.8980 & 6.9044 & 6. 9108 & 6.9171 & 6.9235 \\
\hline .63 & 6.9299 & 6.9363 & 6.9426 & 6.9490 & 6.9554 & 6.9618 & 6.9682 & 6.9746 & 6.9810 & 6.9874 \\
\hline .64 & 6.9937 & 7.0001 & 7.0065 & 7.0129 & 7.0193 & 7.0258 & 7. 0322 & 7.0386 & $7.0450^{\circ}$ & 7.0514 \\
\hline .65 & 7. 0578 & 7.0642 & 7.0706 & 7. 0771 & 7.0835 & 7.0899 & 7.0963 & 7.1028 & 7. 1092 & 7.1156 \\
\hline .66 & 7.1221 & 7. 1285 & 7. 1349 & 7.141.4 & 7.1478 & 7.1543 & 7.1607 & 7.1672 & 7. 1736 & 7. 1801 \\
\hline .67 & 7.1865 & 7.1930 & 7.1994 & 7. 2059 & 7. 2124 & 7.2188 & 7. 2253 & 7.2318 & 7.2382 & 7.2447 \\
\hline .68 & 7.2512 & 7.2576 & 7. 2641 & 7.2706 & 7.2771 & 7.2836 & 7. 2901 & 7.2965 & 7.3030 & 7.3095 \\
\hline .69 & 7.3160 & 7.3225 & 7.3290 & 7.3355 & 7.3420 & 7.3485 & 7. 3550 & 7.3615 & 7. 3680 & 7. 3745 \\
\hline 1. 70 & 7.3810 & 7. 3876 & 7. 3941 & 7. 4006 & 7. 4071 & 7. $413 b^{\circ}$ & 7. 4201 & 7.4267 & 7. 4332 & 7. 4397 \\
\hline .71 & 7.4463 & 7.4528 & 7.4593 & 7. 4659 & 7. 4724 & 7.4789 & 7.4855 & 7.4920 & 7.4986 & 7.5051 \\
\hline .72 & 7.5117 & 7.5182 & 7.5248 & 7. 5313 & 7.5379 & 7. 5445 & 7.5510 & 7.5576 & 7.5641 & 7.5707 \\
\hline .73 & 7.5773 & 7. 5839 & 7. 5904 & 7.5970 & 7. 6036 & 7.6102 & 7. 6167 & 7.6233 & 7.6299 & 7.6365 \\
\hline .74 & 7. 6431 & 7. 6497 & 7. 6563 & 7.6628 & 7. 6694 & 7.6760 & 7.6826 & 7. 6892 & 7. 6958 & 7. 7024 \\
\hline .75 & 7.7091 & 7.7157 & 7.7223 & 7.7289 & 7. 7355 & 7.7421 & 7.7487 & 7.7554 & 7.7620 & 7.7686 \\
\hline .76 & 7.7752 & 7.7819 & 7.7885 & 7. 7951 & 7.8018 & 7. 8084 & 7.8150 & 7.8217 & 7.8283 & 7.8349 \\
\hline .77 & 7.8416 & 7.8482 & 7.8549 & 7.8615 & 7.8682 & 7.8748 & 7.8815 & 7.8882 & 7.8948 & 7.9015 \\
\hline .78 & 7.9081 & 7.9148 & 7.9215 & 7.9281 & 7.9348 & 7.9415 & 7.9482 & 7.9548 & 7.9615 & 7.9682 \\
\hline .79 & 7.9749 & 7.9816 & 7.9882 & 7.9949 & 8.0016 & 8.0083 & 8.0150 & 8.0217 & 8.0284 & 8.0351 \\
\hline
\end{tabular}


TABLE 3.-Discharge over a thin-edged weir per foot of crest-Continued.

\begin{tabular}{|c|c|c|c|c|c|c|c|c|c|c|}
\hline Head $H$, feet. & .000 & .001 & .002 & .003 & .004 & .005 & .006 & .007 & .008 & .009 \\
\hline 1.80 & 8.0418 & 8.0485 & 8.0552 & 8. 0619 & 8.0686 & 8.0753 & 8.0820 & 8.0888 & 8.0955 & 8.1022 \\
\hline .81 & 8.1089 & 8.1156 & 8.1223 & 8.1291 & 8.1358 & 8.1425 & 8.1493 & 8.1560 & 8.1627 & 8.1695 \\
\hline .82 & 8.1762 & 8.1829 & 8.1897 & 8. 1964 & 8.2032 & 8.2099 & 8.2167 & 8.2234 & 8.2302 & 8.2369 \\
\hline .88 & 8.2437 & 8.2504 & 8.2572 & 8.2610 & 8.2707 & 8.2775 & 8.2842 & 8.2910 & 8.2978 & 8.3046 \\
\hline .84 & 8. 3113 & 8.3181 & 8. 3249 & 8.3317 & 8.3385 & 8. 3452 & 8.3520 & 8. 3588 & 8. 3656 & 8.3724 \\
\hline .85 & 8.3792 & 8.3860 & 8. 3928 & 8. 3996 & 8.4064 & 8.4132 & 8.4200 & 8.4268 & 8.4336 & 8.4404 \\
\hline .86 & 8.4472 & 8.4540 & 8.4608 & 8.4677 & 8.4745 & 8.4813 & 8.4881 & 8.4949 & 8.5018 & 8.5086 \\
\hline .87 & 8.5154 & 8.5223 & 8.5291 & 8.5359 & 8.5428 & 8.5496 & 8. 5564 & 8.5633 & 8.5701 & 8.5770 \\
\hline .88 & 8.5838 & 8. 5907 & 8.5975 & 8.6044 & 8.6112 & 8. $6181^{\circ}$ & 8.6250 & 8.6318 & 8. 6387 & 8.6455 \\
\hline .89 & 8. 6524 & 8.6593 & 8.6661 & 8.6730 & 8. 6799 & 8.6868 & 8.6936 & 8. 7005 & 8.7074 & 8. 7143 \\
\hline 1.90 & 8.7212 & 8.7281 & 8.7349 & 8. 7418 & 8.7487 & 8.7556 & 8. 7625 & 8.7694 & 8.7763 & 8. 7832 \\
\hline .91 & 8.7901 & 8. 7970 & 8.8039 & 8.8108 & 8.8177 & 8.8246 & 8.8316 & 8.8385 & 8.8454 & 8.8523 \\
\hline .92 & 8.8592 & 8.8662 & 8.8731 & 8.8800 & 8,8869 & 8.8939 & 8.9008 & 8.9077 & 8.9147 & 8.9216 \\
\hline .93 & 8.9285 & 8.9355 & 8.9424 & 8.9494 & 8.9563 & 8.9633 & 8.9702 & 8.9772 & 8. 9841 & 8.9911 \\
\hline .94 & 8.9980 & 9.0050 & 9.0119 & 9.0189 & 9.0259 & 9.0328 & 9.0398 & 9.0468 & 9.0537 & 9.0607 \\
\hline .95 & 9.0677 & 9.0747 & 9.0816 & 9.0886 & 9.0956 & 9.1026 & 9. 1096 & 9.1165 & 9.1235 & 9.1305 \\
\hline .96 & 9.1375 & 9.1445 & 9.1515 & 9. 1585 & 9.1655 & 9.1725 & 9.1795 & 9.1865 & 9.1935 & 9.2005 \\
\hline .97 & 9.2075 & 9.2145 & 9.2216 & 9.2286 & 9.2356 & 9.2426 & 9.2496 & 9. 2567 & 9.2637 & 9.2707 \\
\hline .98 & 9.2777 & 9.2848 & 9.2918 & 9.2988 & 9. 3059 & 9. 3129 & 9. 3199 & 9.3270 & 9.3340 & 9.3411 \\
\hline .99 & 9.3481 & 9. 3552 & 9. 3622 & 9.3693 & 9.3763 & 9. 3834 & 9. 3904 & 9.3975 & 9.4045 & 9. 4116 \\
\hline 2.00 & 9.4187 & 9. 4257 & 9.4328 & 9.4399 & 9.4469 & 9.4540 & 9.4611 & 9.4682 & 9.4752 & \\
\hline .01 & 9.4894 & 9.4965 & 9.5036 & 9.5106 & 9.5177 & 9.5248 & 9.5319 & 9.5390 & 9.5461 & 9.5532 \\
\hline .02 & 9.5603 & 9.5674 & 9.5745 & 9.5816 & 9.5887 & 9. 5958 & 9. 6029 & 9.6100 & 9.6171 & 9.6243 \\
\hline .03 & 9. 6314 & 9. 6385 & 9. 6456 & 9. 6527 & 9. 65999 & 9.6670 & 9.6741 & 9.6812 & 9.6884 & 9.6955 \\
\hline .04 & 9. 7026 & 9. 7098 & 9. 7169 & 9.7240 & 9.7312 & 9.7383 & 9. 7455 & 9. 7526 & 9. 7548 & 9. 7669 \\
\hline .05 & 9.7741 & 9. 7812 & 9. 7884 & 9.7955 & 9.8027 & 9.8098 & 9.8170 & 9.8242 & 9.8313 & 9.8385 \\
\hline .06 & 9.8457 & 9.8528 & 9.8600 & 9.8672 & 9.8744 & 9.8815 & 9.8887 & 9.8959 & 9.9031 & 9.9103 \\
\hline .07 & 9.9174 & 9.9246 & 9.9318 & 9.9390 & 9.9462 & 9.9534 & 9.9606 & 9.9678 & 9.9750 & 9.9822 \\
\hline .08 & 9.9894 & 9.9966 & 10.004 & 10.011 & 10.018 & 10.025 & 10.083 & 10.040 & 10.047 & 10.054 \\
\hline .09 & 10.062 & 10.069 & 10.076 & 10.083 & 10.090 & 10.098 & 10.105 & 10.112 & 10.119 & 10.127 \\
\hline 2.10 & 10. 134 & 10.141 & 10.148 & 10.156 & 10.163 & 10.170 & 10.177 & 10.185 & 10.192 & 10.189 \\
\hline .11 & 10.206 & 10.214 & 10.221 & 10.228 & 10.235 & 10.243 & 10.250 & 10.257 & 10.264 & 10.272 \\
\hline .12 & 10.279 & 10.286 & |10.293 & 10.301 & 10.308 & 10.315 & 10.323 & 10.330 & 10.337 & 10.344 \\
\hline .13 & 10.352 & 10.359 & 10.366 & 10.374 & 10.381 & 10.388 & 10,396 & 10.403 & 10.410 & 10.417 \\
\hline $.14^{\circ}$ & 10.425 & 10.432 & 10.439 & 10.447 & 10.454 & 10.461 & 10.469 & 10.476 & 10.483 & 10.491 \\
\hline .15 & 10.498 & 10. 505 & 10.513 & 10.520 & 10.527 & 10.5835 & 10.542 & 10.549 & 10.557 & 10.564 \\
\hline .16 & 10.571 & 10.579 & 10.586 & 10.593 & 10.601 & 10.608 & 10.615 & 10.623 & 10.630 & 10.637 \\
\hline .17 & 10.645 & 10.652 & 10.659 & 10.667 & 10.674 & 10.682 & 10.689 & 10.696 & 10.704 & 10.711 \\
\hline .18 & 10.718 & 10.726 & 10.733 & 10.741 & 10.748 & 10.755 & 10.763 & 10.770 & 10.777 & 10.785 \\
\hline .19 & 10.792 & 10.800 & 10.807 & 10.814 & 10.822 & 10.829 & 10.837 & 10.844 & 10.851 & 10.859 \\
\hline 2.20 & 10.866 & 10.874 & 10.881 & 10.888 & 10.896 & 10.903 & 10.911 & 10.918 & 10.926 & 10.933 \\
\hline .21 & 10.940 & 10.948 & 10,955 & 10.963 & 10.970 & 10.978 & 10.985 & 10.992 & 11.000 & 11.007 \\
\hline .22 & 11.015 & 11.022 & 11.030 & 11.037 & 11.045 & 11.052 & 11.059 & 11.067 & 11.074 & 11.082 \\
\hline .23 & 11.089 & 11.097 & 11.104 & 11. 112 & 11. 119 & 11.127 & 11. 134 & 11.141 & 11.149 & 11.156 \\
\hline .24 & 11.164 & 11.171 & 11. 179 & 11. 186 & 11.194 & 11. 201 & 11.209 & 11. 216 & 11.224 & 11. 231 \\
\hline .25 & 11. 239 & 11. 246 & 11.254 & 11.261 & 11.269 & 11. 276 & 11. 284 & 11. 291 & 11.299 & 11.306 \\
\hline .26 & 11.314 & 11.321 & 11. 329 & 11. 336 & 11.344 & 11. 351 & 11. 359 & 11. 366 & 11.374 & 11.881 \\
\hline .27 & 11. 389 & 11. 396 & 11. 404 & 11.412 & 11. 419 & 11. 427 & 11.434 & 11. 442 & 11.449 & 11.457 \\
\hline .28 & 11.464 & 11. 472 & 11. 479 & 11. 487 & 11.494 & 11. 502 & 11.510 & 11.517 & 11. 525 & 11.532 \\
\hline .29 & 11.540 & 11. 547 & 11. 555 & 11.562 & 11.570 & 11.578 & 11.585 & 11.593 & 11.600 & 11.608 \\
\hline
\end{tabular}


TABLE 3.-Discharge over a thin-edged weir per foot of crest-Continued.

\begin{tabular}{|c|c|c|c|c|c|c|c|c|c|c|}
\hline Head $H$, feet. & .000 & .001 & .002 & .008 & .004 & .005 & .006 & .007 & .008 & .009 \\
\hline 2.30 & 11.615 & 11.623 & 11. 631 & 11.638 & 11.646 & 11. 653 & 11.661 & 11.669 & 11.676 & 11.684 \\
\hline .31 & 11.691 & 11.699 & 11. 706 & 11. 714 & 11.722 & 11.729 & 11.737 & 11.744 & 11.752 & 11. 760 \\
\hline .32 & 11. 767 & 11.775 & 11.783 & 11.790 & 11.798 & 11.805 & 11.813 & 11.821 & 11.828 & 11. 836 \\
\hline .33 & 11.843 & 11.851 & 11.859 & 11.866 & 11.874 & 11.882 & 11.889 & 11.897 & 11. 904 & 11.912 \\
\hline .34 & 11.920 & 11.927 & 11.935 & 11. 943 & 11.950 & 11.958 & 11.966 & 11.973 & 11.981 & 11.989 \\
\hline .35 & 11.996 & 12.004 & 12.012 & 12.019 & 12.027 & 12.035 & 12.042 & 12.050 & 12.058 & 12.065 \\
\hline .36 & 12.073 & 12.081 & 12.088 & 12.096 & 12.104 & 12.111 & 12.119 & 12.127 & 12.134 & 12. 142 \\
\hline .37 & 12.150 & 12.157 & 12.165 & 12.173 & 12.181 & 12.188 & 12.196 & 12.204 & 12.211 & 12.219 \\
\hline .38 & 12.227 & 12.234 & 12.242 & 12.250 & 12.258 & 12.265 & 12.273 & 12. 281 & 12.288 & 12.296 \\
\hline .39 & 12.304 & 12.312 & 12.319 & 12.327 & 12.335 & 12,342 & 12.350 & 12.358 & 12.366 & 12.373 \\
\hline 2.40 & 12. 381 & 12.389 & 12.397 & 12.404 & 12.412 & 12.420 & 12.428 & 12.435 & 12.443 & 12.451 \\
\hline .41 & 12.459 & 12.466 & 12.474 & 12.482 & 12.490 & 12.497 & 12.505 & 12.513 & 12.521 & 12.528 \\
\hline .42 & 12.536 & 12.544 & 12.552 & 12.560 & 12.567 & 12.575 & 12.583 & 12.591 & 12.598 & 12.606 \\
\hline .43 & 12.614 & 12.622 & 12.630 & 12.637 & 12.645 & 12.653 & $12.66 \mathrm{I}$ & 12.669 & 12.676 & 12.684 \\
\hline .44 & 12.692 & 12.700 & 12. 708 & 12. 715 & 12.723 & 12. 731 & 12.739 & 12.747 & 12.754 & 12.672 \\
\hline .45 & 12.770 & 12.778 & 12. 786 & 12.794 & 12.801 & 12.809 & 12.817 & 12.825 & 12.833 & 12.840 \\
\hline .46 & 12.848 & 12.856 & 12.864 & 12.872 & 12.880 & 12.888 & 12.895 & 12.903 & 12.911 & 12.919 \\
\hline .47 & 12.927 & 12.935 & 12. 942 & 12.950 & 12.958 & 12.966 & 12.974 & 12.982 & 12.990 & 12. 997 \\
\hline .48 & 13.005 & 13.013 & 13.021 & 13.029 & 13.037 & 13.045 & 13. 053 & 13. 060 & 13.068 & 13.076 \\
\hline .49 & 13.084 & 13.092 & 13.100 & 13.108 & 13.116 & 13.124 & 13.131 & 13.139 & 13.147 & 13.155 \\
\hline 2.50 & 13. 163 & 13. 171 & 13.179 & 13.187 & 13.195 & 13.202 & 13.210 & 13.218 & 13.226 & 13. 234 \\
\hline .51 & 13.242 & 13. 250 & 13.258 & 13.266 & 13. 274 & 13. 282 & 13.290 & 13.297 & 13.305 & 13.313 \\
\hline .52 & 13.321 & 13. 329 & 13.337 & 13. 345 & 13.353 & 13. 361 & 13.369 & 13. 377 & 13.385 & 13.393 \\
\hline .53 & 13.401 & 13. 409 & 13.417 & 13.424 & 13.432 & 13. 440 & 13.448 & 13.456 & 13.464 & 13.472 \\
\hline .54 & 13.480 & 13. 488 & 13. 496 & 13. 504 & 13.512 & 13.520 & 13.528 & 13.536 & 13.544 & 13. 552 \\
\hline .55 & 13.560 & 13.568 & 13.576 & 13. 584 & 13. 592 & 13.600 & 13.608 & 13.616 & 13.624 & 13.632 \\
\hline .56 & 13.640 & 13.648 & 13.656 & 13.664 & 13.672 & 13.680 & 13.688 & 13.696 & 13. 704 & 13.712 \\
\hline .57 & 13. 720 & 13. 728 & 13.736 & 13.744 & 13. 752 & 13.760 & 13.768 & 13.776 & 13. 784 & 13.792 \\
\hline .58 & 13.800 & 13.808 & 13.816 & 13.824 & 13.832 & 13.840 & 13.848 & 13.856 & 13.864 & 13.872 \\
\hline .59 & 13.880 & 13. 888 & 13.896 & 13.904 & 13.912 & 13.920 & 13.928 & 13.936 & 13.944 & 13.953 \\
\hline 2.60 & 13.961 & 13.969 & 13.977 & 13.985 & 13.993 & 14.001 & 14.009 & 14.017 & 14.025 & 14,033 \\
\hline .61 & 14.041 & 14.049 & 14.057 & 14. 065 & 14.074 & 14.082 & 14.090 & 14.098 & 14. 106 & 14.114 \\
\hline .62 & 14. 122 & 14. 130 & 14.138 & 14. 146 & 14.154 & 14.162 & 14. 171 & 14. 179 & 14.187 & 14. 195 \\
\hline .63 & 14.203 & 14.211 & 14.219 & 14.227 & 14.235 & 14.243 & 14. 252 & 14.260 & 14.268 & 14.276 \\
\hline .64 & 14. 284 & 14. 292 & 14.300 & 14.308 & 14. 316 & 14.325 & 14. 333 & 14.341 & 14.349 & 14.357 \\
\hline .65 & 14.356 & 14. 373 & 14.382 & 14. 390 & 14.398 & 14. 406 & 14.414 & 14. 422 & 14.430 & 14. 438 \\
\hline .66 & 14.447 & 14.455 & 14.463 & 14.471 & 14. 479 & 14. 487 & 14.496 & 14.504 & 14.512 & 14. 520 \\
\hline .67 & 14.528 & 14.536 & 14.545 & 14. 553 & 14.561 & 14. 569 & 14.577 & 14.585 & 14.594 & 14.602 \\
\hline .68 & 14.610 & 14.618 & 14.626 & 14. 634 & 14. 643 & 14. 651 & 14.659 & 14.667 & 14.675 & 14.684 \\
\hline .69 & 14. 692 & 14. 700 & 14.708 & 14. 716 & 14.725 & 14. 733 & 14.741 & 14. 749 & 14.757 & 14.766 \\
\hline 2.70 & 14.774 & 14.782 & 14. 790 & 14. 798 & 14.807 & 14.815 & 14.823 & 14.831 & 14.839 & 14.848 \\
\hline .71 & 14.856 & 14.864 & 14.872 & 14.881 & 14.889 & 14.897 & 14.905 & 14.913 & 14.922 & 14. 930 \\
\hline .72 & 14.938 & 14.946 & 14.955 & 14.963 & 14. 971 & 14. 979 & 14. 988 & 14.996 & 15.004 & 15.012 \\
\hline .73 & 15.021 & 15.029 & 15.037 & 15.045 & 15.054 & 15.062 & 15.070 & 15.078 & 15.087 & 15.095 \\
\hline .74 & 15. 103 & 15. 112 & 15.120 & 15.128 & 15.136 & 15.145 & 15.153 & 15. 161 & 15. 169 & 15. 178 \\
\hline .75 & 15.186 & 15. 194 & 15.203 & 15.211 & 15. 219 & 15.227 & 15. 236 & 15.244 & 15. 252 & 15.261 \\
\hline .76 & 15.269 & 15.277 & 15.285 & 15.294 & 15. 302 & 15.310 & 15.319 & 15. 327 & 15. 335 & 15.344 \\
\hline.$\pi$ & 15. 352 & 15. 360 & 15.369 & 15. 377 & 15. 385 & 15. 394 & 15.402 & 15.410 & 15.419 & 15.427 \\
\hline .78 & 15.435 & 15.443 & 15.452 & 15.460 & 15.468 & $15.47 i$ & 15.485 & 15.494 & 15.502 & 15.510 \\
\hline .79 & 15.519 & 15. 527 & 15.535 & 15. 544 & 15. 552 & 15.560 & 15. 569 & 15.577 & 15.585 & 15.594 \\
\hline
\end{tabular}


TABLE 3.-Discharge over a thin-edged weir per foot of crest-Continued.

\begin{tabular}{|c|c|c|c|c|c|c|c|c|c|c|}
\hline Head $H$, feet. & .000 & .001 & .002 & .003 & .004 & .005 & .006 & .007 & .008 & .009 \\
\hline 2.80 & 15.602 & 15.610 & 15.619 & 15.627 & 15. 635 & 15. 644 & 15,652 & 15.661 & 15.663 & 15. 677 \\
\hline .81 & 15. 686 & 15,694 & 15.702 & 15.711 & 15. 719 & 15.728 & 15.736 & 15. 744 & 15.753 & 15.761 \\
\hline .82 & 15. 769 & 15. 778 & 15. 786 & 15.795 & 15. 803 & 15.811 & 15.820 & 15.828 & 15.837 & 15.845 \\
\hline .83 & 15.853 & 15. 862 & 15.870 & 15.879 & 15. 887 & 15.895 & 15,904 & 15.912 & 15.921 & 15.929 \\
\hline .84 & 15. 988 & 15. 946 & 15.954 & 15.963 & 15. 971 & 15. 980 & 15.988 & 15. 997 & 16.005 & 16.013 \\
\hline .85 & 16.022 & 16.030 & 16.0399 & 16.047 & 16.056 & 16.064 & 16.072 & 16.081 & 16.089 & 16.098 \\
\hline .86 & 16.106 & 16.115 & 16.123 & 16. 132 & 16.140 & 16. 148 & 16.157 & 16.165 & 16.174 & 16.182 \\
\hline .87 & 16.191 & 16.199 & 16.208 & 16.216 & 16.225 & 16.233 & 16.242 & 16.250 & 16.258 & 16.267 \\
\hline .88 & 16.275 & 16.284 & 16.292 & 16.301 & 16.309 & 16. 318 & 16.326 & 16.335 & 16.343 & 16.352 \\
\hline .89 & 16.360 & 16.369 & 16.377 & 16.386 & 16.394 & 16.403 & 16.411 & 16.420 & 16.428 & 16.437 \\
\hline 2.90 & 16.445 & 16.454 & 16.462 & 16.471 & 16.479 & 16.488 & 16.496 & 16.505 & 16.513 & 16.522 \\
\hline .91 & 16.530 & 16.539 & 16.547 & 16.556 & 16. 565 & 16.573 & 16.582 & 16.590 & 16.599 & 16.607 \\
\hline .92 & 16.616 & 16.624 & 16.633 & 16.641 & 16.650 & 16. 658 & 16.667 & 16. 675 & 16.684 & 16.693 \\
\hline .93 & 16. 701 & 16.710 & 16.718 & 16. 727 & 16.735 & 16.744 & 16.752 & 16. 761 & 16.770 & 16.778 \\
\hline .94 & 16.787 & 16. 795 & 16.804 & 16.812 & 16.821 & 16. 830 & 16.838 & 16.817 & 16.855 & 16.864 \\
\hline .95 & 16.872 & 16.881 & 16.890 & 16.898 & 16.907 & 16.915 & 16.924 & 16.932 & 16.941 & 16.950 \\
\hline .96 & 16.958 & 16.967 & 16.975 & 16.984 & 16.993 & 17. 001 & 17.010 & 17.018 & 17.027 & 17.036 \\
\hline .97 & 17.044 & 17.053 & 17.062 & 17.070 & 17.079 & 17.087 & 17.096 & 17.105 & 17.113 & 17.122 \\
\hline .98 & 17.130 & 17.139 & 17.148 & 17.156 & 17.165 & 17.174 & 17.182 & 17.191 & 17.199 & 17.208 \\
\hline .99 & 17.217 & 17.225 & 17.234 & 17.243 & 17.251 & 17.260 & 17. 269 & 17.277 & 17.286 & 17.295 \\
\hline 3.00 & 17.3033 & & & & & & & & & \\
\hline
\end{tabular}

TABLE 4.-Discharge oner a thin-edged weir per foot of crest.

\begin{tabular}{|r|r|r|r|r|r|r|r|r|r|r|}
\hline $\begin{array}{r}\text { Head } \\
\text { feet. }\end{array}$ & .00 & .01 & .02 & .03 & .04 & .05 & .06 & .07 & .08 & .09 \\
\hline 0.0 & 0.0000 & 0.0033 & 0.0094 & 0.0173 & 0.0266 & 0.0372 & 0.0489 & 0.0617 & 0.0753 & 0.0899 \\
.1 & .1053 & .1215 & .1384 & .1561 & .1744 & .1935 & .2131 & .2334 & .2543 & .2758 \\
.2 & .2978 & .3205 & .3436 & .3673 & .3915 & .4162 & .4415 & .4672 & .4934 & .5200 \\
.3 & .5472 & .5748 & .6028 & .6313 & .6602 & .6895 & .7193 & .7495 & .7800 & .8110 \\
.4 & .8424 & .8742 & .9084 & .9390 & .9719 & 1.0052 & 1.0389 & 1.0730 & 1.1074 & 1.1422 \\
.5 & 1.1773 & 1.2128 & 1.2487 & 1.2849 & 1.3214 & 1.3583 & 1.3955 & 1.4330 & 1.4709 & 1.5091 \\
.6 & 1.5476 & 1.5865 & 1.6257 & 1.6652 & 1.7050 & 1.7451 & 1.7855 & 1.8262 & 1.8673 & 1.9086 \\
.7 & 1.9503 & 1.9922 & 2.0344 & 2.0770 & 2.1198 & 2.1629 & 2.2063 & 2.2500 & 2.2940 & 2.3382 \\
.8 & 2.3828 & 2.4276 & 2.4727 & 2.5180 & 2.5637 & 2.6096 & 2.6558 & 2.7022 & 2.7490 & 2.7959 \\
.9 & 2.8432 & 2.8907 & 2.9385 & 2.9865 & 3.0348 & 3.0834 & 3.1322 & 3.1813 & 3.2306 & 3.2802 \\
1.0 & 3.3300 & 3.3801 & 3.4304 & 3.4810 & 3.5318 & 3.5828 & 3.6342 & 3.6857 & 3.7375 & 3.7895 \\
1.1 & 3.8418 & 3.8943 & 3.9470 & 4.0000 & 4.0532 & 4.1067 & 4.1604 & 4.2143 & 4.2384 & 4.3228 \\
1.2 & 4.3774 & 4.4322 & 4.4873 & 4.5426 & 4.5981 & 4.6538 & 4.7098 & 4.7660 & 4.8224 & 4.8790 \\
1.3 & 4.9358 & 4.9929 & 5.0502 & 5.1077 & 5.1654 & 5.2233 & 5.2814 & 5.3398 & 5.3984 & 5.4572 \\
1.4 & 5.5162 & 5.5754 & 5.6348 & 5.6944 & 5.7542 & 5.8143 & 5.8745 & 5.9350 & 5.9957 & 6.0565 \\
1.5 & 6.1176 & 6.1789 & 6.2404 & 6.3020 & 6.3633 & 6.4260 & 6.4883 & 6.5508 & 6.6135 & 6.6764 \\
1.6 & 6.7394 & 6.8027 & 6.8662 & 6.9299 & 6.9937 & 7.0578 & 7.1221 & 7.1865 & 7.2512 & 7.3160 \\
1.7 & 7.3810 & 7.4463 & 7.5117 & 7.5773 & 7.6431 & 7.7091 & 7.7752 & 7.8416 & 7.9081 & 7.9749 \\
1.8 & 8.0418 & 8.1689 & 8.1762 & 8.2437 & 8.3113 & 8.3792 & 8.4172 & 8.5154 & 8.5838 & 8.6524 \\
1.9 & 8.7212 & 8.7901 & 8.8592 & 8.9285 & 8.9980 & 9.0677 & 9.1375 & 9.2075 & 8.2777 & 9.3481 \\
\hline & & & & & & & & & & \\
\hline
\end{tabular}


TABLE 4.-Discharge over a thin-edged weir per foot of crest-Continued.

\begin{tabular}{|c|c|c|c|c|c|c|c|c|c|c|}
\hline $\begin{array}{c}\text { Head } \\
H \text {, feet. }\end{array}$ & .00 & .01 & .02 & .08 & .04 & .05 & .06 & .07 & .08 & .09 \\
\hline 2.0 & 4187 & 4894 & 9. 5603 & 9. 6314 & 9.7026 & 9.7741 & 9.8457 & 9. 9174 & 9.9894 & 10.0620 \\
\hline 2.1 & 10.1340 & 10.2060 & 10.2790 & 10.3520 & 10.4250 & 10.4980 & 10.5710 & 10.6450 & 10.7180 & 10.7920 \\
\hline 2.2 & 10.8660 & 10.9400 & 11.0150 & 11.0890 & 11.1640 & 2390 & & 11.3890 & & \\
\hline 2.3 & 11.6150 & 11.6910 & 11.7 & 11.84 & & 11.9960 & 30 & & & \\
\hline 2.4 & 12.3810 & 12.4590 & 12. 5360 & 12. 6140 & 12.6920 & 12.7700 & 12.8480 & & & \\
\hline 2.5 & 13.1630 & 13. 2480 & 13.3210 & 13.4010 & 13.4800 & 5600. & 12.6400 & 13.7200 & 13.8000 & \\
\hline 2.6 & 13. 9610 & 14.0410 & 14.1220 & 14. 2030 & 14. 2840 & 14.3650 & 14. 4470 & 14.5280 & 14. 6100 & 14.6920 \\
\hline 2.7 & 14.7740 & 14.8560 & 14.9380 & 15.0210 & 15.1030 & 15.1860 & 15.2690 & 15.3520 & 15.4350 & 15.5190 \\
\hline 2.8 & 15.6020 & 15.6860 & 15.7690 & 15.8530 & 15.93 & 20 & & & 750 & \\
\hline 2.9 & 16.4450 & 16.5300 & 16.6160 & 16.7010 & 16.7870 & 16.8720 & & & 17.1300 & \\
\hline 3.0 & 3033 & 3899 & 17.4698 & .5634 & 3 & & & 17.9 & 00 & 18.08 \\
\hline 3.1 & 18. 1754 & 18.2634 & 18. 3516 & 18. 4399 & 18.5 & 170 & 18. & 45 & & \\
\hline 3.2 & 19. 0619 & 19.1515 & 19.2410 & 19.3307 & $06^{\circ}$ & 05 & 07 & 10 & 19. 7812 & \\
\hline 3.3 & 19. 9624 & 20.0533 & 20.1442 & 20.2354 & 20.3267 & 20.4179 & $20.5 C 95$ & 20.66 & 20.6930 & 20.7849 \\
\hline 3.4 & 20.8777 & 20.9690 & 21.0613 & 21.15 & 21.2 & & 21.4319 & 21.5248 & 21.6180 & 21.7113 \\
\hline 3.5 & 21.8045 & 21.8980 & 21. 9917 & 22.0856 & 22.1795 & 22.2734 & 22.3677 & 22.4618 & 22.5564 & 22.6510 \\
\hline 3.6 & 22.7456 & 22.8405 & 22.9354 & 23.0306 & 23.1259 & 23. 2211 & 23.3167 & 23.4122 & 23. 5081 & 23.6040 \\
\hline 3.7 & 23.6999 & 23. 7962 & 23.8924 & 23.9887 & 24.0 & 18 & 24,2 & 24.3 & 24. 4728 & 24.5 \\
\hline 3.8 & 24.6673 & 24.7645 & 24. 8621 & 24.9600 & 76 & 55 & & & 02 & \\
\hline 3.9 & 25.6473 & 25.7459 & 25.8748 & 25.9437 & 26.0429 & 26.1422 & 26.2414 & 26.3410 & 26.4405 & 26. 5401 \\
\hline 4. 0 & 26.6400 & 26. 7399 & 26.8101 & 26.9404 & 06 & 12 & 27.2417 & 27.3423 & 27.4432 & 27.5411 \\
\hline 4.1 & 27.6453 & 27.7466 & 27.8478 & 27.9494 & 28.0509 & 28.1525 & 28.2544 & 28.3563 & 28.4582 & 28.5604 \\
\hline 4.2 & 28.6626 & 28.7652 & 28.8678 & 28.9703 & 29.0732 & 29.1761 & 29.2790 & 823 & 29.4855 & 5890 \\
\hline 4.3 & 29.6926 & 29.7962 & 29.90 & 30.0 & & & & & & \\
\hline 4.4 & 30.73 & 30.8 & 30.9 & 31.0 & & & & & & \\
\hline 4. 5 & 31.7878 & 31.8941 & 32.0003 & 32.1065 & 32.2128 & 32.3193 & 32.4259 & 32.5324 & 32.6393 & 32.7462 \\
\hline 4.6 & 32.8534 & 32.9607 & 33.0679 & 33.1755 & 33.2830 & 33,3906 & 33.4985 & 33.6064 & 33.7143 & 33.8225 \\
\hline 4.7 & 33.9307 & 34.0373 & 34.1475 & 34.2560 & 34.3646 & 34. 4735 & 34.5824 & 34.6913 & 34.8005 & 34.9097 \\
\hline 4.8 & 35.0193 & 35.1288 & 35.2354 & 35.3480 & 35.4 & 35.5 & & & 8984 & 0086 \\
\hline 4.9 & 36.1182 & 36.2297 & 36.3406 & 36.4515 & 36.5624 & 36.6736 & 36.7845 & 36.8961 & 37.0073 & \\
\hline 5.0 & .2304 & 37. 3423 & 37.4542 & 5661 & & & & 153 & & 404 \\
\hline 5.1 & 38.3529 & 38.4658 & 28.5787 & 38.6919 & 38.8052 & 38.9184 & 39.0319 & 39.1455 & 39.2591 & 39. 3726 \\
\hline 5.2 & 39. 4865 & 39.6004 & 39.7146 & 39.8288 & 39.9430 & 40.0576 & 40.1718 & 40.2867 & 40.4012 & 40.5161 \\
\hline 5.3 & 40.6310 & 40.7462 & 40.5281 & 40.9766 & & & & & & 6703 \\
\hline 5.4 & & & & & & & & & & \\
\hline 5. & 42.9523 & 43.0700 & 43.1 & & & & & & & \\
\hline 5.6 & 44.1292 & 44.2474 & 44.3659 & 44.4845 & 44.6030 & 44.7216 & 44. 8404 & 93 & 45.0782 & 45.1974 \\
\hline 5.7 & 45. 3166 & 45.4359 & 45.5554 & 45.6746 & 45. 7945 & 45.9140 & 46.0339 & 46. 1538 & 46.2740 & 46.3939 \\
\hline 5.8 & 46.5141 & 46.6347 & 46.7552 & 46.8757 & 46.9963 & 72 & 47. 2380 & 47. 3589 & 47.4798 & $\$ 7.6010$ \\
\hline 5.9 & 47.7226 & 47.8438 & 47.9653 & 48.0869 & 48.2084 & 48.3303 & 48.4522 & 48. 5744 & 48.6963 & 48.8185 \\
\hline & & & & & & & & & & \\
\hline & 50.1694 & 50.2930 & 5 & 11 & 50.6 & 5 & & & & 837 \\
\hline 6.2 & 51.4082 & 51.5324 & 51.6570 & 51.7818 & 51.9034 & 52,0313 & 52.1531 & 52.2813 & 52. 4062 & 52. 5314 \\
\hline 6.3 & 52.6570 & 52.7822 & 52.9077 & 53.0336 & 53.1591 & 53.2850 & 53.4109 & 53,5371 & 53.6630 & 53.7892 \\
\hline 6.4 & 53.9157 & 54.0119 & 1684 & & & & & & & \\
\hline & & & & & & & 500 & 6. 0779 & 56.2061 & \\
\hline 6. & 56.4625 & 910 & 192 & & & & 57.2340 & 57.3233 & 57.4921 & 57.6213 \\
\hline 6 & 57.7505 & & & 88 & & 32 & 281 & & & 8.9180 \\
\hline 6. & 59.0482 & 59.178 & & & & & & & & \\
\hline & & & & & & & & & & \\
\hline
\end{tabular}


TABLE 4.-Discharge over a thin-edged weir per foot of erest-Continued.

\begin{tabular}{|c|c|c|c|c|c|c|c|c|c|c|}
\hline $\begin{array}{l}\text { Head } \\
H \text {, feet. }\end{array}$ & .00 & .01 & .02 & .03 & .04 & .05 & .06 & .07 & .08 & .09 \\
\hline 7.0 & 61.6736 & 61.8048 & 61.9370 & 62.0692 & 62.2017 & 62.3343 & 62.4671 & 62.6000 & 62.7329 & 62.8657 \\
\hline 7.1 & 62.9986 & 63.1318 & 63.2650 & 63. 3992 & 63. 5317 & 63.6653 & 63.7991 & 63. 9327 & 64.0665 & 64.2004 \\
\hline 7.2 & 64.3343 & 64.4685 & 64.6027 & 64.7369 & 64. 8711 & 65.0056 & 65.1268 & 65.2750 & 65.4095 & 65.5444 \\
\hline 7.3 & 65.6793 & 65.8145 & 65. 9493 & 66.0845 & 66.2197 & 66.3552 & 66.4908 & 66.6263 & 66.7618 & 66.8977 \\
\hline 7.4 & 67.0836 & 67.1694 & 67.3053 & 67.4415 & 67.5777 & 67.7139 & 67.8504 & 67.9869 & 68.1235 & 68.2600 \\
\hline 7.5 & 68.3969 & 68.5337 & 68.6706 & 68.8078 & 68.9447 & 69.0818 & 69.2794 & 69.3566 & 69.4941 & 69.6316 \\
\hline 7.6 & 69.7695 & 69.9070 & 70.0449 & 70.1827 & 70.3209 & 70.4591 & 70.5973 & 70.7355 & 70.8737 & 71.0123 \\
\hline 7.7 & 71.1508 & 71.2896 & 71.4282 & 71. 5670 & 71.7059 & 71.8451 & 71.9843 & 72.1235 & 72.2627 & 72.4743 \\
\hline 7.8 & 72.5414 & 72.6809 & 72.8208 & 72.9603 & 73.1002 & 73.2400 & 73.3802 & 73.5201 & 73.6603 & 73.8005 \\
\hline 7.9 & 73.9410 & 74.0815 & 74. 2220 & 74.3626 & 74.5031 & 74.6439 & 74.7848 & 74.9260 & 75.0669 & 75.2081 \\
\hline 8.0 & 75.3492 & 75.4908 & 75.6320 & 75.7735 & 75.9150 & 76.0569 & 76.1987 & 76.3406 & 76.4824 & 76.6243 \\
\hline 8.1 & 76.7665 & 76.9087 & 77.0509 & 77.1934 & 77.3360 & 77.4784 & 77.6210 & 77.7638 & 77. 9067 & 78.0496 \\
\hline 8.2 & 78.1924 & 78.3356 & 78.4788 & 78.6220 & 78.7655 & 78.9087 & 79.0522 & 79.1957 & 79.3396 & 79.4834 \\
\hline 8.3 & 79.6273 & 79.7711 & 79.9153 & 80.0592 & 80.2034 & 80.8479 & 80.4921 & 80.6366 & 80.7811 & 80.9260 \\
\hline 8.4 & 81.0705 & 81.2154 & 81.3602 & 81.5054 & 81.6503 & 81.7955 & 81.9406 & 82.0862 & 82.2314 & 82.3769 \\
\hline 8.5 & 82.5224 & 82.6682 & 82.8141 & 82.9600 & 83.1058 & 83.2517 & 83.3979 & 83.5440 & 83.6902 & 83.8367 \\
\hline 8.6 & 83.9833 & 84. 1298 & 84.2763 & 84.4228 & 84.5697 & 84.7165 & 84.8634 & 85.0106 & 85.1578 & 85.3049 \\
\hline 8.7 & 85.4521 & 85.5996 & 85.7472 & 85.8947 & 86.0455 & 86.1897 & 86.3376 & 86.4854 & 86.6336 & 86.7815 \\
\hline 8.8 & 86.9297 & 87.0778 & 87.2264 & 87.3745 & 87. 5231 & 87.6716 & 87.8204 & 87.9689 & 88.1178 & 88.2666 \\
\hline 8.9 & 88. 4192 & 88.5647 & 88.7139 & 88.8630 & 89.0126 & 89.1617 & 89.3113 & 89.4608 & 89.6103 & 89.7602 \\
\hline 9.0 & 89.9100 & 90,0599 & 90.2064 & 90.3599 & 90.5101 & 90.6602 & 90.4778 & 90.9609 & 91.1115 & 91.2620 \\
\hline 9.1 & 91.4125 & 91.5633 & 91.7142 & 91.8650 & 92.0159 & 92.1671 & 92.3183 & 92.4694 & 92.6206 & 92.7721 \\
\hline 9.2 & 92.9237 & 93.0782 & 93.2267 & 93.3785 & 93. 5304 & 93.6822 & 93.8341 & 93.9863 & 94.1384 & 94.2906 \\
\hline 9.3 & 94.4428 & 94.5950 & 94.7475 & 94.9000 & 95.0529 & 95.2054 & 95.3582 & 95.5111 & 95.6639 & 95.8171 \\
\hline 9.4 & 95.9703 & 96.1234 & 96.2766 & 96.4298 & 96.5833 & 96.7368 & 96.8903 & 97.0442 & 97. 1977 & 97.3516 \\
\hline 9.5 & 97.5057 & 97.6596 & 97.8138 & 97.9679 & 98.1021 & 98.2763 & 98.4308 & 98.5853 & 98.7398 & 98.8943 \\
\hline 9.6 & 99.0492 & 99.2040 & 99.3589 & 99. 5141 & 99.6689 & 99.8241 & 99.9793 & 100.1344 & 100.2899 & 100.4455 \\
\hline 9.7 & 100.6010 & 100.7565 & 100.9123 & 101.0678 & 101. 2237 & 101.3799 & 101.5357 & 101.6919 & 101.8481 & 102.0042 \\
\hline 9.8 & 102.1607 & 102.3169 & 102.4734 & 102.6299 & 102. 7868 & 102.9433 & 103.1001 & 103. 2570 & 103.4141 & 103.5710 \\
\hline 9.9 & 103.7282 & 103. 88.53 & 104.0429 & 104.2000 & 104.3575 & 104.5121 & 104.6726 & 104. 8304 & 104.9882 & 105.1461 \\
\hline 10.0 & 105.3039 & 105.4618 & 105.6199 & 105.7781 & 105.9363 & 106.0945 & 106.2530 & 106.4115 & 106.5700 & 106.7285 \\
\hline
\end{tabular}

When applied to a weir with $N$ end contractions, the measured crest length $L^{\prime}$ should be reduced by the formula

$$
L=L^{\prime}-0.1 \mathrm{NH}
$$

When applied to a weir having appreciable velocity of approach, the measured head should be corrected by the correction formula of Francis (see p. 15), or by one of the simpler approximate equivalents; or the correction may be applied as a percentage to the discharge, by the use of Table 2.

Table 3, taken from Lowell Hydraulic Experiments, by James B. Francis, gives the discharge for heads from zero to 3 feet, advancing by thousandths.

Table 4 is original and gives the discharge for beads from zero to 10.09 feet, advancing by hindredths. 
By increasing the quantities from either table 1 per cent, the discharge by the Cippoletti formula will be obtained,

$$
Q=3.36 \frac{2}{3} L H^{3} \text {. }
$$

In calculating discharge by this formula, the head should be corrected for velocity of approach by the formula

$$
H=D+1.5 \% \text {. }
$$

TABLES 5 AND 6.-THREE-HALVES POWERS.

These tables of three-halves powers (cubes of the square roots) were prepared by the writer to facilitate the calculation of discharge over weirs of various forms, by the use of coefficients taken from the diagrams that accompany this paper and the base formula

$$
Q=C L H^{\frac{3}{2}} \text {. }
$$

\begin{tabular}{|c|c|c|c|c|c|c|c|c|c|c|c|}
\hline Numbers. & .000 & .001 & .002 & .003 & .004 & .005 & .006 & .007 & .008 & .009 & .010 \\
\hline 0.00 & 0.0000 & 0.0001 & 0.0002 & 0.0003 & 0.0001 & 0.0005 & 0.0006 & 0.0007 & 0.0008 & 0.0009 & 0.0010 \\
\hline .01 & .0010 & .00118 & .00136 & .00154 & .00172 & .00190 & .00208 & .00236 & .00244 & .00262 & .0028 \\
\hline .02 & .0028 & .00304 & .00328 & .00352 & .00376 & .00400 & .00424 & .00448 & .00472 & .00496 & .0052 \\
\hline .03 & .0052 & .00548 & .00576 & .00604 & .00632 & .00660 & .00688 & .00716 & .00744 & .00772 & .0080 \\
\hline .04 & .0080 & .00832 & .00864 & .00896 & .00928 & .00960 & .00992 & .01024 & .01056 & .01088 & .0112 \\
\hline .05 & .0112 & .01155 & .01190 & .01225 & .01260 & .01295 & .01330 & .01365 & .01400 & .01435 & .0147 \\
\hline .06 & .0147 & .01508 & .01546 & .01584 & .01622 & .01660 & .01698 & .01736 & .01774 & .01812 & .0185 \\
\hline .07 & .0185 & .01891 & .01932 & .01973 & .02014 & .02055 & .02096 & .02137 & .02178 & .02219 & .0226 \\
\hline .08 & .0226 & .02304 & .02348 & .02392 & .02436 & . 02480 & .02524 & .02568 & .02612 & .02656 & .0270 \\
\hline .09 & .0270 & .02746 & .02792 & .02838 & .02884 & .02930 & .02976 & .03022 & .03068 & .03114 & .0316 \\
\hline 0.10 & 0.0316 & 0.03209 & 0.03258 & 0.03307 & 0.03356 & 0.03405 & 0.03454 & 0.03503 & 00355.2 & 0.03601 & 0.0365 \\
\hline .11 & .0365 & .03701 & .03752 & .03803 & .03854 & .03905 & .03956 & .04007 & .04058 & .04109 & .0416 \\
\hline .12 & .0416 & .04213 & .04266 & .04319 & .04372 & .04425 & .04478 & .04531 & .04584 & .04637 & .0469 \\
\hline .13 & .0469 & .04745 & .04800 & .04855 & .04910 & .04965 & .05020 & .05075 & .05130 & .05185 & .0524 \\
\hline .14 & .0524 & .05297 & .05354 & .05411 & .05468 & .05525 & .05582 & .05639 & .05696 & .05753 & .0581 \\
\hline .15 & .0581 & .05869 & .05928 & .05987 & .06046 & .06105 & .06164 & .06223 & .06282 & .06341 & .0640 \\
\hline .16 & .0640 & .06451 & .06522 & .06583 & .06644 & .06705 & .06766 & .06827 & .06888 & .06949 & .0701 \\
\hline .17 & .0701 & .07073 & .07136 & .07199 & .07262 & .07325 & .07388 & .07451 & .07514 & .07577 & .0764 \\
\hline .18 & .0764 & .07704 & .07768 & .07832 & .07896 & .07960 & .08024 & .08088 & .08152 & .08216 & .0828 \\
\hline .19 & .0828 & .08346 & .08412 & .08478 & .08544 & .08610 & .08676 & .08742 & .08808 & .08874 & .0894 \\
\hline 0.20 & 0.0894 & 0.09008 & 0.09076 & 0.09144 & 0.09212 & 0.09280 & 0.09348 & 0.09416 & $0.09484 \mid$ & 009552 & 0.0962 \\
\hline .21 & .0962 & .09690 & .09760 & .09830 & .09900 & .09970 & .10040 & .10110 & .1018 & .1025 & .1032 \\
\hline .22 & .1032 & .10391 & .10462 & .10533 & .10604 & .10675 & .10746 & .10817 & .10888 & .10959 & .1103 \\
\hline .23 & .1103 & .11103 & .11176 & .11249 & .11322 & .11395 & .11468 & .11541 & .11614 & .11687 & .1176 \\
\hline .24 & .1176 & .11834 & .11908 & .11982 & .12506 & .12130 & .12204 & .12278 & .12352 & .12426 & .1250 \\
\hline .25 & .1250 & .12576 & .12652 & .12728 & .12804 & .12880 & .12956 & .13032 & .13108 & .13184 & .1326 \\
\hline .26 & .1326 & .13337 & .13414 & .13491 & .13568 & .13645 & .13722 & .13799 & .13876 & .13953 & .1403 \\
\hline .27 & .1403 & .14109 & .14188 & .14267 & .14346 & .14425 & .14504 & .14583 & .14662 & .14741 & .1482 \\
\hline .28 & .1482 & .1490 & .1498 & .1506 & .1514 & .1522 & 1530 & .1538 & .1540 & .1554 & .1562 \\
\hline .29 & .1562 & .15701 & .15782 & .15863 & .15944 & .16025 & .16106 & .16187 & .16268 & .16349 & .1643 \\
\hline
\end{tabular}

TABLE 5.-Three-halves powers for numbers 0 to 1.49 . 
TABLE 5.-Three-halves poucers for numbers 0 to 1.49-Continued.

\begin{tabular}{|c|c|c|c|c|c|c|c|c|c|c|c|}
\hline Numbers. & .000 & .001 & .002 & .003 & $.00 t$ & .005 & .006 & .007 & .008 & .009 & .010 \\
\hline 0.30 & 0.1643 & 0.16513 & 0.16596 & 0.16679 & 0.16762 & 0.16845 & 0.16928 & 0.17011 & 0.17094 & 0.171770 & 0.1726 \\
\hline .31 & .1726 & .17344 & $.17 \pm 28$ & .17512 & .17596 & .17680 & $.17,64$ & .17848 & .17932 & .18016 & .1810 \\
\hline .32 & .1810 & .18186 & .18272 & .18358 & .18444 & .18530 & .18616 & .18702 & .18788 & .18874 & .1896 \\
\hline .33 & .1896 & .19047 & .19134 & .19221 & . 19308 & .19395 & .19482 & .19569 & .19656 & .19743 & .1983 \\
\hline .34 & .1983 & . 19918 & .20006 & .20094 & .20182 & .20270 & .20358 & .20446 & .20534 & .20622 & .2071 \\
\hline .35 & .2071 & .20799 & . 20888 & . 20977 & .21066 & .21155 & .21244 & .21333 & .21422 & .21511 & .2160 \\
\hline .36 & .2160 & 21691 & .21782 & .21873 & .21964 & .22055 & .22146 & .22237 & .22328 & .22419 & .2251 \\
\hline .37 & .2251 & .22601 & .22692 & .22783 & .22874 & .22965 & .23056 & .2317 & .23238 & .23329 & .2342 \\
\hline .38 & .2342 & .23514 & 23608 & .23702 & .23796 & .23890 & .23984 & .24078 & .24172 & .24266 & .2436 \\
\hline .39 & .2436 & .24454 & . 24548 & .24642 & .24736 & .24830 & .24924 & .25018 & .25112 & .25206 & .2530 \\
\hline 0.40 & 0.2530 & 0.25395 & 0.25490 & 0.25585 & 0.25680 & 0.25775 & $|0.25870|$ & 0.25965 & 0.26060 & 0.261550 & 0.2625 \\
\hline .41 & .2625 & .26347 & .26444 & .26541 & .26638 & .26735 & .26832 & .26929 & .27026 & .27123 & .2722 \\
\hline .42 & .2722 & .27318 & .27416 & .27514 & .27612 & .27710 & .27808 & .27906 & .28004 & .28102 & .2820 \\
\hline .43 & .2820 & .28299 & .28397 & .28497 & .28596 & .28695 & .28794 & .28893 & .28992 & .29091 & .2919 \\
\hline .44 & .2919 & .2929 & .2939 & .2949 & .2959 & .2969 & .2979 & .2989 & .2999 & .3009 & .3019 \\
\hline .45 & .3019 & .30291 & .30392 & . 30493 & . 30594 & .30695 & .30796 & .30897 & .30998 & .31099 & .3120 \\
\hline .46 & .3120 & .31302 & . 31404 & .31506 & . 31608 & .31710 & .31812 & .31914 & .32016 & .32118 & .3222 \\
\hline .47 & .3222 & .32323 & .32426 & .32529 & .32632 & .32735 & .32838 & .32941 & .33044 & .33147 & .3325 \\
\hline .48 & . 3325 & .33355 & .33460 & .33565 & .33670 & .33775 & .33880 & .33985 & . 34090 & . 34195 & .3430 \\
\hline .49 & .3430 & .34406 & .34512 & .34618 & .34724 & .3483 & .34936 & .35042 & .35148 & .35254 & .3536 \\
\hline 0.50 & 0.3536 & 0.35466 & 0.35572 & 0.35678 & 0.35784 & 0.35890 & 0.35996 & 0.36102 & 0.36208 & 0,36314 & 0.3642 \\
\hline .51 & .3642 & .36528 & .36636 & .36744 & .36852 & .36960 & .37068 & .37176 & .37284 & .37392 & .3750 \\
\hline .52 & .3750 & .37608 & .37716 & . 37824 & .37932 & . 38040 & .38148 & .38256 & .38364 & .38472 & .3858 \\
\hline .53 & .3858 & .38690 & .38800 & . 38910 & .39020 & . 39130 & .39240 & .39350 & .39460 & .3957 & . 3968 \\
\hline .54 & .3968 & 39791 & .39902 & .40013 & . 40124 & .40285 & .40346 & .40457 & .40568 & . 40679 & . 4079 \\
\hline .55 & .4079 & . 40902 & . 41014 & . 41126 & .41238 & .41350 & . 41462 & .41574 & . 41686 & . 41798 & . 4191 \\
\hline .56 & .4191 & . 42022 & .42134 & .42246 & . 42358 & . 42470 & . 42582 & . 42694 & .42806 & . 42918 & . 4303 \\
\hline .57 & .4303 & . 43144 & . 43258 & . 43372 & .43486 & .43600 & .43714 & . 43828 & .43942 & .44026 & .4417 \\
\hline .68 & .4417 & .44285 & .44400 & .44515 & .44630 & .44745 & .44860 & .44975 & .45090 & . 45205 & .4532 \\
\hline .59 & .4532 & . 45436 & . 45552 & .45668 & .45784 & . 45900 & .46016 & .46132 & .46248 & . 46364 & .4648 \\
\hline 0.60 & 0.4648 & 0.46596 & 0.46712 & 0.46828 & 0.46944 & $0.47060 \mid$ & 0.47176 & 0.47292 & $0.47408 \mid$ & $|0.47524|$ & 0.4764 \\
\hline .61 & .4764 & .47758 & .47876 & .47994 & .48112 & .48230 & .48348 & .48466 & .48584 & .48702 & .4882 \\
\hline .62 & .4882 & . 48938 & .49056 & . 49174 & . 49292 & . 49410 & . 49528 & . 49646 & .49764 & .49882 & .5000 \\
\hline .63 & .5000 & .50120 & . 50240 & .5036 & .5048 & .5060 & .5072 & .5084 & .5096 & .5108 & .5120 \\
\hline .64 & .5120 & .5132 & .5144 & .5156 & .5168 & .5180 & .5192 & .5204 & .5216 & .5228 & .5240 \\
\hline .65 & .5240 & .52522 & .52644 & .52766 & .52888 & .53010 & .53132 & .53254 & .53376 & .53498 & .5362 \\
\hline .66 & . 5362 & .53742 & . 53864 & .53986 & . 54108 & .54230 & .54352 & .54474 & . 54596 & . 54718 & .5484 \\
\hline .67 & .5484 & .54963 & .55086 & .55209 & .55332 & .55455 & .55578 & .55701 & .55824 & .55947 & .5607 \\
\hline .68 & .5607 & .56195 & .56320 & .56445 & .56570 & .56695 & .56820 & .56945 & .57070 & -57195 & .5732 \\
\hline .69 & .5732 & .57445 & .5757 & .57695 & .57820 & .57945 & .58070 & .58195 & .58320 & .58445 & .5857 \\
\hline 0.70 & 0.5857 & 0.58696 & 0.58822 & 0.58948 & 0.59074 & 0.59200 & 0.59326 & 0.59452 & 0. 59578 & 0.59704 & 0.5983 \\
\hline .71 & .5983 & .59956 & .60082 & .60208 & .60334 & .60460 & .60586 & .60712 & .60838 & .60964 & .6109 \\
\hline .72 & .6109 & .61218 & .61346 & .61474 & .61602 & .61730 & .61858 & .61986 & .62114 & .62242 & .6237 \\
\hline .73 & .6237 & .62499 & . 62628 & .62757 & .62886 & .63015 & .63144 & .63273 & .63402 & .63531 & .6366 \\
\hline .74 & .6366 & .63789 & .63918 & .64047 & .64176 & .64305 & .64434 & $.64563 \mid$ & .64692 & .64821 & .6495 \\
\hline .75 & .6495 & .65081 & .65212 & .65343 & . 65474 & .65605 & .65736 & .65867 & .65998 & .66129 & .6626 \\
\hline .76 & .6626 & .66391 & .66522 & .66653 & .66784 & .66915 & .67046 & .67177 & .67308 & .67439 & .6757 \\
\hline .77 & .6757 & .67702 & . 67834 & .67966 & 68098 & .68230 & , 68362 & .68494 & .68626 & .68758 & .6889 \\
\hline .78 & .6889 & .69023 & . 69156 & . 69289 & .69422 & .69555 & . 69688 & .69821 & .69954 & .70087 & .7022 \\
\hline .79 & .7022 & .70353 & .70486 & .70619 & .70752 & .70885 & .71018 & .71151 & .71284 & .71417 & .7155 \\
\hline
\end{tabular}


TABLE 5.-Three-halves powers for numbers 0 to 1.49-Continuerl.

\begin{tabular}{|c|c|c|c|c|c|c|c|c|c|c|c|}
\hline Numbers. & .000 & .001 & .002 & .003 & .004 & .005 & .006 & .007 & .008 & .009 & .010 \\
\hline 0.80 & 0.7155 & 0.71685 & 0.71820 & 0.71955 & 0.72090 & 0.72225 & 0.72360 & 0.72495 & 0.72630 & 0.72765 & 0.7290 \\
\hline .81 & .7290 & .73035 & .7317 & .73305 & .73440 & .73575 & .73710 & .73845 & .73980 & .74115 & .7425 \\
\hline .82 & .7425 & .74387 & .74524 & .74661 & .74798 & .74935 & .75072 & .75209 & .75346 & .75483 & .7562 \\
\hline .83 & .7562 & .75757 & .75894 & .76031 & .76168 & .76305 & .76443 & .76579 & .76716 & .76853 & .7699 \\
\hline .84 & .7699 & .77128 & .77266 & .77404 & .77542 & .77680 & .77818 & .77956 & .78094 & .78232 & .7837 \\
\hline .85 & .7837 & .78508 & .78646 & .78784 & .78922 & .79060 & .99198 & .79336 & .79474 & .79612 & .7975 \\
\hline .86 & .7975 & .79890 & .80030 & .80170 & .8031 & .8045 & .8059 & .8073 & .8087 & .8101 & .8115 \\
\hline .87 & .8115 & .8129 & .8143 & .8157 & .8171 & .8185 & .8199 & .8213 & .8227 & .8241 & .8255 \\
\hline .88 & .8255 & .82691 & .82832 & .82973 & .83114 & .83255 & .83396 & .83537 & .83678 & .83819 & .8396 \\
\hline .89 & .8396 & .84102 & .84244 & .84386 & .84528 & .84670 & .84812 & .84954 & .85096 & .85238 & 8.8538 \\
\hline 0.90 & 0.8538 & 0.85523 & 0.85666 & 0.85809 & 0.85952 & 0.86095 & 0.86238 & 0.86381 & 0.86524 & 0.86667 & 0.8681 \\
\hline .91 & .8681 & .86953 & .87096 & .87234 & .87382 & .87525 & .87668 & .87811 & .87954 & .88097 & .8824 \\
\hline .92 & .8824 & .88385 & .8853 & .88675 & $.88 \varsigma 20$ & .88905 & .89110 & .89255 & .8940 & .89545 & .8969 \\
\hline .98 & .8969 & .89835 & .89980 & .90125 & .90270 & .90415 & .9056 & .90705 & .9085 & .90995 & $5 \mid .9114$ \\
\hline .94 & .9114 & .91285 & .9143 & .91575 & .91720 & .91865 & .92010 & .92155 & .9230 & .92445 & \begin{tabular}{|l|l}
5.9259 \\
\end{tabular} \\
\hline .95 & .9259 & .92737 & .92884 & .93081 & .93178 & .93325 & .93472 & .93619 & .93766 & .93913 & .9406 \\
\hline .96 & .9406 & .94207 & .94354 & .94501 & .94648 & .94795 & .94942 & .95089 & .95236 & .95383 & .9553 \\
\hline .97 & .9553 & .95679 & .95828 & .95977 & .96126 & .96275 & .96424 & .96573 & .96722 & .96871 & .9702 \\
\hline .98 & .9702 & .97168 & .97316 & .97464 & .97612 & .97760 & .97908 & .98056 & .98204 & .98352 & .9850 \\
\hline .99 & .9850 & .9865 & .9880 & .9895 & .9910 & .9925 & .9940 & .9955 & .9970 & .9985 & 1.0000 \\
\hline 1.00 & 1.0000 & 1.0015 & 1.0030 & 1. 0045 & 1.0060 & 1.0075 & 1.0090 & 1. 0105 & 1.0120 & 1. 0135 & 1. 0150 \\
\hline 1.01 & 1.0150 & 1.01652 & 1.01804 & 1.01956 & 1. 02108 & 1.02260 & 1.02412 & 1.02564 & 1.02716 & 1.02868 & 1.0302 \\
\hline 1.02 & 1.0302 & 1.03171 & 1.03322 & 1.03473 & 1.03624 & 1.03775 & 1.03926 & 1.04077 & 1.04282 & 1.04379 & 1.0453 \\
\hline 1.03 & 1.0453 & 1.04683 & 1.04836 & 1.04989 & 1.05142 & 1.05295 & 1.05448 & 1. 05601 & 1.05754 & 1.05907 & 1.0606 \\
\hline 1.04 & 1.0606 & 1.06213 & 1.06366 & 1.06519 & 1. 06672 & 1.06825 & 1.06978 & 1. 07131 & 1.07284 & 1.0 & .0759 \\
\hline 1.05 & 1. 0759 & 1.07744 & 1.07898 & 1. 08052 & 1. 08206 & 1. 08360 & 1.08514 & 1. 08668 & 1.08822 & 1.08976 & 1.0913 \\
\hline 1.06 & 1.0913 & 1.09285 & 1.09440 & 1.09595 & 1.09750 & 1.09905 & 1.10060 & 1.10215 & 1.10 & 1.10525 & 1.1068 \\
\hline 1.07 & 1.1068 & 1.10836 & 1.10992 & 1.11148 & 1.11304 & 1.11460 & 1.11616 & 1.11772 & 1.11928 & 1. 12084 & 1.1224 \\
\hline 1.08 & 1. 1224 & 1.12396 & 1. 12552 & 1. 12708 & 1.12864 & 1. 13020 & 1.13176 & 1. 13332 & 1.13488 & 1.13644 & 1380 \\
\hline 1.09 & 1.1380 & 1.13957 & 1.14114 & 1.14271 & 1.14428 & 1.14585 & 1.14742 & 1.14899 & 1. 15056 & $\mid 1.15213$ & 1.1537 \\
\hline 1.10 & 1.1537 & 1. 15528 & 1.15686 & 1.15844 & 1,16002 & 1.16160 & 1.16318 & 1.16476 & 1.16684 & 1.16792 & 1.1695 \\
\hline 1.11 & 1.1695 & 1.17108 & 1.17266 & 1.17424 & 1.17582 & 1.17740 & 1.17898 & 1.18056 & 1.18214 & 1. 18372 & 1. \\
\hline 1.12 & 1.1853 & 1. 18689 & 1.18848 & 1.19007 & 1.19166 & 1. 19325 & 1. 19184 & 1.19643 & 1.19802 & 1.19961 & 1.2012 \\
\hline 1.13 & 1.2012 & 1.20280 & 1. 20440 & 1. 20600 & 1.20760 & 1. 20920 & 1. 21080 & 1.21240 & 1.21400 & 1.21560 & 1.2172 \\
\hline 1.14 & 1. 2172 & 1. 21880 & 1.22040 & 1.22200 & 1.22360 & 1.22520 & 1. 22680 & 1.22840 & 1.23000 & 1.23160 & 1.2332 \\
\hline 1.15 & 1.2332 & 1. 23482 & 1. 23644 & 1.23806 & 1.23968 & 1.24130 & 1. 24292 & 1. 24454 & 1. 24616 & 1. 24778 & 1.2 \\
\hline 1.16 & 1.2494 & 1. 25102 & 1.25264 & 1. 25426 & 1. 25.588 & 1.25750 & 1. 25912 & 1.26074 & 1. 26236 & 1. 26398 & 1.2656 \\
\hline 1.17 & 1.2656 & 1. 26722 & 1. 26884 & 1.27046 & 1. $27: 08$ & 1.27370 & 1. 27532 & 1.27694 & 1.27856 & 1. 28018 & 1. 2818 \\
\hline 1.18 & 1.2818 & 1. 28343 & 1. 28506 & 1. 28669 & 1.28832 & 1.28995 & 1. 29158 & 1.29321 & 1. 29484 & 1.29647 & 1. 2981 \\
\hline 1.19 & 1.2981 & 1. 29974 & 1. 30138 & 1.30302 & 1. 30466 & 1.30630 & 1.30794 & 1.30958 & 1.31122 & 1.31286 & 1.3145 \\
\hline 1. 20 & 1.3145 & 1. 31615 & 1.31780 & 1.31945 & 1.32110 & 1.32275 & 1. 32440 & 1. 32605 & 1. 32770 & 1. 32935 & 1.3310 \\
\hline 1.21 & 1.3310 & 1. 33265 & 1. 33430 & 1. 33595 & 1. 33760 & 1. 33925 & 1. 34090 & 1.34255 & 1.34420 & 1. 34585 & 1.3475 \\
\hline 1.22 & 1.3475 & 1. 34916 & 1. 35082 & 1,35248 & 1.35414 & 1. 35580 & 1.35746 & 1.35912 & 1.36078 & 1.36244 & 1.3641 \\
\hline 1.23 & 1.3641 & 1. 36577 & 1.36744 & 1.36911 & 1. 37678 & 1.37245 & 1.37412 & 1.37579 & 1.37746 & 1. 37913 & 1.3808 \\
\hline 1.24 & 1. 3808 & 1. 38247 & 1. 38414 & 1.38581 & 1.38748 & 1. 38915 & 1. 39082 & 1. 39249 & 1. 39416 & 1. 39583 & 1.3975 \\
\hline 1.25 & 1.3975 & 1.39919 & 1. 40088 & 1. 40257 & 1. 40426 & 1.40595 & 1. 40764 & 1.40983 & 1.41102 & 1.41271 & 1. 4144 \\
\hline 1.26 & 1.4144 & 1. 41608 & 1. 41776 & 1,41944 & 1.42112 & 1. 42280 & 1.42448 & 1.42616 & 1.42784 & 1.42952 & 1.4312 \\
\hline 1.27 & 1.4312 & 1.4329 & 1. 4346 & 1. 4363 & 1.4380 & 1.4397 & 1.4414 & 1.4431 & 1.4448 & 1.4465 & 1.4482 \\
\hline 1.28 & 1.4482 & 1.4499 & 1. 4516 & 1.4533 & 1. 4550 & 1. 4567 & 1. 4584 & 1. 4601 & 1.4618 & 1. 4635 & 1. 4652 \\
\hline 1.29 & 1.4652 & 1,4669 & 1. 4686 & 1.4703 & 1.4720 & 1. 4737 & 1. 4754 & 1.4771 & 1. 4788 & 1. 4805 & 1.4822 \\
\hline
\end{tabular}


TABLE 5.-Three-halves povers for numbers 0 to 1.49-Continued.

\begin{tabular}{|c|c|c|c|c|c|c|c|c|c|c|c|}
\hline Numbers. & .000 & .001 & .002 & .003 & .004 & .005 & .006 & .007 & .008 & .009 & .010 \\
\hline 1.30 & 1. 4822 & 1.48392 & 1.48564 & 1.48736 & 1. 48908 & 1.49080 & 1.49252 & 1.49424 & 1.49596 & $1.49768 \mid 1$ & 31.4994 \\
\hline 1.31 & 1. 4994 & 1.50112 & 1.50284 & 1.50456 & 1.50628 & 1. 50800 & 1.50972 & 1.51144 & 1.51316 & $1.51488]$ & 81. 1.5166 \\
\hline 1. 32 & 1. 5166 & 1. 51832 & 1. 52004 & 1.52176 & 1.52348 & 1.52520 & 1. 52692 & $\mid 1.52864$ & 1.53036 & 1.532081 & 81.5338 \\
\hline 1.33 & 1. 5338 & 1. 53554 & 1.53728 & 1.53902 & $\mid 1.54076$ & 1.54250 & 1.54424 & 1.54598 & $\mid 1.54772$ & 1. 549461 & 1.5512 \\
\hline 1.34 & 1. 5512 & 1.55294 & 1.55468 & 1.55642 & 1.55816 & 1. 55990 & 1. 56164 & 1.56338 & 1.56512 & 1.56686 & 1.5686 \\
\hline 1.35 & 1.5686 & 1.57034 & 1.57208 & 1.57382 & 1.57556 & 1.57730 & 1.57904 & 1.58078 & 1.58252 & 1.58426 & 1.5860 \\
\hline 1.36 & 1. 5860 & 1.58775 & 1. 58950 & 1.59125 & 1.59300 & 1.59475 & 1.59650 & 1.59825 & 1.60000 & 1.60175 & 1.6035 \\
\hline 1.37 & 1. 6035 & 1. 60526 & 1. 60702 & 1. 60878 & 1.61054 & 1.61230 & 1.61406 & 1.61582 & 1.61758 & $|1.61934|$ & 1. 6211 \\
\hline 1.38 & 1. 6211 & $1,6^{2} 2287$ & $1.62464 \mid$ & 1.62641 & 1.62818 & 1. 62995 & 1.63172 & $\mid 1.63349$ & $|1.63526|$ & $1.63703 \mid 1$ & 1.6388 \\
\hline 1.39 & 1.6388 & 1.64057 & 1.64234 & 1.64411 & 1.64588 & 1.64765 & 1. 64942 & 1.65119 & 1. 652296 & 1.65473 & 31.6565 \\
\hline 1.40 & 1.6565 & 1.65828 & 1.66006 & 1.66184 & 1.66362 & 1.66540 & 1.66718 & $\mid 1.66896$ & 1.67075 & $1.67252 \mid$ & 1.6743 \\
\hline 1. 41 & 1.6743 & 1.67608 & 1.67786 & 1.67964 & 1.68142 & 1. 68320 & 1.68498 & 1.68676 & 1. 68854 & 1. 69032 & 1.6921 \\
\hline 1. 42 & 1.6921 . & 1. 69389 & 1. 69568 & 1.69747 & 1.69926 & 1.70105 & 1. 70284 & 1. 70463 & 1.70642 & 1.70821 & 1.7100 \\
\hline 1.43 & 1.7100 & 1.7118 & 1.7136 & 1.7154 & 1.7172 & 1.7190 & 1. 7208 & 1.7226 & 1. 7244 & 1. 7262 & 1.7280 \\
\hline 1.44 & 1. 7280 & 1.7298 & 1.7316 & 1.7334 & 1.7352 & 1. 7370 & 1. 7388 & 1.7406 & 1.7424 & 1.7442 & 1.7460 \\
\hline 1.45 & 1. $74 t i 0$ & 1.74781 & 1. 74962 & 1.75143 & $\mid 1.75324$ & 1.75505 & 1.75686 & 1.75867 & 1.76048 & $|1.76229|$ & 1.7641 \\
\hline 1.46 & 1. 7611 & 1.76592 & 1.76774 & 1.76956 & 1.77138 & 1. 77320 & 1.77502 & 1.77684 & 1.77866 & 1.78048 & 1.7823 \\
\hline 1.47 & 1.7823 & 1.78412 & 1.78594 & 1.78776 & 1.78958 & 1.79140 & 1.79322 & 1.79504 & 1.79686 & $|1.79868|$ & 1.8005 \\
\hline 1. 48 & 1. $\times 005$ & 1.80233 & 1.80416 & 1.80599 & 1.80782 & 1.80965 & 1.81148 & 1.81331 & 1.81514 & $|1.81697|$ & 1.8188 \\
\hline 1.49 & & & & & & & & & & & \\
\hline
\end{tabular}

TABIE 6.-Three-halves powers for numbers from 0 to 12.

\begin{tabular}{|c|c|c|c|c|c|c|c|c|c|c|c|c|}
\hline & & & & & & & & & & & & \\
\hline & & & & & & & & & & & \\
\hline
\end{tabular}


TABLE 6.-Three-halves powers for numbers from 0 to 12-Continued.

\begin{tabular}{|c|c|c|c|c|c|c|c|c|c|c|c|c|}
\hline 然落 & 0 & 1 & 2 & 3 & 4 & 5 & 6 & 7 & 8 & 9 & 10 & 11 \\
\hline 0.20 & 0.0894 & 1.3145 & 3.2631 & 5.7243 & 8.6074 & 11.8578 & 15.4379 & 19.3196 & 23.4812 & 27.9050 & 32.5762 & 37.4824 \\
\hline .21 & .0962 & 1.3310 & 3.2854 & 5.7512 & 8.6382 & 11.8920 & 15.4752 & 19. 3599 & 23.5242 & $2 \cdot 27.9514$ & 32.6241 & 37.5326 \\
\hline .22 & .1032 & 1.3475 & 3. 3077 & 5.7781 & 8.6690 & 11.9263 & 15.5126 & 19.4002 & 23.5672 & 27.9960 & 32.6720 & 37.5828 \\
\hline .23 & .1103 & 1.3641 & 3.3301 & 5.8050 & 8.6998 & 11.9606 & 6) 15.5501 & 19.4405 & 23.6102 & 228.0416 & 32.7200 & 37.6331 \\
\hline .24 & .1176 & 1.3808 & 3.3525 & 5.8320 & 8.7307 & 11.9949 & 15.5866 & 19.4808 & 23.6533 & 328.0872 & 32.7680 & 37.6833 \\
\hline .25 & .1250 & 1. 3975 & 3.3750 & 5.8590 & 8.7616 & 12.0293 & 315.6250 & 19.5212 & 23.6963 & 328.1328 & 32.8160 & 37. 7836 \\
\hline .26 & .1326 & 1. 4144 & 3.3975 & 5.8861 & 8.7925 & 12.0636 & 15.6616 & 19.5576 & 23.7394 & 428.1784 & 132.8640 & 37.7840 \\
\hline .27 & | . .1403 & 1. 4312 & 3.4201 & 5.9132 & 8.8235 & 12.0981 & 15.7001 & 19.6021 & 23.7825 & 528.2241 & 32.9121 & 37.8343 \\
\hline .28 & .1482 & 1. 4482 & 3.4427 & 5.9403 & 8.8545 & 12.1325 & 15.7376 & 19.6425 & 23.8257 & 728.2698 & 32.9600 & 37.8847 \\
\hline .29 & . . 1562 & 1.4652 & 3.4654 & 5.9675 & 8.8856 & 12.1670 & 15.7752 & 19.6830 & 23.8689 & 928.3155 & 33.0083 & 37.9351 \\
\hline 0.30 & 0.1643 & 1.4822 & 3.4881 & 5.9947 & 8.9167 & 12.2015 & 515.8129 & 19.7235 & 23.9121 & $1 \mid 28.3612$ & 33.0564 & 37.9855 \\
\hline .31 & .1726 & 1. 4994 & 3.5109 & 6.0220 & 8.9478 & 12.2361 & 15.8505 & 19.7641 & 23.9553 & 328.4069 & 33.1046 & 38.0359 \\
\hline .32 & .1810 & 1.5166 & 3.5337 & 6.0493 & 8.9790 & 12.2706 & 615.8882 & 19.8046 & 23.9986 & 628.4527 & $33.1527 \mid$ & 38.0864 \\
\hline .33 & .1896 & 1.5338 & 3.5566 & 6.0767 & 9.0102 & 12.3053 & 315.9260 & 19.8452 & 24.0418 & 828.4985 & 33.2009 & 38.1369 \\
\hline .34 & .1983 & 1.5512 & 3.5795 & 6.1041 & 9.0414 & 12.3399 & 915.9637 & 19.8858 & 824.0851 & 128.5444 & 33.2492 & 38.1874 \\
\hline .35 & .2071 & 1.5686 & 3.6025 & 6.1315 & 9.0726 & 12.3746 & 616.0015 & 19.9265 & 24.1285 & 528.5902 & 33.2974 & 38.2379 \\
\hline .36 & .2160 & 1.5860 & 3.6255 & 6.1590 & 9.1040 & 12.4093 & 16.0393 & 19.9672 & 24.1718 & 828.6361 & 33.3457 & 38.2884 \\
\hline .37 & .2251 & 1. 6035 & 3.6486 & 6.1865 & 9.1353 & 12.4440 & 016.0772 & 20.0079 & 924.2152 & 228.6820 & 33.3940 & 38.3390 \\
\hline .38 & .2342 & 1.6211 & 3.6717 & 6.2141 & $9.1667 \mid$ & 712.4788 & 816.1150 & 20.0486 & 24.2586 & 628.7279 & 33.4423 & 38.3896 \\
\hline .39 & .2436 & 1. 6388 & 3. 6949 & 6.2417 & 9.1981 & 12.5136 & 616.1529 & 20.0894 & 424.3021 & \begin{tabular}{l|l|}
1 & 28.7739
\end{tabular} & 33.4906 & 38.4402 \\
\hline 0.40 & 0.2530 & 1.6565 & 3.7181 & 6.2693 & 9. 2295 & 12.5485 & $5 \mid 16.1909$ & 20.1302 & 24.3455 & 528.8199 & 33.5390 & 38.4908 \\
\hline .41 & .2625 & 1.6743 & 3. 7413 & 36.2970 & 9.2610 & 12.5833 & 316.2288 & 20.1710 & 0.24 .3890 & 028.8659 & 33.5874 & 38.5415 \\
\hline .42 & .2722 & 1.6921 & 3. 7646 & 6.3247 & 9.2925 & 512.618 & 216.2668 & 20.2118 & $8 \mid 24.4325$ & $5 \mid 28.9119$ & 33.6358 & 38.5922 \\
\hline .43 & .2820 & 1.7100 & 3.7880 & 6.3525 & 9.3241 & 12.6532 & 16.3048 & 20.2527 & 724.4761 & 128.9579 & 933.6842 & 38.6429 \\
\hline .44 & .2919 & 1. 7280 & 3.8114 & 6.3803 & 9.3557 & 72.6882 & 216.3429 & 20.2936 & 624.5190 & o. 29.0040 & 33.7327 & 38.6936 \\
\hline .45 & .3019 & 1.7460 & 3.8349 & 6.4081 & 9. 3873 & 12.7232 & 216.3810 & 20.3345 & 524.5632 & 229.0501 & 33.7811 & 38.7443 \\
\hline .46 & .3120 & 1.7641 & 3.8584 & 6.4360 & 9.4189 & 912.7582 & 216.4191 & 20.3755 & 24.6068 & 829.0962 & 33.8297 & 38.7951 \\
\hline .47 & .3222 & 1.7823 & 3.8819 & 6.4639 & 9.4506 & 12.7933 & 3). 16.4572 & 20.4165 & 524.6505 & 529.1424 & 33.8782 & 38.8459 \\
\hline .48 & .3325 & 1.8005 & 3.9055 & 6.4919 & 9.4824 & 12.8284 & 416.4954 & 20.4575 & 24.6941 & 129.1885 & 33.9267 & 38.8967 \\
\hline .49 & .3430 & 1.8188 & 3.9292 & 6.5199 & 9.5141 & 12.8635 & 516.5336 & 20.4985 & $5 \mid 24.7378$ & 829.2347 & 733.9753 & 38.9475 \\
\hline 0.50 & 0.3536 & 1.8371 & 3.9529 & 6.5479 & 9.5459 & 12,8986 & 616.5718 & 20.5396 & $6 \mid 24.7815$ & $5 \mid 29.2810$ & 34.0239 & 38.9984 \\
\hline .51 & .3642 & 1.8555 & 3.9766 & 6.5760 & 9.5778 & 12.9338 & 816.6101 & 20.5807 & 724.8253 & 329.3272 & 34.0725 & 39.0493 \\
\hline .52 & .3750 & 1.8740 & 4.0004 & 6.6041 & 9.6097 & 712.9691 & 116.6484 & 20.6218 & $8 \mid 24.8691$ & 129.3735 & 34.1211 & 39.1002 \\
\hline .53 & .3858 & 1. 8925 & 4.0242 & 6.6323 & 9.6416 & 13.0043 & 316.6867 & 20.6630 & 24.9129 & 929.4198 & 34.1698 & 39.1511 \\
\hline .54 & .3968 & 1. 9111 & 4.0481 & 6.6605 & 9.6735 & 13.0396 & 616.7250 & 20.7041 & 24.9567 & 729.4661 & 34.2185 & 39.2020 \\
\hline .55 & .4079 & 1.9297 & 4.0720 & 6.6887 & 9. 7055 & 13.0749 & 916.7634 & 20.7453 & 25.0005 & 529.5124 & 434.2672 & 39.2530 \\
\hline .56 & .4191 & 1. 9484 & 4.0960 & 6.7170 & 9.7375 & 13.1108 & 316.8018 & 20.7866 & 25.0444 & 429.5588 & 34.3159 & 39.3040 \\
\hline .57 & .4303 & 1.9672 & 4.1200 & 6.7458 & 9.7695 & 13.1457 & 716.8402 & 20.8278 & 825.0883 & 329.6052 & 234.3647 & 39.3550 \\
\hline .58 & .4417 & 1.9860 & 4.1441 & 6.7737 & $9.8016 \mid$ & 13.1811 & 116.8787 & 20.8691 & 25.1322 & 229.6516 & 34.4135 & 39.4060 \\
\hline .59 & .4532 & 2.0049 & 4.1682 & 6.8021 & 9.8337 & 73.2165 & 516.9172 & 20.9104 & $4 \mid 25.1762$ & 29.6980 & 34.4623 & 39.4571 \\
\hline 0.60 & 0.4648 & 2.0238 & 4.1924 & 6.8305 & 9.8659 & 13.2520 & 016.9557 & 20.9518 & 825.2202 & 229.7445 & 534.5111 & 39.5082 \\
\hline .61 & .4764 & 2.0429 & 4.2166 & 6.8590 & 9. 8981 & 13.2875 & 516.9943 & 20.9931 & 125.2642 & 229.7910 & 34.5599 & 39.5593 \\
\hline .62 & .4882 & 2.0619 & 4.2408 & 6.8875 & 9.9303 & 13.3231 & 17.0328 & 21.0345 & $5 \mid 25.3082$ & 229.8375 & 34.6088 & 39.6104 \\
\hline .63 & .5000 & 2.0810 & 4.2651 & 6.9161 & 9.9626 & 13.3587 & 717.0714 & 21.0759 & 925.3522 & 229.8841 & 134.6577 & 39.6615 \\
\hline .64 & .5120 & 2.1002 & 4.2895 & 6.9447 & 9.9949 & 13.3943 & 317.1101 & 21.1174 & 25.3963 & 329.9306 & 34.7066 & 39.7127 \\
\hline .65 & .5240 & 2.1195 & 4.3139 & 6.9783 & 10.0272 & 13.4299 & 917.1488 & 21.1589 & 925.4404 & 429.9772 & 34.7557 & 39.7639 \\
\hline .66 & .5362 & 2.1388 & 4. 3383 & 7.0020 & 10.0596 & 13.4656 & \begin{tabular}{l|l}
6 & 17.1874
\end{tabular} & 21.2004 & 25.4845 & 530.0238 & 34.8045 & 39.8151 \\
\hline .67 & .5484 & 2.1581 & 4.3628 & 7.0307 & 10.0920 & 13.5013 & 317.2172 & 21.2419 & 925.5287 & 730.0704 & 34.8535 & 39.8663 \\
\hline .68 & .5607 & 2.1775 & 4.3874 & 7.0595 & 10.1244 & 13.5370 & 017.2649 & 21.2834 & 25.5729 & 930.1171 & 34.9025 & 39.9176 \\
\hline .69 & .5732 & 2.1970 & 4.4119 & 7.0883 & 10.1569 & 13.5728 & 817.3037 & 21.3250 & 25.6171 & 130.1638 & 34.9516 & 39.9689 \\
\hline
\end{tabular}


TABLE 6.-Three-halves powers for numbers from 0 to 12-Continued.

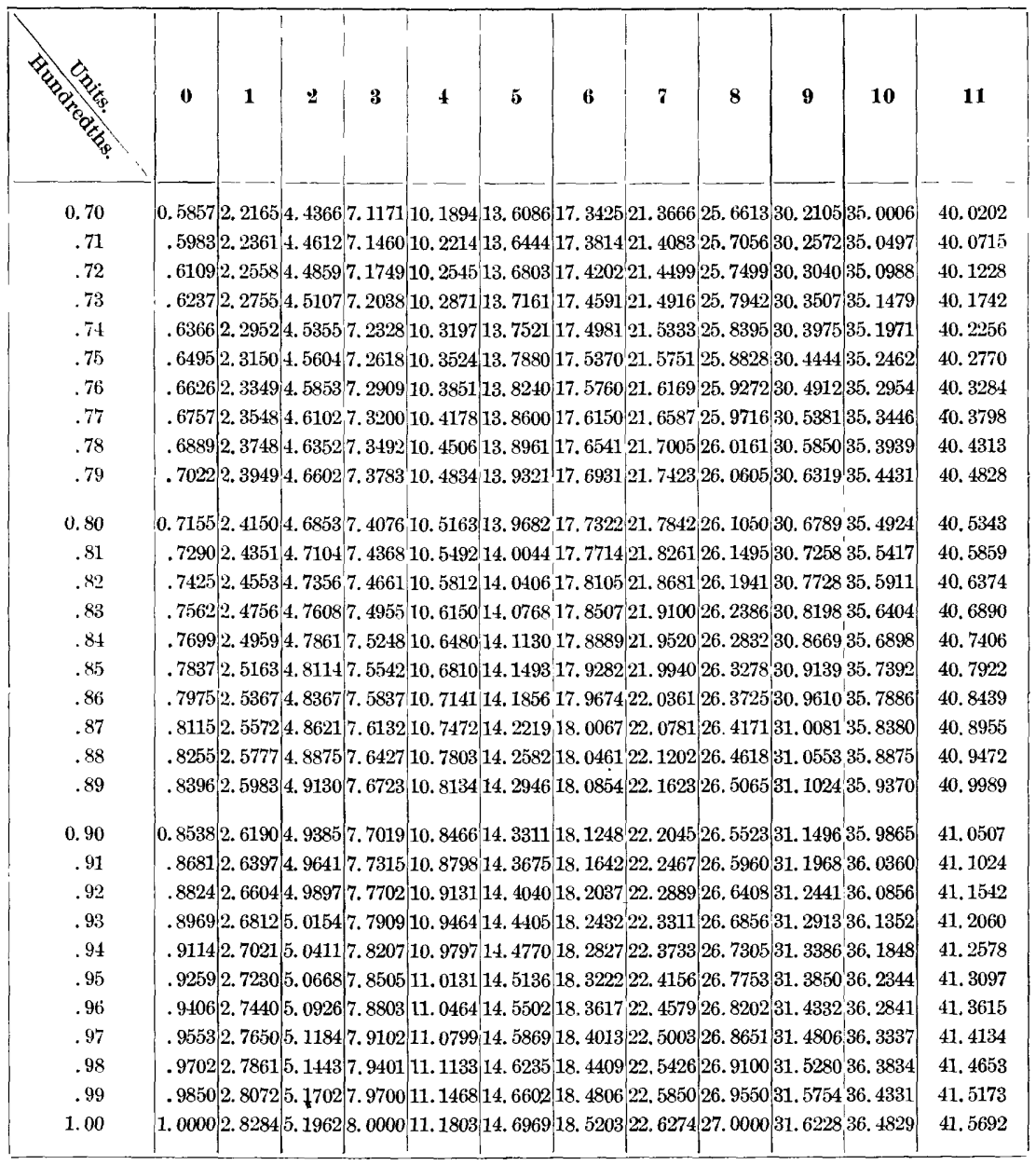

The tables of three-halves powers may conveniently be used in conjunction with Crelle's Rechentafeln, or similar tables of the products of pairs $\approx f$ factors. $C$ will usually be constant, or nearly so. Entering Crelle's tables with $C$ or $C L$ as an argument, the discharge corresponding to values of $H^{\frac{3}{2}}$ read from the tables here given may be taken out directly, and usually with sufficient precision at least for 1 foot length of crest, without any aritnmetical computation. Table 5 gives $H^{\frac{3}{2}}$ for values of $H$ from zero to 1.5 feet, advancing by thousandths. In Table 6 the increment is 0.1 foot, and the range zero to 12 feet. Should $H^{3}$ be required for larger values of $H$, it may be found from the three-halves power of $\frac{1}{4} H$, by the formula

$$
H^{\frac{3}{2}}=8\left(\frac{H}{4}\right)^{\frac{3}{2}} \text {. . . . . . . }
$$


TABLE 7.-FLOW OVER BROAD-CRESTED WEIRS, WITH STABLE NAPPE.

This table gives values of

where

$$
Q=C_{1} L H^{\frac{3}{2}}
$$

$$
\begin{gathered}
L=1 \\
C_{1}=2.64
\end{gathered}
$$

The derivation of this coefficient is given in connection with discussion of broad-crested weirs (pp. 119-121). It may be applied to broadcrested weirs of any width of cross section exceeding 2 feet within such limiting heads that the nappe does not adhere to the downstream face of the weir for low heads nor tend to become detached with increased head. Under the latter condition the coefficient increases to a limit near the value which applies for a thin-edged weir, a point being finally reached where the nappe breaks entirely free from the broad crest and discharges in the same manner as for a thin-edged weir. The coefficient, 2.64, may often be applied for weirs exceeding 2 -feet crest width and for heads from 0.5 foot up to 1.5 or 2 times the breadth of weir crest. If corrections for the velocity of approach are required the Francis correction formula, or its equivalent, should be used.

TABLE 7.- Weir discharge per foot of crest length.

[Coefficient $C_{1}=2.64$.]

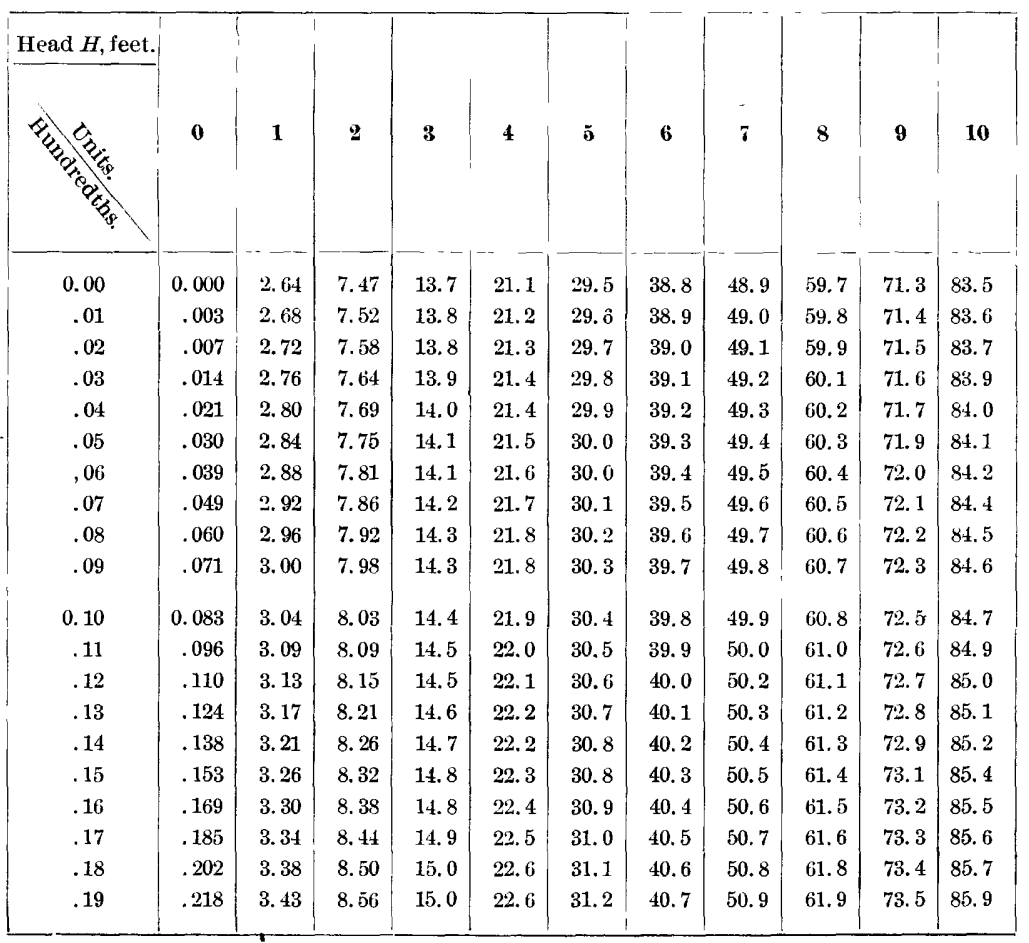


TABLE 7.-Weir discharge per foot of erest length-Continued.

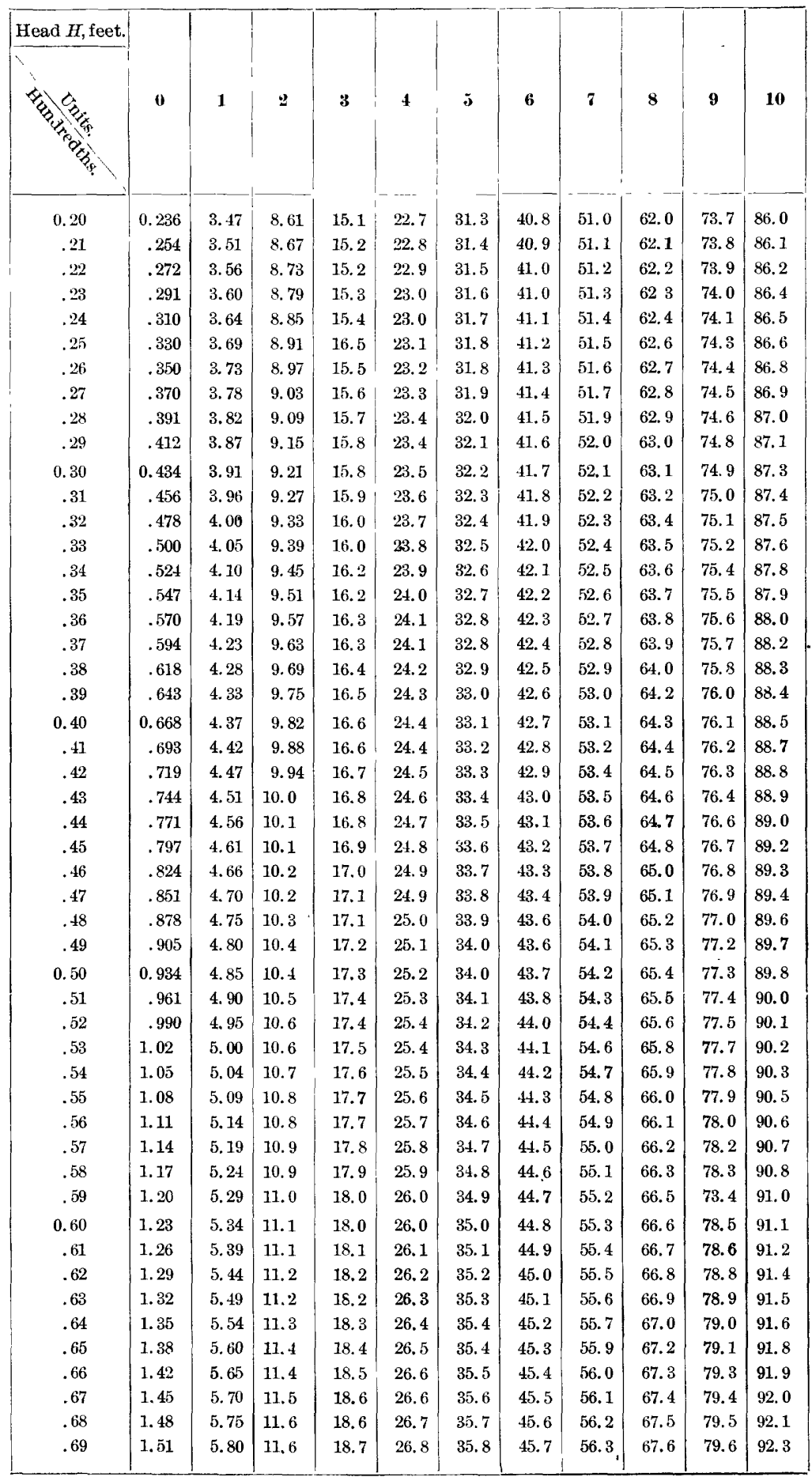


TABLES FOR CALCULATIN $\div$ WEIR DISCHARGE.

TABLE 7.-Weir discharge per foot of erest length-Continued.

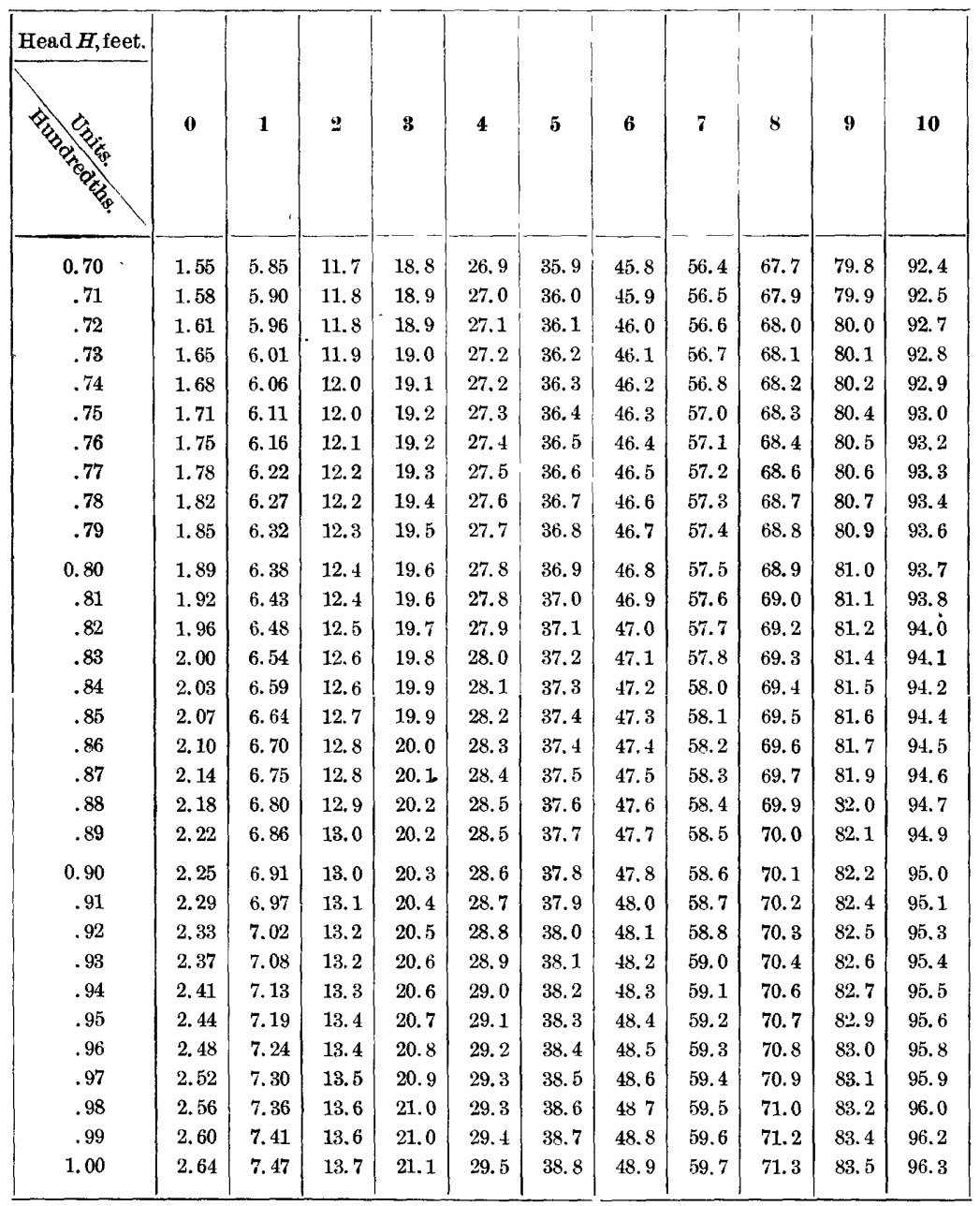


TABLE 8.-BACKWATER CAUSED BY A DAM OR WEIR.

In a channel of uniform depth, width, and slope, let

$D=$ Original uniform depth.

$d_{2}=$ Depth at the dam or obstruction.

$d_{1}=$ Depth at a point upstream.

$l=$ Distance upstream to the point $d_{1}$.

$w=$ Width of channel.

$l_{1}=$ Distance upstream to the "hydrostatic limit."

$S=$ Natural uniform slope or inclination of water surface and stream bed, assumed parallel.

$g=$ Acceleration of gravity.

$C=$ Coefficient in the Chezy or slope formula $v=C \sqrt{R S}$,

where $R$ is the hydraulic radius $=\frac{\text { area of section }}{\text { wetted perimeter }}$.

The value of $C$ varies for rivers from about 50 to 140 .

The distance upstream from the obstruction at which the depth will be $d_{1}$ may be found by the formula

$$
l=\frac{d_{2}-d_{1}}{S}+D\left(\frac{1}{S}-\frac{C^{2}}{g}\right)\left[F_{1}-F_{2}\right] . .
$$

$F$ is a function of $\frac{d}{D}$, whose value can be expressed mathematically only as a transcendental equation. The numerical values of this function are given in Table $8 . \quad F_{1}$ will be found opposite the argument $\frac{D}{d_{1}}$, and $F_{2}$ opposite $\frac{D}{d_{2}}$.

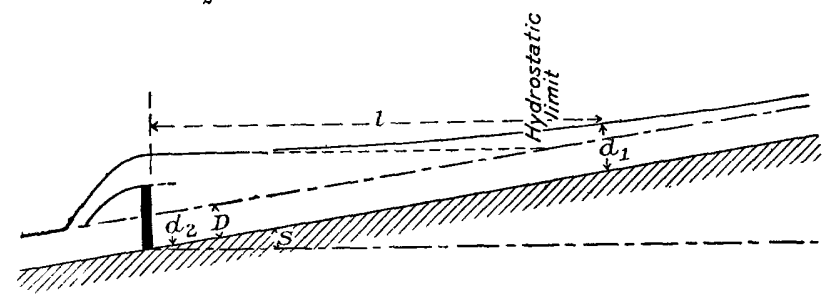

Fig. 15.-Concave backwater surface.

The inverse problem of finding the depth at any given distance $l$. upstream can be solved only by successive trials.

Using the above equation, a series of values of $d_{1}$ may be determined giving in tabular form the corresponding values of $l$. From this data the form of the surface curve may be graphically shown or the depth of back piling at any point may be interpolated.

$$
\text { If } \begin{gathered}
D=5, \quad d_{2}=10, \quad C=75, \quad S=0.0001, \quad \frac{D}{d_{2}}=0.5, \text { and } F_{2}=0.1318, \\
D\left(\frac{1}{S}-\frac{C^{2}}{g}\right)=5\left(10000-\frac{75^{2}}{32.16}\right)=49625
\end{gathered}
$$


Column (2) in the following table gives the values of $l$ for various values of $d_{1}$ computed by means of formula (115).

Form of backwater curce above a dam.

\begin{tabular}{|c|c|c|c|}
\hline$d$ & $l$ & $\delta$ & $d_{1}-\delta$ \\
\hline $\begin{array}{c}\text { Depth, } \\
\text { feet } \\
\text { (1). }\end{array}$ & $\begin{array}{l}\text { Distance } \\
\text { from dam } \\
\text { to depth } d_{1} \text {, } \\
\text { feet } \\
\text { (2). }\end{array}$ & $\begin{array}{c}\text { Hydrostatic } \\
\text { depth at } \\
\text { distance } l, \\
\text { feet } \\
(3) .\end{array}$ & $\begin{array}{l}\text { Depth of } \\
\text { "back } \\
\text { piling," } \\
\text { feet } \\
(4)^{4} .\end{array}$ \\
\hline 9 & 11,687 & 8.83 & .17 \\
\hline 8 & 24,277 & 757 & .43 \\
\hline 7 & 38,526 & 6.15 & .85 \\
\hline 6.5 & 47,024 & 5.30 & 1.20 \\
\hline 6.4 & 48,798 & 5.13 & 1.27 \\
\hline 6.3 & 50,796 & $a 5,00$ & 1.30 \\
\hline 6.2 & 52,813 & a 5.00 & 1.20 \\
\hline 6.1 & 55,010 & a 5.00 & 1.10 \\
\hline 6 & 57,240 & a 5.00 & 1.00 \\
\hline 5.5 & 67,252 & $a 5.00$ & .50 \\
\hline 5.3 & 82,940 & $a 5.00$ & .30 \\
\hline 5.1 & 101,255 & a 5.00 & .10 \\
\hline
\end{tabular}

a Above hydrostatic limit.

If the pond formed by the dam were level, the hydrostatic depth $\delta$ at any distance upstream would be

$$
\delta=d_{2}-l \sin S
$$

Column (3) in the above table shows this factor for the several values of $l$. The true "back piling" or rise due to the surface curvature is expressed by the difference $d_{1}-\delta$, as given in column (4).

This quantity has a maximum value at the hydrostatic limit, or terminus of the level pond, where $\delta=D$.

Its location is such that if $l_{1}$ is the distance upstream from the dam

$$
l_{1}=\frac{d_{2}-D}{\sin S} \cdot \ldots . \quad \text {. . . . . . }
$$

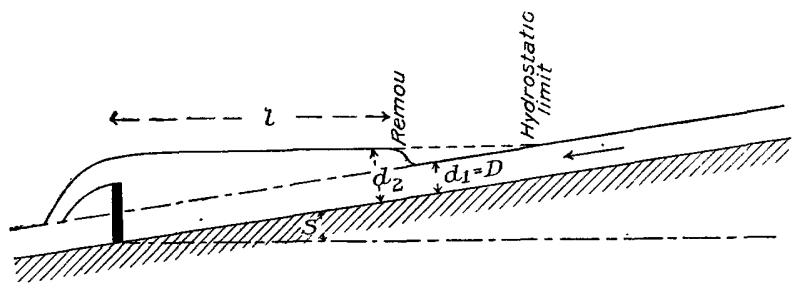

Fig. 16. -Convex backwater surface.

In the example given the hydrostatic limit occurs at a distance $l_{1}=50,000$ feet above the dam, at which point the maximum back piling of about 1.31 feet occurs.

Above the hydrostatic limit the depth of back piling is $d_{1}-D$. 
When

$$
S>\frac{g}{C^{2}} \cdot \cdot \cdot \cdot \cdot \cdot \cdot \cdot
$$

the pond surface will not be concave, but a remou or hydraulic jump will occur, having a height

$$
d_{2}=2 \sqrt{d_{1} \frac{v_{1}^{2}}{2 g}} \cdot \cdot \cdot \cdot \cdot \cdot
$$

where $v_{1}$ is the mean velocity corresponding to $d_{1}$. To find the distance upstream to the point where the jump occurs, solve equation (115) for the value of $d_{2}$, found by formula (119).

$$
\begin{gathered}
\text { If } S=0.004 \quad C=100 \quad \frac{g}{C^{2}}=0.003216 . \\
\text { If } d_{1}=5 \quad w=100 \quad D=5 \quad R=\frac{500}{110}=4.55 . \\
v_{1}=100 \sqrt{4.55 \frac{4}{1000}}=13.49 \text { feet per second. } \\
d_{22}=2 \sqrt{d_{1} \frac{v_{1}^{2}}{2 g}}=2 \sqrt{5 \frac{185}{64.32}}=7.48 .
\end{gathered}
$$

Let the depth at the dam be 10 feet; using $d_{2}$ as found above as the terminal depth in formula (115), we obtain

$$
\begin{array}{rlrl}
l & =\frac{10-7.48}{0.004}+5\left(\frac{1}{0.004}-311\right)\left(F_{2}-F_{1}\right) \\
D & =\frac{5}{7.48}=0.669 & \frac{D}{d_{2}}=0.5 \\
\bar{d}_{1} & =0.2578 & F_{2}=0.1318 \\
F_{1} & =030+(250-311) \times 0.126=622.3 \text { feet. }
\end{array}
$$

The hydrostatic limit in this case is

$$
l_{1}=\frac{10-5}{0.004}=1,250 \text { feet. }
$$

If the channel above an obstruction consists of successive reaches having different slopes or cross sections, the depth at the head of the first reach or level may be found by the method outlined, and using this as the initial depth $d_{2}$, a similar solution may be made for the second and succeeding levels. ${ }^{a}$

a Table 8 has been extended from Bresse's original table by interpolation. Demonstrations of the formulas here given may be found in Merriman's or Bovey's Hydraulics. In case of a fall a different function must be employed. Its values will be found in the works mentioned. 
TABLE 8.-Backwater function $(F)$ for a dam or obstruction.

[The column headings are hundredths for values of $\frac{D}{d}$ from zero to 0.29 , thousandths for values of $\frac{D}{d}$ from 0.30 to 0.899 , and ten-thousandths for values of $\frac{D}{d}$ from 0.900 to 0.999.$]$

\begin{tabular}{|c|c|c|c|c|c|c|c|c|c|c|}
\hline$\frac{D}{d}$ & 0 & 1 & 2 & 3 & 4 & 5 & 6 & 7 & 8 & $\mathbf{9}$ \\
\hline & $F$ & $F$ & $F$ & $F$ & $F$ & $F$ & $F$ & $F$ & $F$ & $F$ \\
\hline 0.0 & 0.0000 & 0.0001 & 0.0003 & 0.0005 & 0.0009 & 0.0013 & 0.0018 & 0.0026 & 0.0034 & 0.0042 \\
\hline .1 & .0050 & .0061 & .0072 & .0085 & .0098 & .0113 & .0128 & .0045 & .0162 & .0181 \\
\hline .2 & .0201 & .0221 & .0243 & .0266 & .0290 & .0314 & .0340 & .0367 & .0395 & .0425 \\
\hline 0.30 & 0.0455 & 0.0458 & 0.0461 & 0.0464 & 0.0467 & 0.0471 & 0.0474 & 0.0477 & 0.0480 & 0.0483 \\
\hline .31 & .0486 & .0489 & .0193 & .0496 & .0499 & .0503 & .0506 & .0509 & .0512 & .0516 \\
\hline .32 & .0519 & .0522 & .0526 & .0529 & .0533 & .0536 & .0539 & .0543 & .0546 & .0550 \\
\hline .33 & .0553 & .0556 & .0560 & .0563 & .0567 & .0570 & .0573 & .0577 & .0580 & .0584 \\
\hline .34 & .0587 & .0591 & .0594 & .0598 & .0601 & .0605 & .0609 & .0612 & .0616 & .0619 \\
\hline .35 & .0623 & .0627 & .0630 & .0684 & .0638 & .0642 & .0645 & .06419 & .0653 & .0656 \\
\hline .36 & .0660 & .0664 & .0668 & .0672 & .0676 & .0680 & .0683 & .0687 & .0691 & .0695 \\
\hline .37 & .0699 & .0703 & .0707 & .0711 & .0715 & .0718 & .0722 & .0726 & .0730 & .0734 \\
\hline .38 & .0738 & .0742 & .0746 & .0750 & .0754 & .0758 & .0763 & .0767 & .0771 & .0775 \\
\hline .39 & .0779 & .0783 & .0787 & .0792 & .0796 & .0800 & .0804 & .0808 & .0813 & .0817 \\
\hline 0.40 & 0.0821 & 0.0825 & 0.0830 & 0.0834 & 0.0839 & 0.0843 & 0.0847 & 0.0852 & 0.0856 & 0.0861 \\
\hline .41 & .0865 & .0869 & .0874 & .0878 & .0883 & .0887 & .0891 & .0896 & .0900 & .0905 \\
\hline .42 & .0909 & .0918 & .0926 & .0935 & .0943 & .0952 & .0961 & .0969 & .0978 & .0986 \\
\hline .43 & .0995 & .0996 & .0997 & .0997 & .0998 & .0999 & .1000 & .1001 & .1001 & .1002 \\
\hline .44 & .1003 & .1008 & .1013 & .1018 & .1023 & .1080 & .1032 & .1037 & .1042 & .1047 \\
\hline .45 & .1052 & .1057 & .1062 & .1067 & .1072 & .1077 & .1082 & .1087 & .1092 & .1097 \\
\hline .46 & .1102 & .1107 & .1112 & .1118 & .1123 & .1128 & .1133 & .1138 & .1144 & .1149 \\
\hline .47 & .1154 & .1159 & .1165 & .1170 & .1175 & .1180 & .1186 & .1191 & .1196 & .1202 \\
\hline .48 & .1207 & .1212 & .1218 & .1224 & .1229 & .1234 & .1240 & .1246 & .1215 & .1256 \\
\hline .49 & .1262 & .1268 & .1273 & .1279 & .1284 & .1290 & .1296 & .1301 & .1307 & .1312 \\
\hline 0.50 & 0.1318 & 0.1324 & 0.1330 & 0.1335 & 0.1341 & 0.1347 & 0.1353 & 0.1359 & 0.1364 & 0.1370 \\
\hline .51 & .1376 & .1382 & .1388 & .1394 & .1400 & .1406 & .1411 & .1417 & .1423 & .1429 \\
\hline .52 & .1435 & .1441 & .1447 & $.145 t$ & .1460 & .1466 & .1472 & .1478 & .1485 & .1491 \\
\hline .53 & .1497 & .1503 & .1510 & .1516 & .1522 & .1528 & .1535 & .1541 & .1547 & .1554 \\
\hline .54 & .1560 & .1566 & .1573 & .1580 & .1586 & .1592 & .1599 & .1606 & .1612 & .1618 \\
\hline .55 & .1625 & .1632 & .1638 & .1645 & .1652 & .1658 & .1665 & .1672 & .1679 & .1685 \\
\hline .56 & .1692 & .1699 & .1706 & .1713 & .1720 & .1726 & .1733 & .1740 & 174 & .1754 \\
\hline .57 & .1761 & .1768 & .1775 & .1782 & .1789 & .1796 & .1804 & .1811 & .1818 & .1825 \\
\hline .58 & .1832 & .1839 & .1847 & .1854 & .1861 & .1868 & .1876 & .1883 & .1890 & .1898 \\
\hline .59 & .1905 & .1912 & .1920 & .1928 & .1935 & .1942 & .1950 & .1958 & .1965 & .1972 \\
\hline 0.60 & 0.1980 & 0.1988 & 0.1996 & 0.2003 & 0.2011 & 0.2019 & 0.2027 & 0.2035 & 0.2042 & 0.2050 \\
\hline .61 & .2058 & .2066 & .2074 & .2082 & .2090 & .2098 & .2106 & .2114 & .2122 & .2130 \\
\hline .62 & .2138 & .2146 & .2155 & .2163 & .2171 & .2180 & .2188 & .2196 & .2204 & .2213 \\
\hline .63 & .2221 & .2230 & .2238 & .2246 & .2255 & .2264 & .2272 & .2280 & .2289 & .2298 \\
\hline .64 & .2306 & .2315 & .2324 & .2333 & .2342 & .2350 & .2359 & .2368 & .2377 & .2386 \\
\hline .65 & .2395 & .2404 & .2413 & .2422 & .2431 & .2440 & .2450 & .2459 & .2468 & .2477 \\
\hline .66 & .2486 & .2495 & .2505 & .2514 & .2524 & .2533 & .2542 & .2552 & .2561 & .2571 \\
\hline .67 & .2580 & .2589 & .2597 & .2606 & .2615 & .2624 & .2632 & .2641 & .2650 & .2658 \\
\hline .68 & .2667 & .2678 & .2689 & .2700 & .2711 & .2722 & .2734 & .2745 & .2756 & .2767 \\
\hline .69 & .2778 & .2788 & .2799 & .2810 & .2820 & .2830 & .2841 & .2852 & .2862 & .2872 \\
\hline
\end{tabular}

IRR $150-06-17$ 
TABLE 8.--Backuater function $(F)$ for a dam or obstruction-Continued.

[The column heudings are hundredths for values of $\frac{D}{d}$ from zero to 0.29 , thousandths for values of $\frac{D}{d}$ from 0.30 to 0.899 , and ten-thousandths for values of ${ }_{d}^{D}$ from 0.900 to 0.999 .I

\begin{tabular}{|c|c|c|c|c|c|c|c|c|c|c|}
\hline$\frac{D}{d}$ & 0 & 1 & 2 & 3 & 4 & j) & 6 & 7 & 8 & 9 \\
\hline & $\boldsymbol{F}^{r}$ & $F$ & $F$ & $F$ & $F$ & $F$ & $F$ & $F$ & $F$ & $F$ \\
\hline 0.70 & 0.2883 & 0.2894 & $0.290 \overline{5}$ & 0.2915 & 0.2926 & 0.2937 & 0.2948 & 0.2959 & 0.2969 & 0.2980 \\
\hline .71 & .2991 & .3002 & .3013 & .3025 & .3036 & .3047 & .3058 & .3070 & .3081 & .3093 \\
\hline .72 & .3104 & .3116 & .3127 & .3139 & .3150 & .3162 & .3174 & .3186 & .3197 & .3209 \\
\hline .73 & .3221 & .3233 & .3245 & .3258 & .3270 & .3282 & .3294 & .3306 & .3319 & .3331 \\
\hline .74 & .3343 & $.3356^{\circ}$ & .3368 & .3381 & .3393 & .3406 & .3419 & .3432 & .3444 & .3457 \\
\hline .75 & 3470 & .3483 & .3496 & .3510 & .3523 & .3536 & .3549 & .3563 & .3576 & .3590 \\
\hline .76 & .3603 & .3617 & .3630 & .3644 & .3657 & .3671 & .3685 & .3699 & .3713 & $.372 \pi$ \\
\hline .77 & .3741 & .3755 & .3770 & .3784 & .3799 & .3813 & .3828 & .3842 & .3857 & .3871 \\
\hline .78 & $.3 \times 86$ & .3901 & .3916 & .3932 & .3947 & $.396^{2} 2$ & .3977 & .3993 & .4008 & .4024 \\
\hline .79 & .4039 & .4055 & .4070 & .4086 & .4101 & .4117 & .4133 & $: 4149$ & .4166 & .4182 \\
\hline 0.80 & 0.4198 & 0.4215 & 0.4231 & 0.4248 & 0.4264 & 0.4281 & $0.429 \mathrm{x}$ & 0.4315 & 0.4333 & 0.4350 \\
\hline .81 & .4367 & .4384 & .4402 & .4419 & .4437 & .4154 & .4472 & .4490 & .4508 & .4526 \\
\hline.$\times 2$ & .4544 & .4563 & $.45 \operatorname{lin} 1$ & 4600 & . & .4687 & .4656 & .4675 & מ & .4714 \\
\hline .8 & .1733 & .4753 & .4772 & .4792 & .4811 & .4831 & .4851 & .4871 & .4892 & .4912 \\
\hline .84 & .4982 & .4953 & .4974 & .4995 & .5016 & .5037 & .5059 & .5081 & .5102 & .5124 \\
\hline .85 & .5146 & . & .5191 & .5213 & .5236 & .5258 & . 5281 & .5304 & .5328 & .5351 \\
\hline.$\times 6$ & .5374 & .5398 & .5422 & .5446 & .5470 & .5494 & .5519 & .5544 & .5569 & .5594 \\
\hline .87 & .5619 & .5645 & .5671 & .5697 & .5723 & .5749 & .5776 & .5803 & .5830 & .5857 \\
\hline .88 & .5884 & .5912 & .5940 & .5969 & .5997 & .6025 & $.605 \overline{5}$ & .6084 & .6114 & .6143 \\
\hline .89 & .6173 & .6204 & .6235 & .6265 & .6296 & $.632 \pi$ & .6359 & .6392 & .6424 & 6457 \\
\hline 0.900 & 0.6489 & 0.6492 & 0.6496 & 0.6499 & .6502 & 0.6506 & 0. 6509 & 0.6512 & 0.6515 & 0. 6519 \\
\hline .901 & .6522 & .6525 & .6529 & .6532 & .6536 & .6539 & .6542 & .6546 & .6549 & .65553 \\
\hline .902 & .6556 & .6559 & .6563 & .6566 & .6570 & .6573 & .6576 & .6580 & $.65 \times 3$ & .6587 \\
\hline .903 & .6590 & .6594 & .6597 & .6600 & .6604 & .6608 & .6011 & .6614 & .6618 & .6622 \\
\hline .904 & .6625 & .6629 & .6632 & .6636 & .6639 & .6642 & .6646 & .6650 & .6653 & .6656 \\
\hline .905 & .6660 & .6664 &.$\partial 667$ & .6670 & .6674 & .6678 & .6681 & .6684 & .6688 & .6692 \\
\hline .906 & .6695 & .6698 & .6702 & .6706 & .6709 & .6712 & .6716 & .6720 & .6723 & .6726 \\
\hline .907 & .6730 & .6734 & .6737 & .6741 & .6744 & .6748 & .6752 & .6755 & .6759 & .6762 \\
\hline .908 & .6766 & .6770 & .6773 & .677 & .6780 & .6784 & .6788 & .6791 & .6795 & .6798 \\
\hline .909 & .6802 & .6806 & .6809 & .6813 & .6817 & .6820 & .6824 & $.68: 28$ & .6832 & .6835 \\
\hline 0.910 & 0.6839 & 0.6843 & 0.6846 & 0.6850 & 0.6854 & 0.6858 & $0.6 \times 61$ & 0.6865 & 0.6869 & 0.6872 \\
\hline .911 & .6876 & .6880 & .6884 & .6887 & .6891 & .6895 & .6899 & .6903 & .6906 & .6910 \\
\hline .912 & .6914 & .6918 & .6922 & .6925 & .6929 & .6933 & .6937 & .6941 & .6944 & .6948 \\
\hline .913 & .6952 & .6956 & .6960 & .6963 & .6967 & .6971 & .6975 & .6979 & .6982 & 6986 \\
\hline .914 & .6990 & .6994 & .6998 & .7002 & .7000 & .7010 & .7013 & .7017 & .7021 & .7025 \\
\hline .915 & .7029 & .7033 & .7037 & .7041 & .7045 & .7049 & .7053 & .7057 & .7061 & .7065 \\
\hline .916 & .7069 & .7073 & .7077 & .7081 & .7085 & .7089 & .7093 & .7097 & .7101 & .7105 \\
\hline .917 & .7109 & .7113 & .7117 & .7121 & .7125 & .7129 & .7133 & .7137 & .7141 & .7145 \\
\hline .918 & .7149 & .7153 & .7157 & .7161 & .7165 & .7170 & .7174 & .7178 & .7182 & .7186 \\
\hline .919 & .7190 & .7194 & .7198 & .7202 & .7206 & .7210 & .721 .5 & .7219 & .7223 & .7227 \\
\hline 0.920 & 0.7231 & 0.7235 & 0.7239 & 0.7244 & 0.7248 & 0.7252 & 0.7256 & 0.7260 & 0.7265 & 0.7269 \\
\hline .921 & .7273 & .7277 & .7281 & .7286 & .7290 & .7294 & .7298 & .7302 & .7307 & .7811 \\
\hline $.92 \cdot 2$ & .7315 & .7319 & .7324 & .7328 & .7332 & .7336 & .7341 & .7345 & .7349 & .7354 \\
\hline .923 & .7358 & .7362 & .7367 & .7371 & .7375 & .7380 & .7384 & .7388 & .7392 & .7397 \\
\hline .924 & .7401 & .7405 & .7410 & 7414 & .7419 & .7423 & .7427 & .7432 & .7436 & .7441 \\
\hline .925 & $.714 \bar{o}$ & .7450 & .7454 & .7458 & .7463 & .7468 & .7472 & .7476 & .7481 & .7486 \\
\hline .9266 & .7490 & .7494 & .7499 & .7504 & $.750 x$ & .7512 & .7517 & .7522 & .7526 & .7530 \\
\hline 927 & .7535 & .7540 & .7544 & .7549 & .7553 & .7558 & .7563 & .7567 & .7572 & .7576 \\
\hline .928 & .7 .781 & .7586 & .7590 & .7595 & .7600 & .7604 & .7609 & .7614 & .7619 & .7623 \\
\hline .929 & .7628 & .7633 & .7637 & .7642 & .7647 & .7652 & .7656 & .7661 & .76666 & .7670 \\
\hline
\end{tabular}


TABLE 8.-Backwater function ( $F$ ) for a dam or obstruction-Continued.

[The column headings are hundredths for values of $\frac{D}{d}$ from zero to 0.29 , thousandths for values of $\frac{D}{d}$ from 0.30 to 0.899 , and ten-thousandths for values of $\frac{D}{d}$ from 0.900 to 0.999 .]

\begin{tabular}{|c|c|c|c|c|c|c|c|c|c|c|}
\hline$\frac{D}{d}$ & 0 & 1 & 2 & 3 & 4 & 5 & 6 & 7 & 8 & 9 \\
\hline & $F$ & $F$ & $F$ & $F$ & $F$ & $F$ & $F$ & $F$ & $F$ & $F$ \\
\hline 0.930 & 0.7675 & 0.7680 & 0.7685 & 0.7689 & 0.7694 & 0.7699 & 0.7704 & 0.7709 & 0.7713 & 0.7718 \\
\hline .931 & .7723 & .7728 & .7724 & .7738 & .7743 & .7748 & .7752 & .7757 & .7762 & .7767 \\
\hline .932 & .7772 & .7777 & .7782 & .7787 & .7792 & .7796 & .7801 & .7806 & .7811 & .7816 \\
\hline .933 & .7821 & .7826 & .7831 & .7836 & .7841 & .7846 & .7851 & .7856 & .7861 & .7866 \\
\hline .934 & .7871 & .7876 & .7881 & .7886 & .7891 & .7896 & .7902 & .7907 & .7912 & .7917 \\
\hline .935 & .7922 & .7927 & .7932 & .7937 & .7942 & .7948 & .7953 & .79 .58 & .7963 & .7968 \\
\hline .936 & .7973 & .7978 & . 7984 & .7989 & .7994 & .8000 & .8005 & .8010 & .8015 & .8021 \\
\hline .937 & .8026 & .8031 & .8037 & .8042 & .8047 & .8052 & .8058 & .8063 & .8068 & .8074 \\
\hline .938 & .8079 & .8084 & .8090 & .8095 & .8101 & .8106 & .8111 & .8117 & .8122 & .8128 \\
\hline .939 & .8133 & .8138 & .8144 & .8150 & .8155 & .8160 & .8166 & .8172 & .8177 & .8182 \\
\hline 0.940 & 0.8188 & 0.8194 & 0.8199 & 0.8205 & 0.8210 & 0.8216 & 0.8222 & 0.8227 & 0.8233 & 0.8238 \\
\hline .941 & .8244 & .8250 & .8256 & .8262 & .8268 & .8274 & .8280 & .8286 & .8292 & .8298 \\
\hline .942 & .8301 & .9307 & .8313 & .8318 & .8324 & .8330 & .8336 & .8342 & .8347 & .8353 \\
\hline .943 & .8359 & .8365 & .8371 & . 8377 & .8383 & .8388 & .8394 & .8400 & .8406 & .8412 \\
\hline .944 & .8418 & .8424 & .8430 & .8436 & .8442 & .8448 & .8454 & .8460 & .8466 & .8472 \\
\hline .945 & .8478 & .8484 & .8490 & .8496 & .8502 & .8508 & .8515 & .8521 & .8527 & .8533 \\
\hline .946 & .8539 & .8545 & .8552 & .8558 & .8564 & .8570 & .8577 & .8583 & .8589 & .8596 \\
\hline .947 & .8602 & .8608 & .8615 & .8621 & .8627 & .8634 & .8640 & .8646 & .8652 & .8659 \\
\hline .948 & .8665 & .8672 & .8678 & .8684 & .8691 & .3698 & .8704 & .8710 & .8717 & .8724 \\
\hline .949 & .8730 & .8736 & .8743 & .8750 & .8756 & .8762 & .8769 & .8776 & .8782 & .8788 \\
\hline 0.950 & 0.8795 & 0.8802 & 0.8809 & .8815 & 0.8822 & 0.8829 & 0.8836 & 0.8843 & 0.8849 & 0.8856 \\
\hline .951 & .8863 & .8870 & .8877 & .8883 & .8890 & .8897 & .8904 & .8911 & .8917 & .8924 \\
\hline .952 & .8931 & .8938 & .8945 & .8952 & .8959 & .8966 & .8974 & .8981 & .8988 & .8995 \\
\hline .953 & .9002 & .9009 & .9016 & .9023 & .9030 & .9038 & .9045 & .9052 & .9059 & .9066 \\
\hline .954 & .9073 & .9080 & .9088 & .9095 & .9103 & .9110 & .9117 & .9125 & .9132 & .9140 \\
\hline .955 & .9147 & .9154 & .9162 & .9169 & .9177 & .9184 & .9191 & .9199 & .9206 & .9214 \\
\hline .956 & .9221 & .9229 & .9236 & .9244 & .9252 & .9260 & .9267 & .9275 & .9283 & .9290 \\
\hline .957 & .9298 & .9306 & .9314 & .9321 & .9329 & .9337 & .9345 & .9353 & .9360 & .9368 \\
\hline .958 & .9376 & .9384 & .9392 & .9400 & .9408 & .9416 & .9425 & .94333 & .9441 & .9449 \\
\hline .959 & .9457 & .9465 & .9473 & .9482 & .9490 & .9498 & .9506 & .9514 & .9523 & .95531 \\
\hline 0.960 & 0.9539 & 0.9548 & 0.9556 & 0.9564 & 0.9573 & 0.9582 & 0.9590 & 0. 9598 & 0.9607 & 0.9616 \\
\hline .961 & .9624 & .9632 & .9641 & .9650 & .9658 & .9666 & .9675 & .9684 & .9692 & .9700 \\
\hline .962 & .9709 & .9718 & .9727 & .9736 & .9745 & .9754 & .9763 & .9772 & .9781 & .9790 \\
\hline .963 & .9799 & .9808 & .9917 & .9826 & .9835 & .9844 & .9854 & .9863 & .9872 & .9881 \\
\hline .964 & .9890 & .9899 & .9909 & .9918 & .9928 & .9937 & .9947 & .9956 & .9966 & .9975 \\
\hline .965 & .9985 & .9994 & 1. 0004 & 1.0013 & 1.0023 & 1. 0032 & 1.0042 & 1. 0051 & 1.0061 & 1.0070 \\
\hline .966 & 1. 0080 & 1.0090 & 1.0100 & 1.0110 & 1.0120 & 1.0130 & 1.0140 & 1.0150 & 1.0160 & 1.0170 \\
\hline .967 & 1.0181 & 1.0191 & 1. 0201 & i. 0211 & 1. 0221 & 1. 0231 & 1.0241 & 1. 0251 & 1.0261 & 1.0271 \\
\hline .968 & 1. 0282 & 1.0292 & 1. 0303 & 1.0314 & 1.0324 & 1.0335 & 1. 0346 & 1. 0356 & 1.0367 & 1. 0378 \\
\hline .969 & 1.0389 & 1.0399 & 1. 0410 & 1.0421 & 1.0432 & 1.0443 & 1.0453 & 1. 0464 & 1.0475 & 1.0486 \\
\hline 0.970 & 1. 0497 & 1. 0508 & 1.0519 & 1. 0530 & 1. 0542 & 1. 0553 & 1. 0565 & 1. 0576 & 1.0587 & 1. 0598 \\
\hline .971 & 1.0610 & 1.0622 & 1. 0633 & 1.0645 & 1. 0657 & 1. 0668 & 1.0680 & 1.0692 & 1.0704 & 1.0715 \\
\hline .972 & 1.0727 & 1.0739 & 1.0751 & 1.0763 & 1.0775 & 1. 0788 & 1.0800 & 1.0812 & 1. 0824 & 1.0836 \\
\hline .973 & 1. 0848 & 1.0861 & 1.0873 & 1. 0886 & 1.0898 & 1. 0911 & 1. 0924 & 1.0936 & 1.0949 & 1. 0961 \\
\hline .974 & 1.0974 & 1. 0987 & 1.1000 & 1.1013 & 1. 1026 & 1. 1040 & 1. 1053 & 1.1066 & 1. 1079 & 1. 1092 \\
\hline .975 & 1.1105 & 1. 1119 & 1. 1132 & 1.1146 & 1.1159 & 1.1173 & 1. 1187 & 1.1200 & 1.1214 & 1. 1227 \\
\hline .976 & 1. 1241 & 1.1255 & 1. 1269 & 1. 1284 & 1. 1298 & 1. 1312 & 1.1326 & 1.1340 & 1.1355 & 1. 1369 \\
\hline .977 & 1.1383 & 1. 1398 & 1.1413 & 1.1427 & 1.1442 & 1. 1457 & 1. 1472 & 1.1487 & 1. 1501 & 1. 1516 \\
\hline .978 & 1.1531 & 1.1546 & 1. 1562 & 1. 1578 & 1.1593 & 1.1608 & 1. 1624 & 1.1640 & 1.1655 & 1. 1670 \\
\hline .979 & 1. 1686 & 1.1702 & 1.1718 & 1. 1735 & 1.1751 & 1.1767 & 1.1783 & 1.1799 & 1.1816 & 1.1832 \\
\hline
\end{tabular}


TABLE 8.-Backwater function ( $F$ ) for a dam or obstruction-Continued.

[The column headings are hundredths for values of $\frac{D}{d}$ from zero to 0.29 , thousandths for values of $\frac{D}{d}$ from 0.30 to 0.899 , and ten-thousandths for values of $\frac{D}{d}$ from 0.900 to 0.999.$]$

\begin{tabular}{|c|c|c|c|c|c|c|c|c|c|c|}
\hline$\frac{n}{d}$ & 0 & 1 & 2 & 3 & $t$ & 5 & 6 & 7 & 8 & 9 \\
\hline & $F$ & $F$ & $F$ & $F$ & $F$ & $F$ & $F$ & $F$ & $F$ & $F$ \\
\hline 0.980 & 1. 1848 & 1. 1865 & 1.1882 & 1.1899 & 1.1916 & 1.1984 & 1.1951 & 1. 1968 & 1.1985 & 1. 2002 \\
\hline .981 & 1. 2019 & 1.2037 & 1. 2055 & 1.2073 & 1.2091 & 1. 2109 & 1.2127 & 1. 2145 & 1. 2163 & 1.2181 \\
\hline .982 & 1. 2199 & 1.2218 & 1.2237 & 1.2256 & 1. 2275 & 1. 2294 & 1.2314 & 1. 2333 & 1. 2352 & 1. 2371 \\
\hline .983 & 1. 2390 & 1.2410 & 1.2430 & 1. 2451 & 1. $247 \mathrm{I}$ & 1.2491 & $1.251 \mathrm{l}$ & 1.2531 & 1. 2552 & 1.2572 \\
\hline .984 & 1. 2592 & 1. 2614 & 1. 2635 & 1.2656 & 1.2678 & 1.2700 & 1.2721 & 1.2742 & 1.2764 & 1. 2786 \\
\hline .985 & 1. 2807 & 1.2830 & 1.2853 & 1. 2876 & 1.2899 & 1. 2922 & 1. 2945 & 1. 2968 & 1.2991 & 1.3014 \\
\hline .986 & 1. 3037 & 1. 3062 & 1. 3086 & 1. 3111 & 1. 3136 & 1.3160 & 1.3185 & 1.3210 & 1. 3235 & 1. 3259 \\
\hline .987 & 1. 3284 & 1. 3311 & 1.3337 & 1. 3364 & 1.3391 & 1.3418 & 1.3444 & 1.3471 & 1.3498 & 1. 3524 \\
\hline .988 & 1. 3551 & 1.3580 & 1. 3609 & 1. 3638 & 1. 3667 & 1. 3696 & 1. 3725 & 1. 3754 & 1.3783 & 1. 3812 \\
\hline .989 & 1.3841 & 1. 3873 & 1.3905 & 1. 3936 & 1. 3968 & 1. 4000 & 1.4032 & 1. 4064 & 1. 4095 & 1. 4127 \\
\hline 0.990 & 1. 4159 & 1. 4194 & 1. 4229 & 1.4264 & 1. 4299 & 1. 4334 & 1.4370 & 1.4405 & 1. 4440 & 1. 4475 \\
\hline .991 & 1. 4510 & 1.4549 & 1. 4588 & 1.4628 & 1.4667 & 1.4706 & 1.4745 & 1.4784 & 1.4824 & 1.4863 \\
\hline .992 & 1. 4902 & 1. 4947 & 1. 4991 & 1. 5036 & 1. 5080 & 1.5125 & 1.5170 & 1.5214 & 1.5259 & 1.5308 \\
\hline .993 & 1. 5348 & 1.5899 & 1. 5451 & 1,5502 & 1.5553 & 1. 5604 & 1.5656 & 1.5707 & 1.5758 & 1.5810 \\
\hline .994 & 1. 5861 & 1.5922 & 1. 5983 & 1.6043 & 1. 6104 & 1.6165 & 1. 6226 & 1.6287 & 1. 6347 & 1. 6408 \\
\hline .995 & 1. 6469 & 1.6543 & 1.6618 & 1. 6692 & 1.6767 & 1.6841 & 1. 6915 & 1.6990 & 1.7064 & 1.7139 \\
\hline .996 & 1. 7213 & 1. 7309 & 1.7405 & 1. 7501 & 1.7597 & 1. 7692 & 1. 7788 & 1. 7884 & 1.7980 & 1.8076 \\
\hline .997 & 1.8172 & 1.8307 & 1.8442 & 1.8577 & 1.8712 & 1.8848 & 1.8982 & 1.9118 & 1.9253 & 1.9388 \\
\hline .998 & 1.9523 & 1. 9754 & 1.9985 & 2.0216 & 2. 0447 & 2.0678 & 2.0910 & 2.1141 & 2.1378 & 2.1603 \\
\hline .999 & 2.1834 & & & & & & & & & \\
\hline 1. 000 & & & & & & & & & & \\
\hline
\end{tabular}




\section{N D E X .}

Albion, Mass., dam at, flow over

Angular weirs. See Weirs, angular.

Approach, channel of. See Channel of approach.

section of, definition of

velocity of. See Velocity of approach.

Austin, Tex., dam at, flow over ............

Authorities cited, list of .

Backwater, depth of ....................
depth of, figures showing $\ldots \ldots \ldots \ldots \ldots$
180.181

depth of, flg
table showing .................... $1 \times 3-186$

Baziu, H., base formula of............... 9

coefficients of, for thin-edged weirs .... 61

plate showing ................... 32

correction of, for velocity of approach . 63-65

experiments of, on effect of rounding upstream crest edge ............

on submerged weirs of irregular section ................... 143-144

on thin-edged weirs .............. 29-31

on trapezoidal weirs............. 127

on triangular weirs............. 124-126

on weirs of irregular cross section.. 63-85

on weirs with compound slopes. . 127-128

on weirs with varying upstream

slopes................... 128-129

plate showing ................... 66

formula of, comparison of, with other formulas................... 40-42

for submerged weirs............ 141-142

for thin-edged weirs............. 31-34

for weirs with end contraction, use of ...........................

formulas and experiments of, on broadcrested weirs .............. 117-119

Bellasis, - , on falls................... 135

Blackstone River, dam on, fiow over...... 132

Blackwell, T. E., experiments of, on broadcrested weirs ...........112-114, 122

Boileau, P., experiments of, on thin-crested weirs ..................... 21-22

formula of, compared with other formulas .................... 40-41

Broad-crested weirs. See Weirs, broaderested.

Castel, M., experiments of, on thin-crested weirs ...................... 20-21

formula of, compared with other formulas ....................... 40-41

Chambly dam, model of, experiments on.. 101
Page.

Channel, leading, definition of............ 7

Channel of approach, definition of ........ 7

depth of, for weir gaging............ 50

energy in, distribution of ............ 17-20

velocity in, distribution of . .......... 16-17

Chanoine and Mary, formula of, for submerged weirs................ 140

Cippoletti, Cesare, formula of, for trapezoidal weirs ................. 48-49

weir of, definition of ............... 47-48

Clegg's dam, flow over ................. 112

Coefficients, relations of ................. 9

Compound weirs, flow over ............. 46

Contracted weirs, definition of............ 7

Contraction, crest, definition of.......... 8

Contraction, end, formula for........... 44-45

Contraction, vertical, definition of........ 8

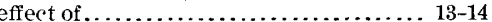

Cornell University, hydraulic laboratory of, deseription of ............... 86 867 hydraulic laboratory of, experiments at..................... 39,85-107 experiments at, plate showing ..... 86

Crest, character of ................... 52 roughness of, corrections for........ 133-134

Crest, contraction, definition of......... 8

Croton dam, crest of, correction for....... 134 model of, flow over, experiments on.... 90-94 fiow over, experiments on, plate showing ................... 94

Dams, backwater caused by, depth of.... 180-182 backwater caused by, depth of, table showing ................... 183-186

Dams, actual, fiow over, experiments on .. 131-133 fiow over, experiments on, plate showing........................ 132

Dams, model, crest of, correction for...... 133 flow over, experiments on............ 88-90 Dams, submerged, data concerning ...... 144-145 D'A ubuisson, J. F., formula of ............ 21

Deep Waterways, U. S. Board of Engineers on, experiments of, on submerged weirs................. experiments of, on weirs of irregular section $\ldots . . . \ldots \ldots \ldots \ldots \ldots \ldots . .65-90$

on weirs with varying upstream slopes...................... 128-130

plate showing.................. 90

formula of, for broad-crested weirs... 121-122 Definitions of terms .................. $7-8$ Desplaines River dam, flow over ......... $\quad 112$ Dimensions, methods of expressing ........ 8 
Dolgeville dam, model of, experiments

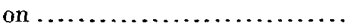

Dyas, -, formula of, for submerged weirs ..

Dyer, C. W. D., and Flinn, A. D., experiments of ..................45,48

East Indies, engineers of, formulas of, for broad-crested weirs ...... 114-116,121

formulas of, for thin-edged weirs...... 22, 40 submerged dams in, data concerning $\ldots \ldots \ldots \ldots \ldots \ldots \ldots \ldots .144-145$

Energy, distribution of, in channel of approach................... 17-20

Error, effect of, in determining head...... $\tilde{53}$

Essex County,dam of, model of, experiments on ..................... 107-109

Falls, flow over......................

flow over, figure showing .............

Farm Pond, Mass., experiments on thinedged weirs at..................

Flinn, A. D., and Dyer, C. W. D., experiments of ....................45, 48

Flow, method of expressing ..............

Formulas, comparison of .............. $40-42$ list of .

Francis, J. B., base formula of ............ experiments and formulas of, for thincrested weirs

formula of, compared with other formulas......................... 40

discharge by, table showing....... 162-171

for end contractions................

for weirs of irregular cross sections.

weir of, diagram showing .............

Francis, J. B., and Smith, H., formula of, for thin-edged weirs.

Francis, J. B., Stearns, F. P., and Fteley, A., formula of, for thin-edged weirs .............. $26,29,34,40-41$

Freeman, J. R., experiments of .......... 90-94

Frizell, J. P., formula of, for broad-crested weirs .................. 110-112

Fteley and Stearns. Sce Stearns and Fteley.

Fteley, A., Stearns, F. P., and Francis, J. B., formula of, for thin-edged weirs $\ldots \ldots \ldots \ldots \ldots \ldots 26,29,34,40-41$

Gaging, accuracy of ................. 53-58 requirements for .................. 49-58

Geological Survey, United States, experiments of, on broad-crested weirs .................... 119-121

- experiments of, on rounding upstream edge ...................... 123, 124

on weirs of irregular section...... 98-107

on weirs with varying slopes....... 130

plate showing ................... 106

Gould, E. L., formula of, for discharge from nonprismatic reservoir....

formula of, for discharge from prismatic reservoir .............150-152

Gould, E. S., formula of, for discharge from prismatic reservoir ..... 151-152

Hart and Hunking, formula of, for thinedged weirs
Page.

Head, determination of, error in, effect of. 53-57 determination of, error in, effect of,

plate showing .............. 54 effect of velocities on, table showing. 157-159 increase in, effect of ................ 39-40 from submerged weir............ 142-143

variation in ................ 53-54,97-98 diagram showing............... 150 effect of...................... 146-156 Herschel, C., formula of, for submerged weirs .................... 139-140

Horton, R. E., experiments of.......... 95-107 Hunking and Hart, formula of, for thinedged weirs ................. 25-26

Inclined weirs. See Weirs, inclined.

India. See East Indies.

Inflow, effect of, on reservoir.

$148-156$

Johnston, T. T., on flow over Desplaines

River dam...................

Lawrence, Mass., dam at, model of, experiments on ................. 107-109

dam at, model of, experiments on, plate showing .................... 106

Leading channel, definition of ........... 7

Lesbros, experiments of, on thin-edged weirs

formulas of, compared with other formulas.........................

Lesbros and Poncelet, experiments of, on thin-edged weirs .............. 21

Lowell, Mass., experiments at..... 23-26, 107-109

Merrimac River, dam on, experiments on.. 106

dam on, experiments on, plate showing. 106 Metz, Germany, experiments on thin-edged weirs at.................... 21-2:

Morris, Elwood, on Clegg's dam.......... $\quad 112$ Muskingum River, dam on, flow over..... 132

Nappe, definition of $\ldots . . \ldots \ldots \ldots \ldots \ldots \ldots, 7$

form of, modifleations of ............ $60-61$ modifications of, plate showing .... $\quad 60$

Nelles, George T., data collected by....... 131

Notation, explanation of $\ldots \ldots \ldots \ldots \ldots \ldots . \quad 8-9$

O'Connell, P. P. L., formula of, for discharge from nonprismatic reservoir.... 153

Orifice, flow through ................. 12-13

fiow through, figure showing.......... 12

Ottawa River dam, Canada, flow over..... 132

Parabolic law of velocity, application of, to weirs ........................

Parmley, w. C., formula of, compared with other formulas ..............40-41

formula of, for thin-edged weirs ....... 37-38 Plattsburg dam, model of, experiments on. 98-100 Poncelet and Lesbros, experiments of, on thin-edged weirs $\ldots \ldots \ldots, \ldots . . .21$

Rafter, G. W., experiments of .......... $85-90$

Rankine, W. J., formula of, for submerged weirs .................... 142

Reservoirs, lowering of, time required for. 146-156 Rhind,R. H., formula of, for submerged weirs 141 
Section of approach, definition of......... Pasge. 7 sharp-crested weirs, definition of .......... Smith, Hamilton, base formula of.......... formula of, for thin-edged weirs ...... 22, $34-36,40-41,44$

Smith, H., and Francis, J. B., formula of, for thin-edged weirs.......... Stearns, F. P., and Fteley, A., base formula of experiments of, on broad-crested weirs .................. 116-117

on rounding upper crest......... 122-124

on thin-edged weirs ............ 26-29

formula of, compared with other formulas....................... 40-41

for submerged weirs........... 138-139

for thin-edged weirs.............. 34

Stearns, F. P., Fteley, A., and Francis, J. B., formula of, for thin-edged weirs. 26 , $29,34,40-41$

submerged weirs. See Weirs, submerged.

suppressed weirs, definition of.

Thin-edged weirs. See Weirs, thin-edged.

Thomson, James, experiments of, on coefficient of contraction for thinedged weirs ................ 46-47

Three-halves powers, table of .......... 171-176

Torricelli, G., theory of................. 10-11 theory of, application of, to weir, figure showing ......................

Toulouse, France, experiments at, on thinedged weirs

Trapezoidal weirs. Siee Weirs, trapezoidal.

Triangular weirs. See Weirs, triangular.

United States Board of Engineers on Deep Waterways. See Deep Waterways.

United States Geological Survey. See Geological Survey.

Unwin, W. C., formula of, for broad-crested weirs ................... 110-112

Vlocities, method of expressing.......... 8

Velocity, parabolic law of, application of.. 12

Velocity of approach, distribution of...... 16-17

distribution of, figure showing ......... 16

effect of, on weir discharge ........ 14-20, 58 correction for ......... 14-16,41-43,63-66 table showing (Hunking and

Hart formula) ...............

table showing (Parmly and

Bazin formula) ............ 38

table showing .................. 159-162

energy of, distribution of ........... 17-20

formulas for ..................... 14-20

head due to, table'showing .......... 157-159

Vertical coutraction. See Contraction, vertical.

Weir section, definition of.

Weirs, aprons of variation in, effect of . 124-127

backwater caused by, depth of...... 180-182
Weirs, backwater caused by, depth of, table showing ................ 183-186

definition of....................... 7

discharge over, relative approximate.. 10-11 variation in ................ 146-154 diagram showing ............ 150

flow over, calculation of, tables for .. 156-186 measurement of, formulas for..... 9 , $9-12,11-13,40-43$

theory of $10-14$ gaging at. See Gaging.

head on. See Head.

Weirs, angular, flow over ............... $136^{\circ}$

fiow over, figure showing .......... 136

Weirs, broad-crested, edge of, rounding of, effect of ................... 124

flow over ...................... 110-122

figure showing ................ 110

table showing ................ 177-179

Weirs, compound, fiow over............. 46

Weirs, contracted, definition of ........... 7

Weirs, curved, fiow over ............... 136

fiow over, figure showing ........... 136

Weirs, East Indian, flow over......... 144-145 fiow over, figures showing .......... 145

Weirs, fiat-top, models of, experiments on. 103-105

Weirs, inclined, flow over............. 127-130 flow over, figure showing ............ 57

Weirs, irregular, fiow over, experiments on. 61-110 flow over, formulas for, basic . ....... 62-63 use of $\ldots \ldots \ldots \ldots \ldots \ldots \ldots \ldots \ldots \ldots . .59$

Weirs, of sensible crest width, flow over... 52

Weirs, ogee cross-sectioned, fiow over... 130-131 fiow over, plate showing ............ 130

Weirs, submerged, fiow over ........... 137-146 fiow over, figure showing ........... 137 increase of head due to ............ 142-143

Weirs, suppressed, definition of ............ 7

Weirs, thin-edged, definition of .......... 7 discharge over, table showing ....... 162-171 fiow over, measurement of, experiments on and formulas for ...... 20-29,31-46 measurement of, formulas for, comparison of .................... 40-41

formulas for, extension of......... $39-40$

Weirs, trapezoidal, aprons of, variation in, effect of.................... 127

cross-section of .................... 47

fiow over, formulas for, figures showing. $\quad 47$

formulas for ................... $\quad 47$

Weirs, triangular, aprons of, variation in, effect of ................... 124-126

coefficient curve for, figure showing ... 125 fiow over, experiments on, figure show- ing .......................... 46 experiments on and formulas for .. 46-47 Weirs, uneven, fiow over............... 57-58 Weisbach, formula of................. 40 "Wetted underneath," definition of ...... 7 Williams, G. S., experiments by......... 90-107 Woodman, R. S., formula of, for discharge from prismatic reservoir ..... 151-152 


\section{CLASSIFICATION OF THE PUBLICATIONS OF THE UNITED STATES GEOLOGICAL SURVEY.}

[Water-Supply Paper No. 150.]

The serial publications of the United States Geological Survey consist of (1) Annual Reports, (2) Monographs, (3) Professional Papers, (4) Bulletins, (5) Mineral Kesources, (6) 11 ater-Supply and Irrigation Papers, (7) Topographic Atlas of United States-folios and separate sheets thereof, (8) Geologic Atlas of the United States-folios thereof. The classes numbered 2, 7 , and 8 are sold at cost of publication; the others are distributed free. A circular giving complete lists may be had on application.

Most of the above publications may be obtained or consulted in the following ways:

1. A limited number are delivered to the Director of the Survey, from whom they nay be obtained, free of charge (except classes 2,7 , and 8 ), on application.

2. A certain number are delivered to Senators and Representatives in Congress, for distribution.

3. Other copies are deposited with the Superintendent of Documents, Washington, D. C., from whom they may be had at prices slightly above cost.

4. Copies of all Government publications are furnished to the principal public libraries in the large cities throughout the United States, where they may be consulted by those interested.

The Professional Papers, Bulletins, and Water-Supply Papers treat of a variety of subjects, and the total number issued is large. They have therefore been classified into the following series: A, Economic geology; B, Descriptive geology; C, Systematic geology and paleontology; D, Petrography and mineralogy; E, Chemistry and physics; F, Geography; G, Miscellaneous; H, Forestry; I, Irrigation; J, Water storage; K, Pumping water; L, Quality of water; M, General hydrographic investigations; N, Water power; O, Underground waters; P, Hydrographic progress reports. This paper is the sixteenth in Series $\mathrm{M}$, the complete list of which follows. (PP= Professional Paper; $B=$ Bulletin; WS =Water-Supply Paper):

SERIES M-GeNeral Hydrographic Investigations.

W' 56. Methods of stream measurement. 1901. 51 pp., 12 pls.

WS 64. Accuracy of stream measurements, by E. C. Murphy. 1902.99 pp., 4 pls.

WS 76. Observations on the flow of rivers in the vicinity of New York City, by H. A. Pressey. 1902. 108 pp. 13 pls.

WS 80. The relation of rainfall to run-off, by G. W. Rafter. 1903. 104 pp.

WS 81. California hydrography, by J. B. Lippincott. 1903.488 pp., 1 pl.

WS 88. The Passaic flood of 1902, by G. B. Hollister and M. O. Leighton. 1903. 56 pp., 15 pls.

IVS 91. Natural features and economic development of the Sandusky. Maumee, Muskingum, and Miami drainage areas in Ohio, by B. H. Flynn and M. S. Flynn. 1904.130 pp.

WS 92. The Passaic flood of 1903, by M. O. Leighton. 1904. 48 pp., 7 pls.

WS 94. Hydrographic manual of the United States Geological Survey, prepared by E. C. Murphy, J. C. Hoyt, and G. B. Hollister. 1904. 76 pp., 3 pls.

Wi 95. Accuracy of stream measurements (second edition), by E. C. Murphy. 1904.169 pp., 6 pls.

WS 96 Destructive floods in the United States in 1903, by E. C. Murphy. $1904.81 \mathrm{pp} ., 13 \mathrm{pls}$.

Ws 106. Water resources of the Philadelphia district, by Florence Bascom. 1904. 75 pp., 4 pls.

WS 109. Hydrography of the Susquehanna River drainage basin, by I. C. Hoyt and R. H. Anderson. 1904. 215 pp., 28 pls.

WS 116. Water resources near Santa Barbara, California, by J. B. Lippincott. 1904.99 pp., 8 pls.

Ws 147. Destructive floods in the United States in 1904, by E. C. Murphy and others. 1905.206 pp., 18 pls.

WS 150. Weir experiments, coefficients, and formulas, by R. E. Hortou. 1906.189 pp., 38 pls.

Correspondence should be addressed to

The Director,

United States Geological Survey, Washinciton, D. C.

JANUARY, 1906. 